\author{
UNIVERSIDADE DE SÃO PAULO \\ ESCOLA DE ENGENHARIA DE SÃO CARLOS \\ ÁREA DE PÓS-GRADUAÇÃO EM ENGENHARIA MECÂNICA
}

\title{
OBTENÇÃO DE DISTRIBUIÇÃO DE PRESSÃO EM ASAS USANDO REDES NEURAIS
}

\author{
ANDRÉ LUIZ FONTES DA SILVA
}

Dissertação apresentada à Escola de Engenharia de São Carlos, da Universidade de São Paulo, como parte dos requisitos para obtenção do título de Mestre em Engenharia Mecânica - área de aeronaves.

ORIENTADOR: Prof. Dr. Fernando Martini Catalano 
Aos meus pais Luiz Carlos e Maria Penha pelo fruto da educação que me deram. 


\section{AGRADECIMENTOS}

Ao Conselho Nacional de Desenvolvimento Científico e Tecnológico (CNPq), pelo apoio financeiro concedido sob a forma de bolsa de mestrado.

Ao meu orientador Fernando Martini Catalano, pelo incentivo e auxílio necessários à conclusão deste trabalho.

Ao Prof. Dr. Michael George Maunsell, pela amizade, dedicação e compreensão durante o início do mestrado.

Ao amigo Eng. Juliano Machado Tenório Cavalcanti, por fornecer as teorias básicas das redes neurais e pelo apoio e estímulo constantes durante a pesquisa.

Ao Prof. Dr. José Demísio, pelas importantes aulas sobre redes neurais.

Ao meu primo Eng. Rafael Fontes Vieira, pelo apoio, incentivo e valiosas idéias que me auxiliaram no desenvolvimento desta dissertação.

Ao Eng. Juliano Duarte, pelos comentários técnicos e apoio.

À Empresa Brasileira de Aeronáutica (EMBRAER), por permitir o uso do código computacional usado na geração dos conjuntos de treinamento necessários à alimentação da rede neural.

Aos meus pais e minha irmã pela força e apoio diante das dificuldades.

A minha Camila pela compreensão durante o trabalho.

A todos os professores e alunos que sempre lutaram e continuam trabalhando para fortalecer a Engenharia Aeronáutica na Escola de Engenharia de São Carlos. 


\section{RESUMO}

SILVA, A. L. F. (2009). Obtenção de distribuição de pressão em asas usando redes neurais. São Carlos. 206p. Dissertação de Mestrado - Escola de Engenharia de São Carlos - Universidade de São Paulo.

Este trabalho apresenta uma metodologia para predição da distribuição de pressão sobre uma asa bi-trapezoidal genérica usando redes neurais artificiais. $O$ toolbox de redes neurais do MatLab® foi utilizado para o treinamento e validação das redes neurais e os conjuntos de treinamentos foram obtidos por meio do software BLWF® versão 28 (Boundary Layer Wing-Fuselage) um código CFD (Computacional Fluid Dynamics) de potencial completo com correção de camada limite.

Levando em consideração o nível de complexibilidade do problema, optou-se por dividir o estudo em três etapas de desenvolvimento. Inicialmente, uma rede neural foi treinada considerando apenas as variáveis de condição de voo e de forma em planta. Resultados promissores motivaram a criação de uma segunda rede neural, mais genérica, na qual foram adicionadas variáveis de três perfis distribuídos ao longo da asa. Porém apenas um desses perfis era variável, enquanto que os demais eram parametrizados com relação à este perfil. Criou-se, por fim, uma rede neural ainda mais genérica, desta vez atentando também para as variáveis dos três perfis de modo independente.

Os resultados obtidos mostram que esta metodologia pode ser usada como interessante ferramenta para obtenção de distribuição de pressão, especialmente em projetos de MDO (Multi-Disciplinary Optimization), uma vez que ela possibilita 
uma predição rápida, precisa e de fácil automatização da distribuição de pressão em uma asa genérica.

Palavras-chave: distribuição de pressão, redes neurais, CFD. 


\begin{abstract}
SILVA, A. L. F. (2009). Prediction of Pressure Distribution on Wings Using Neural Network. São Carlos. 206p. Dissertação de Mestrado - Escola de Engenharia de São Carlos - Universidade de São Paulo (In Portuguese).
\end{abstract}

This work shows a method for predicting pressure distribution over a generic bi-trapezoidal wing using artificial neural networks. The MatLab® Neural Network Toolbox was used for the neural network implementation and the training set was obtained using the BLWF® version 28 (Boundary Layer Wing-Fuselage), a full potential CFD (Computational Fluid Dynamics) code with boundary layer correction.

The work was divided in three development phases, according with the problem complexibiblity level. Initially, a neural network considering only flight conditions and plan form variables was trained. Promising results motivated the generation of a more generic neural network, considering also parameters of three airfoils distributed along the wing spanwise and chordwise. However only one airfoil was variable, the two others were parametrized in relation to the variable airfoil. At last, an even more generic neural network was generated, this time considering also the variables of the three profiles independently.

The results show that this methodology can be successfully used as an interesting tool to obtain the pressure distribution, especially on the solution of MDO (Multi-Disciplinary Optimization) problems, since it allows fast prediction, automation facility and accurate measuring of the pressure distribution under a generic wing.

Keywords: pressure distribution, neural networks, CFD. 


\section{GLOSSÁRIO DE SÍMBOLOS}

Símbolo

$2 \mathrm{Y} / \mathrm{b}$

a

$a_{1}, a_{2}, \ldots, a_{5}$

acle

acte

Alfa, AOA, $\alpha$

AR

atte

b

$b_{1}, b_{2}, \ldots, b_{6}$

BA

Beta, $\beta$

BF

$\mathrm{b}_{\mathrm{k}}$

BLWF

CFD

CM

$\mathrm{CM}_{\text {BLWF }}$

$\mathrm{CM}_{\text {NNET }}$

$\mathrm{CN}$

$\mathrm{CN}_{\text {BLWF }}$

$\mathrm{CN}_{\text {NNET }}$

CP

DCp, dCp

Dih

DOE

E, e

epsil

J

LHSDesign

Mach, M

MDO

MSE

$\mathrm{N}$

NNET

REY, R

Sweep

Taper

$\mathrm{V}_{\mathrm{K}}, \mathrm{v}_{\mathrm{k}}, \mathrm{u}_{\mathrm{k}}$
Descrição

Posição relativa ao longo da semi-envergadura

Parâmetro de inclinação da função sigmóide

Coeficientes do polinômio da curva de arqueamento de Sobieczky

Ângulo da linha de arqueamento no bordo de ataque

Ângulo da linha de arqueamento no bordo de fuga

Ângulo de ataque do avião

Razão de aspecto - Aspect ratio

Ângulo da linha de espessura no bordo de fuga

Envergadura

Coeficientes do polinômio da curva de espessura de Sobieczky

Bordo de ataque

Ângulo de derrapagem do avião

Bordo de fuga

Bias

Programa Boundary Layer Wing Fuselage

Dinâmica dos fluídos Computacional (sigla em Inglês)

Coeficiente de momento de arfagem

Adim.

Coeficiente de momento de arfagem obtido do BLWF

Adim.

Coeficiente de momento de arfagem obtido da rede neural

Adim.

Coeficiente de força normal

Adim.

Coeficiente de força normal obtido do BLWF

Adim.

Coeficiente de força normal obtido da rede neural

Adim.

Coeficiente de Pressão

Adim.

Adim.

graus

Diedro da asa

Projeto de experimentos (sigla em Inglês)

Erro da rede neural

Torção geométrica de cada perfil

Joules

graus

J

Hipercubo latino (sigla em Inglês)

Número de Mach

Otimização multidisciplinar (sigla em Inglês)

Erro médio quadrático (sigla em inglês)

Número de indivíduos do conjunto de treinamento

Redes neurais (sigla em inglês)

Número de Reynolds

Adim.

Enflechamento do bordo de ataque da asa

graus

Afilamento

Adim.

Saída do combinador linear dos sinais de entrada de cada neurônio 
Símbolo

Descrição

Unidade

$\begin{array}{ll}W, W_{k} & \text { Pesos sinápticos } \\ X / C, x / c & \text { Posição relativa ao longo da corda } \\ X_{1}, X_{2}, \ldots, X_{N} & \text { Dados de entrada das redes neurais } \\ x c m c & \text { Ponto de máximo arqueamento } \\ X_{c p} & \text { Posição relativa ao longo da corda } \\ X O R & \text { Problema do "ou" exclusivo } \\ \text { xtle } & \text { Posição do ponto de controle do raio do bordo de ataque } \\ x t t h & \text { Posição da máxima espessura do perfil } \\ Y, Y_{k} & \text { Sinal de saída de cada neurônio } \\ Y_{c} & \text { Curva de arqueamento da formulação de Sobieczky } \\ y c m c & \text { Máximo arqueamento do perfil } \\ Y_{c p} & \text { Posição relativa ao longo da semi-envergadura } \\ y c t e & \text { Arqueamento no bordo de fuga } \\ y c t h & \text { Arqueamento na posição de máxima espessura } \\ Y_{k i n k} & \text { Posição relativa da quebra } \\ Y_{t} & \text { Curva de espessura da formulação de Sobieczky } \\ y t l e & \text { Espessura no ponto de controle do raio do bordo de ataque } \\ y t t e & \text { Espessura do perfil no bordo de fuga } \\ y t t h & \text { Máxima espessura do perfil } \\ \phi & \text { Função de ativação do neurônio }\end{array}$

Adim.

Adim.

Adim.

Adim.

Adim.

Adim.

Adim.

Adim.

Adim.

Adim. 


\section{ÍNDICE}

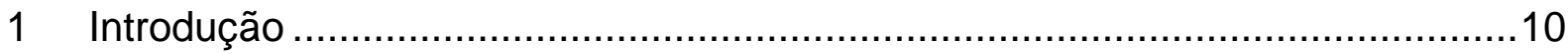

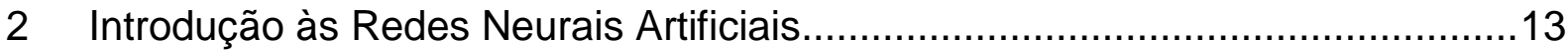

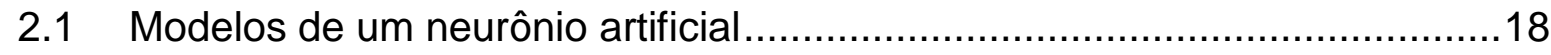

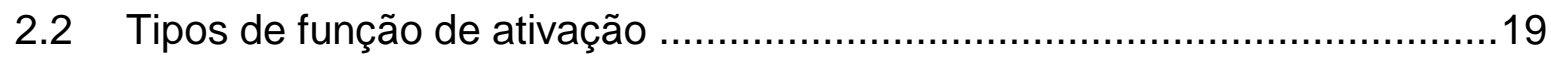

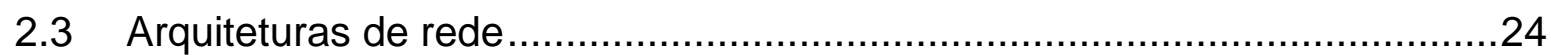

2.4 A Rede Neural Perceptron de Múltiplas Camadas .....................................27

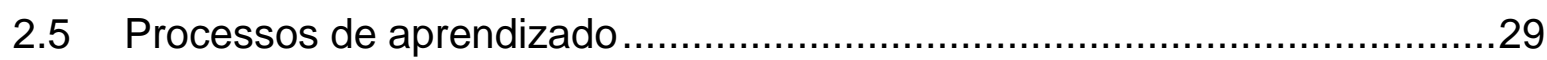

2.5.1 Processo de aprendizagem por retroalimentação (Back-Propagation)...31

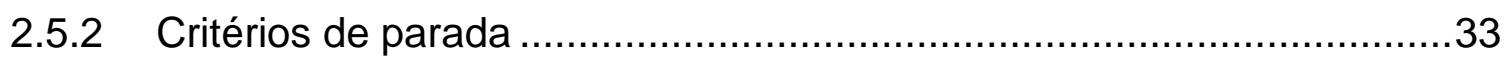

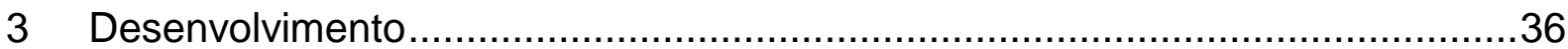

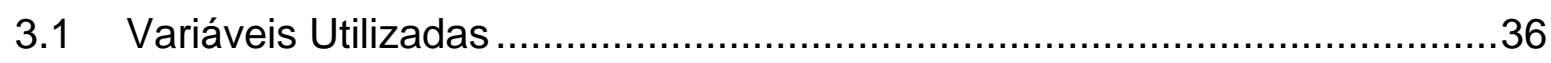

3.2 Geração dos conjuntos de treinamento e validação....................................38

3.3 Primeira Rede Neural - Forma em Planta ...............................................49

3.3.1 Resultados da Primeira Rede Neural .............................................51

3.4 Segunda Rede Neural - Forma em Planta ….........................................58

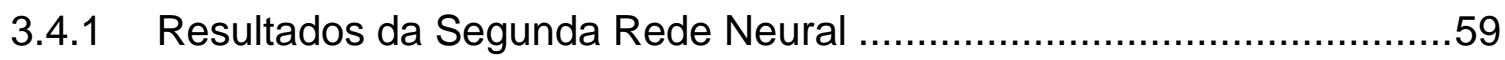

3.5 Terceira Rede Neural - Perfis parametrizados .........................................69

3.5.1 Resultados da Terceira Rede Neural - Perfis Parametrizados...............75

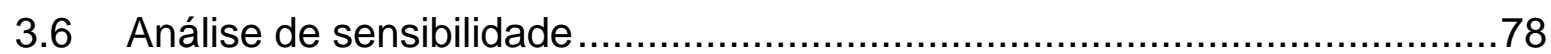

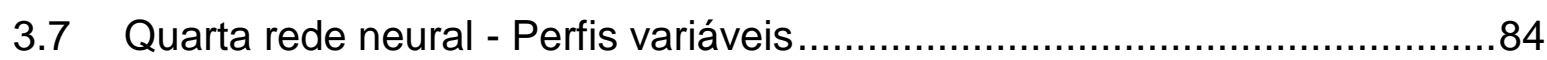

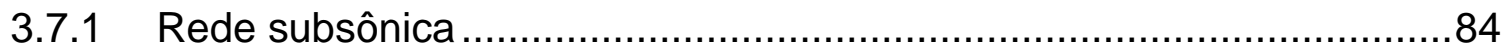

3.7.2 Rede transônica.......................................................................115

3.7.3 Rede transônica - Análise de Balanceamento do conjunto de

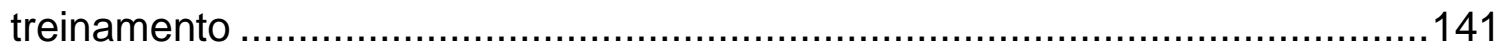

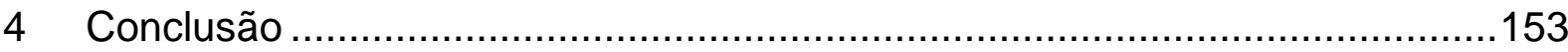

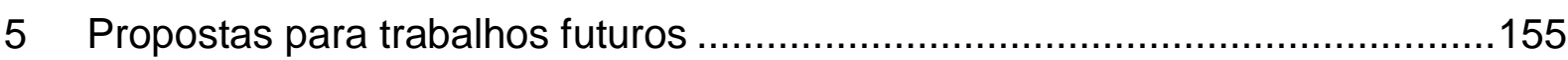

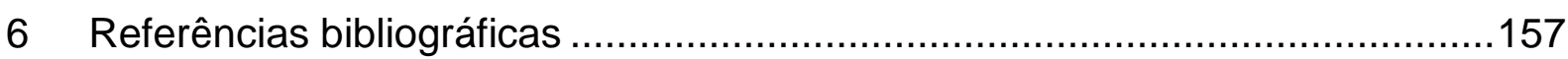

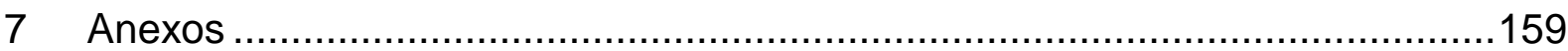

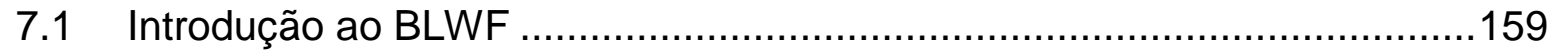

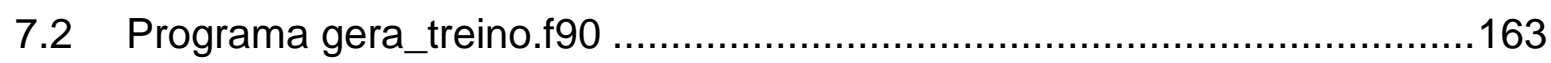

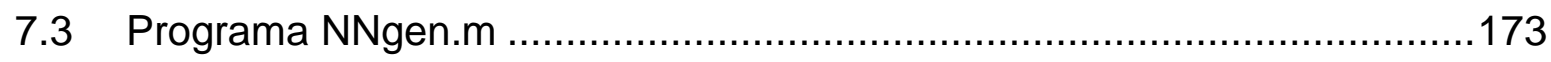

7.4 Exemplo de arquivo de entrada do BLWF v. 28 ...................................178 


\section{INTRODUÇÃO}

São vários os métodos disponíveis para a obtenção de distribuições de pressão em asas, dos quais podemos citar: ensaios em túnel de vento - onde a pressão estática é medida em vários pontos por meio de transdutores ou por meio de tinta sensível a pressão - simulações por meio de dinâmica dos fluidos computacional (CFD - Computational Fluid Dynamics) e até mesmo medidas da pressão estática em voo. Cada um destes métodos apresenta características diferentes com relação a precisão, custos e tempo de modelagem e calibração.

Testes em túnel de vento têm a capacidade de gerar resultados muito precisos, porém com um elevado custo operacional e de preparação dos modelos. Além disso, uma campanha de ensaios completa pode consumir um grande período de tempo, a ponto de prejudicar o desenvolvimento de um projeto. Outro ponto relevante é que, neste caso, a representatividade dos resultados é diretamente proporcional ao nível de fidelidade do modelo testado em relação ao avião real.

Por outro lado, há um grande número de softwares de dinâmica dos fluídos computacional disponíveis no mercado, com diferentes formulações e níveis de complexibilidade.

A evolução tecnológica tem proporcionado o lançamento de computadores mais poderosos e estes possibilitam a criação e implementação de softwares cada vez mais complexos e, consequentemente, mais precisos, de modo que certos resultados obtidos com o uso dos CFD's aproximam-se muito dos experimentais. Contudo, os softwares de CFD comerciais, mais robustos e confiáveis, requerem a aquisição de licenças, normalmente muito caras, e também exigem um trabalho 
normalmente alto para geração dos modelos e malhas necessárias para as simulações.

Assim, uma ferramenta ou metodologia que possibilite a obtenção de distribuições de pressão em um tempo menor que os CFD's convencionais, a um custo mais baixo e com acuracidade equivalente seria muito útil para a determinação dos carregamentos aerodinâmicos, especialmente em projetos de otimização.

Este trabalho tem como objetivo criar uma ferramenta, com estas características, utilizando para tanto as redes neurais artificiais para gerar distribuições de pressão em asas bitrapezoidais (mais comuns na aviação comercial). A proposta é treinar uma rede neural com dados extraídos de resultados de CFD.

Entretanto as redes neurais, usualmente, são capazes apenas de prever saídas escalares, o que significa que, dadas as entradas a rede neural é capaz de prever uma ou mais saídas escalares. Porém, a pressão estática é função de sua posição na asa, ou seja, da posição em relação à corda e a envergadura. Problemas desta natureza usualmente são resolvidos obtendo a distribuição de pressão por uma aproximação polinomial; assim, as respostas do metamodelo seriam os coeficientes do polinômio. Tal método, contudo, não apresenta uma solução muito robusta, uma vez que, em condições de Mach elevado, podem ocorrer ondas de choque na asa, resultando em não-linearidades muito grandes na distribuição de pressão, as quais dificultam ou impossibilitam o ajuste de um polinômio, mesmo que de alta ordem.

A solução proposta neste trabalho é de criar variáveis de posicionamento e adicioná-las às variáveis de projeto, assim a posição relativa na envergadura e na corda determinam onde se deseja obter a pressão estática. Optamos por obter como 
saída o $\Delta \mathrm{Cp}$, que é, por convenção, a diferença entre as pressões estáticas do intradorso e do extradorso da asa em um determinado ponto. Todavia, nada impediria de obtermos as pressões estáticas no intradorso e no extradorso, bastando para tanto que a rede apresentasse duas saídas.

As redes neurais empregadas foram alimentadas com resultados gerados via BLWF, ref. [7], para configurações de asas bastante genéricas, mas com fuselagem fixa.

Adicionalmente, na Seção 7, são apresentados os códigos fonte dos programas usados para a rede neural de perfil variável: Fortran gera_treino.f90 e Matlab NNgen.m - o primeiro utilizado para gerar e submeter ao CFD os indivíduos dos conjuntos de treinamento e validação, o segundo aplicado no treinamento e validação das redes. Na Seção 7 também se encontra, na integra, um arquivo de entrada do software de CFD utilizado para a geração dos conjuntos de treinamento que alimentaram as redes neurais deste trabalho. 


\section{INTRODUÇÃO ÀS REDES NEURAIS ARTIFICIAIS}

Desde a criação das primeiras máquinas, um dos grandes desejos do homem tem sido a criação de um mecanismo que possa operar sem a necessidade do controle humano, cuja independência seja desenvolvida de acordo com seu próprio aprendizado; uma máquina capaz de interagir com ambientes por ela desconhecidos, que possa ser denominada autônoma, inteligente ou cognitiva.

O sucesso de uma máquina autônoma depende única e exclusivamente de sua capacidade de lidar com uma variedade de eventos inesperados no ambiente em que atua. Tais máquinas devem ter maior capacidade de aprender tarefas de alto nível cognitivo dificilmente manipuladas pelas máquinas atuais e continuariam gradualmente adaptando-se e realizando tais tarefas com maior eficiência, mesmo que em condições imprevisíveis. Seriam, portanto, bastante úteis em locais onde a atuação humana é perigosa, tediosa ou inviável - como, por exemplo, em reatores nucleares, operações militares, no combate ao fogo ou na exploração do espaço a distâncias para além do alcance da Terra, de modo que a nave possa enviar as informações colhidas a despeito da impossibilidade de controle.

Os organismos humanos são uma fonte de motivação no desenvolvimento dessas máquinas, servindo de inspiração para o desenvolvimento de algoritmos de aprendizado e adaptação. Deste modo, espera-se que certas características dos organismos biológicos estejam presentes nas mesmas.

O cérebro humano é considerado o mais fascinante processador baseado em carbono existente, sendo composto por aproximadamente 10 bilhões de neurônios. Todas as funções e movimentos do organismo estão relacionados ao funcionamento dessas pequenas células. Os neurônios estão conectados uns aos outros por meio 
de sinapses; juntos, formam uma grande rede, denominada REDE NEURAL. As sinapses transmitem estímulos através de diferentes concentrações de $\mathrm{Na}+$ (Sódio) e K+ (Potássio), cujo resultado pode ser estendido por todo o corpo. Essa grande rede proporciona uma altissima capacidade de processamento e armazenamento de informação.

As redes neurais artificiais consistem em métodos de solucionar problemas a partir da construção de um sistema que simula o cérebro humano, inclusive seu comportamento; isto é, trata-se de uma composição de circuitos que funciona do seguinte modo: aprendendo, errando e fazendo descobertas. São técnicas computacionais cujo modelo foi inspirado na estrutura neural de organismos inteligentes, os quais adquirem conhecimento através da experiência. Uma grande rede neural artificial pode ter centenas ou milhares de unidades de processamento, enquanto que o cérebro de um mamífero pode ter bilhões de neurônios.

Uma rede neural artificial é um processador distribuido de forma paralelizada e constituído de unidades de processamento simples (os neurônios), que têm a propensão natural para armazenar conhecimento experimental e torná-lo disponível para uso. A rede neural artificial se assemelha ao cérebro em dois aspectos básicos: - O conhecimento é adquirido a partir de sua iteração com o ambiente através de um processo de aprendizagem;

- Forças de conexão entre neurônios, conhecidas como pesos sinápticos, são utilizadas para armazenar o conhecimento adquirido.

O processo de aprendizado é realizado a partir de um procedimento chamado algoritmo de treinamento (também conhecido por aprendizagem), cuja função é modificar ordenadamente os pesos sinápticos da rede a fim de alcançar um objetivo de projeto desejado. Ademais, é possível que uma rede neural modifique sua própria 
topologia, ou seja, sua estrutura, motivada pelo fato de que, no cérebro humano, neurônios morrem, bem como conexões inteiras deixam de existir para ceder espaço a outras.

Fica evidente que uma rede neural extrai todo seu poder computacional através, primeiramente, de sua estrutura paralela maciçamente distribuída e em segundo lugar pela sua habilidade de aprender e generalizar. A generalização se refere a rede ser capaz de reproduzir saídas adequadas para entradas que não estavam presentes durante o treinamento, ou seja, fornecer saídas válidas para entradas desconhecidas. Estas duas capacidades aliadas tornam possível que a rede neural seja capaz de resolver problemas complexos.

As redes neurais possuem propriedades que as tornam muito úteis em diversas aplicações práticas, das quais podemos destacar:

- Não linearidade: um neurônio artificial pode ser linear ou não linear. Uma rede neural constituída por neurônios não lineares faz com que ela própria seja não-linear - propriedade importante, que torna-a capaz de aprender e reproduzir fenômenos não lineares;

- Mapeamento de entrada e saída: um paradigma bastante conhecido, denominado treinamento supervisionado, envolve a modificação dos pesos sinápticos de uma rede neural pela aplicação de um conjunto de amostras de entradas e correspondentes saídas desejadas. Nesta modalidade de treinamento apresenta-se à rede uma entrada do conjunto escolhida ao acaso, de modo que os pesos sinápticos sejam modificados a fim de minimizar a diferença entre a resposta obtida pela rede e a resposta esperada. Esse processo é repetido para vários exemplos, os quais podem ser reapresentados a rede, porém numa ordem distinta. Desta forma, a rede 
retira informação dos exemplos, gerando um mapeamento entrada-saída para o problema considerado; este é o modelo de treinamento usado neste trabalho;

- Adaptabilidade: as redes neurais possuem ampla capacidade de adaptar seus pesos sinápticos de acordo com alterações ocorridas no meio ambiente, de modo que uma rede neural treinada em um ambiente específico pode ser facilmente retreinada para incluir as modificações sofridas pelo meio. Ademais, quando a rede está operando em um ambiente não estacionário (onde ocorrem mudanças com o tempo), esta pode ser projetada para modificar seus pesos em tempo real e atualizar-se. Essa característica torna as redes neurais muito úteis nas aplicações em classificação de padrões, processamento de sinais e controle adaptativo;

- Resposta a evidências: uma rede neural pode ser projetada para oferecer como saídas não apenas valores, mas também a confiabilidade de cada resposta - informação profícua no descarte de respostas inconsistentes, o que acarreta melhoria do desempenho da rede como um todo;

- Tolerância a falhas: implementada em sua forma física, isto é, de hardware, uma rede neural tem o potencial de ser tolerante a falhas, no sentido de que seu desempenho degrada-se suavemente sob condições de operação adversas. Se neurônios ou conexões desta rede são perdidos ou danificados, parte da informação armazenada pode ser perdida, no entanto o dano precisa ser extenso para que a informação global contida na rede seja seriamente degragada. Por exemplo, uma rede treinada para reconhecimento de padrões que possua uma quantidade razoável de neurônios pode perder algum destes e ainda assim continuar a reconhecer os padrões corretamente; 
- Analogia neurobiológica: a grande semelhança entre a rede neural biológica e as redes artificiais faz com que tanto neurobiólogos enxerguem estas como ferramenta na interpretação de fenômenos neurofisiologistas, como os engenheiros e cientistas, em contrapartida, inspirem-se naquelas para propor redes capazes de solucionar questões cada vez mais complexas.

O caminho para a compreensão do funcionamento do cérebro humano foi facilitado após o pioneiro trabalho de Ramón y Cajál (1911), que introduziu a idéia de neurônios como constituíntes do cérebro. Tipicamente, os neurônios são de cinco a seis ordens de grandeza mais lentos que as portas lógicas baseadas em silício - os eventos em um circuito de silício se dão na ordem de nanossegundos $\left(10^{-9}\right)$, enquanto que os eventos neurais acontecem na ordem de milissegundos $\left(10^{-3}\right)$. Tal lentidão, entretanto, é compensada pelo espantoso número de neurônios presentes no cérebro, altamente conectados entre si. Estima-se que o cérebro humano seja formado por aproximadamente 10 bilhões de neurônios e 60 trilhões de conexões (Kock, Segev, 1989), resultando em uma estrutura altamente eficiente.

Além disso, a eficiencia energética do cérebro é de aproximadamente $10^{-16}$ joules por operação por segundo, enquanto que o valor correspondente para os melhores computadores em uso é de cerca de $10^{-6}$ joules por operação por segundo (Faggin, 1991). 


\subsection{Modelos de um neurônio artificial}

Um neurônio é uma unidade de processamento de informação fundamental para a operação de uma rede neural.

Uma rede neural pode conter de um a centenas de neurônios. A Figura 1, mostra o modelo de um neurônio, que serve de base para o projeto das redes neurais artificiais.

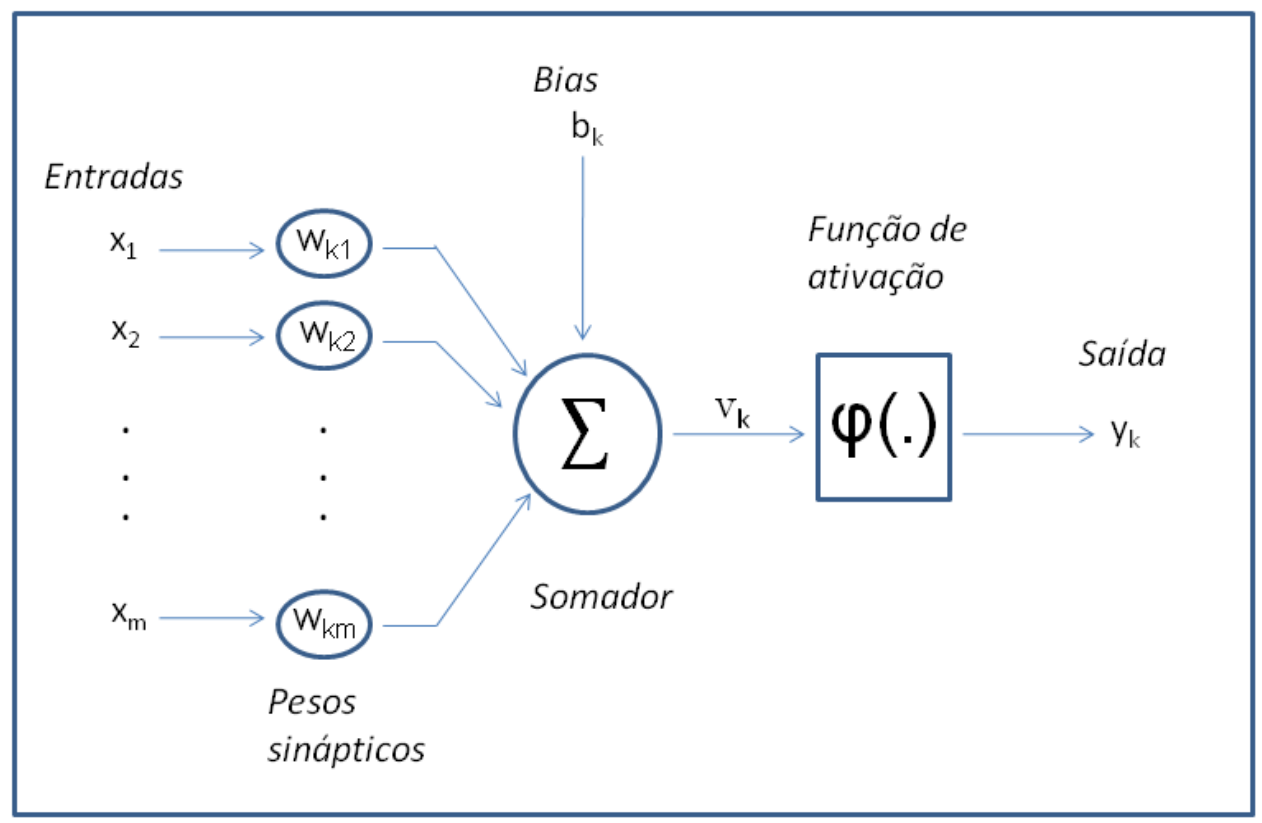

FIGURA 1: REPRESENTAÇÃO BÁSICA DE UM NEURÔNIO ARTIFICIAL.

Quatro elementos básicos do modelo neuronal podem ser identificados na Figura 1:

1) Um conjunto de sinapses, cada uma representada por um peso $\left(w_{k i}\right)$. Especificamente, um sinal $x_{j}$ na entrada da sinapse $j$, conectado ao neurônio $k$, é multiplicado pelo seu peso sináptico $w_{\mathrm{kj}}$. Ao contrário do que ocorre na sinápse cerebral, o peso sináptico de um neurônio artificial pode assumir tanto valores negativos como positivos;

2) Um somador dos sinais de entrada, ponderados pelas respectivas sinapses do neurônio. Tais operações constituem um combinador linear; 
3) Uma função de ativação, usada para restringir a amplitude da saída de um neurônio. É conhecida também como função restritiva, uma vez que limita o intervalo permissível de amplitude do sinal de saída a um valor finito. Tipicamente, o intervalo normalizado da amplitude da saída de um neurônio é escrito como o intervalo unitário fechado [0,1] ou [-1,1];

4) $O$ bias, representado por $b_{k}$, o qual altera a entrada líquida da função de ativação de um neurônio. Se o bias é positivo, há um aumento de entrada líquida; se este é negativo, ocorre o inverso.

Podemos definir um neurônio k, em termos matemáticos, da seguinte forma:

$$
\begin{gathered}
u_{k}=\sum_{j=1}^{m} w_{k j} x_{j} \\
y_{k}=\varphi\left(u_{k}+b_{k}\right),
\end{gathered}
$$

Onde $x_{1}, x_{2}, \ldots, x_{m}$ são os sinais de entrada; $w_{k 1}, w_{k 2}, \ldots, w_{k m}$ os pesos sinápticos do neurônio k; $u_{k}$ a saída do combinador linear dos sinais de entrada; $\varphi($.$) a função$ de ativação; e $y_{k} 0$ sinal de saída do neurônio.

\subsection{Tipos de função de ativação}

A função de ativação, representada por $\varphi(v)$, define a saída de um neurônio em termos do campo local induzido $v$. A seguir serão identificados alguns dos tipos mais comuns de funções de ativação:

1. Função de Limiar: também conhecida como função de Heaviside. A equação matemática que a define pode ser vista na equação 3: 


$$
\varphi(v)=\left\{\begin{array}{l}
1 \text { se } v \geq 0 \\
0 \text { se } v<0
\end{array}\right\}
$$

Aplicando a função limiar à saída do campo induzido $v$, temos:

$$
y_{k}=\left\{\begin{array}{lll}
1 & \text { se } & v_{k} \geq 0 \\
0 & \text { se } & v_{k}<0
\end{array}\right\}
$$

Onde,

$$
v_{k}=\sum_{j=1}^{m} w_{k j} x_{j}+b_{k}
$$

Esse modelo de neurônio é conhecido na literatura como modelo de McCulloch-Pitts. Nele, a saída de um neurônio assume o valor 1 se o campo induzido daquele neurônio for não-negativo; do contrário, assume valor 0 . Tal definição descreve a propriedade do tudo-ou-nada do modelo de McCulloch-Pitts.

2. Função Sinal: a função sinal é uma variação da função limiar, como pode ser visto na matemática (equação 6):

$$
\varphi(v)=\left\{\begin{array}{lr}
1 & \text { se } v>0 \\
0 & \text { se } v=0 \\
-1 & \text { se } v<0
\end{array}\right\}
$$

3. Função Linear: a equação matemática que define a função linear pode ser vista na equação 7 :

$$
\varphi(v)=v
$$

A função linear simplesmente assume como valor de saída do neurônio o valor do campo induzido $v$, deste neurônio. 
4. Função Sigmóide: função de ativação mais utilizada na construção de redes neurais artificiais, cujo gráfico tem o formato de um 'S'. É definida como uma função estritamente crescente, que exibe um balanceamento adequado entre comportamento linear e não-linear.

Um exemplo de função do tipo sigmóide é a função logística, definida matemáticamente por:

$$
\varphi(v)=\frac{1}{1+\exp (-a v)}
$$

Sendo a o parâmetro de inclinação da função; ou seja, variações nesse parâmetro resultam em funções com diferentes inclinações. Quando atinge o limite, com o parâmetro de inclinação aproximando-se de infinito, a função sigmóide tornase função limiar, mas com a vantagem de ser diferenciável. A função logística assume valores contínuos entre 0 e 1 .

Muitas vezes é desejável que a função de ativação estenda-se de -1 a 1 , assumindo uma forma anti-simétrica em relação a origem, ou seja, uma função do tipo $f(-x)=-f(x)$. Outra função do tipo sigmóide com a mesma característica é a função tangente hiperbólica, ou tangente sigmóide, definida por:

$$
\varphi(v)=\tanh (v)
$$

A possibilidade de uma função de ativação do tipo sigmóide assumir valores negativos traz benefícios analíticos que serão discutidos mais adiante.

As Figuras 2, 3, 4, 5 e 6 mostram os gráficos das funções de ativação descritas: 


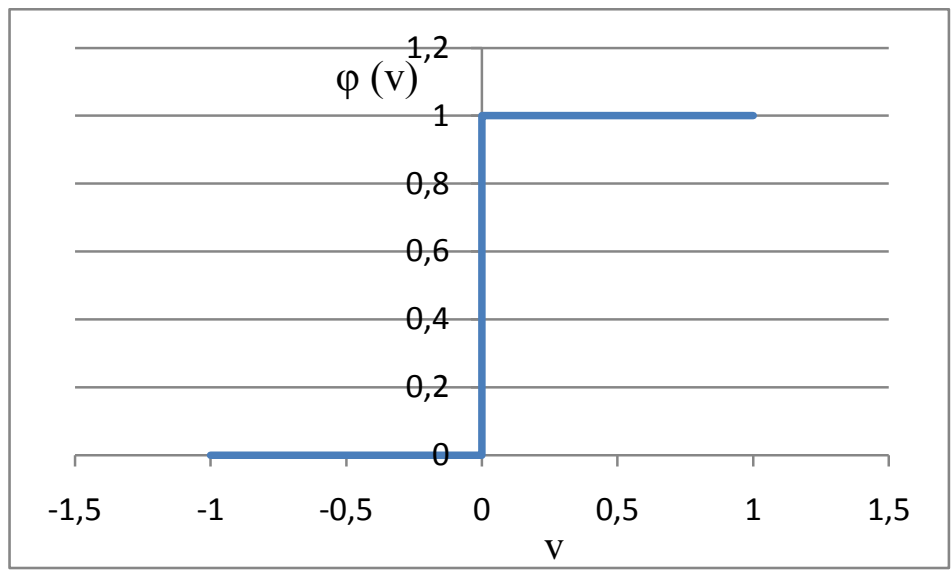

FIGURA 2: FUNÇÃO LIMIAR

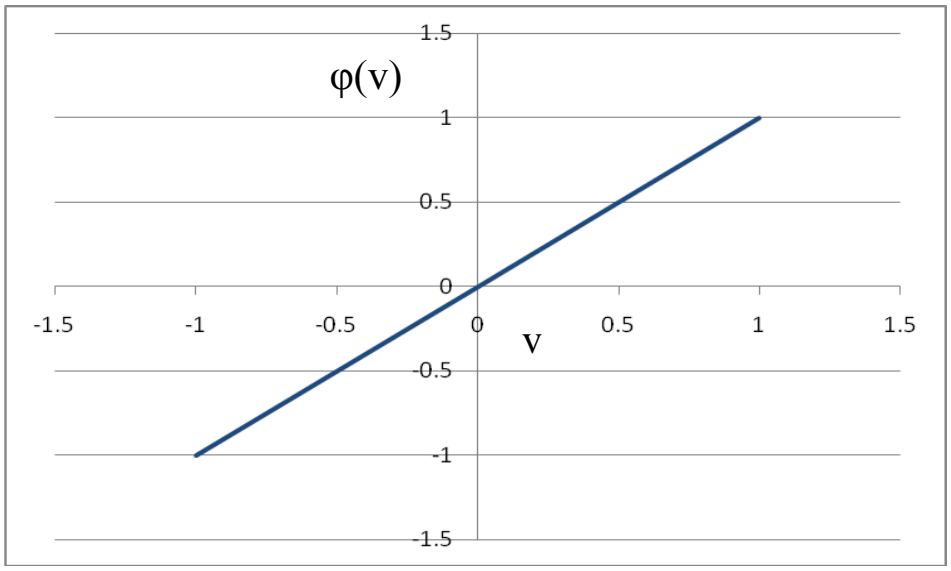

FIGURA 3: FUNÇÃO LINEAR

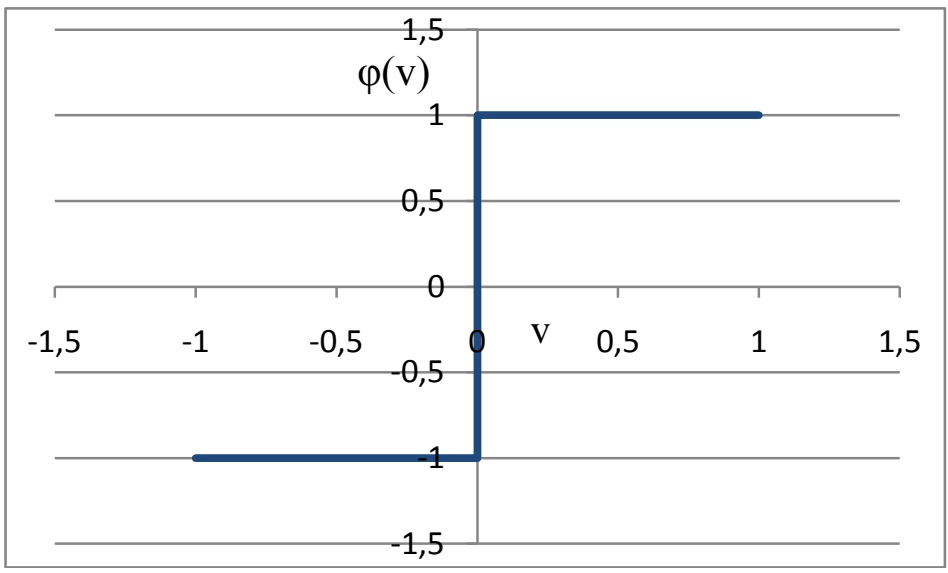

FIGURA 4: FUNÇÃO SINAL 


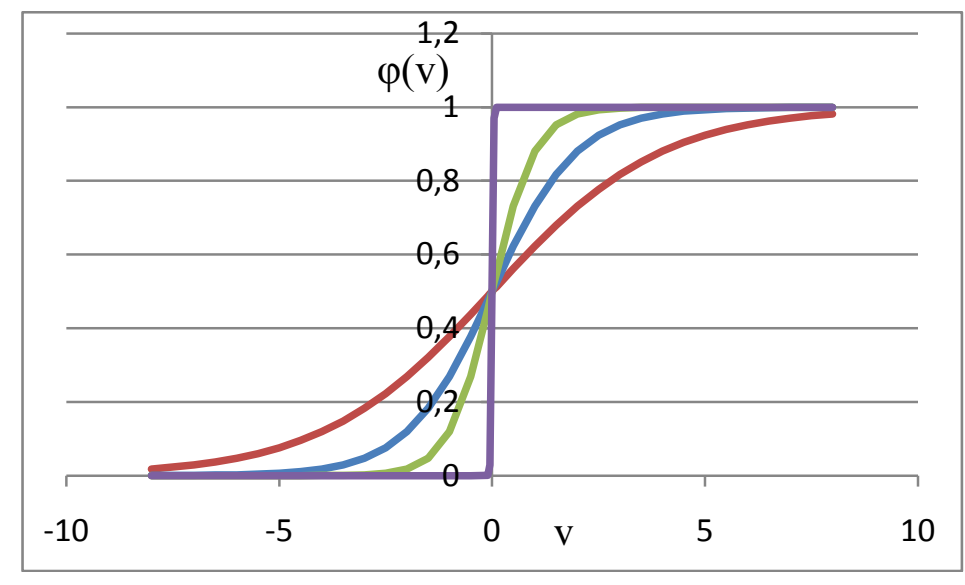

FIGURA 5: FUNÇÃO LOGISTICA SIGMÓIDE COM DIFERENTES PARAMETROS DE INCLINAÇÃO

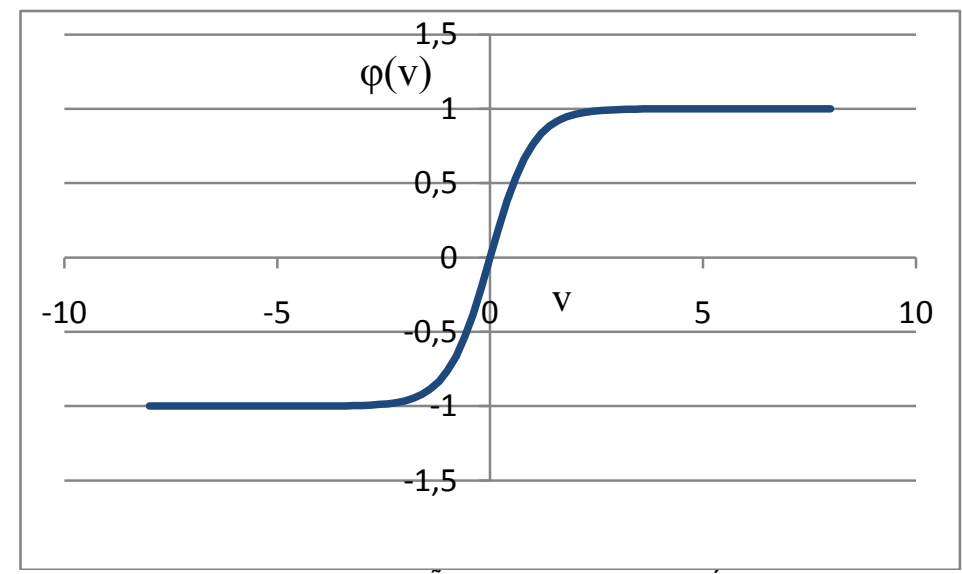

FIGURA 6: FUNÇÃO TANGENTE SIGMÓIDE 


\subsection{Arquiteturas de rede}

A arquitetura de uma rede neural é a forma como os neurônios de uma rede estão estruturados. A arquitetura da rede é geralmente relacionada com o algoritmo de que será usado para treinar a rede.

Pode-se identificar três classes de arquiteturas de redes fundamentalmente diferentes:

1. Redes alimentadas adiante com camada única: os neurônios estão dispostos em apenas uma camada de processamento e uma camada de saída. Nesta arquitetura, o sentido de propagação do sinal é feito somente adiante; todos os neurônios da camada de processamento recebem informações de todas as entradas, processam o sinal e o transmitem aos neurônios de saída.

A Figura 7 ilustra uma rede deste tipo:

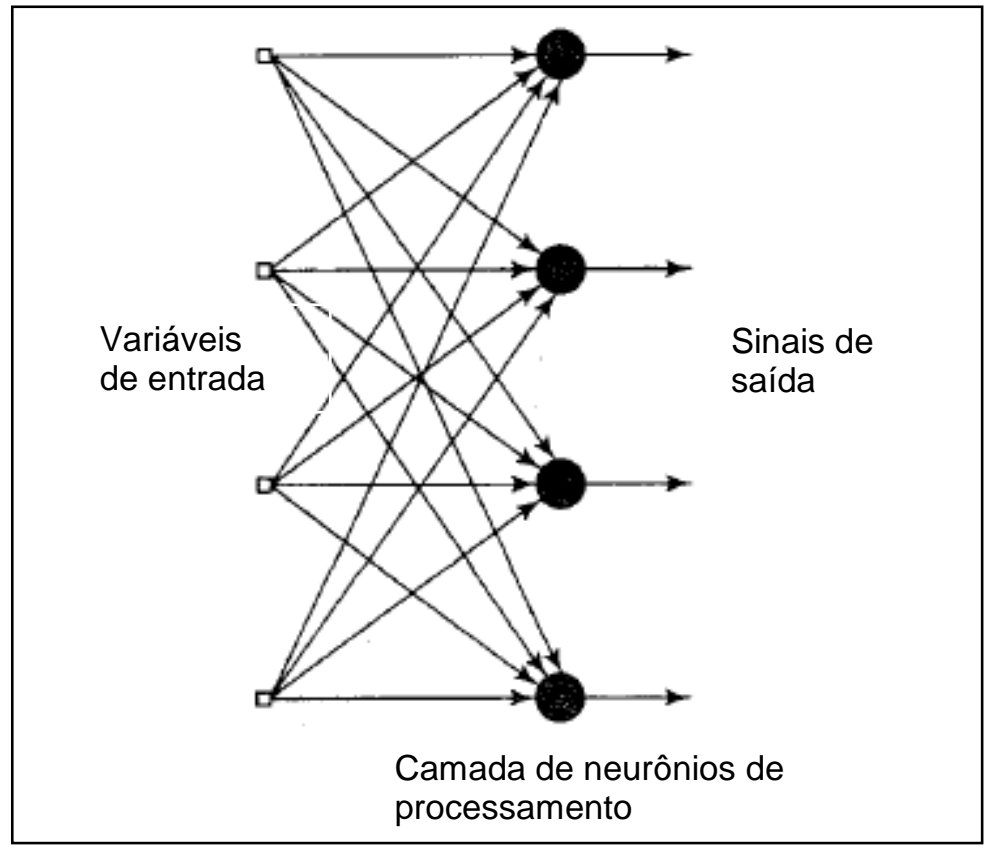

FIGURA 7: REDE ALIMENTADA ADIANTE COM CAMADA ÚNICA 
2. Redes alimentadas adiante com múltiplas camadas: este tipo de arquitetura distingue-se por apresentar uma ou mais camadas ocultas de neurônios, ou seja, de camadas de processamento. A função das camadas de processamento é intervir entre as entradas externas e a saída da rede.

Os nós de fonte (ou das entradas) fornecem sinais com as entradas, os quais serão combinados com os pesos para formar o padrão de ativação. Tal ativação será aplicada aos neurônios da primeira camada oculta, cujos sinais de saída serão combinados aos pesos, formando a ativação da segunda camada oculta de neurônios, e assim por diante. É importante lembrar que cada neurônio da rede possui obrigatóriamente uma função de ativação que processa o sinal de entrada. $\mathrm{O}$ conjunto de sinais de saída dos neurônios da camada de saída da rede constitui a resposta global desta.

A rede representada na Figura 8 é dita totalmente conectada, pois cada um dos nós de uma camada da rede está conectado a todos os nós da camada seguinte. Se, no entanto, algumas destas conexões estiverem faltando, diz-se que a rede é parcialmente conectada. 


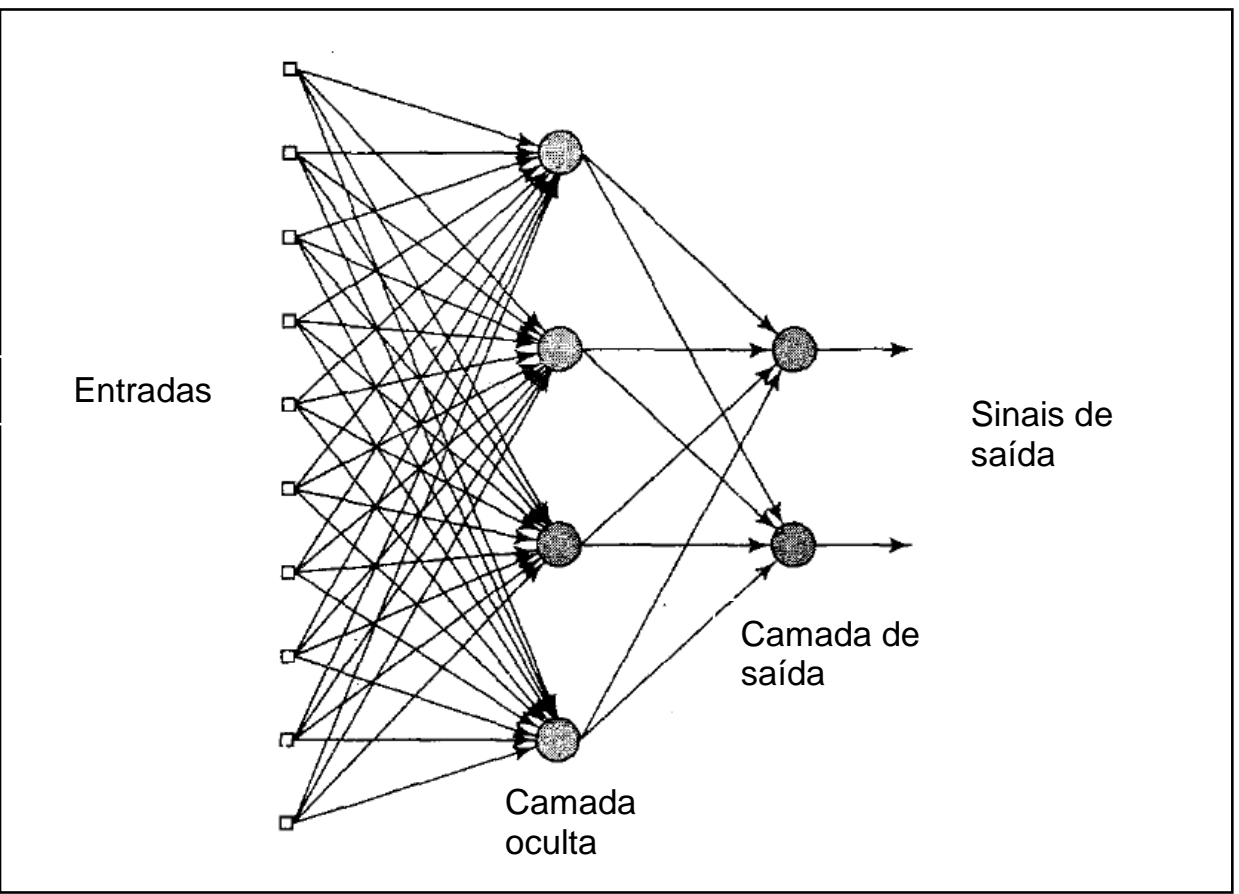

FIGURA 8: REDE ALIMENTADA ADIANTE COM UMA CAMADA OCULTA E UMA CAMADA DE SAÍDA

A adição de camadas ocultas torna a rede mais hábil a extrair características dos dados de entrada. Num sentido bastante livre, a rede adquire uma perspectiva global apesar de sua conectividade local, devido ao conjunto extra de conexões sinápticas e à dimensão extra de interações neurais (Churchland, Sejnowski, 1992). Tal característica adquire especial importância quando em face a um grande número de entradas.

3. Redes recorrentes: diferenciam-se das redes alimentadas adiante por ter pelo menos um laço de realimentação. Uma rede recorrente pode ser constituída de uma única camada de neurônios, com cada neurônio alimentando a si próprio e aos outros neurônios com sua saída.

A presença de realimentação - ou recorrência - gera um impacto profundo no desempenho da rede e em sua capacidade de aprendizagem. A Figura 9 ilustra um exemplo de rede com arquitetura recorrente: 


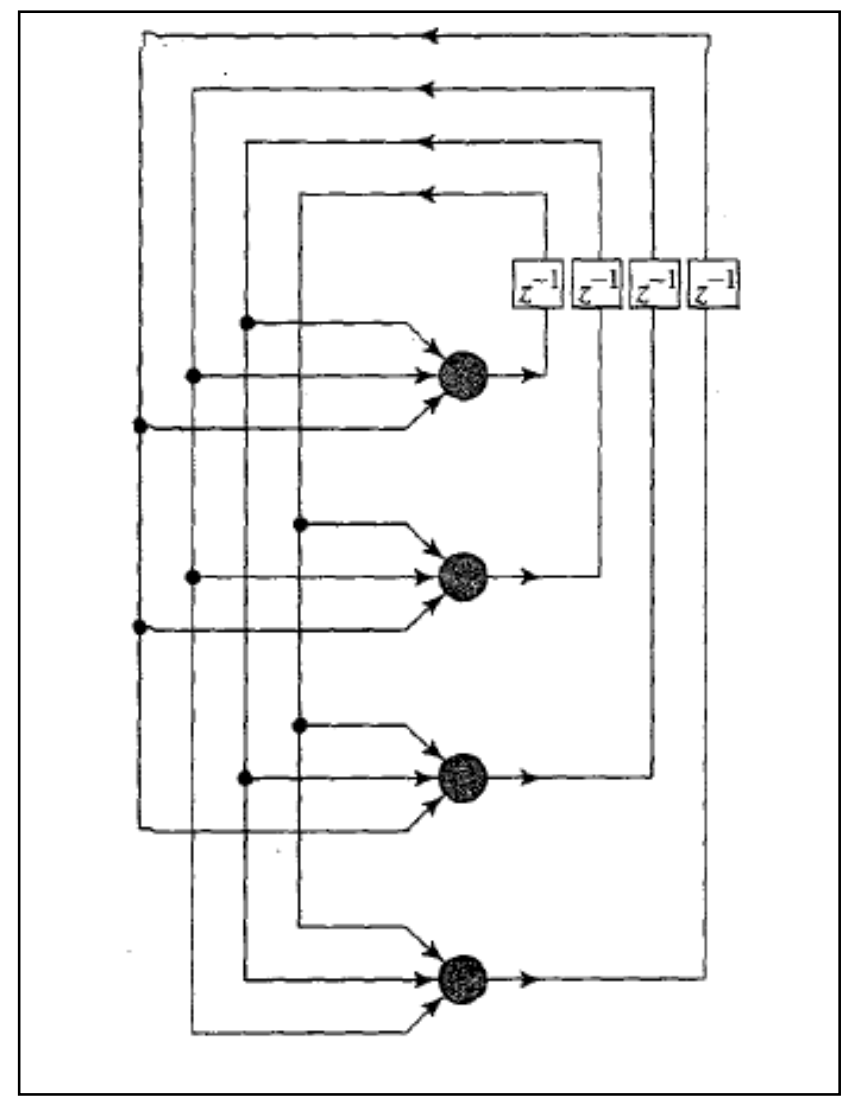

FIGURA 9: REDE RECORRENTE

\subsection{A Rede Neural Perceptron de Múltiplas Camadas}

A rede neural artificial é um sistema de neurônios ligados por conexões sinápticas, divididos em: neurônios de entrada - que recebem estímulos do meio externo, neurônios internos ou ocultos - que fazem o processamento da informação e neurônios de saída - que se comunicam com o exterior.

O arranjo de perceptrons em camadas é denominado Perceptron de múltiplas camadas, concebido para resolver problemas mais complexos, incapazes de serem solucionados pelo modelo de neurônio básico. Um único perceptron ou uma combinação das saídas de alguns perceptrons poderia realizar uma operação XOR (problema do "ou" exclusivo), mas seria incapaz de aprendê-la. Para isto são necessárias mais conexões, as quais só existem em uma rede de perceptrons 
dispostos em camadas e também como o problema XOR é não-linear, deve-se utilizar funções de ativação igualmente não-lineares, para que esta característica possa ser representada.

Os neurônios internos são de suma importância na rede perceptron, pois foi provado que sem estes a resolução de problemas linearmente não separáveis tornase impossível (Haykin, 1999). Em outras palavras, pode-se dizer que uma rede é composta por várias unidades de processamento, que realizam operações apenas sobre seus dados locais - entradas recebidas pelas suas conexões. O comportamento inteligente de uma rede neural artificial vem das interações entre os neurônios.

As redes neurais aprendem através uma regra de treinamento, na qual os pesos de suas conexões são ajustados de acordo com os padrões apresentados. Em outras palavras, o aprendizado é feito através de exemplos.

O processo de treinamento pelo qual a rede neural passa dá-se a partir de casos reais conhecidos, através dos quais ela adquire a sistemática necessária para executar adequadamente o processo desejado dos dados fornecidos. Sendo assim, a rede neural é capaz de extrair regras básicas a partir de dados reais, diferindo da computação programada, na qual um conjunto de regras rígidas pré-fixadas e algoritmos são necessários.

Em Haykin (1999), é dito frequentemente que o projeto de uma rede neural de múltiplas camadas utilizando o algoritmo de retropropagação (este algoritmo será melhor abordado na seção 2.5.1) é mais uma arte do que uma ciência, já que muitos dos numerosos fatores envolvidos no projeto são o resultado da experiência particular de cada um. Não existem regras exatas na determinação de fatores como o número de camadas a ser utilizado, a quantidade de neurônios em cada camada e 
quantos indivíduos necessários para cada conjunto de treinamento da rede. Neste trabalho, a determinação de tais parâmetros foi realizada de maneira totalmente experimental, via tentativa e erro, sem o auxílio de nenhuma heurística no apontamento do número ideal de cada parâmetro. Mais detalhes serão mostrados na Seção 3.2.

\subsection{Processos de aprendizado}

A propriedade fundamental das redes neurais é a habilidade de extrair informação de seu ambiente melhorando com isso seu desempenho, ou seja, a capacidade de aprendizado. Isto dá-se mediante um processo iterativo de ajustes aplicados a seus pesos - o treinamento. Quando a rede neural atinge uma solução generalizada para uma classe de problemas, cumpre-se o aprendizado.

No contexto das redes neurais artificiais, pode-se definir aprendizagem como "um processo pelo qual os parâmetros livres de uma rede neural (pesos) são adaptados através de um processo de estimulação pelo ambiente no qual está inserida. O tipo de aprendizagem é determinado pela forma como a modificação dos parâmetros ocorre".

Denomina-se algoritmo de aprendizado a um conjunto de regras estabelecidas para a solução de um problema de aprendizado. Há diversos tipos de algoritmos de aprendizado específicos para determinados modelos de redes neurais, os quais diferem entre si principalmente pelo modo como os pesos são modificados.

A rede neural baseia-se nos dados para extrair um modelo geral. Portanto, a fase de aprendizado tem de ser rigorosa e verdadeira, a fim de evitar modelos espúrios. Todo o conhecimento de uma rede neural está armazenado nas sinapses, 
ou seja, nos pesos atribuídos às conexões entre os neurônios. Segundo Haykin (1999), 50 a 90\% do total de dados devem ser separados para o treinamento da rede neural, dados estes escolhidos aleatoriamente a fim de que a rede "aprenda" as regras e não "decore" exemplos. O restante dos dados só é apresentado à rede neural na fase de validação, que são testes impostos para comprovar sua capacidade de representar corretamente o inter-relacionamento entre os dados.

Outro fator importante é de que modo a rede neural se relaciona com o ambiente. Nesse contexto, existem três paradigmas de aprendizado:

1. Por independência de quem aprende: as redes neurais artificiais aprendem através da memorização, do contato, de exemplos, por analogia, exploração e descoberta;

2. Por retroação do mundo: diz respeito à ausência ou presença de realimentação explícita do mundo exterior, ou seja, que em certos intervalos de tempo um agente assinale acertos e erros. Assim, este paradigma de aprendizado se subdivide em dois outros:

2.1 Aprendizado Supervisionado: utiliza-se um agente externo o qual indica à rede um comportamento bom ou ruim segundo o padrão de entrada;

2.2 Aprendizado Não Supervisionado (auto-organização): utiliza-se, não um agente externo, mas exemplos semelhantes para que a rede responda de maneira semelhante.

\section{Por Finalidade do Aprendizado}

3.1 Auto-associador: uma coleção de exemplos é apresentada à rede para que esta os memorize. Quando um dos elementos da coleção 
de exemplos é apresentado de modo errôneo, a rede deve mostrar o exemplo original, funcionando, portanto, como um filtro;

3.2 Hétero-associador. variação do auto-associador, no qual se memoriza um conjunto de pares. O sistema aprende a reproduzir o segundo elemento do par ainda que o primeiro esteja pouco modificado, funcionando, desta maneira, como um reconhecedor de padrões.

Existem cinco regras básicas de aprendizagem: a aprendizagem por correção de erro, que corrige os pesos de modo a minimizar a diferença entre as saídas da rede e as saídas esperadas; a aprendizagem baseada em memória, que opera memorizando explicitamente os dados de treinamento; a aprendizagem de Boltzmann, que é baseada em ideias de mecânica estatística; e as aprendizagens hebbiana e a competitiva, ambas inspiradas em considerações neurobiológicas.

\subsubsection{Processo de aprendizagem por Retroalimentação (Back- PROPAGATION)}

O presente trabalho é composto por um grande conjunto de variáveis variáveis de condição de voo, variáveis de forma em planta e variáveis dos perfis - e uma saída esperada $(\Delta \mathrm{Cp})$. Faz-se necessário, portanto, um esquema de aprendizagem supervisionado e com correção de erros.

É fundamental neste tipo de aprendizado a definição de um conjunto de treinamento bastante representativo do problema proposto, com suas variáveis de entrada e respectivas saídas esperadas. Segundo Haykin (1999), é imprescindível que as entradas estejam normalizadas a fim de que o valor médio destas seja muito 
próximo a zero, evitando que os pesos sinápticos da camada de entrada cresçam ou decresçam ao mesmo tempo, o que tornaria tipicamente lenta a aprendizagem.

O processo de treinamento é bastante simples e consiste em alguns passos: Inicialização: primeiramente, os pesos das sinapses neurais devem ser inicializados. Os valores iniciais assumidos por eles têm grande impacto na curva de aprendizado e, consequentemente, no desempenho do treinamento da rede neural. De acordo com Haykin (1999), para uma rede do tipo perceptron de múltiplas camadas não deve-se inicializar os pesos com valores muito altos, de modo a evitar a saturação dos neurônios; isto é, que o campo induzido de cada neurônio torne-se tão grande - positiva ou negativamente - a ponto da função de ativação não mais responder adequadamente ao sinal, fornecendo como saída o valor máximo da função. No entanto, com valores muito baixos na inicialização dos pesos o algoritmo de retropropagação pode operar em uma "região muito plana" da superfície de erro, desacelerando o treinamento. Logo, o ponto ideal encontra-se numa posição média entre os dois casos extremos.

Apresentação: apresenta-se à rede neural cada indivíduo do conjunto do treinamento (ou conjunto de variáveis). Denomina-se época a apresentação de todos os indivíduos do conjunto de treinamento à rede neural.

Propagação: o sinal de entrada fornecido pelos indivíduos é processado pela rede, obtendo suas saídas. O resultado é comparado com o esperado e então calcula-se um erro para cada indivíduo ou uma média de todos os erros.

Retropropagação: ajusta-se os pesos de acordo com os gradientes locais da rede, ou seja, calcula-se para cada peso uma derivada do erro em relação ao peso, cuja correção será feita de modo proporcional à sua derivada. 
Iteração: a junção de cada evento de apresentação, propagação e retropopagação de todos os indivíduos do conjunto de treinamento é conhecido como iteração, ou também época. São feitas quantas iterações sejam necessárias até que se atinja algums dos critérios de parada (que serão tratados na seção 2.5.2).

Cabe salientar a importância de alternar-se a ordem de apresentação dos indivíduos do conjunto de treinamento à rede em cada fase de propagação; isto força o algoritmo a modificar os pesos de diferentes formas a cada iteração.

A correção dos pesos no decorrer de uma época pode ser feita de dois modos:

1. Modo sequencial: a correção ocorre a cada apresentação de um exemplo do conjunto de treinamento à rede. Cada correção baseia-se somente no erro do exemplo apresentado naquela iteração. Logo, em cada época são feitas tantas correções (para cada peso) quantos exemplos de treinamento existirem.

2. Modo por lote: é feita apenas uma correção por época. Todos os exemplos do conjunto de treinamento são apresentados à rede, o erro médio é calculado e a partir deste são realizadas as correções dos pesos.

Segundo Haykin (1999), o modo sequencial é o método de correção mais eficiente para redes maiores e com grande número de variáveis, pois somente um ajuste por época, neste caso, poderia tornar a convergência muito trabalhosa ou até mesmo ineficiente.

\subsubsection{CRITÉRIOS DE PARADA}

Em geral, não há como demonstrar que o algoritmo de treinamento atingiu convergência, bem como não existem critérios bastante definidos para encerrar a 
sua operação. Tem-se à disposição, em contrapartida, critérios bem razoáveis para o encerramento do ajuste dos pesos, cada qual com seu mérito particular. Alguns desses critérios são: o número limite de épocas de treinamento, o mínimo erro médio quadrático admitido, derivada dos erros e por validação cruzada.

O critério de parada pelo limite de épocas determina que o treinamento seja finalizado quando o processo atingir um limite pré-determinado de épocas. A vantagem desse método é evitar o encerramento prematuro do processo de treinamento (caso ele esteja em um mínimo local, por exemplo); entretanto, para aumentar as chances de encontrar um mínimo global, o limite de épocas precisa, em geral, ser ajustado para um valor bastante alto, acabando por retardar o processo.

No caso do critério de parada pelo erro médio quadrático o treinamento é feito até que seja obtido de todos os indivíduos do conjunto de treinamento um erro médio quadrático menor do que um valor pré-estabelecido. Apresenta como benefício a possibilidade de fixar um alvo ou uma meta para o desempenho final da rede; tal método também evita prolongamento desnecessário do treinamento. Contudo, é indispensável que o usuário conheça o valor desejado para seu erro médio quadrático aceitável, tarefa árdua dependendo do tamanho e do grau de complexidade da rede.

Já o critério de parada pela derivada do vetor gradiente dos erros baseia-se no fato de que a correção feita nos pesos é proporcional à derivada parcial de primeira ordem do erro em relação a cada peso (gradiente dos erros); quando a norma euclidiana do vetor gradiente alcança um valor suficientemente pequeno, o treinamento pode ser finalizado. Critério bastante eficaz, uma vez que é capaz de impedir que o treinamento estenda-se desnecessariamente. Porém, tal qual o método anterior, o usuário deve saber qual o mínimo valor aceitável para a derivada. 
Há ainda outro critério de parada útil e teoricamente fundamentado - a validação cruzada - consiste em, finda cada época, submeter a rede a um teste de desempenho e capacidade de generalização. O treinamento é interrompido quando o desempenho de generalização for adequado ou atingir o seu máximo de modo evidente. 


\section{DESENVOLVIMENTO}

O presente estudo limitou-se em obter a distribuição de pressão em asas bitrapezoidais, definidas por três perfis independentes, com posição de quebra variável e com número de Reynolds constante. Por tratar-se de um problema complexo - seja pelo número de variáveis, seja pela natureza não linear da distribuição de pressão -, decidiu-se iniciar o modelamento da rede neural para um problema mais simples e aumentar gradualmente seu nível de complexidade.

As redes neurais implementadas neste trabalho foram treinadas com conjuntos de treinamento criados com a utilização de um código de dinâmica dos fluidos computacional (CFD) chamado Boundary Layer Wing-Fuselage (BLWF), versão 28 (mais detalhes na seção 7.1).

\subsection{Variáveis Utilizadas}

Uma asa como as de interesse neste estudo são definidas por algumas variáveis. São variáveis que descrevem a forma em planta da asa, como o enflechamento, cordas na raiz, na quebra e na ponta, posição de quebra, envergadura e área de referência. Tais variáveis serão de agora em diante tratadas simplificadamente por variáveis de forma em planta. A Figura 10 mostra algumas destas variáveis de maneira esquemática. 


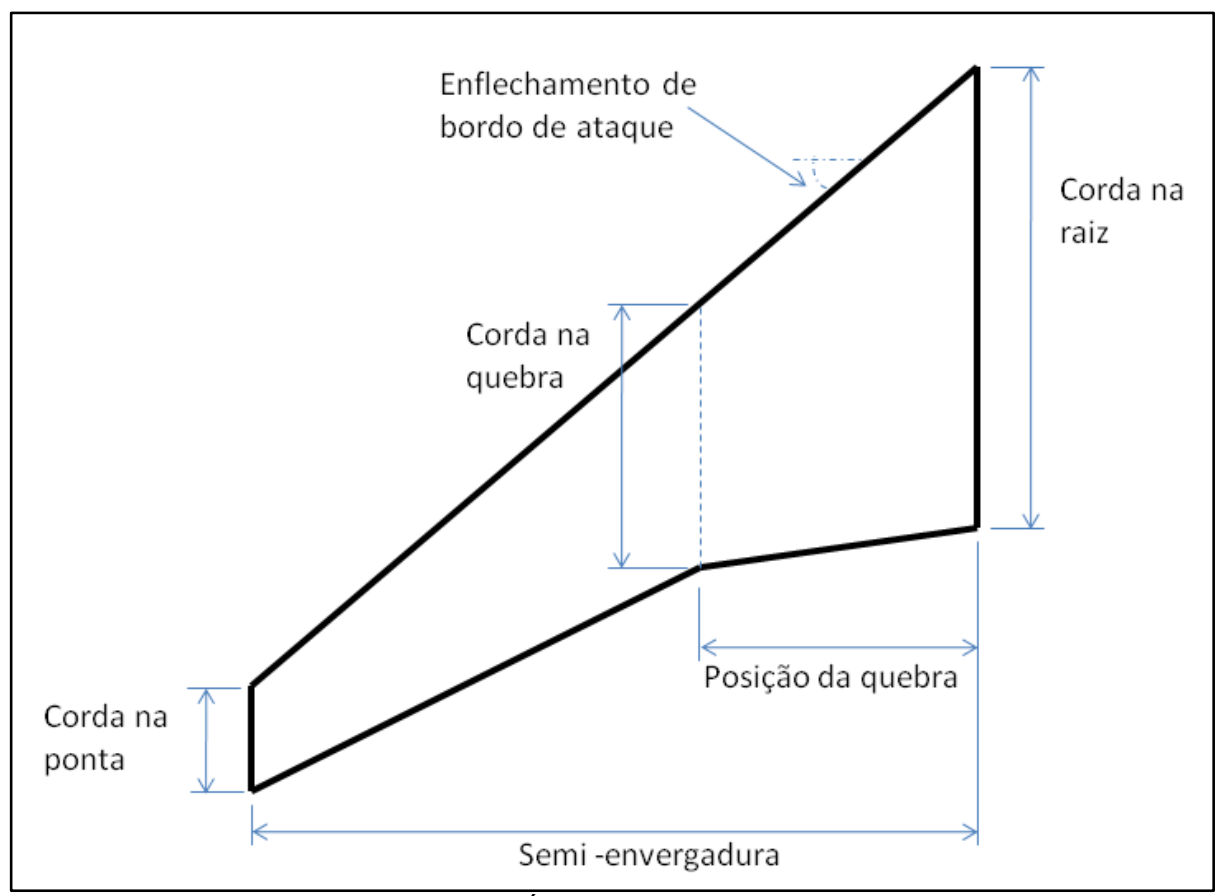

FIGURA 10: VARIÁVEIS DE FORMA EM PLANTA

Porém, neste trabalho usaremos como variável o afilamento - que é relação entre a corda na ponta e a corda na raiz, o alongamento - que é dado pela relação entre o quadrado da envergadura e a área de referência. Optamos por manter a área de referência constante, com um valor de 50 metros quadrados. Assim, definindo o alongamento (variável c), o enflechamento (variável d), o afilamento (variável e), a posição da quebra (variável f), e já teremos as outras variáveis definidas implicitamente.

Além disso, optamos por considerar apenas o efeito do ângulo de ataque (variável b) sob a distribuição de pressão, não considerando condições de rolamento e derrapagem. Outra variável importante considerada neste estudo é o número de Mach (variável a).

Com estas variáveis conseguimos definir uma asa (em planta) e uma determinada condição de voo. Porém como o objetivo deste trabalho é obter a distribuição de pressão na asa, ou seja, o valor da pressão estática em determinados pontos ao longo da superficie da asa, ainda necessitamos de variáveis 
de posicionamento para os pontos onde se quer obter a pressão. Assim, criamos mais duas variáveis, a posição ao longo da semi-envergadura (variável g), e a posição ao longo da corda (variável h). A Figura 11 ilustra estas duas últimas variáveis.

Temos ainda as variáveis que definem cada um dos três perfis que compõem a asa. Ao todo são 10 variáveis por perfil. Mais adiante, na seção 3.2.1, trataremos mais a fundo todo o equacionamento bem como as variáveis necessárias para a definição dos perfis.

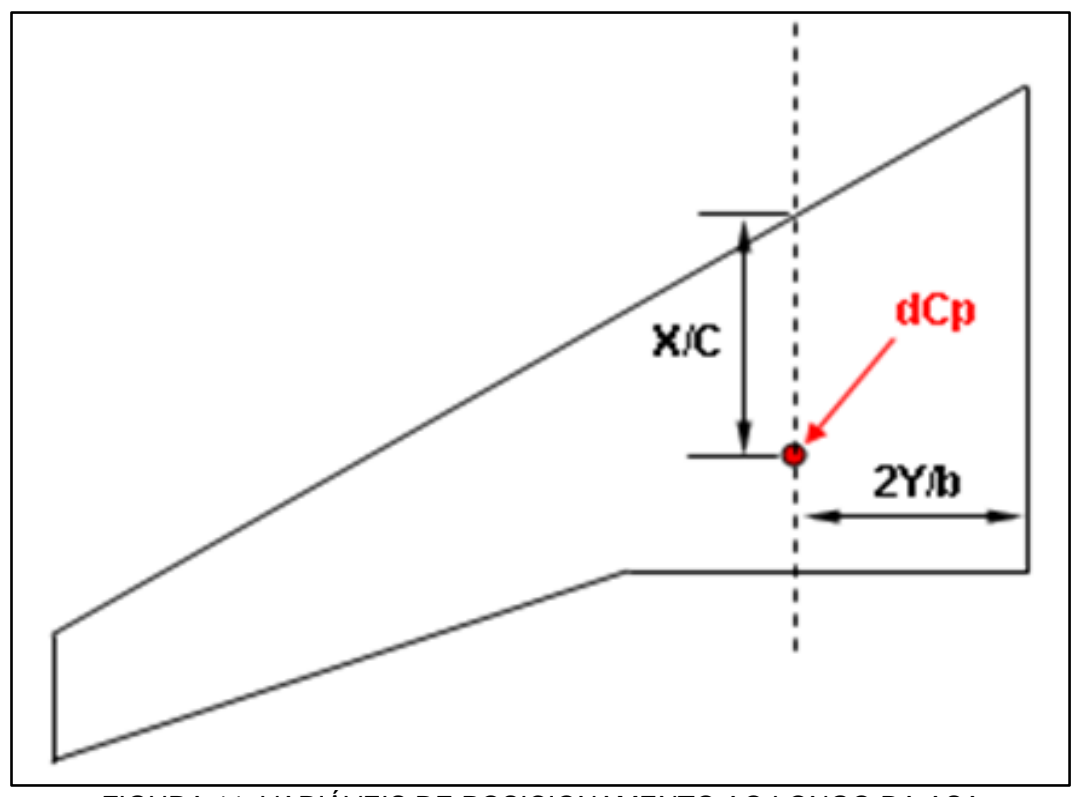

FIGURA 11: VARIÁVEIS DE POSICIONAMENTO AO LONGO DA ASA

\subsection{Geração dos conjuntos de treinamento e validação}

Um ponto importante para a geração dos conjuntos de treinamento é a diversidade entre os indivíduos. Quanto maior a diversidade melhor será a eficiência do processo de treinamento.

Como os indivíduos dos conjuntos de treinamento serão obtidos via CFD, teoricamente podemos obter quaisquer indivíduos, criados pela combinação das 
variáveis consideradas. Porém para obtermos os indivíduos mais diversos possíveis uns dos outros optamos por utilizar uma função do Matlab®, a "LHSDesign" (Latin Hipercube Sample).

Segundo Iman, L. R. (1983), no contexto da estatística, uma matriz pode ser chamada de hipercubo latino se cada linha desta matriz é única em relação à cada uma de suas variáveis (colunas). Além disso, no hipercubo latino o espaço amostral é dividido em sub-espaços igualmente prováveis. Todos os pontos de amostragem são escolhidos simultaneamente, certificando-se que o conjunto total de pontos da amostra é um hipercubo latino, e que cada sub-espaço é amostrado com a mesma densidade. Assim, esta metodologia garante que o conjunto de números aleatórios é um representante muito bom da variabilidade real.

Assim, esta função é bastante útil para este tipo de aplicação, pois ela fornece a garantia de gerar indivíduos uniformemente distribuidos ao longo de cada dimensão (no caso cada dimensão é uma variável), deste modo teremos indivíduos os mais variados possivel uns dos outros, algo que provavelmente não seria garantido se fosse utilizado um gerador completamente randômico.

A matriz gerada via LHSDesign é formada por números reais entre 0.0 e 1.0.

A Figura 12 traz um gráfico de densidade populacional de uma matriz 125000x2 (125.000 indivíduos e duas variáveis) gerada via "LHSdesign", a título de ilustrar a homogeneidade e balanceamento do conjunto de treinamento gerado por este método. 


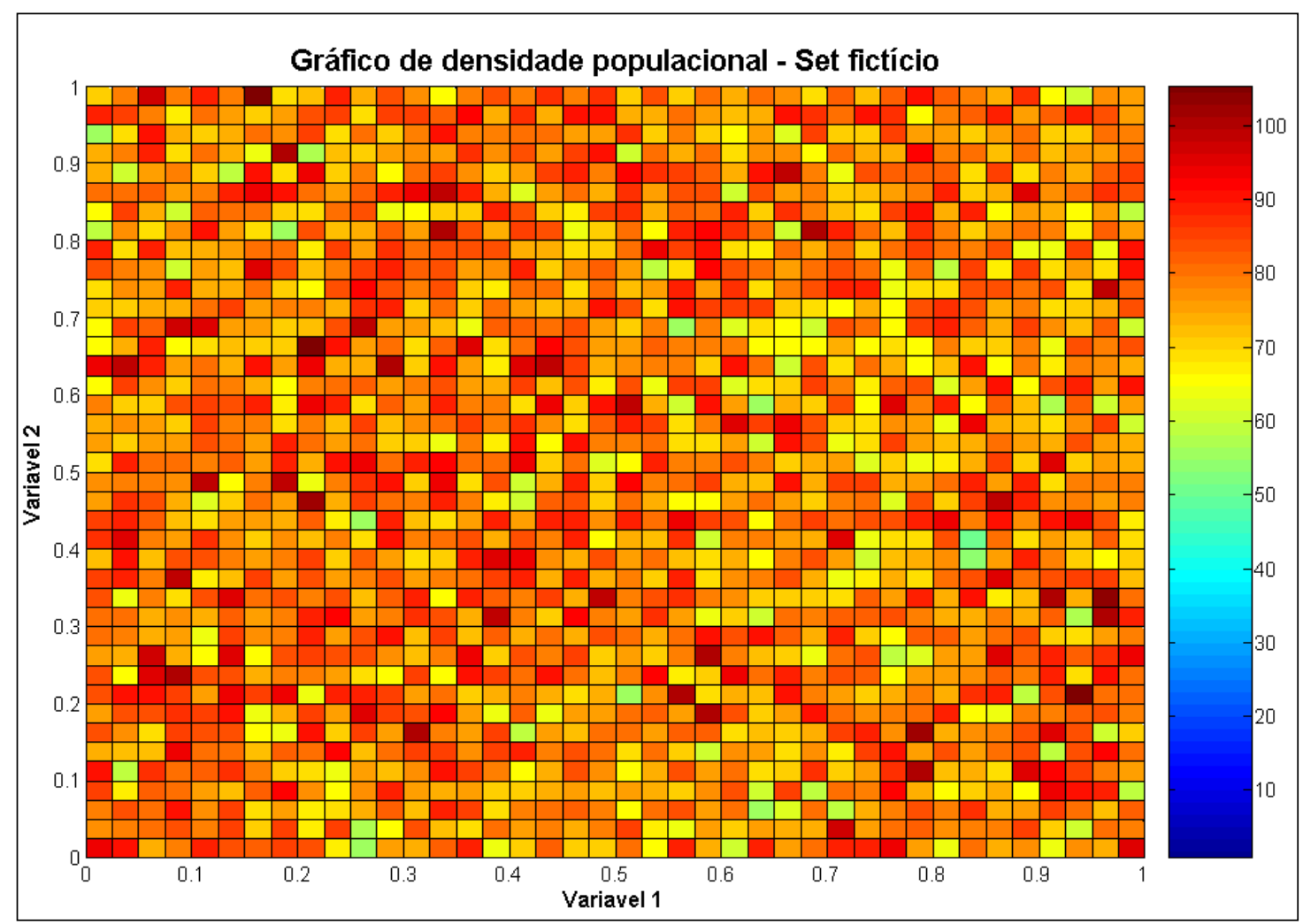

FIGURA 12: DENSIDADE POPULACIONAL DE UM CONJUNTO DE TREINAMENTO FICTÍCIO USANDO LHS-DESIGN

Um programa fortranß - programa "gera_treino.f90" - foi desenvolvido para transformar a matriz criada pelo "LHSDesign" em indivíduos a serem submetidos ao CFD.

Cada linha da matriz representa um indivíduo e cada coluna uma variável. Para cada indivíduo, os valores provenientes da matriz devem ser submetidos aos limites pré-estabelecidos para cada variável. Por exemplo, imaginemos que para a primeira linha tenhamos os valores de 0.5 e 0.75 para as duas primeiras variáveis (Mach e ângulo de ataque). Considerando ainda que os limites escolhidos para a variável Mach seja 0.4 a 0.8 e para o ângulo de ataque seja -2 a $2^{\circ}$. Assim, as variáveis finais deste indivíduo seria 0.6 para Mach e 1 grau para o ângulo de ataque.

O programa "gera_treino.f90" cria o arquivo de entrada do CFD, em formato texto, para cada um dos indivíduos, os submete ao CFD e obtem o resultado de pressão estática no ponto determinado pelas variáveis de posicionamento. Assim é 
gerado um arquivo texto que contem a saída desejada correspondente a cada individuo da matriz. A matriz gerada pelo Matlab® juntamente com o arquivo com as pressões estáticas gerado pelo programa compõem um conjunto de treinamento da rede.

O processo de treinamento de todas as redes neurais apresentadas neste trabalho foi feito utilizando o pacote de redes neurais do Matlab® (NNET®). O tipo de rede escolhida foi a rede Perceptron de múltiplas camadas, com correção dos pesos por retropropagação (backpropagation) pela alta eficiencia deste tipo de rede no processo de mapeamento de entrada e saída. $O$ algoritmo de treinamento utilizado foi o Levenberg-Marquardt. Este algoritmo é uma junção entre os algoritmos de Gauss-Newton e do gradiente descendente. O algoritmo de Levenberg-Marquardt é mais robusto que o algoritmo de Gauss-Newton pois na maioria dos casos ele encontra uma solução mesmo que as condições iniciais não sejam bem escolhidas. Porém, por outro lado, para funções bem comportadas este método tende a ser um pouco mais lento.

De maneira simplificada, o algoritmo calcula a derivada parcial do erro em relação a cada peso da rede e corrige cada peso com relação a estas derivadas.

Os critérios de parada do algoritmo são:

1) Máximo número de épocas;

2) Tempo de processamento;

3) Atingimento da performance esperada (meta para o erro);

4) Gradiente da performance é muito baixo (quando o ganho em termos de performance de uma época para outra é muito pequeno); 
Segundo Haykin (1999), não há uma regra definida para a determinação do número ideal de neurônios ou camadas a serem utilizados numa rede neural. De acordo com o autor, há, todavia, algumas heurísticas as quais indicam o número apropiado de neurônios. Uma delas inclusive afirma que um número de neurônios igual a aproximadamente duas vezes o número de variáveis do problema em geral produz bons resultados. Por não haver um consenso com relação a esse valor, optou-se por não seguir nenhuma heuristica à risca e determinar através de tentativas o número de neurônios.

Para cada rede neural um estudo foi feito com a intenção de aferir qual deveria ser o número de neurônios a ser usado. A arquitetura já havia sido escolhida, seria uma rede perceptron com duas camadas ocultas, uma camada de saída com um neurônio. Para um destes estudos consideramos uma rede que será treinada com um conjunto de treinamento com 9500 indivíduos e 8 variáveis (de forma em planta). Basicamente o treinamento foi executado cinco vezes, usando 5 , 10, 15, 20 e 25 neurônios em cada camada oculta. Foi feita uma validação para estas redes, as quais utilizaram 50 indivíduos diferentes dos utilizados no treinamento. $\mathrm{O}$ desempenho de cada treinamento foi medido por análise estatística dos coeficientes de força normal e de momento de arfagem. Os resultados das validações podem ser vistos nas Figuras 13 e 14 . 


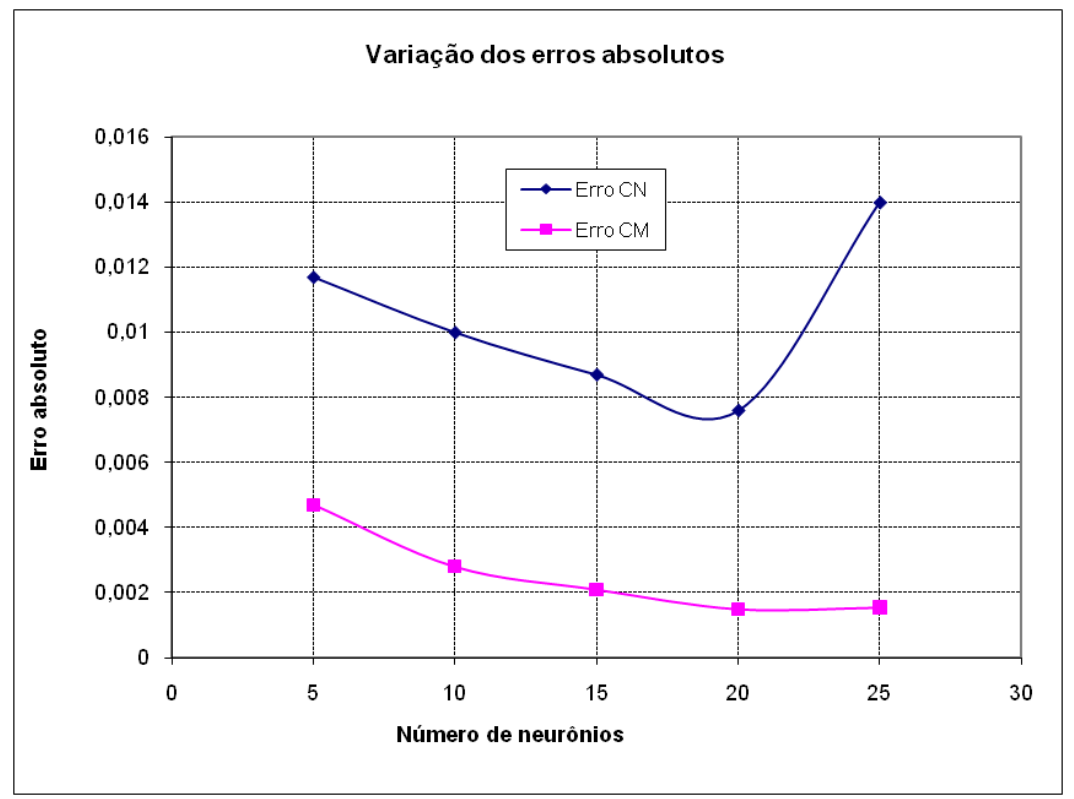

FIGURA 13: VARIAÇÃO DOS ERROS ABSOLUTOS EM RELAÇÃO AO NÚMERO DE NEURÔNIOS

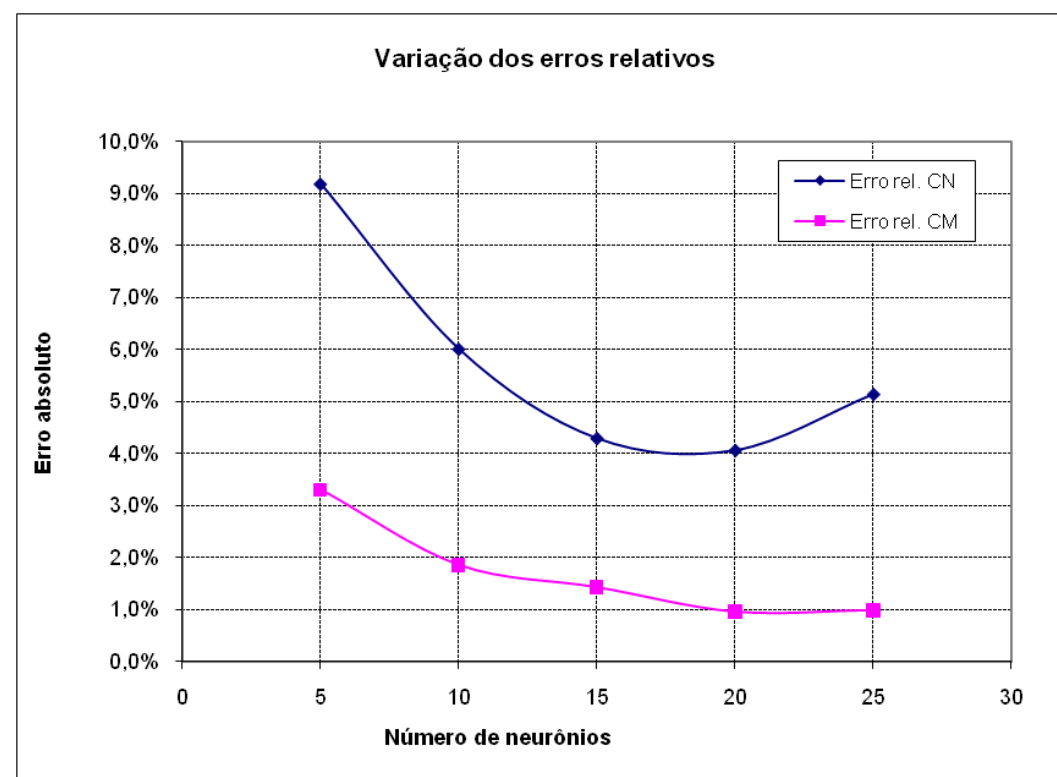

FIGURA 14: VARIAÇÃO DOS ERROS RELATIVOS EM RELAÇÃO AO NÚMERO DE NEURÔNIOS

Analisando os resultados das Figuras 13 e 14, podemos perceber que os erros médios (absoluto e relativo) de força normal calculado nas validações das redes testadas diminui até 20 neurônios e depois volta a aumentar.

Também foi feito um estudo estatísco com base no desvio padrão destes coeficientes. Para tanto, o desvio padrão dos erros absolutos de força normal e momento de arfagem foi calculado e considerando que os resultados das validações 
obedecem a distribuição normal de probabilidades. Aplicamos a lei dos 3 sigma, que diz que se adicionarmos à média três vezes o desvio padrão teremos $99,7 \%$ dos dados neste intervalo. Este resultado pode ser visto nas Figuras 15 e 16.

Analisando estes dados, podemos confirmar que utilizando por exemplo 5 neurônios em cada camada oculta teremos um erro médio absoluto nos coeficientes de força normal da ordem de 0.012 , porém poderemos encontrar erros da ordem de 0.12. Já para 20 neurônios por camada oculta teremos o erro médio absoluto por volta de 0.008 , sendo que este erro não deve exceder o valor de 0.06 .

Assim, seguindo este estudo, o número ótimo de neurônios para este conjunto de treinamento seria algo em torno de 20 por camada oculta.

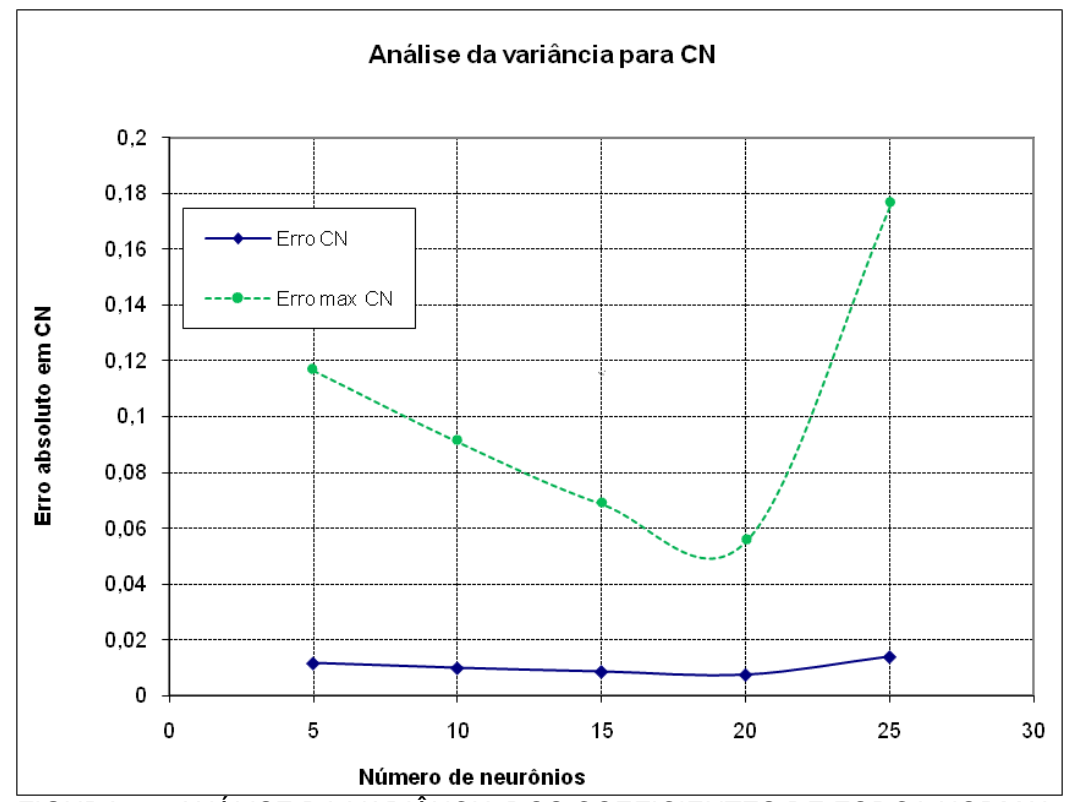

FIGURA 15: ANÁLISE DA VARIÂNCIA DOS COEFICIENTES DE FORÇA NORMAL 


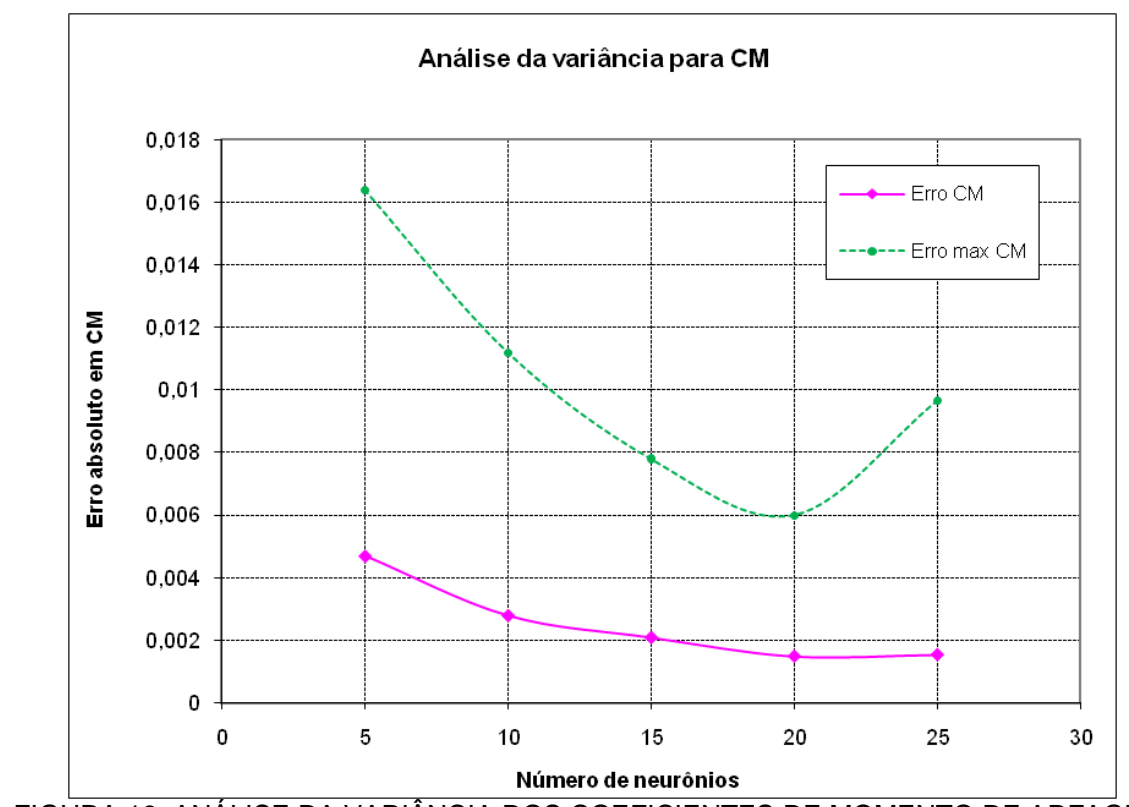

FIGURA 16: ANÁLISE DA VARIÂNCIA DOS COEFICIENTES DE MOMENTO DE ARFAGEM

Resta ainda escolher a função de ativação para os neurônios. Segundo Haykin (1999), qualquer função pode ser escolhida como função de ativação para os neurônios, porém para problemas não lineares como este caso, existem funções que respondem de maneira mais satisfatória, como o caso das funções do tipo sigmóides: logística e tangente hiperbólica. Ver seção 2.2 para maiores detalhes.

Ainda segundo Haykin (1999), um perceptron de múltiplas camadas treinado com algoritmo de retropropagação - como é o caso das redes usadas neste trabalho - pode, em geral, aprender mais rapidamente quando a função sigmóide empregada for do tipo antissimétrica do que quando ela for não simétrica. A função logística aqui aplicada é do tipo não-simétrica, e a função tangente hiperbólica é antissimétrica. A razão desta escolha reside no fato de que, como foi visto na seção 2.5 , para o tempo de aprendizagem de uma rede ser minimizado, deve-se evitar o uso de entradas com média diferente de zero. Para a primeira camada, não é difícil atender a essa premissa, basta gerar entradas normalizadas. Mas para as camadas seguintes, se uma função como a logística for aplicada, as camadas seguintes estarão 
condenadas a terem médias de entrada entre 0 e 1, ou seja, distante de zero. Porém se a função tangente hiperbólica, que varia de -1 a 1, for empregada, a média das entradas para as camadas ocultas será bem próxima de zero, o que é desejável. Por esta razão, neste trabalho optou-se pelo uso da função tangente hiperbólica como função de ativação dos neurônios das camadas ocultas. Para a saída, como o interesse está em valores de pressão relativamente baixos, uma função linear é o suficiente.

Assim como não existe uma regra que defina com exatidão o número ideal de neurônios em uma rede neural, também não há uma regra para estabelecer a quantidade ideal de indivíduos para o conjunto de treinamento. Isto se deve ao fato de que esse valor varia muito de acordo com a natureza do fenômeno que se pretende reproduzir com a rede neural. Sabe-se, no entanto, que ele é diretamente proporcional ao número de variáveis do problema.

Desta forma, tanto para a primeira rede neural como para as subsequentes, o número de indivíduos que compõem os conjuntos de treinamento foram definidos por meio de experiências, ou seja, tentiva e erro.

Para a rede neural usada no estudo do número de neurônios, testamos agora o número ideal de indivíduos para o conjunto de treinamento. Assim, foram gerados quatro conjuntos de treinamento, com 2010, 3960, 5945 e 9532 indivíduos. As redes foram treinadas e validadas e os resultados podem ser vistos na Figura 17. 


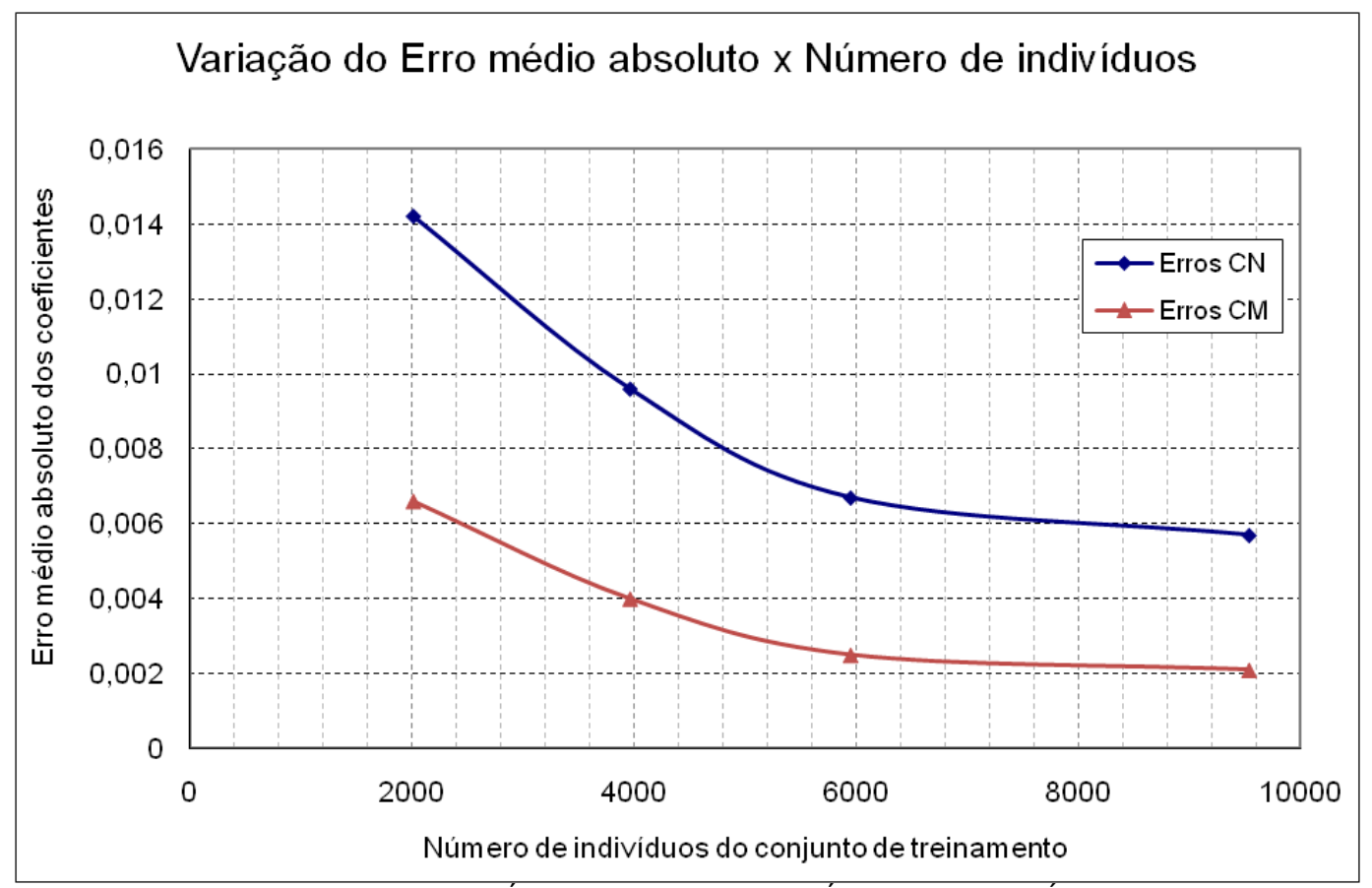

FIGURA 17: ERRO MÉDIO ABSOLUTO POR NÚMERO DE INDIVÍDUOS

Importante notar que, como esperado, quanto maior o número de indivíduos do conjunto de treinamento, melhor será o aprendizado da rede e, consequentemente, o resultado final. Isto porque consideramos que o processo de geração dos indivíduos ("LHSDesign") contribui para que a diversidade aumenta juntamente com o tamanho do conjunto. Pode-se perceber que a rede com 5945 indivíduos produz uma rede quase tão boa quanto a rede com 9532 indivíduos. E a partir deste ponto podemos perceber que o aumento do número de indivíduos influi cada vez menos no desempenho da rede.

Existe, porém, um alto custo computacional envolvido na geração dos conjuntos de treinamento, de modo há um compromisso entre o número de indivíduos por tempo de processamento, o qual deve ser estudado atentamente antes do número final de indivíduos ser definido.

Na prática, foi feita para cada rede neural uma estimativa inicial, baseada na experiência, do número de indivíduos necessários, e um posterior aumento dessa estimativa. Se o resultado fosse aceitável, o conjunto de treinamento seria mantido, 
pois não faria sentido submeter novamente ao CFD um conjunto menor; caso o número de indivíduos não fosse suficiente, partiria-se para um conjunto maior.

O mesmo programa utilizado para geração dos conjuntos de treinamento também é empregado no processo de validação de cada rede neural. No processo de validação uma nova matriz é gerada via "LHSDesign", os indivíduos são criados e submetidos ao CFD e os resultados obtidos são comparados com os resultados fornecidos pela rede para cada indivíduo.

É muito importante perceber que para cada indivíduo do conjunto de treinamento apenas um valor de $\Delta \mathrm{Cp}$ é obtido, na posição determinada pelas variáveis de posição ao longo da corda e ao longo da semi-envergadura. Da mesma forma, o resultado fornecido pela rede neural é o $\Delta \mathrm{Cp}$ em uma determinada posição ao longo da asa definida pelas mesmas variáveis citadas acima.

Também foi feito um programa em Matlab®, chamado "NNgen.m", este programa é utilizado para treinar as redes neurais (usando o pacote de redes neurais do Matlab®) assim como para validá-las.

No processo de validação apresentado neste trabalho, optamos por apresentar as comparações para três cortes ao longo da semi-envergadura (a 10\%, $50 \%$ e $90 \%$ ) por indivíduo. Na validação cada indivíduo é gerado e submetido ao CFD. São calculados 100 pontos de $\Delta$ Cp para cada um dos três cortes desejados e a rede neural é chamada 100 vezes para gerar cada corte da comparação (variando de 0 a 1 apenas a variável de posição ao longo da corda (h)). Desta forma, na validação, a rede neural deve ser executada 300 vezes por indivíduo. 


\subsection{Primeira Rede Neural - Forma em Planta}

Como citado anteriormente, a estratégia usada neste trabalho foi de abordarmos primeiramente um caso particular, onde temos os perfis da asa fixos e temos como variáveis, apenas os parâmetros de forma em planta e de condição de vôo. As Figuras 18 e 19 mostram os perfis escolhidos para a rede de forma em planta.

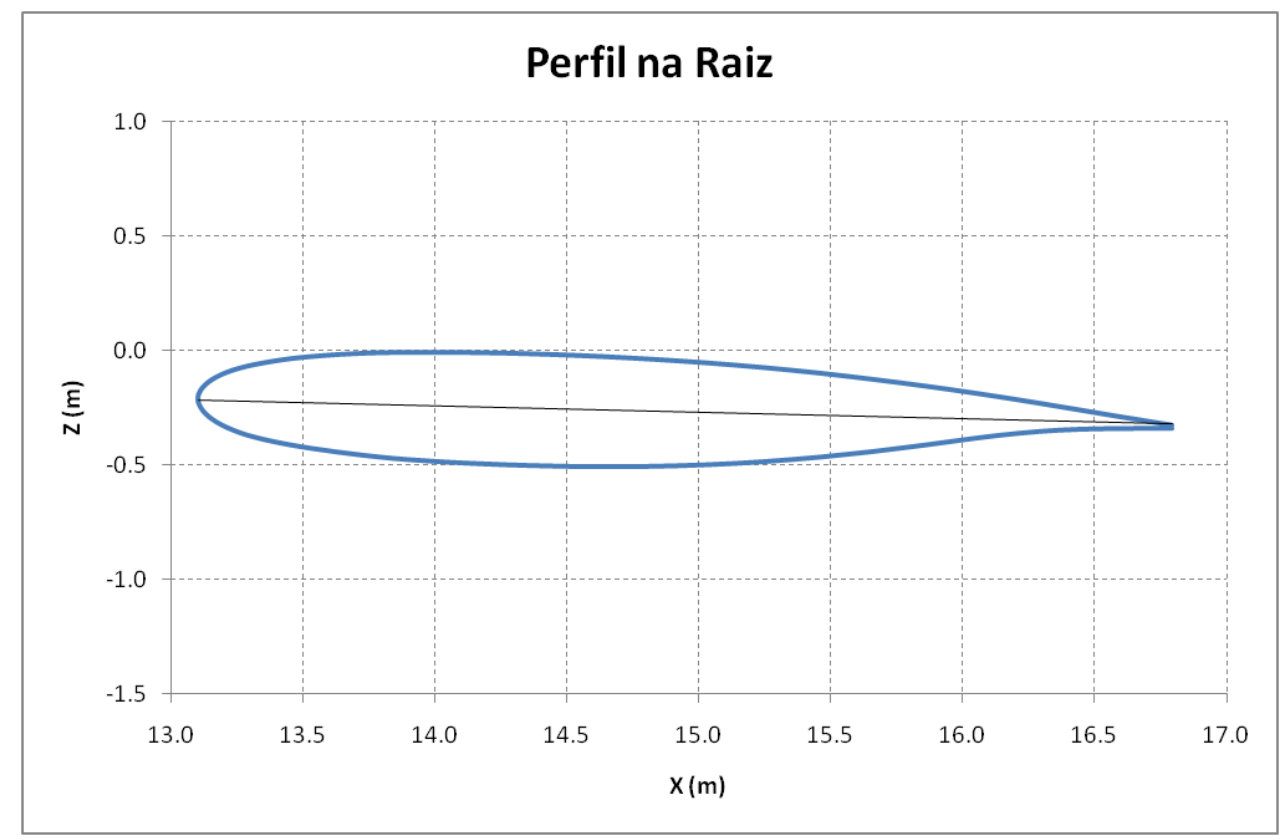

FIGURA 18: PERFIL DA RAIZ PARA A REDE DE FORMA EM PLANTA. 


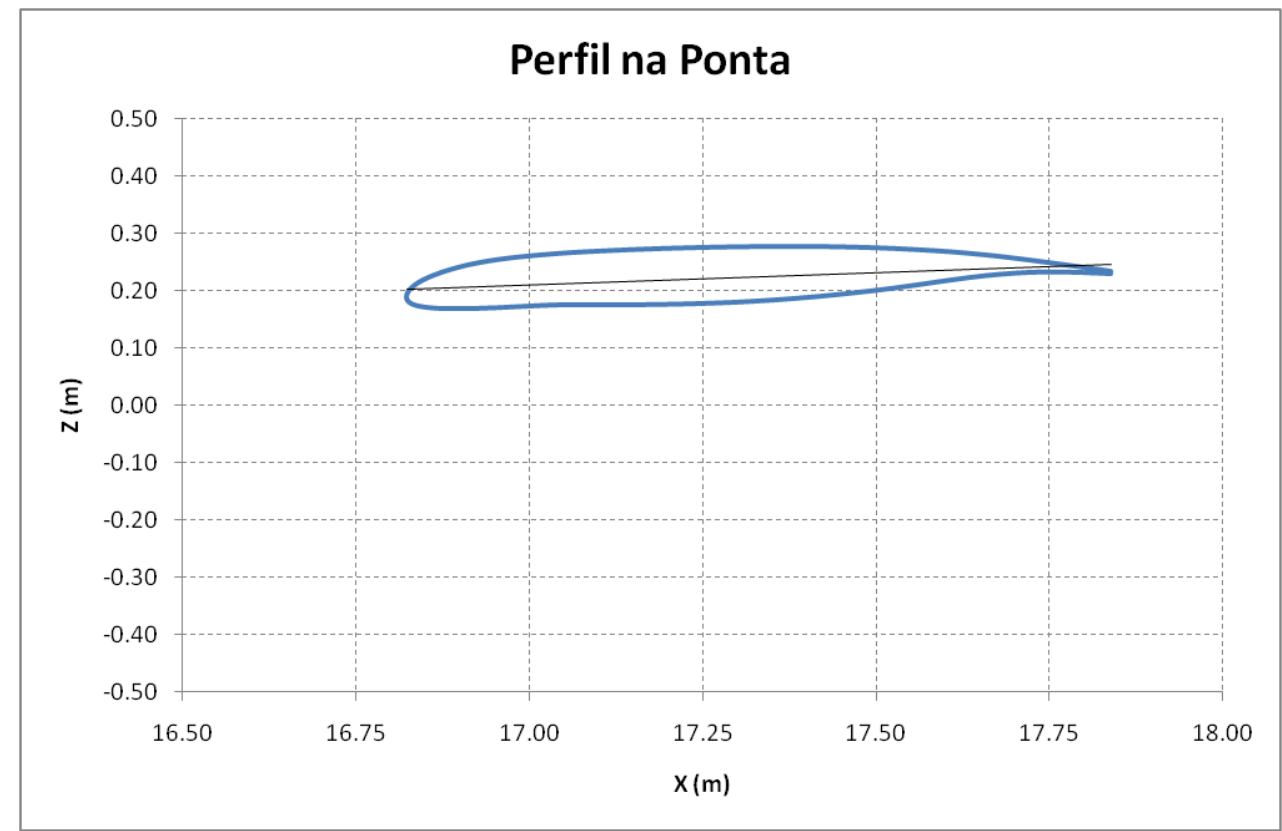

FIGURA 19: PERFIL DA PONTA PARA A REDE DE FORMA EM PLANTA.

Considerando as variáveis de forma em planta e condição de voo temos um total de oito variáveis.

Com a intenção de estudar configurações mais usuais, foram escolhidos os seguintes limites para as variáveis da primeira rede:

TABELA 1: LIMITES PARA A PRIMEIRA REDE NEURAL

\begin{tabular}{|c|c|c|c|}
\hline $\begin{array}{c}\text { Código da } \\
\text { variável }\end{array}$ & Variável & Limite inferior & Limite superior \\
\hline $\mathrm{a}$ & Número de Mach & 0.30 & 0.82 \\
\hline $\mathrm{b}$ & Ângulo de ataque & $-2.0^{\circ}$ & $3.0^{\circ}$ \\
\hline $\mathrm{c}$ & Alongamento & 6.0 & 10.0 \\
\hline $\mathrm{d}$ & Enflexamento no bordo de ataque & $15.0^{\circ}$ & $3^{\circ}$ \\
\hline $\mathrm{e}$ & Afilamento & 0.1 & 0.4 \\
\hline $\mathrm{f}$ & $\begin{array}{c}\text { Posição da quebra (ao longo da semi- } \\
\text { envergadura) }\end{array}$ & 0.2 & 0.4 \\
\hline $\mathrm{g}$ & $\begin{array}{c}\text { Posição na semi-envergadura } \\
\text { (mapeamento de pressão) }\end{array}$ & 0.0 & 1.0 \\
\hline $\mathrm{h}$ & $\begin{array}{c}\text { Posição na corda (mapeamento de } \\
\text { pressão) }\end{array}$ & 0.0 & 1.0 \\
\hline
\end{tabular}

Um estudo semelhante ao mostrado na Seção 3.2 foi feito para a determinação do número de indivíduos do conjunto de treinamento. Neste estudo foi escolhido um conjunto de treinamento com 18760 indivíduos. Para geração deste conjunto um DOE inicial com 20.000 indivíudos foi gerado via LHSDesign, o que resultou em um aproveitamento de $93,8 \%$ do conjunto inicial. 
O processo de treinamento foi realizado até que fosse alcançado um erro menor do que $1 \times 10^{-5}$.

Conforme descrito na Seção 3.2, foram feitos alguns testes com diferentes números de neurônios e arquiteturas de rede até chegar a uma arquitetura de duas camadas ocultas - cada uma com vinte neurônios usando função de transferência tangente sigmoídal, e uma camada de saída com um neurônio apenas - usando função de transferência linear. Este foi o arranjo que mostrou o melhor desempenho para o problema em questão.

Já para o processo de validação optou-se pela criação de um conjunto de treinamento gerado de maneira aleatória, com 40 indivíduos diversos daqueles usados no processo de treinamento. O processo de validação foi realizado como descrito acima, ou seja, os resultados foram comparados para três cortes ao longo da envergadura.

\subsubsection{Resultados da Primeira Rede Neural}

Nestas figuras da validação, a linha cheia apresenta o resultado fornecido diretamente para o CFD para a condição desejada, enquanto que os circulos azuis são os resultados fornecidos pela rede neural para as mesmas condições. Nestas figuras também são mostrados resultados em termos de coeficientes de força normal $\left(C_{N}\right)$ e de momento de arfagem $\left(C_{M}\right)$ para a rede neural e para o resultado do CFD.

As Figuras 20 e 21 mostram os resultados para um número de Mach de aproximadamente 0.6 e ângulo de ataque negativo e número de Mach 0.47 com ângulo de ataque positivo, respectivamente. A distribuição de pressão mostrou uma 
correlação muito boa entre os resultados obtidos via CFD e via rede neural. Os coeficientes de força e momento apresentaram os mesmos resultados para os três cortes analisados em ambas condições.

As Figuras 22 e 23 mostram os resultados para um número de Mach de aproximadamente 0.75 e ângulo de ataque positivo e número de Mach 0.76 com ângulo de ataque próximo de zero, respectivamente. Na Figura 17 podemos perceber que a rede neural não acusou a ocorrência de ondas de choque claramente notáveis no resultado do CFD. Os coeficientes de força e momento também apontaram diferenças não percebidas nas Figuras 15 e 16 . Na Figura 18 podemos perceber que a rede neural acusou a ocorrência das ondas de choque, porém com erros na posição e intensidade dos choques.

Os mesmos padrões foram identificados nos demais indivíduos do conjunto de validação.

A dificuldade da rede neural em representar bem a distribuição de pressão para números de Mach maiores está diretamente ligada à ocorrência de nãolinearidades bastante pronunciadas, no caso, as ondas de choque. No entanto a rede apresentou um resultado bastante consistente para números de Mach mais baixos, onde não observamos a existência deste fenômeno.

Para a solução deste problema poderiamos indicar o aumento do número de indivíduos na região de Mach mais alto, porém esta solução poderia acarretar em um grande número de tentativas, e em consequencia a geração de vários conjuntos de treinamento. Assim, a solução encontrada foi de dividirmos a rede neural em duas redes, uma para os números de Mach mais baixos, onde a formação de ondas de choque são menos pronunciadas e outra rede neural para números de Mach mais altos, com grande formação de ondas de choque. Por comodidade vamos 
denominar a rede com número de Mach mais baixo de Rede Subsônica e a rede neural com número de Mach mais alto de Rede Transônica. $\mathrm{O}$ desenvolvimento destas duas redes será mostrado na próxima Seção. 


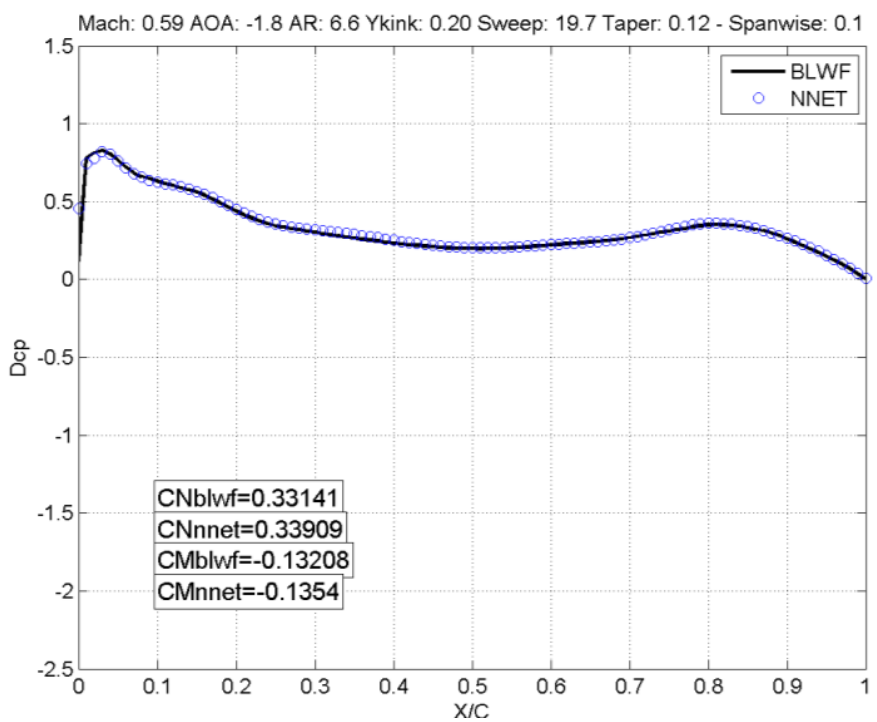

(a)

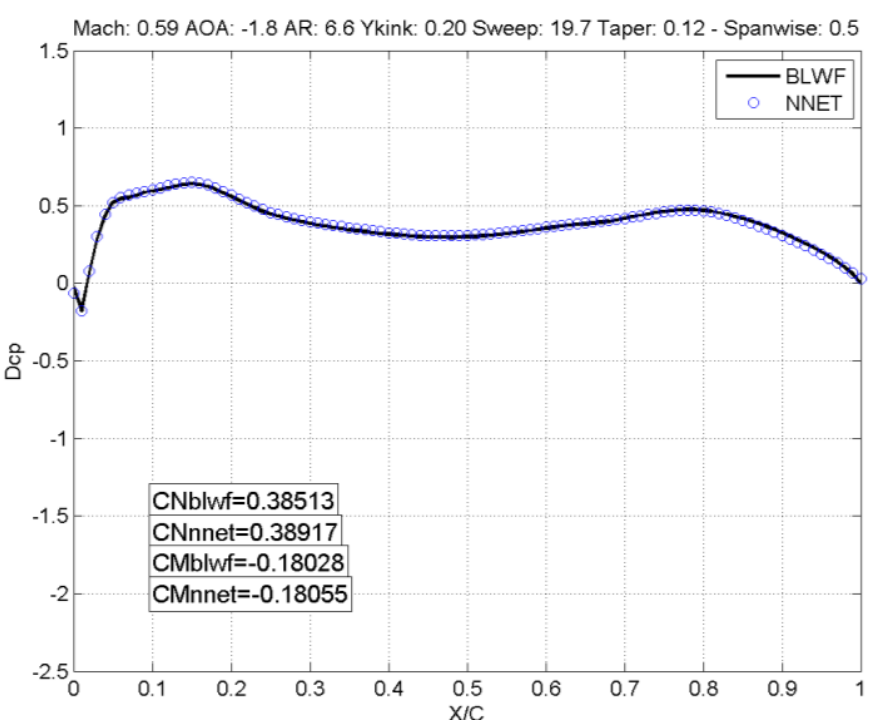

(b)

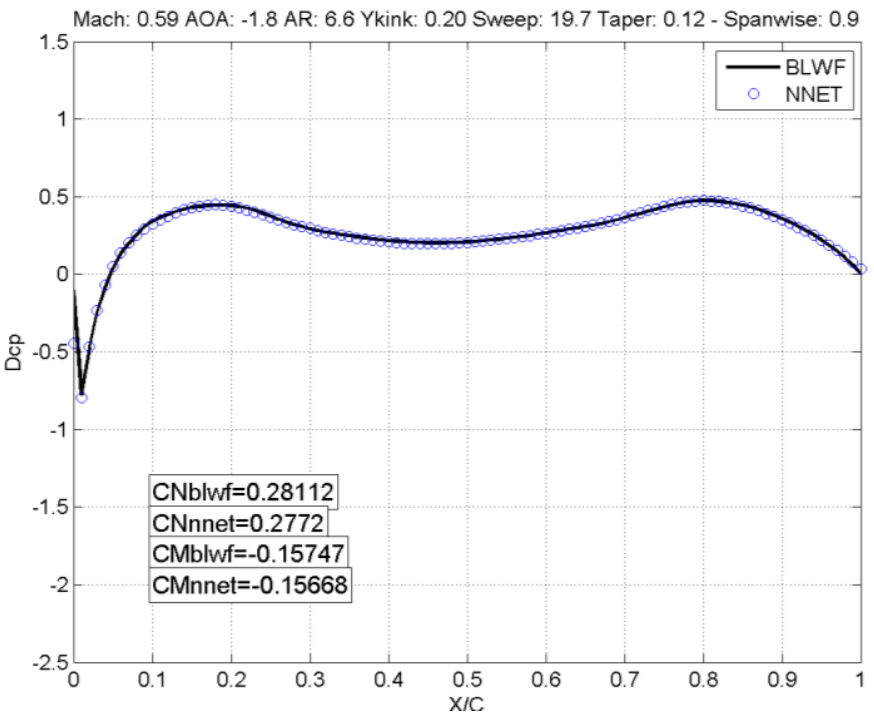

(c)

FIGURA 20: ESCOAMENTO SUBSONICO COM ANGULO DE ATAQUE NEGATIVO: (A) ESTAÇÃO NA RAIZ (B) ESTAÇÃO NO MEIO DA ASA (C) ESTAÇÃO NA PONTA DA ASA. 


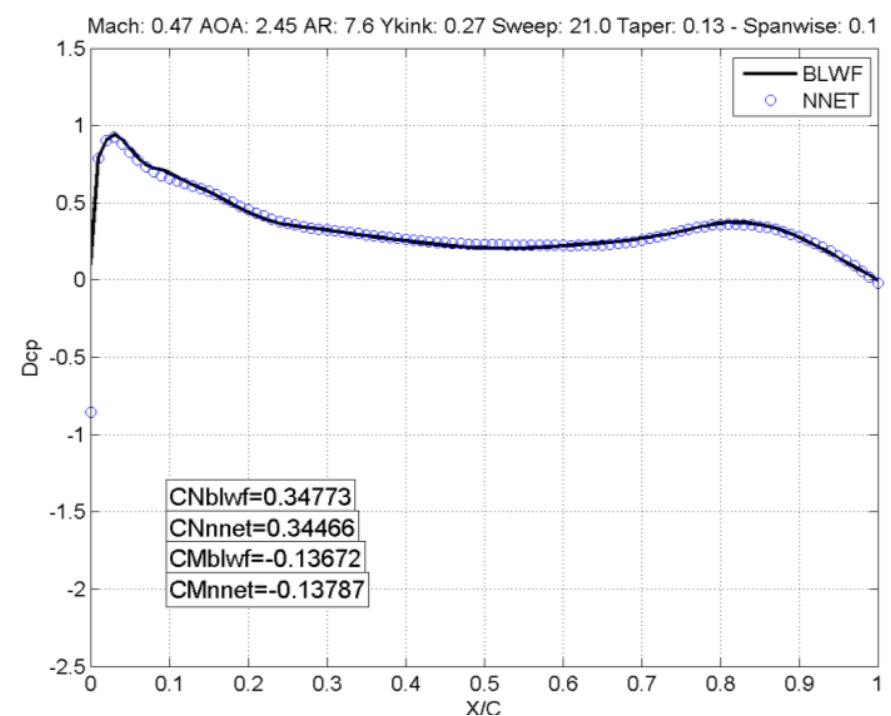

(a)

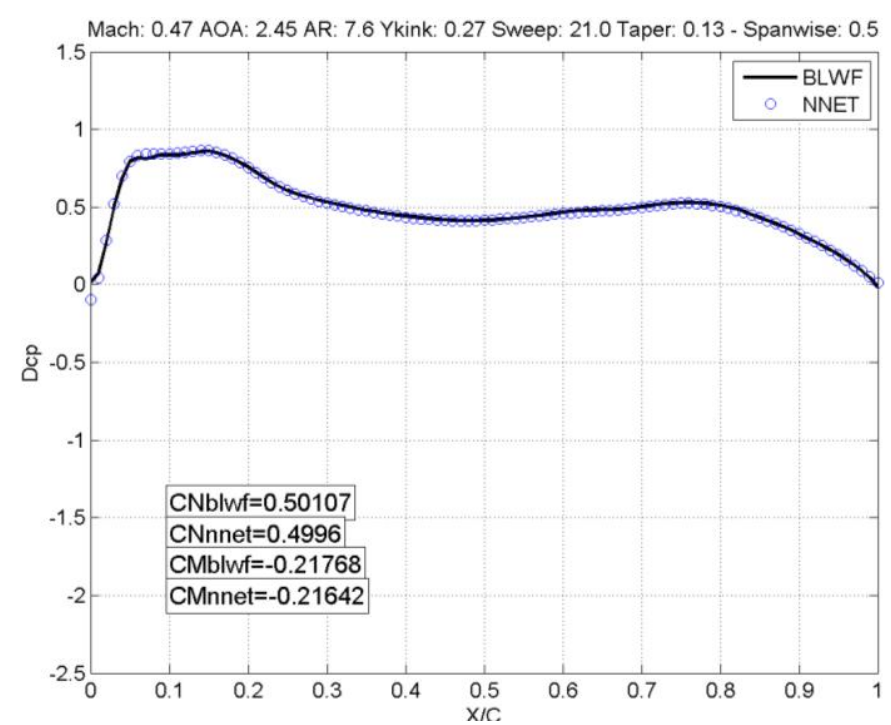

(b)

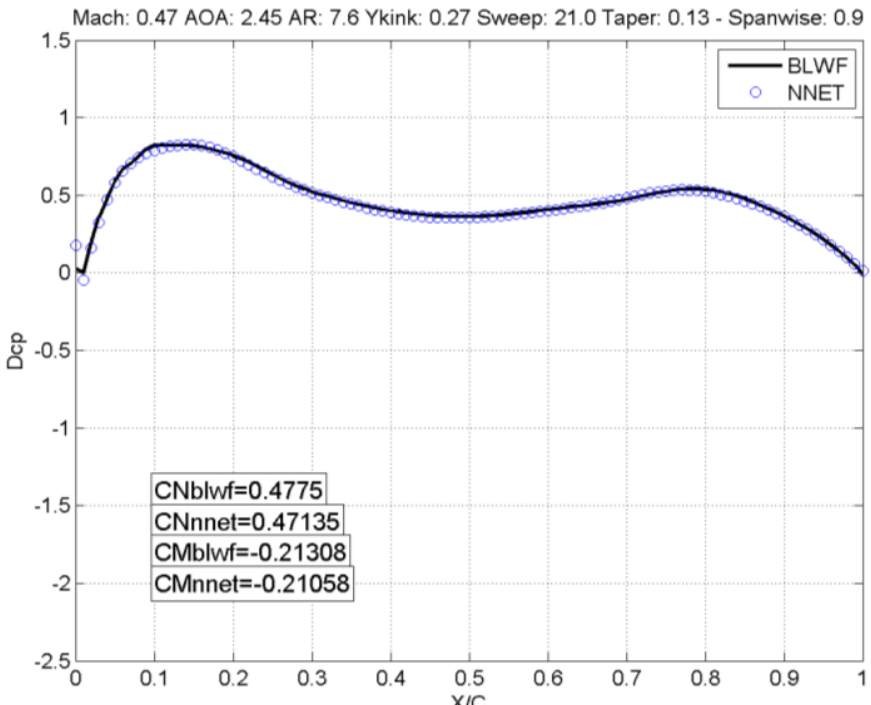

(c)

FIGURA 21: ESCOAMENTO SUBSONICO COM ANGULO DE ATAQUE POSITIVO: (A) ESTAÇÃO NA RAIZ (B) ESTAÇÃO NO MEIO DA ASA (C) ESTAÇÃO NA PONTA DA ASA. 


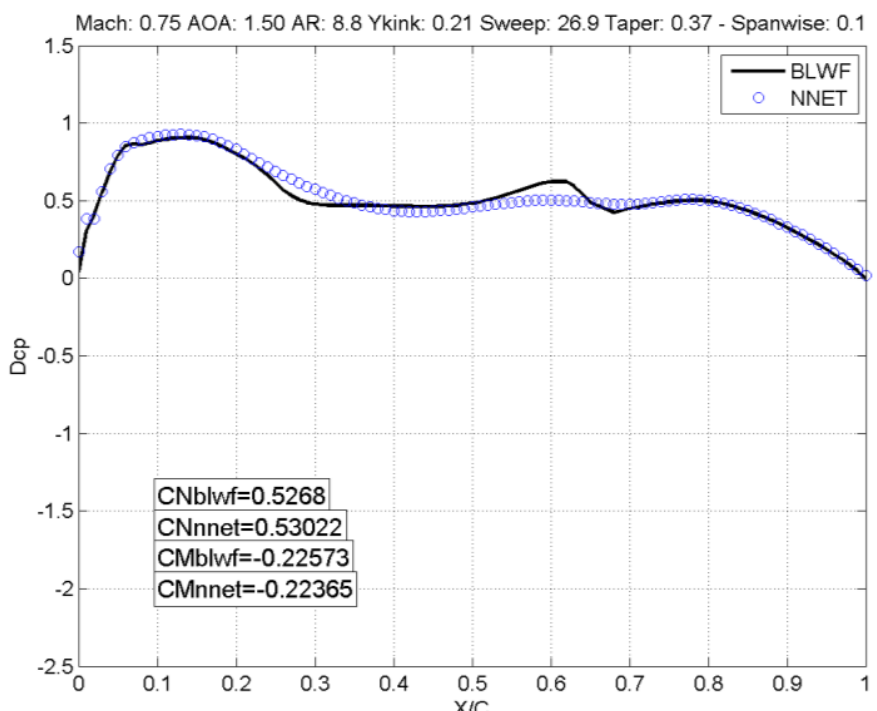

(a)

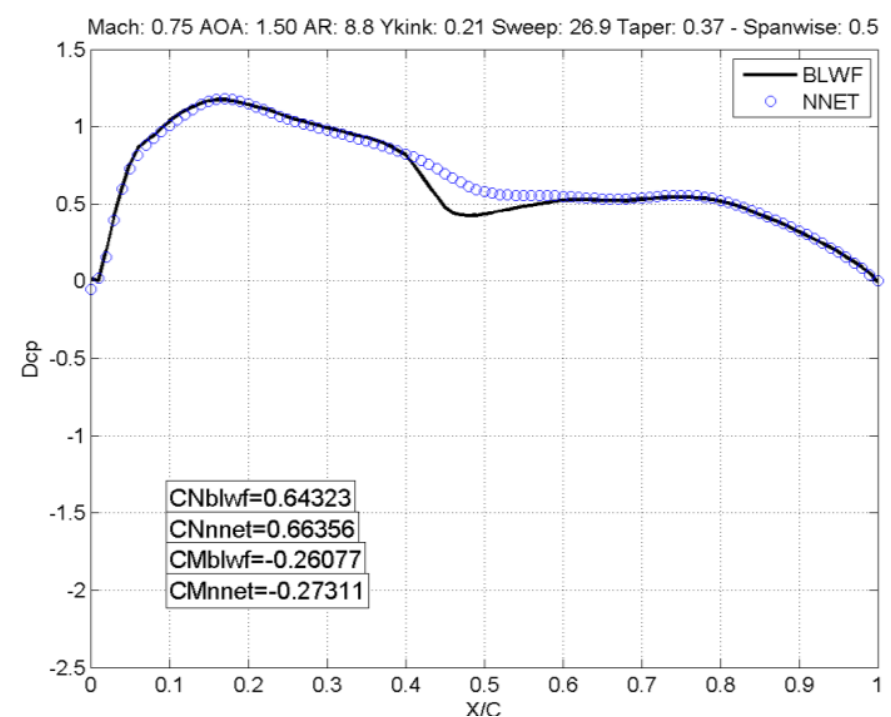

(b)

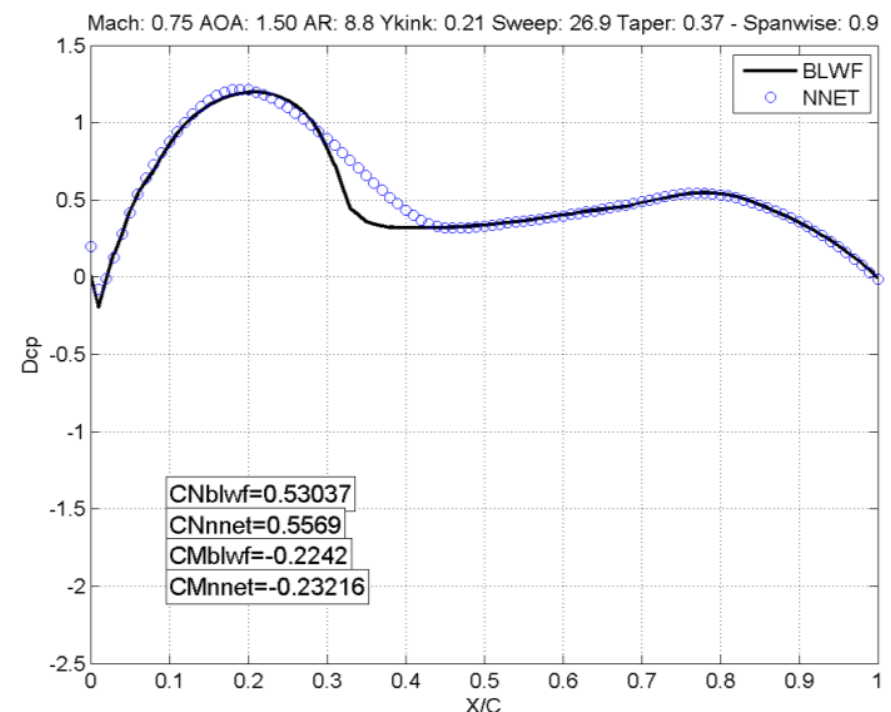

(c)

FIGURA 22: ESCOAMENTO BAIXO TRANSONICO COM ÂNGULO DE ATAQUE POSITIVO: (A) ESTAÇÃO NA RAIZ (B) ESTAÇÃO NO MEIO DA ASA (C) ESTAÇÃO NA PONTA DA ASA. 


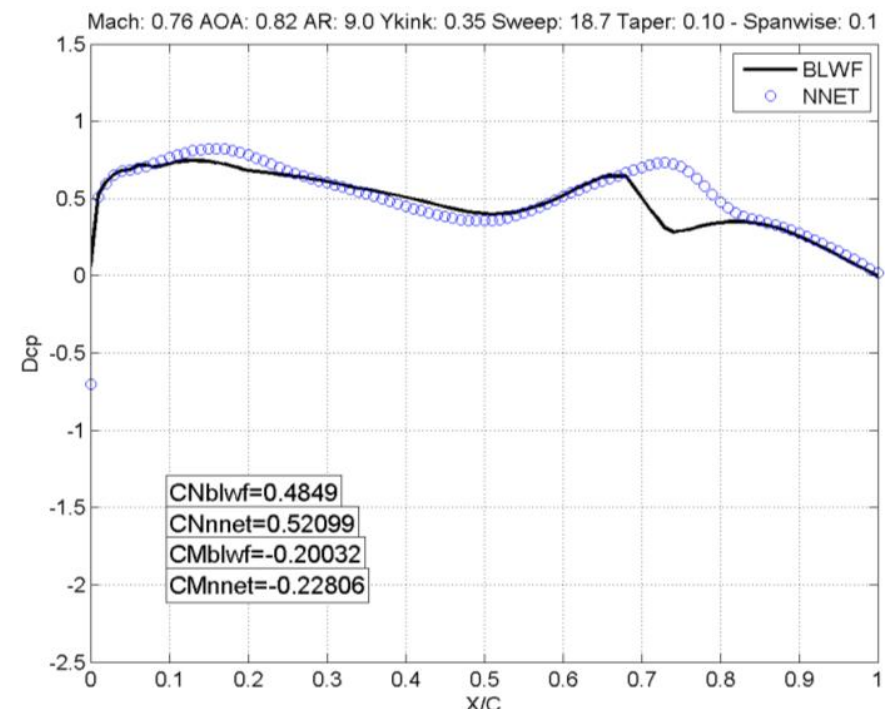

(a)

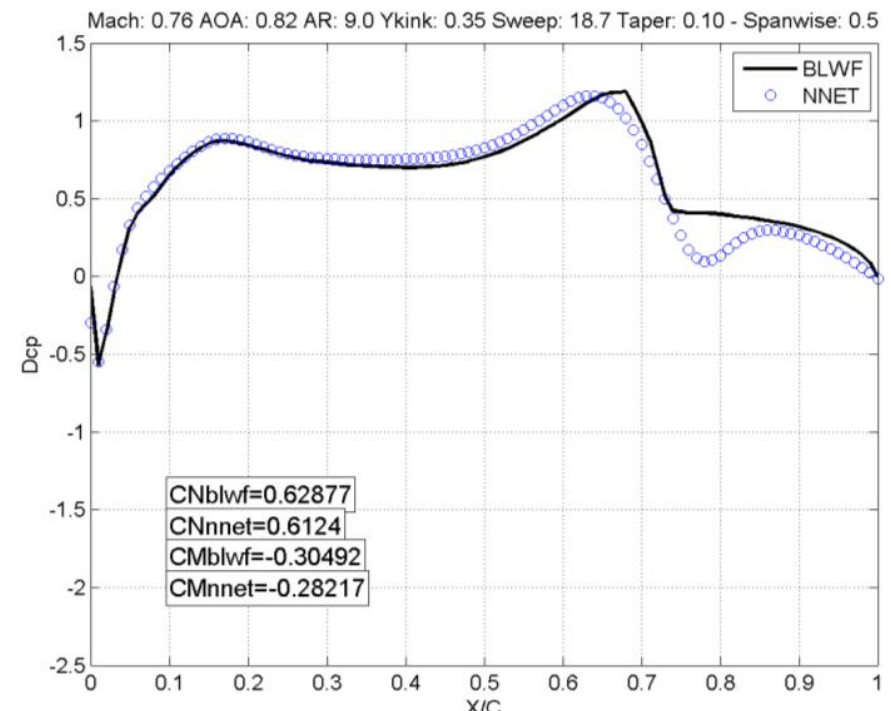

(b)

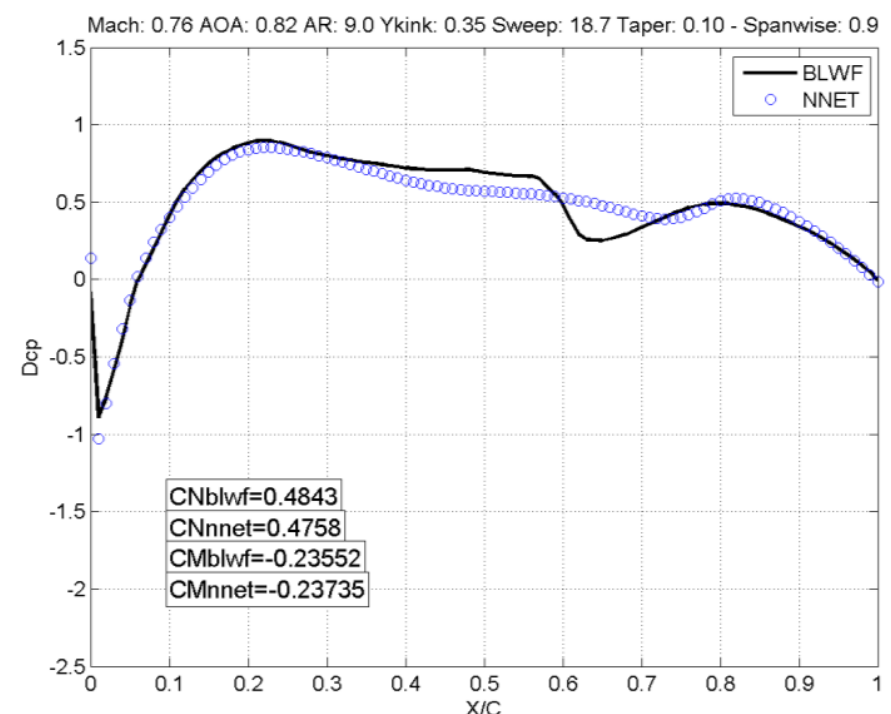

FIGURA 23: BAIXO TRANSONICO COM ÂNGULO DE ATAQUE POCSITIVO: (A) ESTAÇÃO NA RAIZ (B) ESTAÇÃO NO MEIO DA ASA (C) ESTAÇÃO NA PONTA DA ASA. 


\subsection{Segunda Rede Neural - Forma em Planta}

Seguindo a estratégia descrita na Seção 3.3, decidiu-se pela implementação de duas redes neurais, uma para o caso subsônico e outra para o caso transônico. As duas redes neurais utilizaram as mesmas variáveis e os mesmos limites de variáveis estabelecidos para a rede anterior, porém com números de Mach diferentes, como podemos observar nas Tabelas 2 e 3:

TABELA 2: LIMITES PARA A SEGUNDA REDE NEURAL - CASO SUBSONICO

\begin{tabular}{|c|c|c|c|}
\hline $\begin{array}{c}\text { Código da } \\
\text { variável }\end{array}$ & Variável & Limite inferior & Limite superior \\
\hline $\mathrm{a}$ & Número de Mach & 0.30 & 0.72 \\
\hline $\mathrm{b}$ & Ângulo de ataque & $-2^{\circ}$ & $3^{\circ}$ \\
\hline $\mathrm{c}$ & Alongamento & 6 & 10 \\
\hline $\mathrm{d}$ & Enflexamento no bordo de ataque & $15^{\circ}$ & 0.4 \\
\hline $\mathrm{e}$ & Afilamento & 0.1 & 0.4 \\
\hline $\mathrm{f}$ & Posição da quebra (ao longo da semi- \\
envergadura) & 0.2 & 1 \\
\hline $\mathrm{g}$ & Posição na envergadura (mapeamento \\
de pressão) & 0 & 1 \\
\hline $\mathrm{h}$ & Posição na corda (mapeamento de \\
pressão) & 0 & 1 \\
\hline
\end{tabular}

TABELA 3: LIMITES PARA A SEGUNDA REDE NEURAL - CASO TRANSONICO

\begin{tabular}{|c|c|c|c|}
\hline $\begin{array}{l}\text { Código da } \\
\text { variável }\end{array}$ & Variável & Limite inferior & Limite superior \\
\hline $\mathrm{a}$ & Número de Mach & 0.72 & 0.82 \\
\hline$b$ & Ângulo de ataque & $-2^{0}$ & $3^{\circ}$ \\
\hline C & Alongamento & 6 & 10 \\
\hline d & Enflexamento no bordo de ataque & $15^{\circ}$ & $30^{\circ}$ \\
\hline e & Afilamento & 0.1 & 0.4 \\
\hline$f$ & $\begin{array}{c}\text { Posição da quebra (ao longo da semi- } \\
\text { envergadura) }\end{array}$ & 0.2 & 0.4 \\
\hline g & $\begin{array}{c}\text { Posição na envergadura (mapeamento } \\
\text { de pressão) }\end{array}$ & 0 & 1 \\
\hline $\mathrm{h}$ & $\begin{array}{c}\text { Posição na corda (mapeamento de } \\
\text { pressão) }\end{array}$ & 0 & 1 \\
\hline
\end{tabular}

Seguindo o estudo que apontou a arquitetura ideal para a rede anterior, mantivemos a mesma arquitetura para ambas as redes.

Na rede subsônica, seguindo a estratégia adotada para a determinação do número de indivíduos, definiu-se que este conjunto de treinamento deveria contar 
com mais de 9000 indivíduos. Assim, um conjunto com 10.000 indivíduos foi submetido ao CFD, porém apenas 9500 indivíduos obtiveram convergência, ou seja, um aproveitamento de $95 \%$ dos indivíduos do conjunto inicial.

$\mathrm{Na}$ rede transônica, um breve estudo determinou que seria desejável um conjunto de treinamento com mais de 10000 indivíduos. Contando com uma alta taxa de divergencia no CFD construiu-se um conjunto de treinamento com 15.000 indivíduos. Destes, 11800 indivíduos obtiveram convergência no CFD, ou seja, um aproveitamento de $78.67 \%$ dos indivíduos do conjunto inicial, mas bem acima do valor desejado.

Para ambas as redes, o processo de treinamento foi feito até que se obtivesse um erro da ordem de $10^{-5}$.

O processo de validação utilizado foi exatamente o mesmo usado na rede anterior, comparando os resultados da rede neural com os resultados obtidos via CFD para três estações ao longo da asa. Para a validação das redes subsônica e transônica foram criados dois conjuntos com 50 indivíduos cada, sendo que destes 45 obtiveram convergência no CFD para o caso subsônico e 40 para o caso transônico, viabilizando a comparação.

\subsubsection{Resultados da Segunda Rede Neural}

Nas figuras mostradas na validação, novamente, a linha cheia apresenta o resultado fornecido diretamente para o CFD para a condição desejada, enquanto que os circulos azuis são os resultados fornecidos pela rede neural para as mesmas condições. Nestas figuras também são mostrados resultados em termos de 
coeficientes de força normal $\left(\mathrm{C}_{N}\right)$ e de momento de arfagem $\left(\mathrm{C}_{\mathrm{M}}\right)$ para a rede neural e para o resultado do CFD.

As Figuras 24, 25 e 26 mostram os resultados para ângulos de ataque positivos e com números de Mach de 0.36, 0.49 e 0.71. A distribuição de pressão mostrou uma correlação muito boa entre os resultados obtidos via CFD e via rede neural. Os coeficientes de força e momento apresentaram os mesmos resultados para os três cortes analisados em ambas condições.

Resultados semelhantes foram encontrados para os outros indivíduos do conjunto de validação.

A Tabela 4 mostra uma análise estatística dos coeficientes obtidos pela rede neural e pelo CFD para os mesmos indivíduos do conjunto de validação. Analisando esta tabela podemos perceber que as médias dos erros absolutos de $C_{N}$ e $C_{M}$ foram muito baixas. Os desvios padrão para os mesmos coeficientes também foram bastante pequenos. Se adotarmos a regra da distribuição normal, usando três sigma para o resultado de $\mathrm{C}_{\mathrm{N}}$, por exemplo, teremos que $99,7 \%$ dos indivíduos do conjunto de validação apresentou erro variando entre 0.000 e 0.0115 em $C_{N}$, o que é podemos considerar um resultado muito bom para o ponto de vista de cálculo de cargas (um provável uso deste tipo de resultados - distribuição de pressão).

TABELA 4: RESULTADOS PARA REDE SUBSONICA DE FORMA EM PLANTA
\begin{tabular}{|l|r|}
\hline Média dos erros absolutos de CN & 0.005741 \\
\hline Média dos erros absolutos de CM & 0.002112 \\
\hline Média dos erros relativos de CN & 0.021400 \\
\hline Média dos erros relativos de CM & 0.013275 \\
\hline Desvio padrão dos erros absolutos de CN & 0.005542 \\
\hline Desvio padrão dos erros absolutos de CM & 0.001908 \\
\hline
\end{tabular}




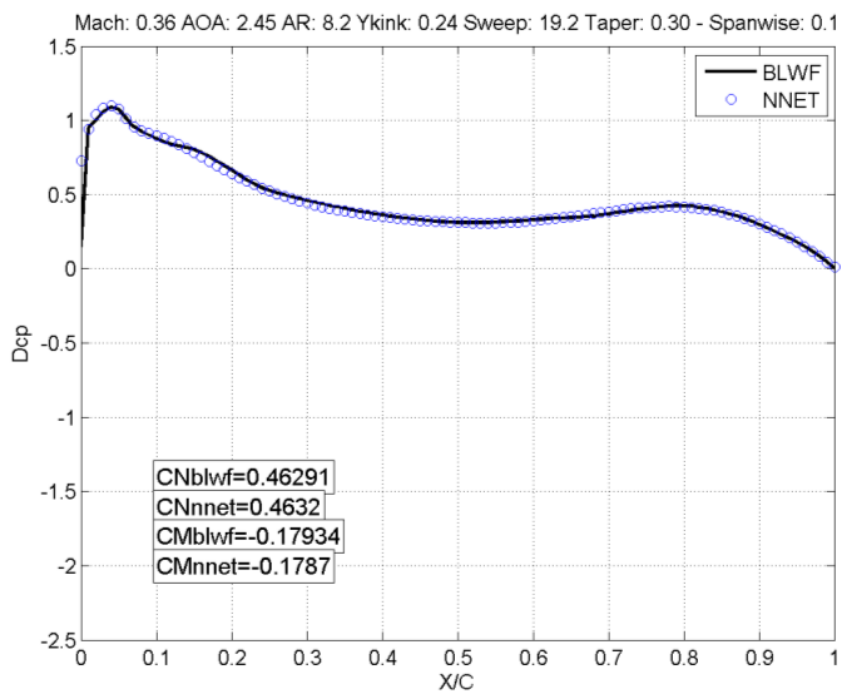

(a)

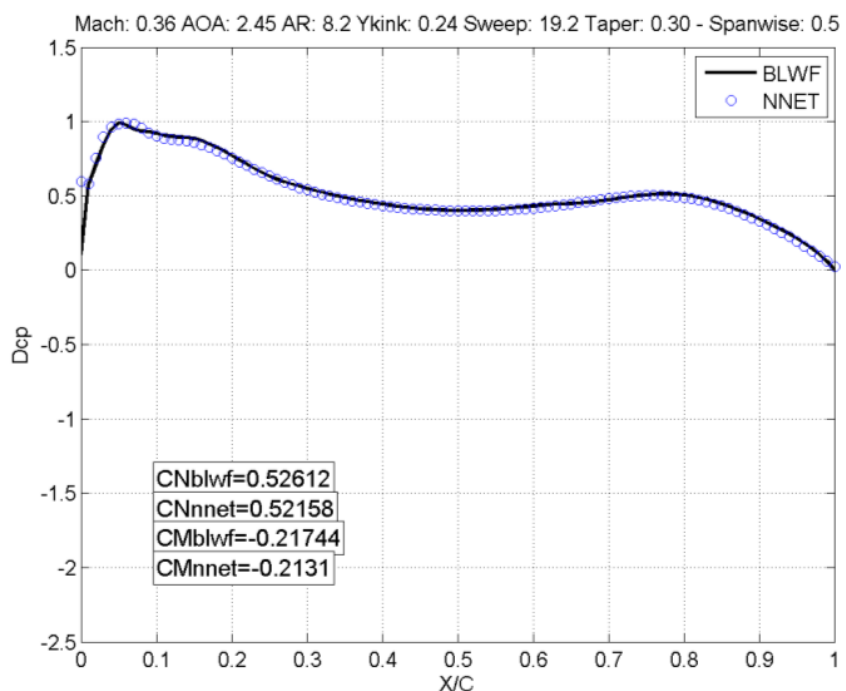

(b)

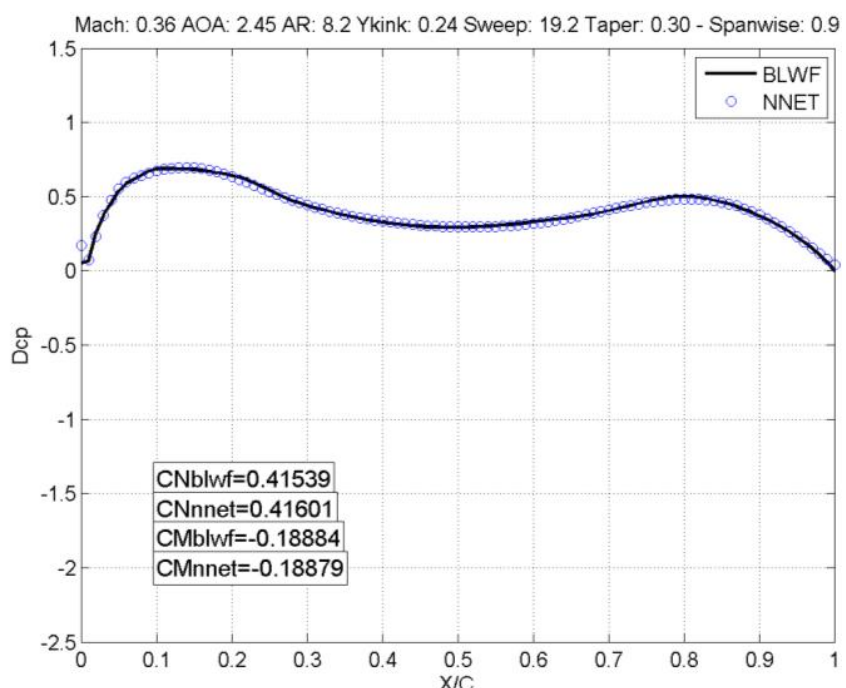

(c)

FIGURA 24: ESCOAMENTO SUBSONICO COM ANGULO DE ATAQUE POSITIVO: (A) ESTAÇÃO NA RAIZ (B) ESTAÇÃO NO MEIO DA ASA (C) ESTAÇÃO NA PONTA DA ASA. 


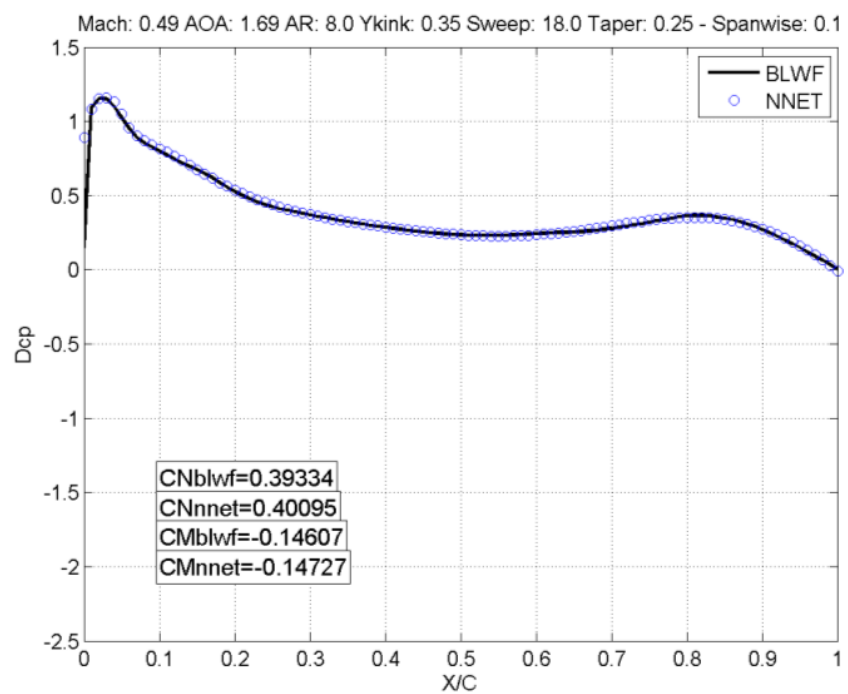

(a)

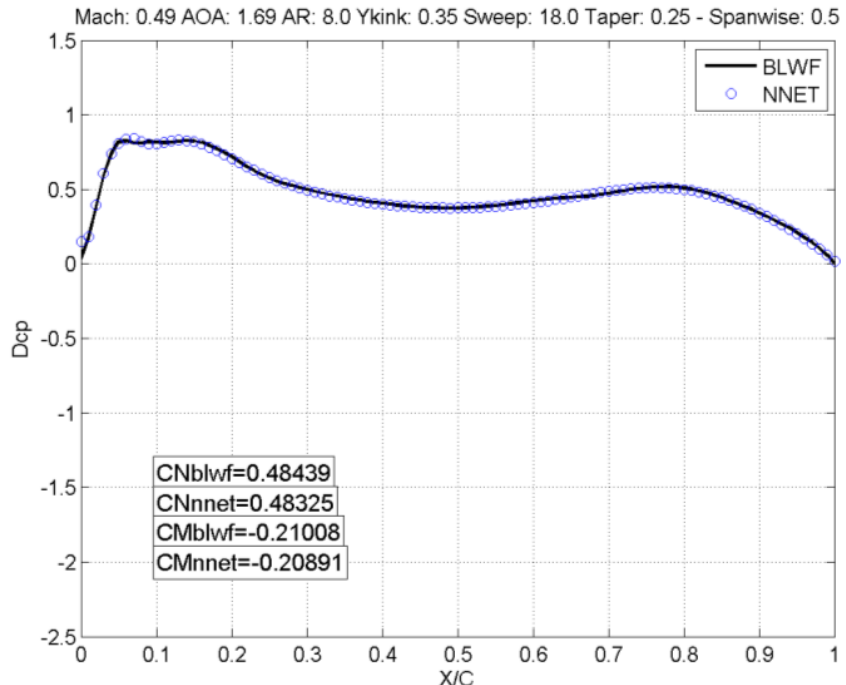

(b)

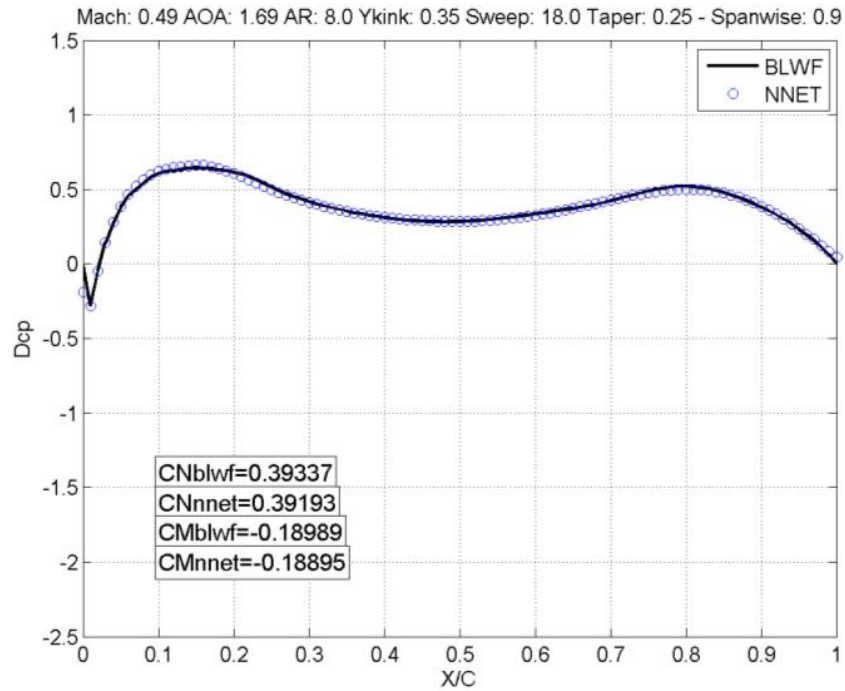

(c)

FIGURA 25: ESCOAMENTO SUBSONICO COM ANGULO DE ATAQUE POSITIVO: (A) ESTAÇÃO NA RAIZ (B) ESTAÇÃO NO MEIO DA ASA (C) ESTAÇÃO NA PONTA DA ASA. 


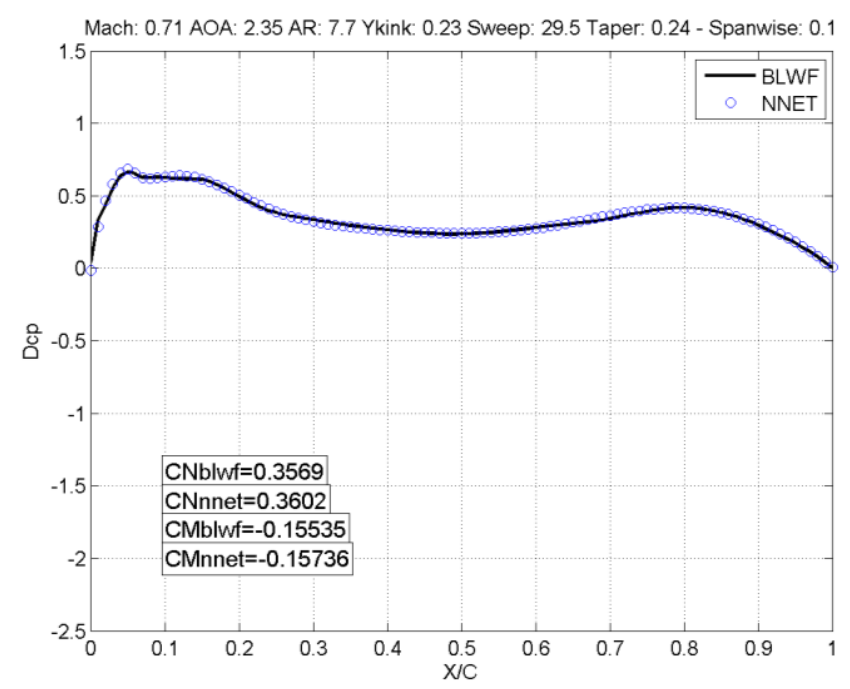

(a)

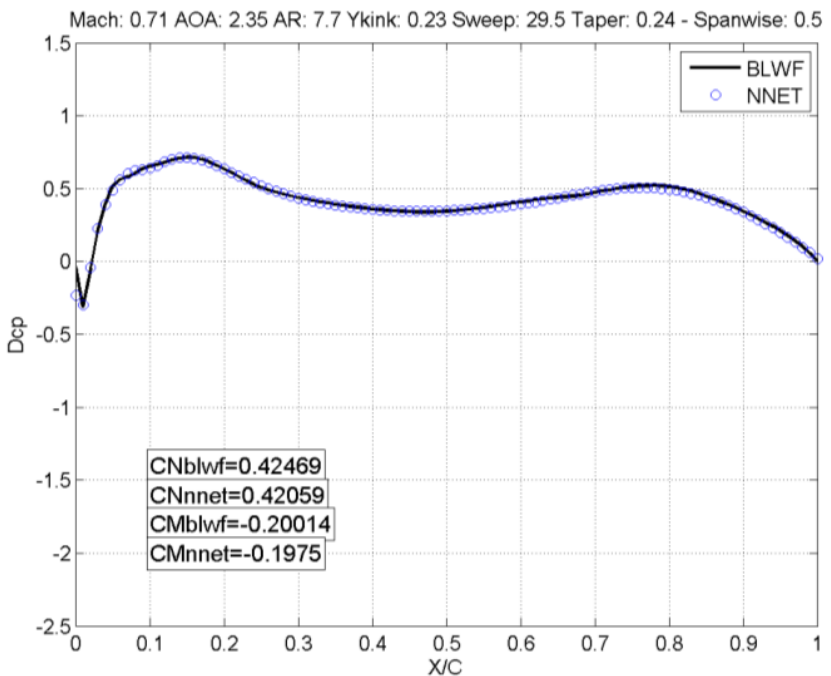

(b)

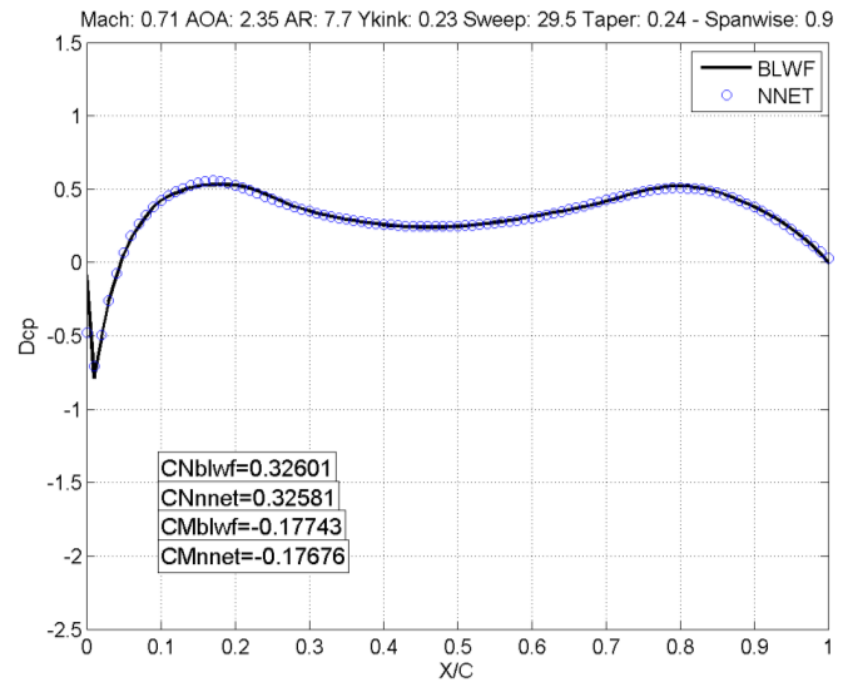

(c)

FIGURA 26: ESCOAMENTO SUBSONICO COM ANGULO DE ATAQUE POSITIVO: (A) ESTAÇÃO NA RAIZ (B) ESTAÇÃO NO MEIO DA ASA (C) ESTAÇÃO NA PONTA DA ASA. 
As Figuras 27, 28, 29 e 30 mostram os resultados para ângulos de ataque $1.0,2.1,0.3$ e 0.0 respectivamente, e com número de Mach de $0.73,0.76$ e 0.80 e 0.81 respectivamente.

Nesta segunda rede, com condição de voo transônica, a distribuição de pressão apontou resultados muito próximos entre os obtidos via CFD e via rede neural. Especialmente nas Figuras 27 e 29 pode-se notar que as ondas de choque não capturadas na rede anterior (primeira rede neural) foram perfeitamente representadas por esta rede neural. Os coeficientes de força e momento apresentaram os mesmos bons resultados para os três cortes analisados em ambas condições. Resultados semelhantes também foram encontrados para os outros indivíduos do conjunto de validação.

A Tabela 5 mostra uma análise estatística dos coeficientes obtidos pela rede neural e pelo CFD para os mesmos indivíduos do conjunto de validação. Analisando esta tabela podemos perceber que, semelhante ao que aconteceu com a rede subsônica de forma em planta, as médias dos erros absolutos de $C_{N}$ e $C_{M}$ foram, novamente, muito baixas. Os desvios padrão para os mesmos coeficientes também foram bastante pequenos.

TABELA 5: RESULTADOS PARA REDE TRANSONICA DE FORMA EM PLANTA:
\begin{tabular}{|l|c|}
\hline Média dos erros absolutos de CN & 0.0073 \\
\hline Média dos erros absolutos de CM & 0.0036 \\
\hline Média dos erros relativos de CN & 0.0252 \\
\hline Média dos erros relativos de CM & 0.0204 \\
\hline Desvio padrão dos erros absolutos de CN & 0.0062 \\
\hline Desvio padrão dos erros absolutos de CM & 0.0035 \\
\hline
\end{tabular}

Tais resultados forneceram a confiança necessária para avançarmos um passo na direção do objetivo principal deste trabalho, ou seja, a consideração das variáveis de perfil. Assim, a Seção 3.5 apresenta todo o desenvolvimento da rede neural de perfis paramatrizados. 


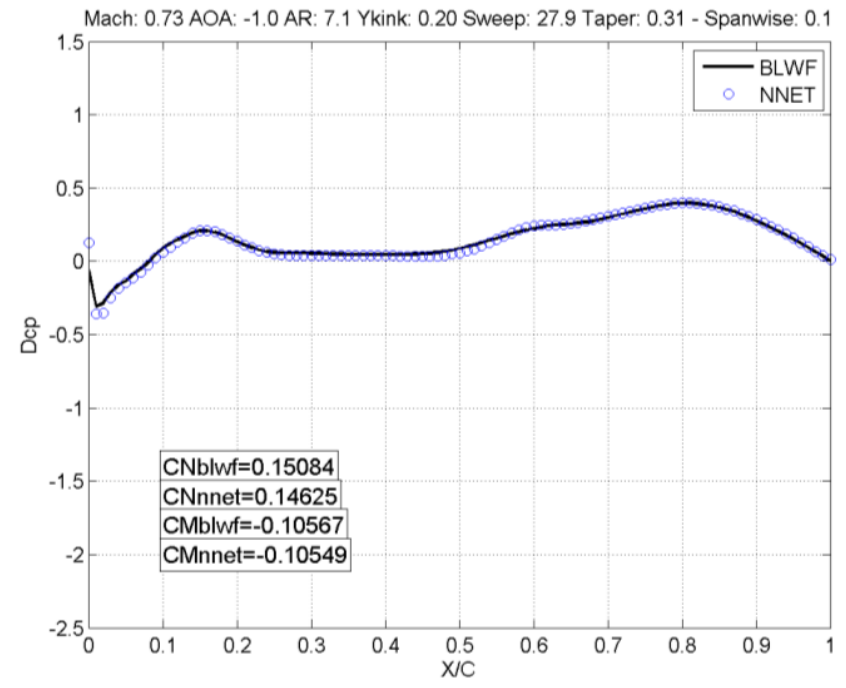

(a)

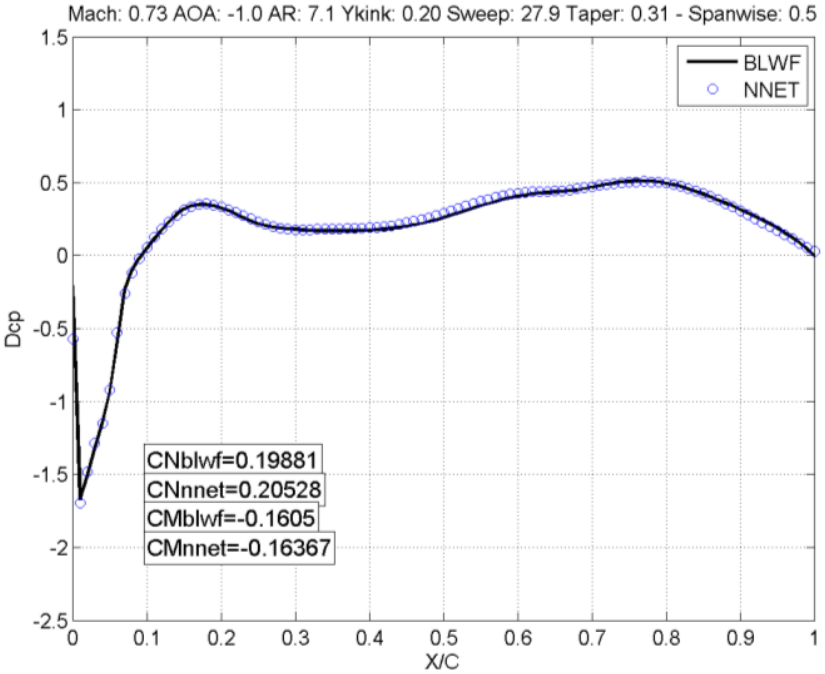

(b)

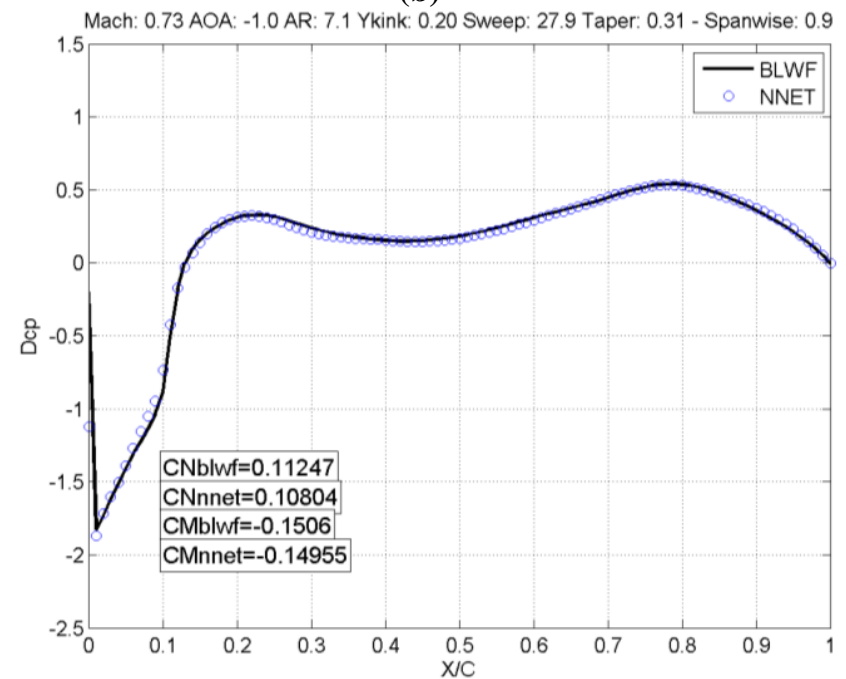

(c)

FIGURA 27: ESCOAMENTO TRANSONICO COM ANGULO DE ATAQUE NEGATIVO: (A) ESTAÇÃO NA RAIZ (B) ESTAÇÃO NO MEIO DA ASA (C) ESTAÇÃO NA PONTA DA ASA. 


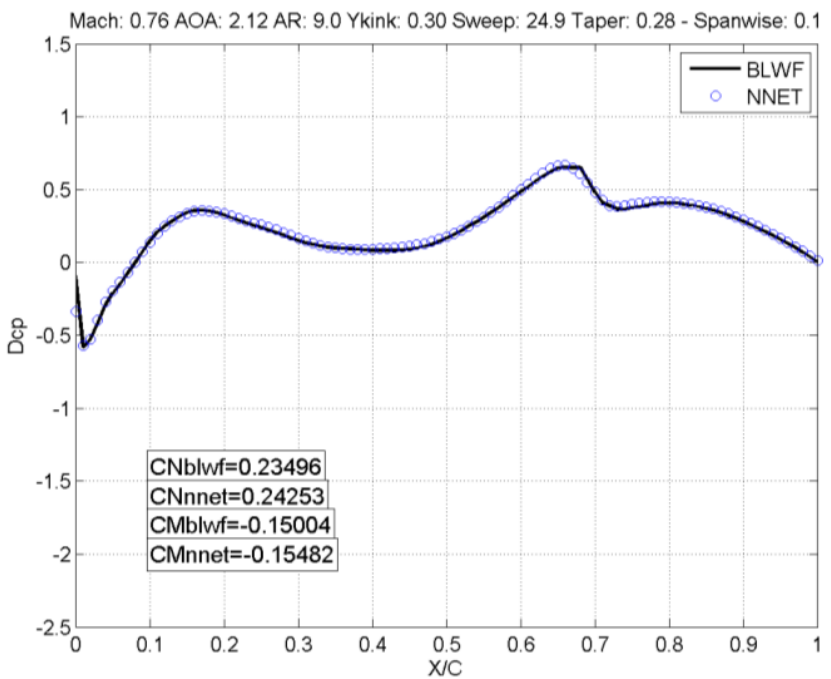

(a)

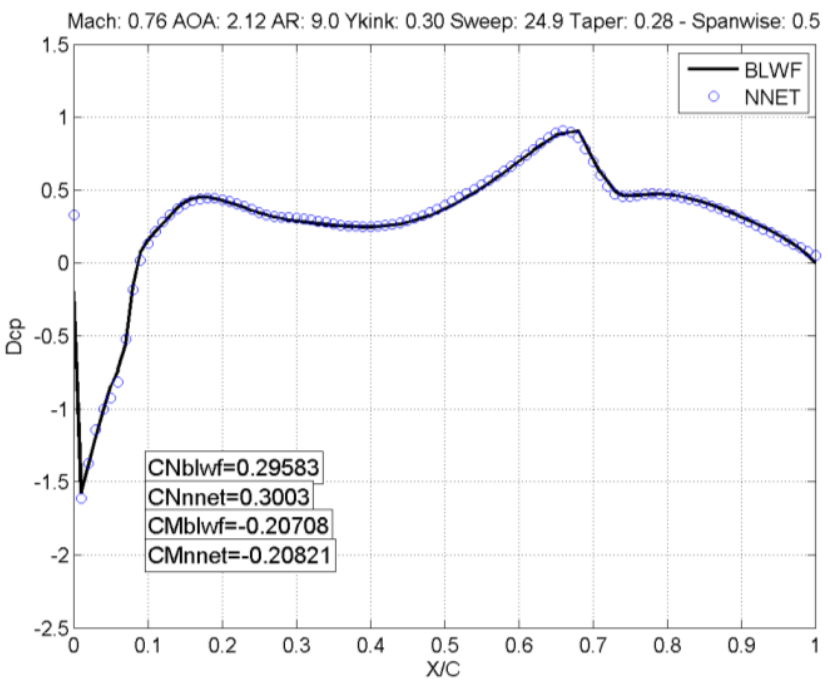

(b)

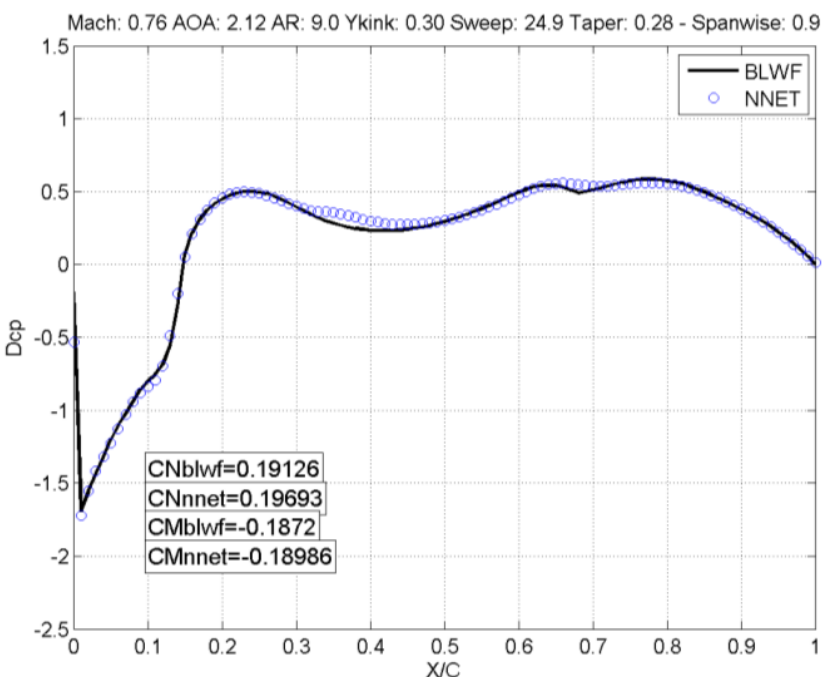

(C)

FIGURA 28: ESCOAMENTO TRANSONICO COM ANGULO DE ATAQUE POSITIVO: (A) ESTAÇÃO NA RAIZ (B) ESTAÇÃO NO MEIO DA ASA (C) ESTAÇÃO NA PONTA DA ASA. 


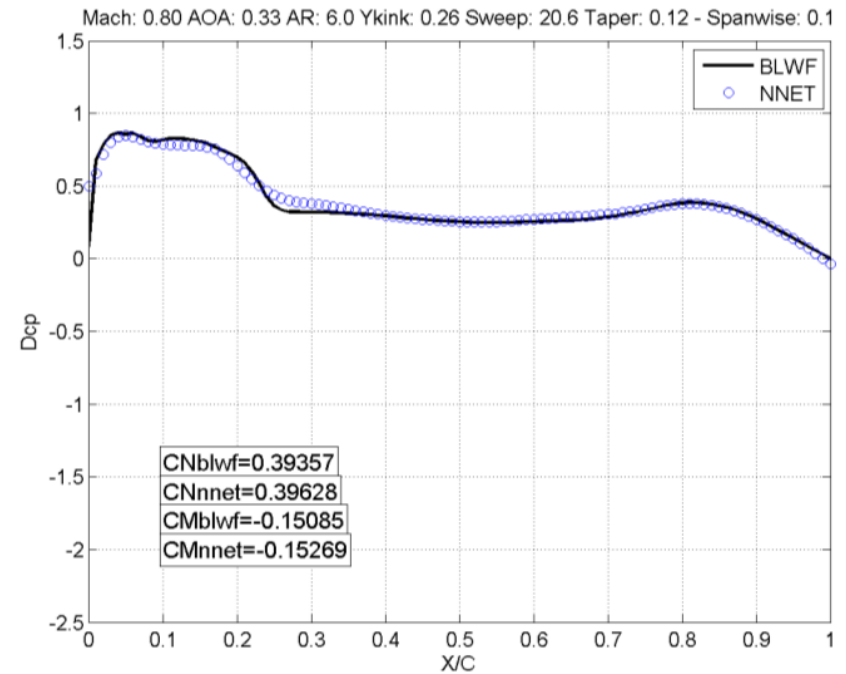

(a)

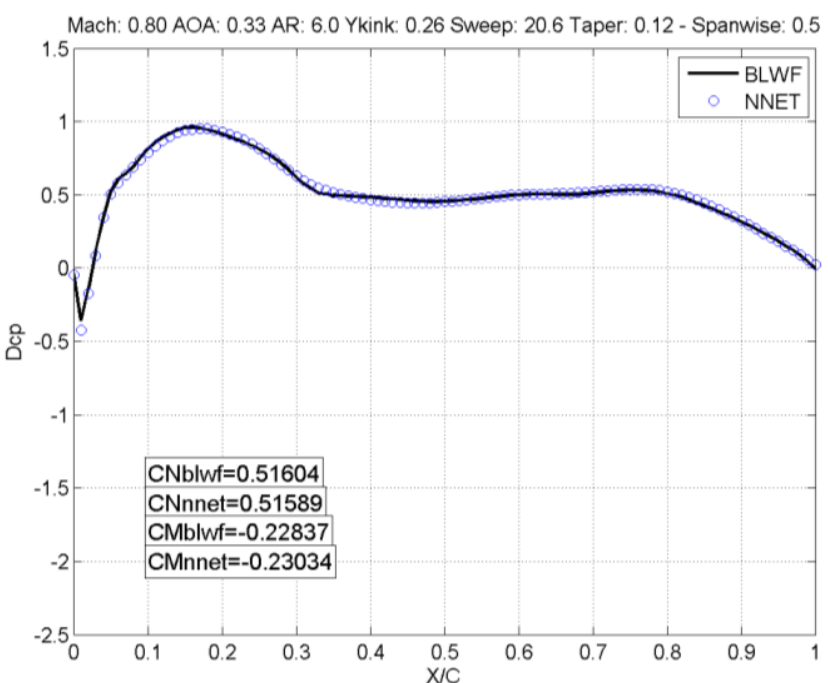

(b)

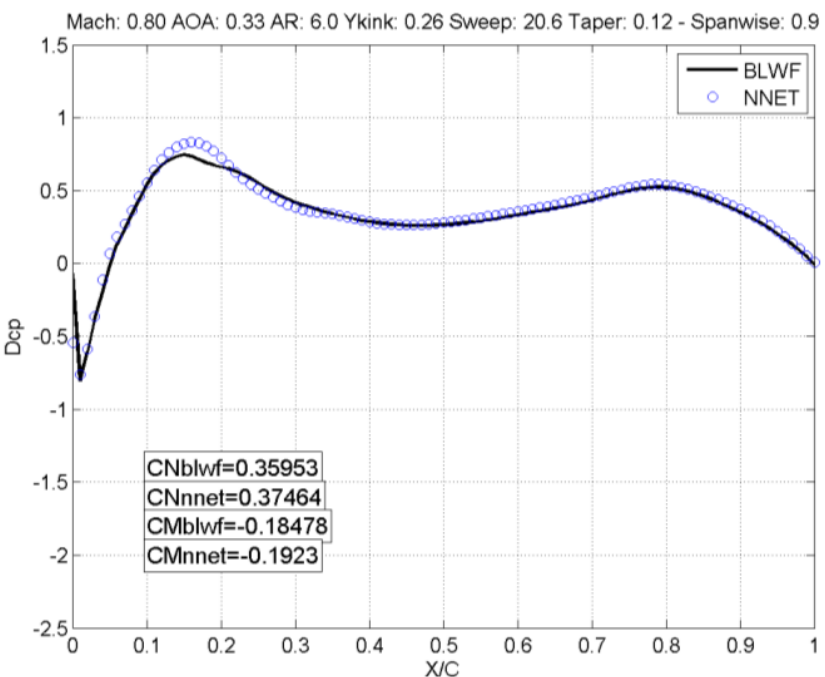

(c)

FIGURA 29: ESCOAMENTO TRANSONICO COM ANGULO DE ATAQUE POSITIVO: (A) ESTAÇÃO NA RAIZ (B) ESTAÇÃO NO MEIO DA ASA (C) ESTAÇÃO NA PONTA DA ASA. 


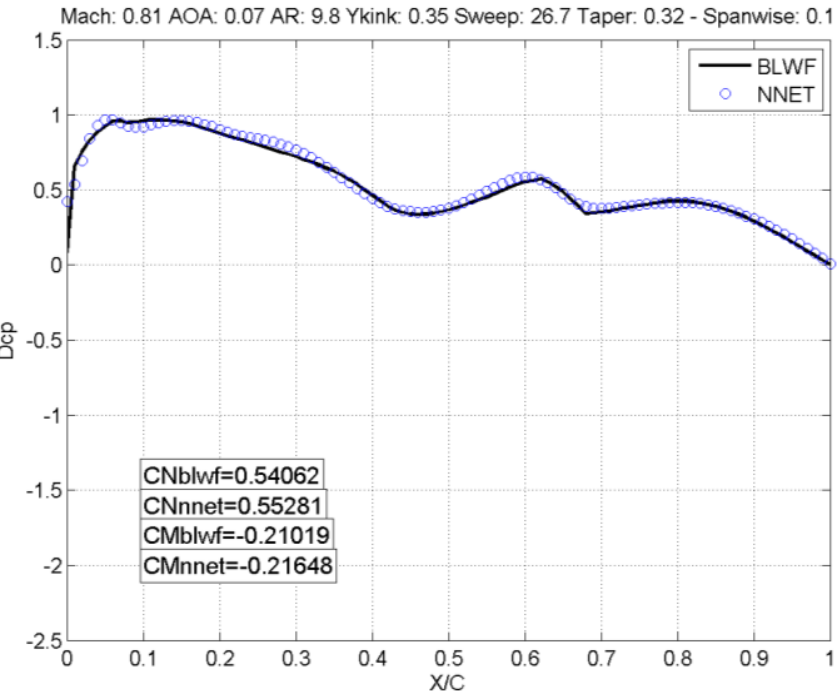

(a)

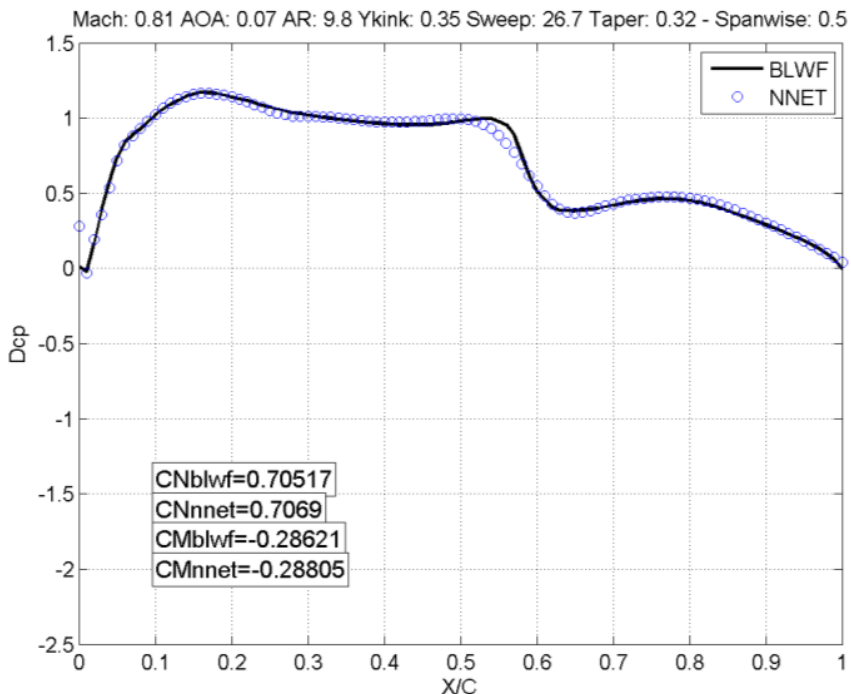

(b)

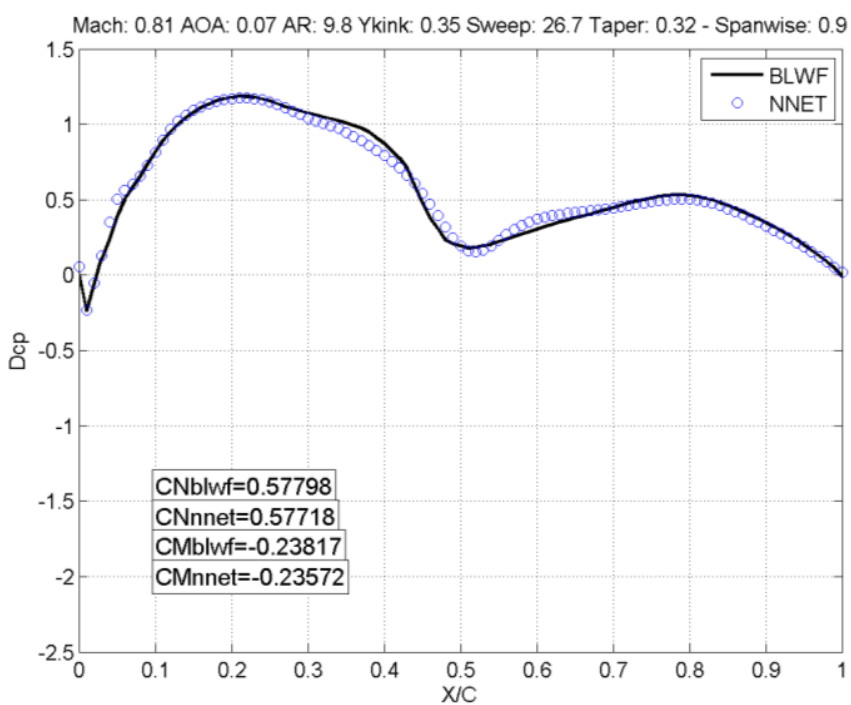

(c)

FIGURA 30: ESCOAMENTO TRANSONICO COM ANGULO DE ATAQUE POSITIVO: (A) ESTAÇÃO NA RAIZ (B) ESTAÇÃO NO MEIO DA ASA (C) ESTAÇÃO NA PONTA DA ASA 


\subsection{Terceira Rede Neural - Perfis parametrizados}

A solução desenvolvida nesta seção é a consideração das já mencionadas variáveis de condição de vôo e de forma em planta adicionadas das variáveis de apenas um dos três perfis (perfil da raiz) e obter as variáveis dos perfis da quebra e da ponta da asa de forma parametrizada, com algumas leis previamente definidas. Optou-se também por implementar somente uma rede subsônica nesta etapa.

As funções de forma de Sobieczky, $H$. (1998), foram implementadas para a definição dos perfis, uma vez que esta metodologia apresentou bons resultados para aerofólios supercríticos, Lyrio, J. A. A. (2006). Ainda, esta metodologia tem a vantagem de utilizar parâmetros físicos do perfil para gerar os pontos que o descrevem. Utilizando as funções de forma de Sobieczky (1998) e aplicando as condições de contorno corretas é possível representar uma grande variedade de aerofólios supercríticos.

As funções de forma de Sobieczky (1998) utilizam polinônios para descrever as curvas de arqueamento $\left(\mathrm{y}_{\mathrm{c}}\right)$ e de espessura $\left(\mathrm{y}_{\mathrm{t}}\right)$ de perfis:

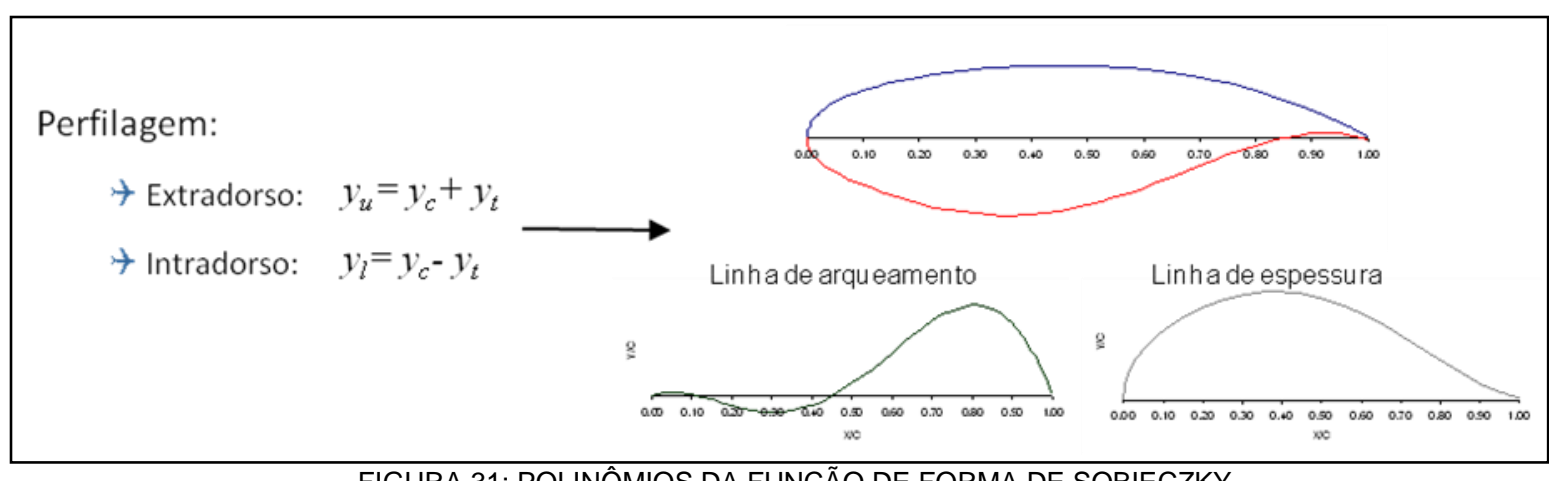

FIGURA 31: POLINÔMIOS DA FUNÇÃO DE FORMA DE SOBIECZKY

$$
\begin{aligned}
& y_{t}=a_{1} \sqrt{x}+a_{2} x+a_{3} x^{2}+a_{4} x^{3}+a_{5} x^{4} \\
& y_{c}=b_{1} x+b_{2} x^{2}+b_{3} x^{3}+b_{4} x^{4}+b_{5} x^{5}+b_{6} x^{6}
\end{aligned}
$$

onde:

x é a posição (adimensionalizada) ao longo da corda do perfil; 
$a_{i}$ são os coeficientes do polinônio correspondente à espessura do perfil;

e $b_{i}$ são os coeficientes do polinônio correspondente ao arqueamento do perfil.

Os vetores de coeficientes a e b podem ser definidos por:

$y_{t} \times A=C_{t}$

$\mathrm{y}_{\mathrm{c}} \times \mathrm{B}=\mathrm{C}_{\mathrm{c}}$

onde:

$y_{t}=\left[\begin{array}{ccccc}x t l e^{0.5} & x t l e^{1} & x t l e^{2} & x t l^{3} & x t l e^{4} \\ x t t h^{0.5} & x t t h^{1} & x t t h^{2} & x t h^{3} & x t t h^{4} \\ 0.5 & 1 & 2 & 3 & 4 \\ 1 & 1 & 1 & 1 & 1 \\ \frac{0.5}{x t h^{0.5}} & 1 & 2 * x t h & 3 * x t t h^{2} & 4 * x t h^{3}\end{array}\right]$

$C_{t}=\left[\begin{array}{c}y t l e \\ y t t h \\ \text { atte } * / 180 \\ y t t e \\ 0\end{array}\right]$

$y_{c}=\left[\begin{array}{cccccc}1 & 0 & 0 & 0 & 0 & 0 \\ x t t h^{1} & x t t h^{2} & x t t h^{3} & x t t h^{4} & x t t h^{5} & x t t h^{6} \\ x c m c^{1} & x c m c^{2} & x c m c^{3} & x c m c^{4} & x c m c^{5} & x c m c^{6} \\ 1 * x c m c^{0} & 2 * x c m c^{1} & 3 * x c m c^{2} & 4 * x c m c^{3} & 5 * x c m c^{4} & 6 * x c m c^{5} \\ 1 & 1 & 1 & 1 & 1 & 1 \\ 1 & 2 & 3 & 4 & 5 & 6\end{array}\right]$

$\mathrm{e}$

$C_{c}=\left[\begin{array}{c}\text { acle } * / 180 \\ y c t h \\ y c m c \\ 0 \\ y c t e \\ \text { acte } * \pi / 180\end{array}\right]$ 
A Figura 32 ilustra cada uma das características geométricas utilizadas para a obtenção dos parâmetros do equacionamento.

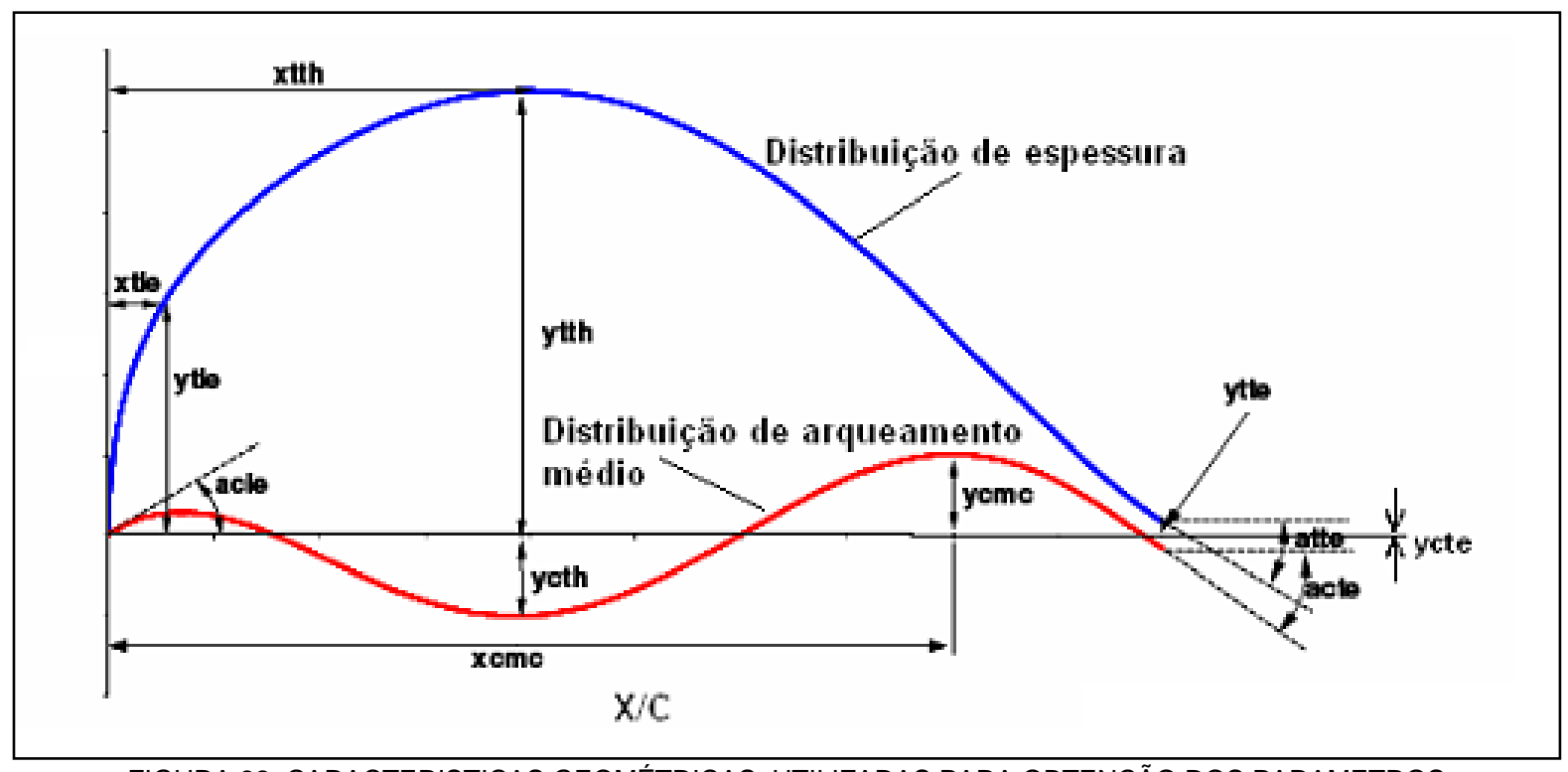

FIGURA 32: CARACTERISTICAS GEOMÉTRICAS UTILIZADAS PARA OBTENÇÃO DOS PARAMETROS

\begin{tabular}{|c|l|}
\hline acle & $\begin{array}{l}\text { Ângulo da linha de arqueamento no bordo de } \\
\text { ataque }\end{array}$ \\
\hline acte & $\begin{array}{l}\text { Ângulo da linha de arqueamento no bordo de } \\
\text { fuga }\end{array}$ \\
\hline atte & $\begin{array}{l}\text { Ângulo da linha de espessura no bordo de } \\
\text { fuga }\end{array}$ \\
\hline xcmc & Posição do máximo arqueamento \\
\hline xtle & $\begin{array}{l}\text { Posição } x \text { do ponto de controle do raio do } \\
\text { bordo de ataque }\end{array}$ \\
\hline xtth & Posição da máxima espessura \\
\hline ycmc & Máximo arqueamento \\
\hline ycte & Arqueamento no bordo de fuga \\
\hline ycth & $\begin{array}{l}\text { Arqueamento na posição de máxima } \\
\text { espessura }\end{array}$ \\
\hline ytte & $\begin{array}{l}\text { Espessura no ponto de controle do raio do } \\
\text { bordo de ataque }\end{array}$ \\
\hline Espessura no bordo de fuga \\
\hline Máxima espessura
\end{tabular}

FIGURA 33: DESCRIÇÃO DAS CARACTERÍSTICAS DE PERFIL 
Assim, as variáveis de condição de vôo e de forma em planta consideradas foram: número de Mach (a), ângulo de ataque (b), alongamento (c), enflexamento do bordo de ataque (d), afilamento (e), posição da quebra (f) e as posições ao longo da envergadura (g) e ao longo da corda (h) para obtenção da pressão e diedro (i).

Utilizando a formulação de Sobieczy (1998), temos ainda as seguintes variáveis de perfil: Ponto de controle para a espessura no bordo de ataque (j), espessura do bordo de ataque (k), posição de máxima espessura (I), máxima espessura (m), ângulo da linha de espessura no bordo de fuga (n), ângulo da linha de arqueamento no bordo de ataque (o), arqueamento no ponto de máxima espessura ( $p)$, posição do máximo arqueamento (q), máximo arqueamento $(r)$, ângulo da linha de arqueamento no bordo de fuga (s), espessura do bordo de fuga $(\mathrm{t})$, arqueamento no bordo de fuga $(\mathrm{u})$, torção geométrica do perfil $(\mathrm{v})$.

Para a definição do raio de curvatura do perfil basta que a espessura do bordo de ataque seja variável, neste caso pode-se deixar a posição desta espessura como um valor fixo. O valor convencionado foi de $5 \%$ da corda. Segundo Lyrio, J. A. A. (2006), a espessura do bordo de fuga pode ser um valor fixo, já que tal valor é uma referência. $O$ valor utilizado foi de 0.003 . Outra variável que optamos por fixar foi o arqueamento do perfil no bordo de fuga, e o valor utilizado foi de 0․ Feitas estas considerações, chegamos a um total de dez variáveis por perfil.

A exemplo do que foi feito para as redes neurais de forma em planta anteriores, procurou-se estabelecer limites para as variáveis de forma a produzir indivíduos mais usuais porém sem perder a generalidade. Assim, os limites utilizados para as variáveis de condição de vôo, forma em planta e de perfil para o perfil da raiz da asa se encontram na Tabela 6: 
TABELA 6: LIMITES DE VARIÁVEIS PARA A TERCEIRA REDE NEURAL

\begin{tabular}{|c|c|c|c|c|}
\hline $\begin{array}{l}\text { Código } \\
\text { da } \\
\text { variável }\end{array}$ & Simbolo & Variável & $\begin{array}{l}\text { Limite } \\
\text { inferior }\end{array}$ & $\begin{array}{l}\text { Limite } \\
\text { superior }\end{array}$ \\
\hline $\mathrm{a}$ & $\mathrm{M}$ & Número de Mach & 0.30 & 0.72 \\
\hline $\mathrm{b}$ & $\alpha$ & Ângulo de ataque & $-2^{0}$ & $3^{\circ}$ \\
\hline $\mathrm{C}$ & AR & Alongamento & 6 & 10 \\
\hline$d$ & Sweep & $\begin{array}{c}\text { Enflexamento no bordo de } \\
\text { ataque }\end{array}$ & $15^{\circ}$ & $30^{\circ}$ \\
\hline e & Taper & Afilamento & 0.10 & 0.40 \\
\hline$f$ & Yk & $\begin{array}{c}\text { Posição da quebra (ao longo da } \\
\text { semi-envergadura) }\end{array}$ & 0.20 & 0.40 \\
\hline g & Ycp & $\begin{array}{l}\text { Posição na envergadura } \\
\text { (mapeamento de pressão) }\end{array}$ & 0.00 & 1.00 \\
\hline $\mathrm{h}$ & Xсp & $\begin{array}{c}\text { Posição na corda (mapeamento } \\
\text { de pressão) }\end{array}$ & 0.00 & 1.00 \\
\hline $\mathrm{i}$ & Dih & Diedro & $0^{\circ}$ & $5^{\circ}$ \\
\hline j & xtle & $\begin{array}{c}\text { Ponto de controle para a } \\
\text { espessura no bordo de ataque } \\
\text { (valor fixo) }\end{array}$ & 0.05 & 0.05 \\
\hline $\mathrm{k}$ & ytle & Espessura no bordo de ataque & 0.01 & 0.06 \\
\hline I & $x t$ th & Posição de máxima espessura & 0.25 & 0.40 \\
\hline $\mathrm{m}$ & ytth & Máxima espessura & 0.10 & 0.20 \\
\hline $\mathrm{n}$ & atte & $\begin{array}{c}\text { Ângulo da linha de espessura no } \\
\text { bordo de fuga }\end{array}$ & $-20^{\circ}$ & $0^{\circ}$ \\
\hline 0 & acle & $\begin{array}{c}\text { Ângulo da linha de arqueamento } \\
\text { no bordo de ataque }\end{array}$ & $-8^{\circ}$ & $10^{\circ}$ \\
\hline $\mathrm{p}$ & ycth & $\begin{array}{l}\text { Arqueamento no ponto de } \\
\text { máxima espessura }\end{array}$ & -0.01 & 0.03 \\
\hline$q$ & $\mathrm{xcmc}$ & $\begin{array}{l}\text { Posição do máximo } \\
\text { arqueamento }\end{array}$ & 0.60 & 0.80 \\
\hline$r$ & $y c m c$ & Máximo arqueamento & 0.00 & 0.02 \\
\hline S & acte & $\begin{array}{l}\text { Ângulo da linha de arqueamento } \\
\text { no bordo de fuga }\end{array}$ & $-15^{\circ}$ & $0^{\circ}$ \\
\hline $\mathrm{t}$ & ytte & $\begin{array}{l}\text { Espessura do bordo de fuga } \\
\text { (valor fixo) }\end{array}$ & 0.003 & 0.003 \\
\hline $\mathrm{u}$ & ycte & $\begin{array}{l}\text { Arqueamento no bordo de fuga } \\
\text { (valor fixo) }\end{array}$ & 0.00 & 0.00 \\
\hline v & epsil & Torção geométrica do perfil & $-3^{\circ}$ & $5^{\circ}$ \\
\hline
\end{tabular}

Como mencionado anteriormente, como forma de simplificação, adotamos as mesmas variáveis do perfil da raiz para os perfis da quebra e da ponta da asa. Com exceção das seguintes variáveis: Máxima espessura (ytth) e ângulo da linha de arqueamento no bordo de fuga (acte). Não poderíamos adotar exatamente os mesmos valores das variáveis do perfil da raiz para os outros dois perfis, pois o resultado seria uma asa muito não usual, ou muito espessa, ou muito arqueada. 
Para resolvermos esta questão a solução adotada foi parametrizarmos estas variáveis com relação às mesmas variáveis do perfil da raiz. As regras utilizadas encontram-se na Tabela 7.

Para o caso da torção geométrica optamos por deixar variável para todos os perfis, apenas adicionamos a restrição para sempre haja uma diminuição no ângulo de torção da raiz para a ponta da asa. Esta limitação também esta descrita na Tabela 7.

TABELA 7: PARAMETRIZAÇÃO ADOTADA PARA VARIAVEIS

\begin{tabular}{|c|c|}
\hline Variável & Parametrização \\
\hline ytth $_{\text {quebra }}$ & $\mathrm{ytth}_{\text {quebra }}=\mathrm{ytth}_{\text {raiz }} \times 0.75$ \\
\hline ytth $_{\text {ponta }}$ & $\mathrm{ytth}_{\text {ponta }}=\mathrm{ytth}_{\text {quebra }} \times 0.90$ \\
\hline acte $_{\text {quebra }}$ & acte $_{\text {quebra }}=$ acte $_{\text {raiz }}-$ range de acte $_{\text {raiz }}$ \\
\hline acte $_{\text {ponta }}$ & acte $_{\text {quebra }}=$ acte $_{\text {quebra }}-$ range de acte raiz $\times 0.70$ \\
\hline epsil ${ }_{\text {quebra }}$ & epsil $_{\text {quebra }}=$ epsil $_{\text {raiz }}-$ epsil $_{\text {quebra }}$ \\
\hline epsil $_{\text {ponta }}$ & epsil ${ }_{\text {ponta }}=$ epsil $_{\text {quebra }}-$ epsil \\
\hline
\end{tabular}

Para esta rede neural, a exemplo do que foi feito para as redes anteriores, estimou-se que o número necessário de indivíduos seria por volta de 50000. Assim, o conjunto de treinamento inicial foi gerado com 70.000 indivíduos, porém apenas 54.781 indivíduos obtiveram convergência no CFD, ou seja, um aproveitamento de $78.26 \%$ dos indivíduos do conjunto inicial.

O tipo de rede escolhida foi, novamente, o perceptron de múltiplas camadas, com correção dos pesos por retropropagação usando o algoritmo de LevenbergMarquardt. A arquitetura selecionada foi a de duas camadas ocultas, cada uma com 25 neurônios, cada um deles usando a função tangente hiperbólica como função de ativação, e uma camada de saída com um neurônio usando simplesmente uma função linear como função de ativação.

O processo de treinamento foi aplicado até que fosse obtido um erro menor que $1 \times 10^{-4}$. Esse aumento no erro aceitado deve-se ao fato ao aumento do número 
de variáveis. Neste caso, a validação foi realizada com 120 indivíduos, gerados aleatóriamente porém diferentes daqueles usados no processo de treinamento. Esses indivíduos foram então submetidos ao CFD e à rede neural, sendo que 101 deles obtiveram convergência.

\subsubsection{Resultados da Terceira Rede Neural - Perfis Parametrizados}

A Figura 34 mostra os resultados da validação feita para a rede subsônica com perfis parametrizados para um indivíduo. Nesta figura, os circulos azuis apresentam o resultado fornecido diretamente para o CFD para a condição desejada, enquanto que a linha cheia representa os resultados fornecidos pela rede neural para as mesmas condições. Nesta figura também é mostrado o resultado em termos de coeficientes de força normal $\left(\mathrm{C}_{N}\right)$ e de momento de arfagem $\left(\mathrm{C}_{\mathrm{M}}\right)$ para a rede neural e para o resultado do CFD.

A figura 34 apresenta resultados para um ângulo de ataque negativo e com números de Mach de 0.437 . A distribuição de pressão, novamente apresentou uma excelente correlação entre os resultados obtidos via CFD e via rede neural. Os coeficientes de força e momento apresentaram uma diferença um pouco maior que a apresentadas para as redes anteriores, porém como o grau de complexidade foi bastante aumentado, consideramos que os resultados para os três cortes analisados são bastante satisfatórios.

Resultados semelhantes foram encontrados para os outros indivíduos do conjunto de validação.

A Tabela 8 mostra uma análise estatística dos coeficientes obtidos pela rede neural e pelo CFD para os mesmos indivíduos do conjunto de validação. Analisando 
esta tabela podemos perceber que as médias dos erros absolutos de $C_{N}$ e $C_{M}$ foram uma ordem de grandeza maiores que os resultados apresentados pelas redes anteriores, porém ainda dentro de uma faixa aceitável, considerando o grau de complexidade do problema. Os desvios padrão para os mesmos coeficientes também podem ser considerados razoáveis.

TABELA 8: RESULTADOS PARA REDE DE PERFIS PARAMETRIZADO
\begin{tabular}{|l|c|}
\hline Média dos erros absolutos de CN & 0.0236 \\
\hline Média dos erros absolutos de CM & 0.0080 \\
\hline Média dos erros relativos de CN & 0.0737 \\
\hline Média dos erros relativos de CM & 0.0807 \\
\hline Desvio padrão dos erros relativos de CN & 0.0417 \\
\hline Desvio padrão dos erros relativos de CM & 0.0081 \\
\hline
\end{tabular}

Assim, de posse destes resultados, novamente, há a percepção de que o método é robusto o suficiente para passarmos para o próximo e último passo proprosto neste trabalho - a obtenção de distribuição de pressão em asas considerando variáveis de forma em planta e de três perfis de forma independente. 


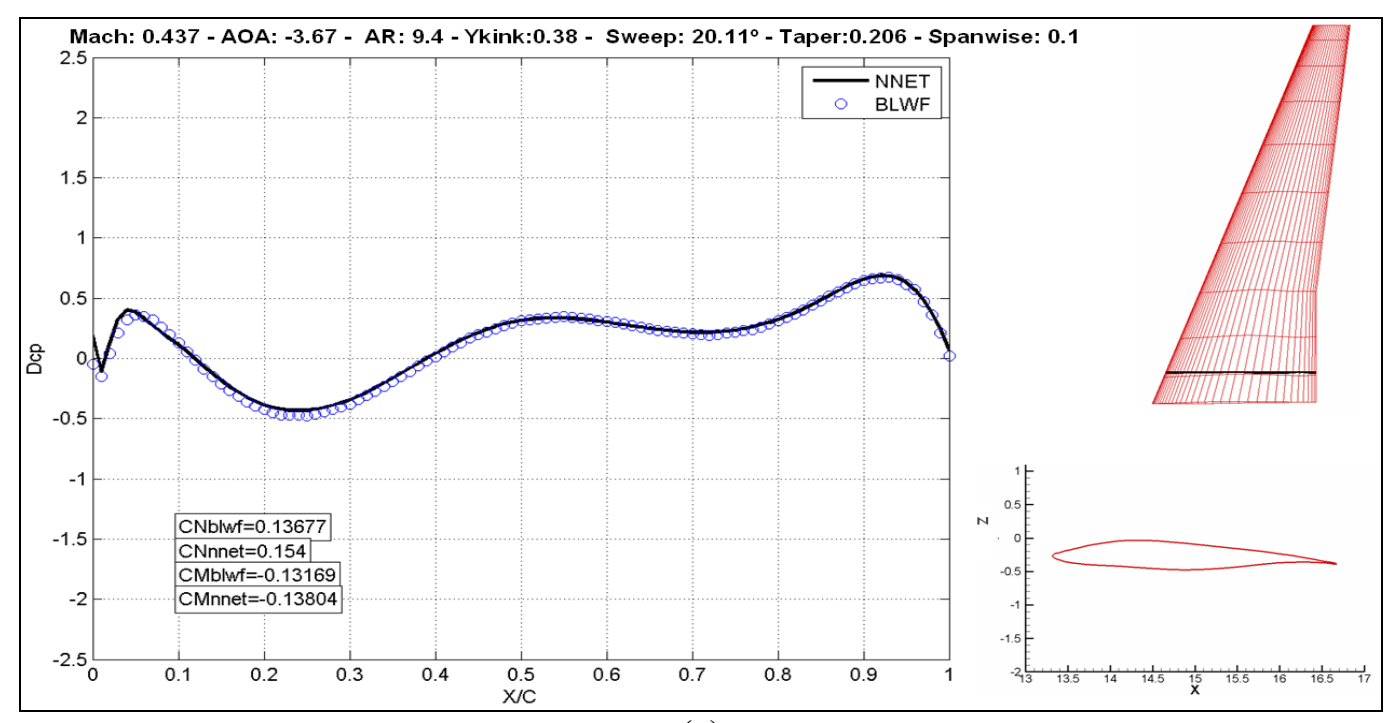

(a)

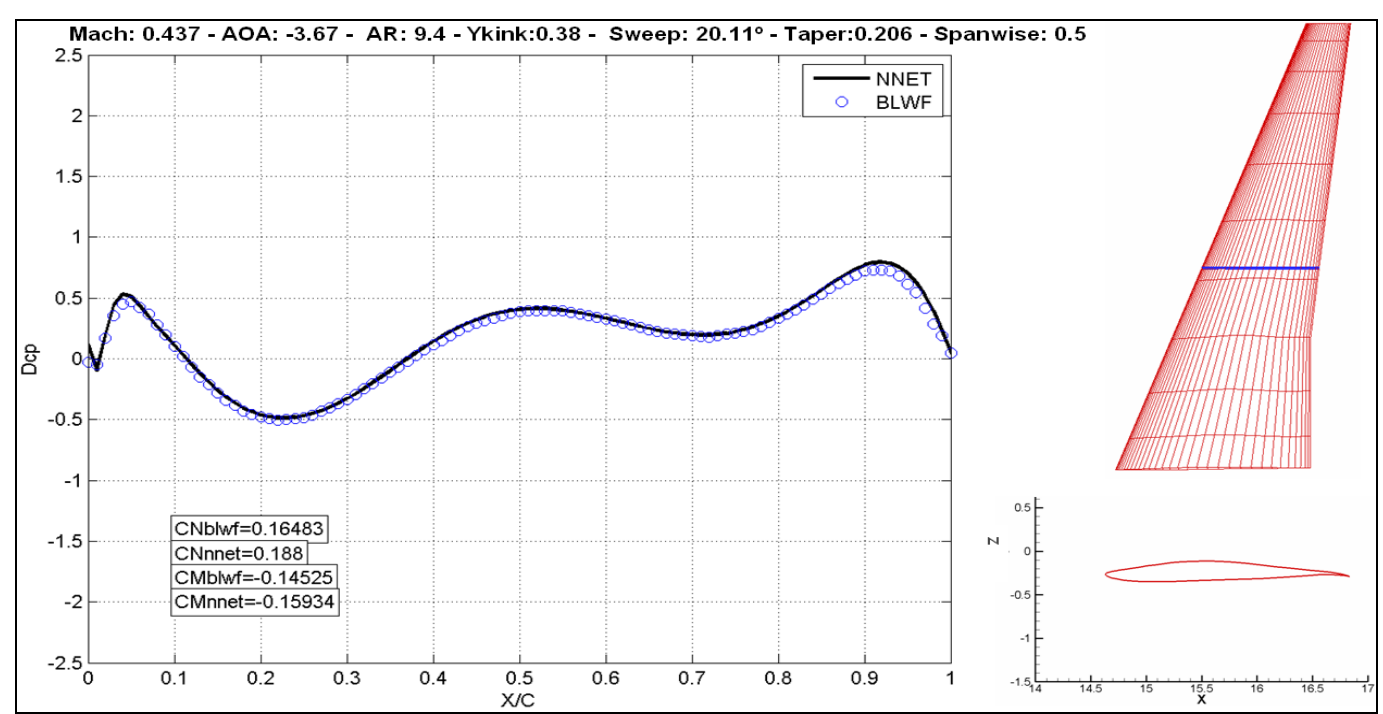

(b)

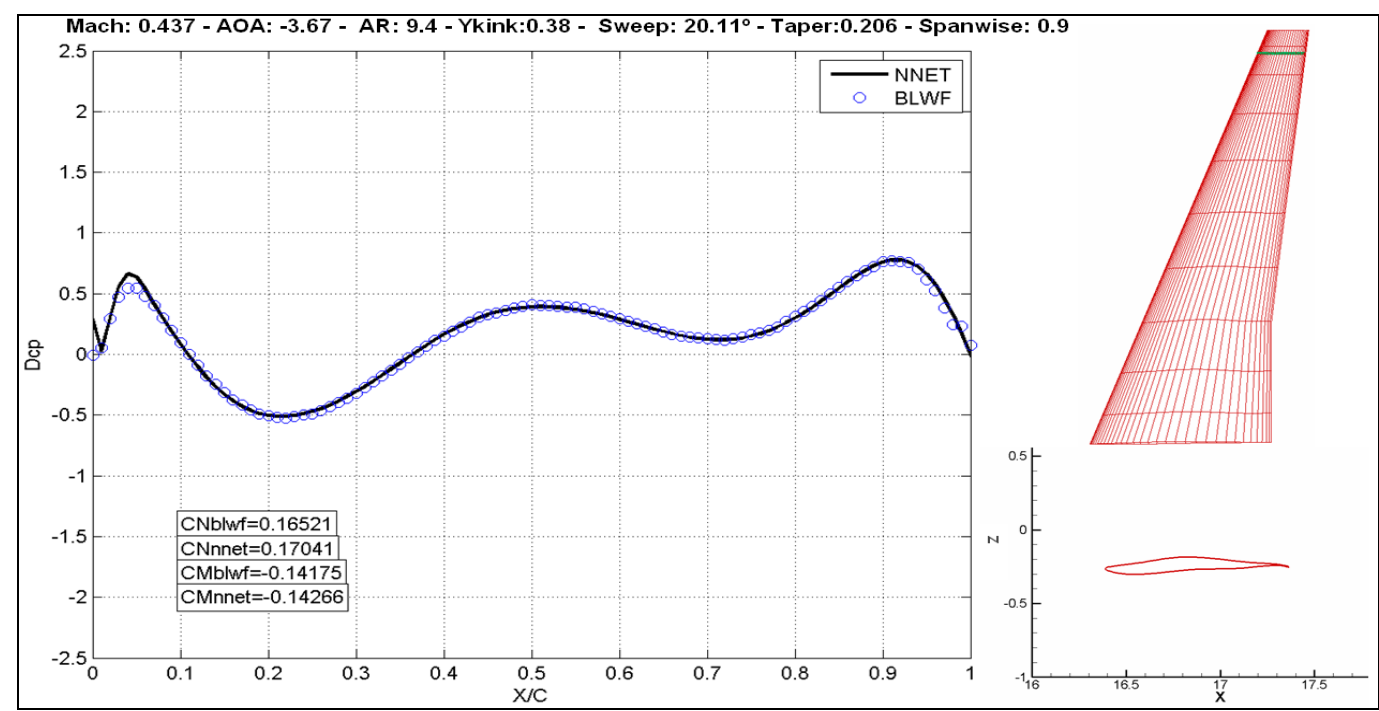

(c)

FIGURA 34: ESCOAMENTO SUBSONICO COM ANGULO DE ATAQUE NEGATIVO: (A) ESTAÇÃO NA RAIZ (B) ESTAÇÃO NO MEIO DA ASA (C) ESTAÇÃO NA PONTA DA ASA. 


\subsection{Análise de sensibilidade}

Antes de partirmos para o desenvolvimento das duas últimas redes neurais, devido ao grande número de variáveis a serem consideradas agora, consideramos sensata uma análise do grau de importância relativa de cada variável considerada no resultado final.

Para realizar esta análise de sensibilidade, novamente uma função do Matlab® foi utilizada, a 'mregress.m', que é uma ferramenta de regressão linear que mede o grau de dependência de uma variável y com relação a outra variável x. Neste caso, a função testou qual o grau de dependência do resultado (dCp) em relação a cada uma das variáveis consideradas.

Essa análise fornece o indicativo de quais variáveis podem ser eventualmente descartadas, ou seja, reduzindo assim o número total de variáveis a serem consideradas e com isso reduzindo a dimensão do problema. Para tanto, um conjunto de treinamento com pouco mais de 42.000 indivíduos foi gerado, considerando todas as variáveis de forma em planta e dos três perfis.

A Figura 35 traz uma representação gráfica do resultado da análise de sensibilidade realizada. Os "p-values" indicam a importância relativa de cada variável; variáveis relativamente mais importantes apresentarão " $p$-values" menores que as demais. 


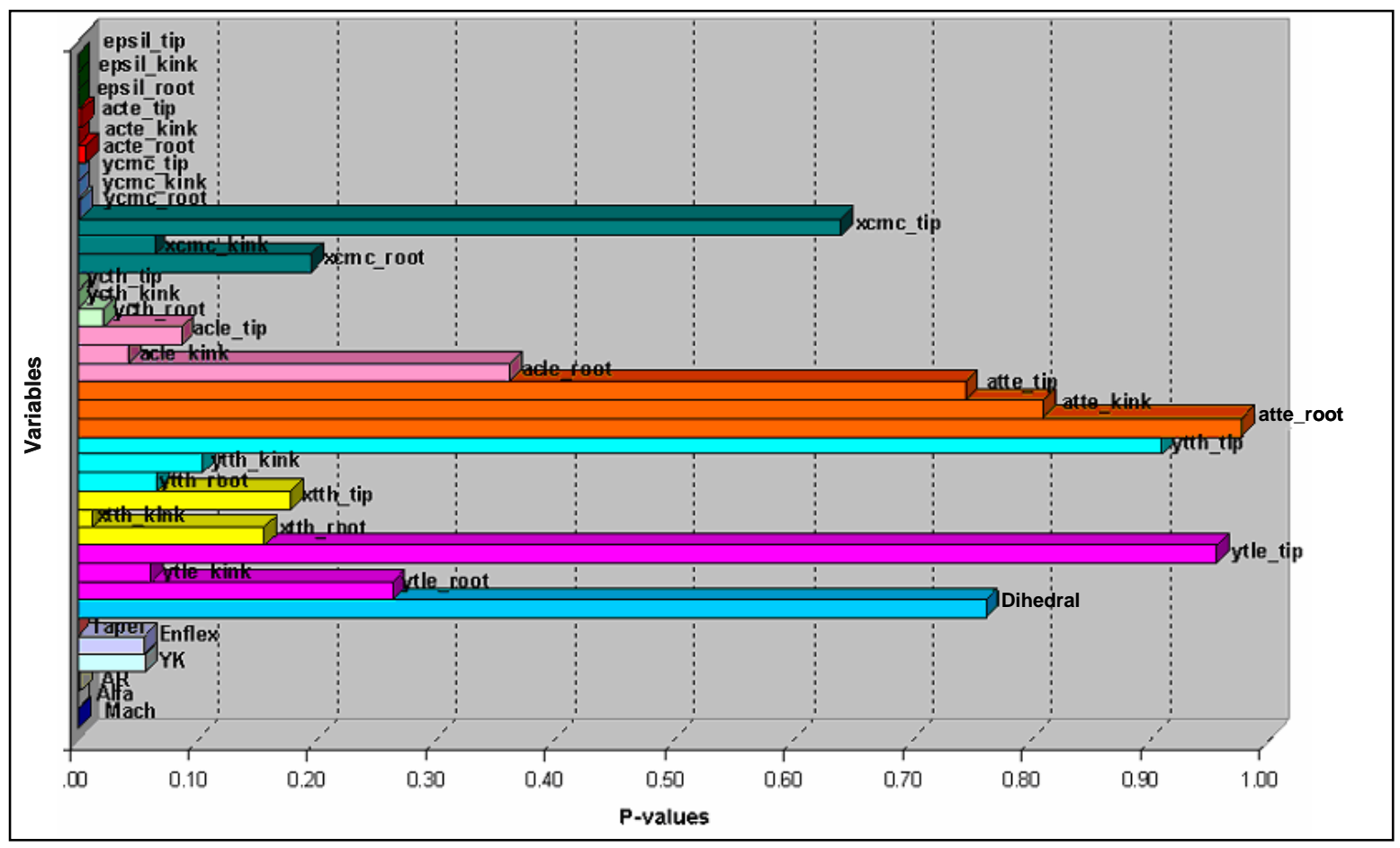

FIGURA 35: ANALISE DE SENSIBILIDADE

Foi apontado pela análise que a variável ângulo da linha de espessura no bordo de fuga (atte) e o diedro da asa, por possuírem maiores valores de "p-values", produzem menor efeito que as demais variáveis no resultado final de $\Delta \mathrm{Cp}$. Outras variáveis de perfil apresentaram-se como possíveis candidatas a valores constantes, no entanto, optou-se por considerar somente as variáveis que apresentassem valores elevados de "p-values" para os três perfis simultaneamente. Este foi o caso das variáveis $x c m c$ e $y$ tle, as quais apresentaram "p-values" relativamente altos para os perfis da ponta e baixos para os demais perfis.

Uma análise mais refinada foi feita com a intenção de investigar o resultado obtido na análise de sensibilidade. Assim, geramos alguns indivíduos e artificialmente modificamos as variáveis em questão (atte e dih) para isolarmos o impacto destas variáveis no $\triangle \mathrm{Cp}$. O software de CFD (BLWF) foi rodado para todas as configurações de teste e os resultados foram confrontados. 
As próximas figuras mostram o estudo feito para um indivíduo em particular, a título de exemplo. Na Figura 36, todas as variáveis foram mantidas constantes, enquanto que a variável diedro variou de 0 a 5 graus, ou seja, cada curva da figura mostra o resultado de dCp ao longo da corda para cada grau de diedro na estação 2y/b igual a 0.1. Na Figura 37, analogamente, o mesmo foi feito, porém alterando o valor da variável atte de -20 a 0 graus. As Figuras 38 e 39 mostram o mesmo resultado para as estações com 2y/b igual a 0.5 e as Figuras 40 e 41 mostram o resultado para as estações com $2 \mathrm{y} / \mathrm{b}$ igual a 0.9 .

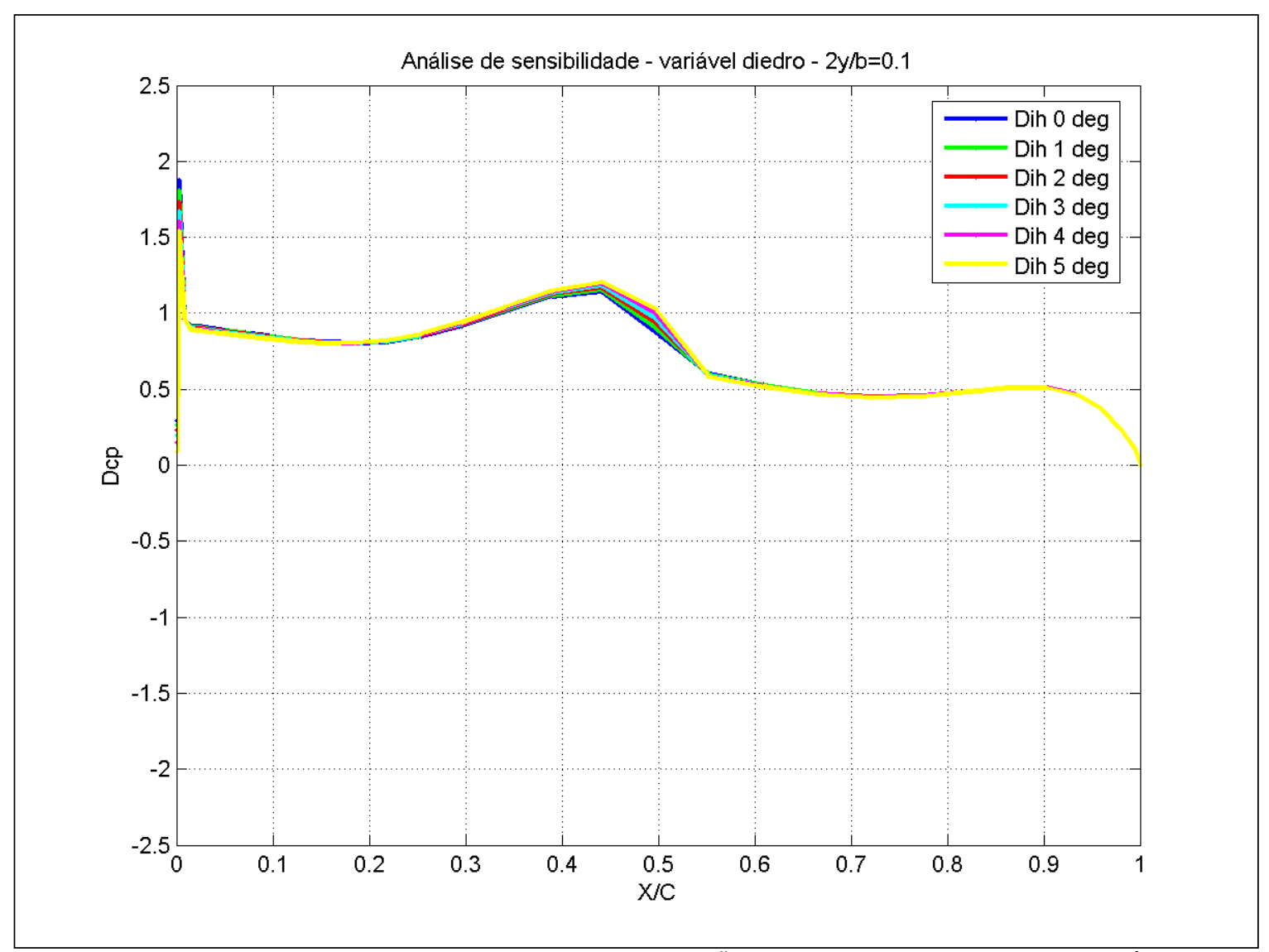

FIGURA 36: INFLUENCIA DA VARIAVEL DIEDRO NA ESTAÇÃO 2Y/B = 0.1 EM UM INDIVIDUO GENÉRICO 


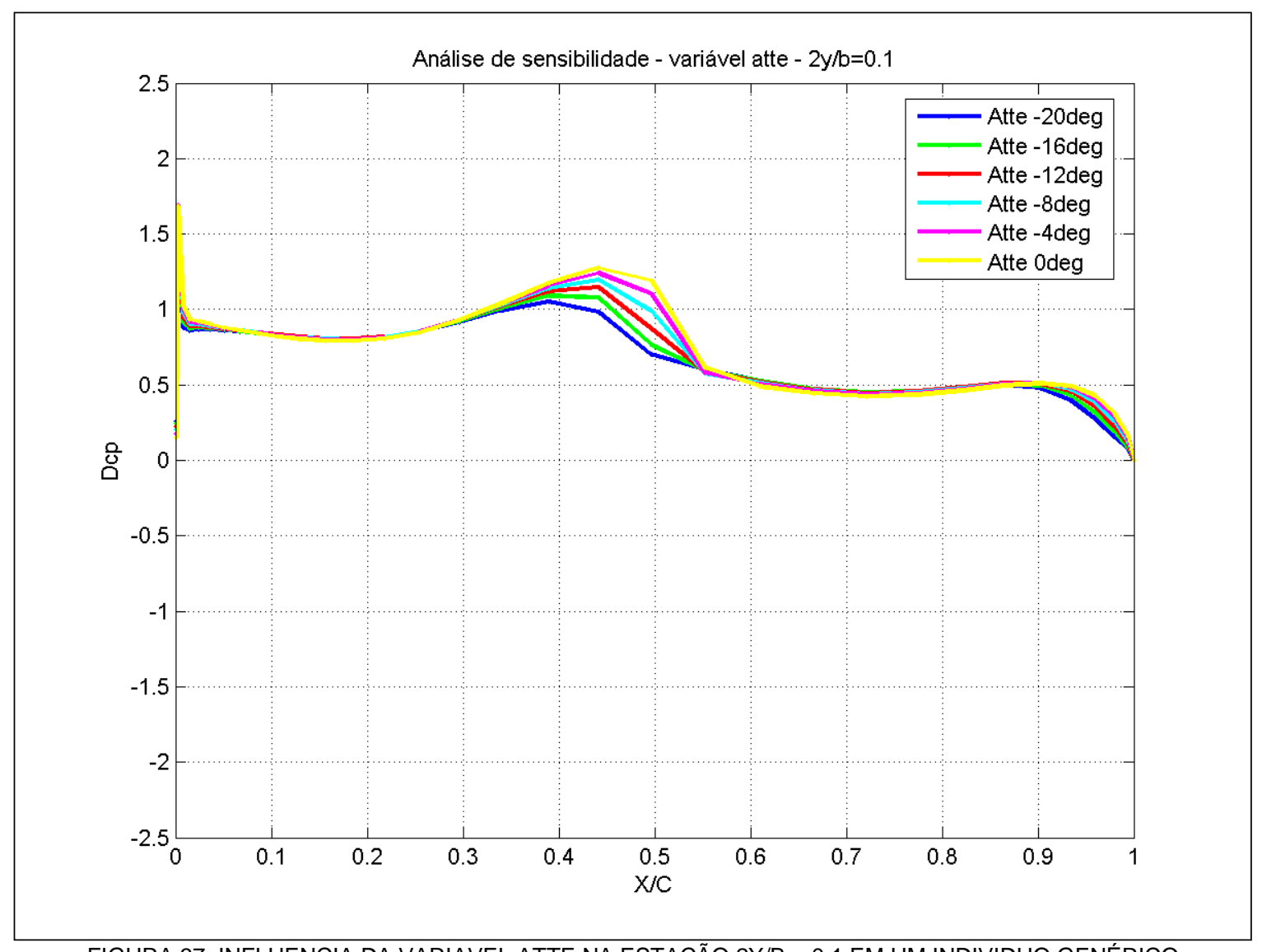

FIGURA 37: INFLUENCIA DA VARIAVEL ATTE NA ESTAÇÃO 2Y/B = 0.1 EM UM INDIVIDUO GENÉRICO

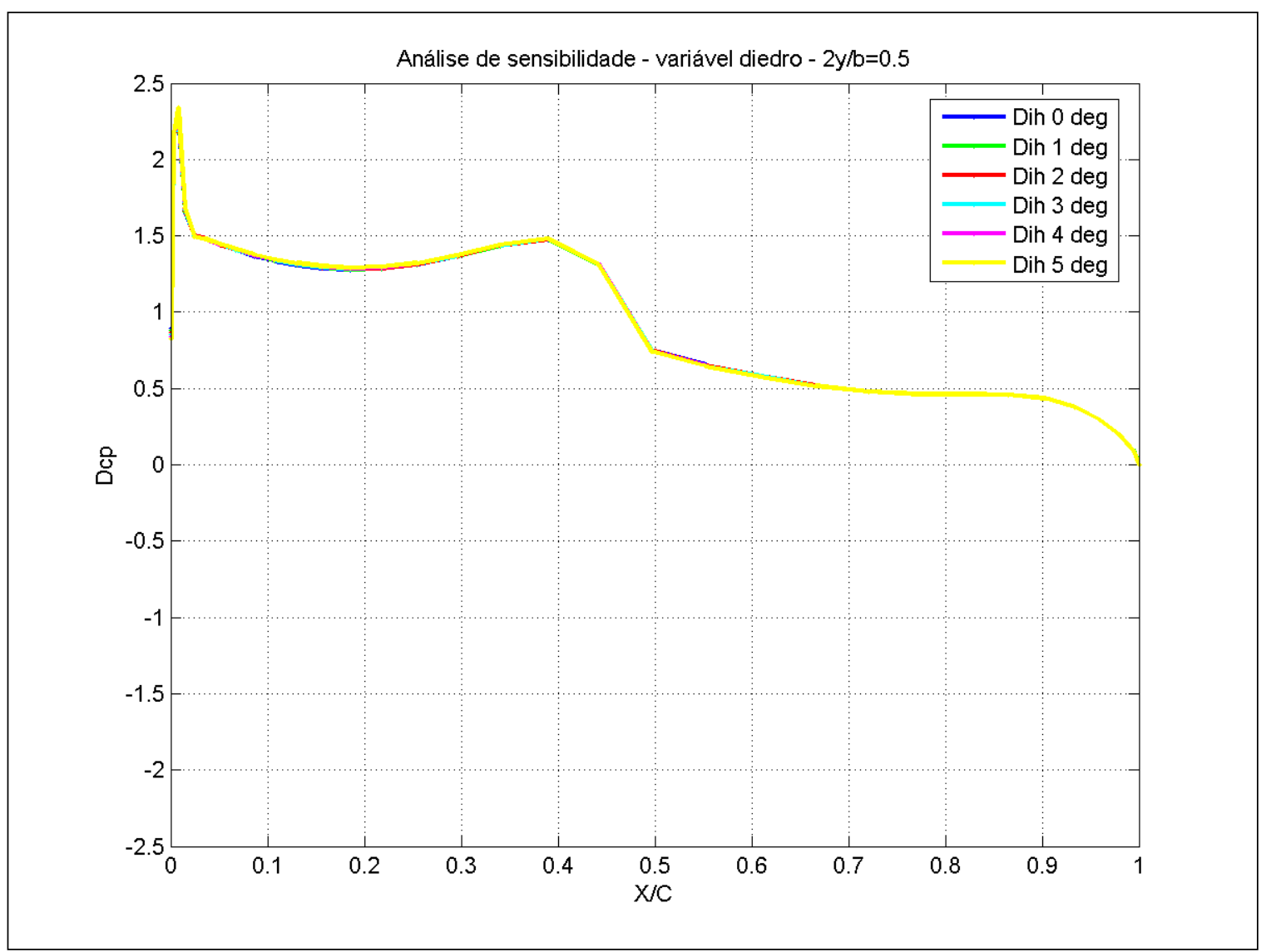

FIGURA 38: INFLUENCIA DA VARIAVEL DIEDRO NA ESTAÇÃO 2Y/B = 0.5 EM UM INDIVIDUO GENÉRICO 


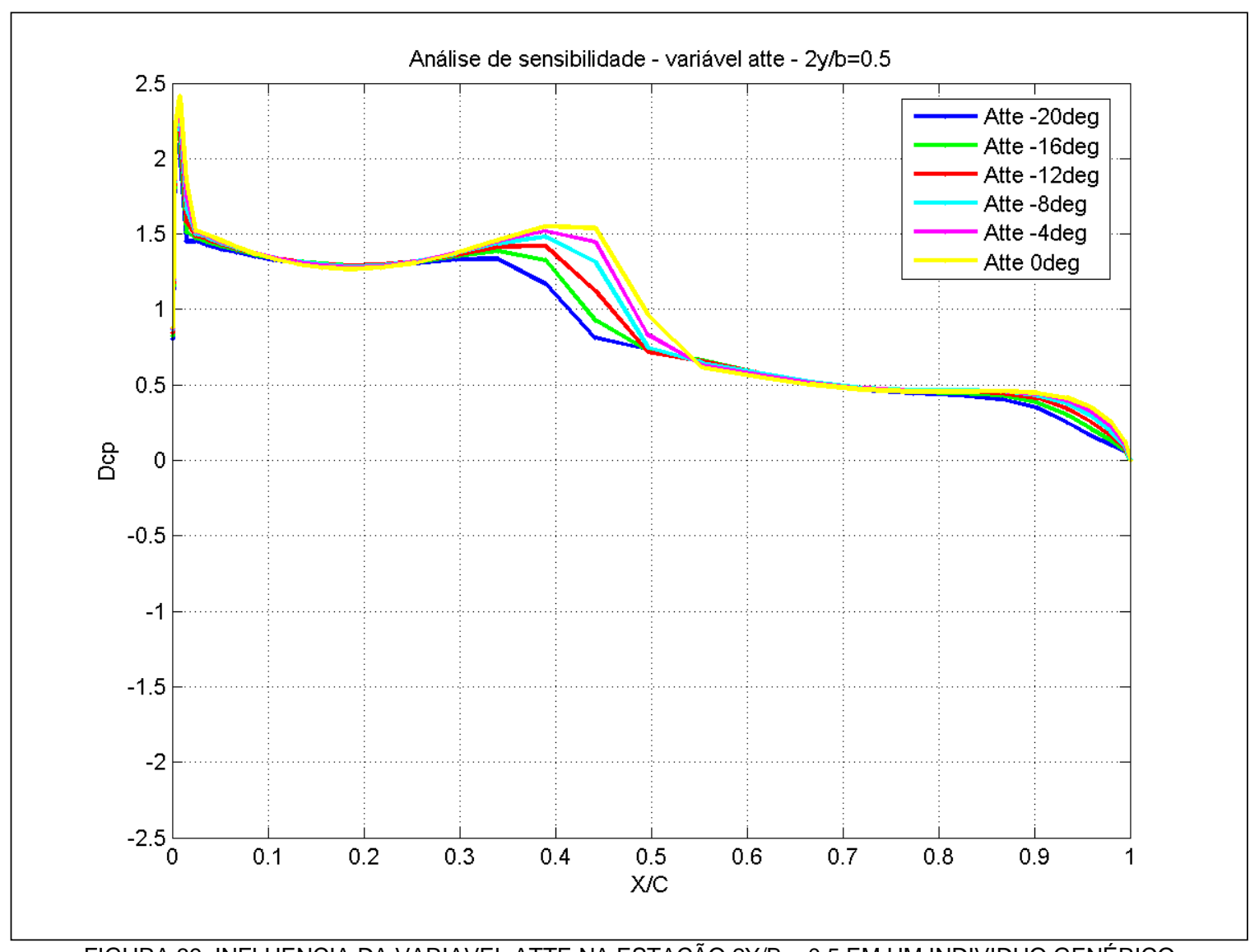

FIGURA 39: INFLUENCIA DA VARIAVEL ATTE NA ESTAÇÃO 2Y/B = 0.5 EM UM INDIVIDUO GENÉRICO

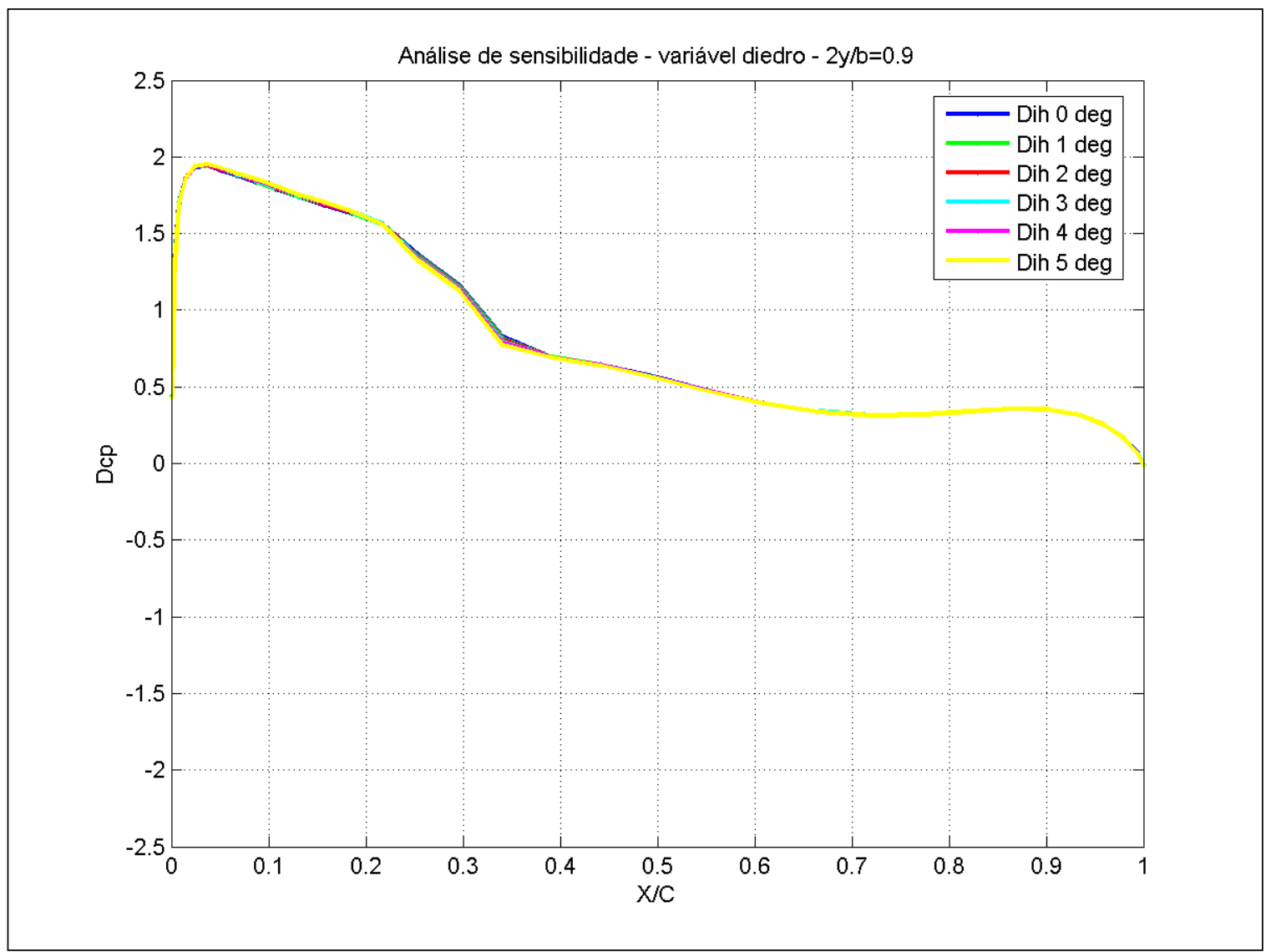

FIGURA 40: INFLUENCIA DA VARIAVEL DIEDRO NA ESTAÇÃO 2Y/B = 0.9 EM UM INDIVIDUO GENÉRICO 


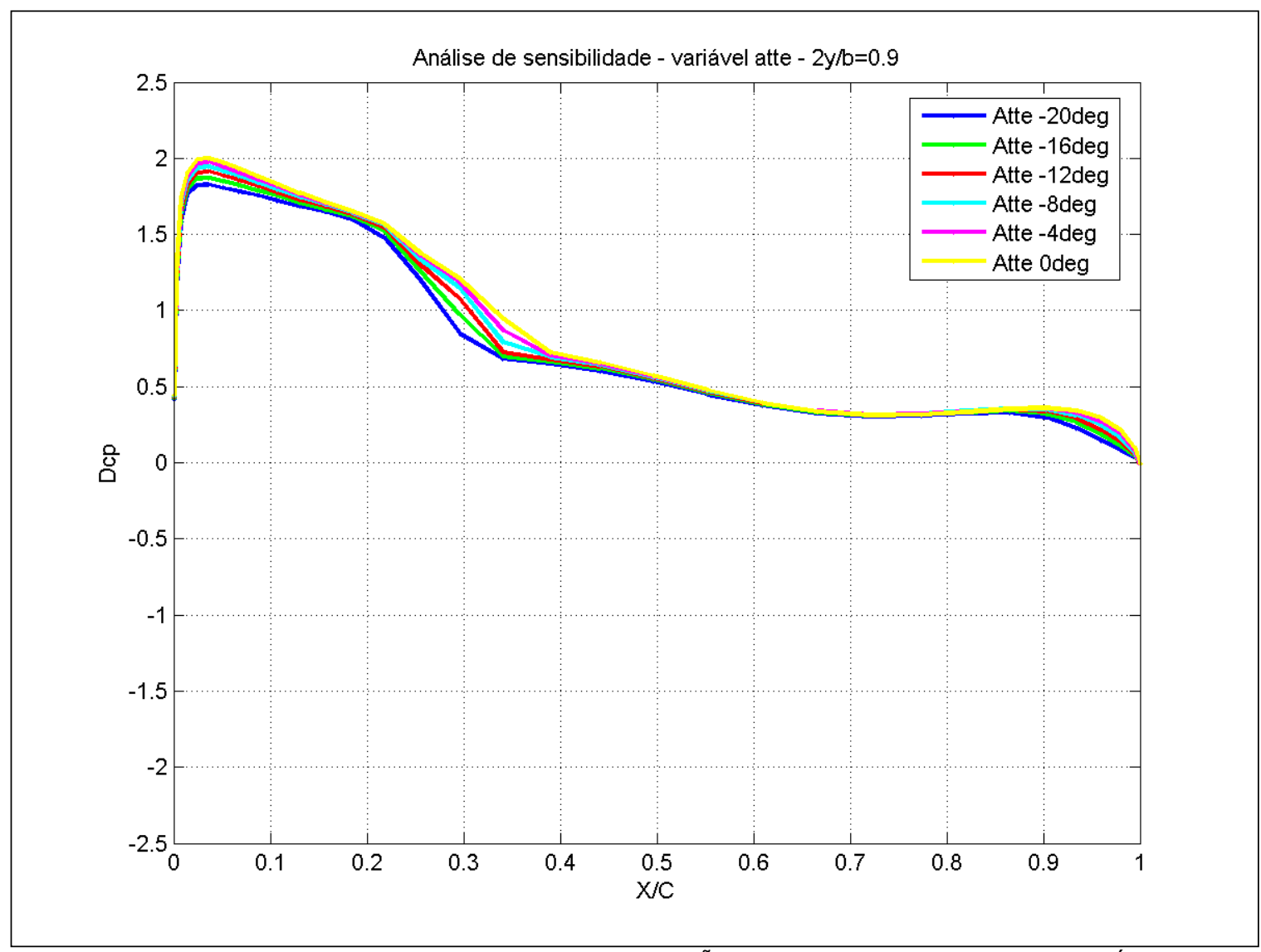

FIGURA 41: INFLUENCIA DA VARIAVEL ATTE NA ESTAÇÃO 2Y/B = 0.9 EM UM INDIVIDUO GENÉRICO

Observa-se que a variável atte tem efeito maior no resultado final de dCp que a variável diedro. Com base nesses resultados, optou-se por considerar a variável diedro como uma constante nas análises seguintes. 


\subsection{Quarta rede neural - Perfis variáveis}

\subsubsection{REDE SUBSÔNICA}

Com base na experiência adquirida nas redes anteriores e nos resultados da análise de sensibilidade, decidiu-se implementar uma nova rede neural considerando agora todas as variáveis, incluindo as variáveis dos três perfis.

Desta forma consideramos as variáveis de condição de vôo e de forma em planta: número de Mach (a), ângulo de ataque (b), alongamento (c), enflexamento do bordo de ataque (d), afilamento (e), posição da quebra (f) e as posições ao longo da envergadura (g) e ao longo da corda (h) para obtenção da pressão. A variável diedro (i) foi considerada como zero, levando-se em conta o resultado da analise de sensibilidade.

Utilizou-se a formulação de Sobieczy (1998) como aplicada para a rede parametrizada, porém considerando as variáveis para cada perfil de forma independente. Assim, as variáveis consideradas foram: espessura do bordo de ataque $(k)$, posição de máxima espessura (I), máxima espessura $(m)$, ângulo da linha de espessura no bordo de fuga (n), ângulo da linha de arqueamento no bordo de ataque (o), arqueamento no ponto de máxima espessura (p), posição do máximo arqueamento (q), máximo arqueamento (r), ângulo da linha de arqueamento no bordo de fuga (s) e torção geométrica do perfil (v).

Para a variável máxima espessura $(\mathrm{m})$ na quebra 0 valor da variável corresponde à porcentagem do valor da variável na raiz. E o valor da variável na ponta corresponde à porcentagem do valor da variável na quebra. Já para a variável torção geométrica (v), o valor da variável na quebra é o valor a ser diminuído da torção do perfil da raiz e o valor da variável para o perfil da ponta é o valor a ser 
diminuído do perfil da quebra. Isto foi feito para garantir que tanto a espessura quanto a torção não aumentem ao longo da envergadura, gerando indivíduos fora dos padrões usuais.

Novamente, para definição do raio de curvatura do perfil consideramos apenas a variável espessura do bordo de ataque $(k)$, deixando fixa a posição da espessura do bordo de ataque. O valor utilizado foi de 0.003 . Outra variável que novamente optamos por fixar foi o arqueamento do perfil no bordo de fuga $(u)$, e o valor utilizado foi de 0 ‥

Feitas estas considerações, chegamos a um total de dez variáveis por perfil, totalizando 30 variáveis para representar adequadamente os três perfis.

Os limites utilizados para as variáveis se encontram na Tabela 9. 
TABELA 9: LIMITES DE VARIÁVEIS PARA A QUARTA REDE NEURAL

\begin{tabular}{|c|c|c|c|c|}
\hline $\begin{array}{c}\text { Código } \\
\text { da } \\
\text { variável }\end{array}$ & Símbolo & Variável & Limite inferior & $\begin{array}{l}\text { Limite } \\
\text { superior }\end{array}$ \\
\hline$a$ & $\mathrm{M}$ & Número de Mach & 0.30 & 0.70 \\
\hline $\mathrm{b}$ & $\alpha$ & Ângulo de ataque & $-5^{\circ}$ & $5^{0}$ \\
\hline $\mathrm{C}$ & $\mathrm{AR}$ & Alongamento & 6 & 10 \\
\hline $\mathrm{d}$ & Sweep & Enflexamento no bordo de ataque & $15^{\circ}$ & $30^{\circ}$ \\
\hline e & Taper & Afilamento & 0.10 & 0.40 \\
\hline$f$ & Yk & $\begin{array}{c}\text { Posição da quebra (ao longo da semi- } \\
\text { envergadura) }\end{array}$ & 0.20 & 0.40 \\
\hline$g$ & Ycp & $\begin{array}{c}\text { Posição na envergadura (mapeamento de } \\
\text { pressão) }\end{array}$ & 0.00 & 1.00 \\
\hline $\mathrm{h}$ & Xcp & $\begin{array}{l}\text { Posição na corda (mapeamento de } \\
\text { pressão) }\end{array}$ & 0.00 & 1.00 \\
\hline $\mathrm{i}$ & Dih & Diedro & $\begin{array}{c}\text { Não } \\
\text { considerado }\end{array}$ & $\begin{array}{c}\text { Não } \\
\text { considerado }\end{array}$ \\
\hline j & xtle & $\begin{array}{c}\text { Ponto de controle para a espessura no } \\
\text { bordo de ataque (valor fixo) }\end{array}$ & 0.05 & 0.05 \\
\hline $\mathrm{k}$ & $y$ tle & $\begin{array}{c}\text { Espessura no bordo de ataque na raiz, } \\
\text { quebra e ponta }\end{array}$ & 0.01 & 0.06 \\
\hline I & xtth & $\begin{array}{c}\text { Posição de máxima espessura na raiz, } \\
\text { quebra e ponta }\end{array}$ & 0.25 & 0.40 \\
\hline $\mathrm{m}$ & ytth & Máxima espessura na raiz & 0.10 & 0.20 \\
\hline $\mathrm{m}$ & ytth & Máxima espessura na quebra & 0.0 & 1.0 \\
\hline $\mathrm{m}$ & ytth & Máxima espessura na ponta & 0.0 & 1.0 \\
\hline $\mathrm{n}$ & atte & $\begin{array}{l}\text { Ângulo da linha de espessura no bordo de } \\
\text { fuga na raiz, quebra e ponta }\end{array}$ & $-20^{\circ}$ & $0^{\circ}$ \\
\hline 0 & acle & $\begin{array}{c}\text { Ângulo da linha de arqueamento no bordo } \\
\text { de ataque na raiz, quebra e ponta }\end{array}$ & $-8^{\circ}$ & $10^{\circ}$ \\
\hline$p$ & ycth & $\begin{array}{l}\text { Arqueamento no ponto de máxima } \\
\text { espessura na raiz, quebra e ponta }\end{array}$ & -0.01 & 0.03 \\
\hline$q$ & $\mathrm{xcmc}$ & $\begin{array}{c}\text { Posição do máximo arqueamento na raiz, } \\
\text { quebra e ponta }\end{array}$ & 0.60 & 0.80 \\
\hline r & ycmc & $\begin{array}{l}\text { Máximo arqueamento na raiz, quebra e } \\
\text { ponta }\end{array}$ & 0.00 & 0.02 \\
\hline S & acte & $\begin{array}{c}\text { Ângulo da linha de arqueamento no bordo } \\
\text { de fuga na raiz, quebra e ponta }\end{array}$ & $-15^{0}$ & $0^{\circ}$ \\
\hline $\mathrm{t}$ & ytte & Espessura do bordo de fuga (valor fixo) & 0.003 & 0.003 \\
\hline $\mathrm{u}$ & ycte & Arqueamento no bordo de fuga (valor fixo) & 0.00 & 0.00 \\
\hline $\mathrm{V}$ & epsil & Torção geométrica do perfil na raiz & $-3^{\circ}$ & $5^{\circ}$ \\
\hline $\mathrm{V}$ & epsil & Torção geométrica do perfil na quebra & $0^{\circ}$ & 10 \\
\hline $\mathrm{v}$ & epsil & Torção geométrica do perfil na ponta & $0^{\circ}$ & $2^{\circ}$ \\
\hline
\end{tabular}

Um estudo semelhante ao mostrado na Seção 3.2 foi feito para esta rede neural e, com isso, o conjunto de treinamento inicial para esta rede foi gerado com 155.000 indivíduos, dos quais apenas 136.832 obtiveram convergência no CFD; em 
outras palavras, houve um aproveitamento de $88.28 \%$ dos indivíduos do conjunto inicial. A melhor taxa de aproveitamento deve-se ao baixo número de Mach (de 0.30 a 0.70), o qual favorece a convergência do software de CFD (BLWF) pela a menor ocorrência de ondas de choque e consequentes descolamentos da camada limite.

O tipo de rede escolhida foi novamente a perceptron com múltiplas camadas, com correção dos pesos por retropropagação usando algoritmo de LevenbergMarquardt. Analogamente ao estudo mostrado na Seção 3.2, melhores resultados foram obtidos com a arquitetura de duas camadas ocultas, cada uma com 18 neurônios, cada um deles usando a função tangente hiperbólica como função de ativação, e uma camada de saída com um neurônio usando apenas uma função linear como função de ativação.

O processo de treinamento foi feito até completar 1.000 épocas. O erro médio quadrático não foi usado como condição de parada neste caso devido à falta de sensibilidade ao erro para esta rede, já que esta conta agora com 38 variáveis. Deve-se tomar muito cuidado com este tipo de critério de parada devido à possibilidade de causar o super-treinamento, ou seja, uma condição na qual os neurônios da rede se especializam tanto que "decoram" cada uma das amostras do conjunto de treinamento, perdendo a capacidade de generalização.

Para a validação das redes com variáveis de perfil optou-se por preparar um conjunto de validação especial, gerado não de maneira randômica, mas com indivíduos com forma em planta e perfis usuais. Seis indivíduos foram escolhidos para a validação, sendo que a distribuição de pressão foi obtida para os seguintes limites de ângulo de ataque e Mach, apresentados na Tabela 10.

TABELA 10: CONDIÇÕES DE VOO ESCOLHIDAS PARA O CONJUNTO DE VALIDAÇÃO

\begin{tabular}{|c|c|c|c|}
\hline Variável & Limite inferior & Limite superior & Incremento \\
\hline Número de Mach & 0.30 & 0.70 & 0.04 \\
\hline Ângulo de ataque & $-5.0^{\circ}$ & $5.0^{\circ}$ & $1.0^{\circ}$ \\
\hline
\end{tabular}


O conjunto de validação a ser submetido tanto para a rede neural quanto para o CFD é, portanto, formado por 726 (6 x 121) indivíduos. Os limites de alfa e Mach foram escolhidos para possibilitar a avaliação da resposta da rede em todas as condições de alfa e Mach treinados. Cabe ressaltar que, de 726 rodadas, somente 653 obtiveram convergência no CFD, possibilitando a comparação com o resultado da rede. A geometria dos seis indivíduos usados na validação (forma em planta e perfil) pode ser vista na Figura 42.

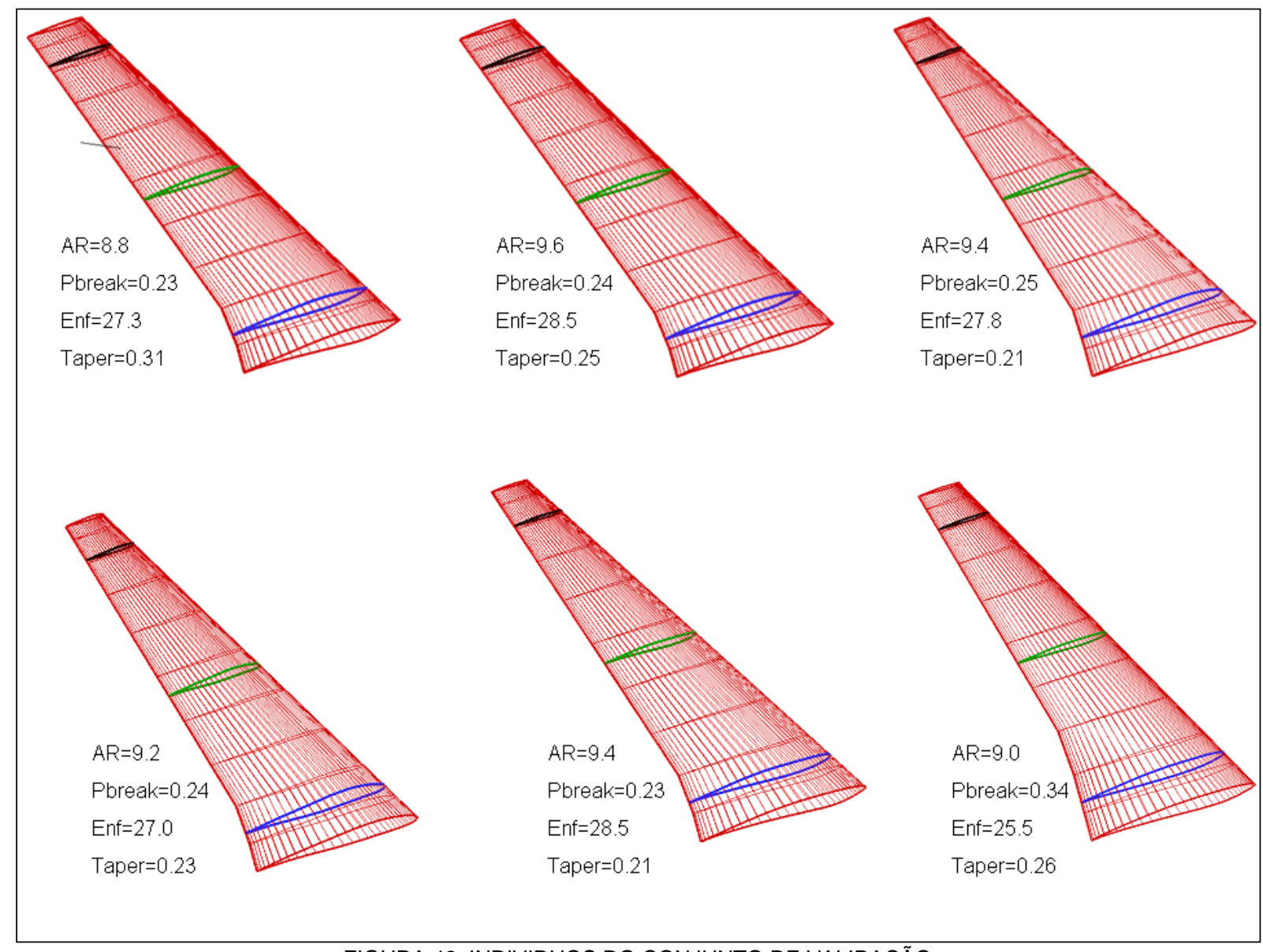

FIGURA 42: INDIVIDUOS DO CONJUNTO DE VALIDAÇÃO

\subsubsection{Resultados da Rede Neural de Perfis Variáveis - Subsônica}

As Figuras 43 a 67 mostram os resultados da validação feita para a rede subsônica com perfis variáveis para um indivíduo. Nestas figuras, os circulos azuis apresentam o resultado fornecido pela rede neural e a linha cheia o resultado obtido 
diretamente pelo CFD para a condição desejada. Nesta figura também é mostrado o resultado em termos de coeficientes de força normal $\left(C_{N}\right)$ e de momento de arfagem $\left(\mathrm{C}_{\mathrm{M}}\right)$ para a rede neural e para o resultado do CFD.

As figuras mostram uma correlação bastante boa entre os resultados obtidos via CFD e via rede neural, levando em conta o grande número de variáveis representadas nesta rede.

A Tabela 11 mostra uma análise estatística dos coeficientes. Os coeficientes de força e momento também apresentaram valores bastante semelhantes, melhores até que os resultados apresentados para a rede de perfis parametrizados. Consideramos assim que os resultados para os três cortes analisados são bastante satisfatórios.

Resultados semelhantes foram encontrados para os outros indivíduos do conjunto de validação não mostrados.

TABELA 11: RESULTADOS PARA REDE SUBSONICA COM PERFIS VARIAVEIS:

\begin{tabular}{|l|l|}
\hline Média dos erros absolutos de CN & 0.0166 \\
\hline Média dos erros absolutos de CM & 0.0053 \\
\hline Média dos erros relativos de CN & 0.3001 \\
\hline Média dos erros relativos de CM & 0.0678 \\
\hline Desvio padrão dos erros relativos de CN & 0.0203 \\
\hline Desvio padrão dos erros relativos de CM & 0.0047 \\
\hline Erro médio quadrático & 0.0428 \\
\hline
\end{tabular}




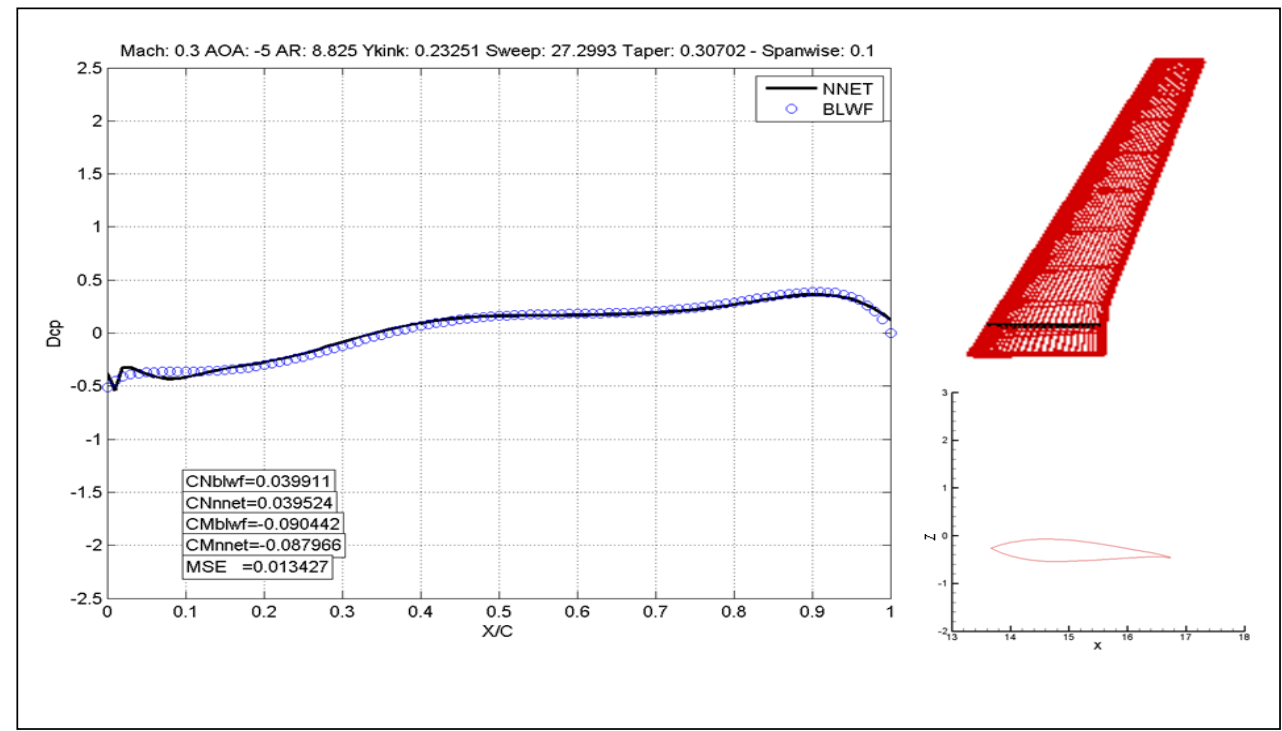

(a)

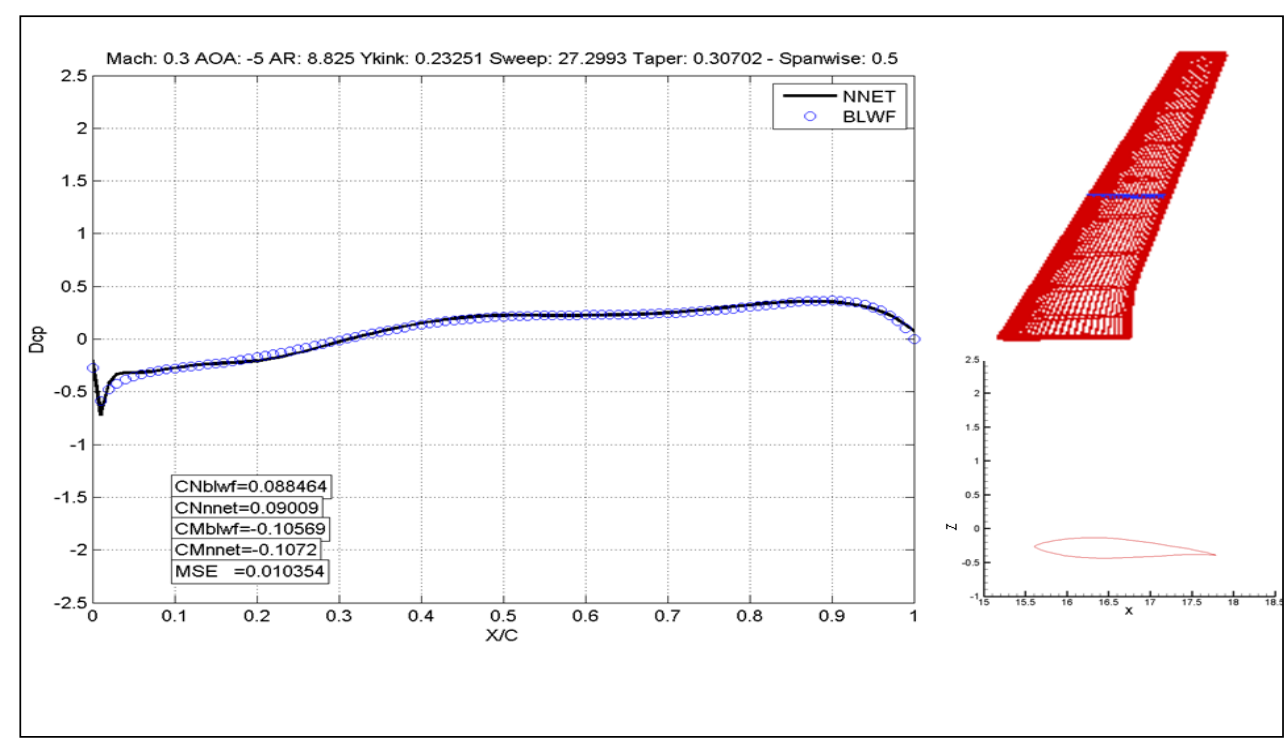

(b)

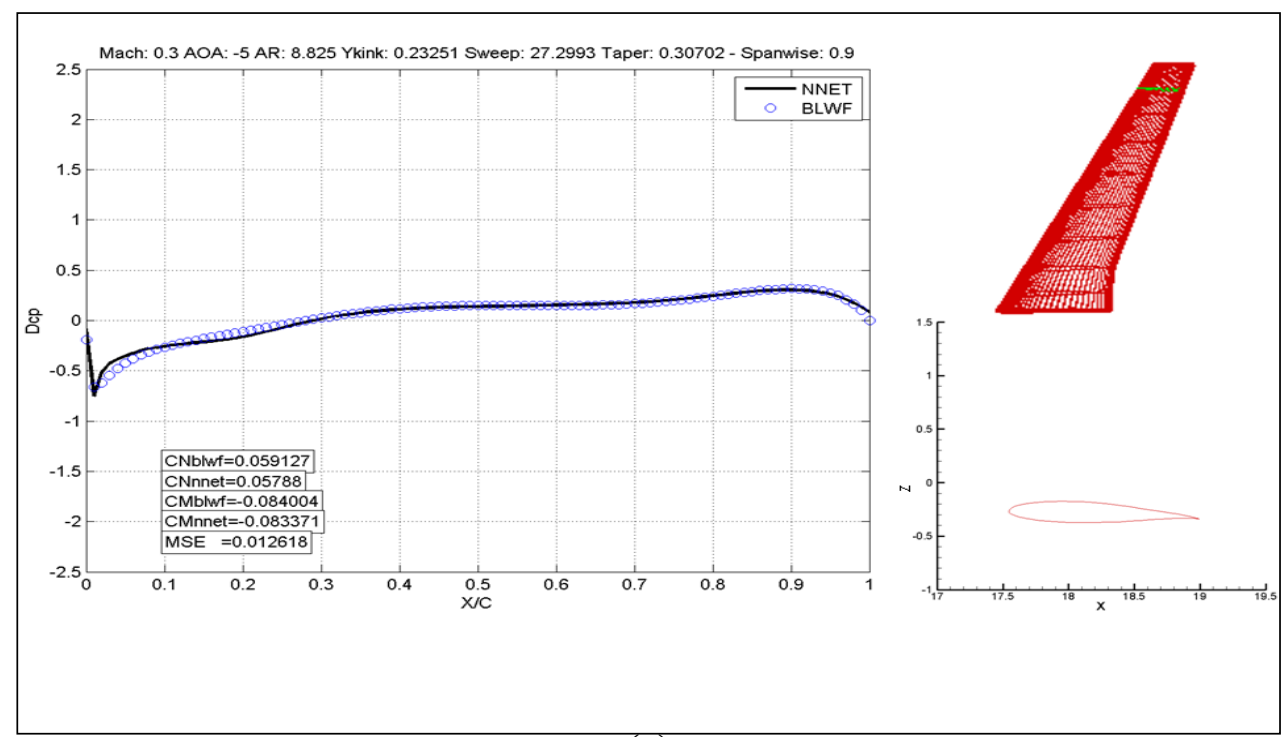

(c)

FIGURA 43: ESCOAMENTO SUBSONICO VALIDAÇÃO INDIVIDUO 1: (A) ESTAÇÃO NA RAIZ (B) ESTAÇÃO NO MEIO DA ASA (C) ESTAÇÃO NA PONTA DA ASA. 


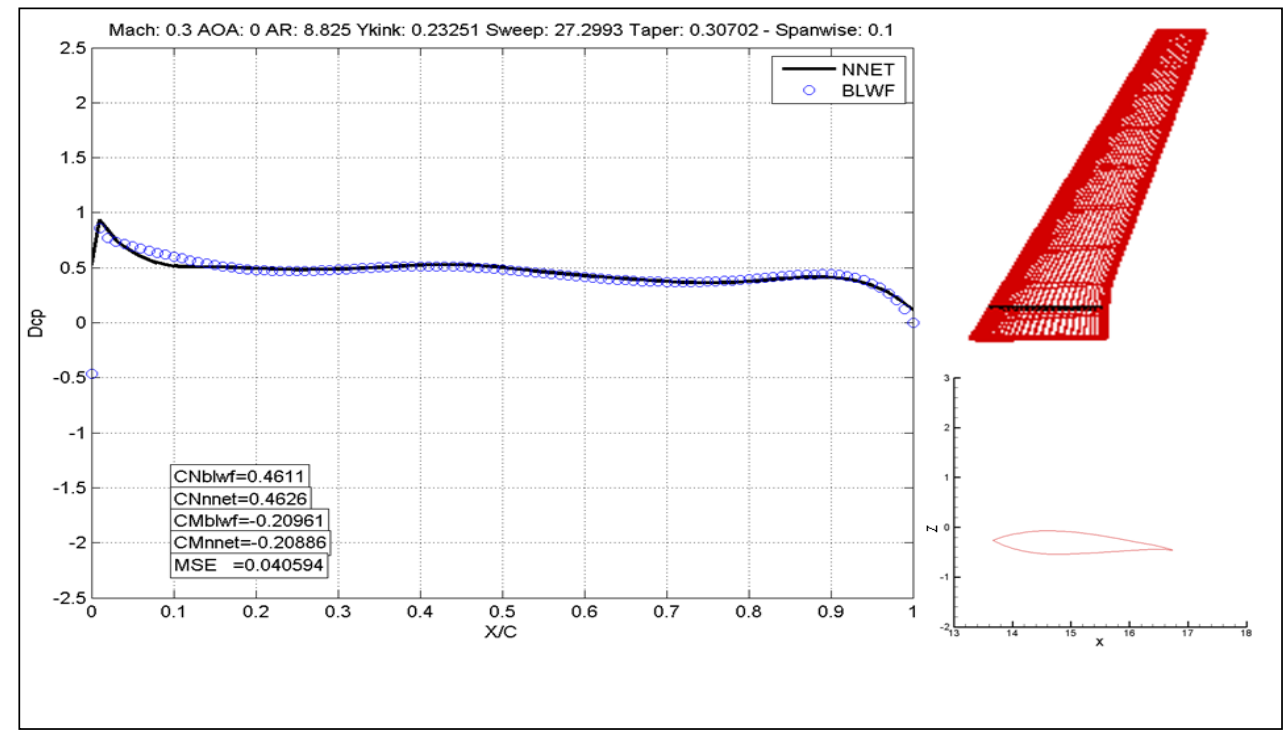

(a)

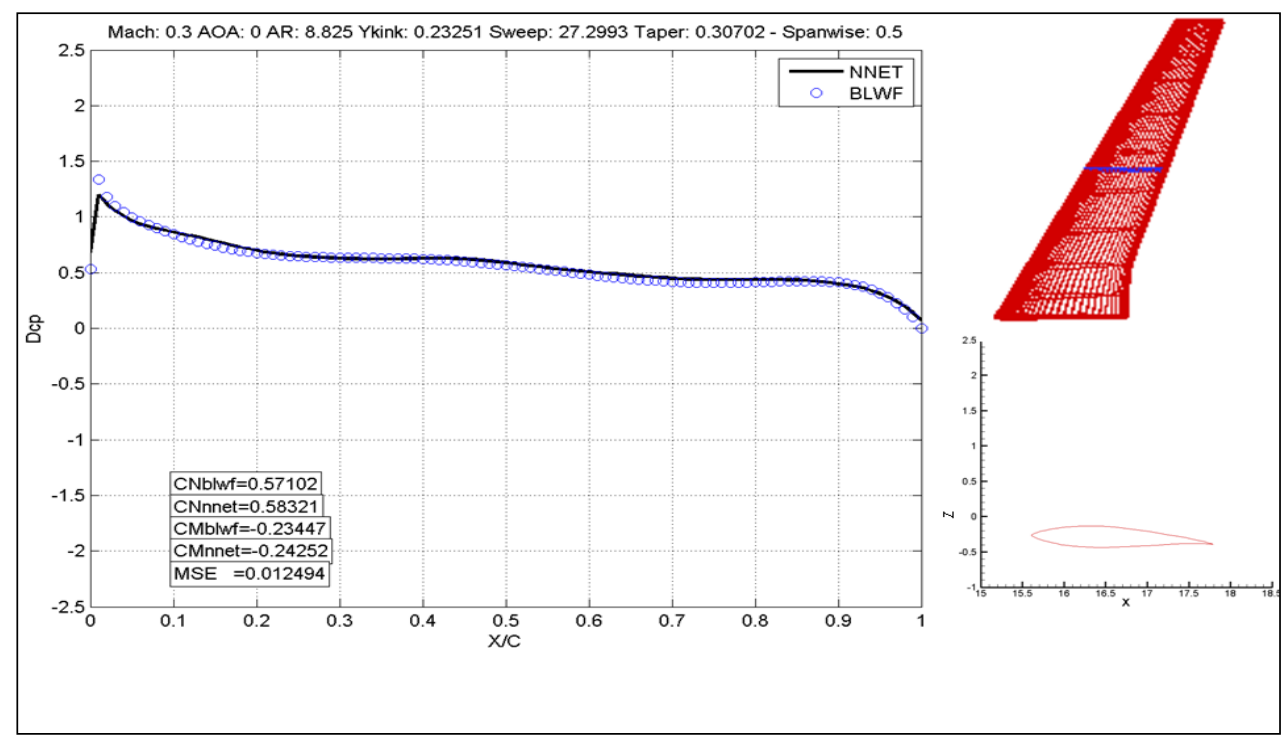

(b)

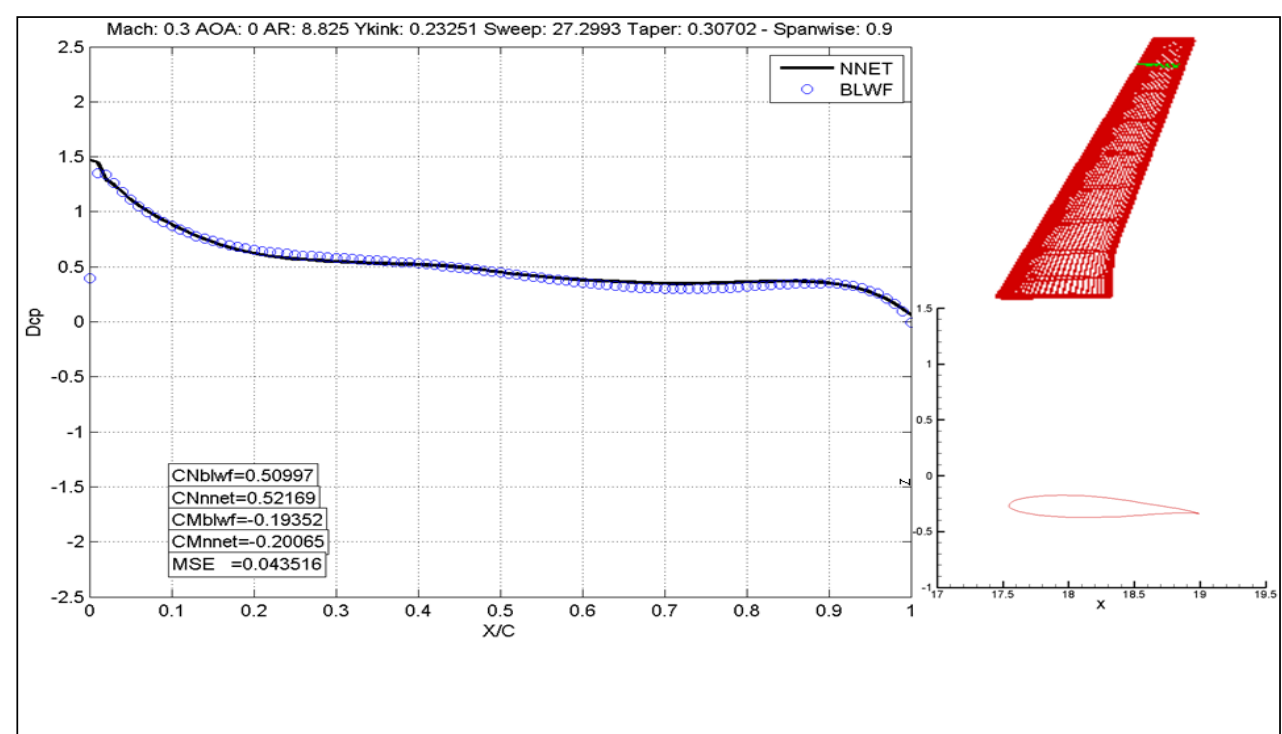

(c)

FIGURA 44: ESCOAMENTO SUBSONICO VALIDAÇÃO INDIVIDUO 1: (A) ESTAÇÃO NA RAIZ (B) ESTAÇÃO NO MEIO DA ASA (C) ESTAÇÃO NA PONTA DA ASA.. 


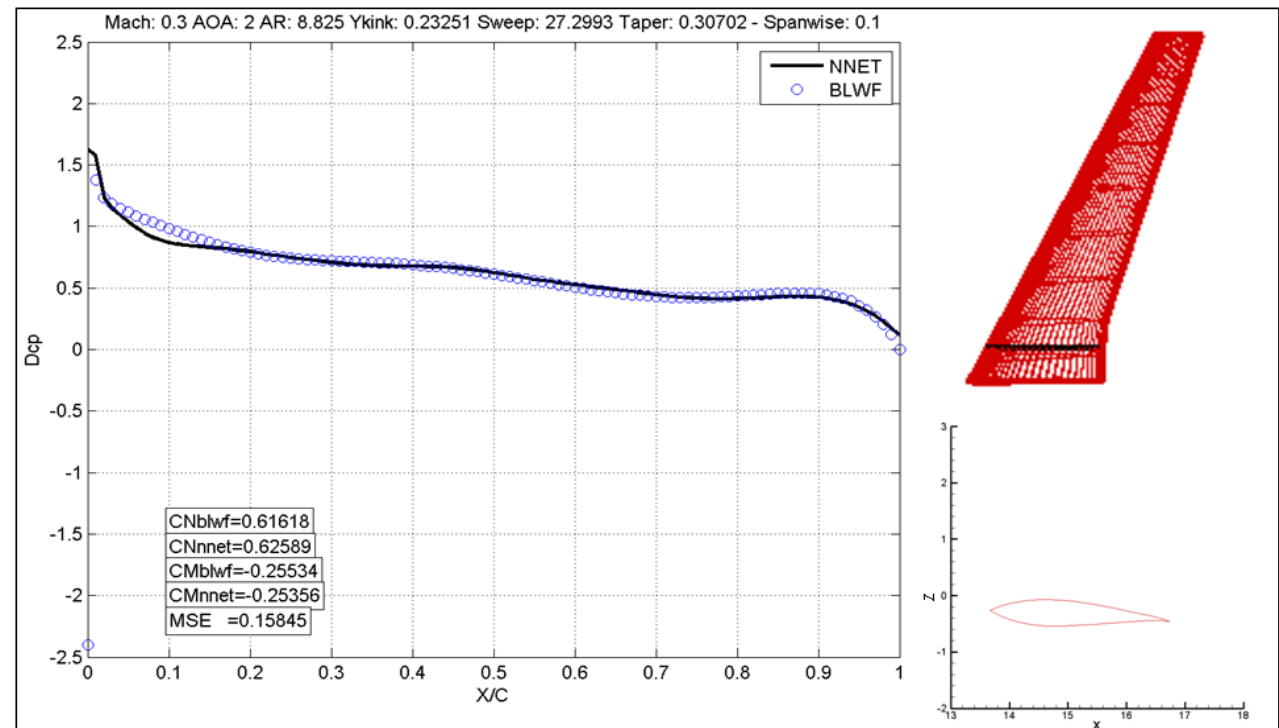

(a)

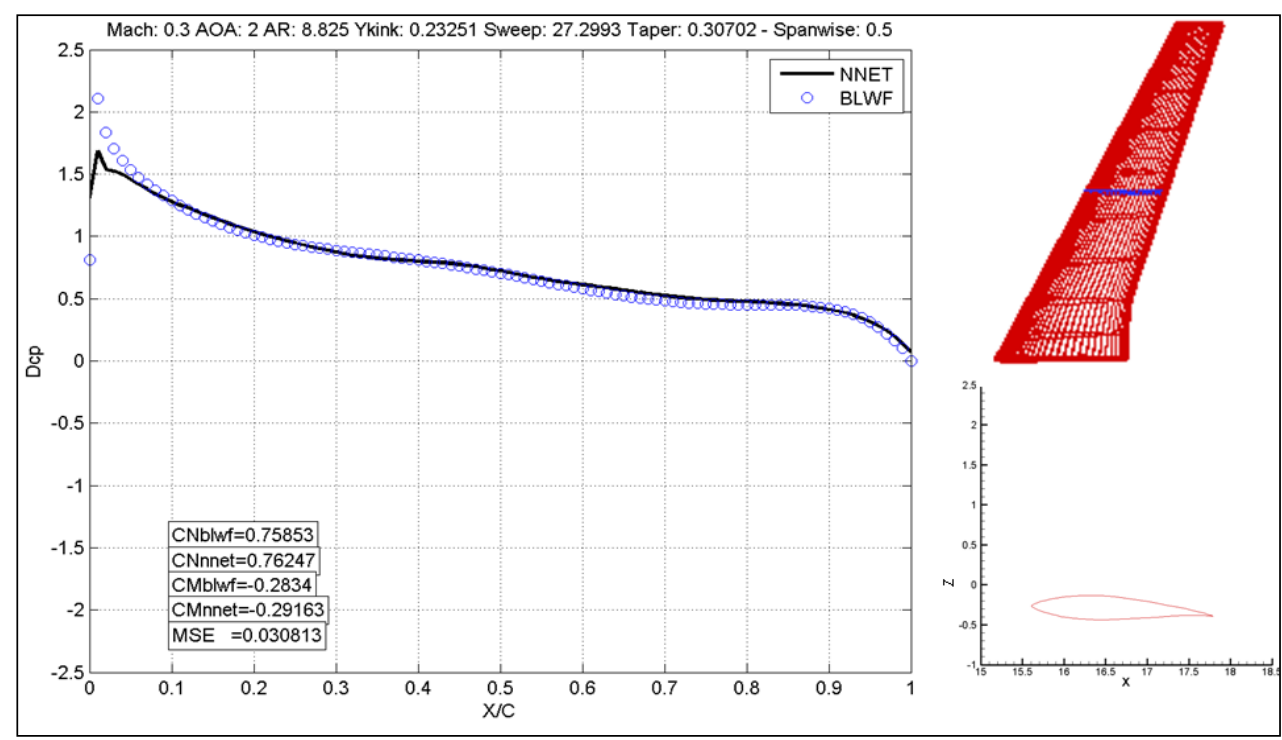

(b)

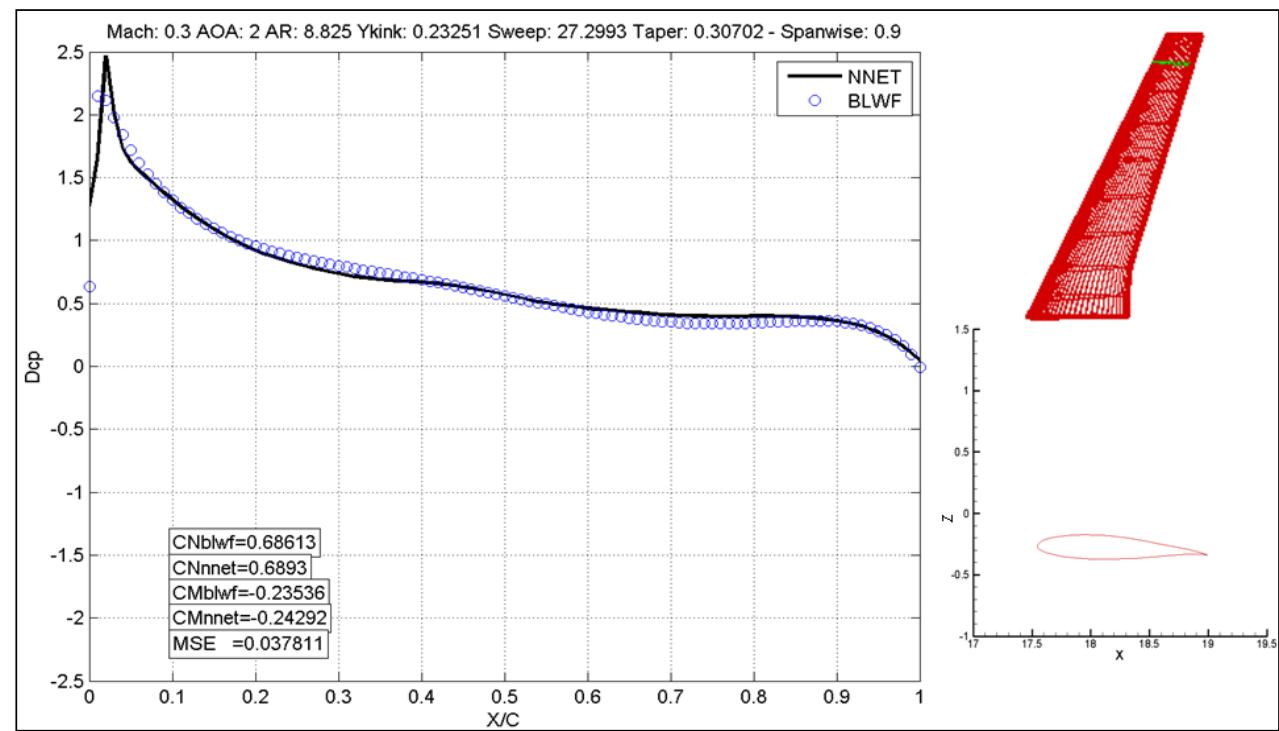

(c)

FIGURA 45: ESCOAMENTO SUBSONICO VALIDAÇÃO INDIVIDUO 1: (A) ESTAÇÃO NA RAIZ (B) ESTAÇÃO NO MEIO DA ASA (C) ESTAÇÃO NA PONTA DA ASA. 


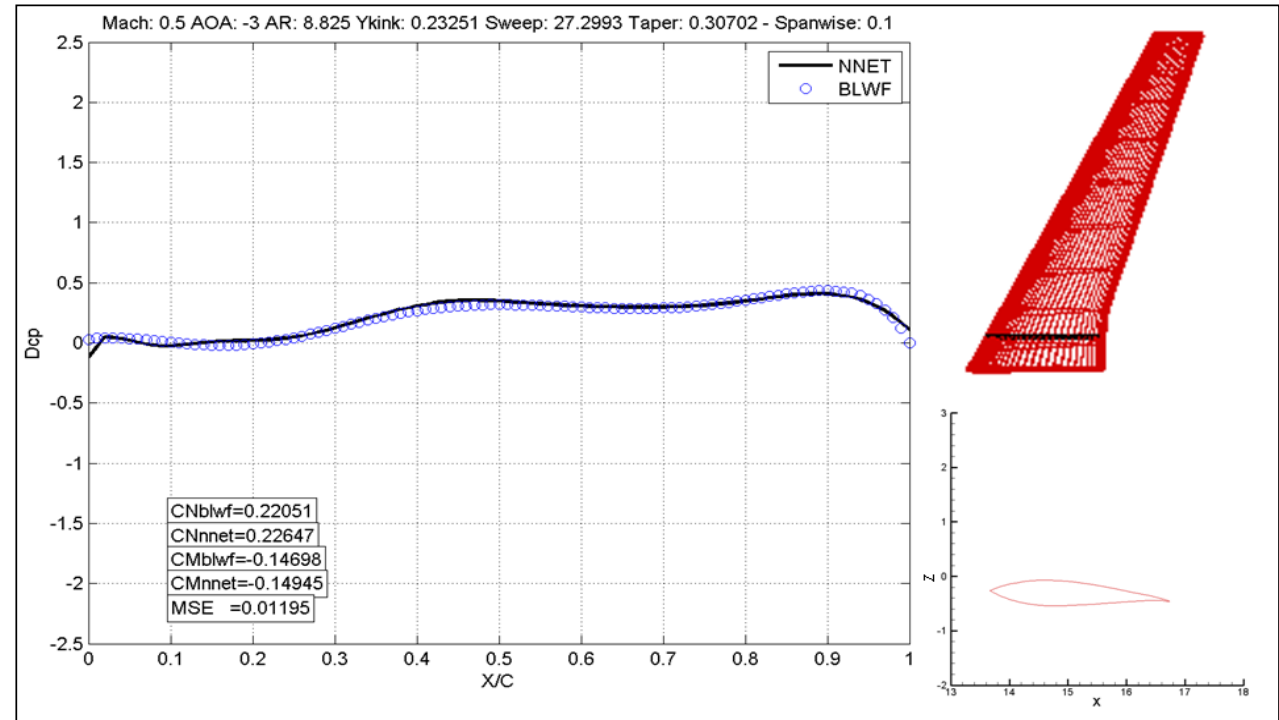

(a)

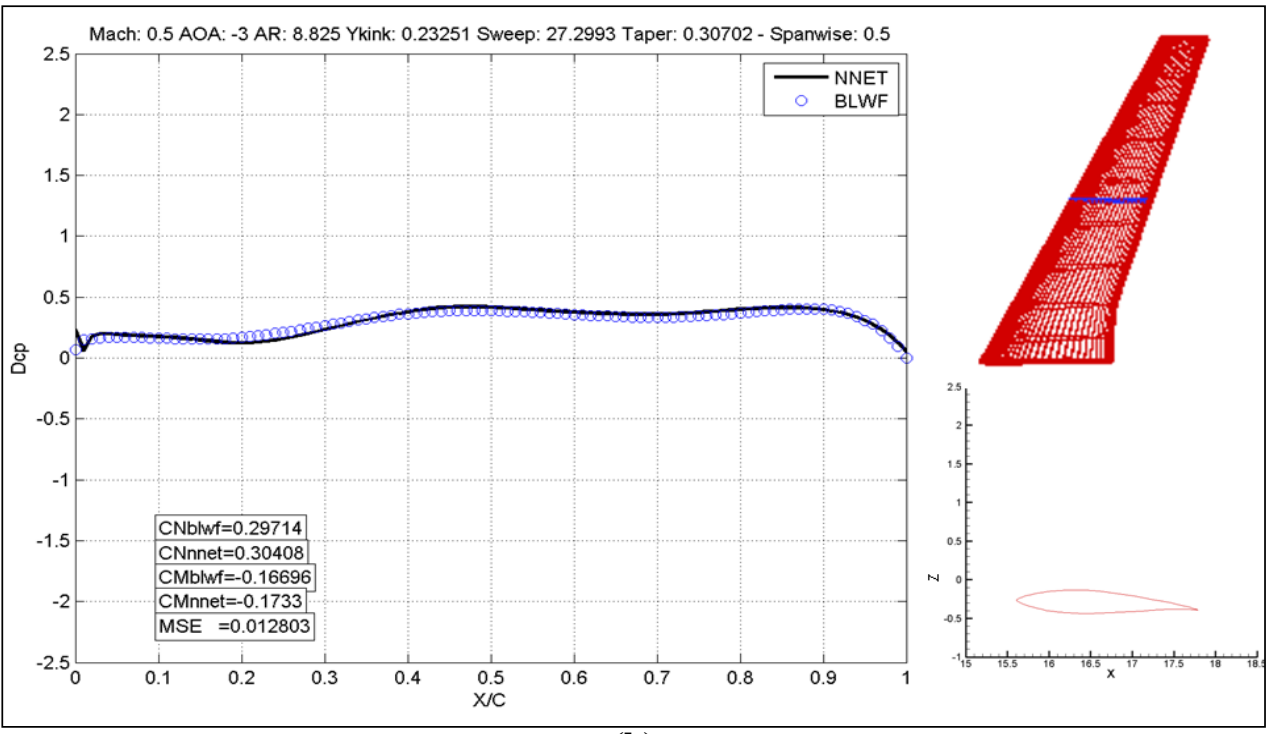

(b)

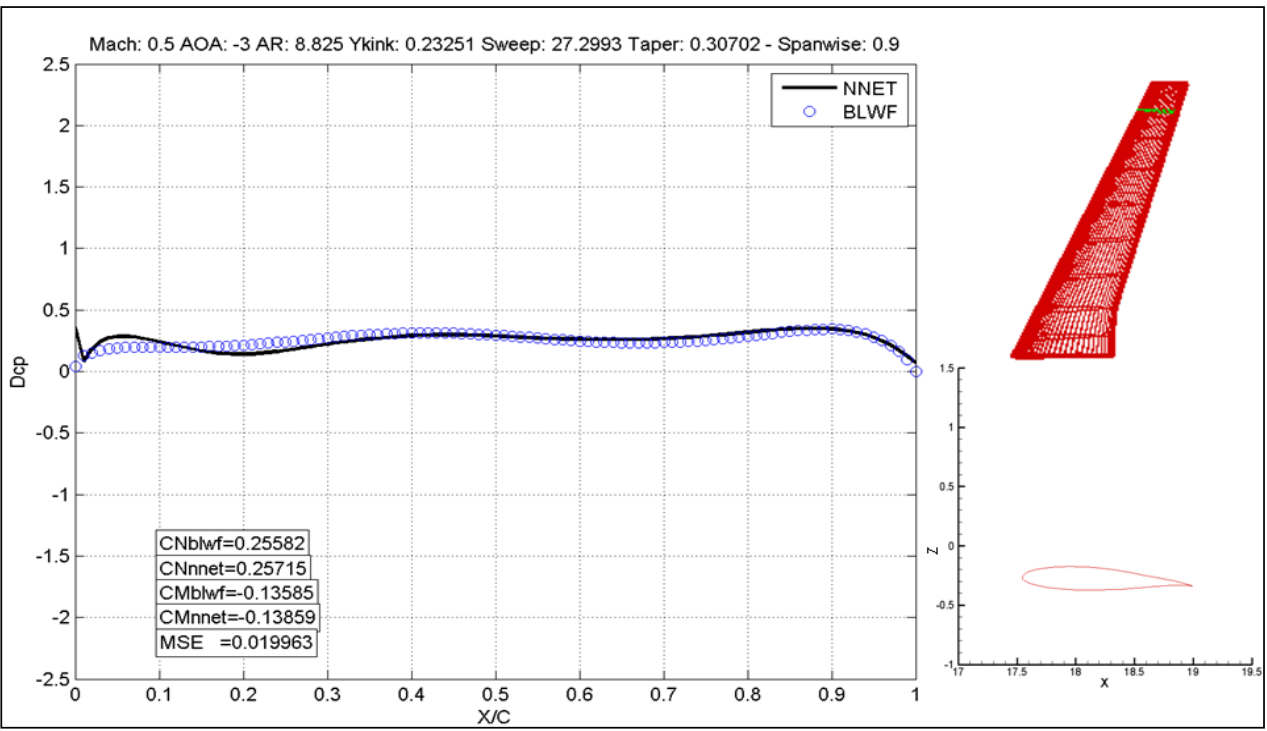

(c)

FIGURA 46: ESCOAMENTO SUBSONICO VALIDAÇÃO INDIVIDUO 1: (A) ESTAÇÃO NA RAIZ (B) ESTAÇÃO NO MEIO DA ASA (C) ESTAÇÃO NA PONTA DA ASA. 


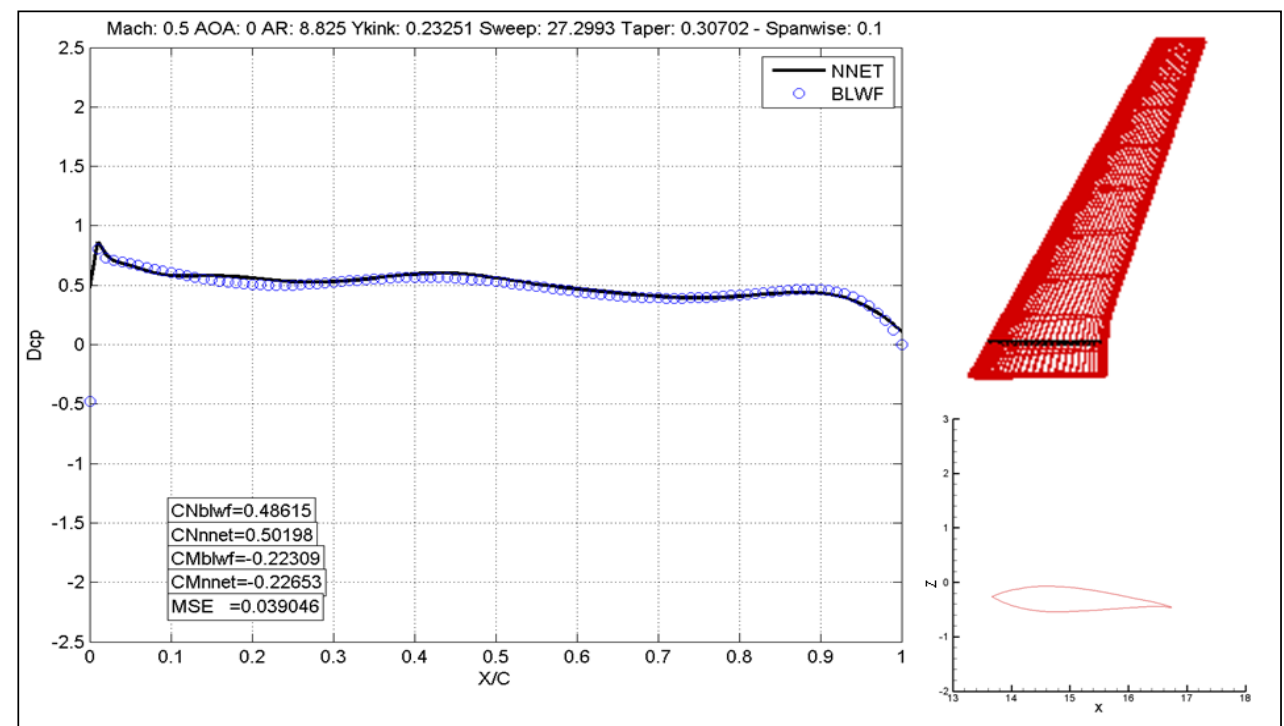

(a)

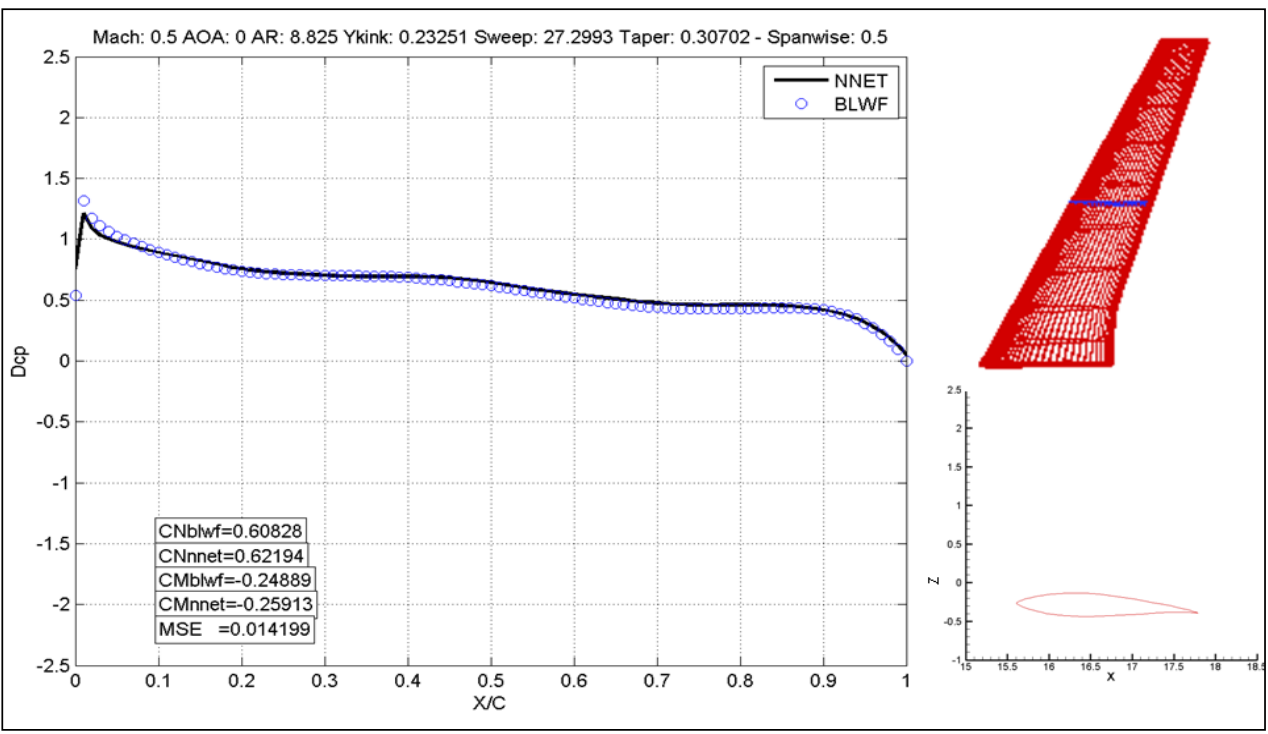

(b)

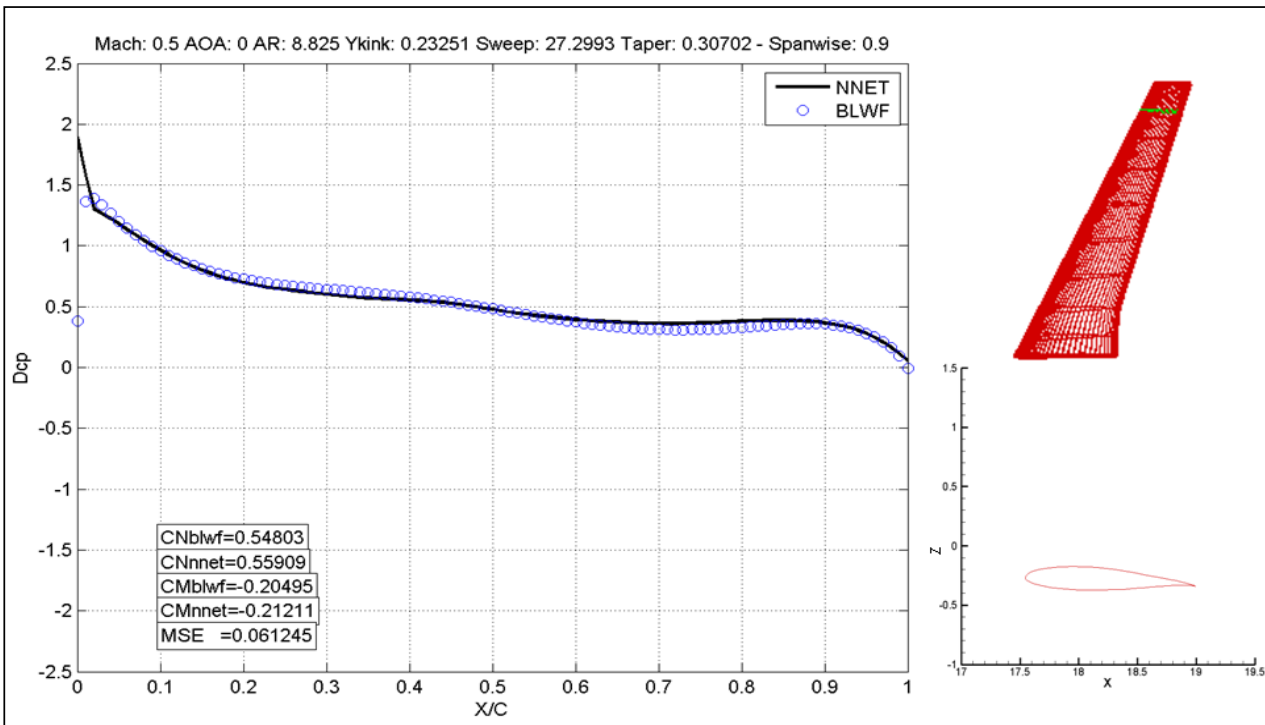

(c)

FIGURA 47: ESCOAMENTO SUBSONICO VALIDAÇÃO INDIVIDUO 1: (A) ESTAÇÃO NA RAIZ (B) ESTAÇÃO NO MEIO DA ASA (C) ESTAÇÃO NA PONTA DA ASA.. 


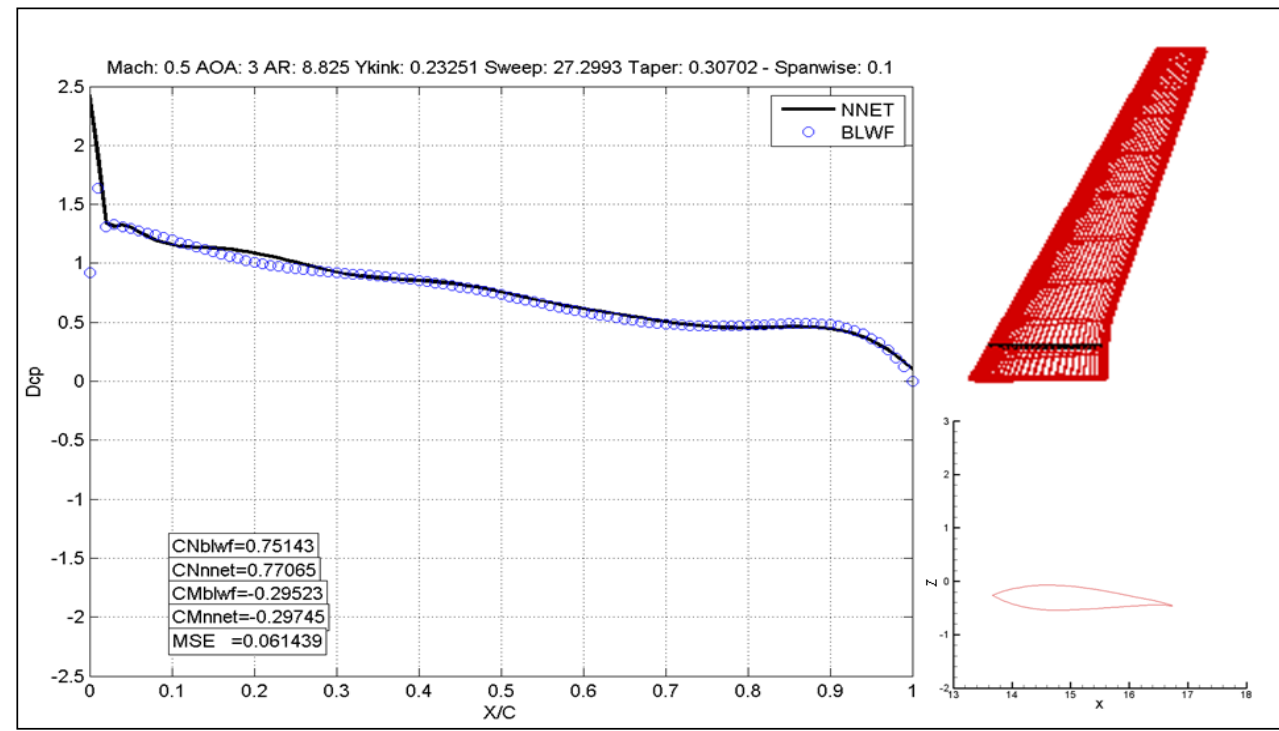

(a)

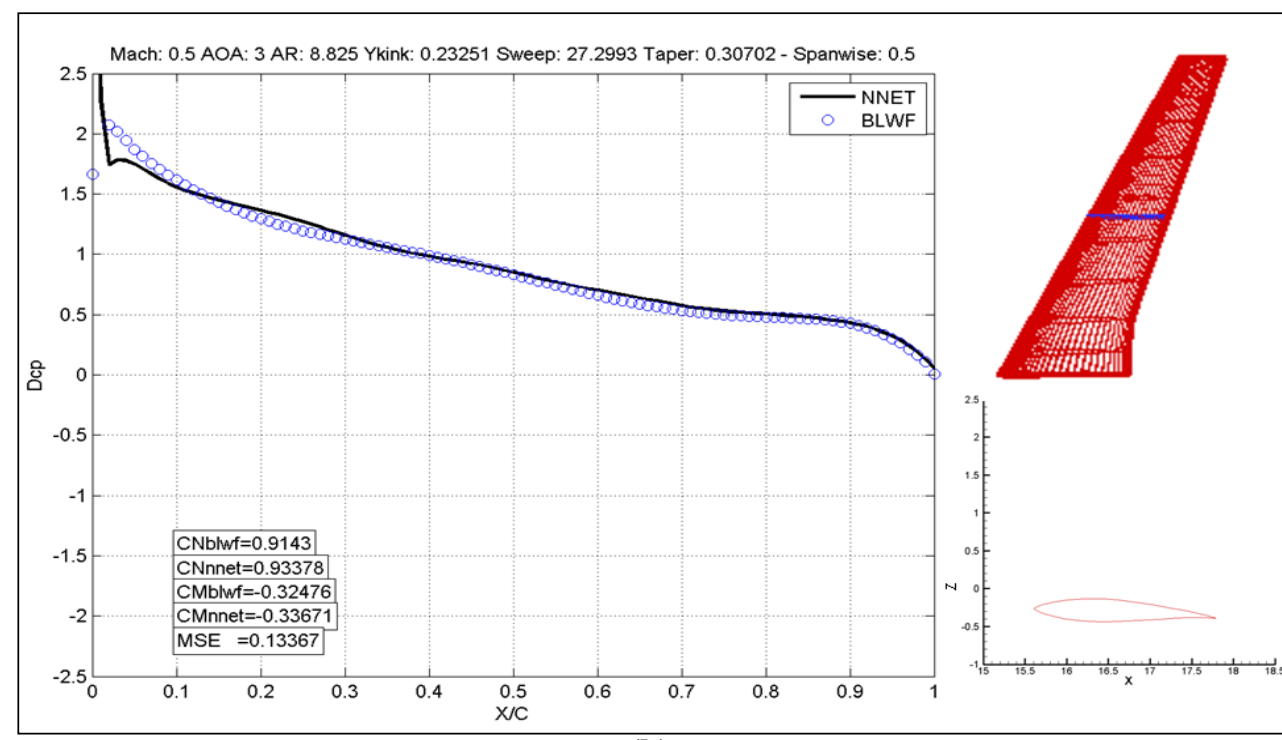

(b)

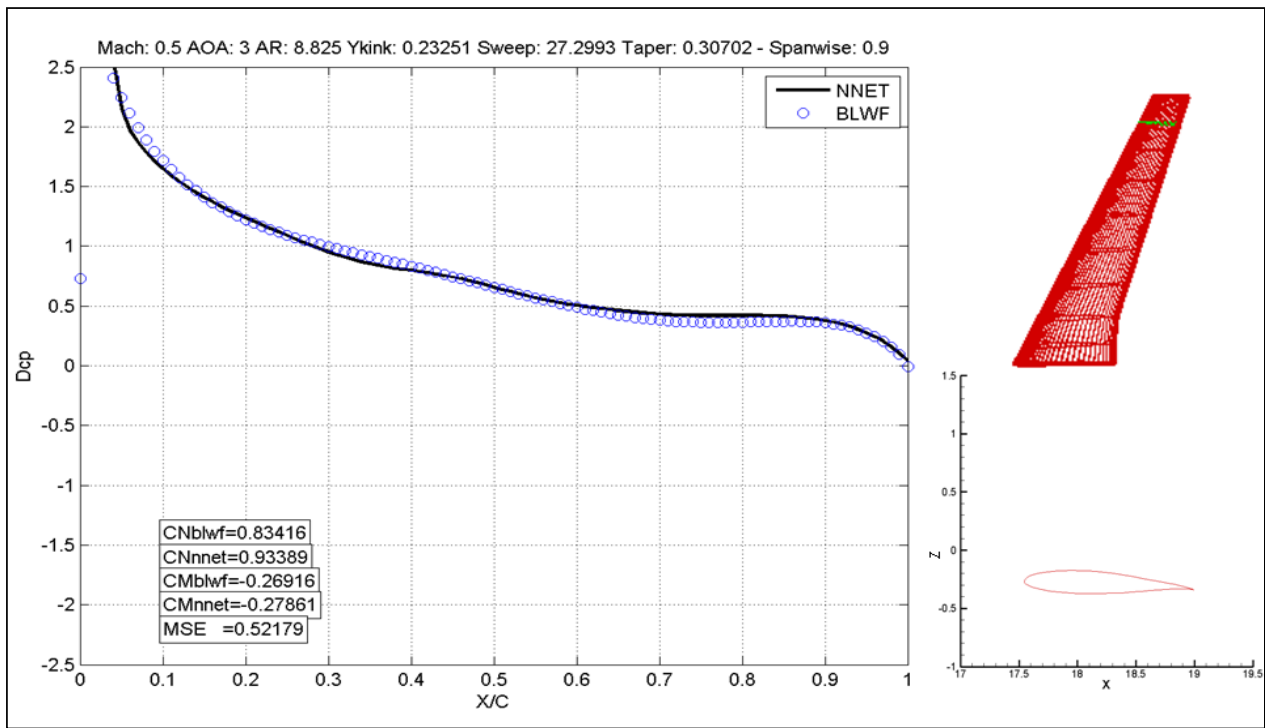

(c)

FIGURA 48: ESCOAMENTO SUBSONICO VALIDAÇÃO INDIVIDUO 1: (A) ESTAÇÃO NA RAIZ (B) ESTAÇÃO NO MEIO DA ASA (C) ESTAÇÃO NA PONTA DA ASA. 


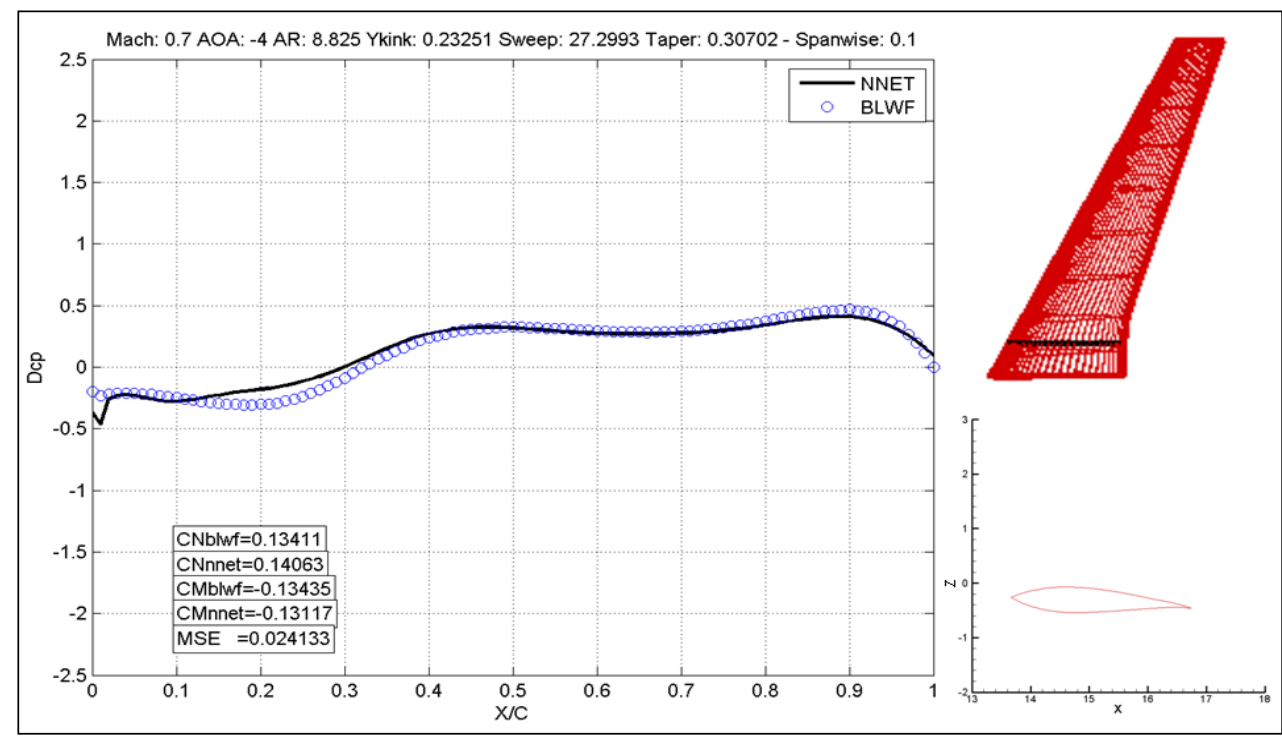

(a)

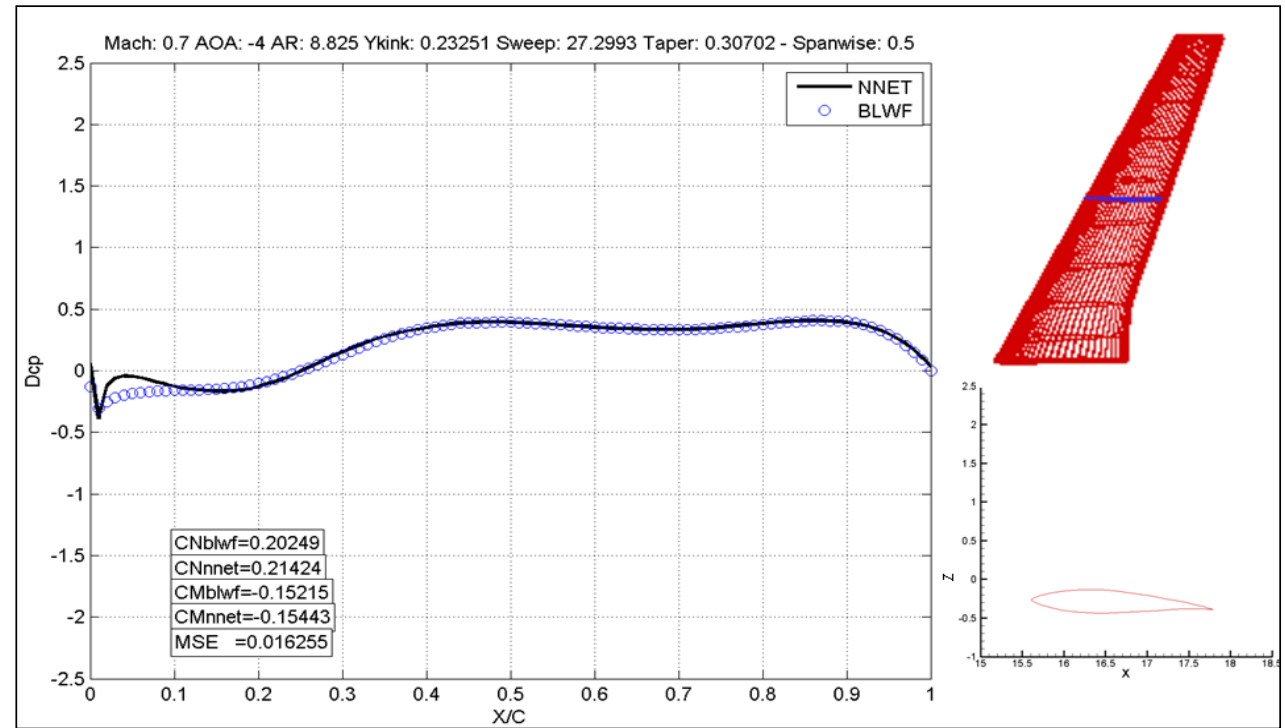

(b)

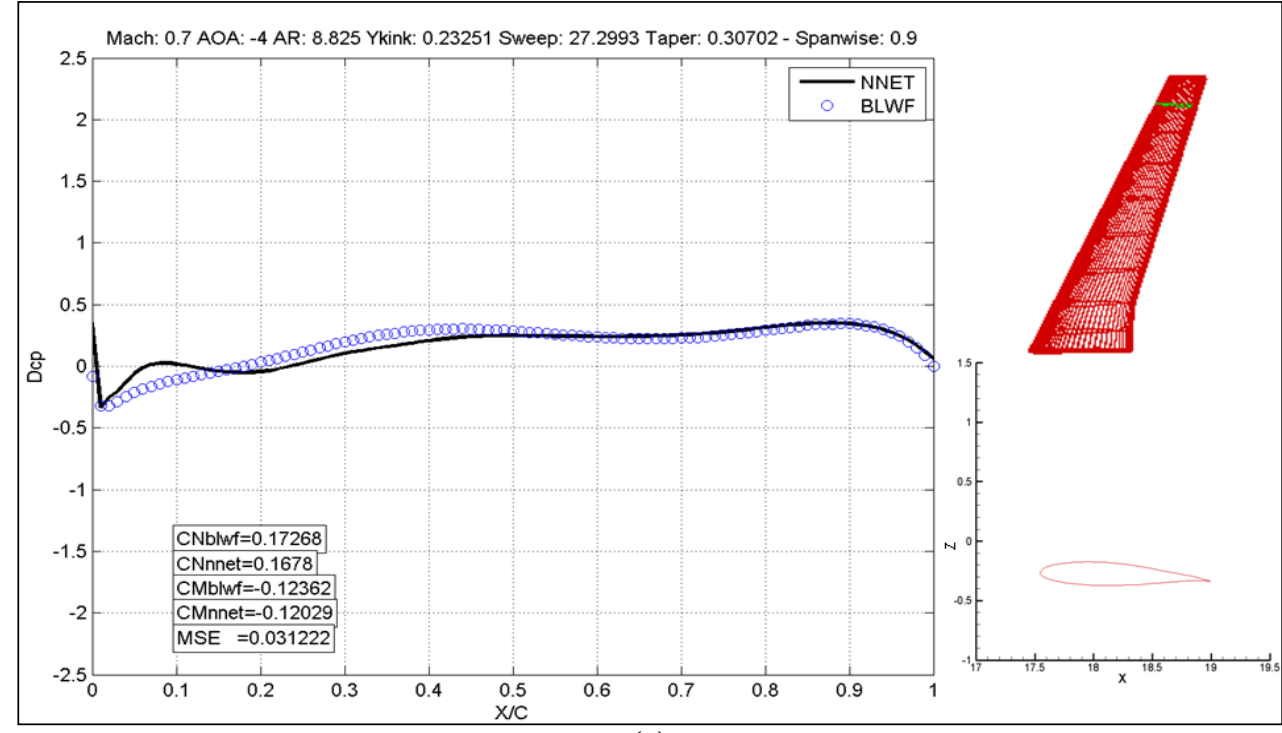

(c)

FIGURA 49: ESCOAMENTO SUBSONICO VALIDAÇÃO INDIVIDUO 1: (A) ESTAÇÃO NA RAIZ (B) ESTAÇÃO NO MEIO DA ASA (C) ESTAÇÃO NA PONTA DA ASA. 


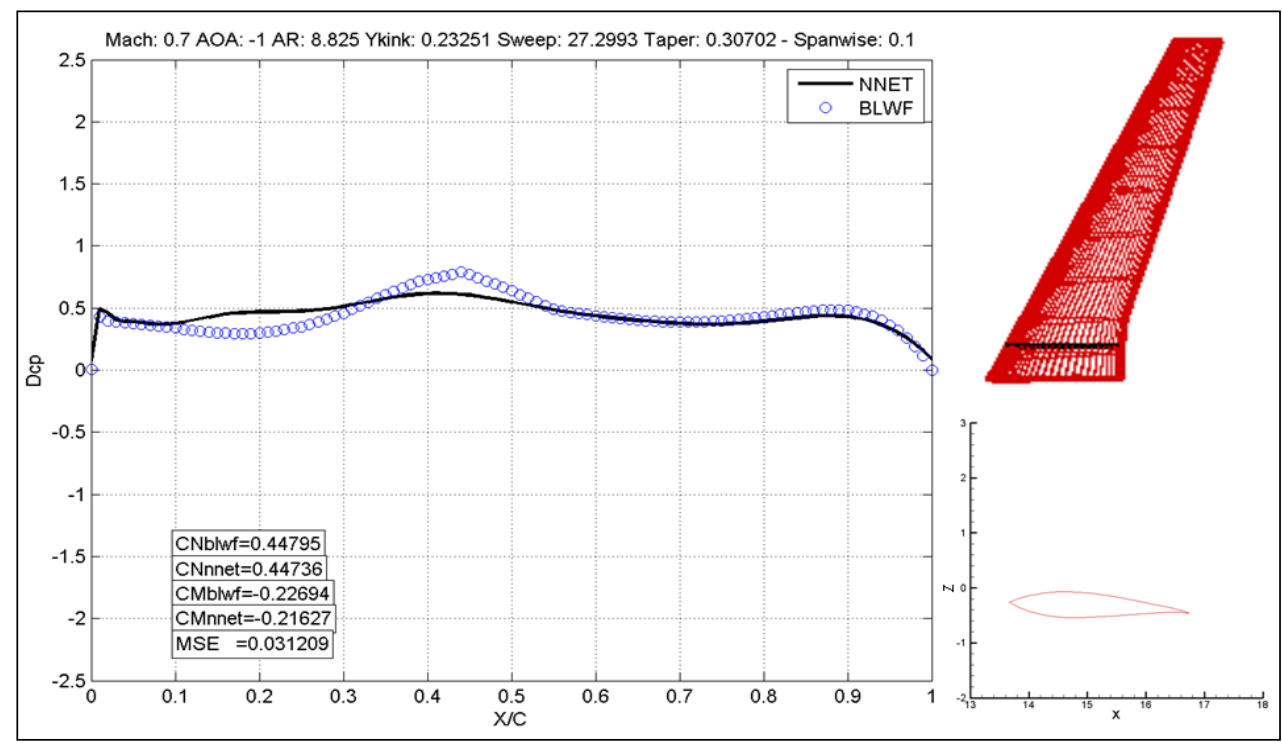

(a)

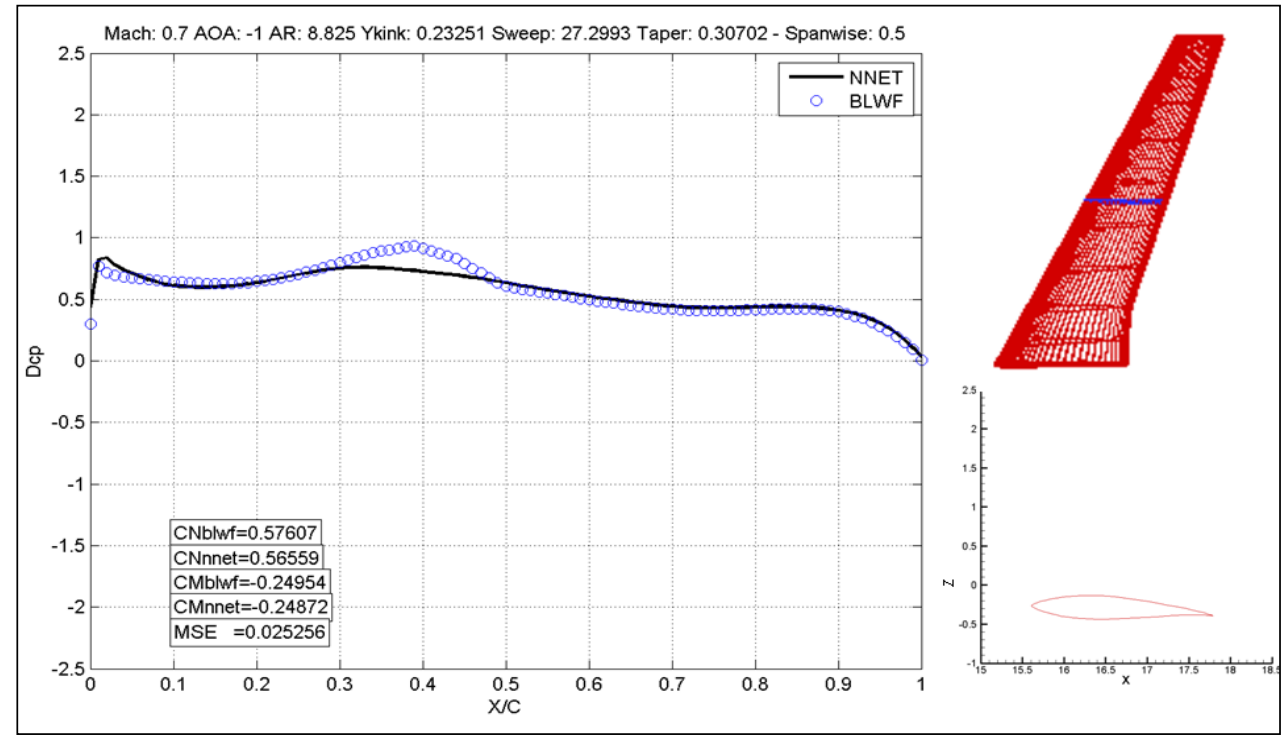

(b)

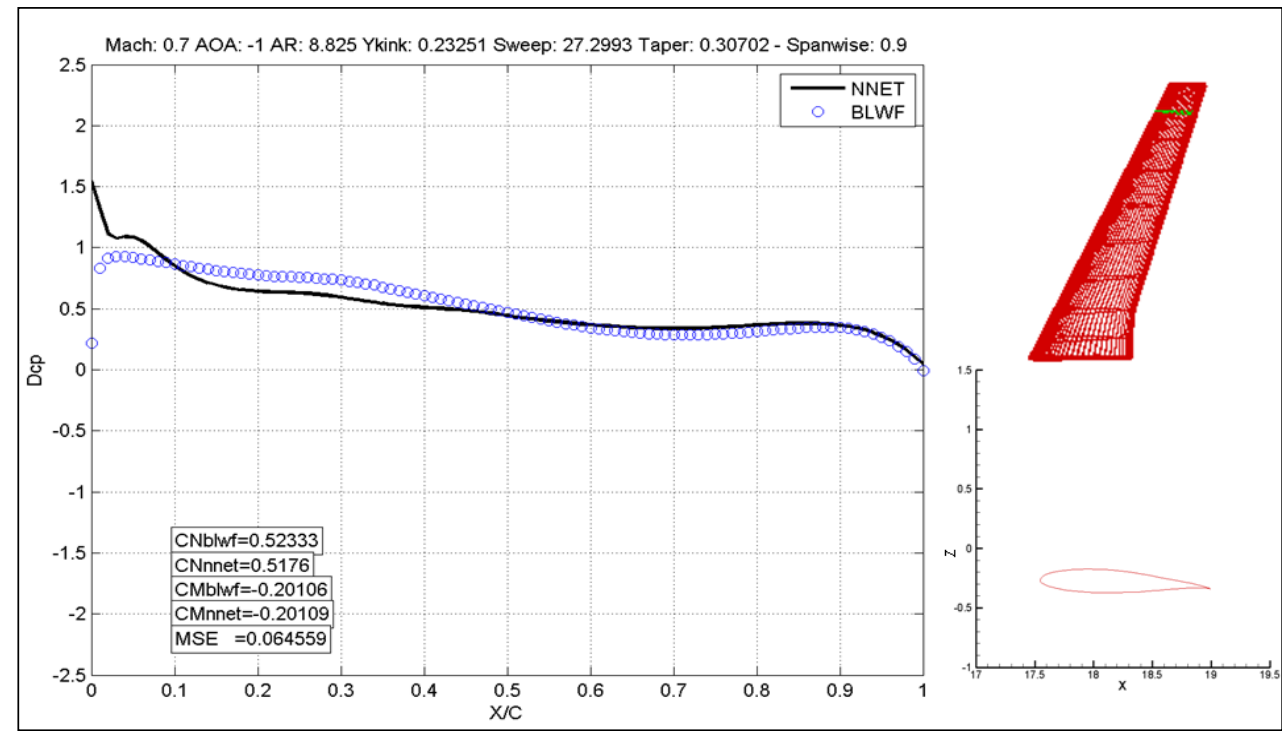

(c)

FIGURA 50: ESCOAMENTO SUBSONICO VALIDAÇÃO INDIVIDUO 1: (A) ESTAÇÃO NA RAIZ (B) ESTAÇÃO NO MEIO DA ASA (C) ESTAÇÃO NA PONTA DA ASA. 


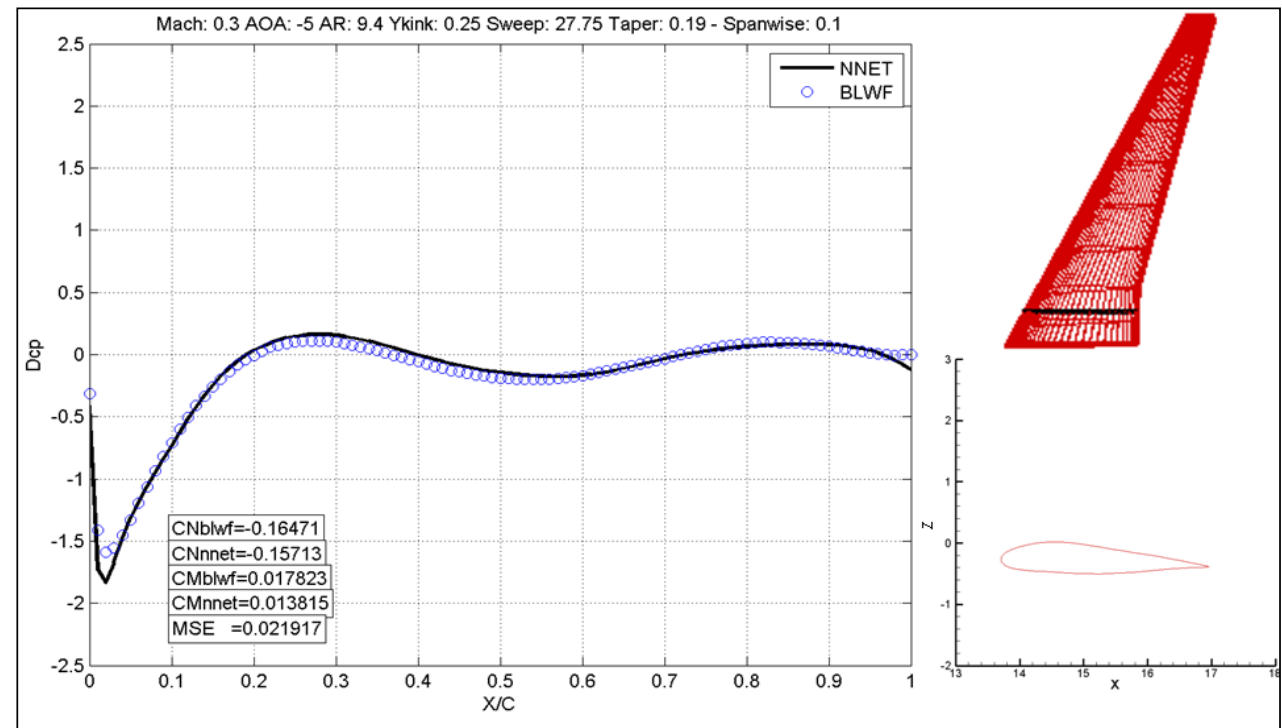

(a)

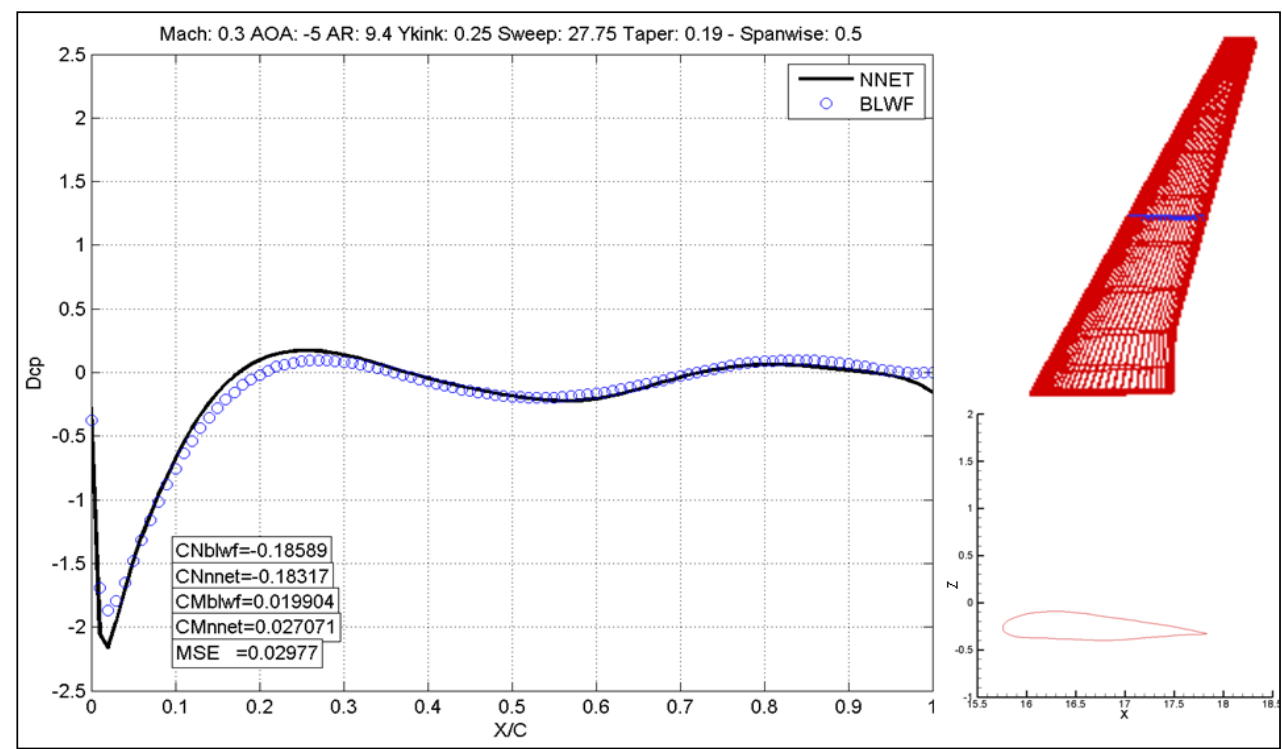

(b)

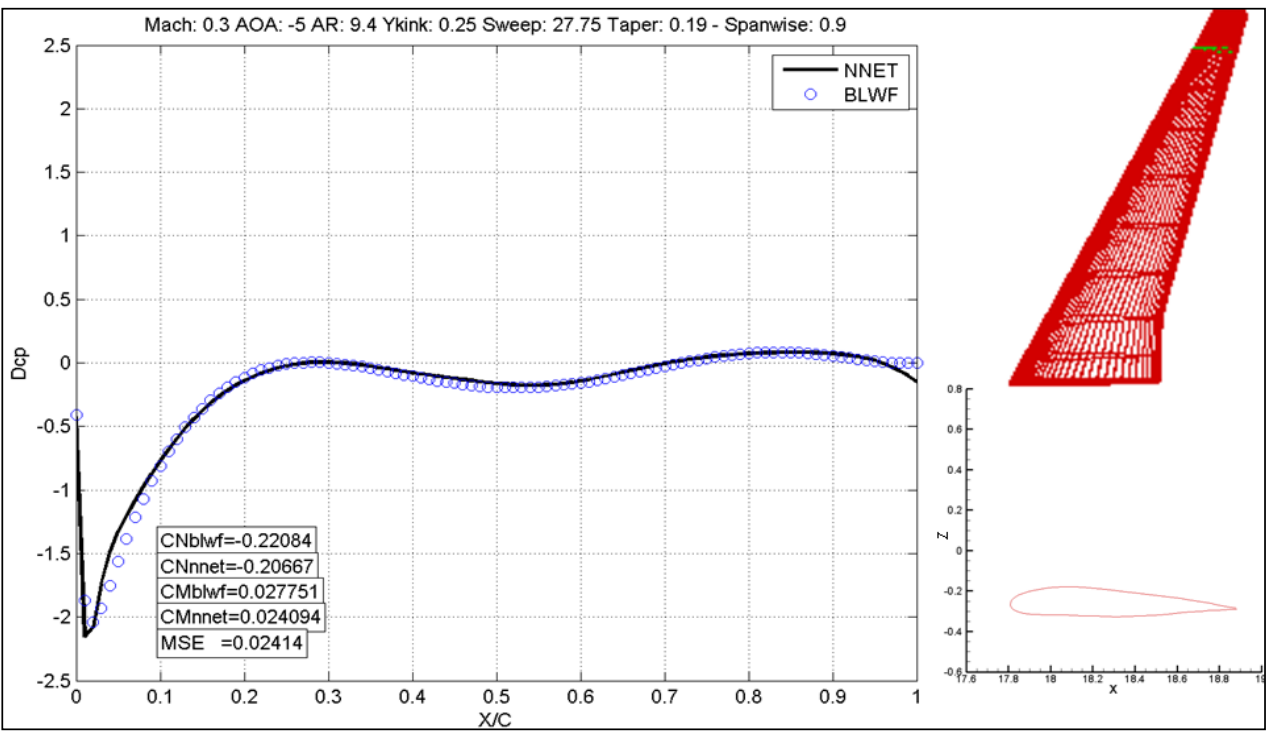

(c)

FIGURA 51: ESCOAMENTO SUBSONICO VALIDAÇÃO INDIVIDUO 3: (A) ESTAÇÃO NA RAIZ (B) ESTAÇÃO NO MEIO DA ASA (C) ESTAÇÃO NA PONTA DA ASA. 


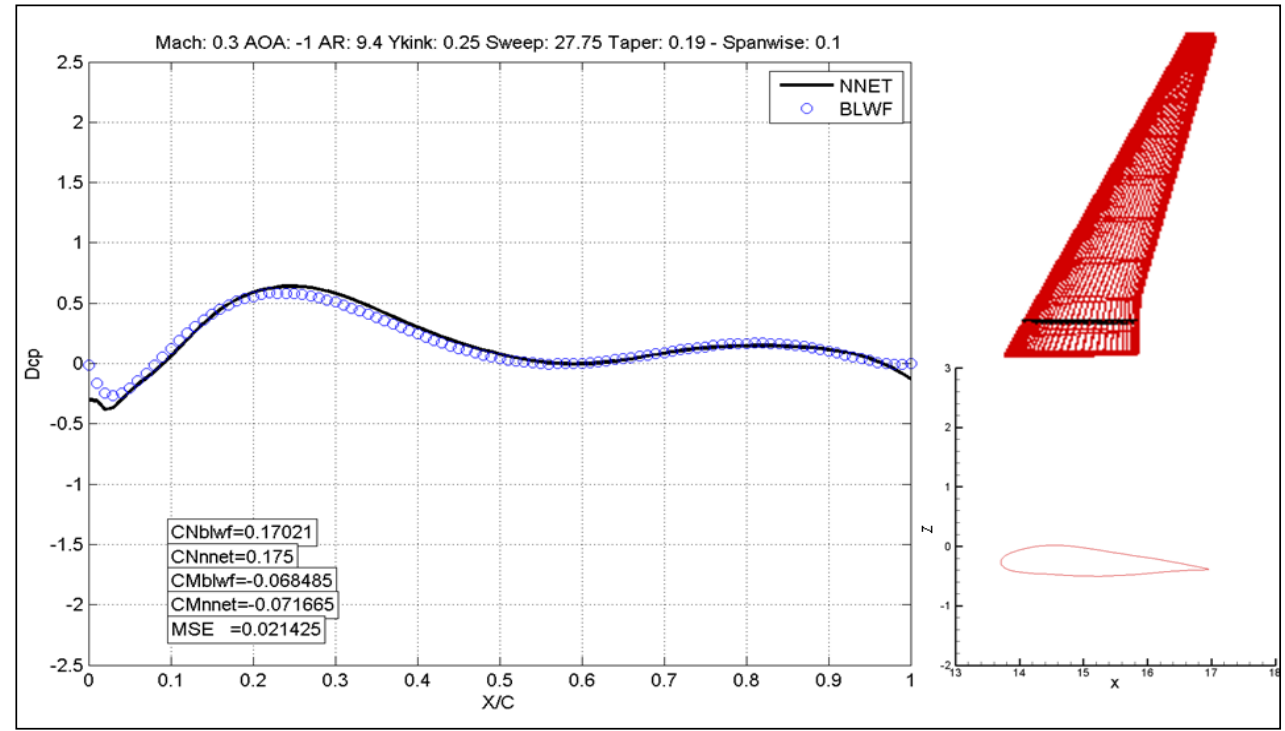

(a)

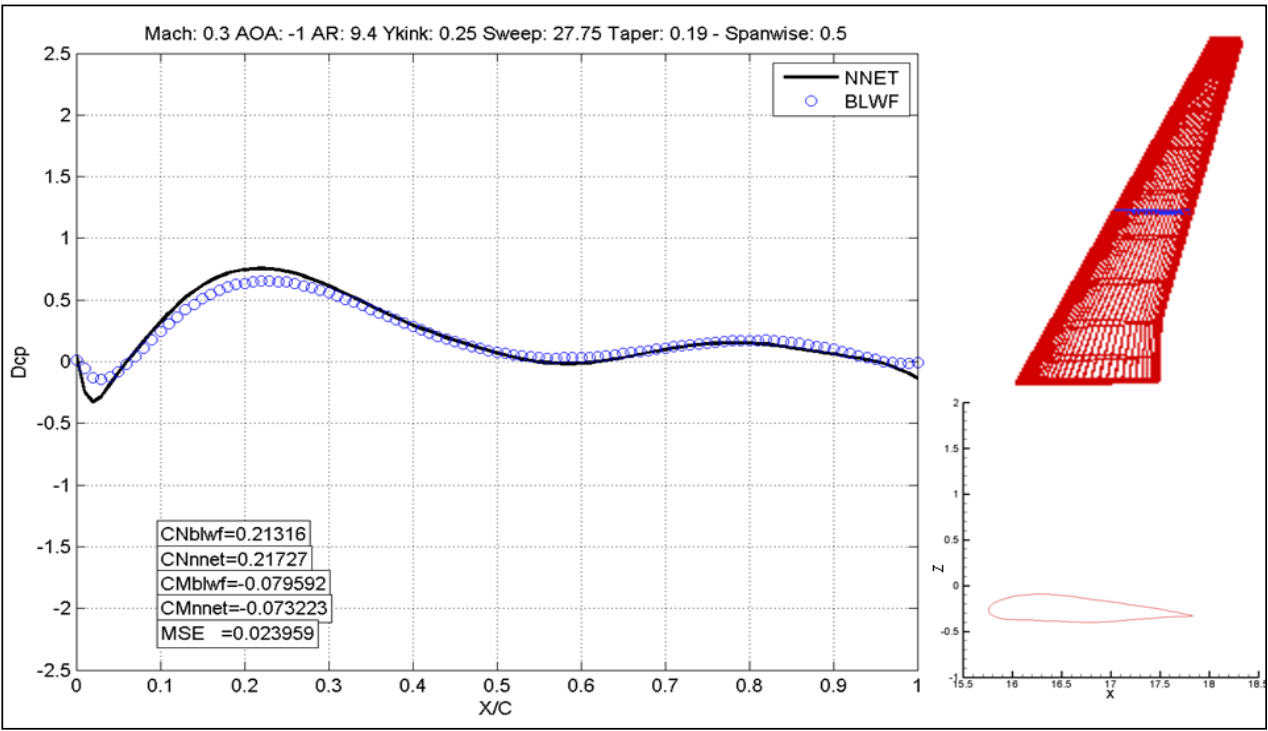

(b)

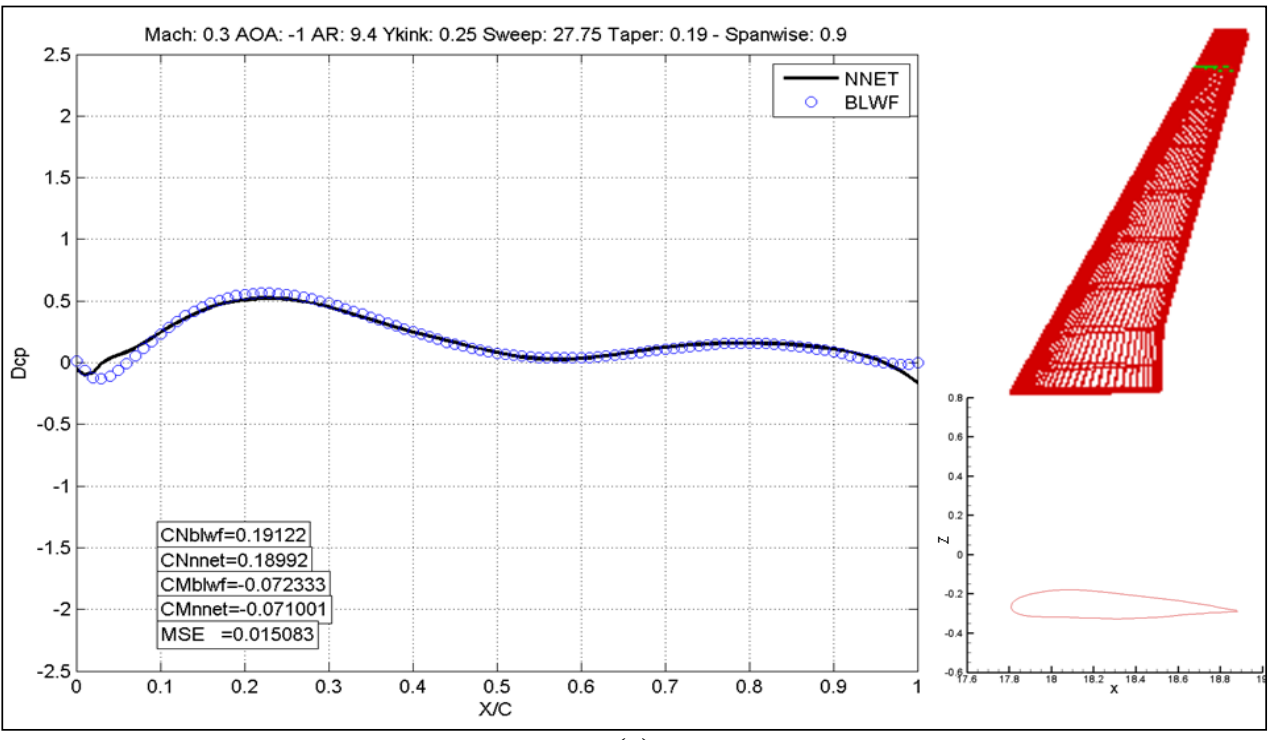

(c)

FIGURA 52: ESCOAMENTO SUBSONICO VALIDAÇÃO INDIVIDUO 3: (A) ESTAÇÃO NA RAIZ (B) ESTAÇÃO NO MEIO DA ASA (C) ESTAÇÃO NA PONTA DA ASA. 


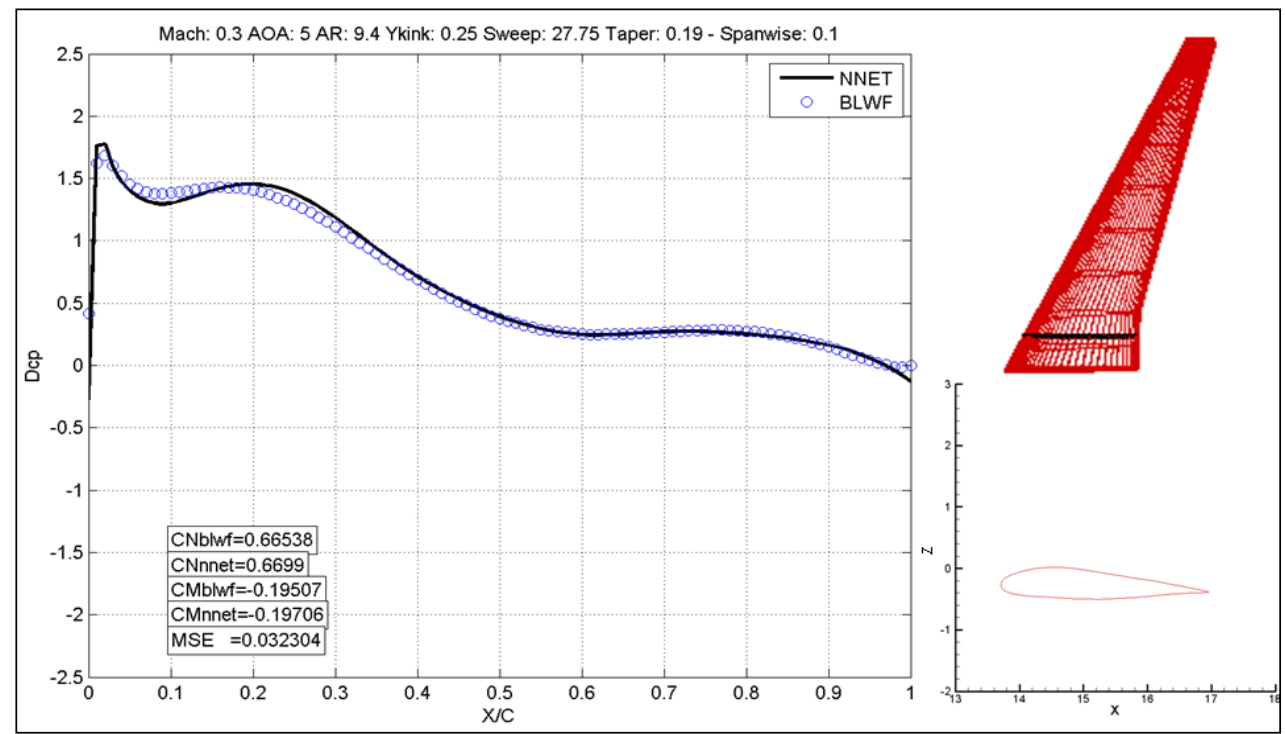

(a)

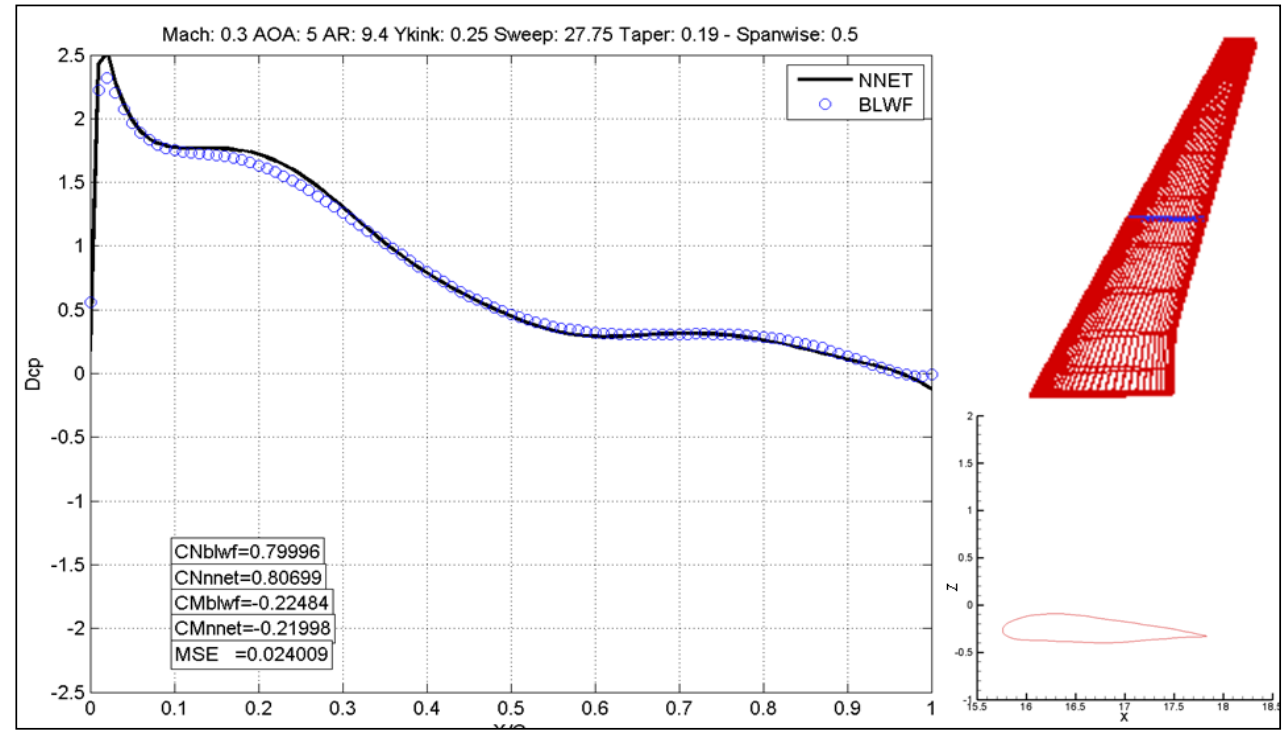

(b)

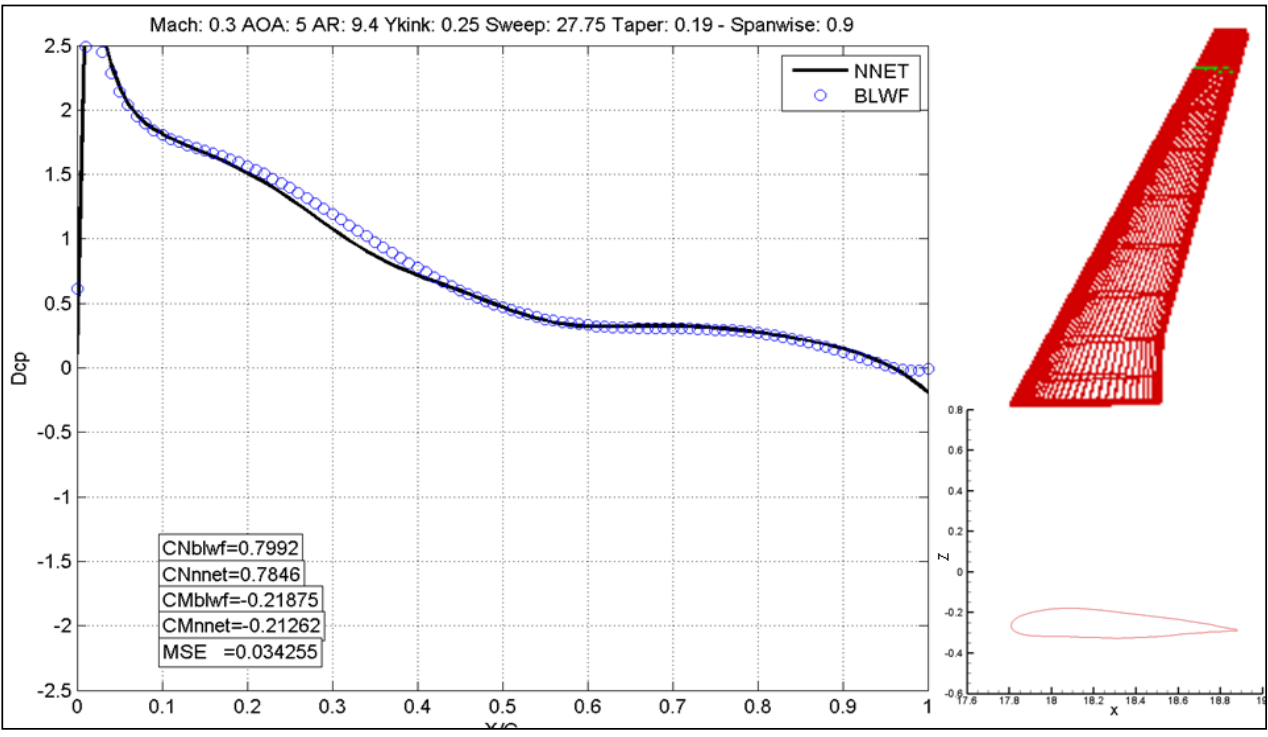

(c)

FIGURA 53: ESCOAMENTO SUBSONICO VALIDAÇÃO INDIVIDUO 3: (A) ESTAÇÃO NA RAIZ (B) ESTAÇÃO NO MEIO DA ASA (C) ESTAÇÃO NA PONTA DA ASA. 


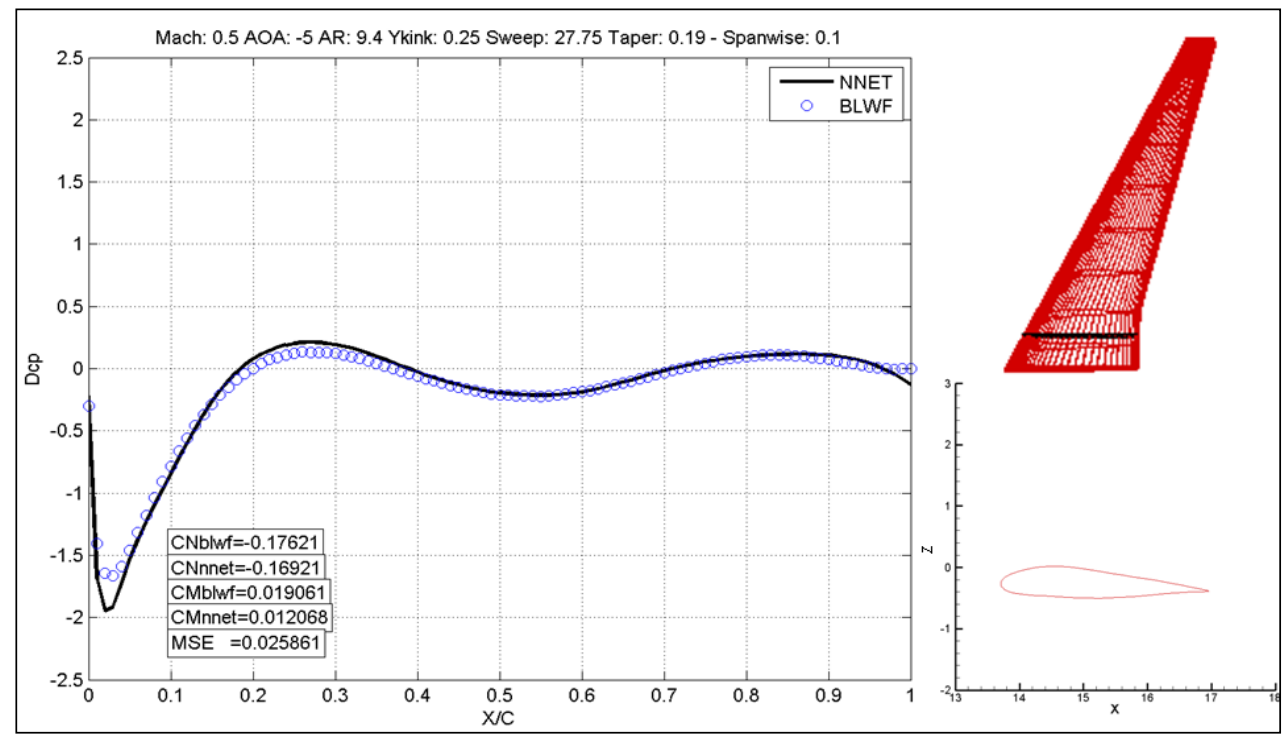

(a)

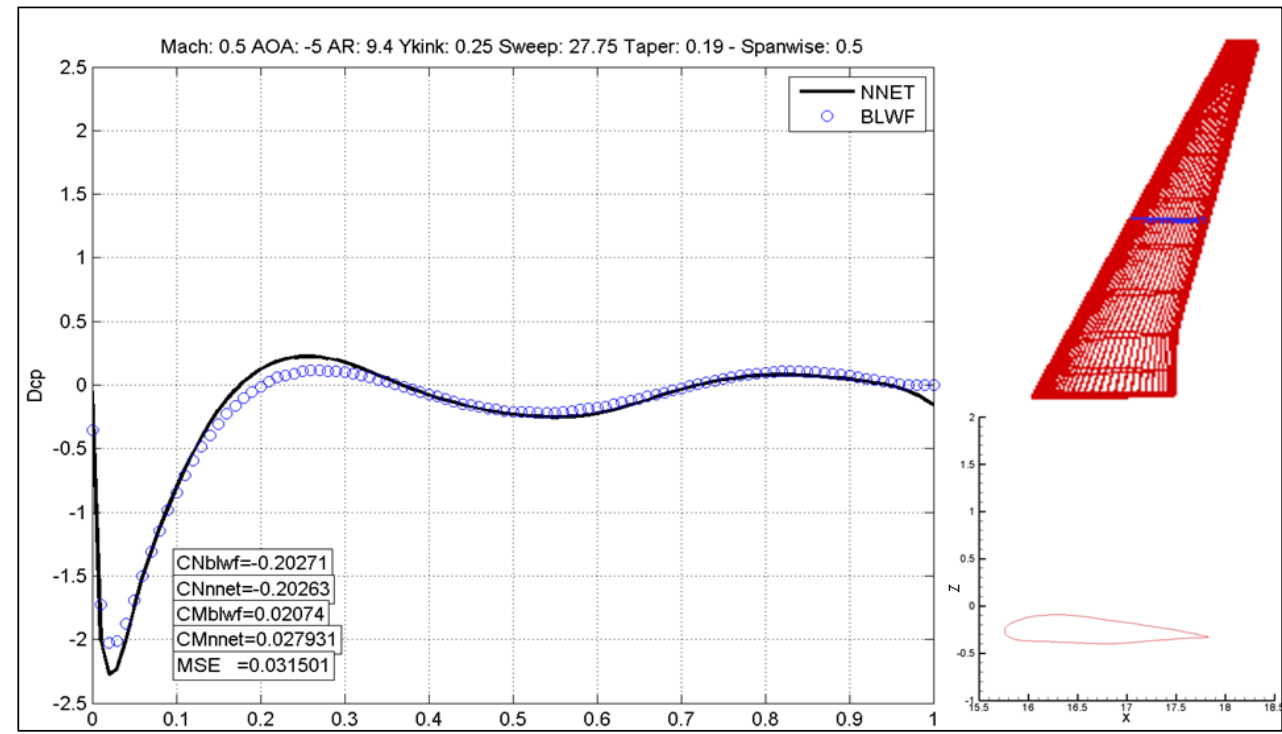

(b)

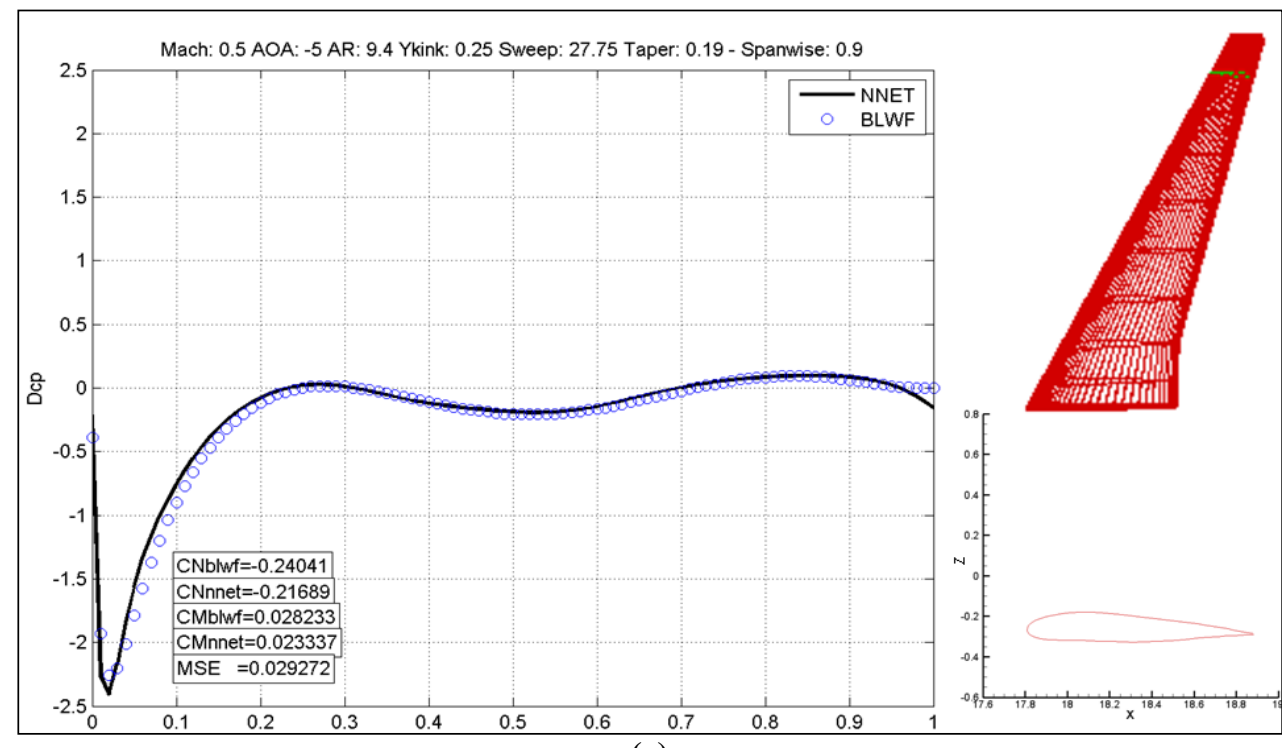

(c)

FIGURA 54: ESCOAMENTO SUBSONICO VALIDAÇÃO INDIVIDUO 3: (A) ESTAÇÃO NA RAIZ (B) ESTAÇÃO NO MEIO DA ASA (C) ESTAÇÃO NA PONTA DA ASA. 


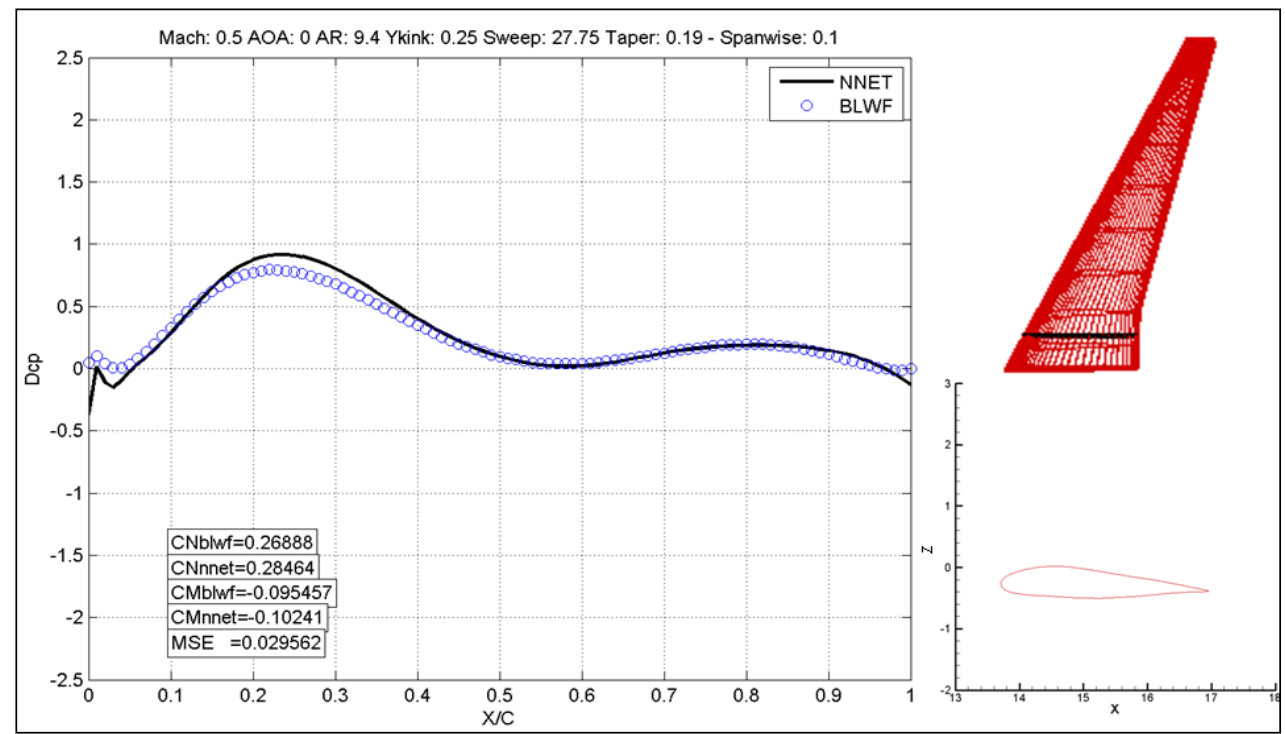

(a)

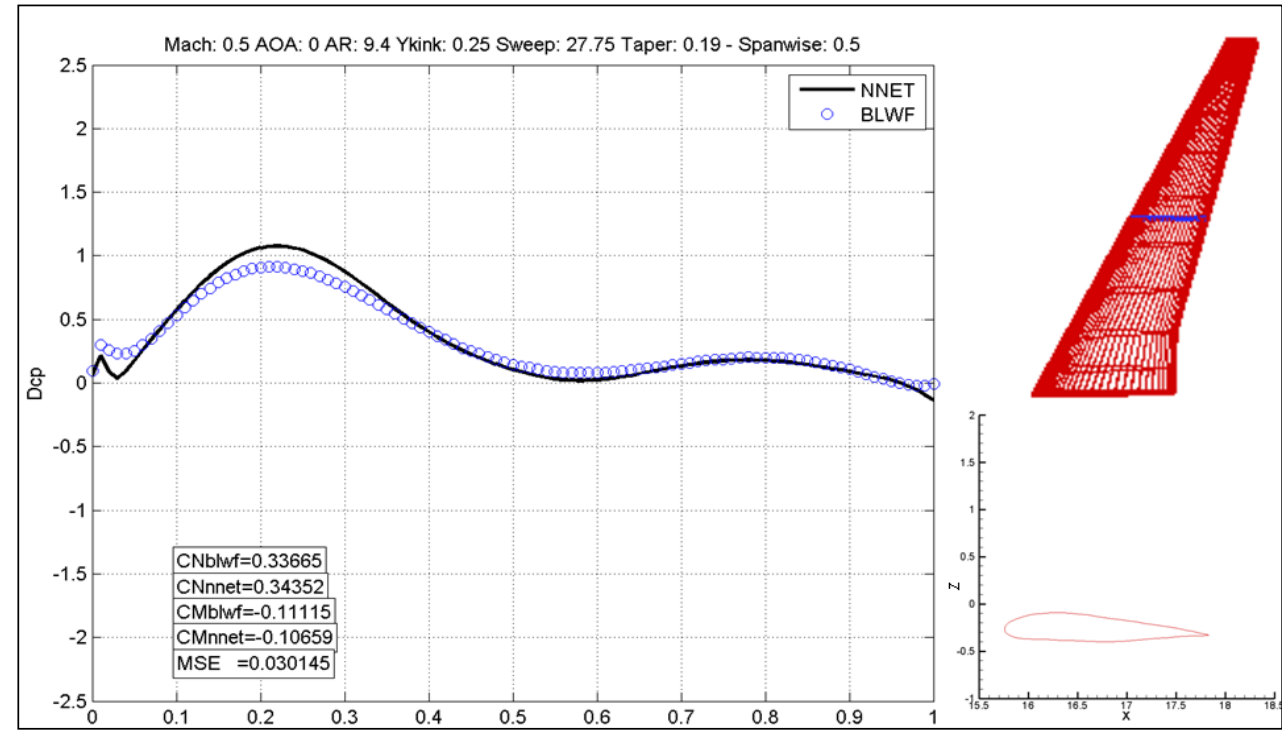

(b)

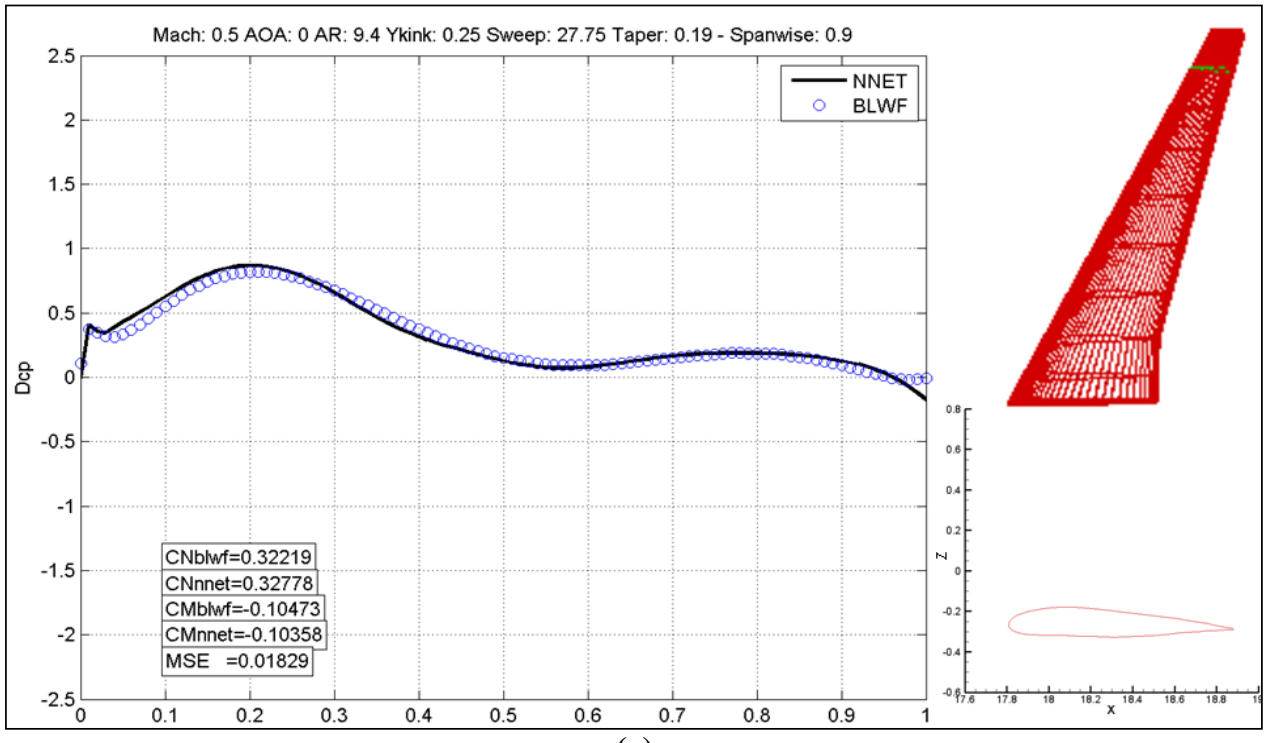

(c)

FIGURA 55: ESCOAMENTO SUBSONICO VALIDAÇÃO INDIVIDUO 3: (A) ESTAÇÃO NA RAIZ (B) ESTAÇÃO NO MEIO DA ASA (C) ESTAÇÃO NA PONTA DA ASA. 


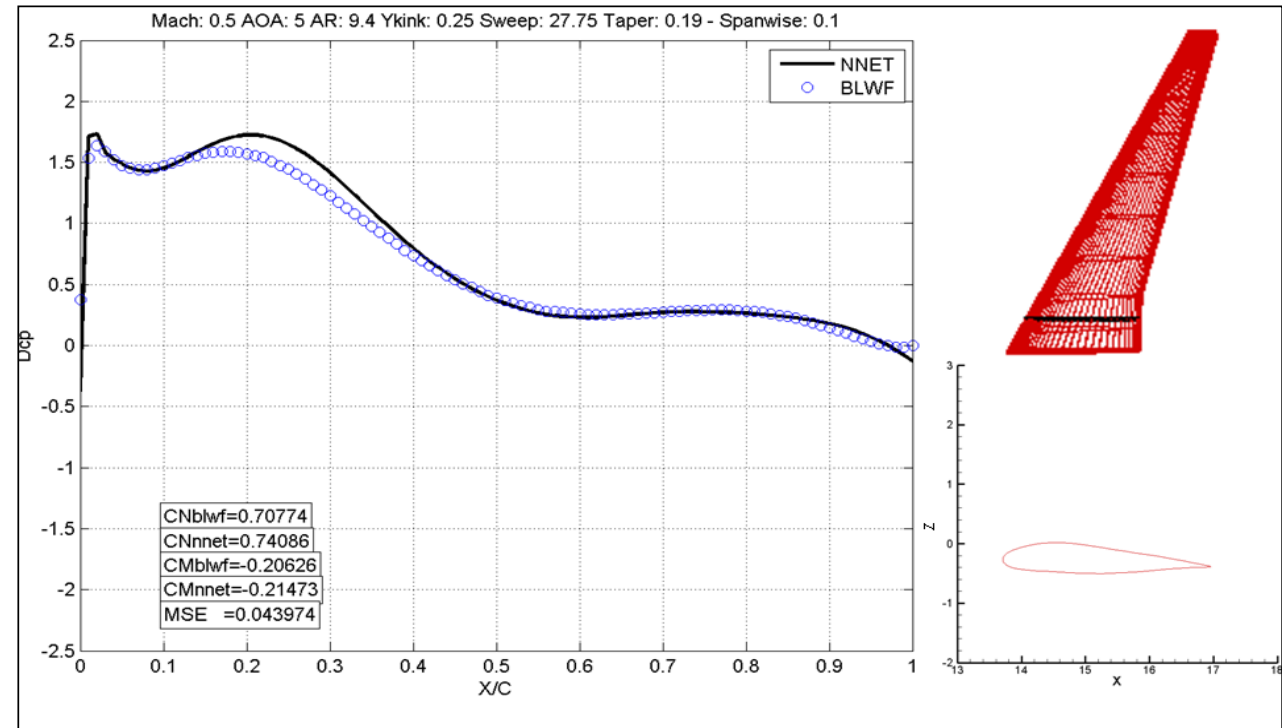

(a)

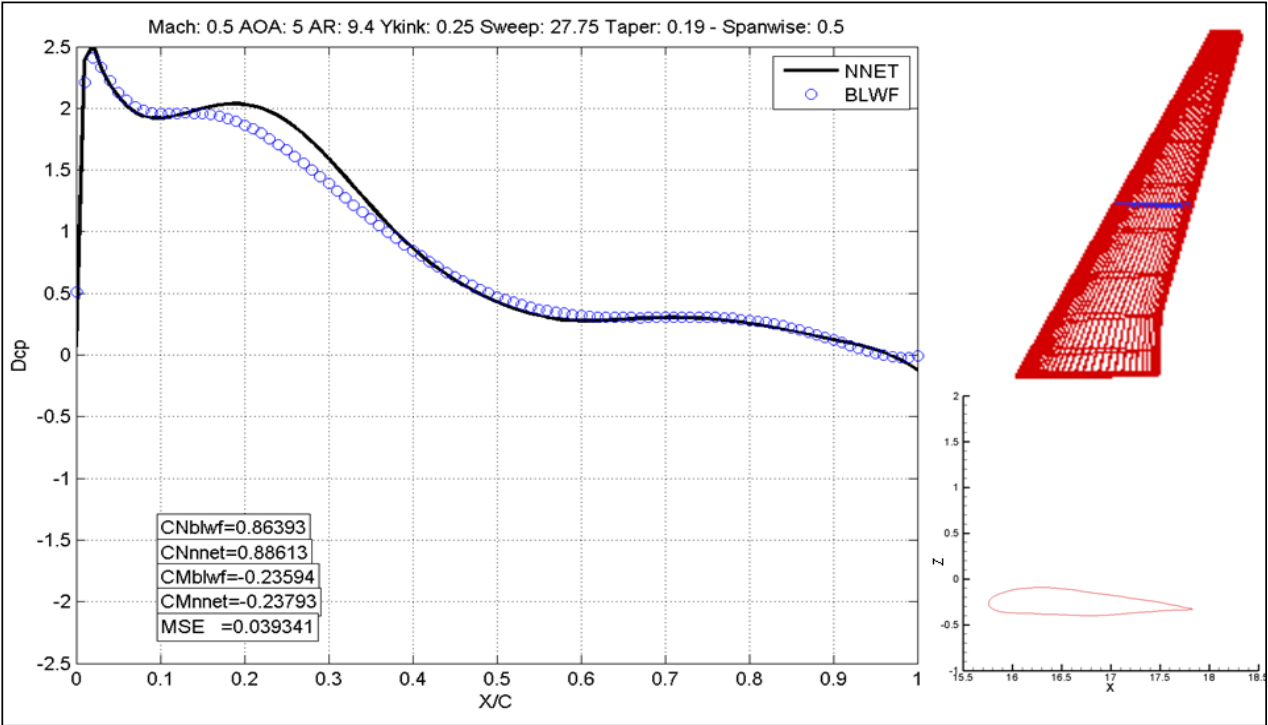

(b)

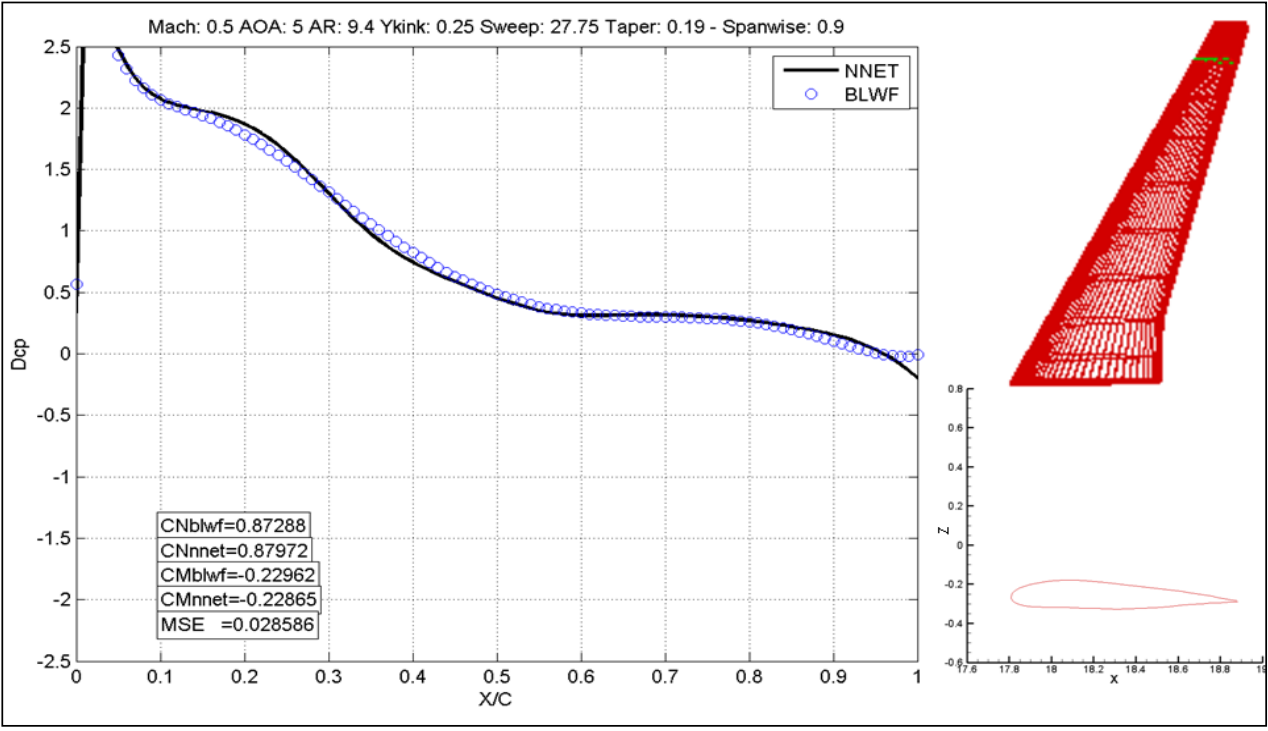

(c)

FIGURA 56: ESCOAMENTO SUBSONICO VALIDAÇÃO INDIVIDUO 3: (A) ESTAÇÃO NA RAIZ (B) ESTAÇÃO NO MEIO DA ASA (C) ESTAÇÃO NA PONTA DA ASA. 


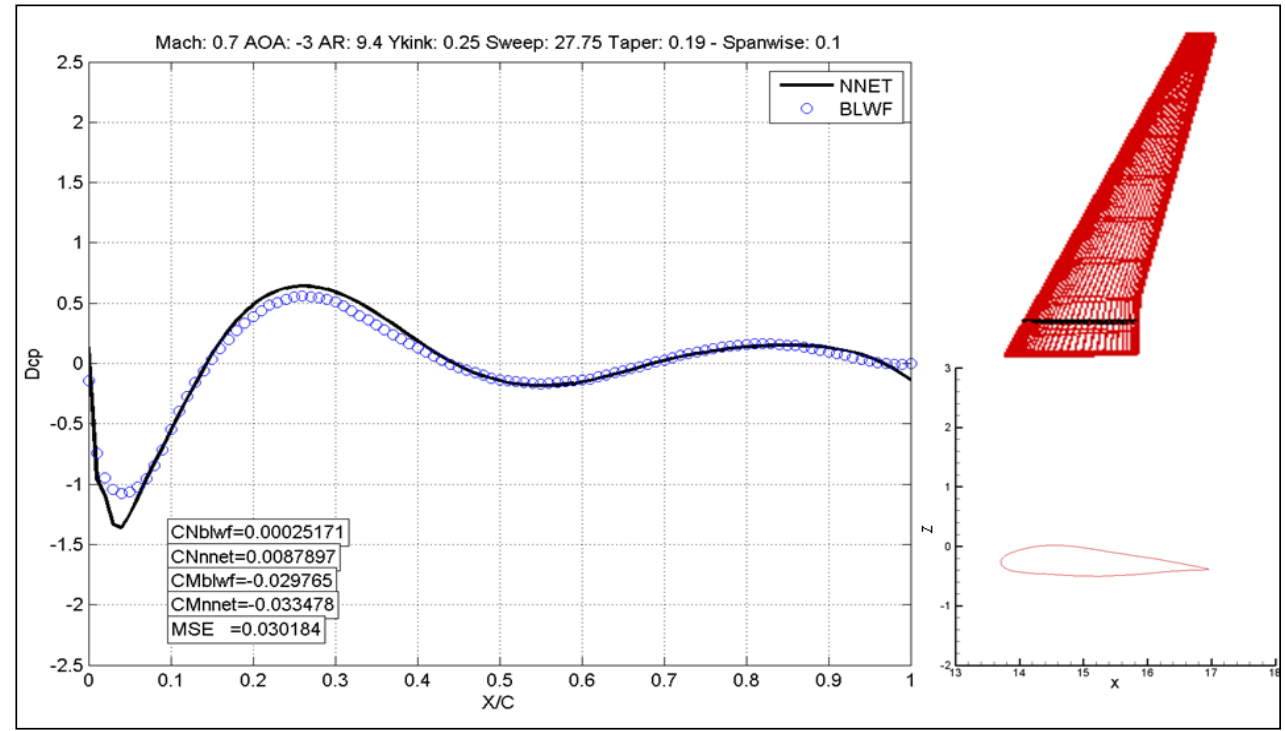

(a)

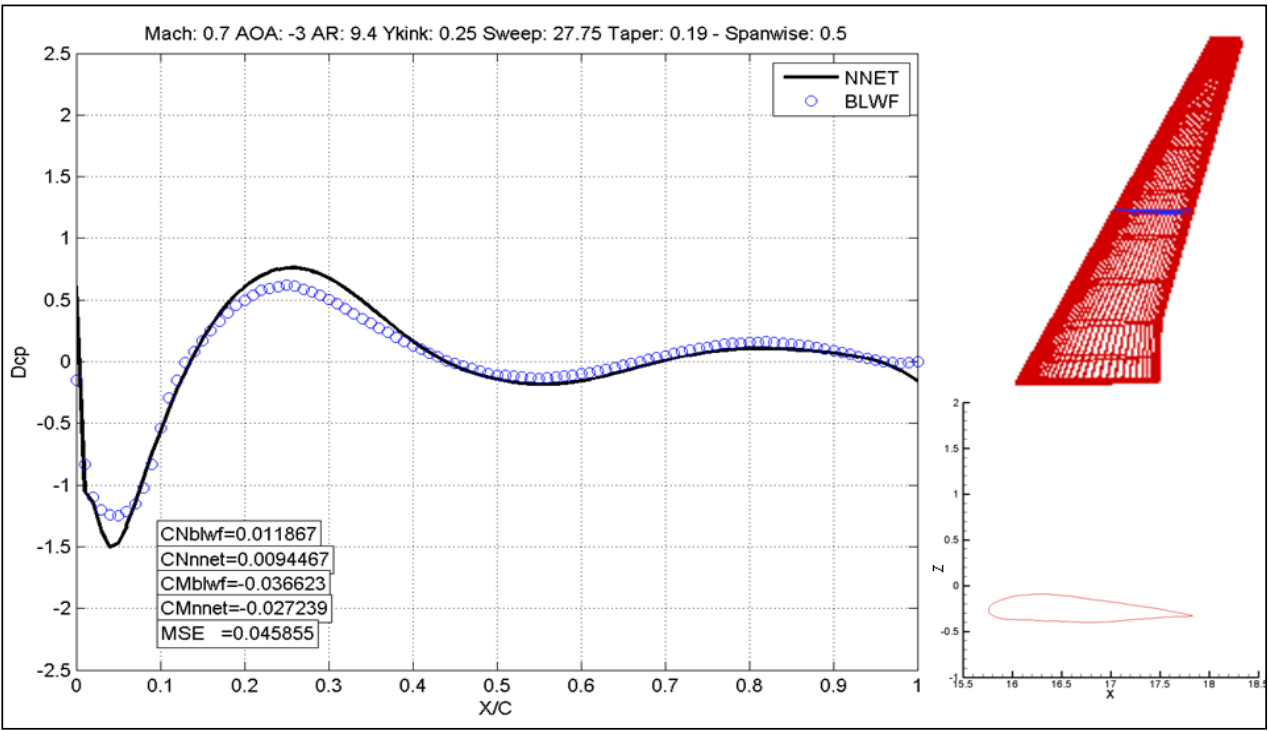

(b)

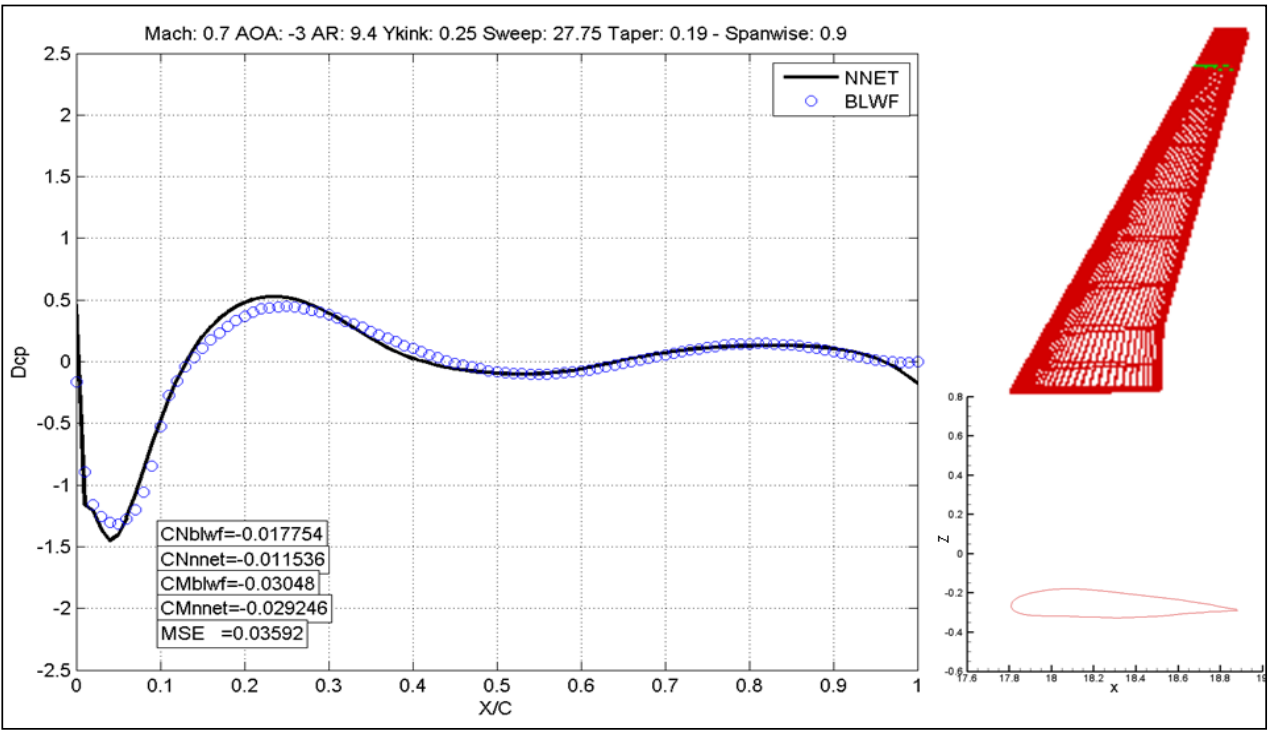

(c)

FIGURA 57: ESCOAMENTO SUBSONICO VALIDAÇÃO INDIVIDUO 3: (A) ESTAÇÃO NA RAIZ (B) ESTAÇÃO NO MEIO DA ASA (C) ESTAÇÃO NA PONTA DA ASA. 


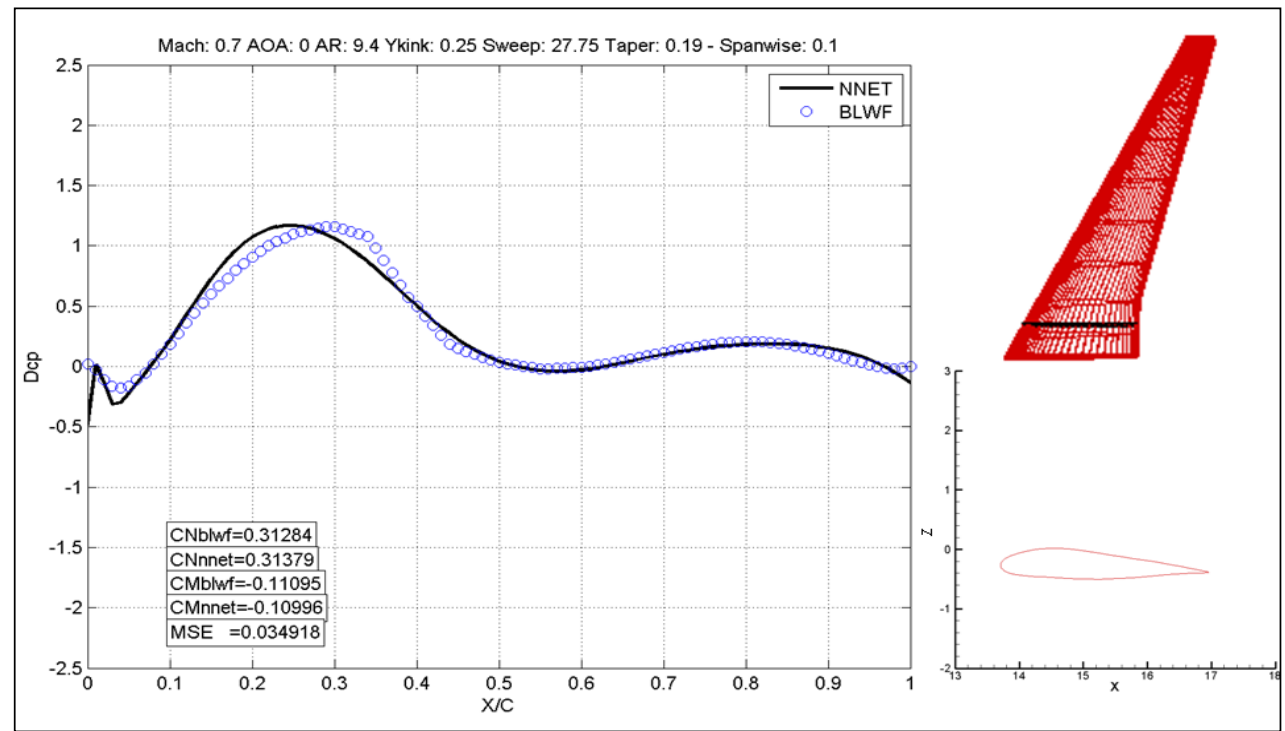

(a)

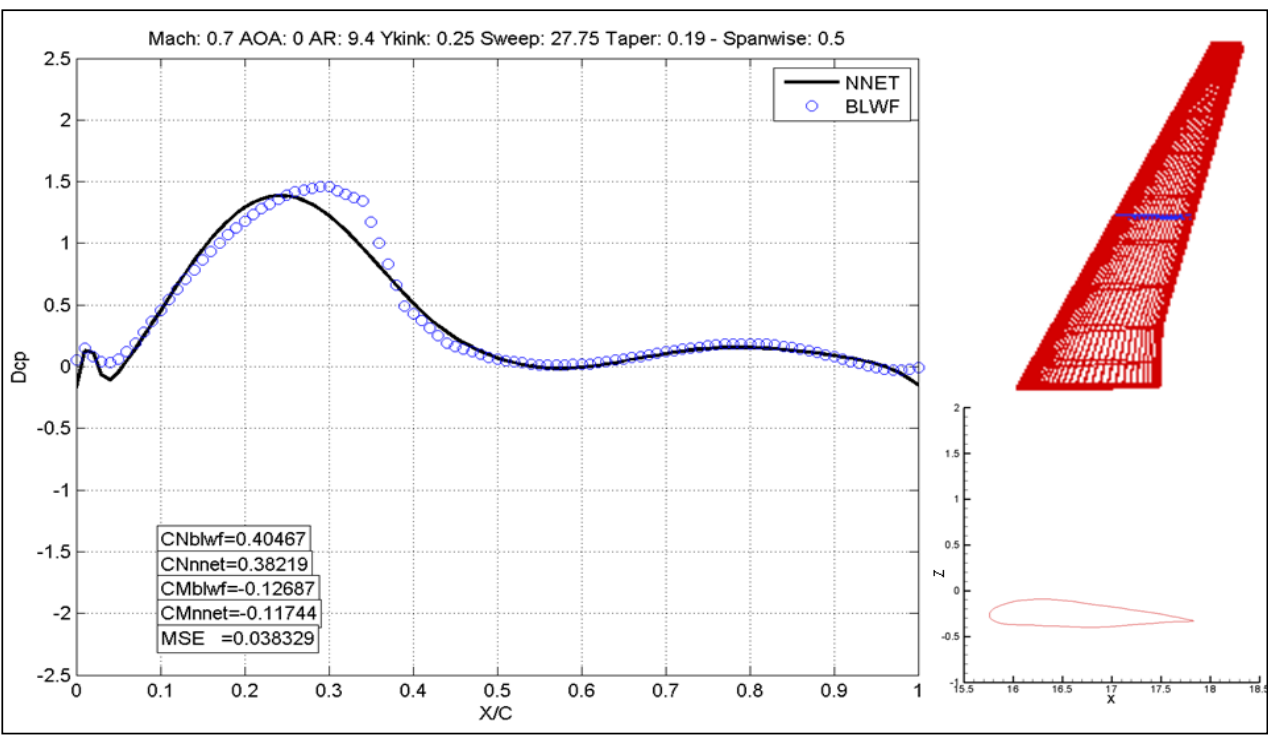

(b)

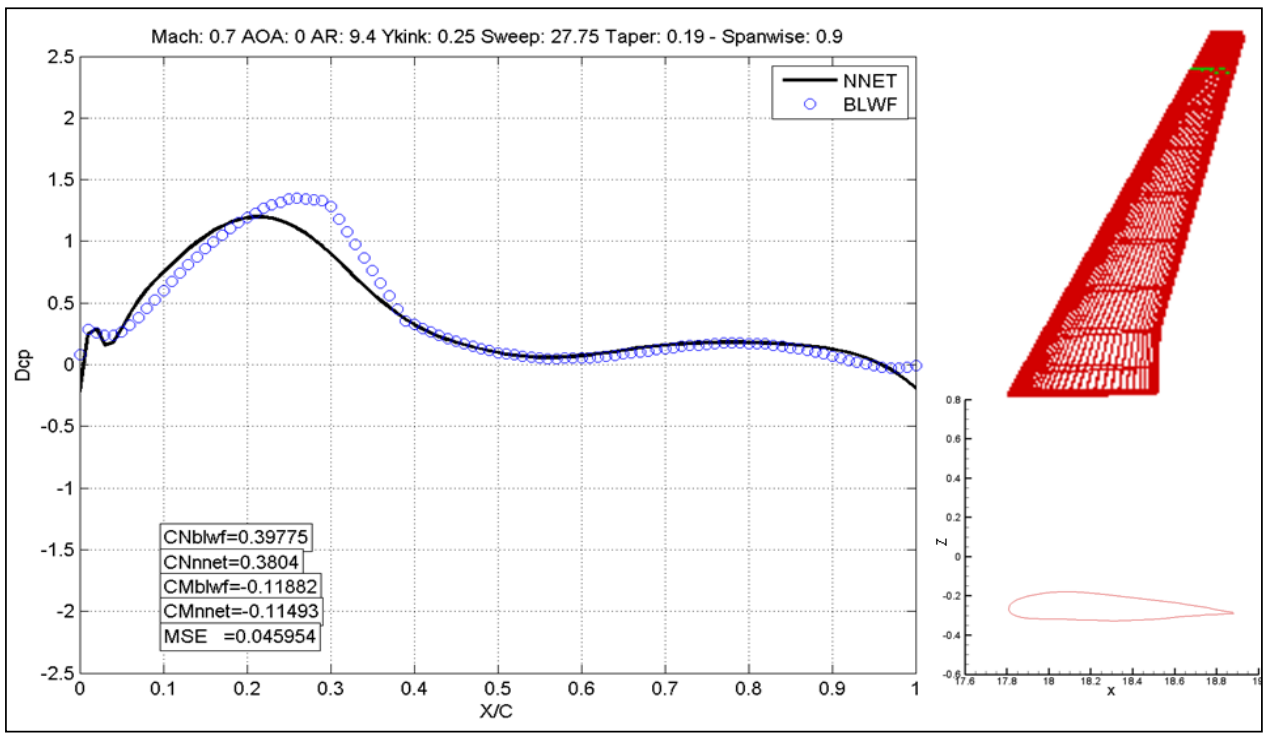

(c)

FIGURA 58: ESCOAMENTO SUBSONICO VALIDAÇÃO INDIVIDUO 3: (A) ESTAÇÃO NA RAIZ (B) ESTAÇÃO NO MEIO DA ASA (C) ESTAÇÃO NA PONTA DA ASA. 


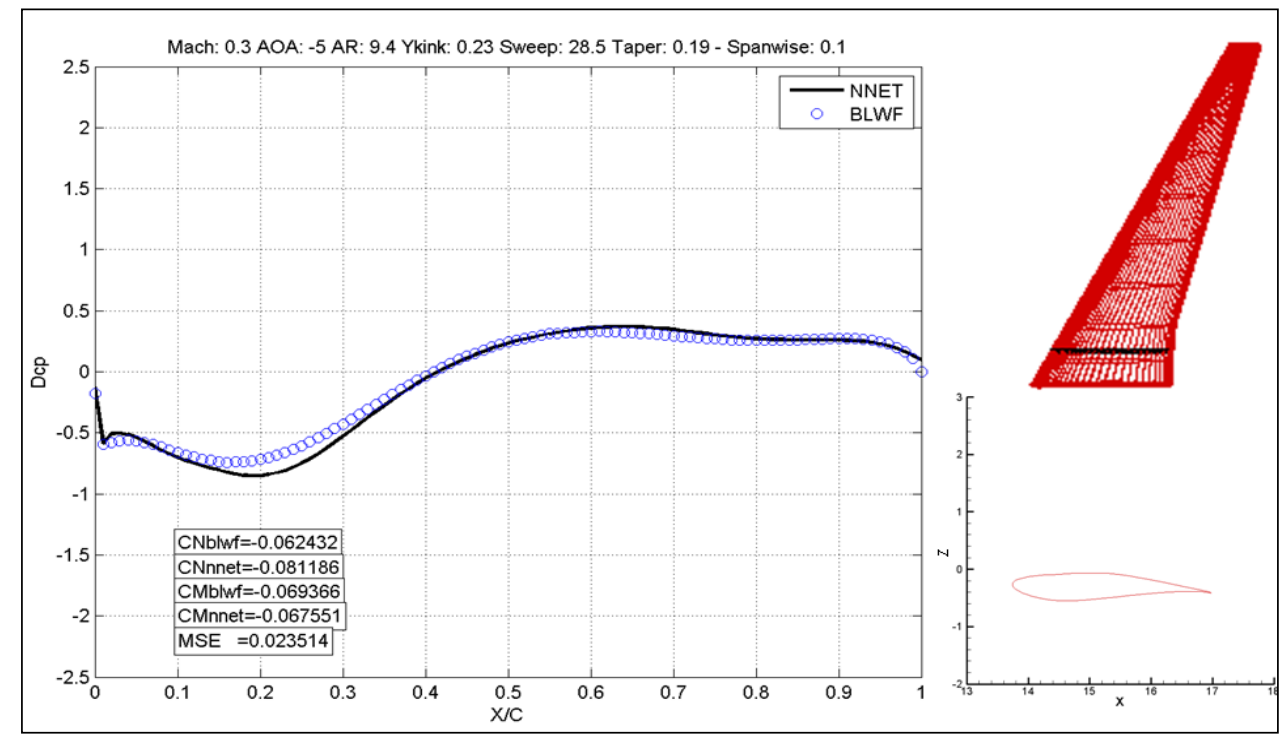

(a)

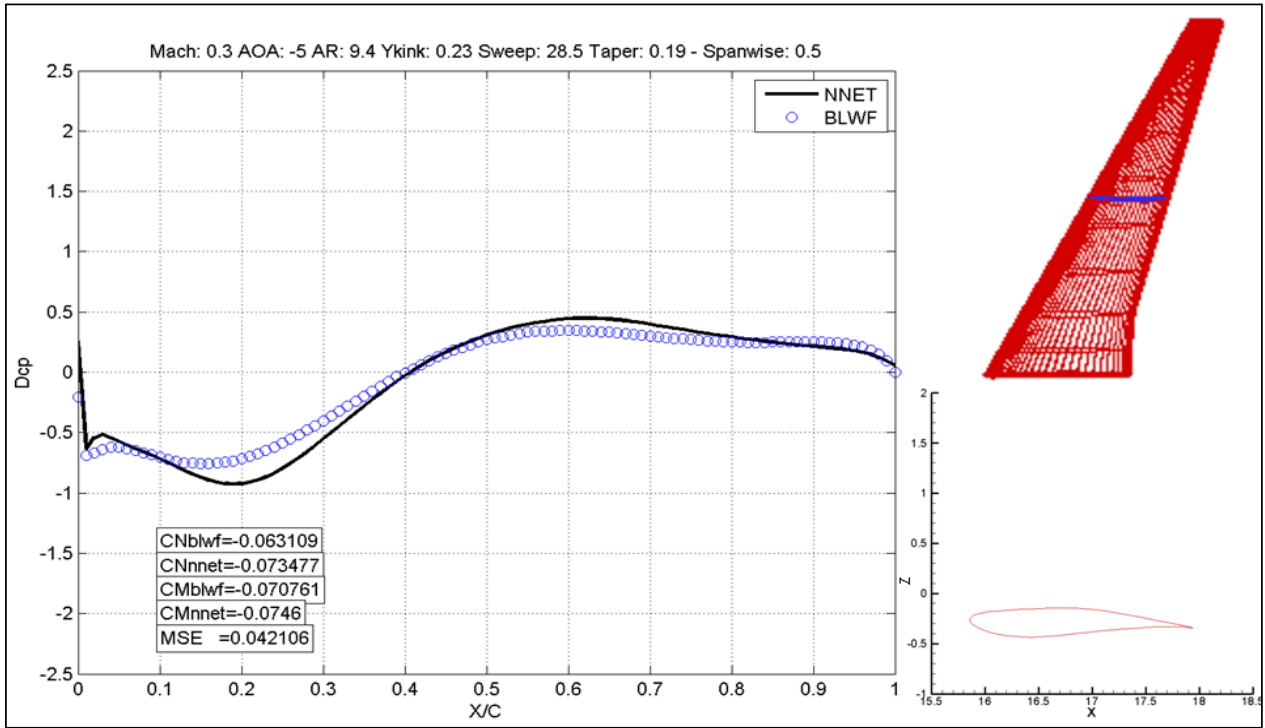

(b)

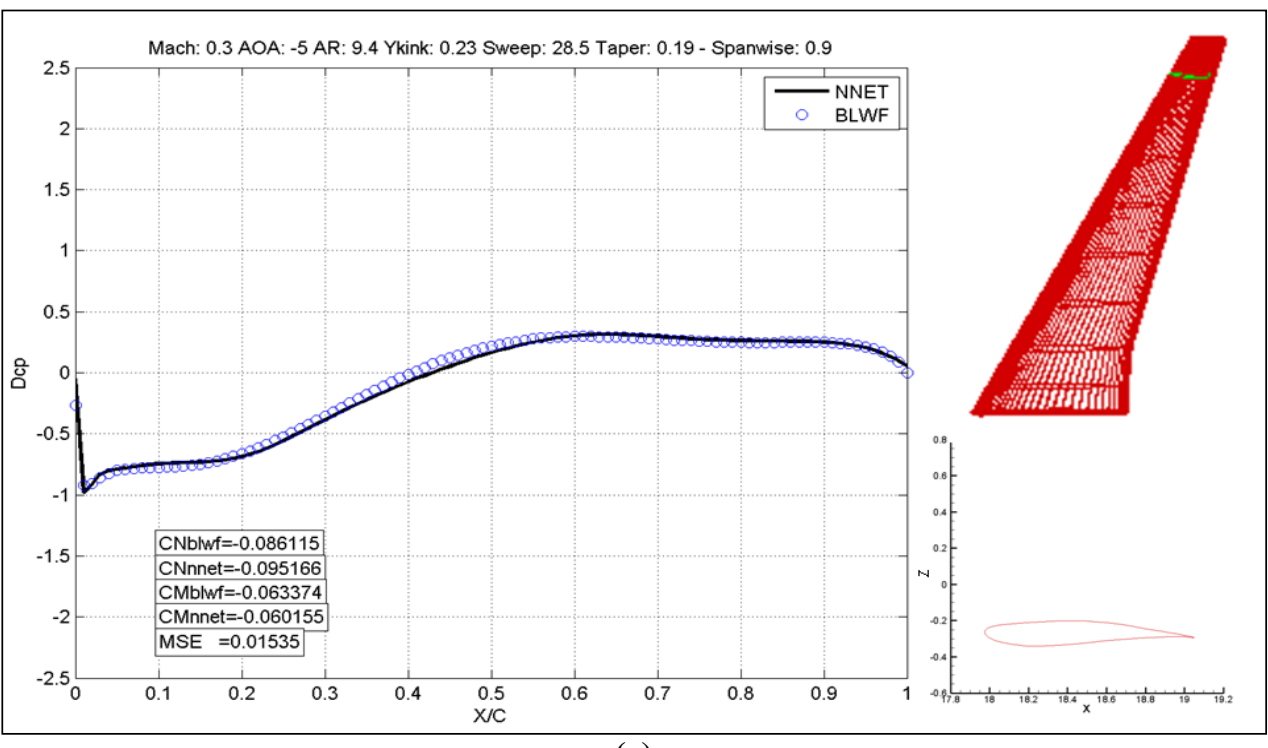

(c)

FIGURA 59: ESCOAMENTO SUBSONICO VALIDAÇÃO INDIVIDUO 5: (A) ESTAÇÃO NA RAIZ (B) ESTAÇÃO NO MEIO DA ASA (C) ESTAÇÃO NA PONTA DA ASA. 


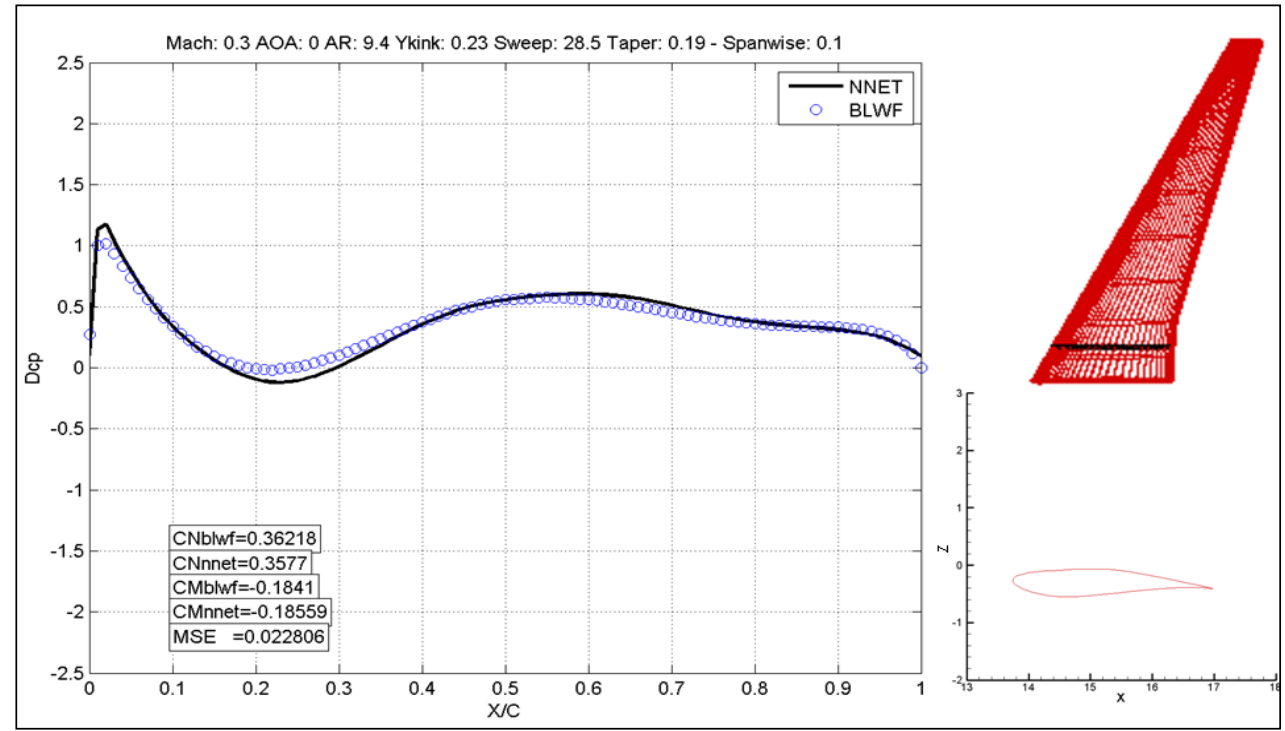

(a)

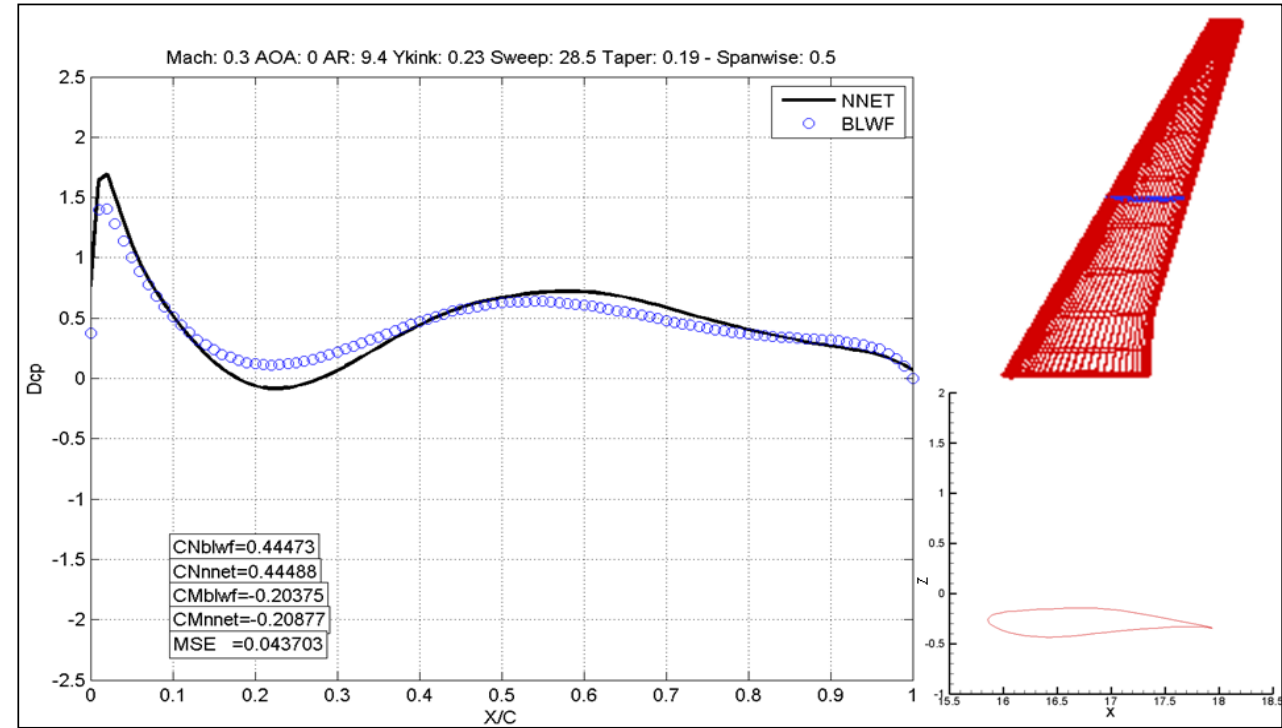

(b)

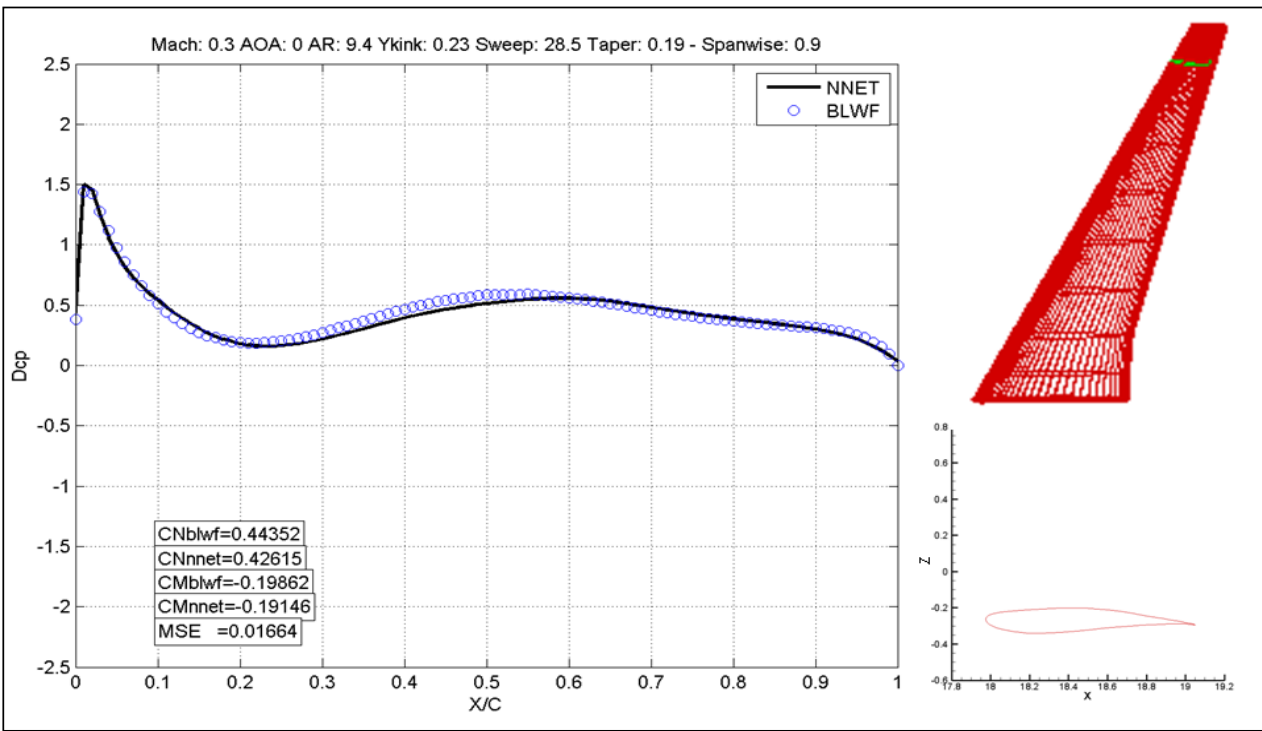

(c)

FIGURA 60: ESCOAMENTO SUBSONICO VALIDAÇÃO INDIVIDUO 5: (A) ESTAÇÃO NA RAIZ (B) ESTAÇÃO NO MEIO DA ASA (C) ESTAÇÃO NA PONTA DA ASA. 


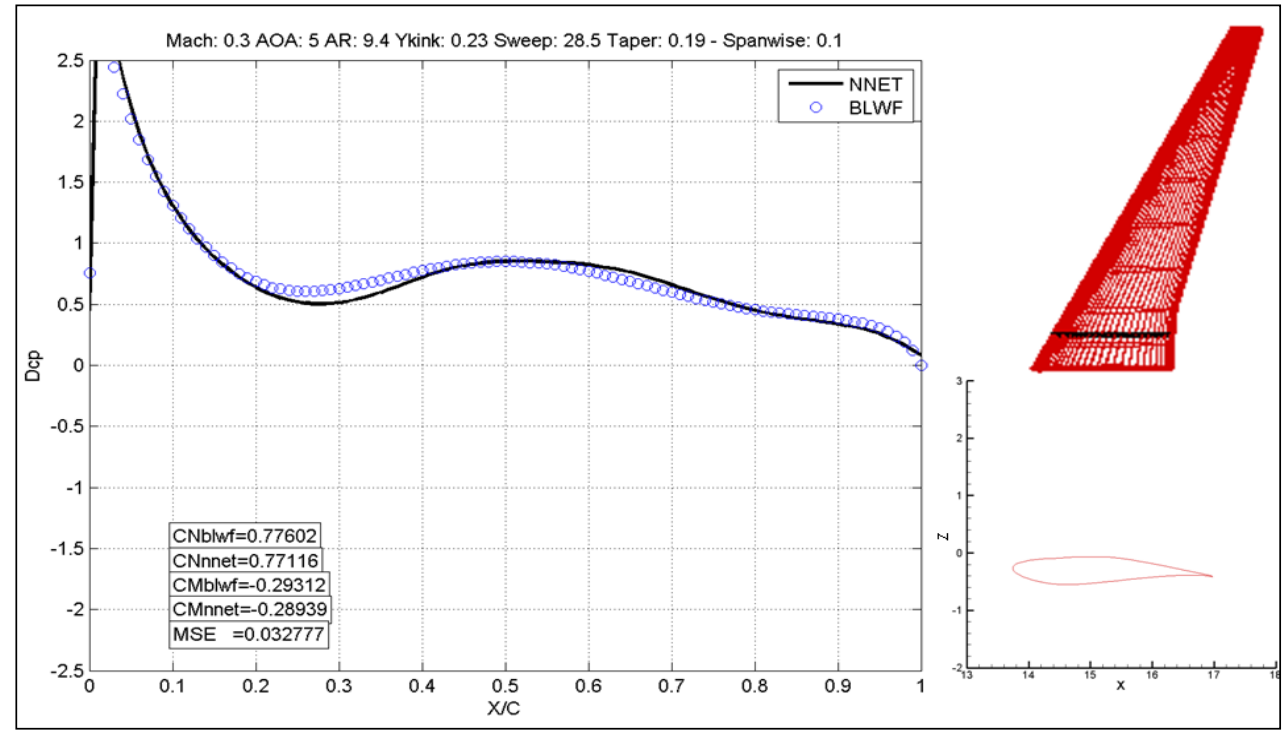

(a)

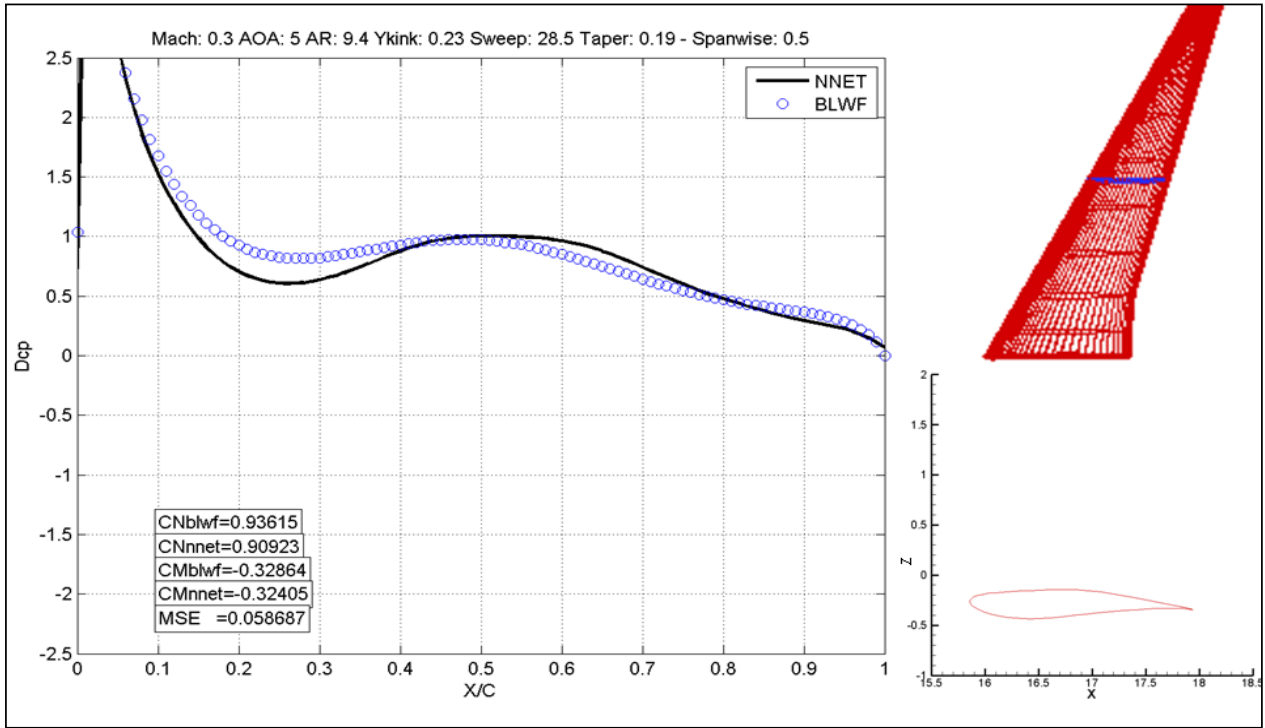

(b)

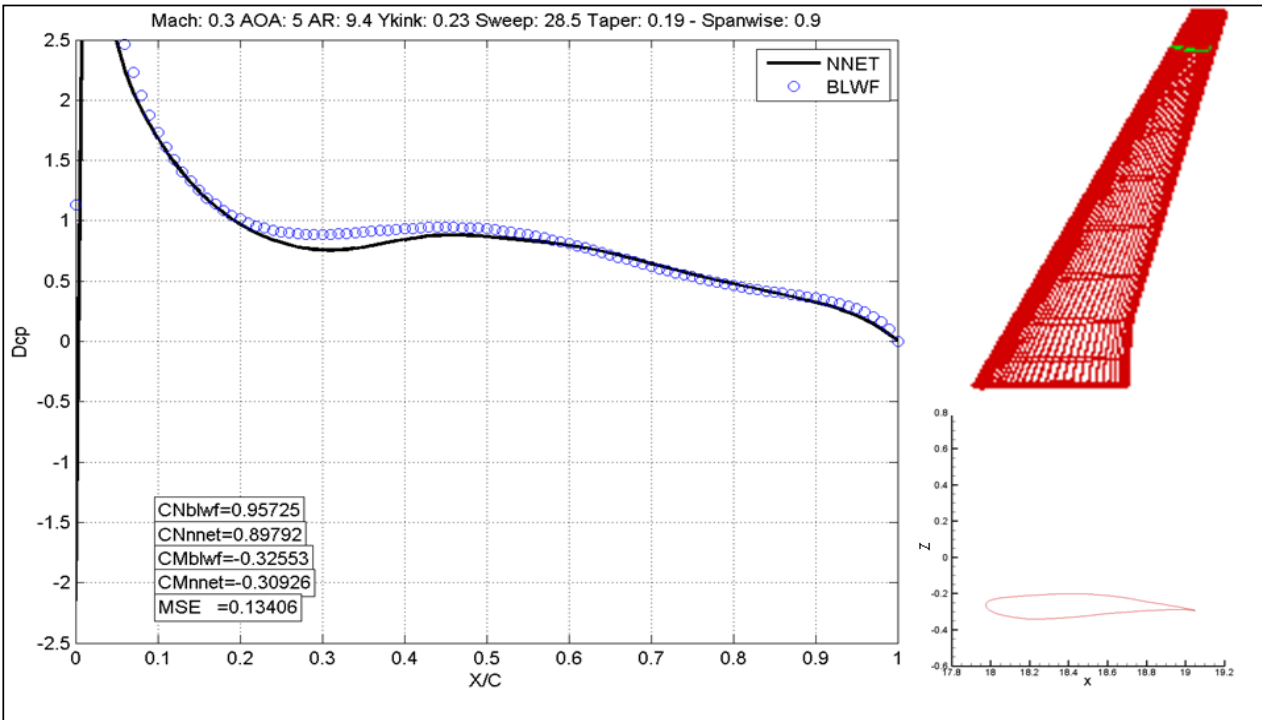

(c)

FIGURA 61: ESCOAMENTO SUBSONICO VALIDAÇÃO INDIVIDUO 5: (A) ESTAÇÃO NA RAIZ (B) ESTAÇÃO NO MEIO DA ASA (C) ESTAÇÃO NA PONTA DA ASA. 


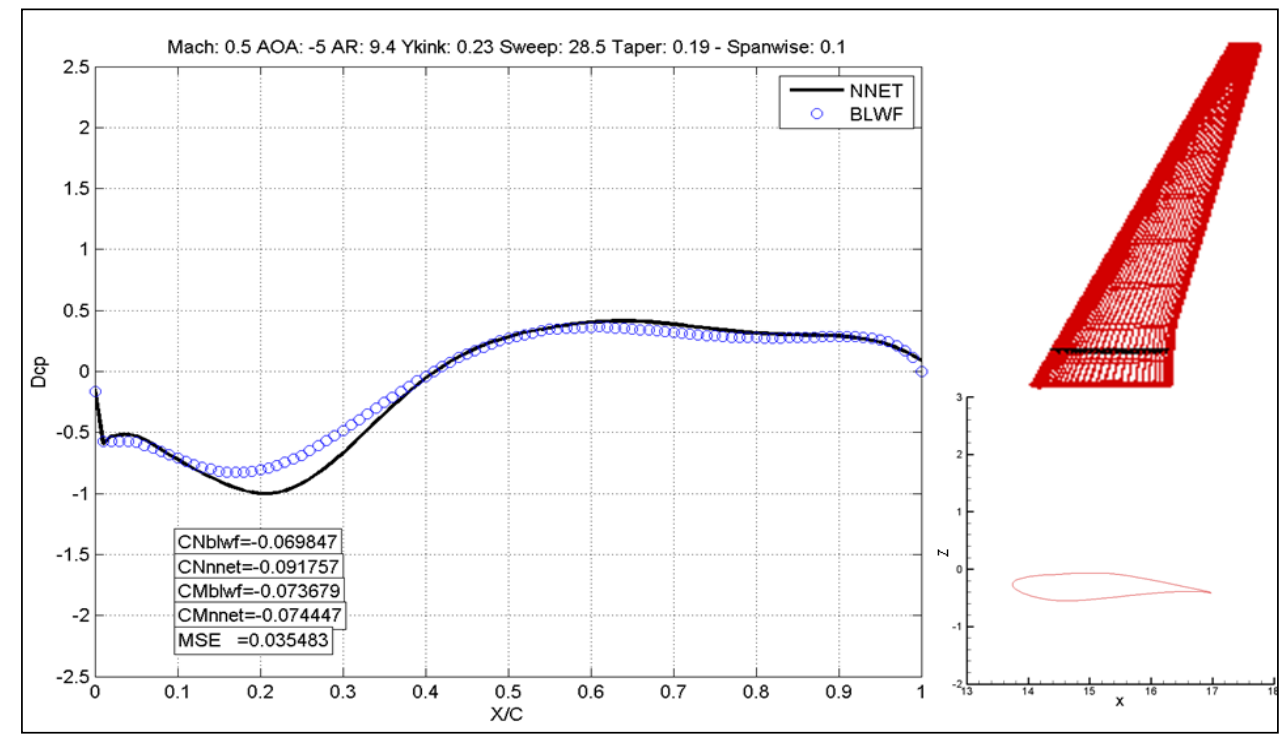

(a)

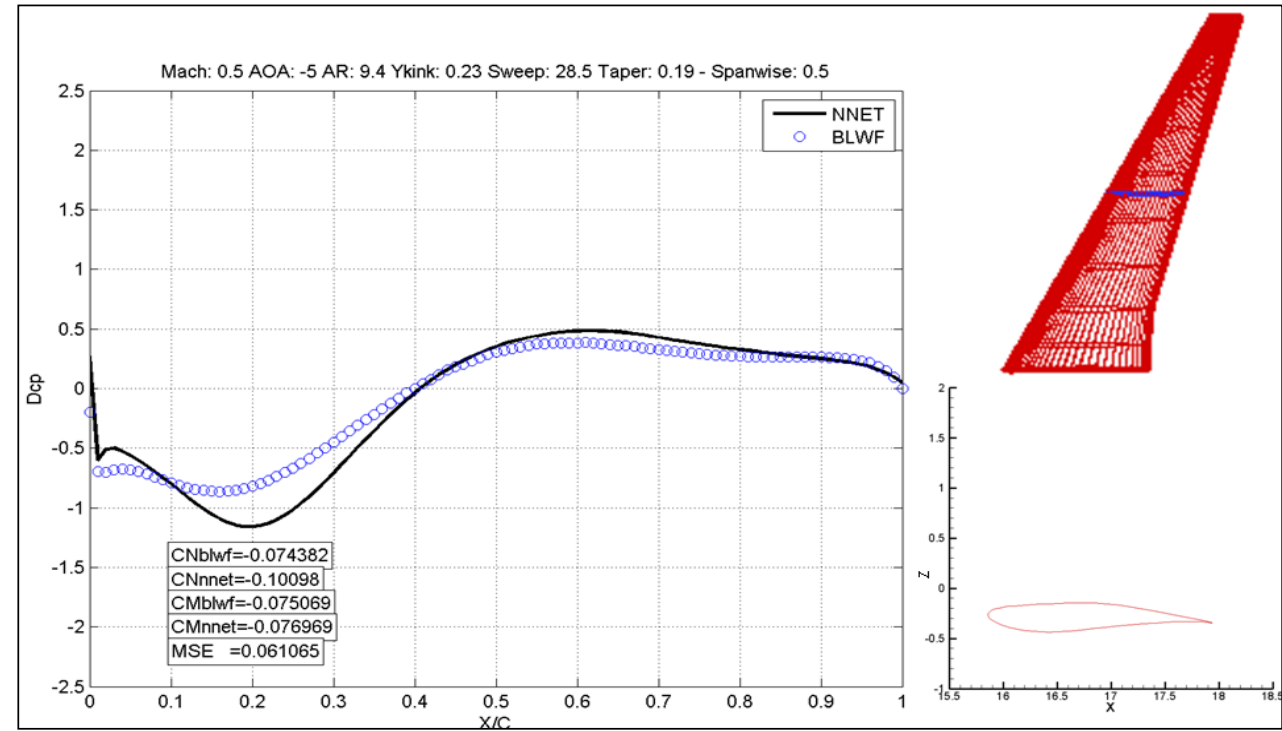

(b)

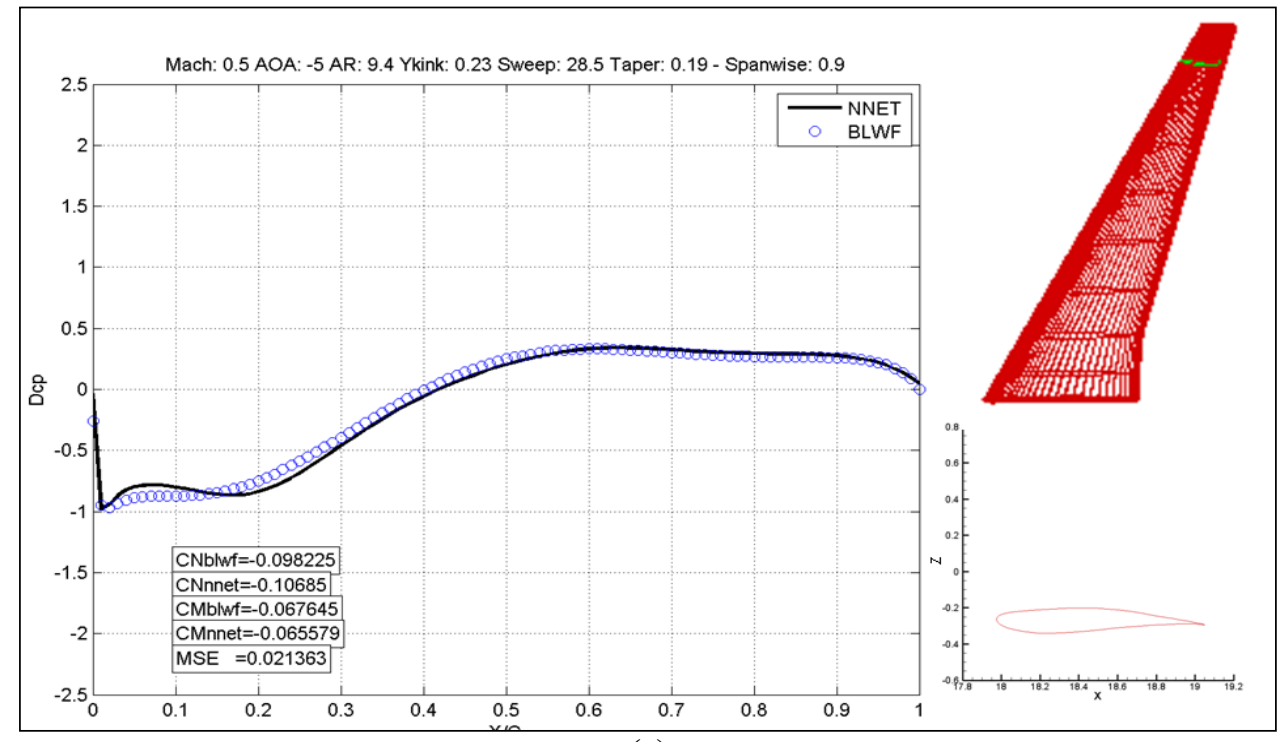

(c)

FIGURA 62: ESCOAMENTO SUBSONICO VALIDAÇÃO INDIVIDUO 5: (A) ESTAÇÃO NA RAIZ (B) ESTAÇÃO NO MEIO DA ASA (C) ESTAÇÃO NA PONTA DA ASA. 


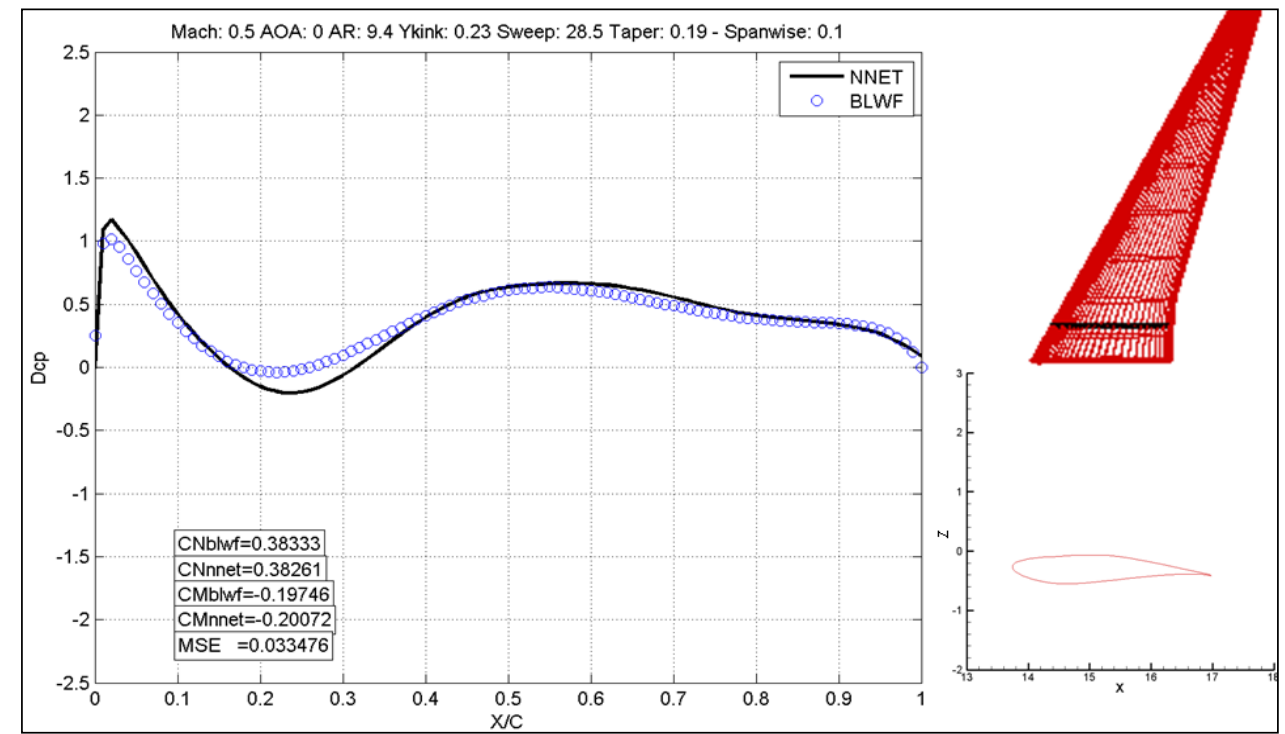

(a)

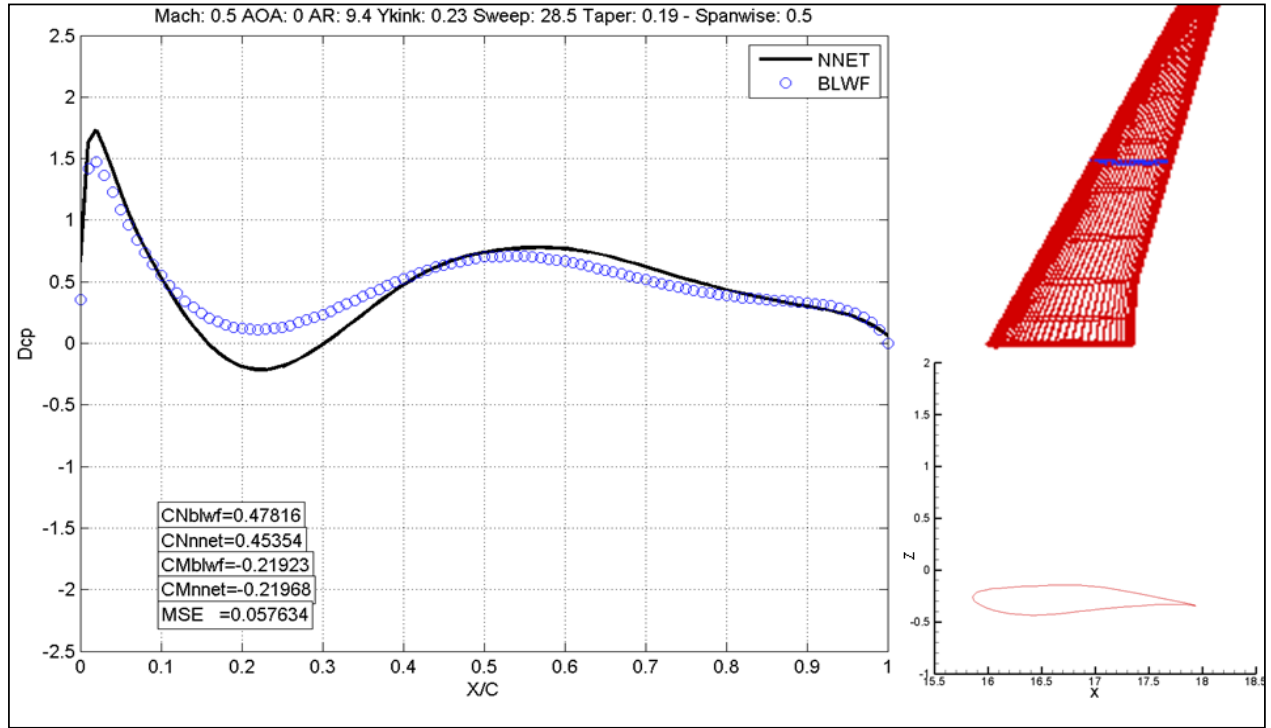

(b)

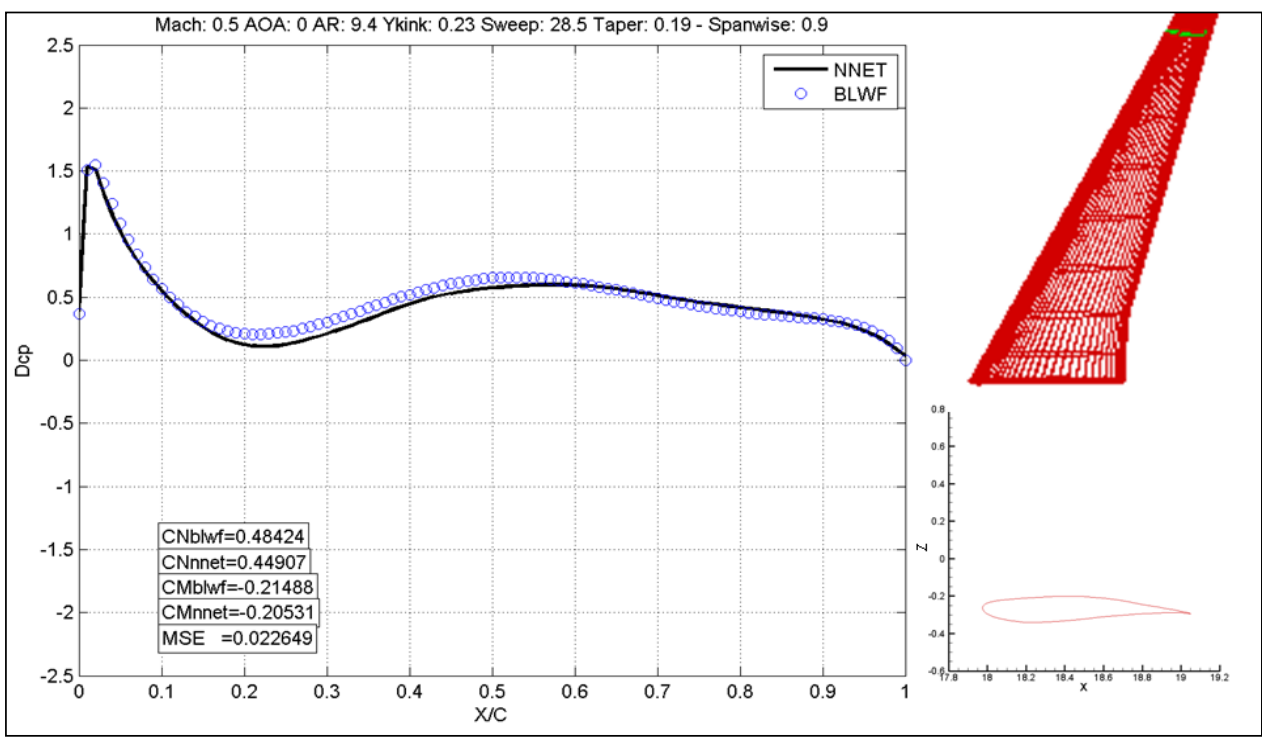

(c)

FIGURA 63: ESCOAMENTO SUBSONICO VALIDAÇÃO INDIVIDUO 5: (A) ESTAÇÃO NA RAIZ (B) ESTAÇÃO NO MEIO DA ASA (C) ESTAÇÃO NA PONTA DA ASA. 


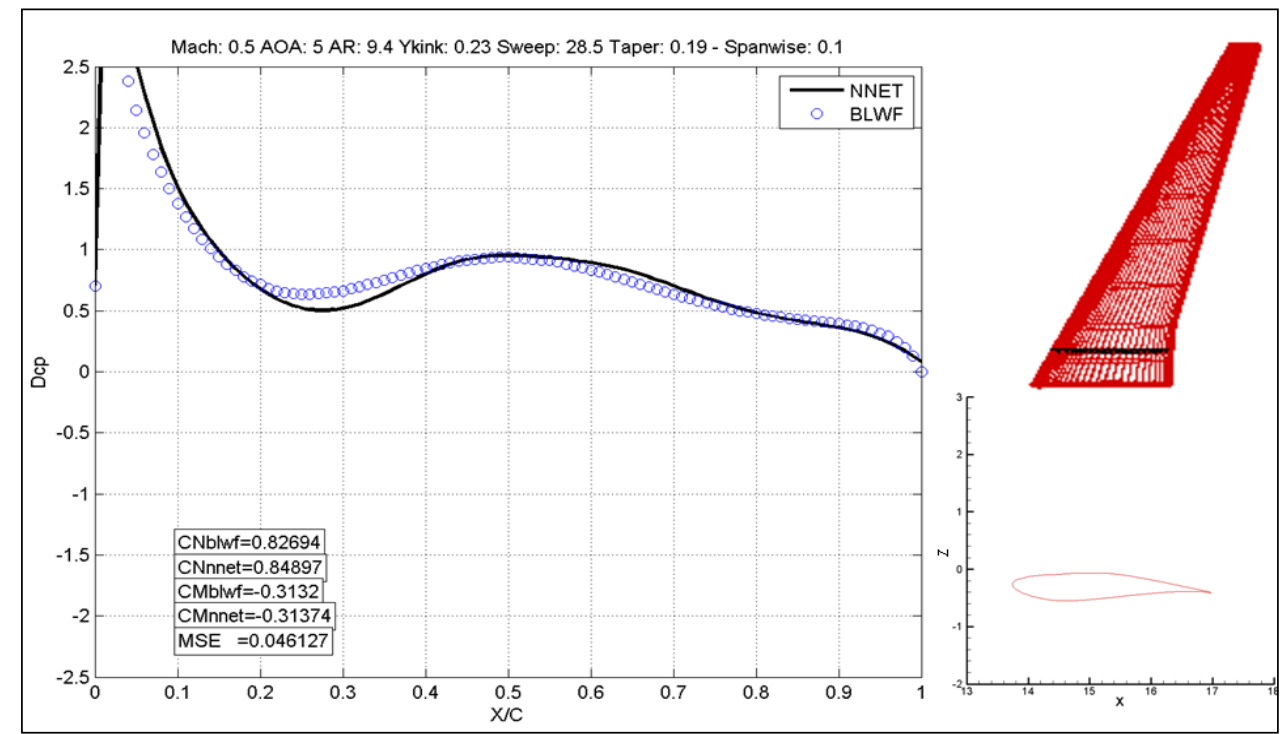

(a)

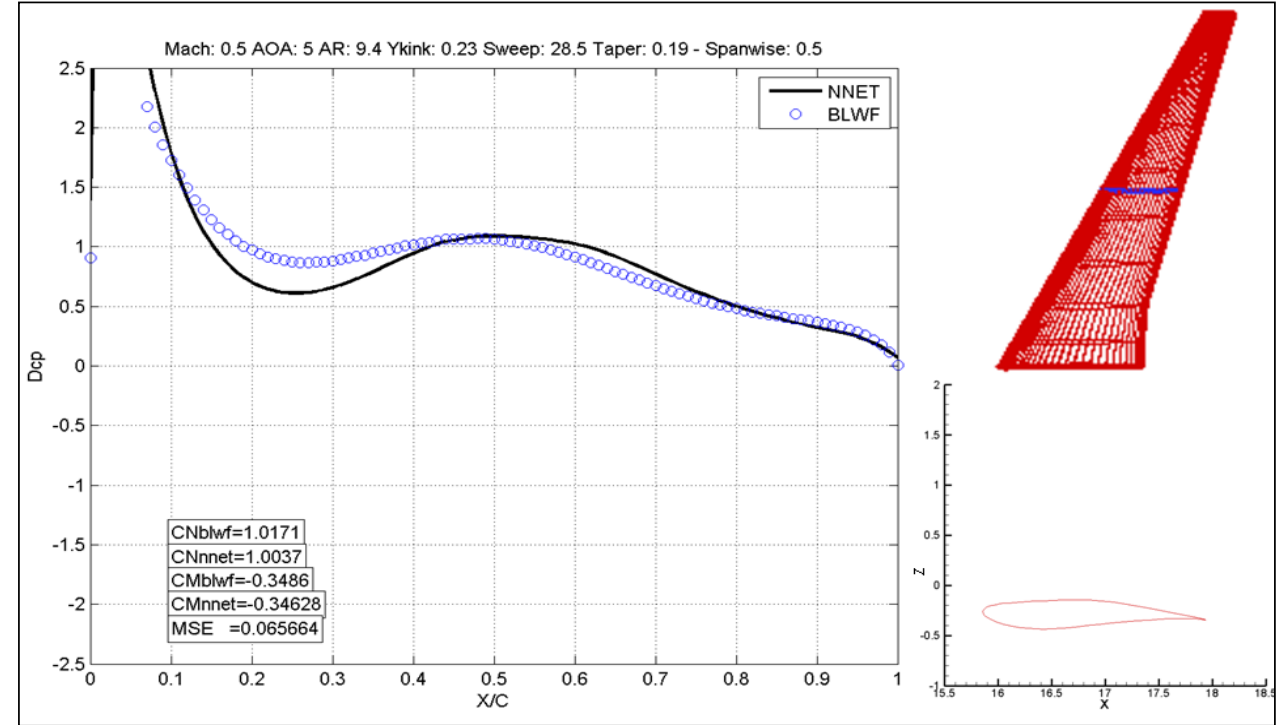

(b)

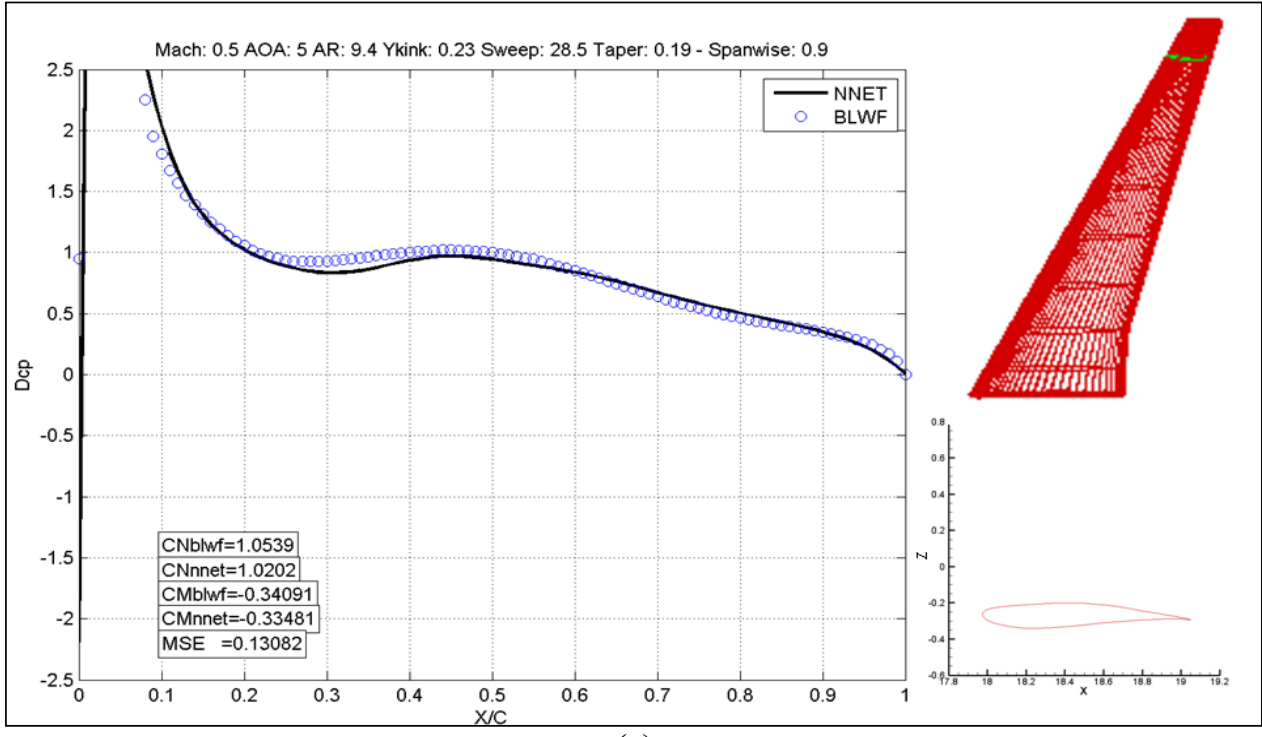

(c)

FIGURA 64: ESCOAMENTO SUBSONICO VALIDAÇÃO INDIVIDUO 5: (A) ESTAÇÃO NA RAIZ (B) ESTAÇÃO NO MEIO DA ASA (C) ESTAÇÃO NA PONTA DA ASA. 


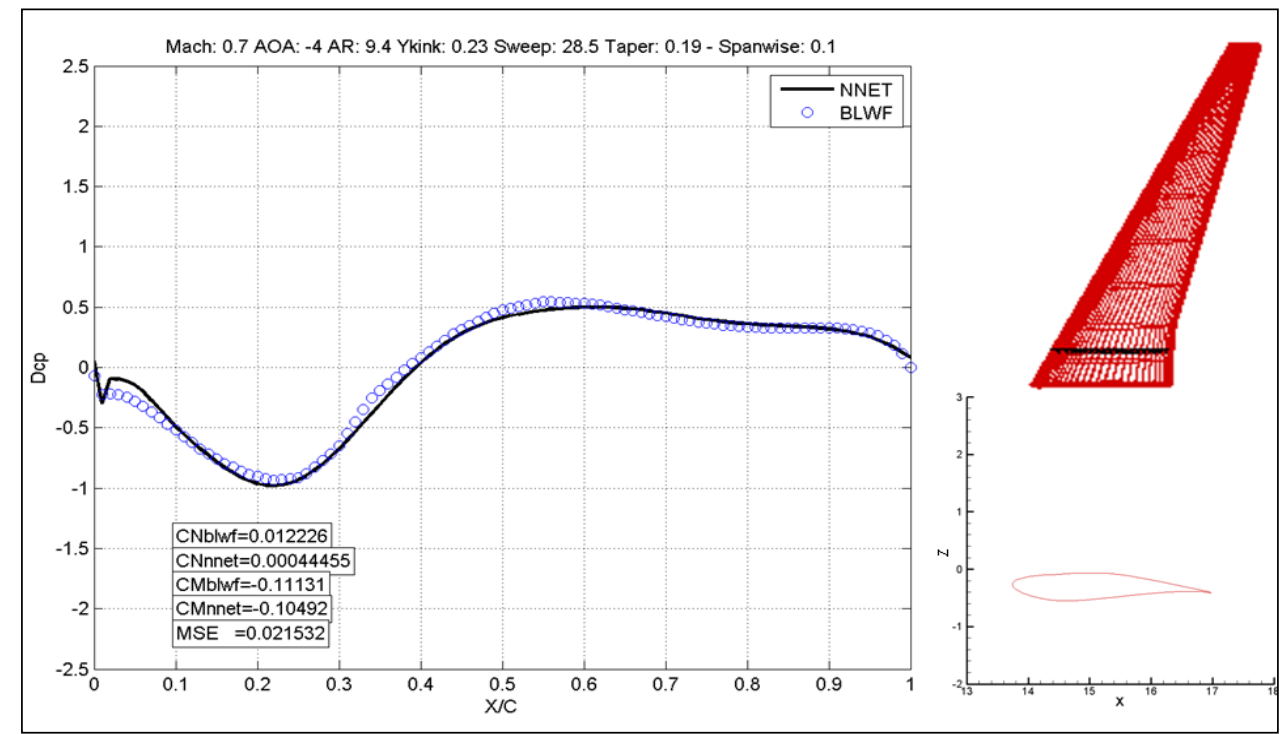

(a)

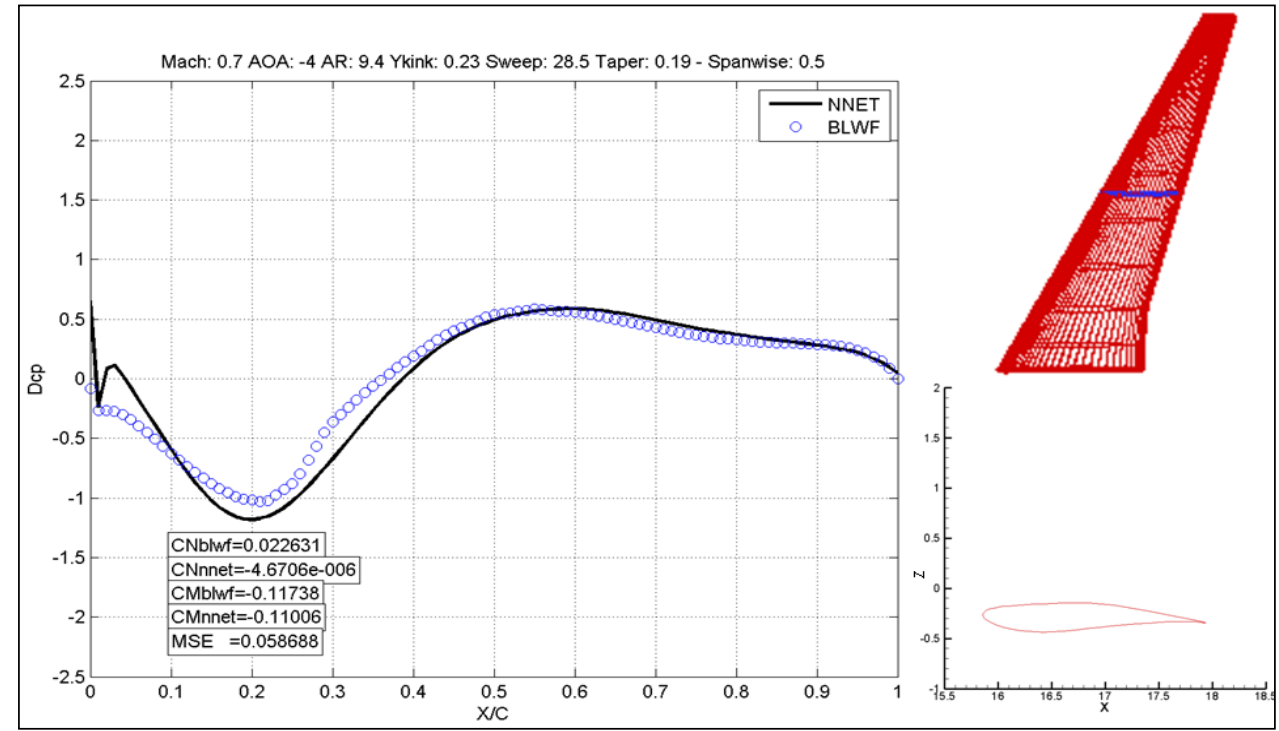

(b)

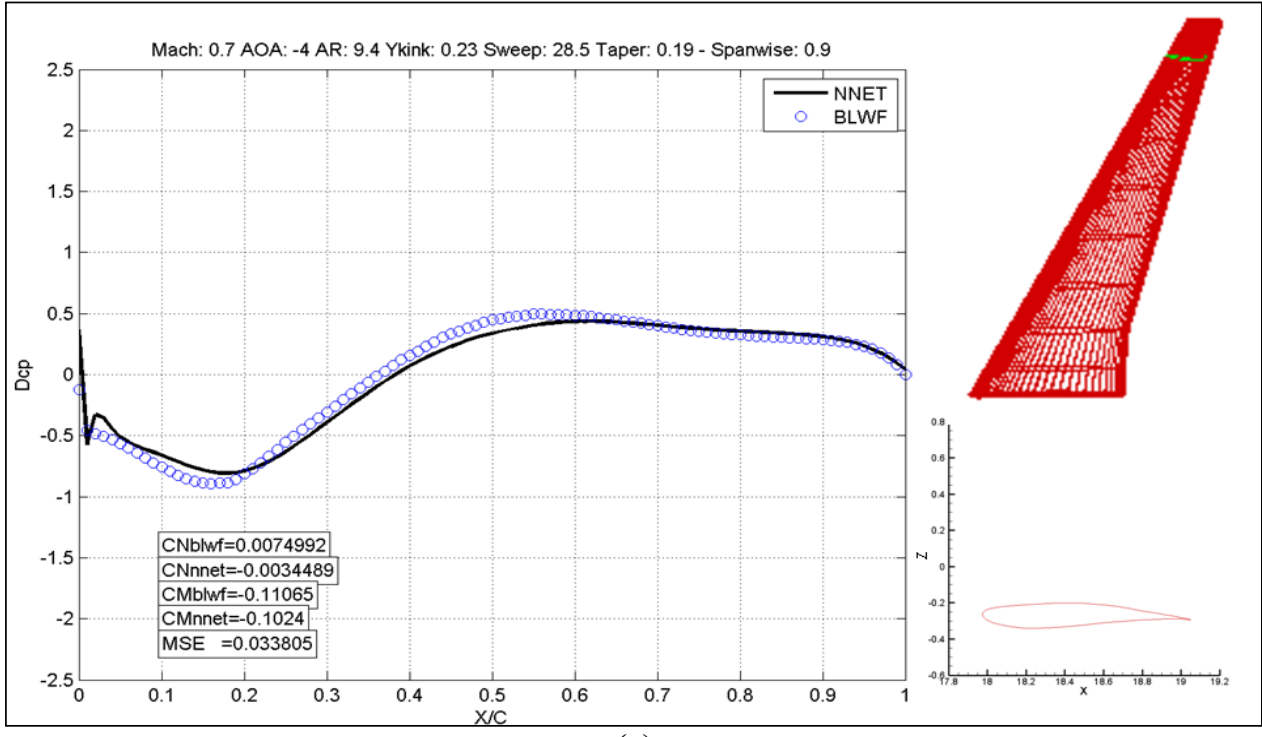

(c)

FIGURA 65: ESCOAMENTO SUBSONICO VALIDAÇÃO INDIVIDUO 5: (A) ESTAÇÃO NA RAIZ (B) ESTAÇÃO NO MEIO DA ASA (C) ESTAÇÃO NA PONTA DA ASA. 


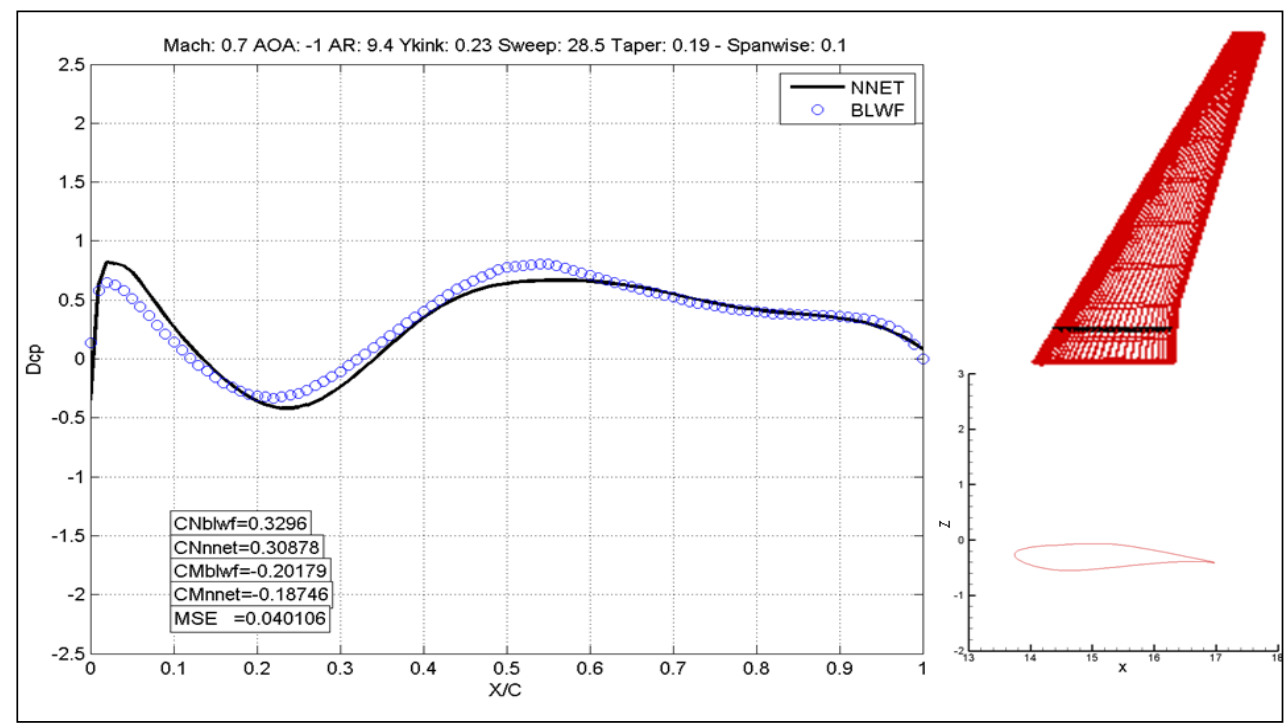

(a)

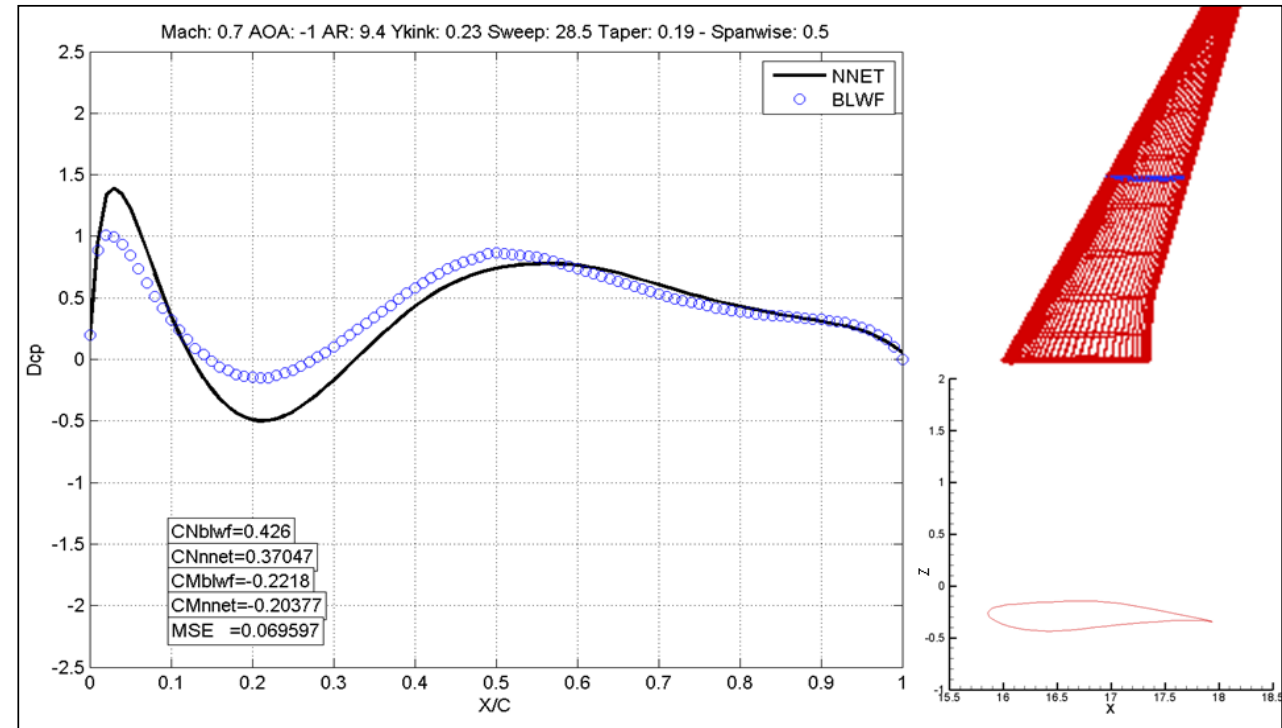

(b)

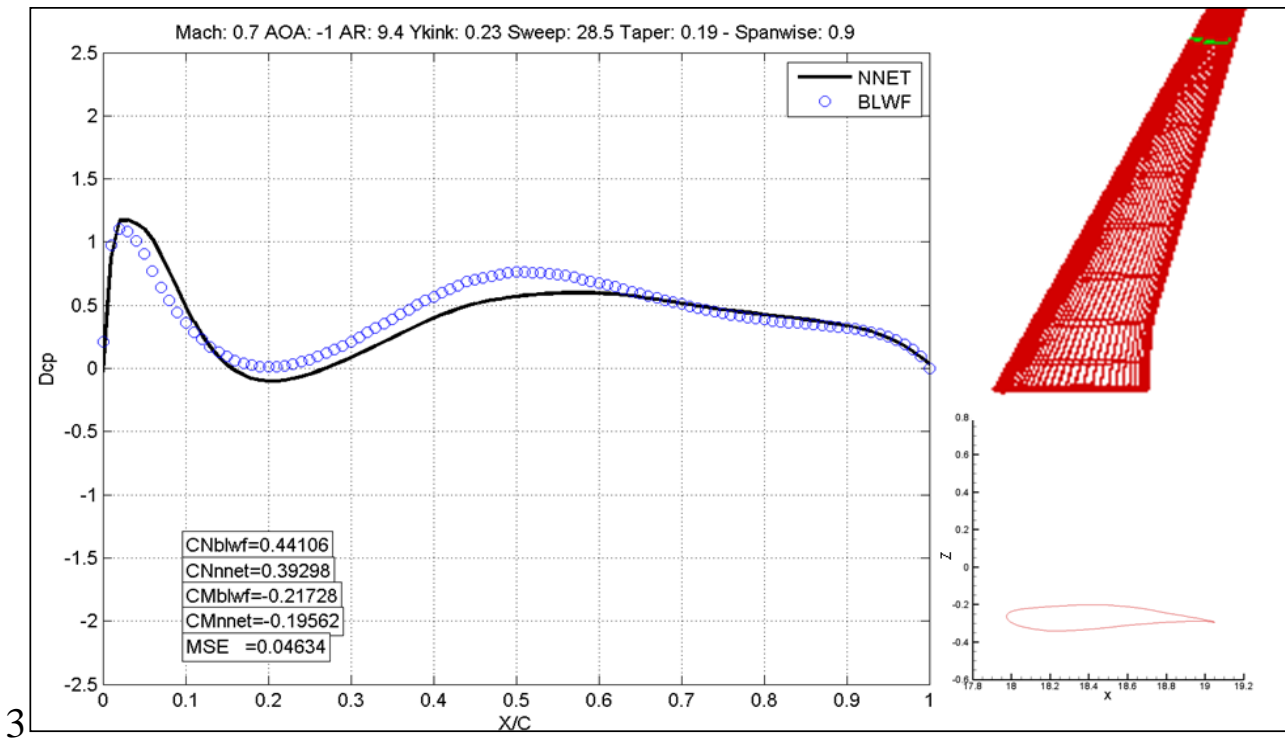

(c)

FIGURA 66: ESCOAMENTO SUBSONICO VALIDAÇÃO INDIVIDUO 5: (A) ESTAÇÃO NA RAIZ (B) ESTAÇÃO NO MEIO DA ASA (C) ESTAÇÃO NA PONTA DA ASA. 


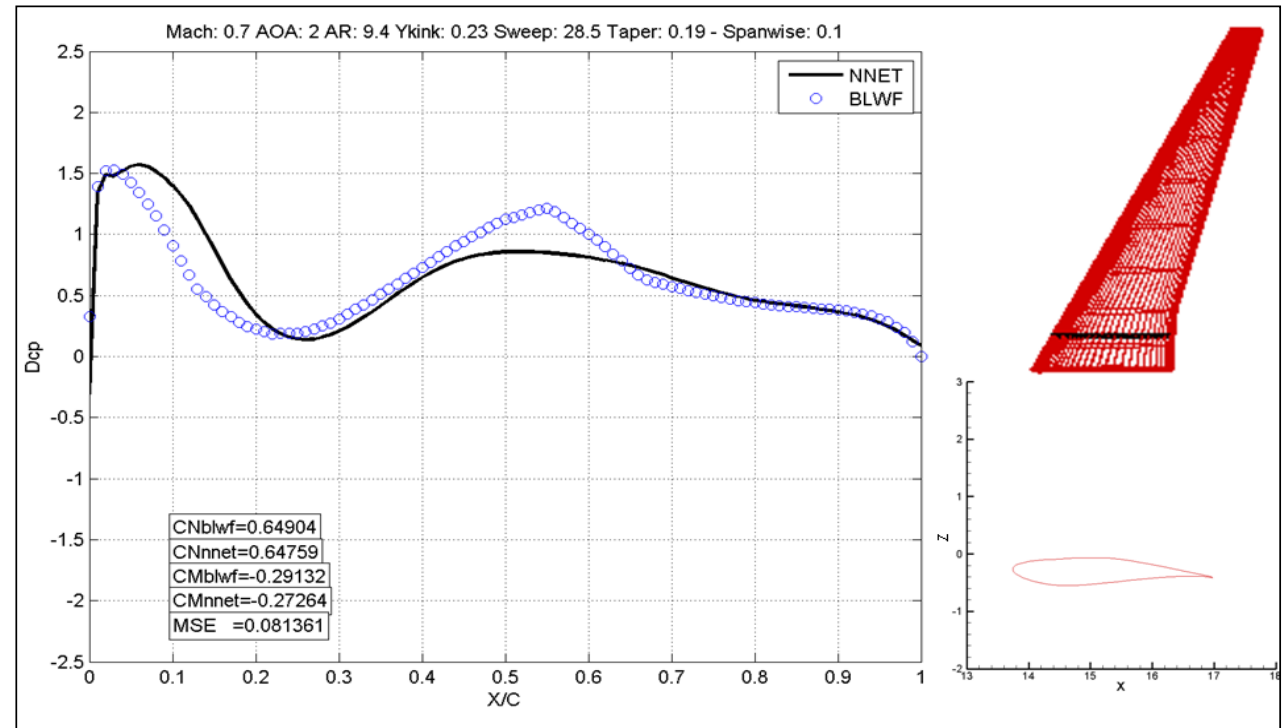

(a)

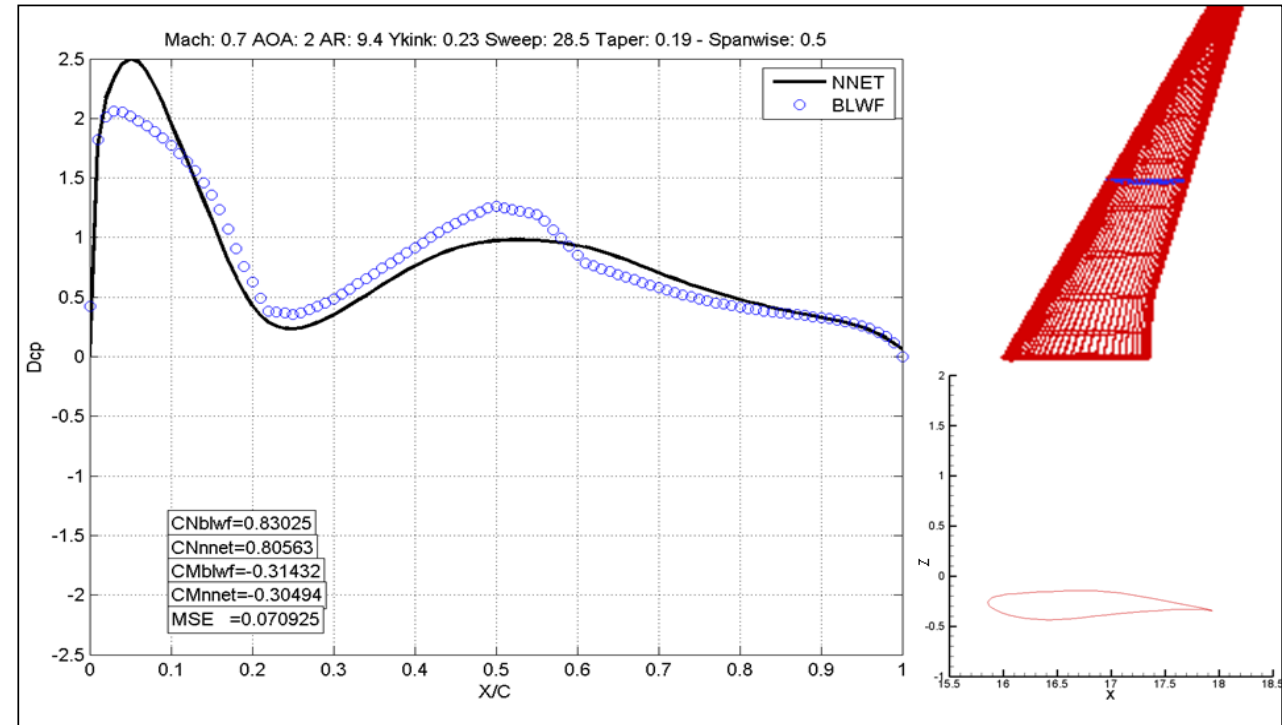

(b)

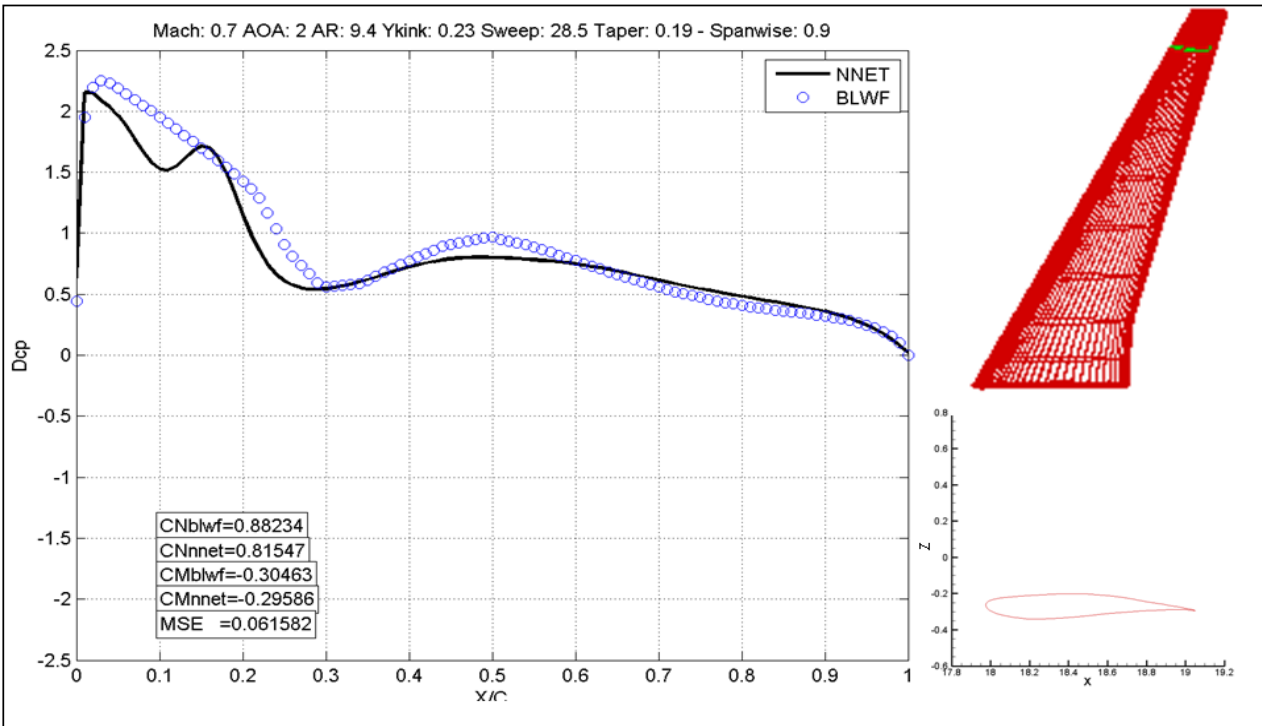

(c)

FIGURA 67: ESCOAMENTO SUBSONICO VALIDAÇÃO INDIVIDUO 5: (A) ESTAÇÃO NA RAIZ (B) ESTAÇÃO NO MEIO DA ASA (C) ESTAÇÃO NA PONTA DA ASA.. 


\subsubsection{REDE TRANSÔNICA}

Assim como nos passos anteriores, uma nova rede neural foi implementada considerando as variáveis de perfil, porém agora estendendo o limite de Mach de 0.70 a 0.82 para a faixa transônica. Foram utilizadas as mesmas variáveis e considerações feitas para a rede anterior, totalizando mais uma vez em 38 variáveis.

As modificações feitas nos limites das variáveis com relação à rede anterior restringiram-se ao número de Mach e ao range de ângulo de ataque, o qual passou de -5 a 5 para -4 a 4 graus.

Os limites aplicados para as variáveis da rede transônica de perfil encontramse na Tabela 12.

TABELA 12: LIMITES DE VARIÁVEIS PARA A REDE NEURAL TRANSONICA DE PERFIL

\begin{tabular}{|c|c|c|c|c|}
\hline $\begin{array}{l}\text { Código da } \\
\text { variável }\end{array}$ & Simbolo & Variável & $\begin{array}{l}\text { Limite } \\
\text { inferior }\end{array}$ & $\begin{array}{l}\text { Limite } \\
\text { superior }\end{array}$ \\
\hline $\mathrm{a}$ & $\mathrm{M}$ & Número de Mach & 0.70 & 0.82 \\
\hline $\mathrm{b}$ & $\alpha$ & Ângulo de ataque & $-4^{0}$ & $4^{\circ}$ \\
\hline C & AR & Alongamento & 6 & 10 \\
\hline d & Sweep & Enflexamento no bordo de ataque & $15^{\circ}$ & $30^{\circ}$ \\
\hline e & Taper & Afilamento & 0.10 & 0.40 \\
\hline$f$ & Yk & $\begin{array}{c}\text { Posição da quebra (ao longo da semi- } \\
\text { envergadura) }\end{array}$ & 0.20 & 0.40 \\
\hline g & Ycp & $\begin{array}{l}\text { Posição na envergadura (mapeamento de } \\
\text { pressão) }\end{array}$ & 0.00 & 1.00 \\
\hline $\mathrm{h}$ & Xcp & Posição na corda (mapeamento de pressão) & 0.00 & 1.00 \\
\hline i & Dih & Diedro & $\begin{array}{c}\text { Não } \\
\text { considerado }\end{array}$ & $\begin{array}{c}\text { Não } \\
\text { considerado }\end{array}$ \\
\hline j & xtle & $\begin{array}{l}\text { Ponto de controle para a espessura no bordo de } \\
\text { ataque (valor fixo) }\end{array}$ & 0.05 & 0.05 \\
\hline k & ytle & $\begin{array}{l}\text { Espessura no bordo de ataque na raiz, quebra e } \\
\text { ponta }\end{array}$ & 0.01 & 0.06 \\
\hline I & $x t t h$ & $\begin{array}{l}\text { Posição de máxima espessura na raiz, quebra e } \\
\text { ponta }\end{array}$ & 0.25 & 0.40 \\
\hline $\mathrm{m}$ & ytth & Máxima espessura na raiz & 0.10 & 0.20 \\
\hline $\mathrm{m}$ & ytth & Máxima espessura na quebra & 0.0 & 1.0 \\
\hline $\mathrm{m}$ & ytth & Máxima espessura na ponta & 0.0 & 1.0 \\
\hline $\mathrm{n}$ & atte & $\begin{array}{l}\text { Ângulo da linha de espessura no bordo de fuga } \\
\text { na raiz, quebra e ponta }\end{array}$ & $-20^{\circ}$ & $0^{\circ}$ \\
\hline 0 & acle & $\begin{array}{l}\text { Ângulo da linha de arqueamento no bordo de } \\
\text { ataque na raiz, quebra e ponta }\end{array}$ & $-8^{\circ}$ & $10^{\circ}$ \\
\hline
\end{tabular}


TABELA 13: LIMITES DE VARIÁVEIS PARA A REDE NEURAL TRANSONICA DE PERFIL (CONTINUAÇÃO)

\begin{tabular}{|c|c|c|c|c|}
\hline $\begin{array}{l}\text { Código da } \\
\text { variável }\end{array}$ & Simbolo & Variável & $\begin{array}{l}\text { Limite } \\
\text { inferior }\end{array}$ & $\begin{array}{l}\text { Limite } \\
\text { superior }\end{array}$ \\
\hline $\mathrm{p}$ & ycth & $\begin{array}{c}\text { Arqueamento no ponto de máxima espessura na } \\
\text { raiz, quebra e ponta }\end{array}$ & -0.01 & 0.03 \\
\hline q & $\mathrm{xcmc}$ & $\begin{array}{c}\text { Posição do máximo arqueamento na raiz, quebra e } \\
\text { ponta }\end{array}$ & 0.60 & 0.80 \\
\hline r & $y c m c$ & Máximo arqueamento na raiz, quebra e ponta & 0.00 & 0.02 \\
\hline S & acte & $\begin{array}{c}\text { Ângulo da linha de arqueamento no bordo de fuga } \\
\text { na raiz, quebra e ponta }\end{array}$ & $-15^{\circ}$ & $0^{\circ}$ \\
\hline $\mathrm{t}$ & ytte & Espessura do bordo de fuga (valor fixo) & 0.003 & 0.003 \\
\hline $\mathrm{u}$ & ycte & Arqueamento no bordo de fuga (valor fixo) & 0.00 & 0.00 \\
\hline v & epsil & Torção geométrica do perfil na raiz & $-3^{0}$ & $5^{\circ}$ \\
\hline v & epsil & Torção geométrica do perfil na quebra & $0^{\circ}$ & $1^{0}$ \\
\hline v & epsil & Torção geométrica do perfil na ponta & $0^{\circ}$ & $2^{0}$ \\
\hline
\end{tabular}

Para esta rede neural, novamente, um estudo semelhante ao mostrado na Seção 3.2, os melhores resultados foram obtidos com um conjunto de treinamento de 141.800 indivíduos. Este conjunto foi construído com base em um DOE (gerado via LHSDesign do Matlab) com 300.000 indivíduos. A pequena taxa de aproveitamento deve-se a dois motivos básicos: o primeiro é o fato de que, para números de Mach elevados, é freqüente ocorrer um descolamento da camada limite, o que dificulta a convergência do CFD; a segunda causa reside no fato dos três perfis desta rede serem variáveis, o que possivelmente acarreta na ocorrência de certos indivíduos espúrios os quais geram instabilidades no CFD. Os limites das variáveis de perfil foram adotados, juntamente com algumas regras, na tentativa de controlar a criação destes indivíduos. No entanto, esses parâmetros não podem ser enrijecidos sobremaneira sob o risco de perder a generalidade na rede.

Novamente optou-se pela rede do tipo perceptron de múltiplas camadas, com correção dos pesos por retropropagação usando o algoritmo de LevenbergMarquardt. Do mesmo modo que na Seção 3.2, um estudo foi feito para a determinação do melhor número de indivíduos. A arquitetura escolhida foi a de duas 
camadas ocultas, cada qual com 20 neurônios, cada um deles usando a função tangente hiperbólica como função de ativação, e uma camada de saída com um neurônio usando somente uma função linear como função de ativação.

Assim como na rede subsônica, o processo de treinamento foi feito até se completar 1000 épocas. Novamente o erro médio quadrático não foi usado como condição de parada para este treinamento devido à falta de sensibilidade com relação ao erro para esta rede já que agora estamos com 38 variáveis. Novamente vale lembrar que deve-se cuidar para que haja o super-treinamento da rede, o que acarreta a perda de generalidade.

Para a validação foram utilizados os mesmos indivíduos usados para a validação da rede subsônica, porém os limites das variáveis número de Mach e ângulo de ataque tiveram que ser reajustados como mostra a Tabela 13.

TABELA 14: CONDIÇÕES DE VOO ESCOLHIDAS PARA O CONJUNTO DE VALIDAÇÃO

\begin{tabular}{|c|c|c|c|}
\hline Variável & Limite inferior & Limite superior & Incremento \\
\hline Número de Mach & 0.70 & 0.82 & 0.012 \\
\hline Ângulo de ataque & $-4.0^{\circ}$ & $4.0^{\circ}$ & $0.8^{\circ}$ \\
\hline
\end{tabular}

O conjunto de validação a ser submetido tanto à rede neural quanto ao CFD conta novamente com 726 ( 6 x 12) indivíduos. Fez-se tal escolha de limites de alfa e Mach de modo a possibilitar a avaliação da resposta da rede em todas as condições de alfa e Mach treinados. Importante descatar que de 726 rodadas apenas 302 obtiveram convergência no CFD, proporcionando uma comparação com o resultado da rede. 


\subsubsection{Resultados da Rede Neural de Perfis Variáveis - Transônica}

As Figuras 68 a 89 mostram os resultados da validação feita para a rede transônica com perfis variáveis para um indivíduo. Nestas figuras, os circulos azuis apresentam o resultado fornecido pela rede neural e a linha cheia o resultado obtido diretamente pelo CFD para a condição desejada. Nestas figuras também é mostrado o resultado em termos de coeficientes de força normal $\left(C_{N}\right)$ e de momento de arfagem $\left(\mathrm{C}_{\mathrm{M}}\right)$ para a rede neural e para o resultado do CFD.

As figuras mostram uma correlação razoável entre os resultados obtidos via CFD e via rede neural. Percebe-se que a rede neural capturou bem as tendências das distribuições de pressão, porém, novamente os resultados para a rede transônica não foram tão bons quanto os da rede subsônica.

A Tabela 14 mostra uma análise estatística dos coeficientes. Os coeficientes de força e momento também apresentaram valores bastante bons, contudo também inferiores aos obtidos na rede subsônica.

TABELA 15: RESULTADOS PARA REDE TRANSONICA COM PERFIS VARIAVEIS:

\begin{tabular}{|l|l|}
\hline Média dos erros absolutos de CN & 0.0227 \\
\hline Média dos erros absolutos de CM & 0.0108 \\
\hline Média dos erros relativos de CN & 0.1847 \\
\hline Média dos erros relativos de CM & 0.1091 \\
\hline Desvio padrão dos erros relativos de CN & 0.0225 \\
\hline Desvio padrão dos erros relativos de CM & 0.0114 \\
\hline Erro médio quadrático & 0.0673 \\
\hline
\end{tabular}




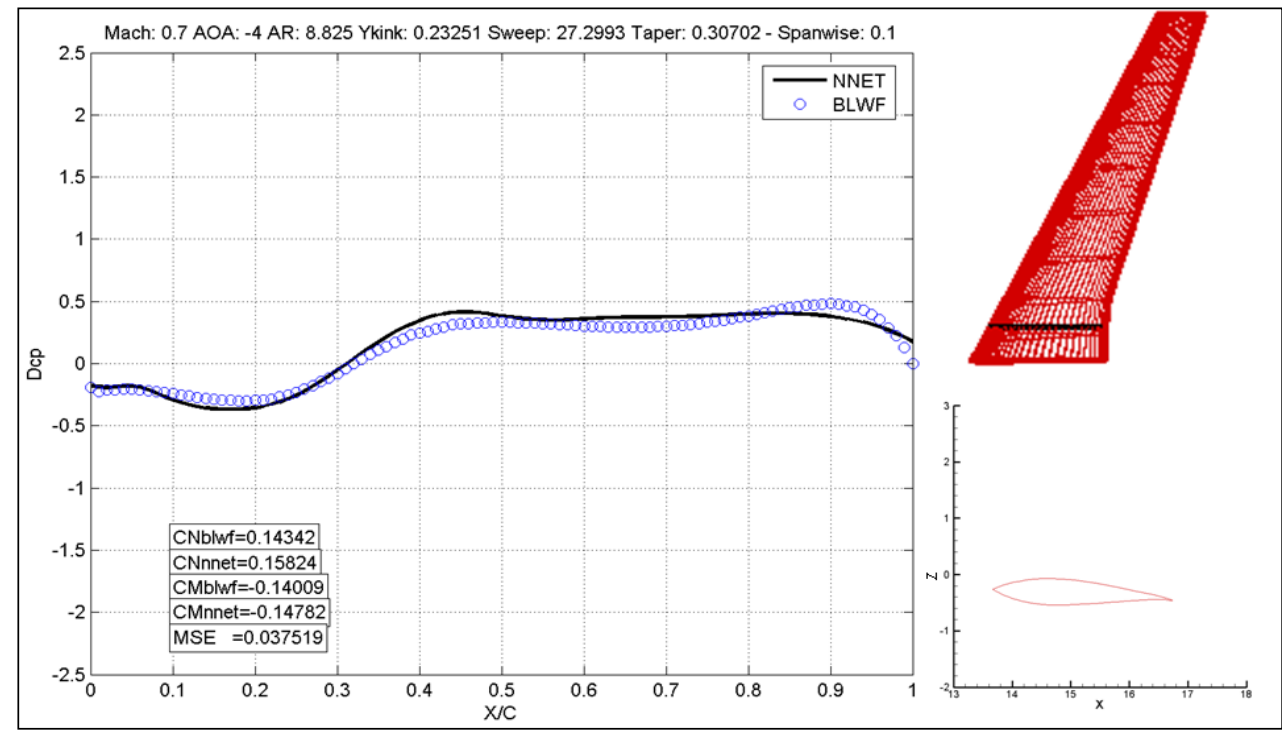

(a)

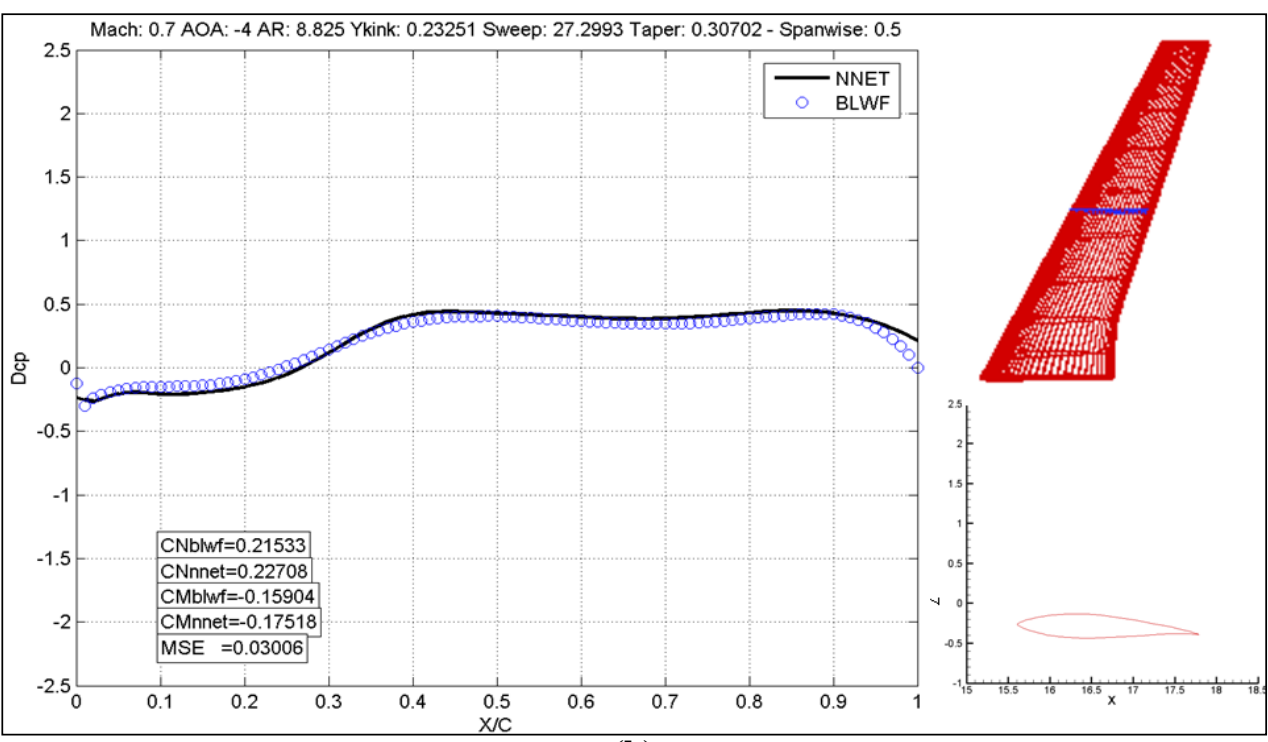

(b)

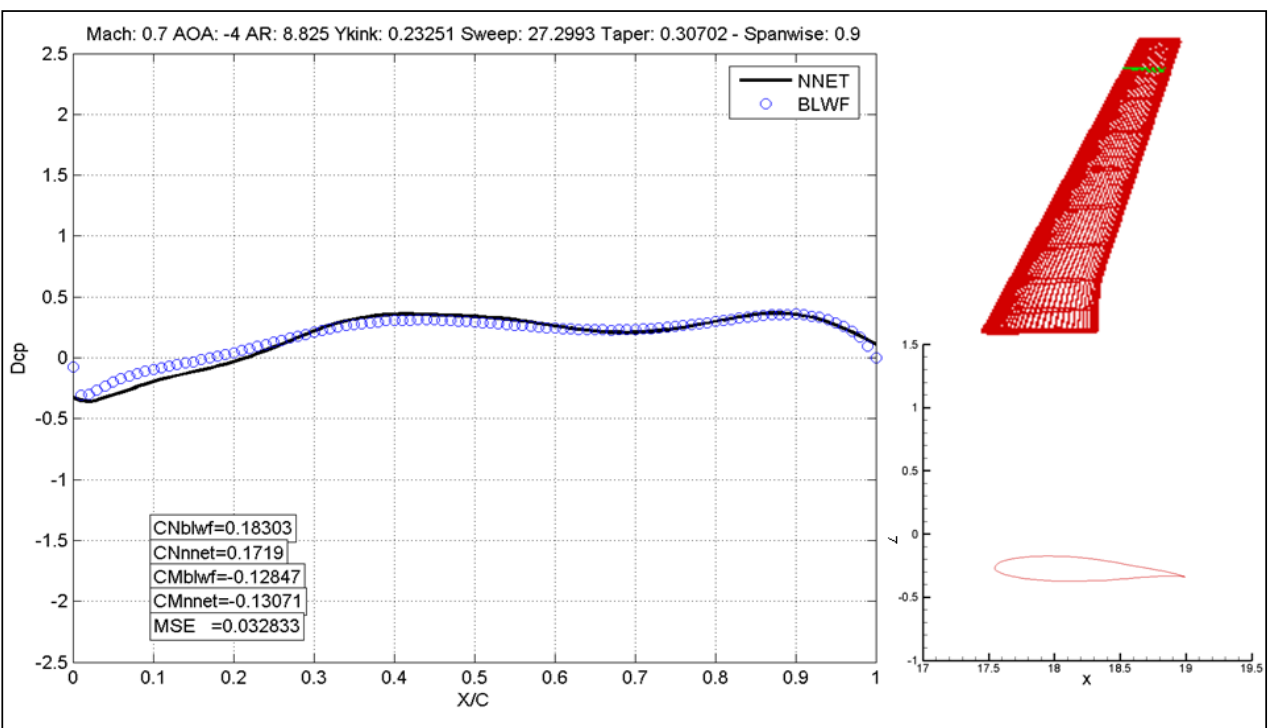

(c)

FIGURA 68: ESCOAMENTO SUBSONICO VALIDAÇÃO INDIVIDUO 1: (A) ESTAÇÃO NA RAIZ (B) ESTAÇÃO NO MEIO DA ASA (C) ESTAÇÃO NA PONTA DA ASA. 


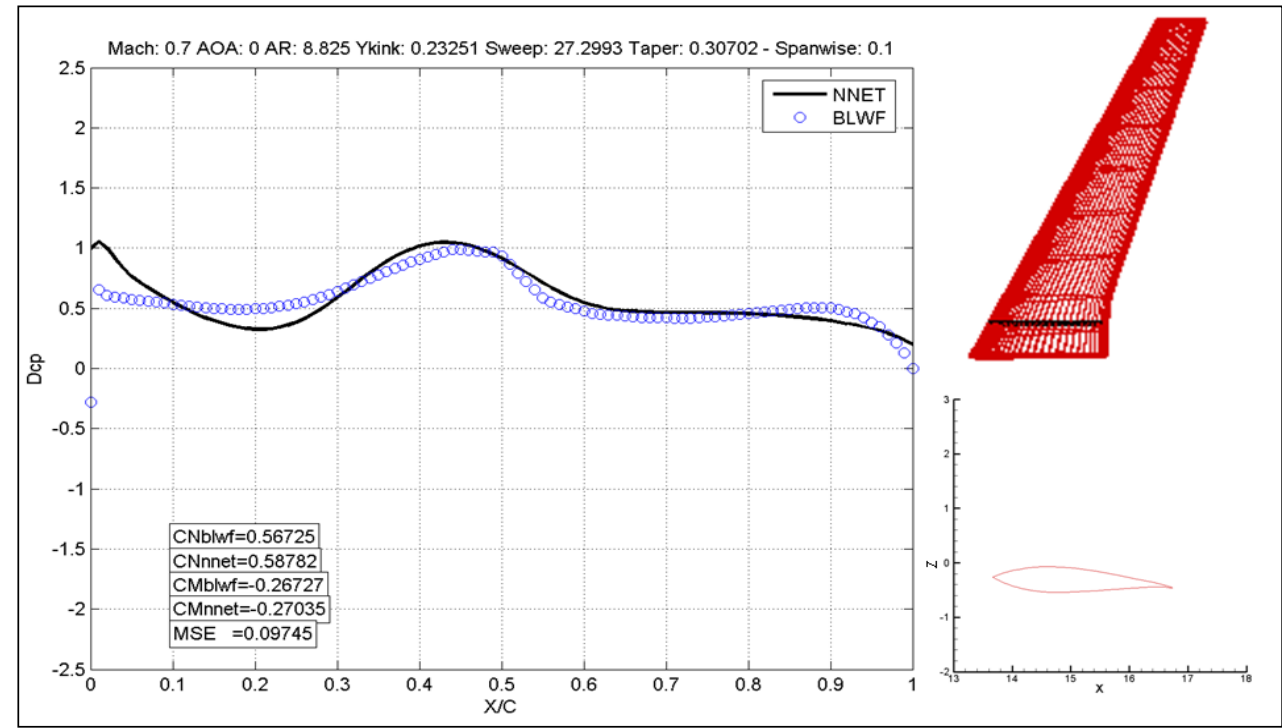

(a)

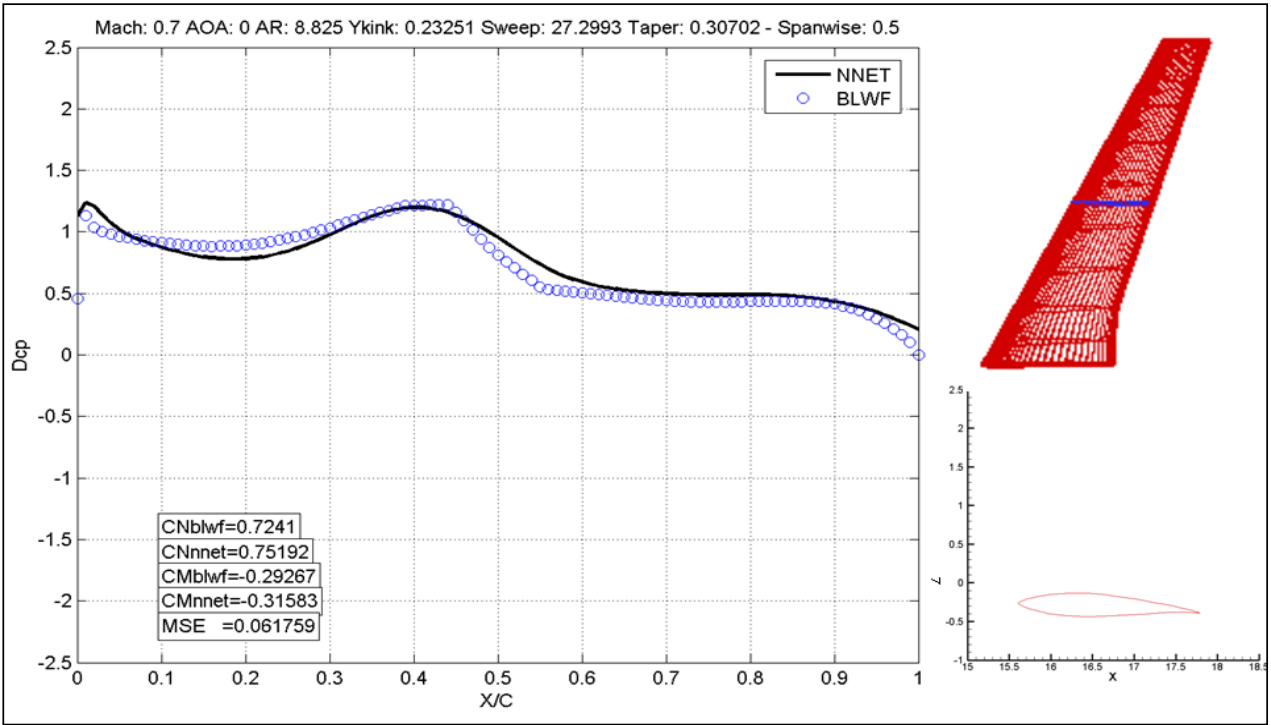

(b)

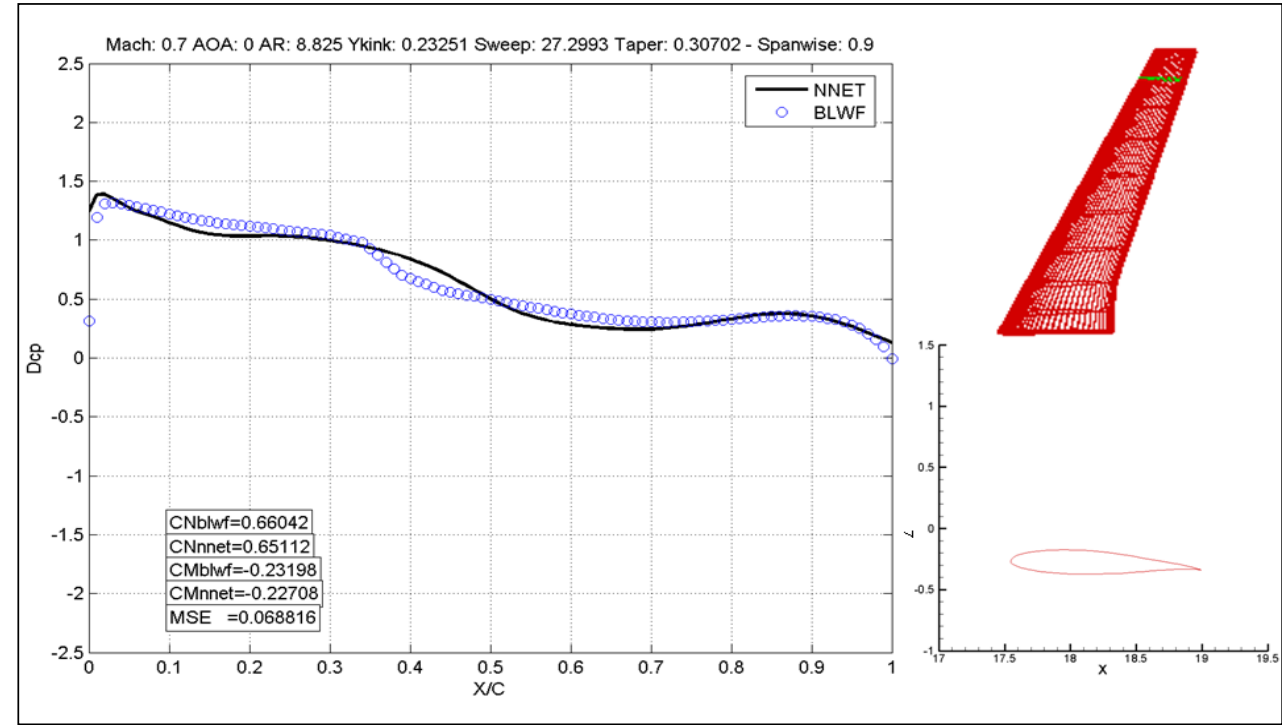

(c)

FIGURA 69: ESCOAMENTO SUBSONICO VALIDAÇÃO INDIVIDUO 1: (A) ESTAÇÃO NA RAIZ (B) ESTAÇÃO NO MEIO DA ASA (C) ESTAÇÃO NA PONTA DA ASA. 


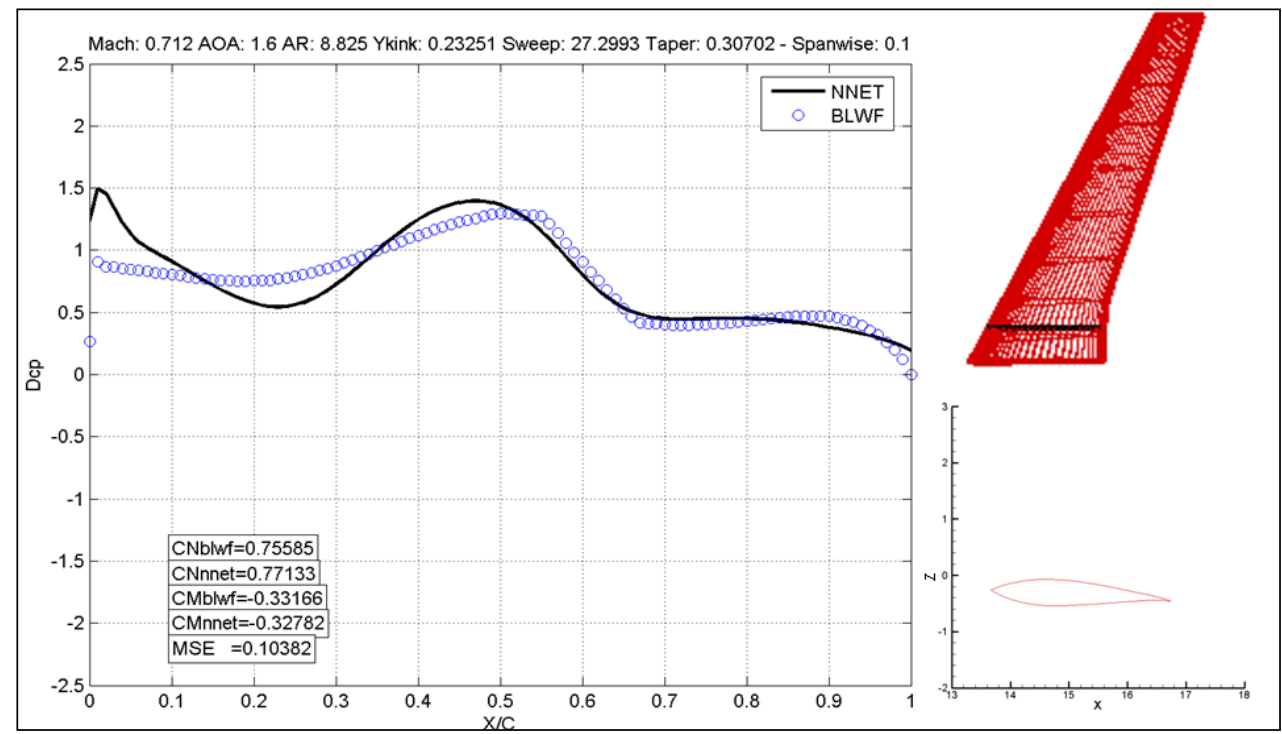

(a)

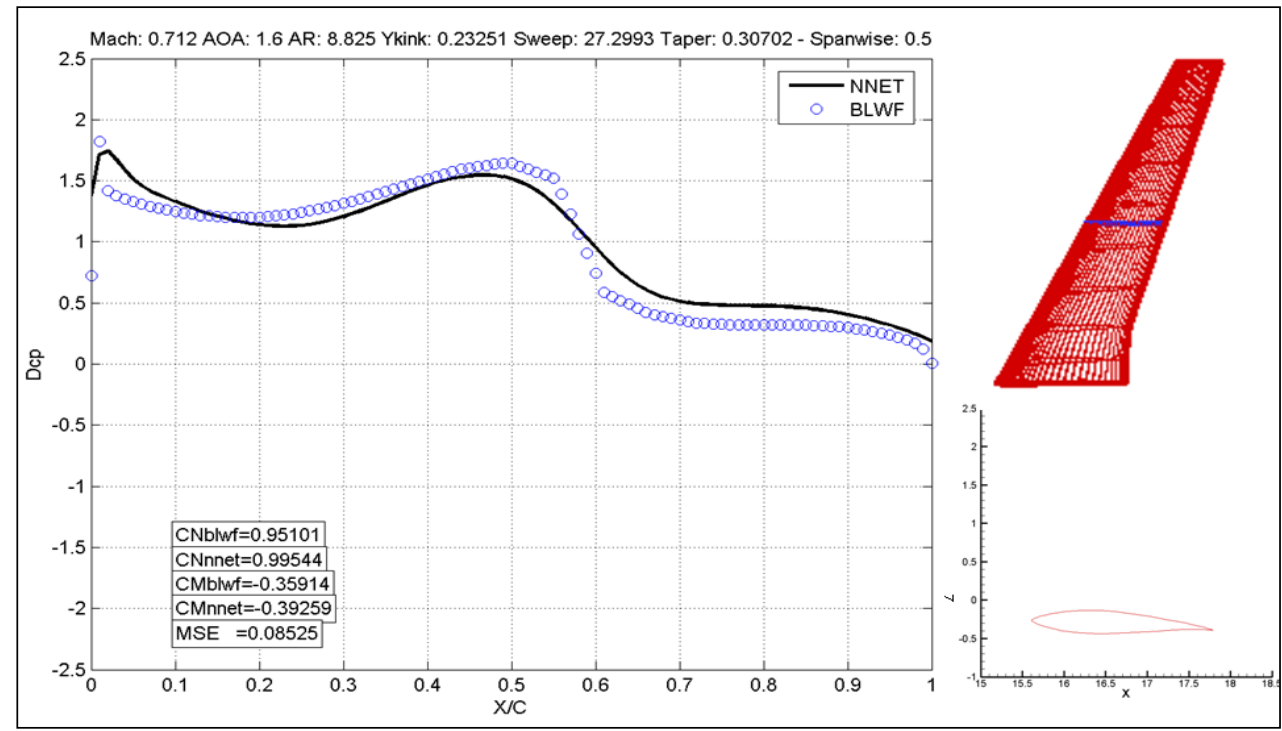

(b)

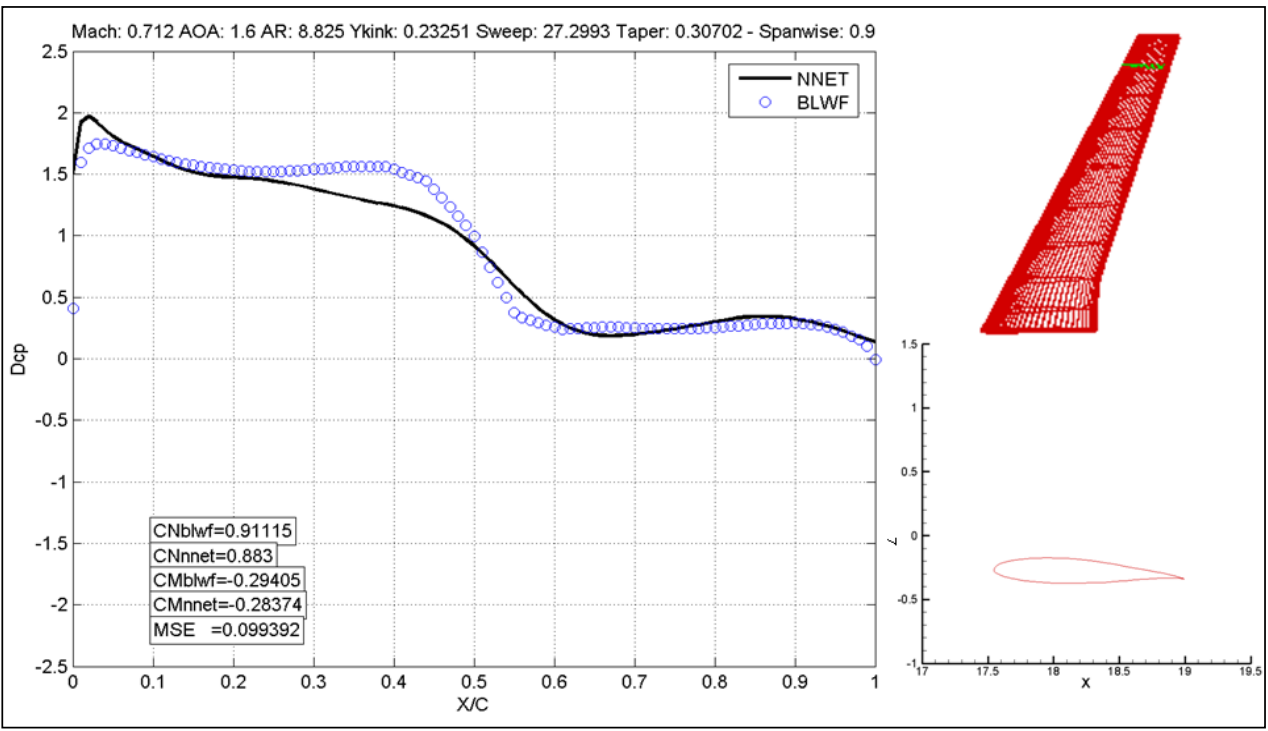

(c)

FIGURA 70: ESCOAMENTO BAIXO TRANSONICO VALIDAÇÃO INDIVIDUO 1: (A) ESTAÇÃO NA RAIZ (B) ESTAÇÃO NO MEIO DA ASA (C) ESTAÇÃO NA PONTA DA ASA 


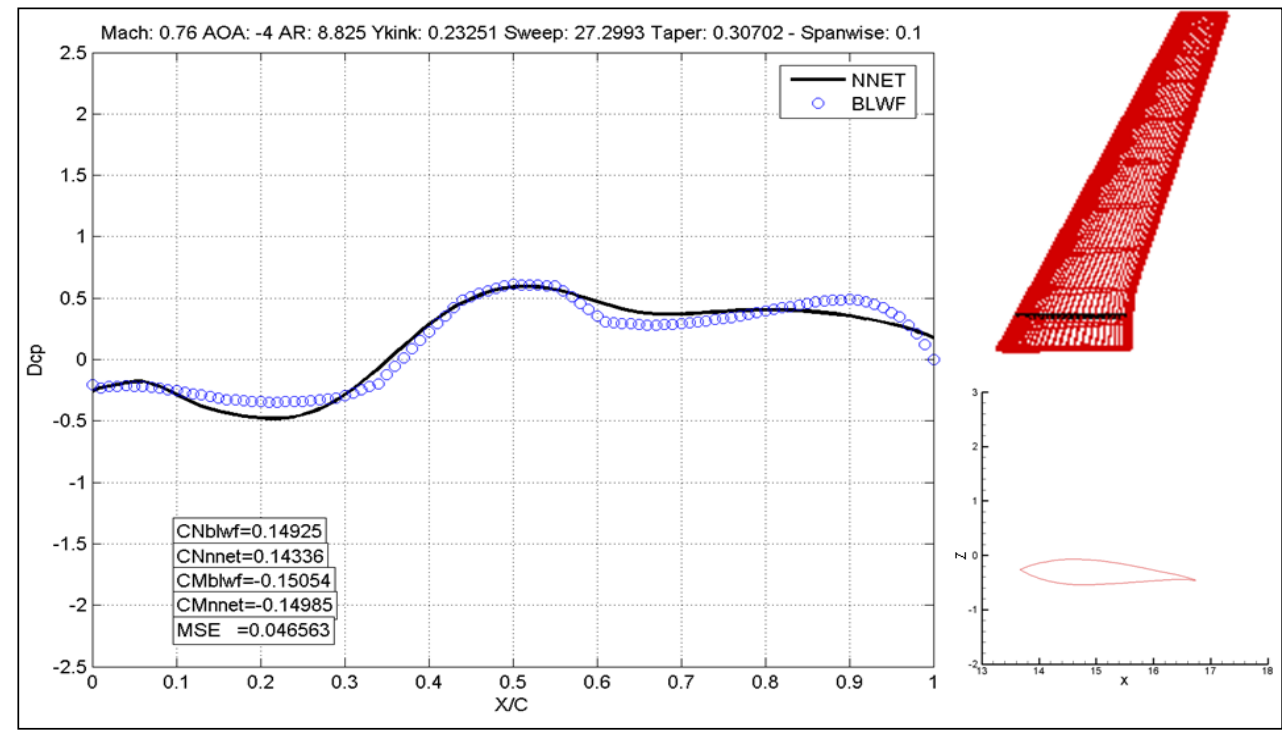

(a)

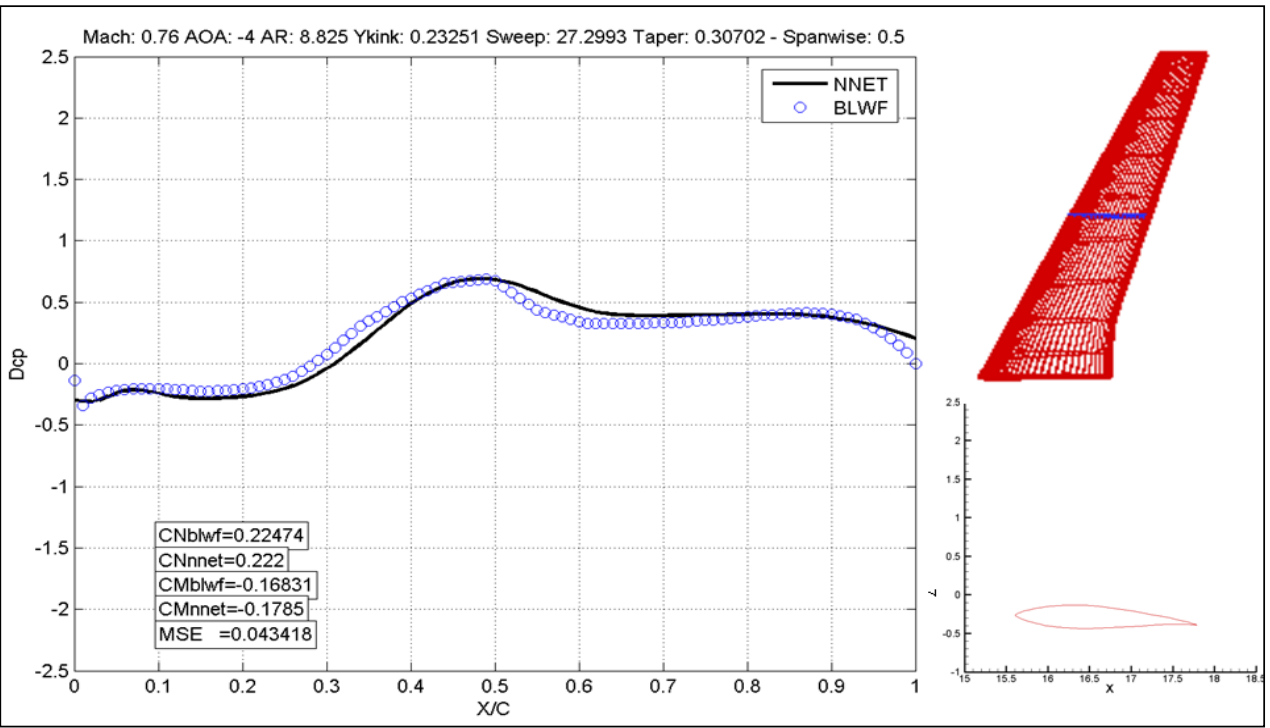

(b)

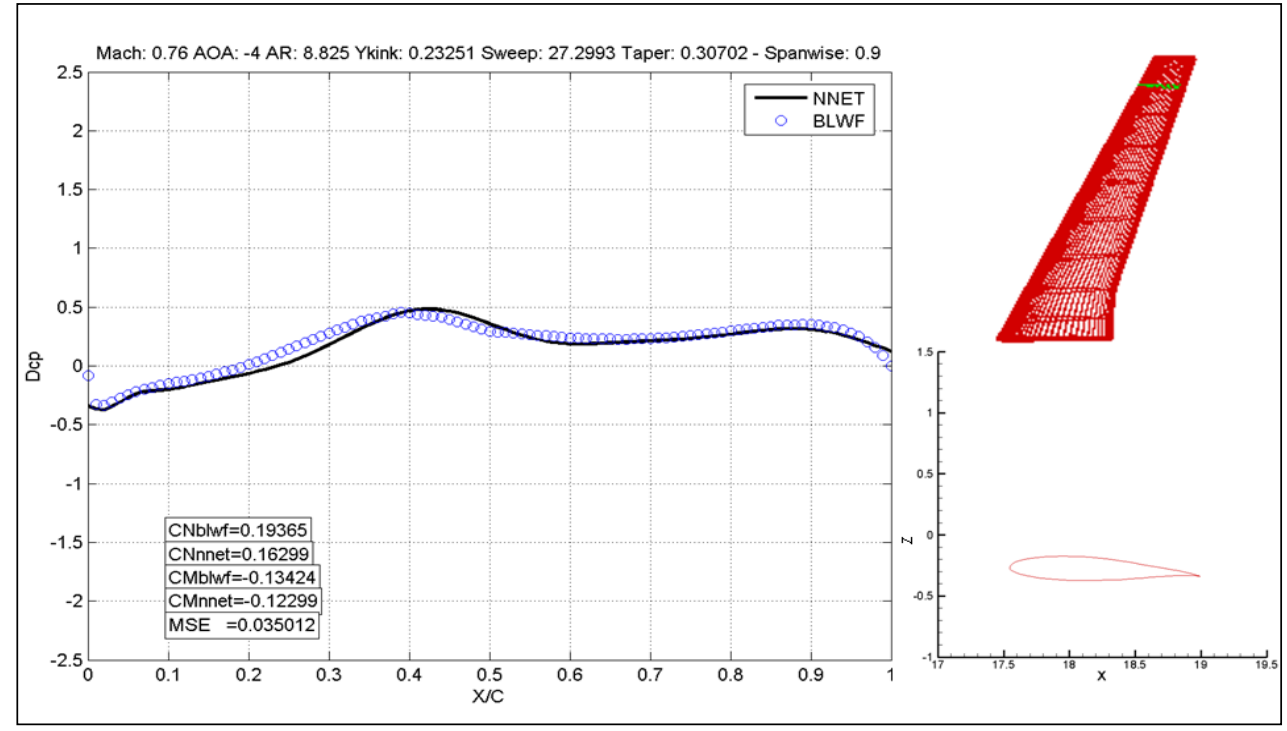

(c)

FIGURA 71: ESCOAMENTO TRANSONICO VALIDAÇÃO INDIVIDUO 1: (A) ESTAÇÃO NA RAIZ (B) ESTAÇÃO NO MEIO DA ASA (C) ESTAÇÃO NA PONTA DA ASA. 


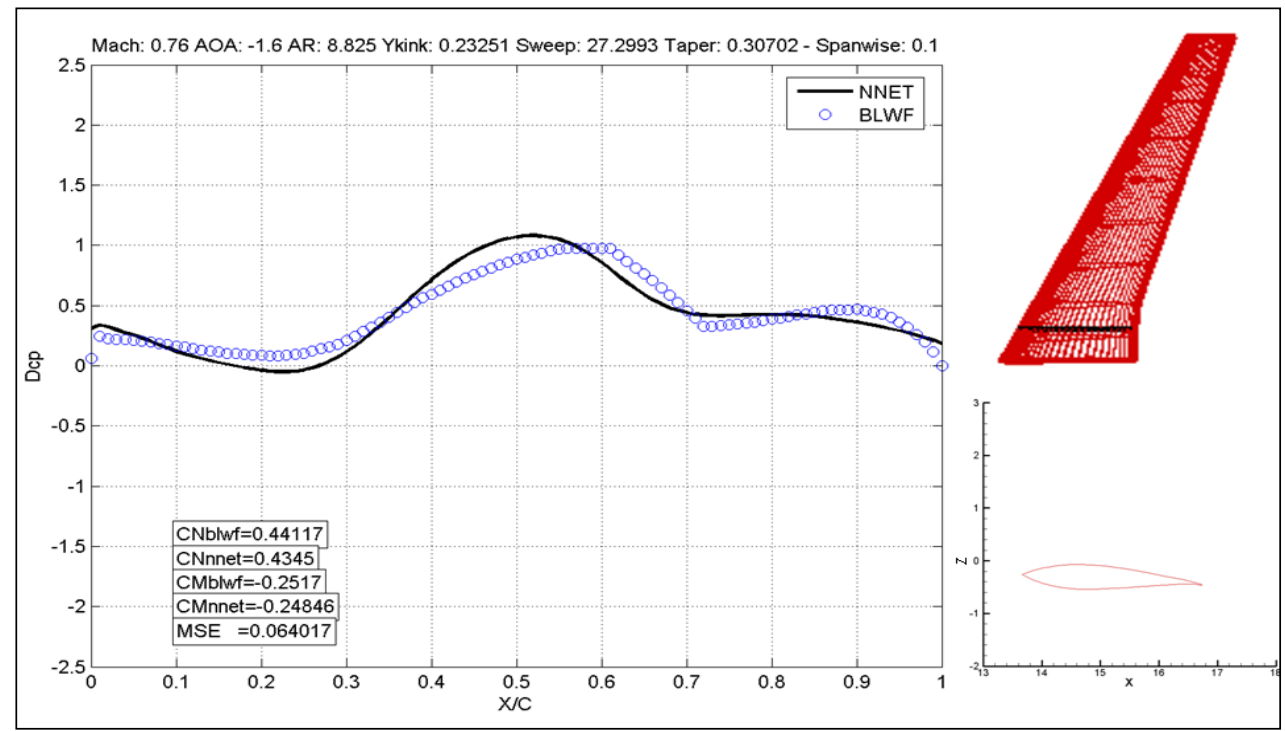

(a)

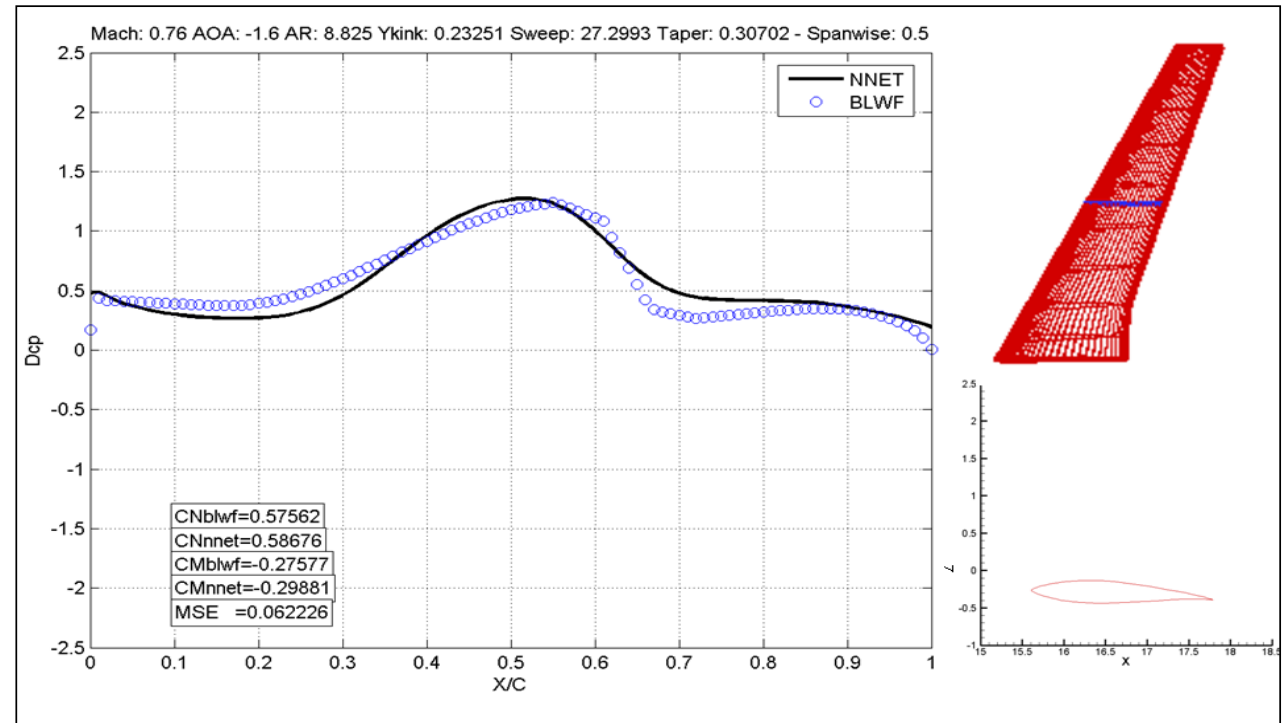

(b)

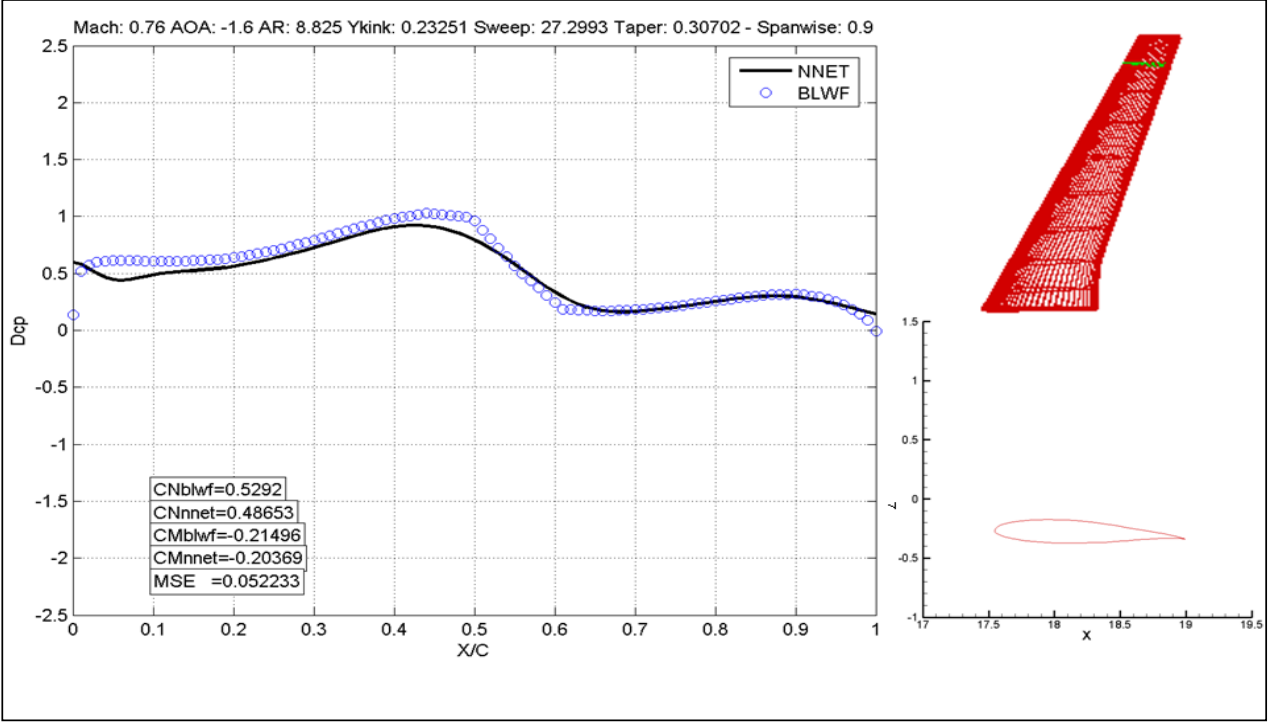

(c)

FIGURA 72: ESCOAMENTO TRANSONICO VALIDAÇÃO INDIVIDUO 1: (A) ESTAÇÃO NA RAIZ (B) ESTAÇÃO NO MEIO DA ASA (C) ESTAÇÃO NA PONTA DA ASA. 


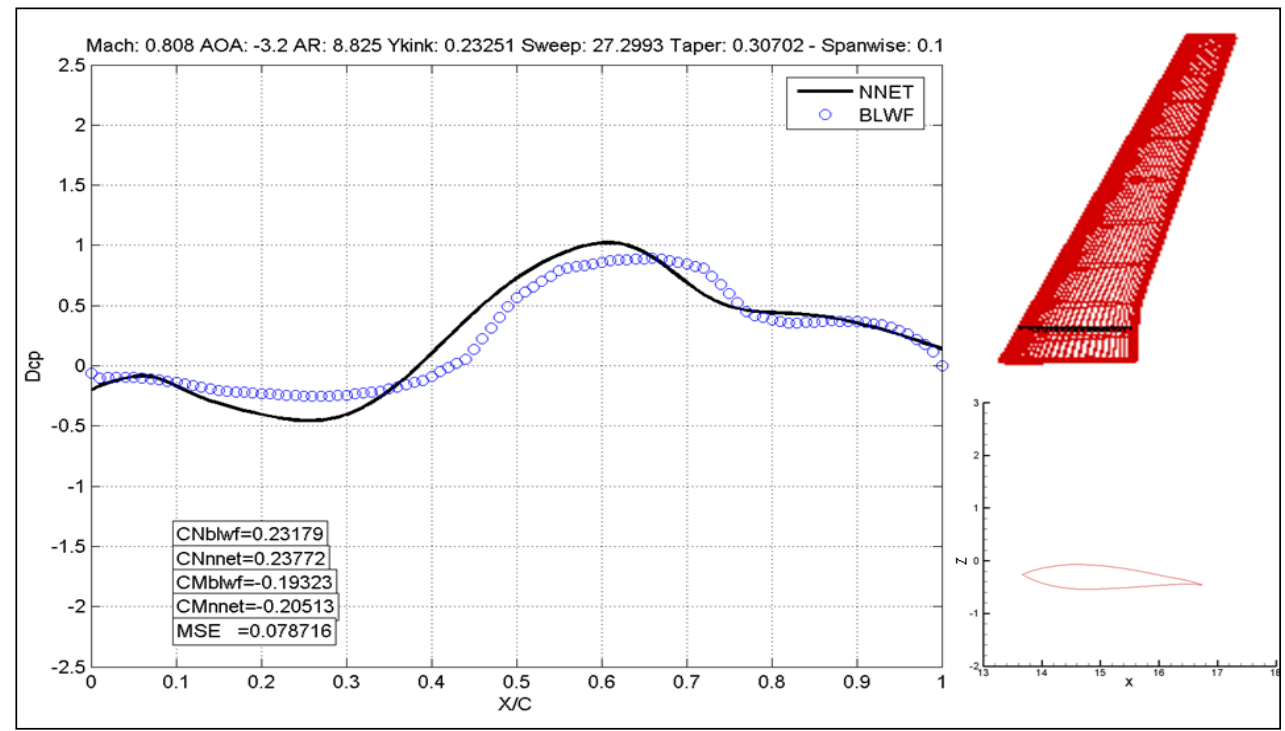

(a)

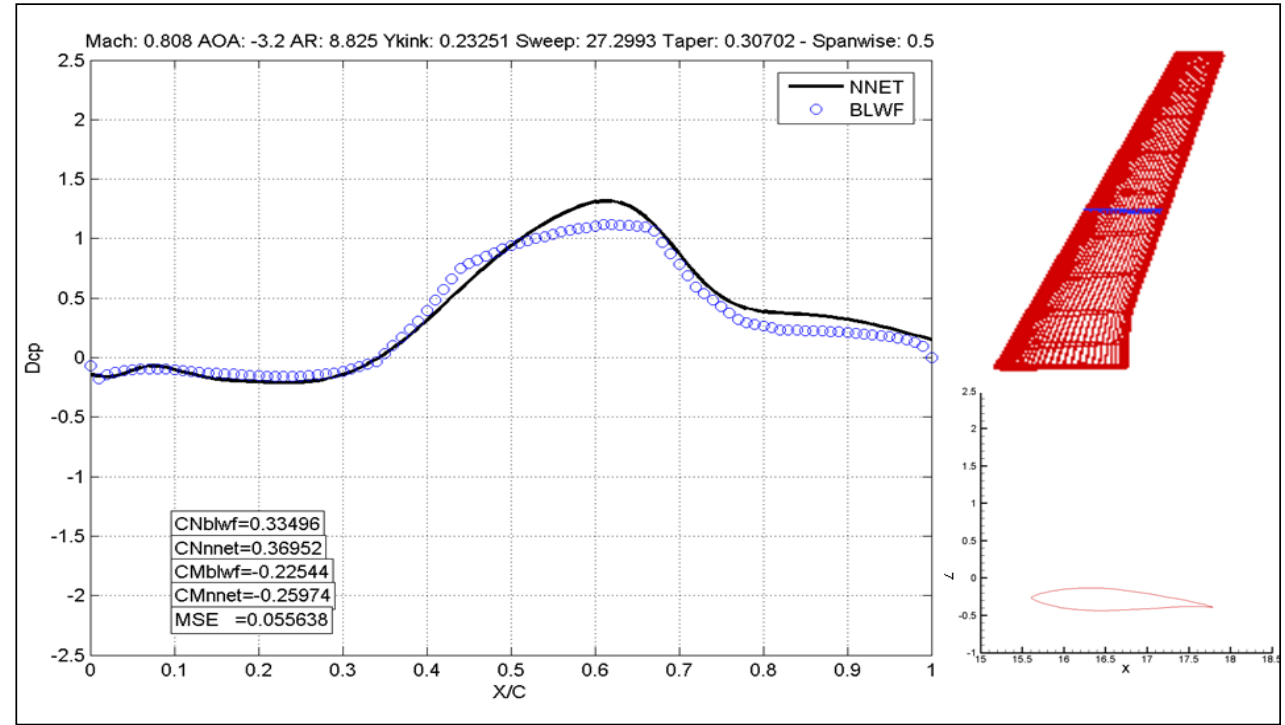

(b)

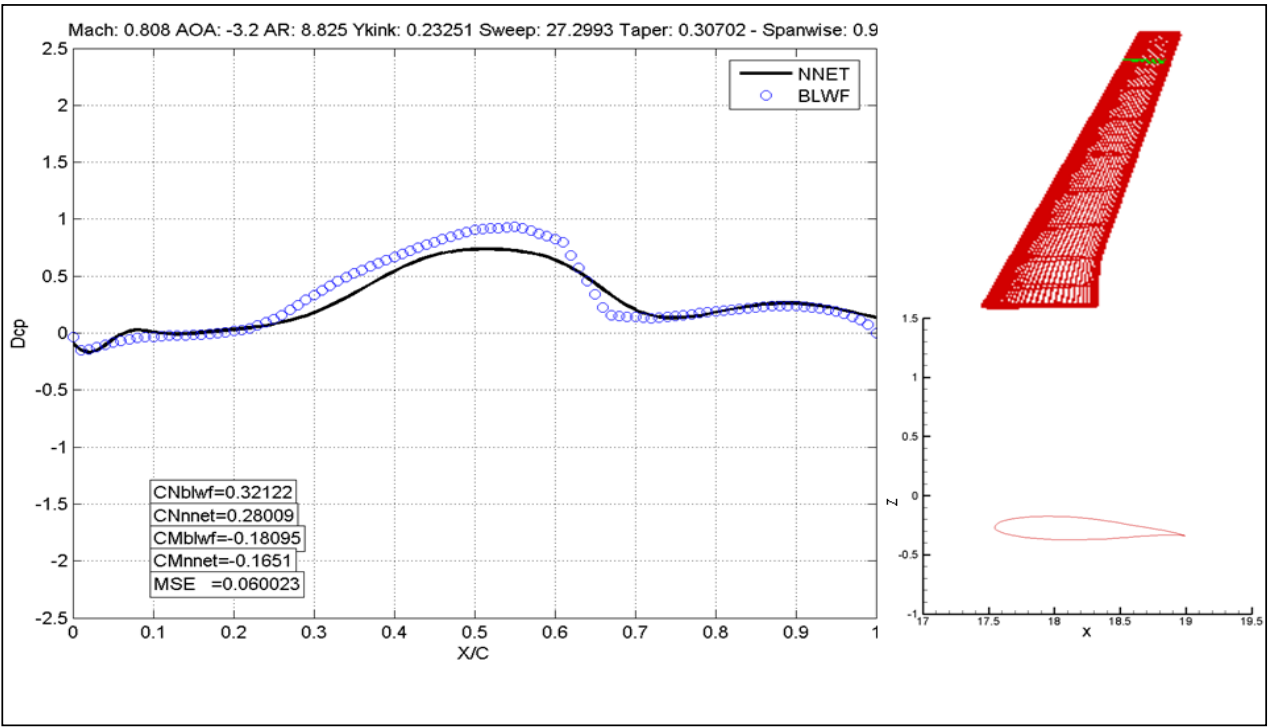

(c)

FIGURA 73: ESCOAMENTO TRANSONICO VALIDAÇÃO INDIVIDUO 1: (A) ESTAÇÃO NA RAIZ (B) ESTAÇÃO NO MEIO DA ASA (C) ESTAÇÃO NA PONTA DA ASA. 


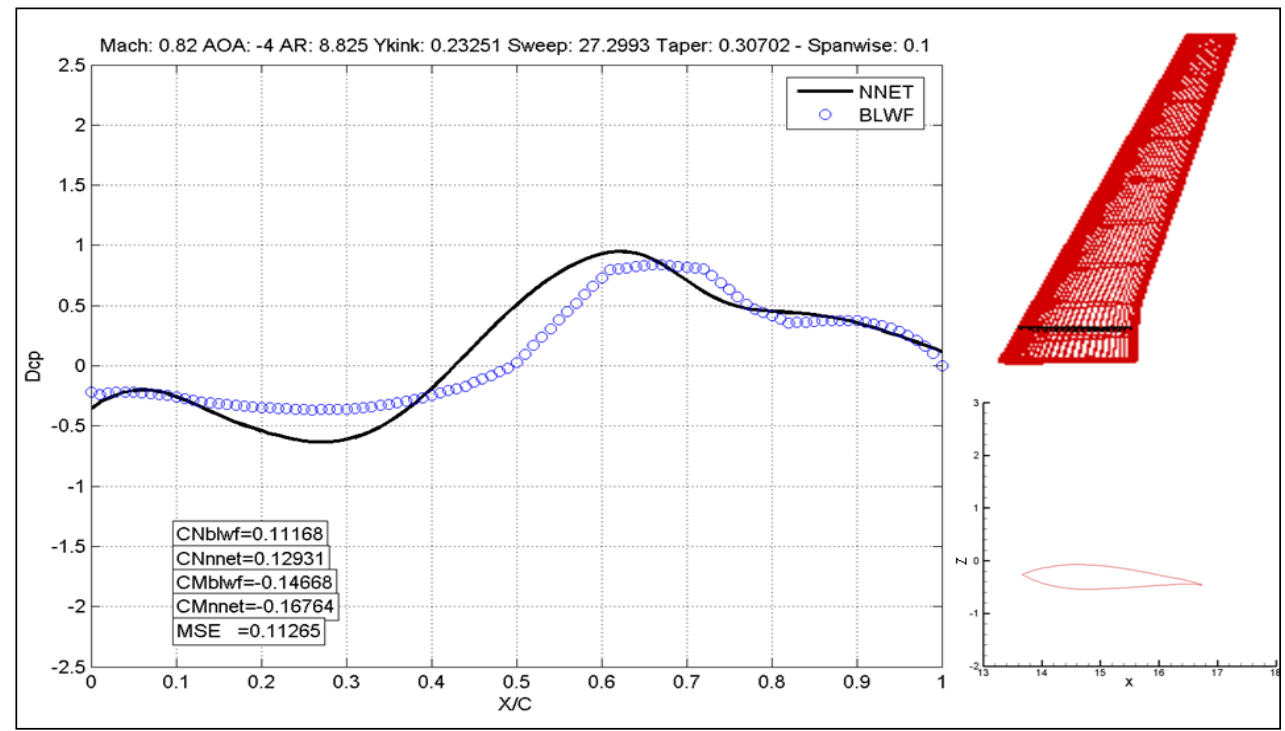

(a)

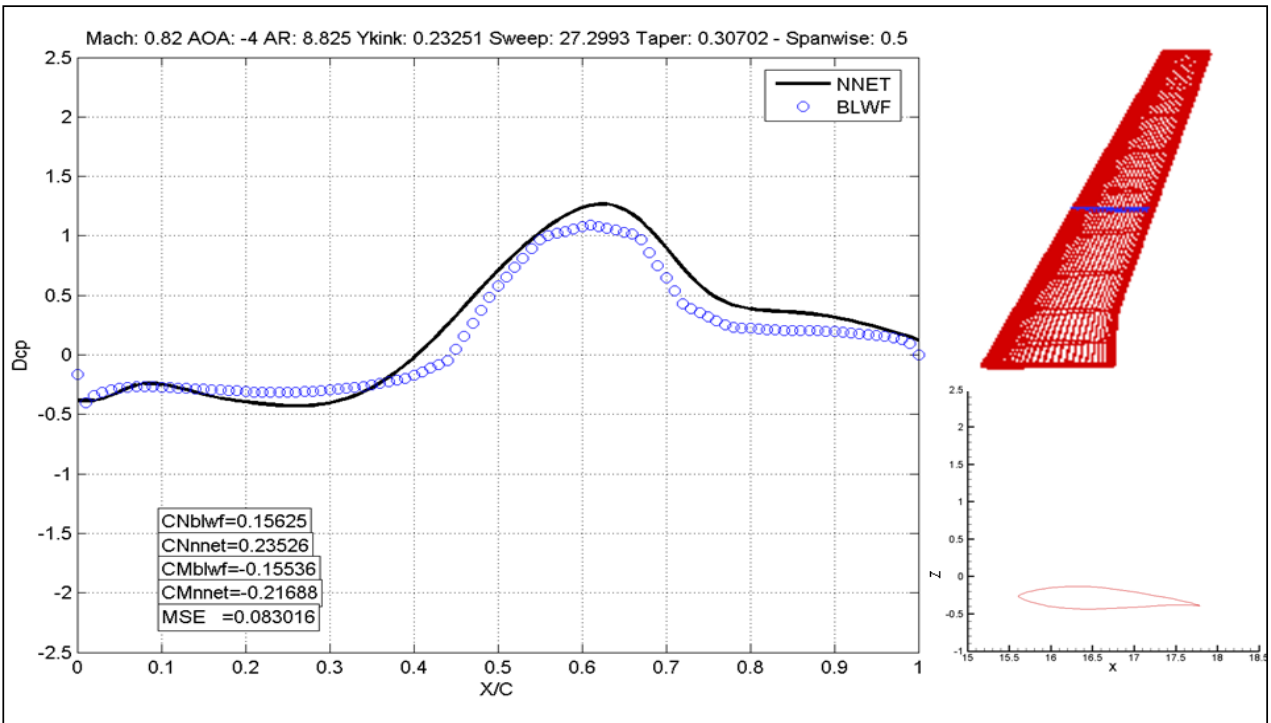

(b)

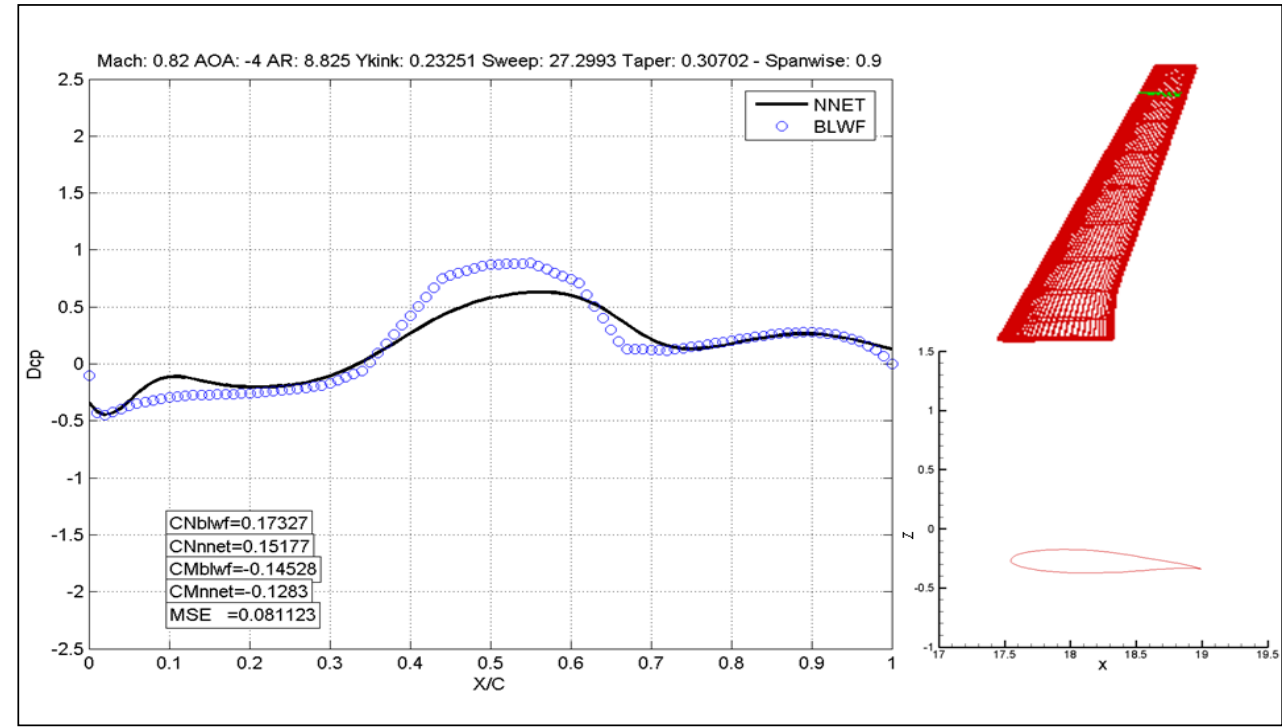

(c)

FIGURA 74: ESCOAMENTO TRANSONICO VALIDAÇÃO INDIVIDUO 1: (A) ESTAÇÃO NA RAIZ (B) ESTAÇÃO NO MEIO DA ASA (C) ESTAÇÃO NA PONTA DA ASA. 


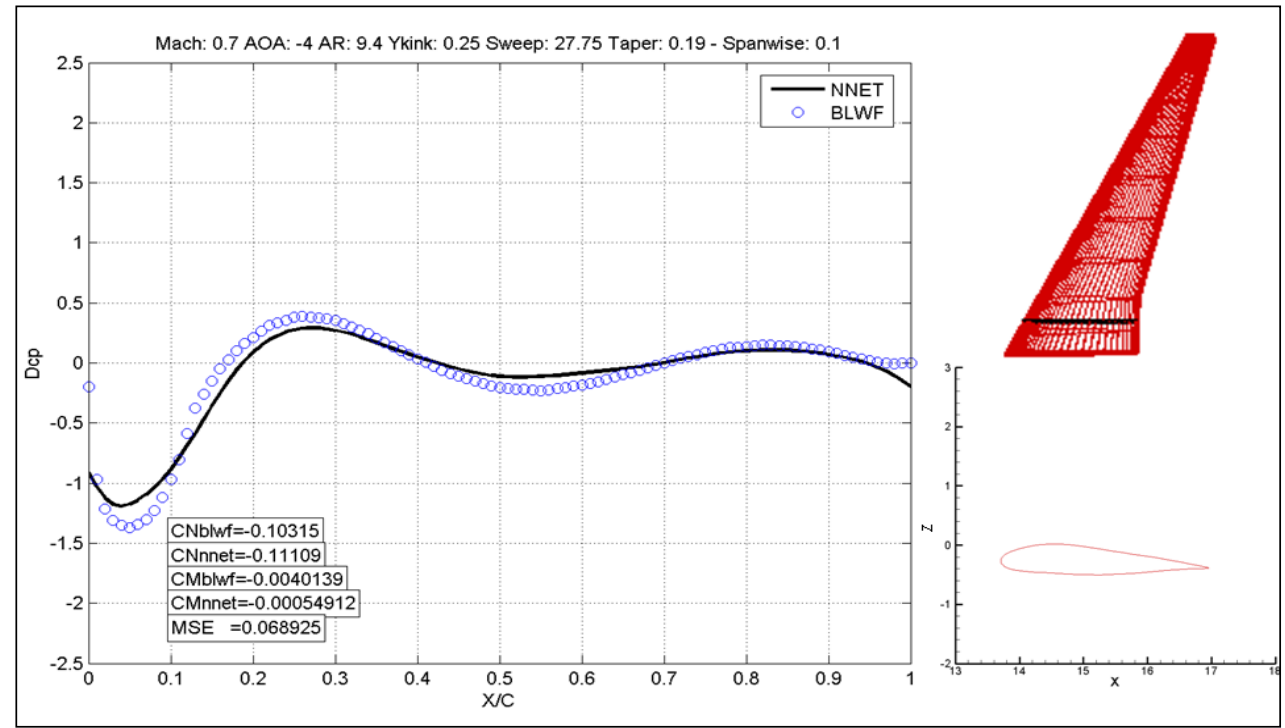

(a)

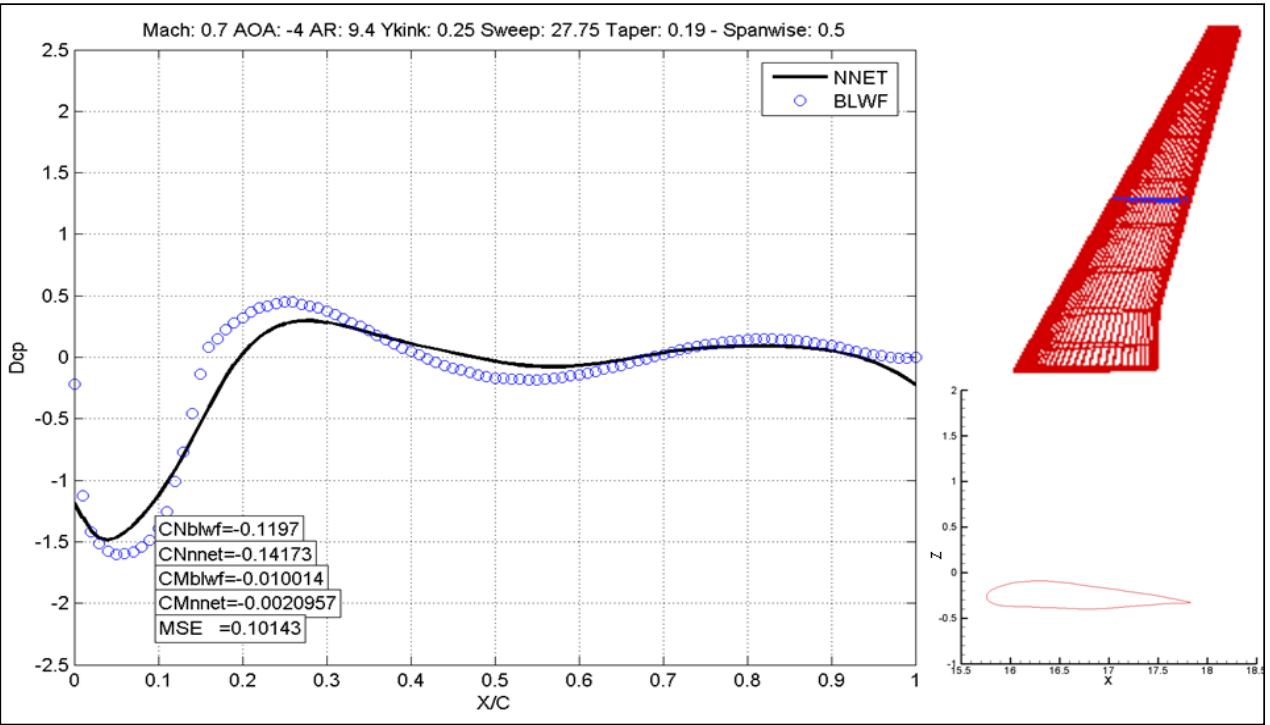

(b)

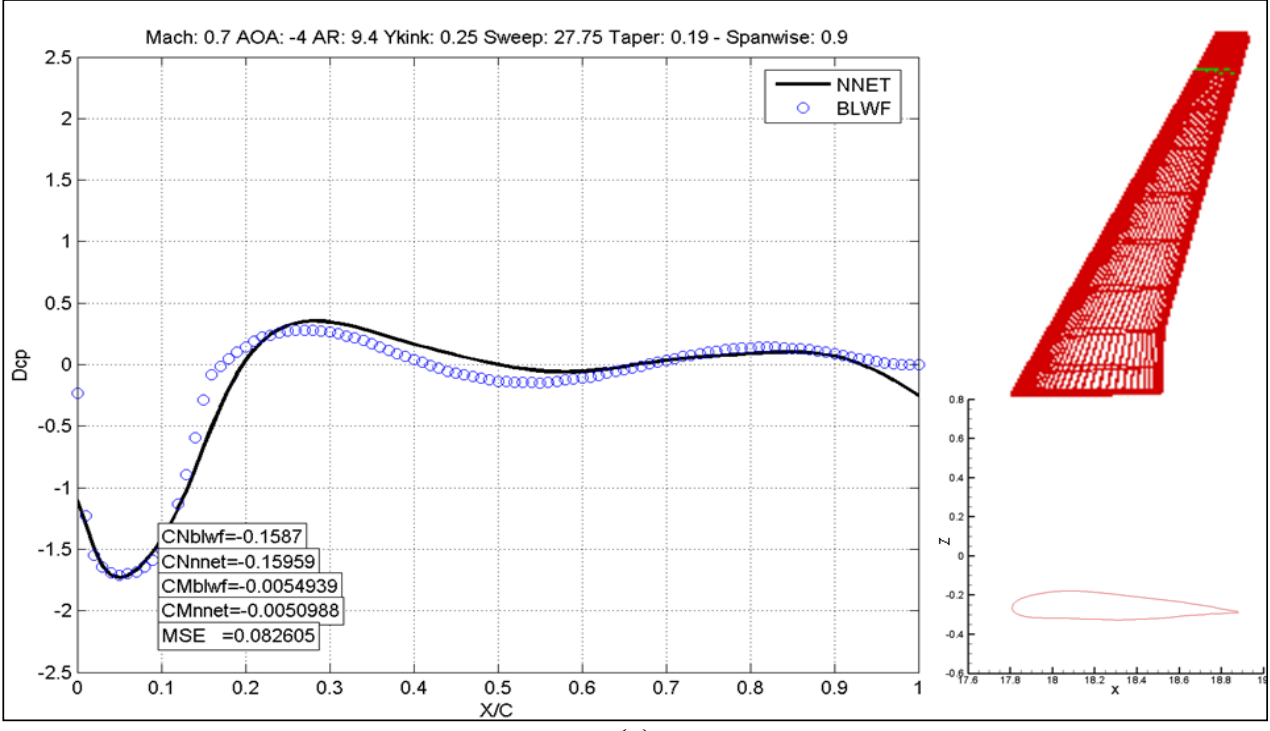

(c)

FIGURA 75: ESCOAMENTO SUBSONICO VALIDAÇÃO INDIVIDUO 3: (A) ESTAÇÃO NA RAIZ (B) ESTAÇÃO NO MEIO DA ASA (C) ESTAÇÃO NA PONTA DA ASA. 


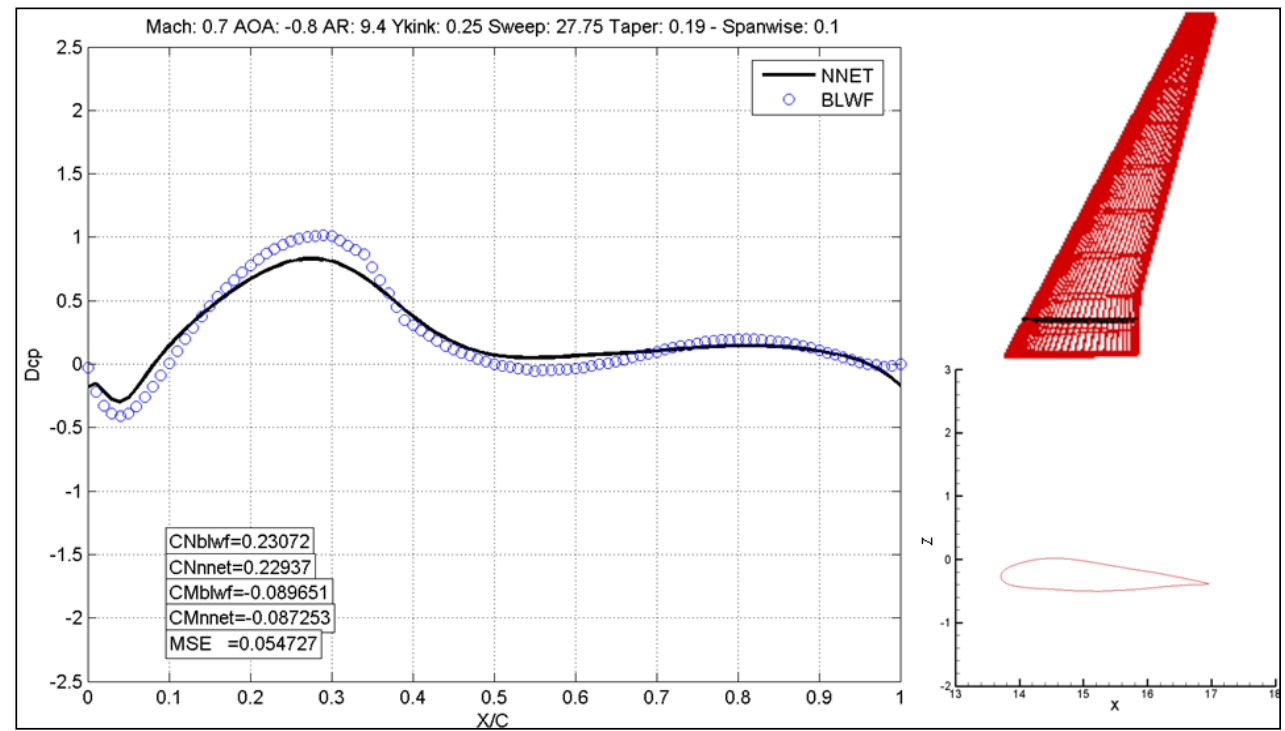

(a)

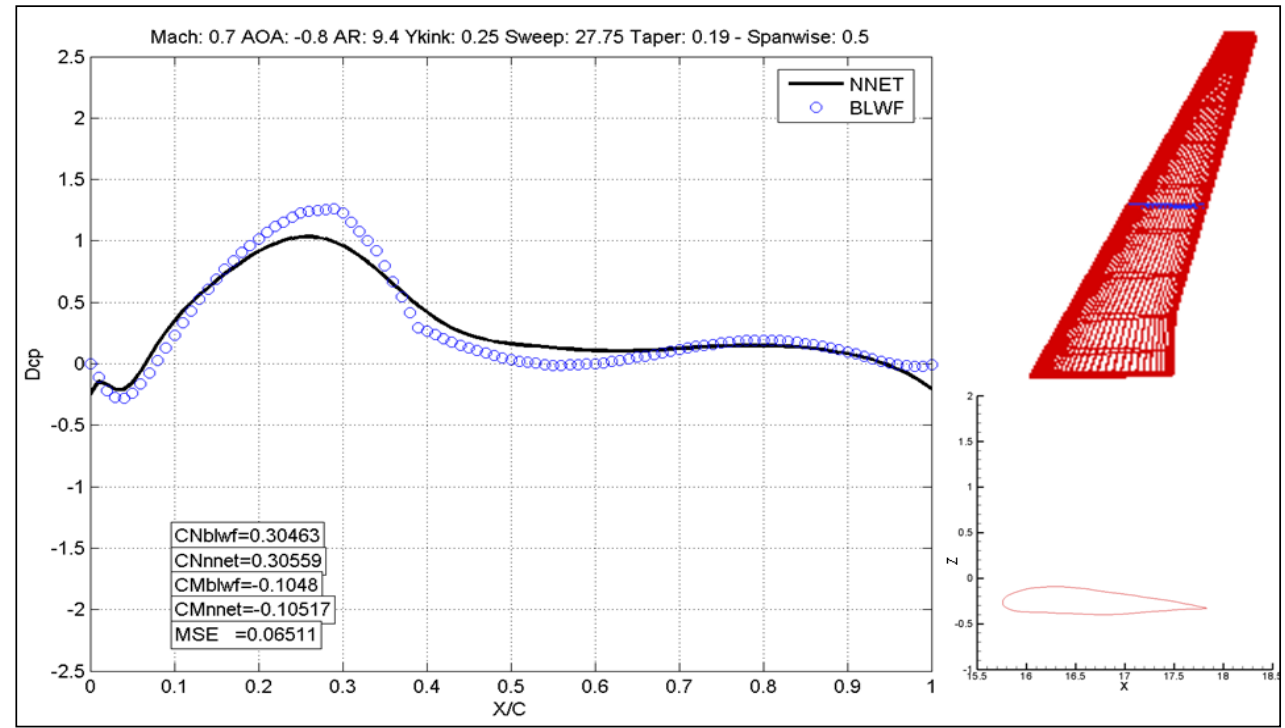

(b)

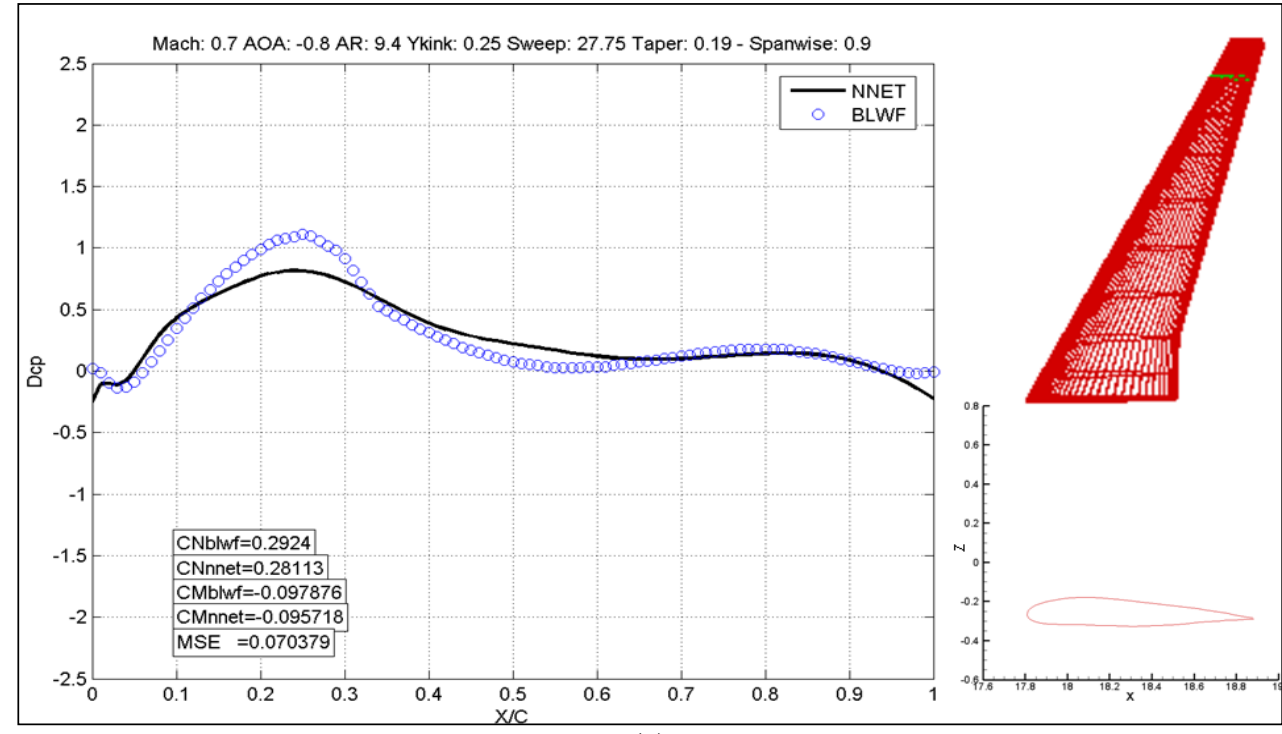

(c)

FIGURA 76: ESCOAMENTO SUBSONICO VALIDAÇÃO INDIVIDUO 3: (A) ESTAÇÃO NA RAIZ (B) ESTAÇÃO NO MEIO DA ASA (C) ESTAÇÃO NA PONTA DA ASA. 


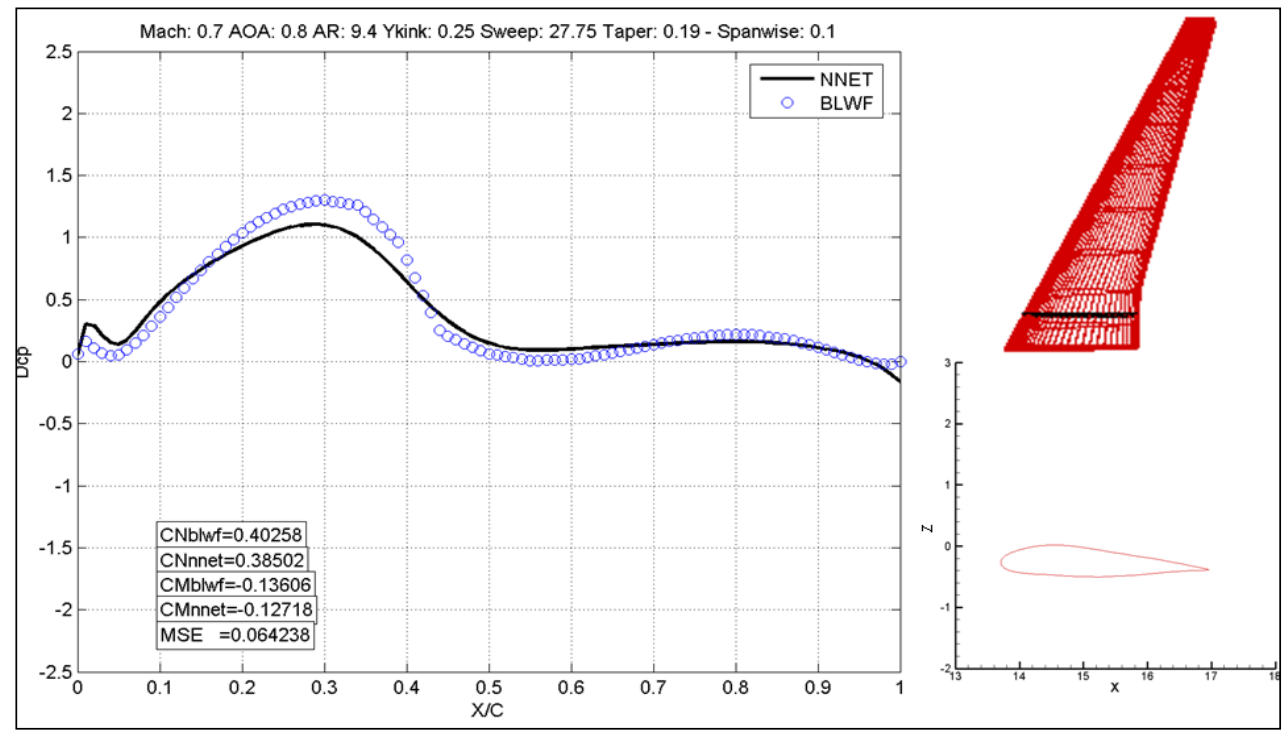

(a)

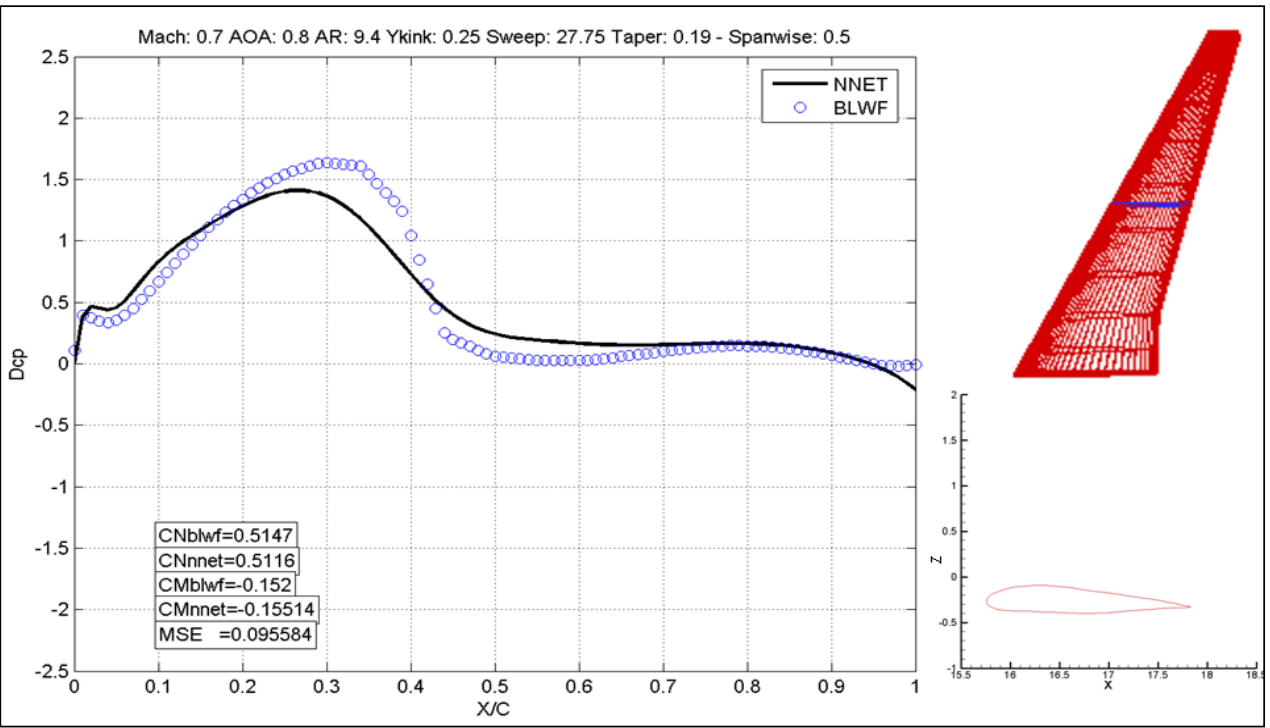

(b)

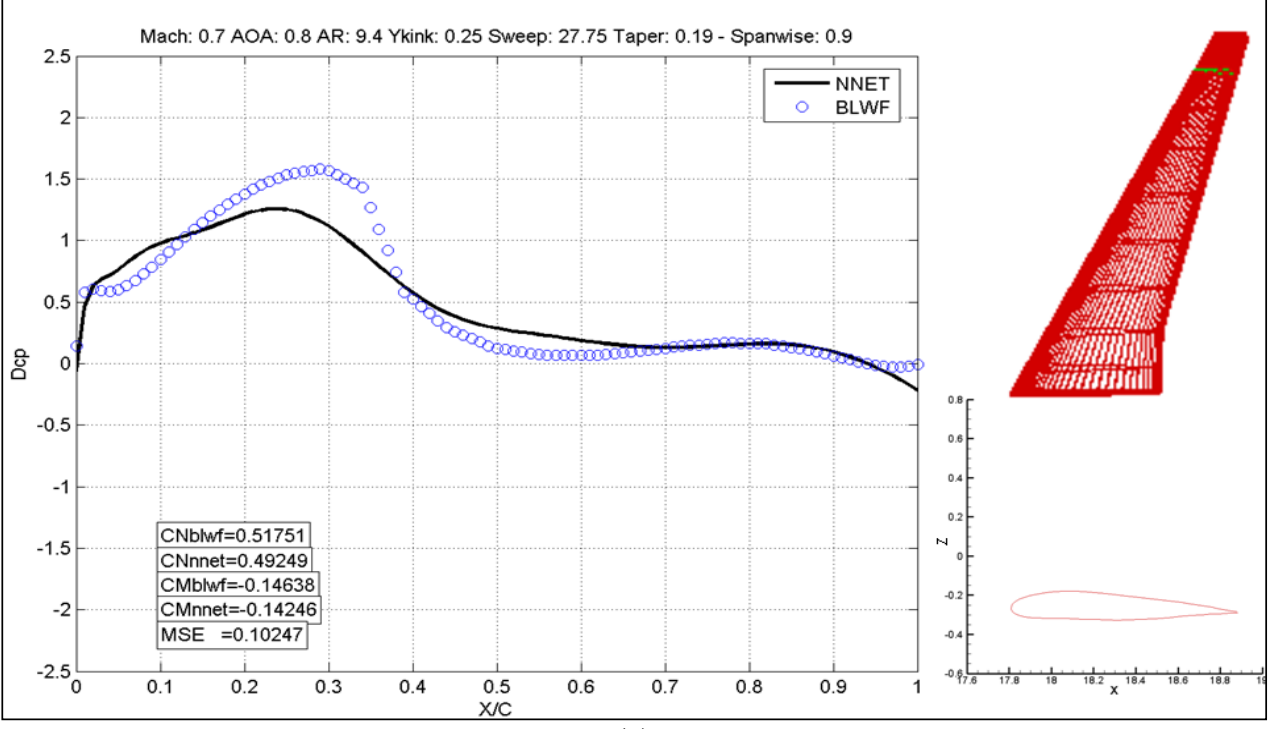

(c)

FIGURA 77: ESCOAMENTO SUBSONICO VALIDAÇÃO INDIVIDUO 3: (A) ESTAÇÃO NA RAIZ (B) ESTAÇÃO NO MEIO DA ASA (C) ESTAÇÃO NA PONTA DA ASA. 


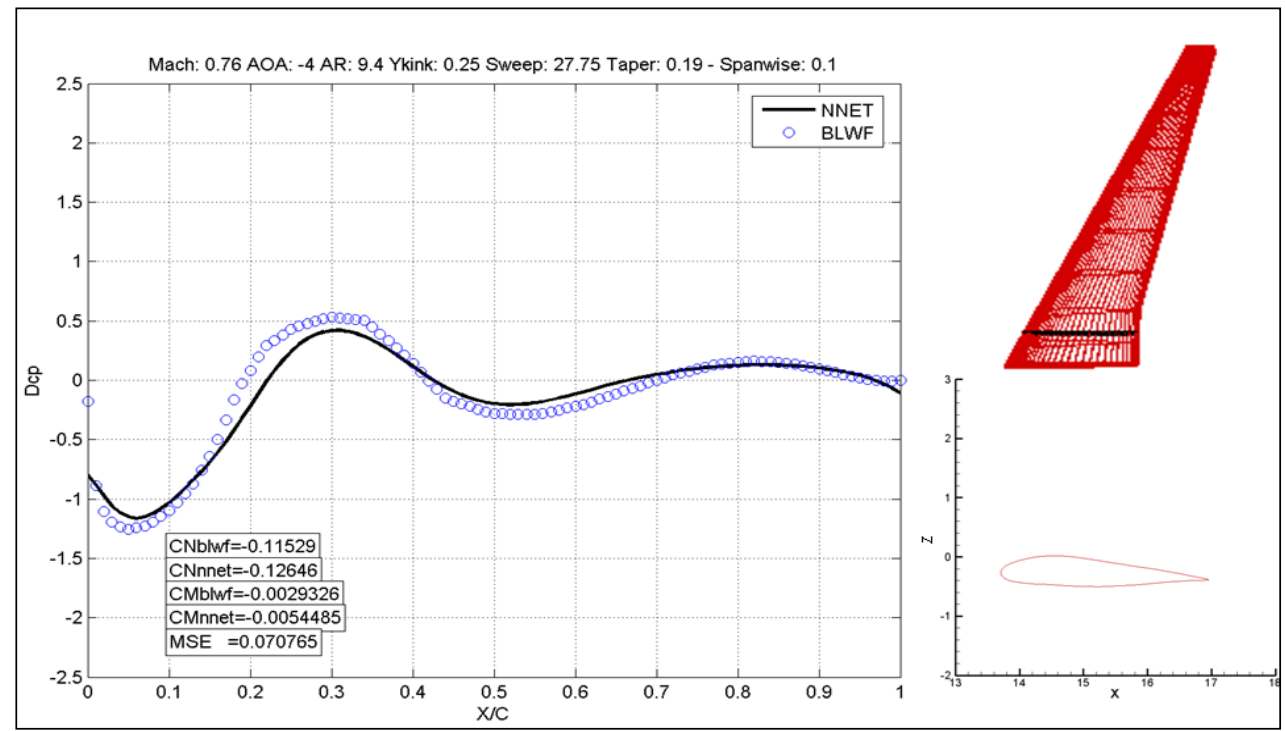

(a)

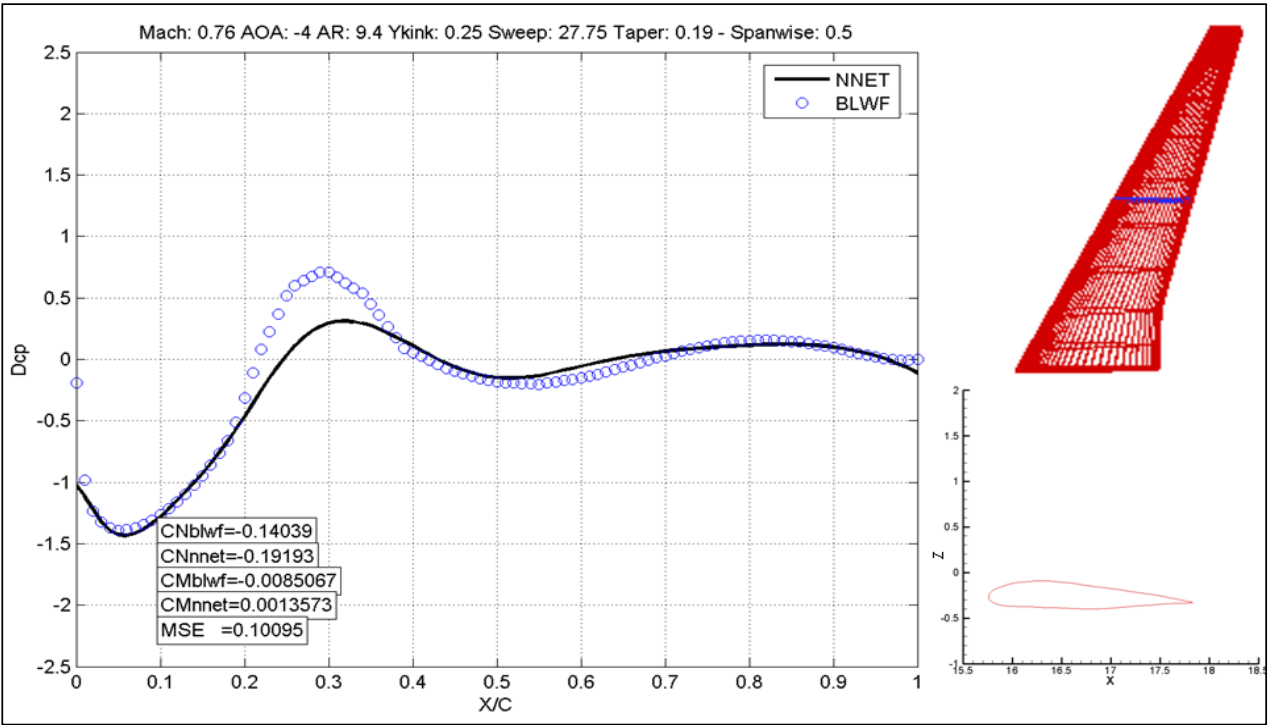

(b)

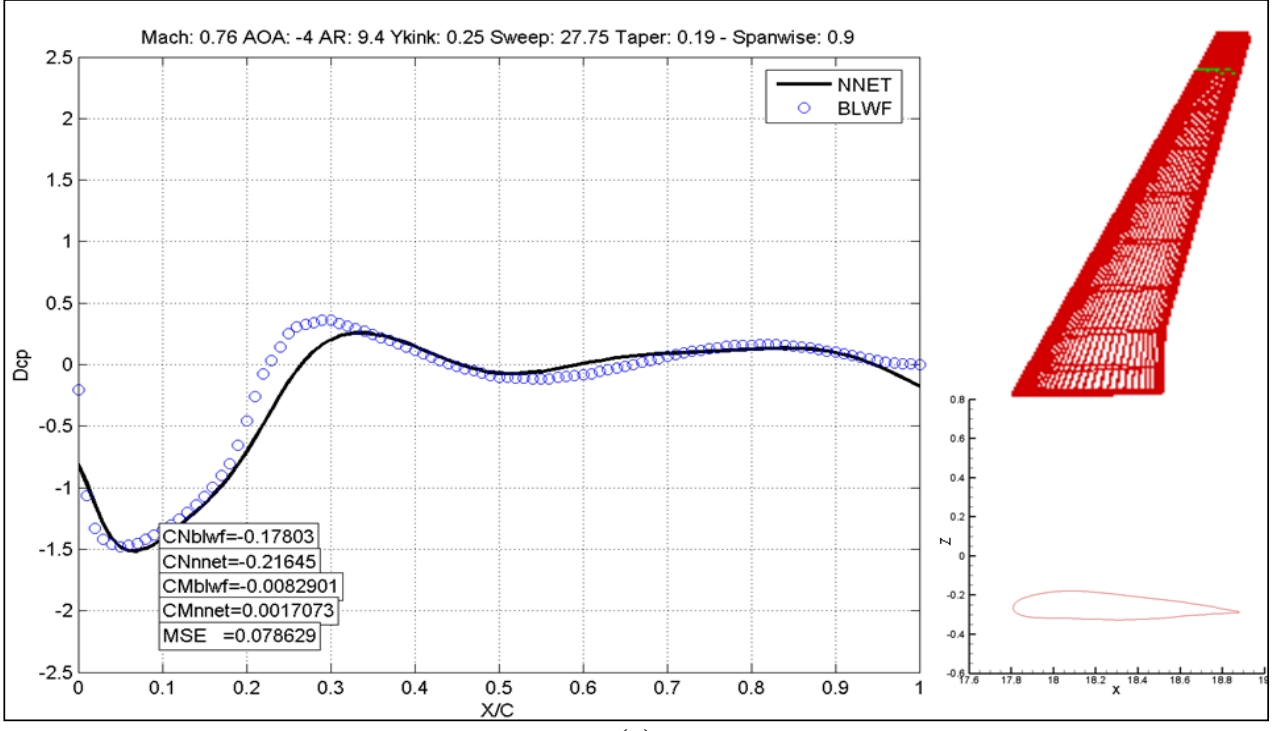

(c)

FIGURA 78: ESCOAMENTO TRANSONICO VALIDAÇÃO INDIVIDUO 3: (A) ESTAÇÃO NA RAIZ (B) ESTAÇÃO NO MEIO DA ASA (C) ESTAÇÃO NA PONTA DA ASA. 


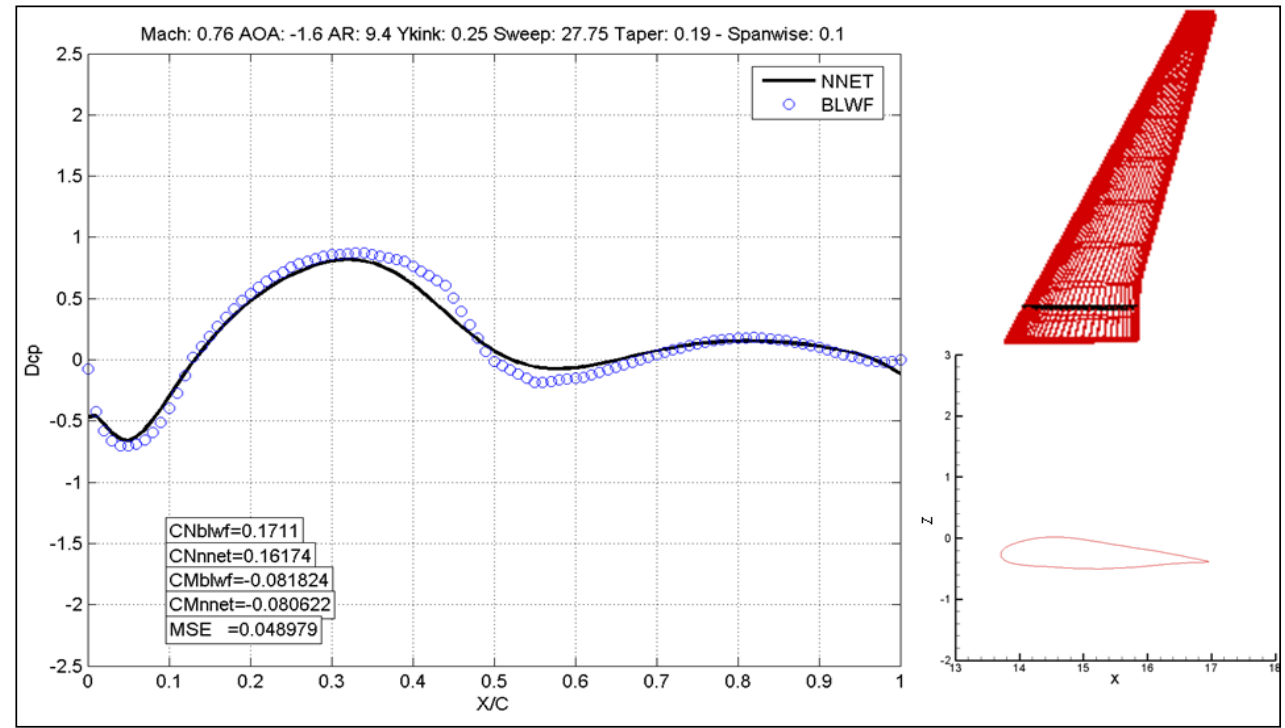

(a)

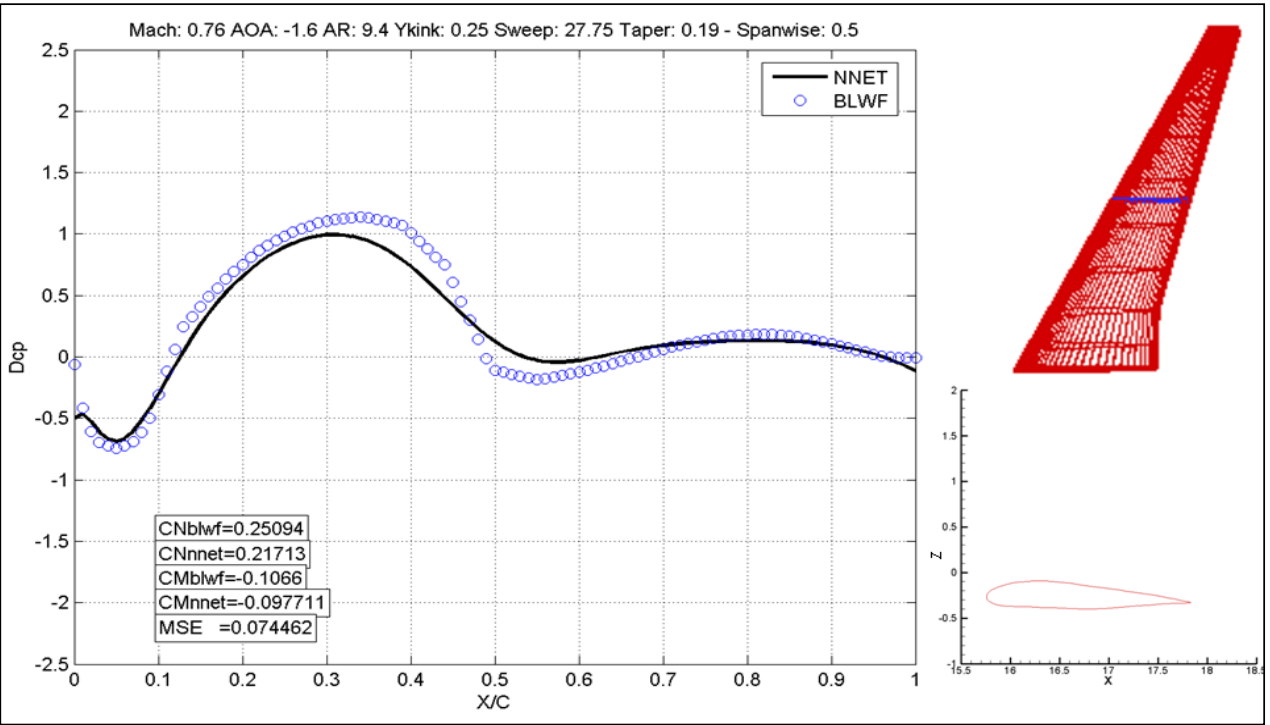

(b)

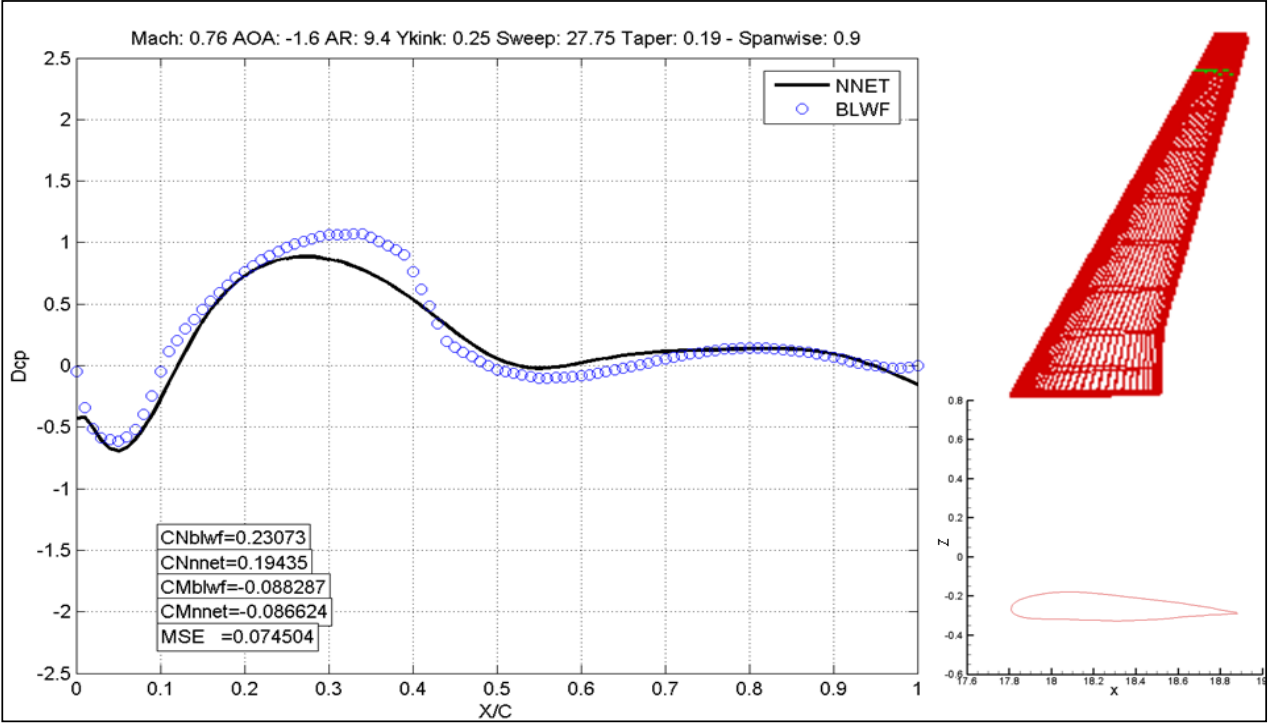

(c)

FIGURA 79: ESCOAMENTO TRANSONICO VALIDAÇÃO INDIVIDUO 3: (A) ESTAÇÃO NA RAIZ (B) ESTAÇÃO NO MEIO DA ASA (C) ESTAÇÃO NA PONTA DA ASA. 


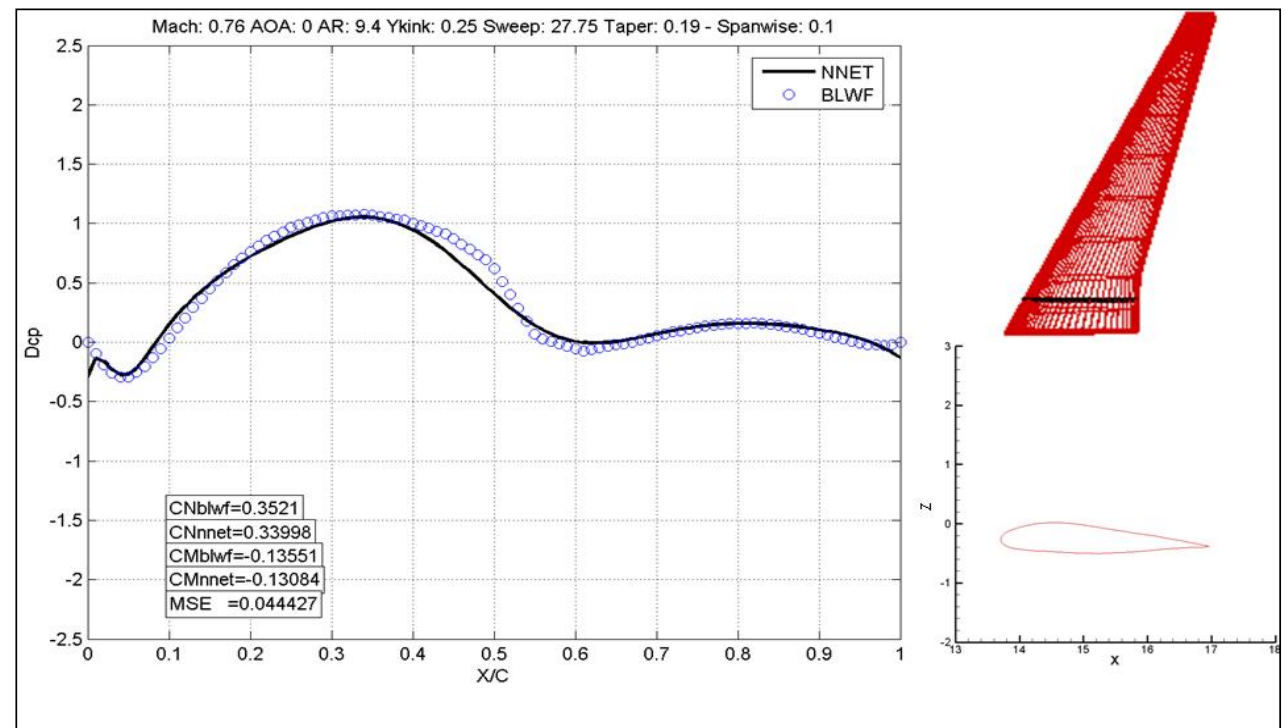

(a)

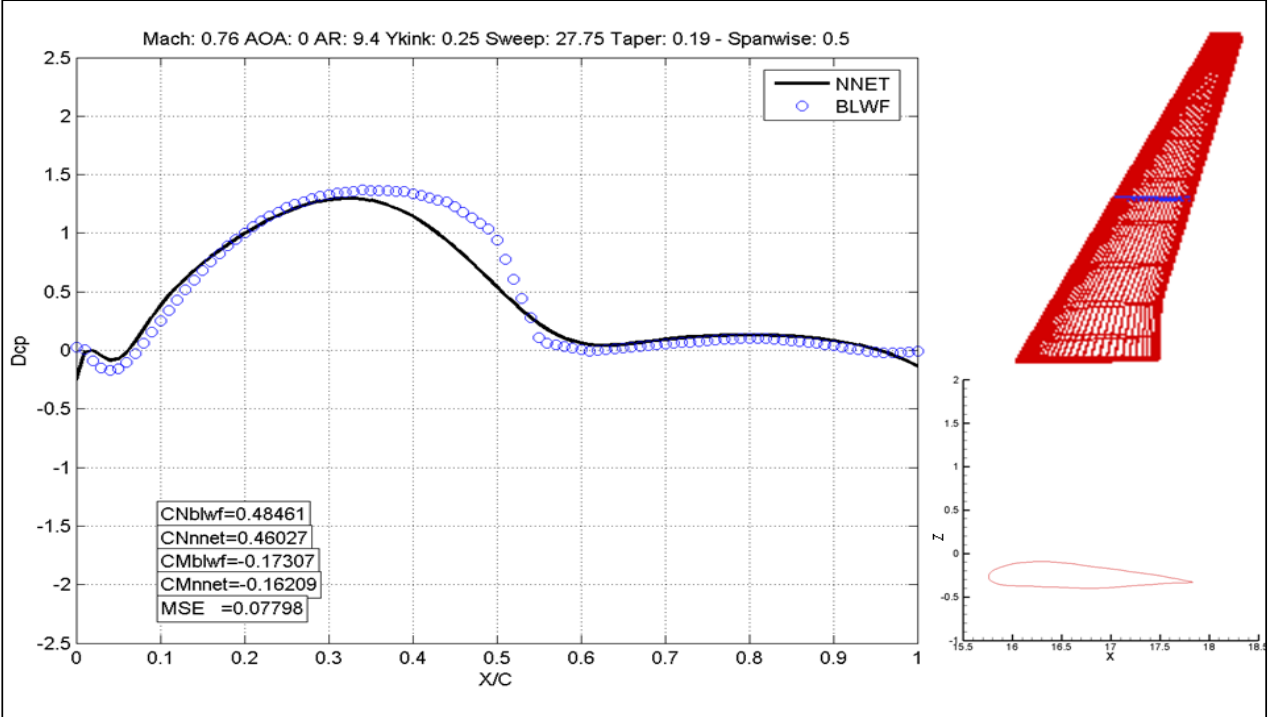

(b)

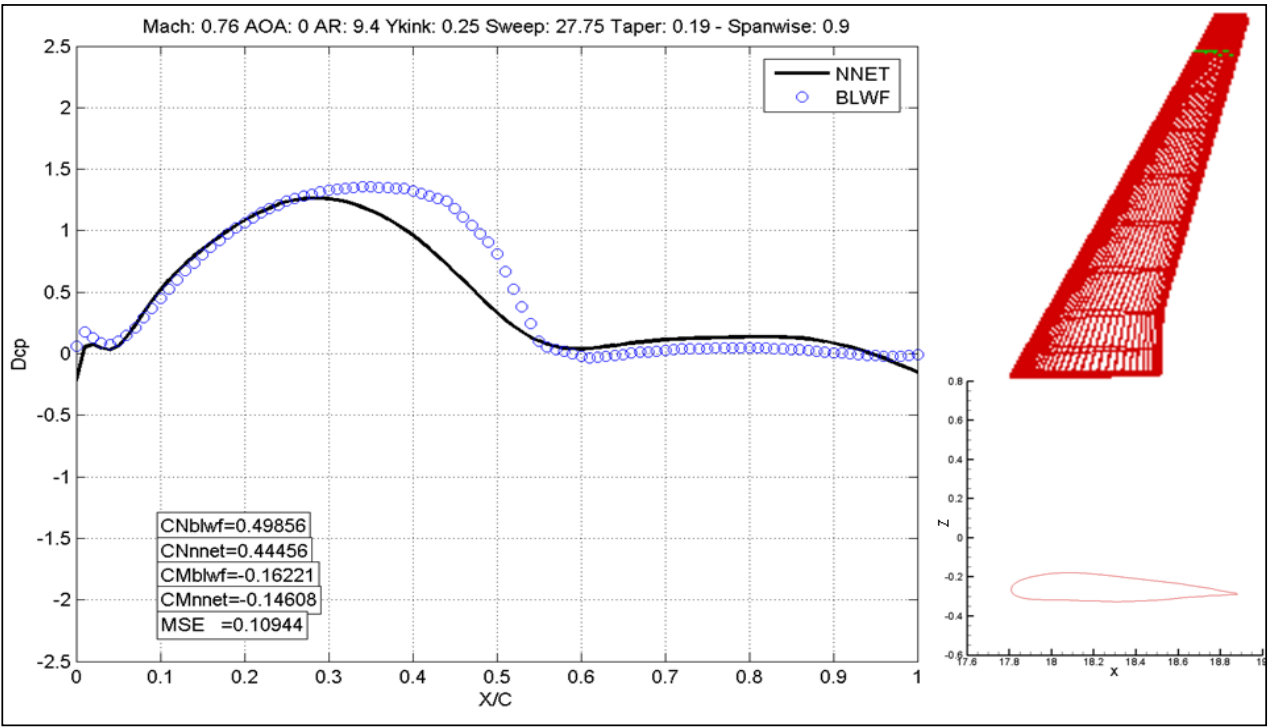

(c)

FIGURA 80: ESCOAMENTO TRANSONICO VALIDAÇÃO INDIVIDUO 3: (A) ESTAÇÃO NA RAIZ (B) ESTAÇÃO NO MEIO DA ASA (C) ESTAÇÃO NA PONTA DA ASA. 


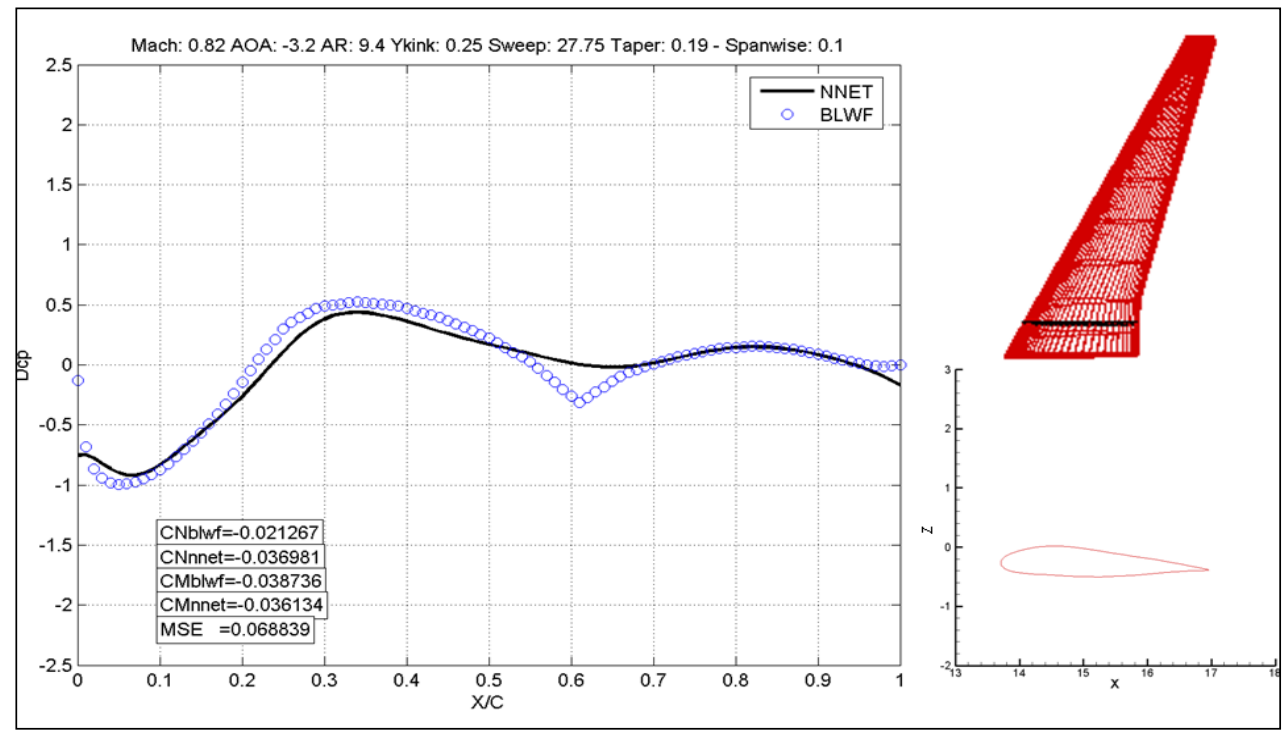

(a)

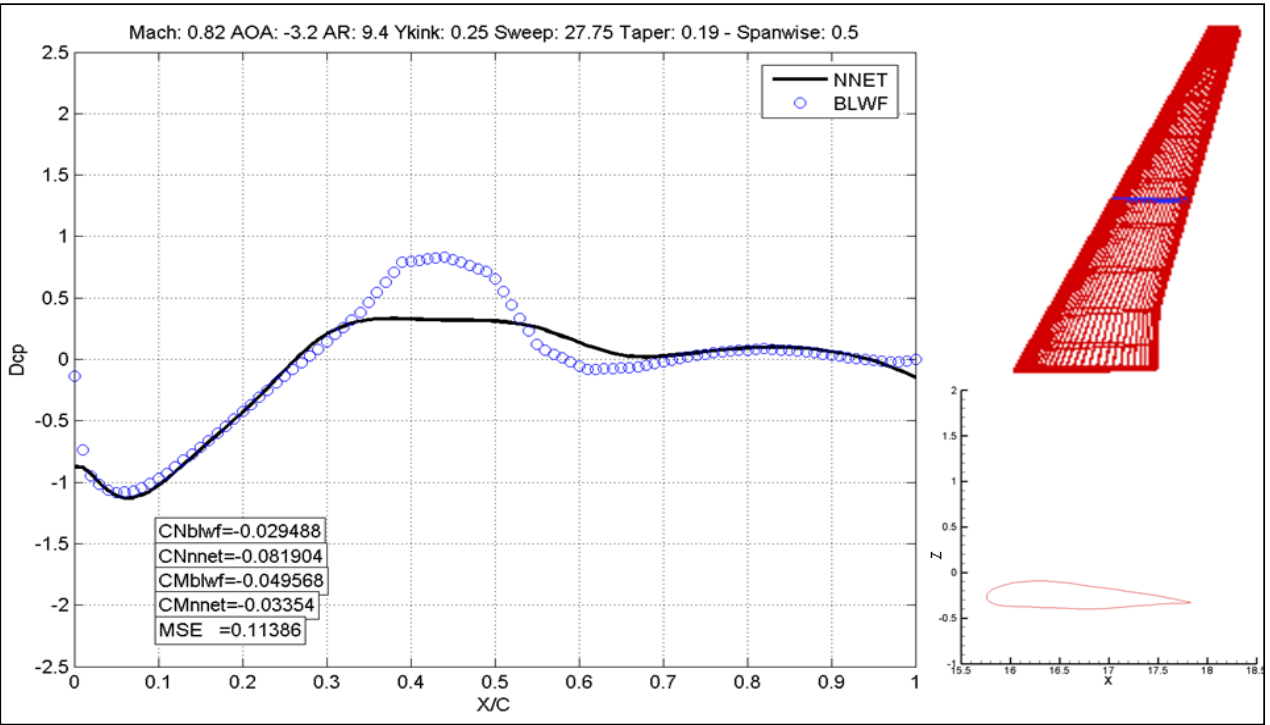

(b)

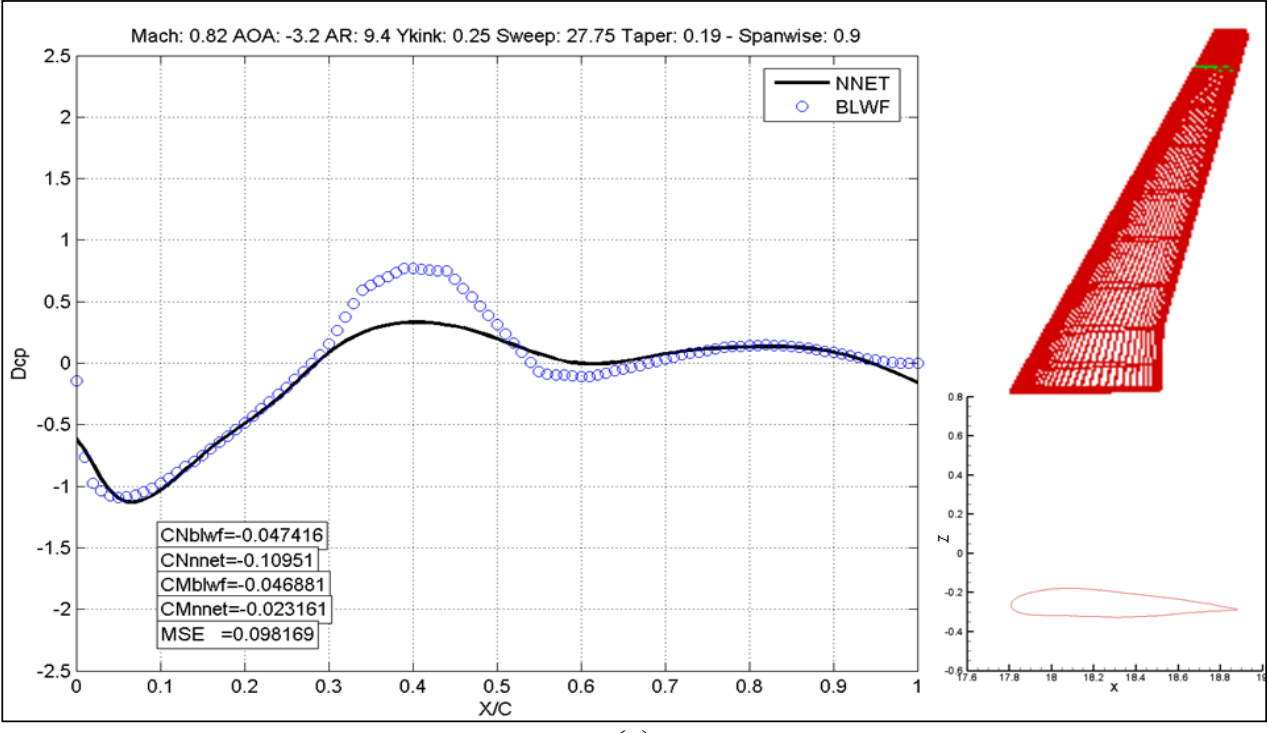

(c)

FIGURA 81: ESCOAMENTO TRANSONICO VALIDAÇÃO INDIVIDUO 3: (A) ESTAÇÃO NA RAIZ (B) ESTAÇÃO NO MEIO DA ASA (C) ESTAÇÃO NA PONTA DA ASA. 


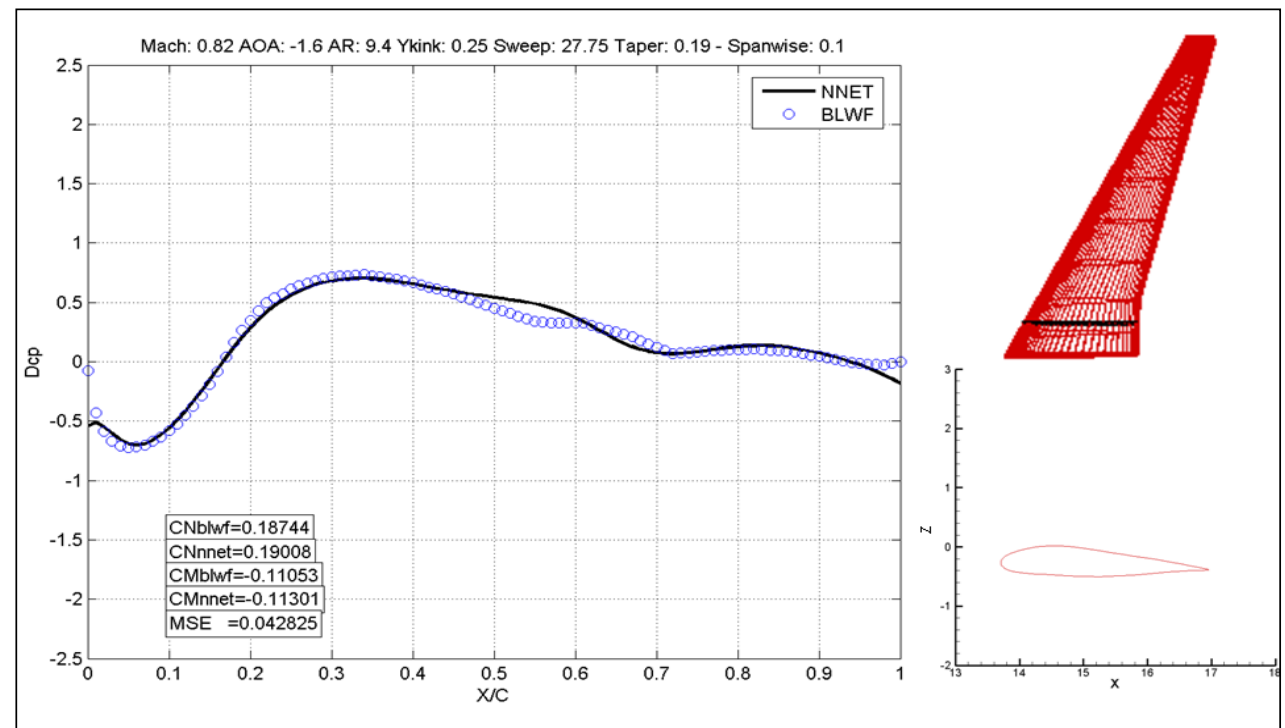

(a)

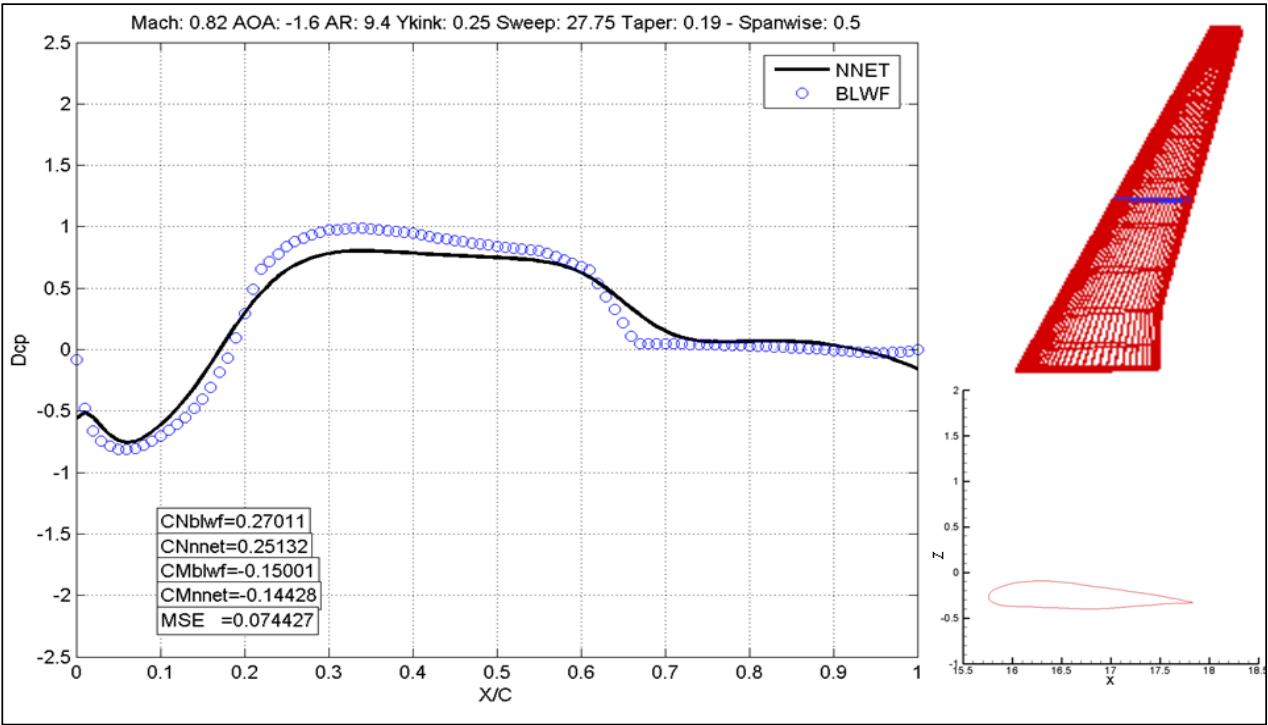

(b)

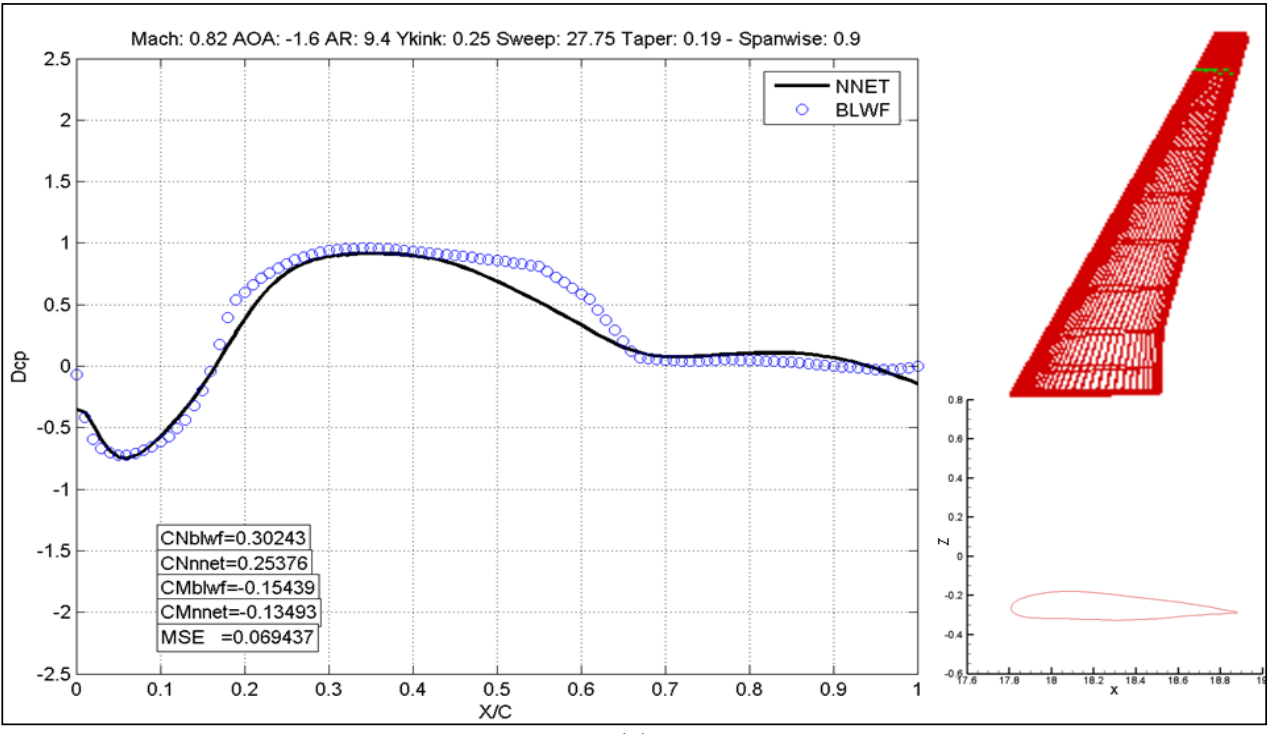

(c)

FIGURA 82: ESCOAMENTO TRANSONICO VALIDAÇÃO INDIVIDUO 3: (A) ESTAÇÃO NA RAIZ (B) ESTAÇÃO NO MEIO DA ASA (C) ESTAÇÃO NA PONTA DA ASA. 


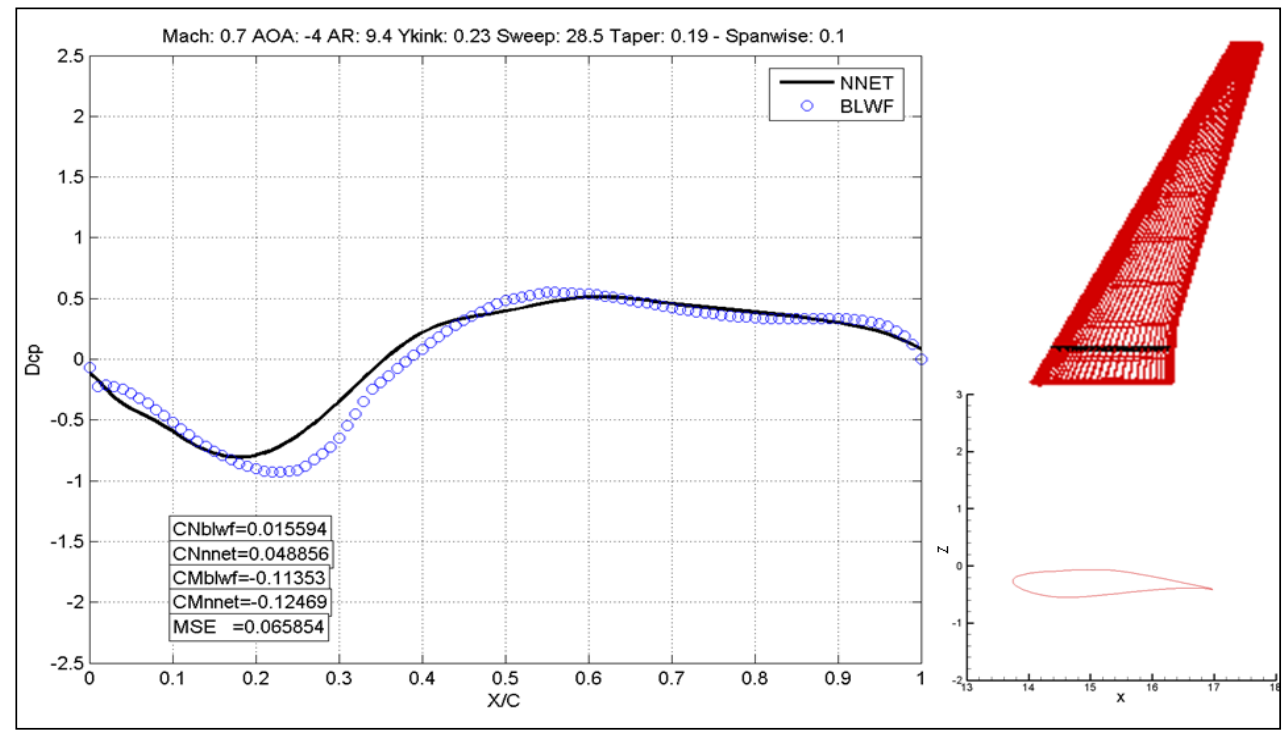

(a)

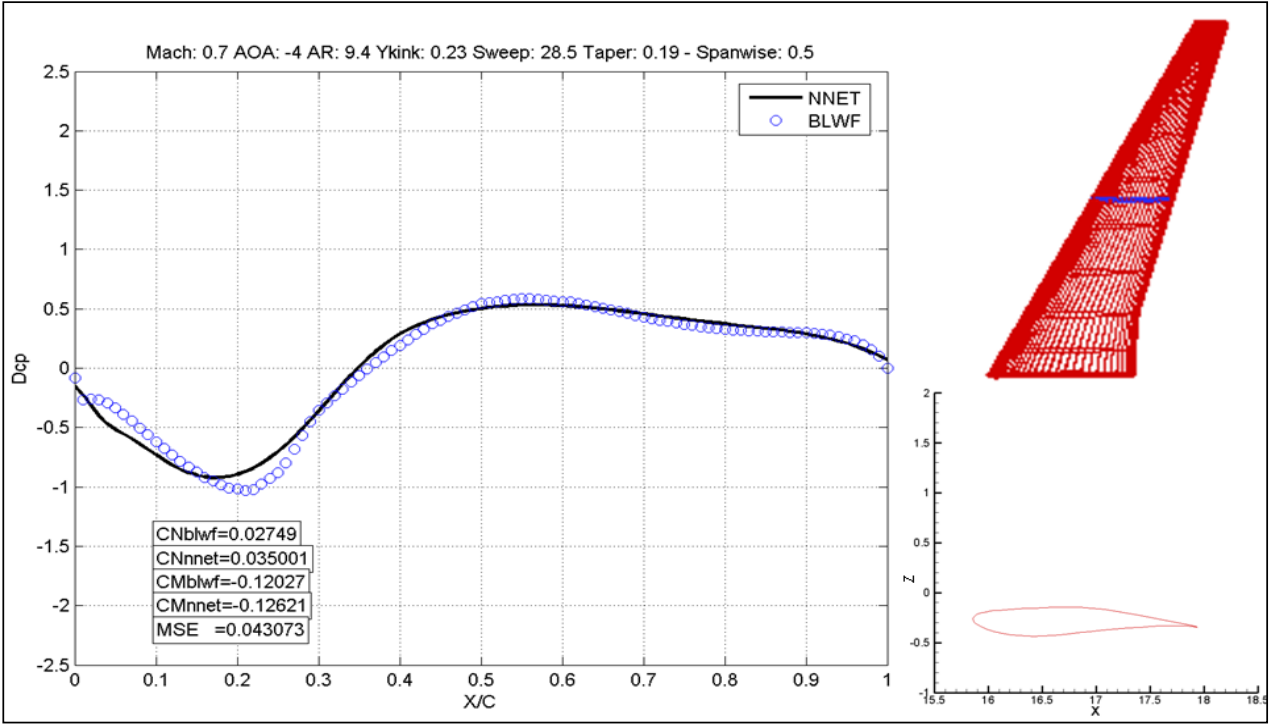

(b)

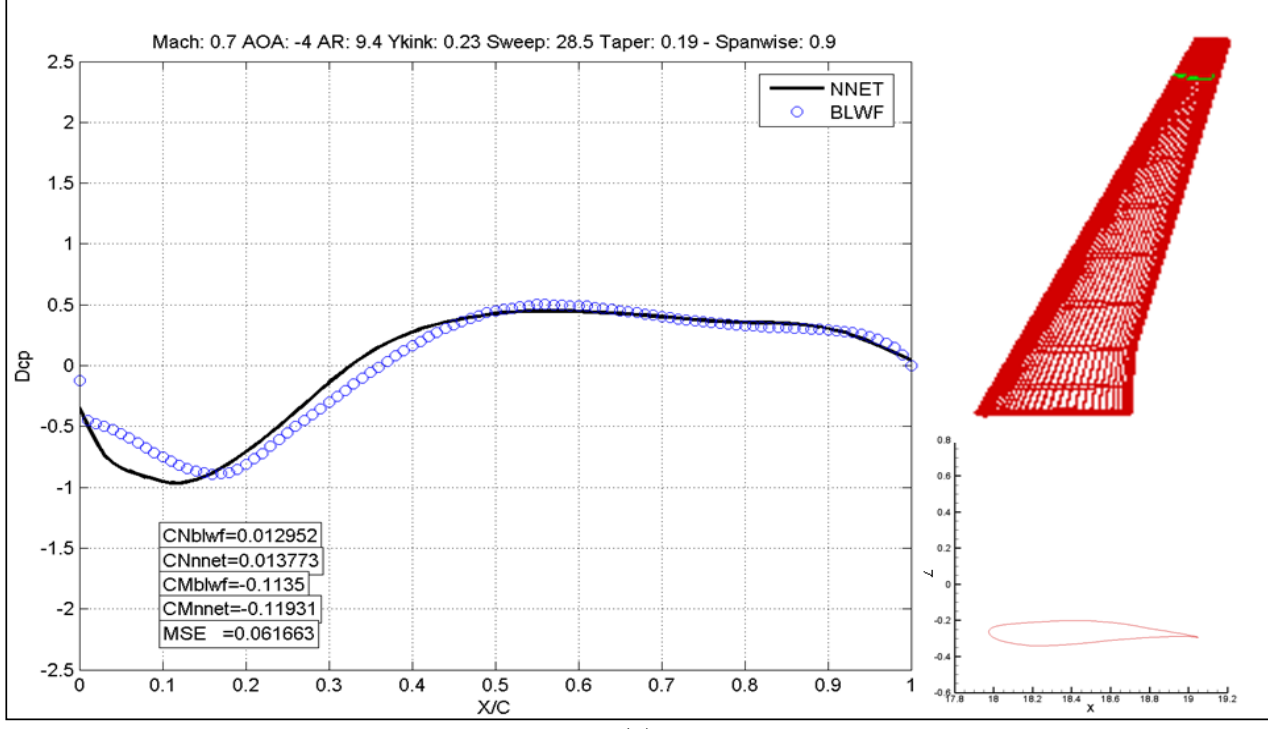

(c)

FIGURA 83: ESCOAMENTO SUBSONICO VALIDAÇÃO INDIVIDUO 5: (A) ESTAÇÃO NA RAIZ (B) ESTAÇÃO NO MEIO DA ASA (C) ESTAÇÃO NA PONTA DA ASA. 


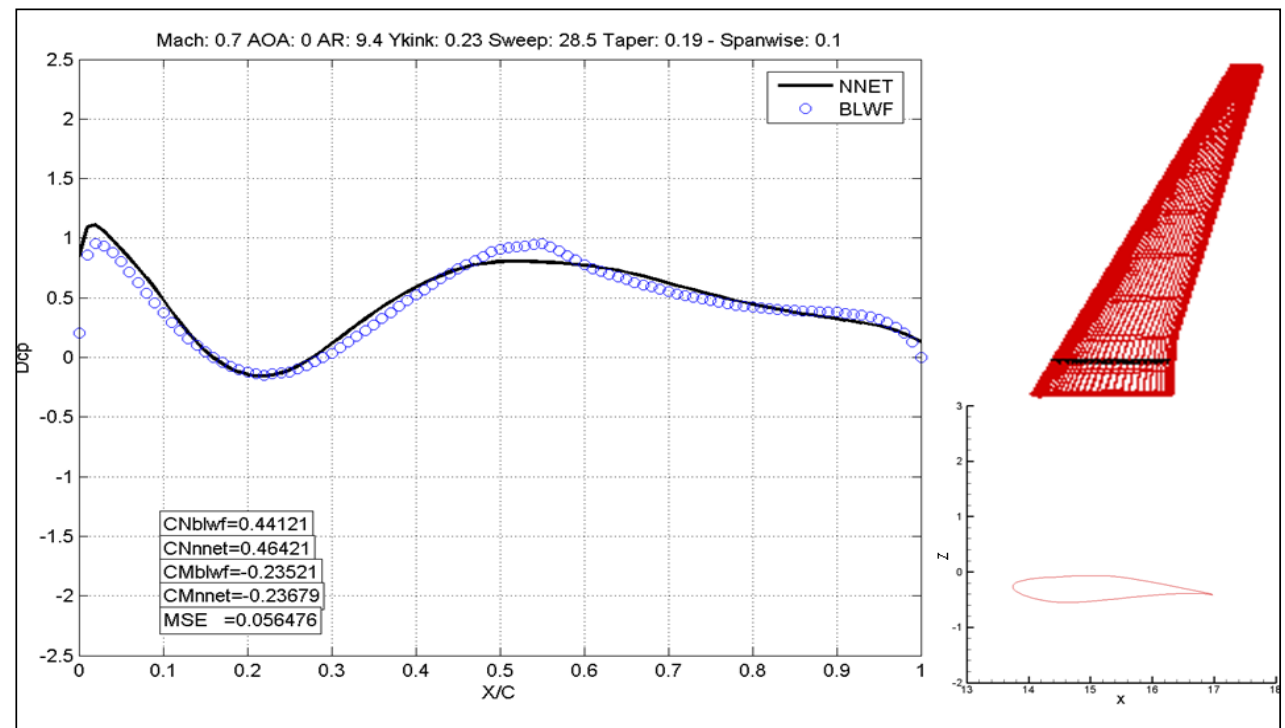

(a)

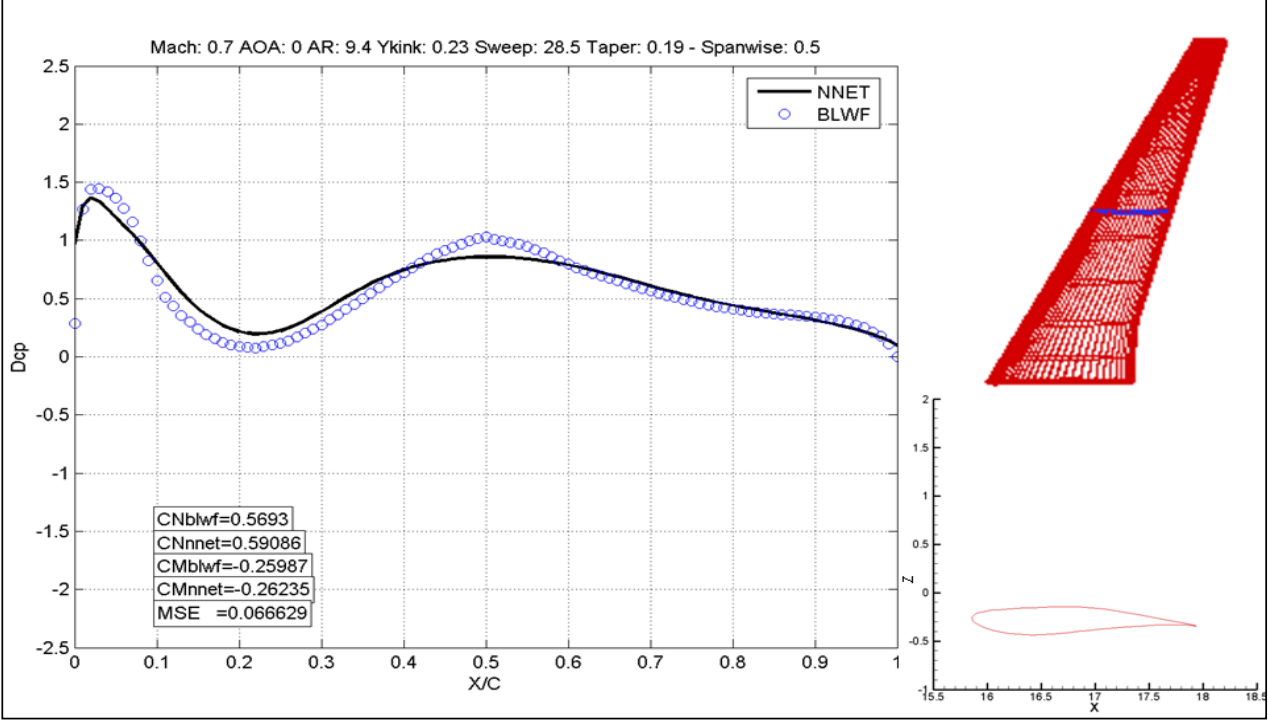

(b)

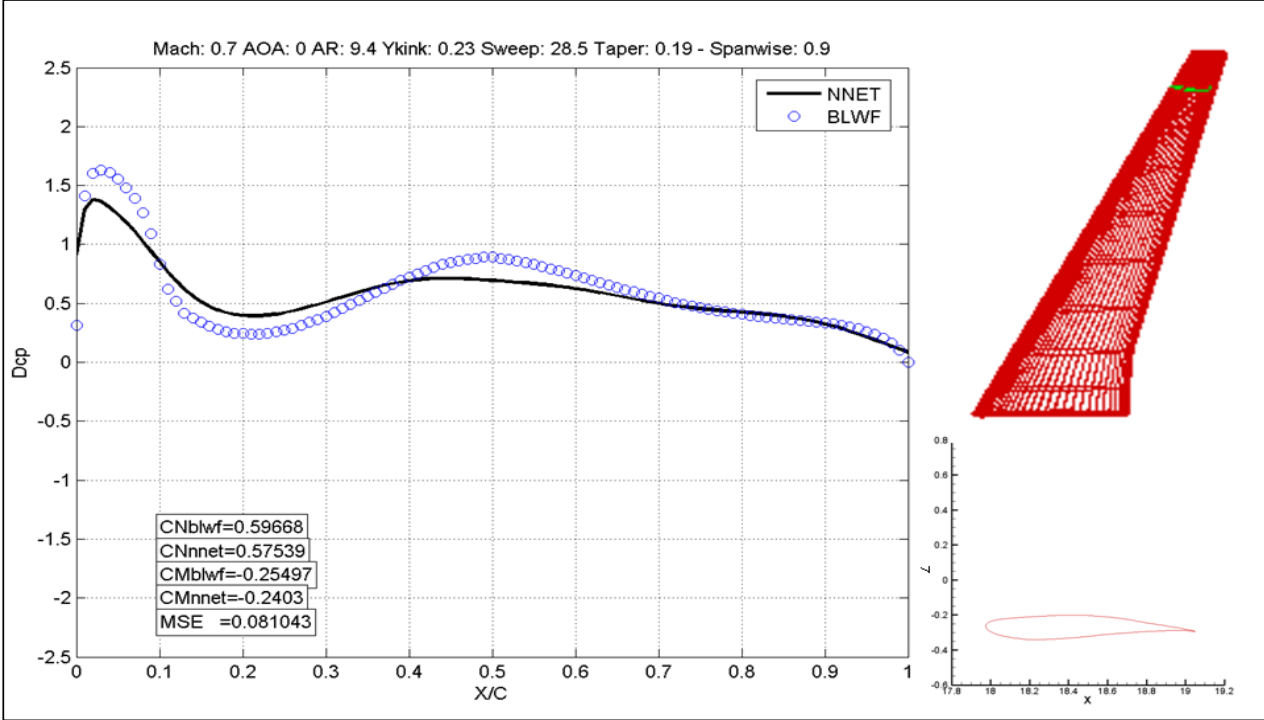

(c)

FIGURA 84: ESCOAMENTO SUBSONICO VALIDAÇÃO INDIVIDUO 5: (A) ESTAÇÃO NA RAIZ (B) ESTAÇÃO NO MEIO DA ASA (C) ESTAÇÃO NA PONTA DA ASA. 


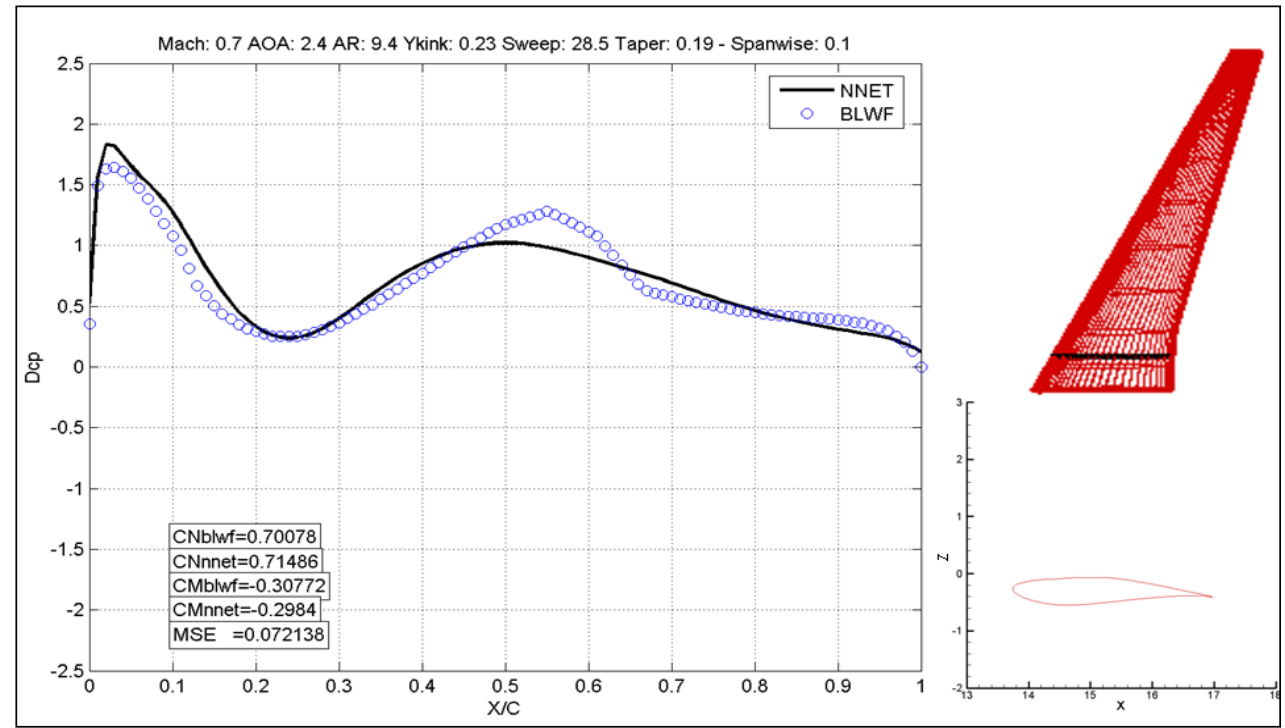

(a)

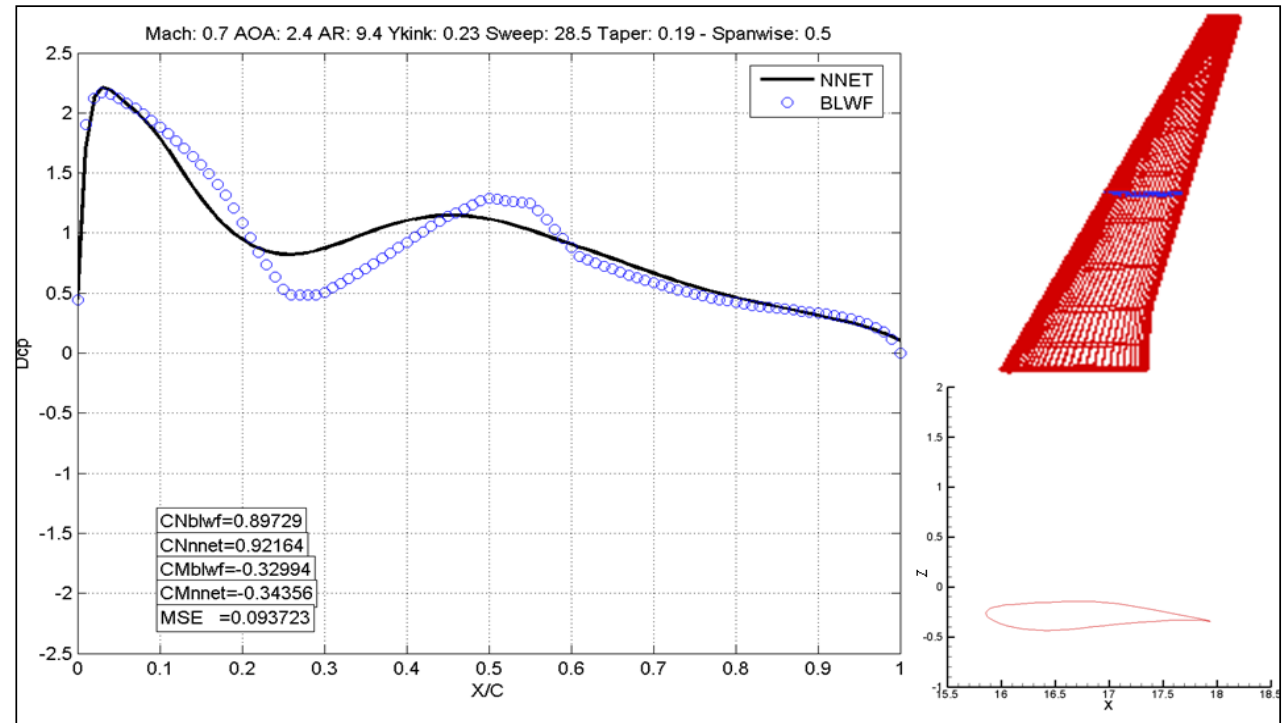

(b)

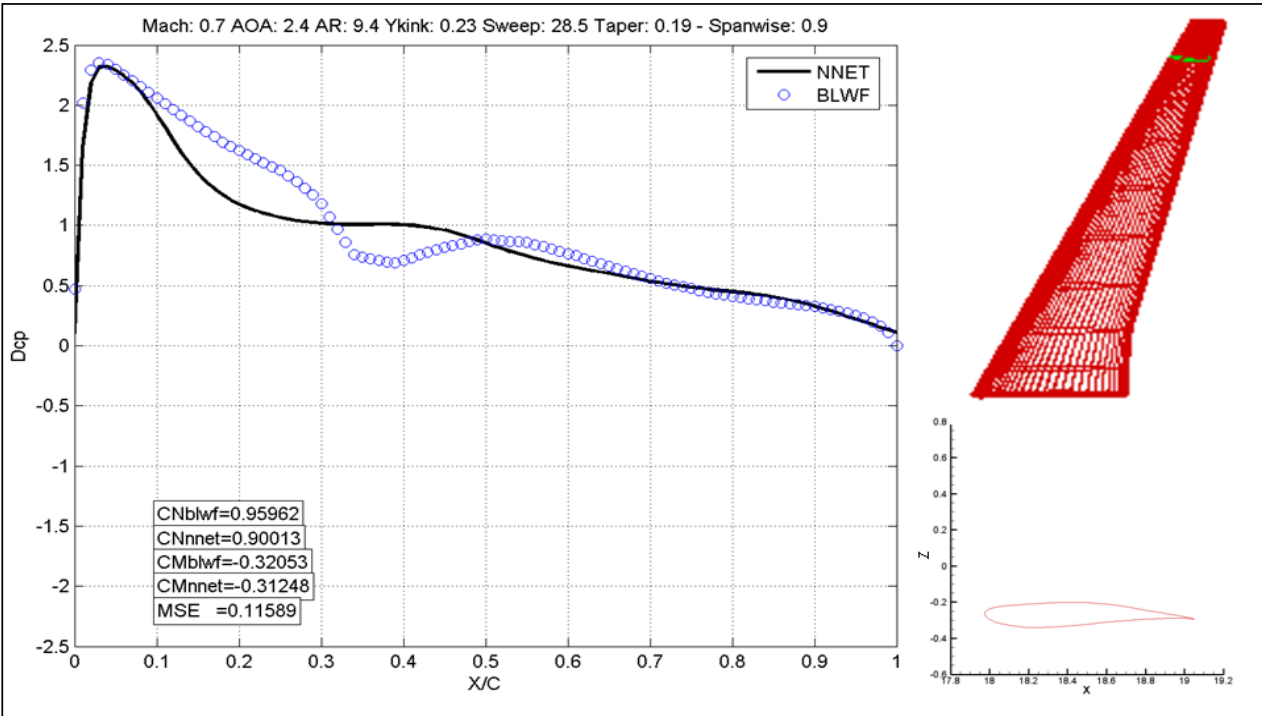

(c)

FIGURA 85: ESCOAMENTO SUBSONICO VALIDAÇÃO INDIVIDUO 5: (A) ESTAÇÃO NA RAIZ (B) ESTAÇÃO NO MEIO DA ASA (C) ESTAÇÃO NA PONTA DA ASA. 


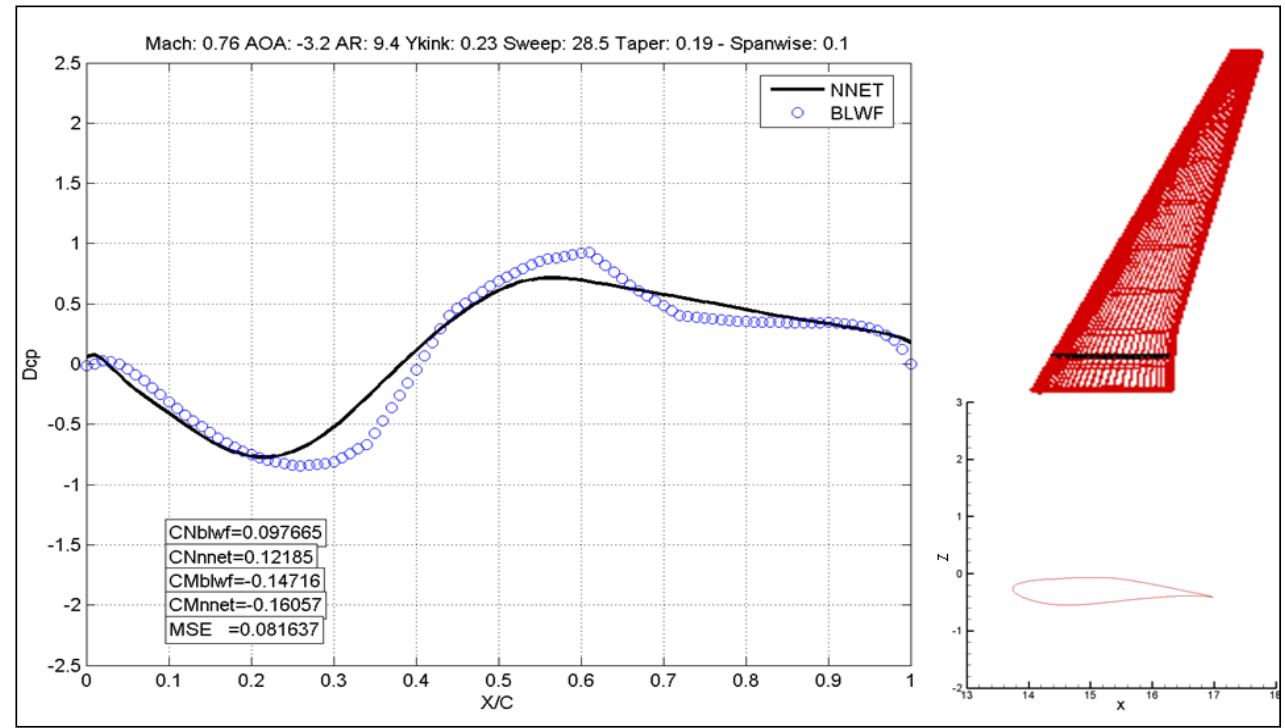

(a)

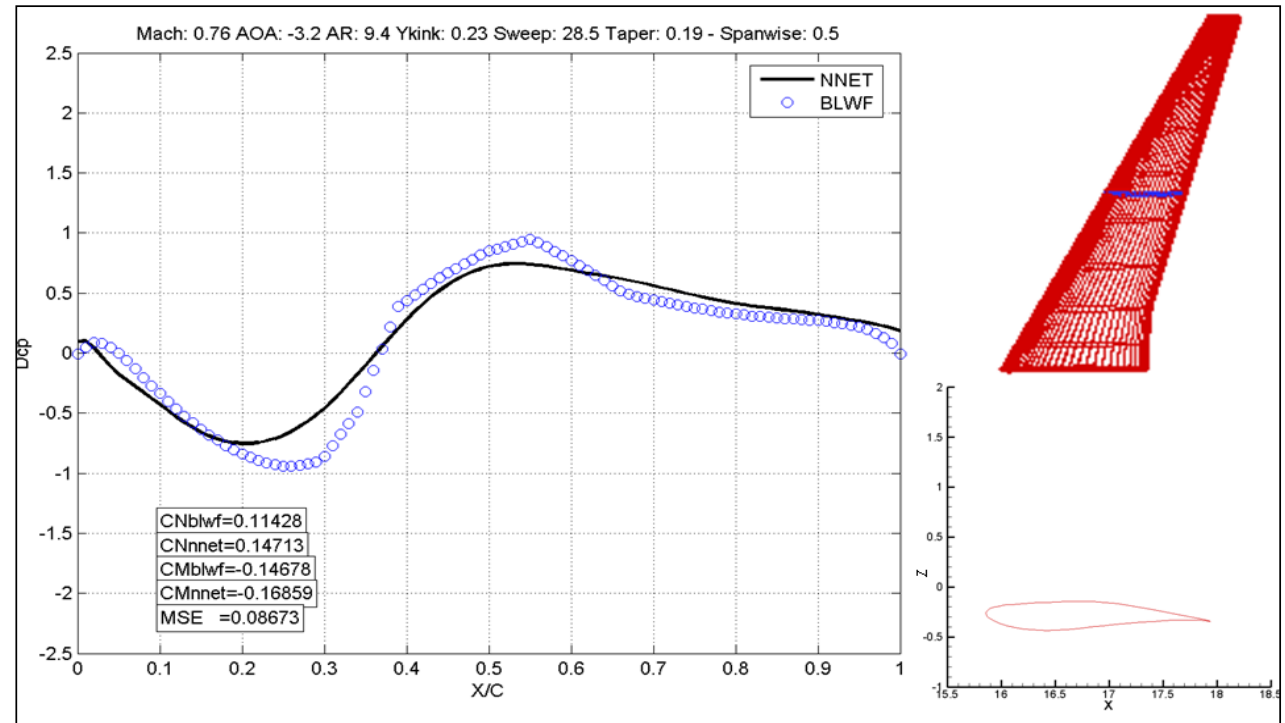

(b)

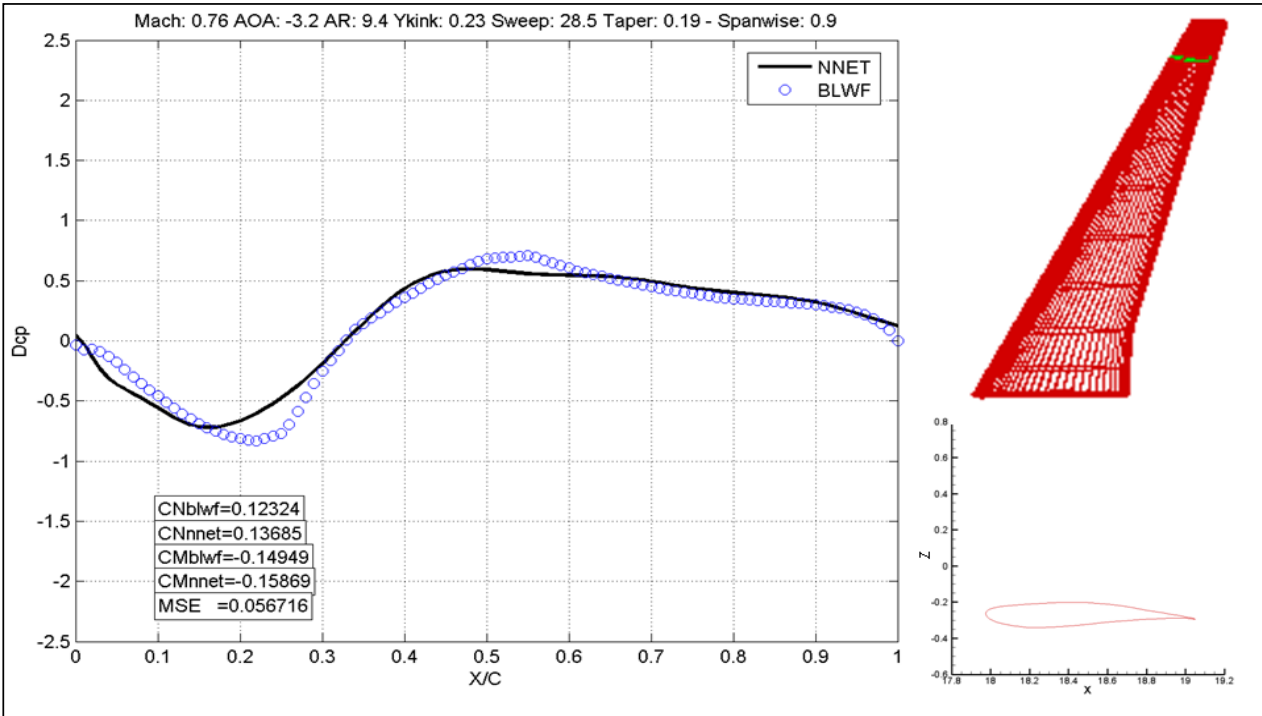

(c)

FIGURA 86: ESCOAMENTO TRANSONICO VALIDAÇÃO INDIVIDUO 5: (A) ESTAÇÃO NA RAIZ (B) ESTAÇÃO NO MEIO DA ASA (C) ESTAÇÃO NA PONTA DA ASA. 


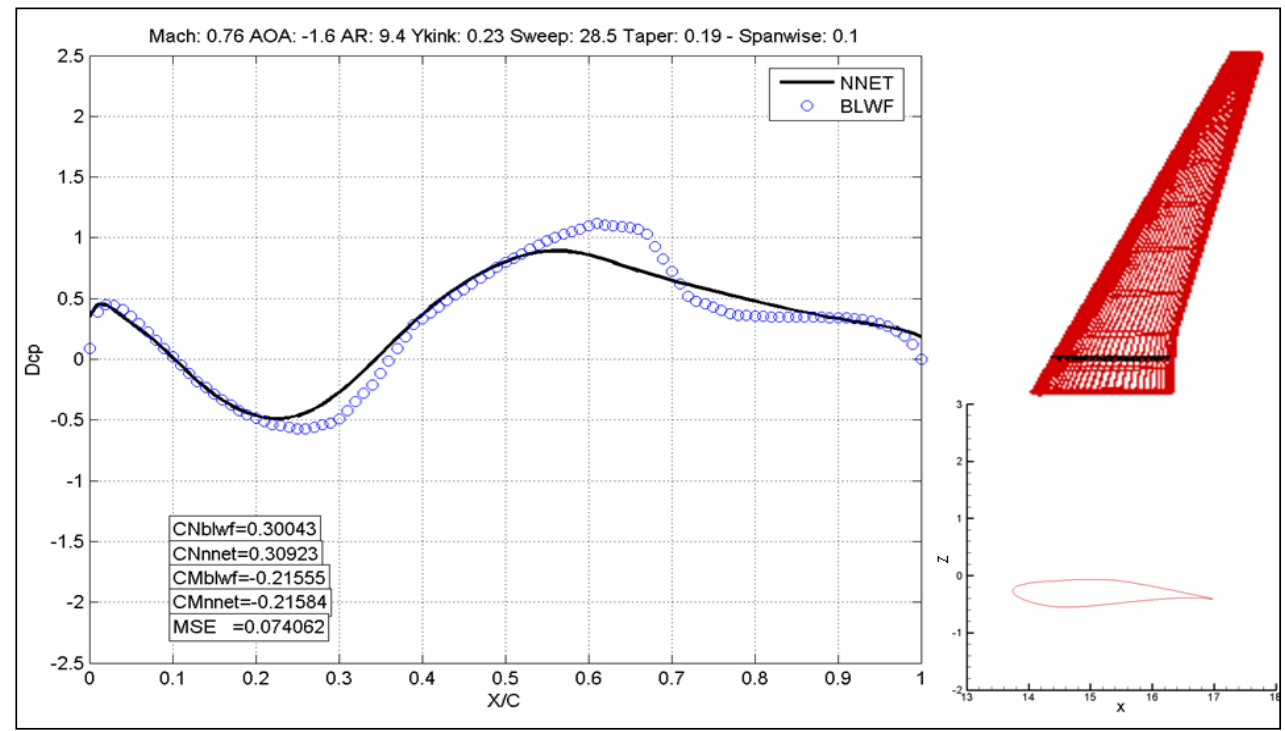

(a)

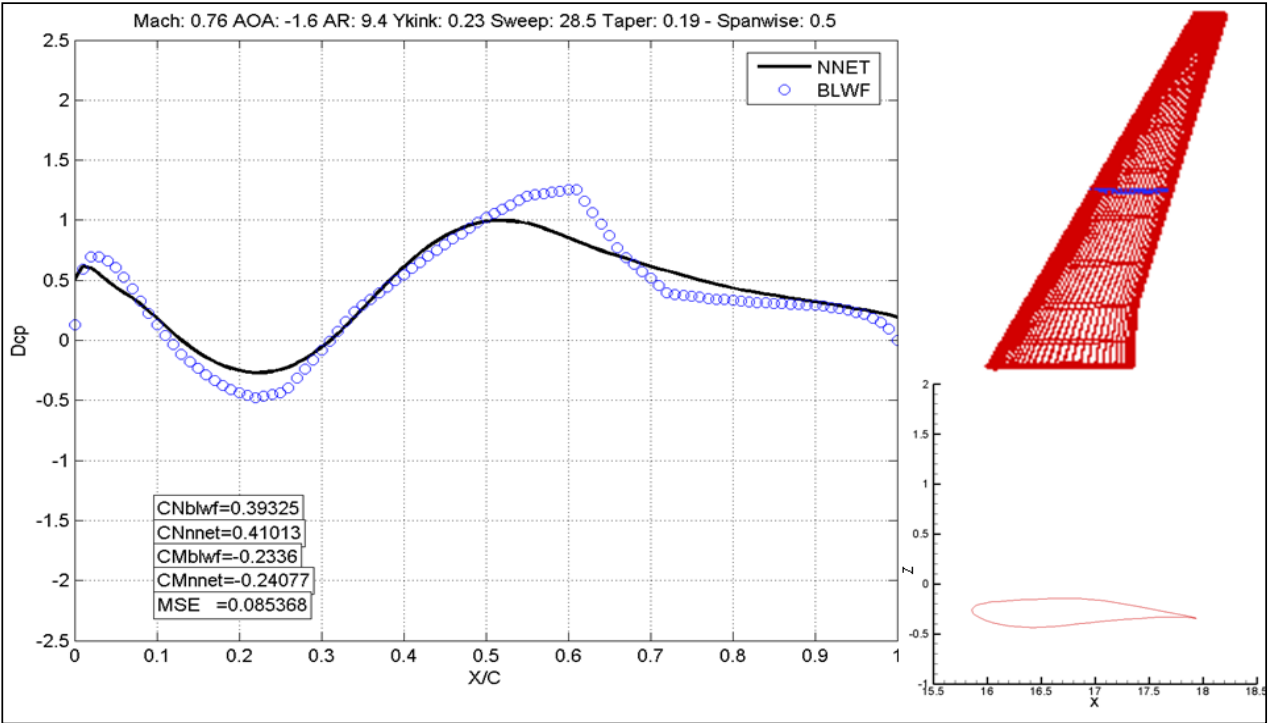

(b)

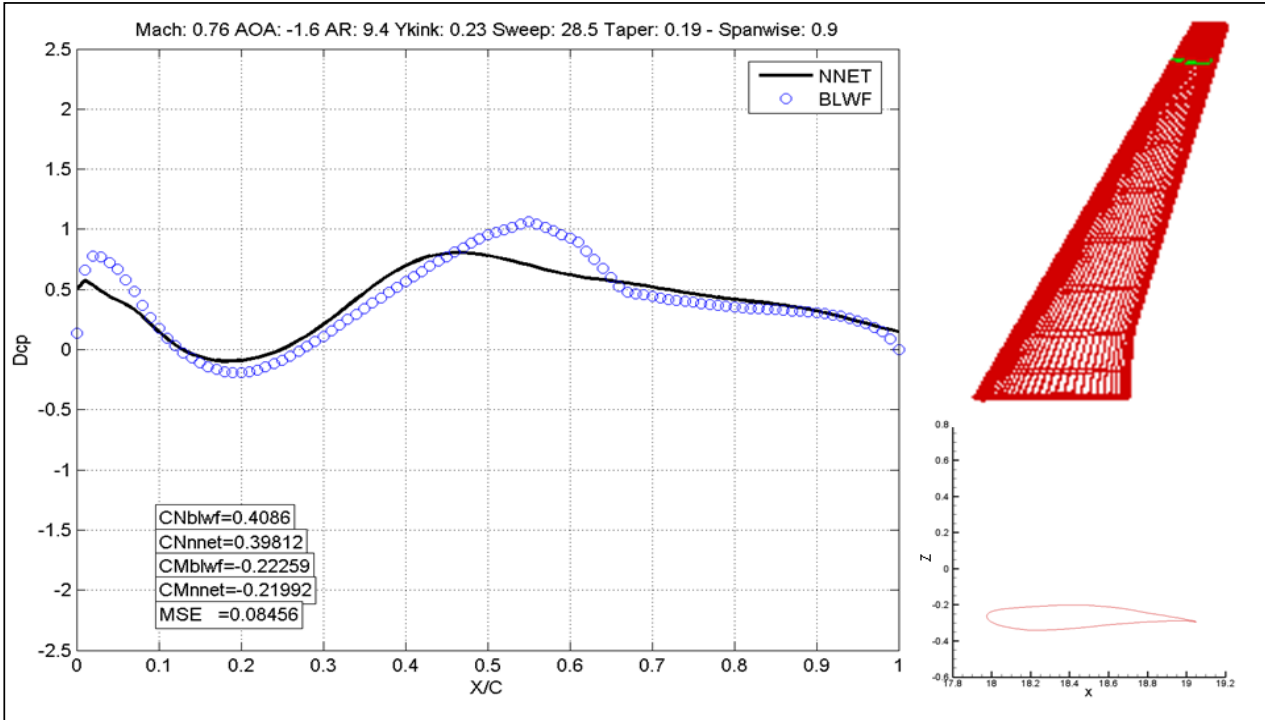

(c)

FIGURA 87: ESCOAMENTO TRANSONICO VALIDAÇÃO INDIVIDUO 5: (A) ESTAÇÃO NA RAIZ (B) ESTAÇÃO NO MEIO DA ASA (C) ESTAÇÃO NA PONTA DA ASA. 


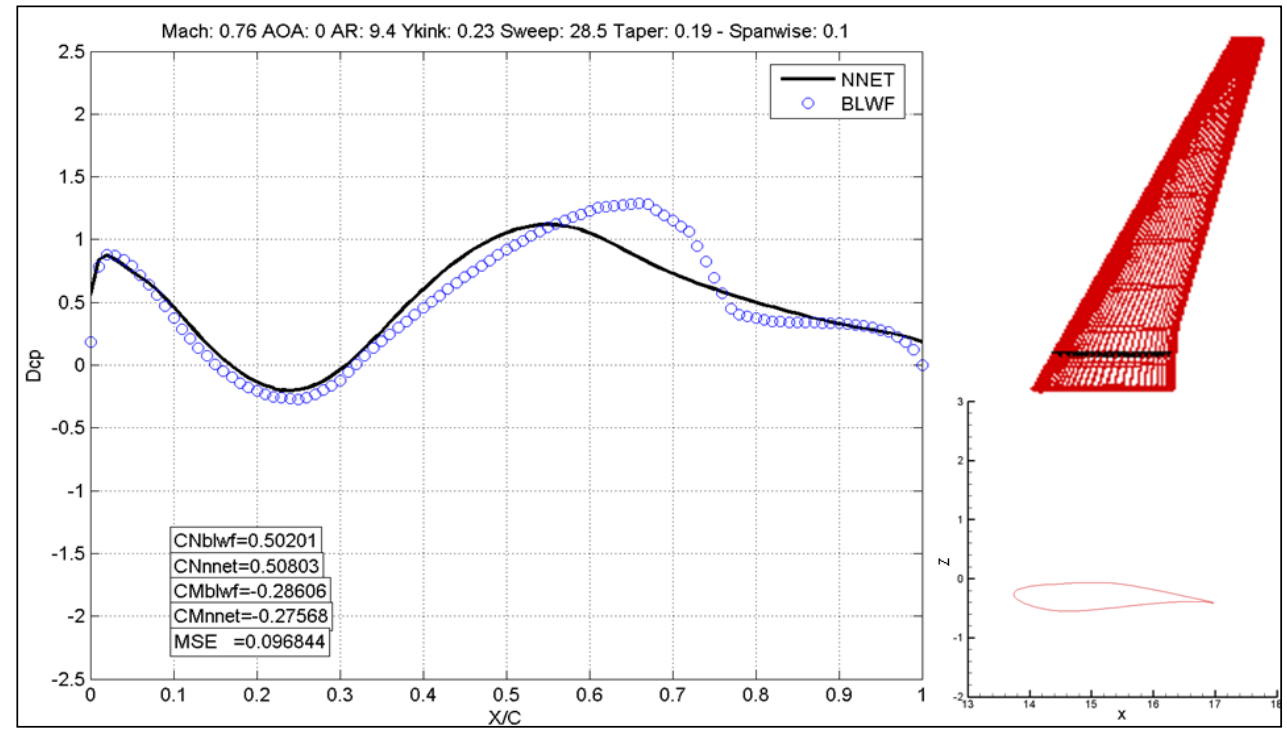

(a)

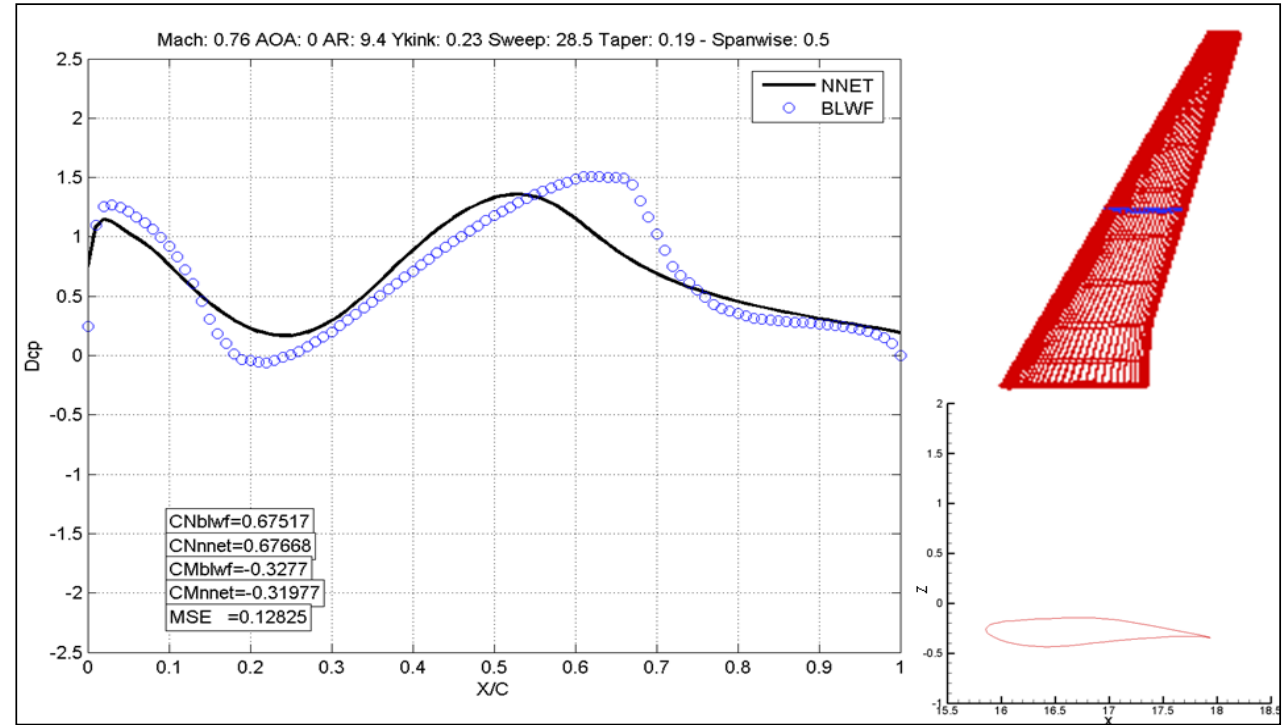

(b)

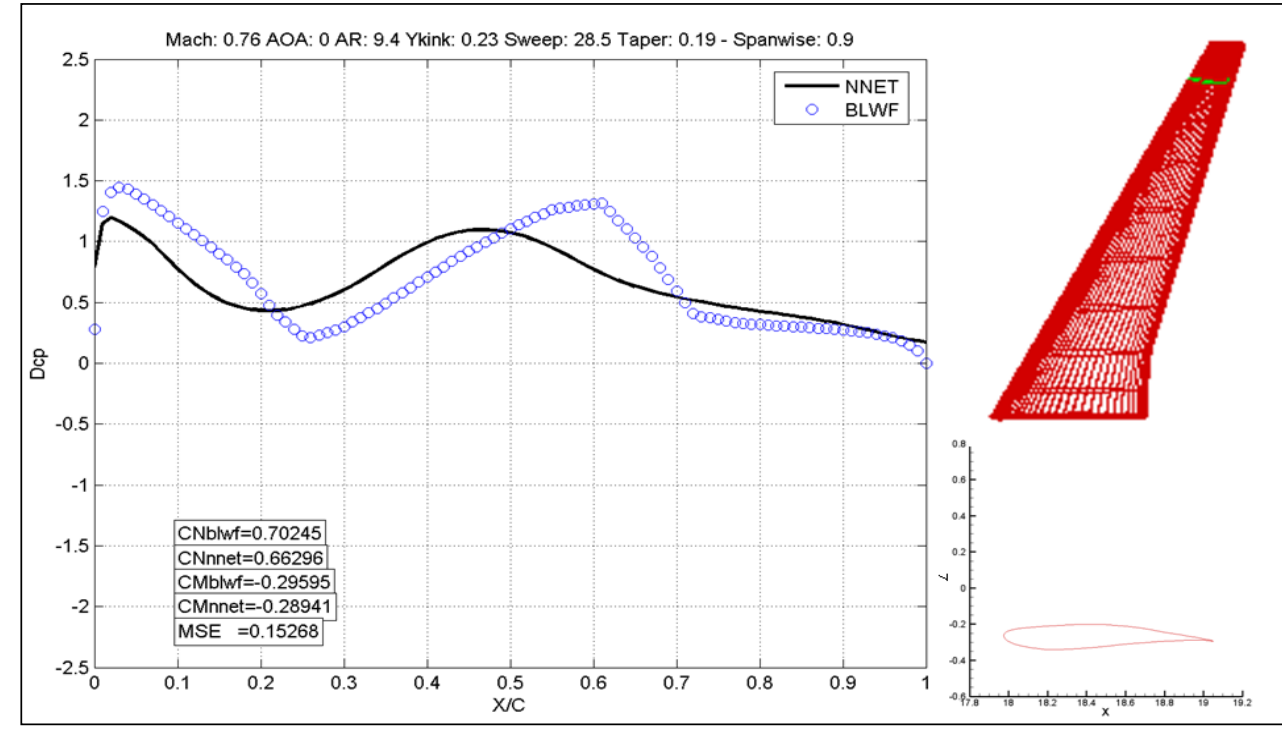

(c)

FIGURA 88: ESCOAMENTO TRANSONICO VALIDAÇÃO INDIVIDUO 5: (A) ESTAÇÃO NA RAIZ (B) ESTAÇÃO NO MEIO DA ASA (C) ESTAÇÃO NA PONTA DA ASA. 


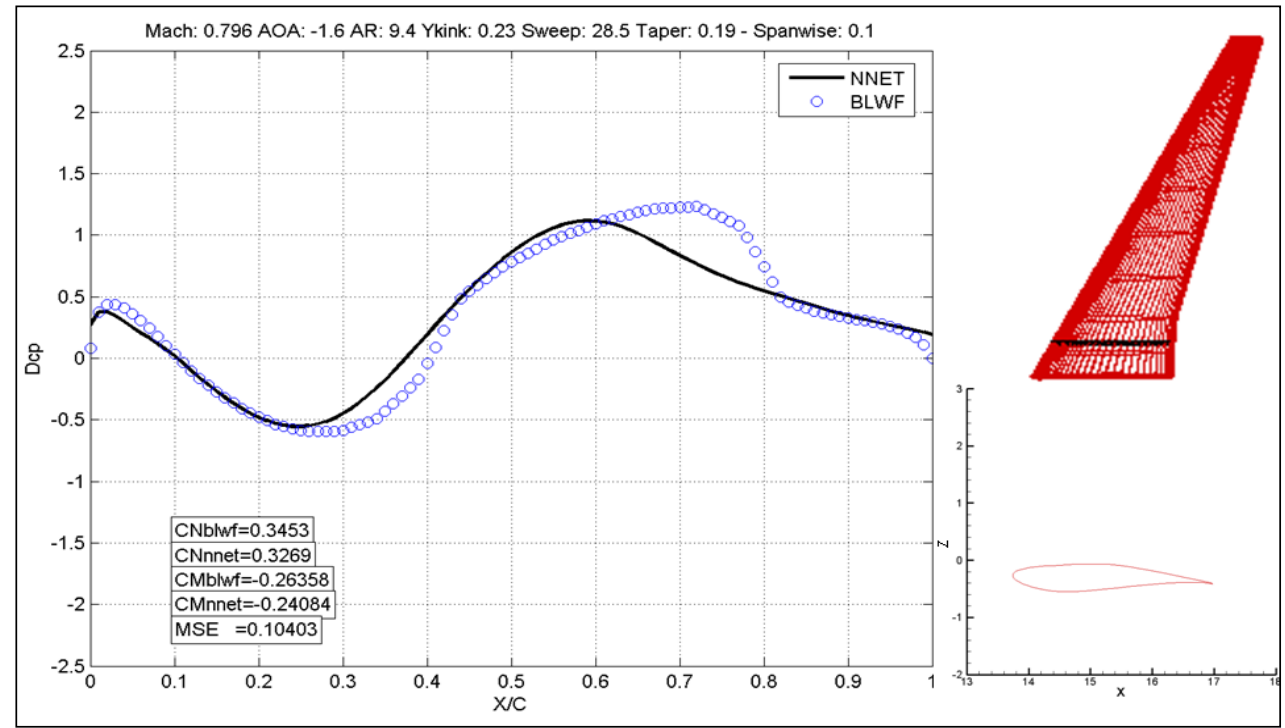

(a)

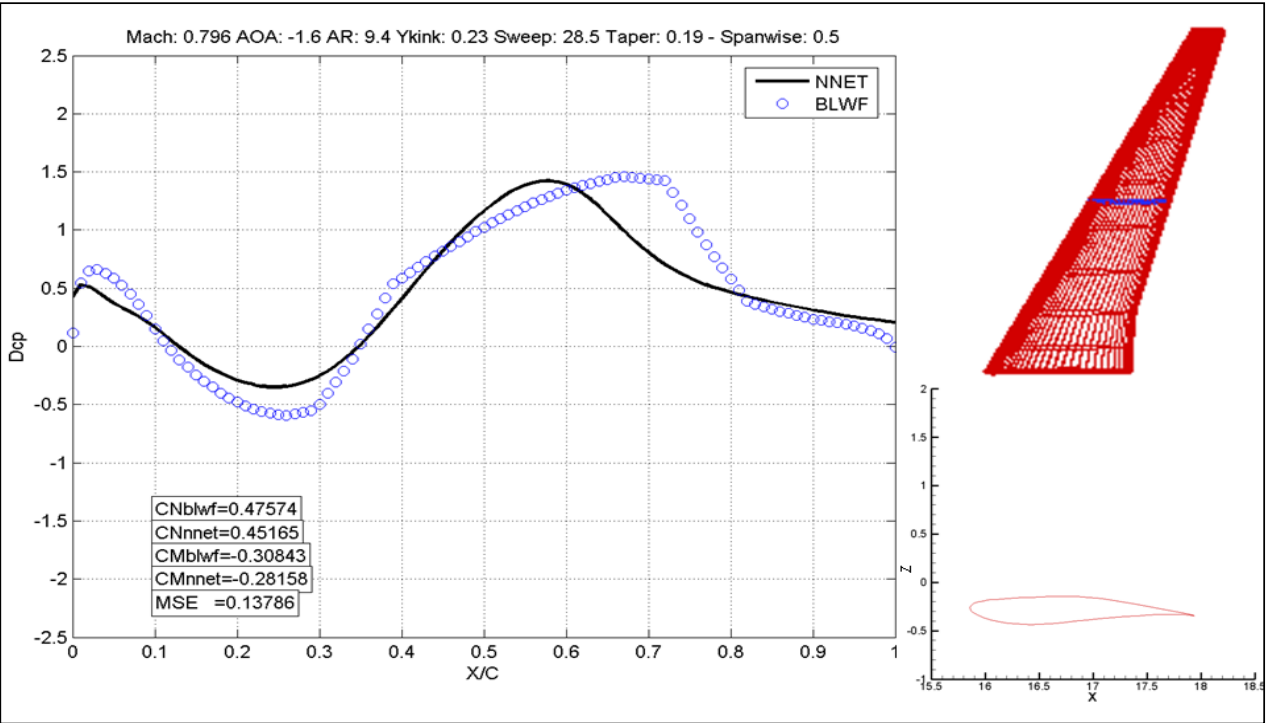

(b)

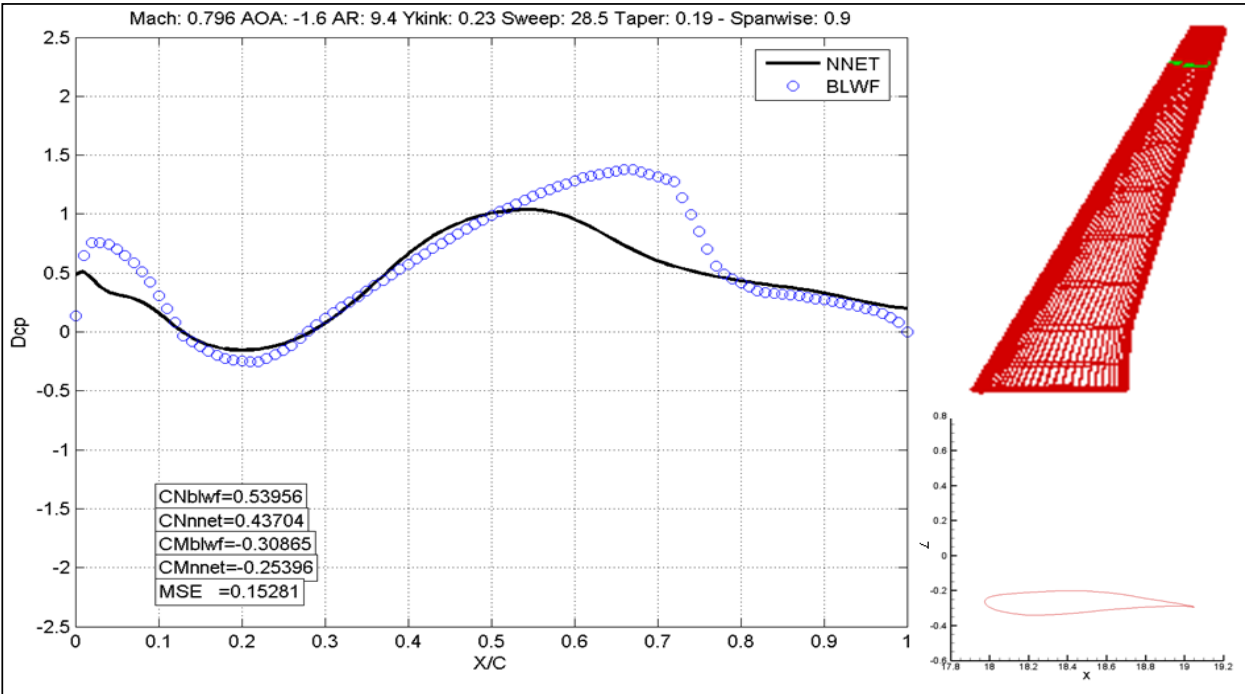

(c)

FIGURA 89: ESCOAMENTO TRANSONICO VALIDAÇÃO INDIVIDUO 5: (A) ESTAÇÃO NA RAIZ (B) ESTAÇÃO NO MEIO DA ASA (C) ESTAÇÃO NA PONTA DA ASA. 


\subsubsection{Rede tRansônica - ANÁlise de BaLANCEAMENTO do CONJUNTO DE TREINAMENTO}

Tendo em vista o problema da convergência do BLWF, o qual poderia gerar um desbalanceamento no conjunto de treinamento da rede, optou-se pela realização de uma análise mais aprofundada deste problema.

Decidiu-se analisar a distribuição dos indivíduos do conjunto final em relação ao Mach e ao ângulo de ataque, uma vez que estas são as variáveis que mais influem na convergência do BLWF. Para isto foi feito um gráfico de distribuição populacional dos indivíduos baseado nas variáveis acima citadas. O resultado pode ser visto na Figura 90.

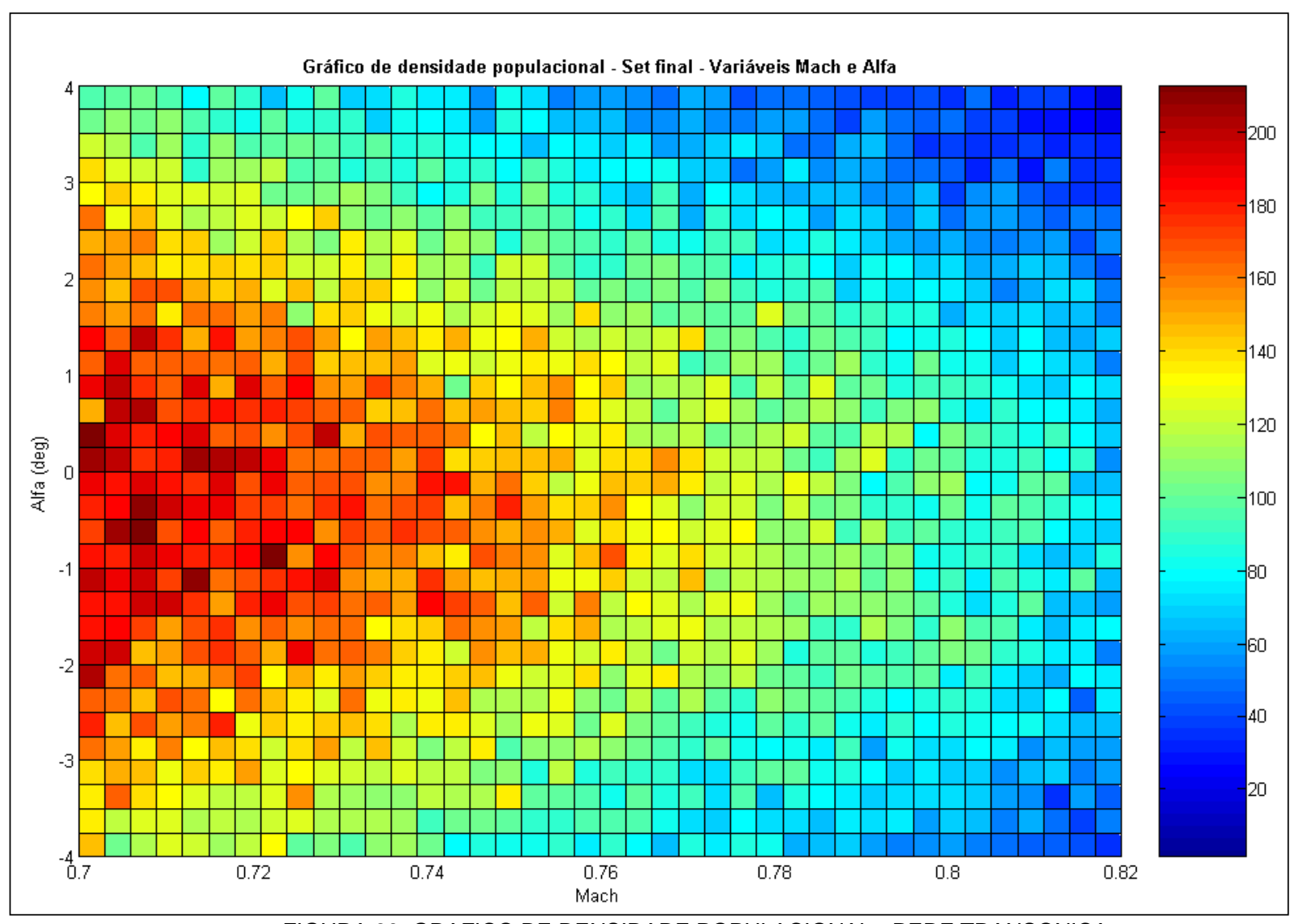

FIGURA 90: GRAFICO DE DENSIDADE POPULACIONAL - REDE TRANSONICA

Pela análise da Figura 90, percebe-se claramente a existência de uma quantidade menor de indivíduos na região de Mach maior, especialmente nas proximidades das fronteiras de alfa. Este resultado aponta para uma possibilidade 
de desbalanceamento no conjunto de treinamento utilizado para treinar a rede transônica, fato prejudicial à eficiência da rede.

Deste modo, um novo conjunto de treinamento foi gerado para mensurar o impacto deste nível de desbalanceamento na rede, com uma distribuição mais uniforme de indivíduos em todas as faixas de Mach, levando em conta os problemas de convergência do BLWF em condições de separação de camada limite.

A estratégia inicial consistia em um estudo da convergência do BLWF por zonas de Mach, cujo resultado serviria de base para a montagem de DOE's específicos a cada umas destas zonas, a fim de que o número de indivíduos resultantes em cada zona fosse parecido. Garantiria-se, assim, a obtenção de um conjunto mais balanceado que o anterior, ao menos no tocante às variáveis ângulo de ataque e número de Mach.

Seria possível que a aplicação desse procedimento causasse o desbalanceamento das demais variáveis do conjunto de treinamento; sabe-se, no entanto, que o Mach e o ângulo de ataque são váriáveis muito mais relevantes que as demais na convergência do CFD. Por tal razão, esta foi a solução escolhida.

Este novo conjunto de treinamento foi gerado seguindo a estratégia descrita acima e inicialmente, antes de passar pelo CFD, contava com 357.650 indivíduos.

A Figura 91 mostra um gráfico de densidade populacional deste novo conjunto de treinamento que será descrito daqui para frente como conjunto de treinamento transônico balanceado. 


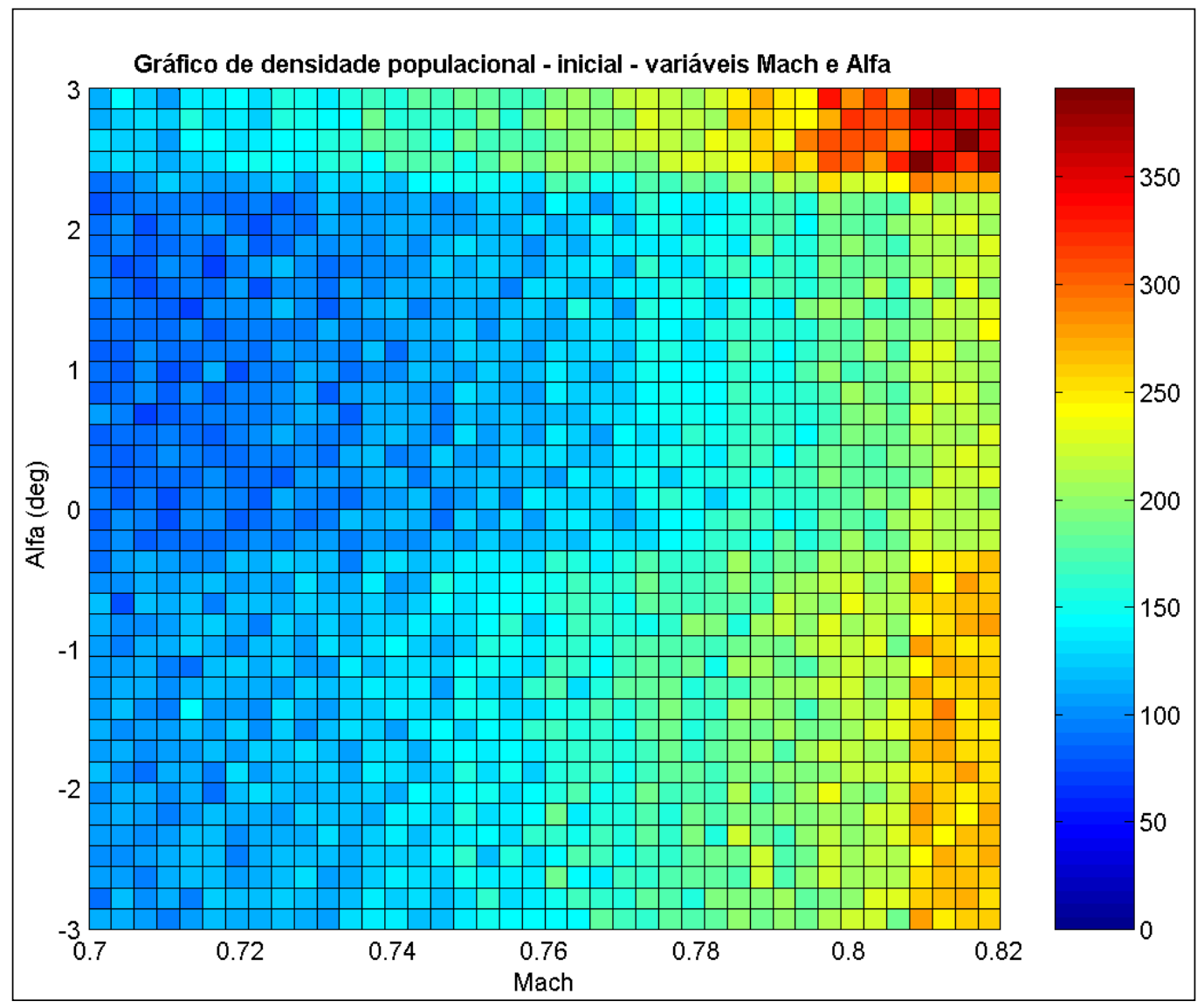

FIGURA 91: DENSIDADE POPULACIONAL DO CONJUNTO DE TREINAMENTO ANTES DO CFD

Esta Figura mostra claramente uma região "menos povoada", na região de baixo número de Mach e ângulo de ataque e regiões mais povoadas, concentradas nas regiões de números de Mach maiores. Como dito anteriormente, isto foi feito para que após a submissão deste conjunto ao CFD o resultado seja um conjunto mais uniforme.

Este conjunto foi submetido ao CFD e 174.611 indivíduos obtiveram convergência. O gráfico de densidade populacional deste conjunto após o CFD pode ser visto na Figura 92. 


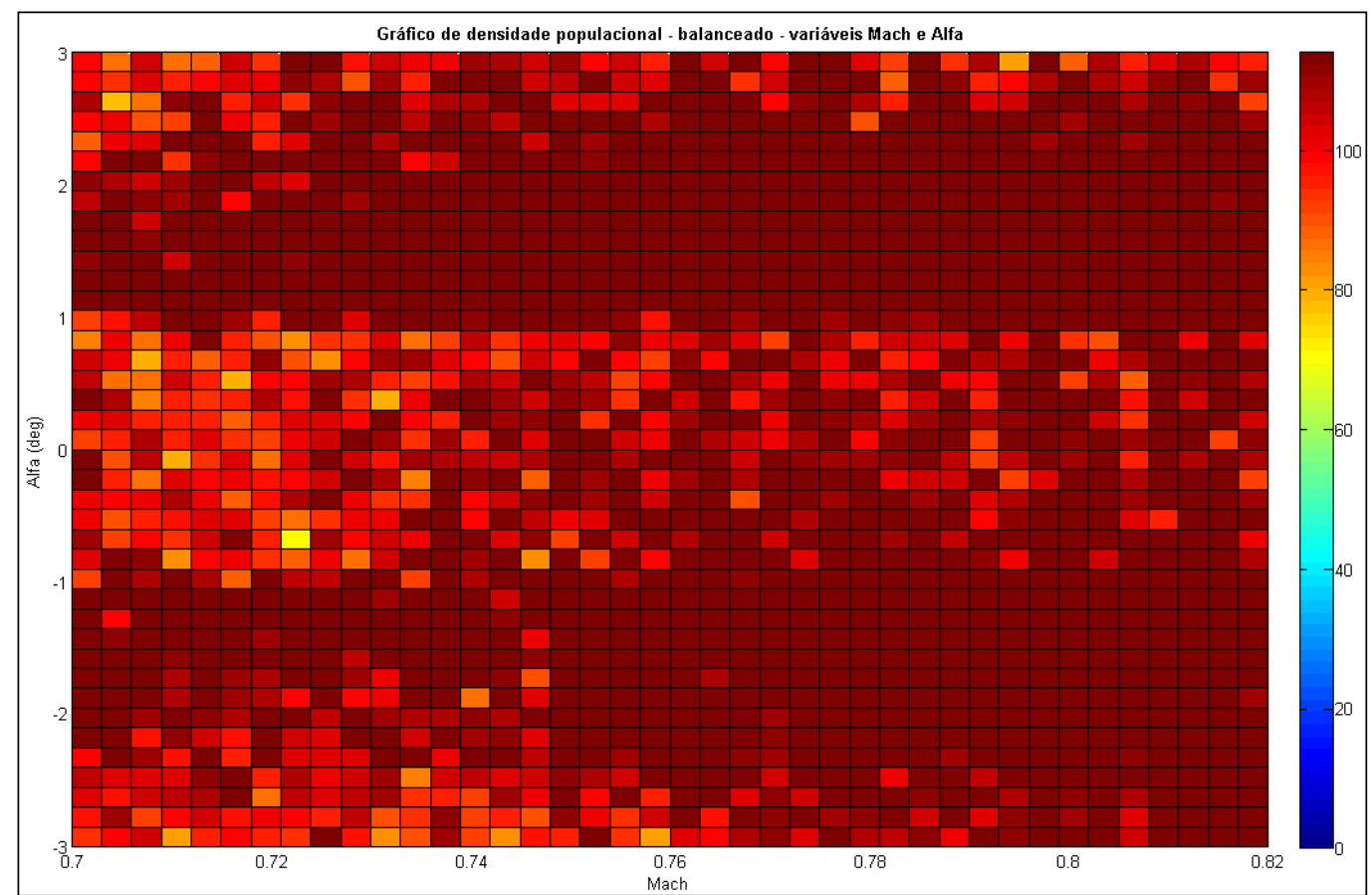

FIGURA 92: DENSIDADE POPULACIONAL DO CONJUNTO DE TREINAMENTO DEPOIS DO CFD

Aparentemente, pela análise da Figura 92, o objetivo que motivou a construção deste conjunto foi alcançado, ou seja, os indivíduos do conjunto que obtiveram convergência no CFD formaram um conjunto bem mais balanceado que o utilizado para o treinamento da rede transônica anterior do ponto de vista das variáveis número de Mach e ângulo de ataque.

Uma nova rede foi treinada com este conjunto de treinamento. Para este treinamento todos os parâmetros de rede foram mantidos, como a arquitetura, tipos de função de ativação e condição de parada (treinamento finalizado em 1000 épocas).

Submentendo a rede ao mesmo conjunto de validação usado nas redes anteriores, com 726 pontos de validação, podemos observar que o resultado foi bastante parecido com o obtido na rede anterior, como pode ser visto na Tabela 15. 
TABELA 16: RESULTADOS PARA REDE TRANSÔNICA BALANCEADA COM PERFIS VARIAVEIS.

\begin{tabular}{|l|c|}
\hline Média dos erros absolutos de CN & 0.0275 \\
\hline Média dos erros absolutos de CM & 0.0132 \\
\hline Média dos erros relativos de CN & 0.2868 \\
\hline Média dos erros relativos de CM & 0.0740 \\
\hline Desvio padrão dos erros relativos de CN & 0.0263 \\
\hline Desvio padrão dos erros relativos de CM & 0.0150 \\
\hline Erro médio quadrático & 0.0793 \\
\hline
\end{tabular}

Este resultado seria desapontador se analisado apenas por estes dados. Porém, também na validação o CFD apresenta dificuldade de convergência com relação ao número de Mach e ângulos de ataque, e quando o CFD não obtem convergência a validação não pode ser feita. Desta forma, com este conjunto e treinamento fica dificil apontar uma melhoria na eficiência da rede.

Assim, optou-se por criar mais dois novos indivíduos, com perfilagem supercrítica de modo a facilitar a convergência do CFD e possibilitar a comparação. Uma figura mostrando estes dois novos indivíduos pode ser vista abaixo:

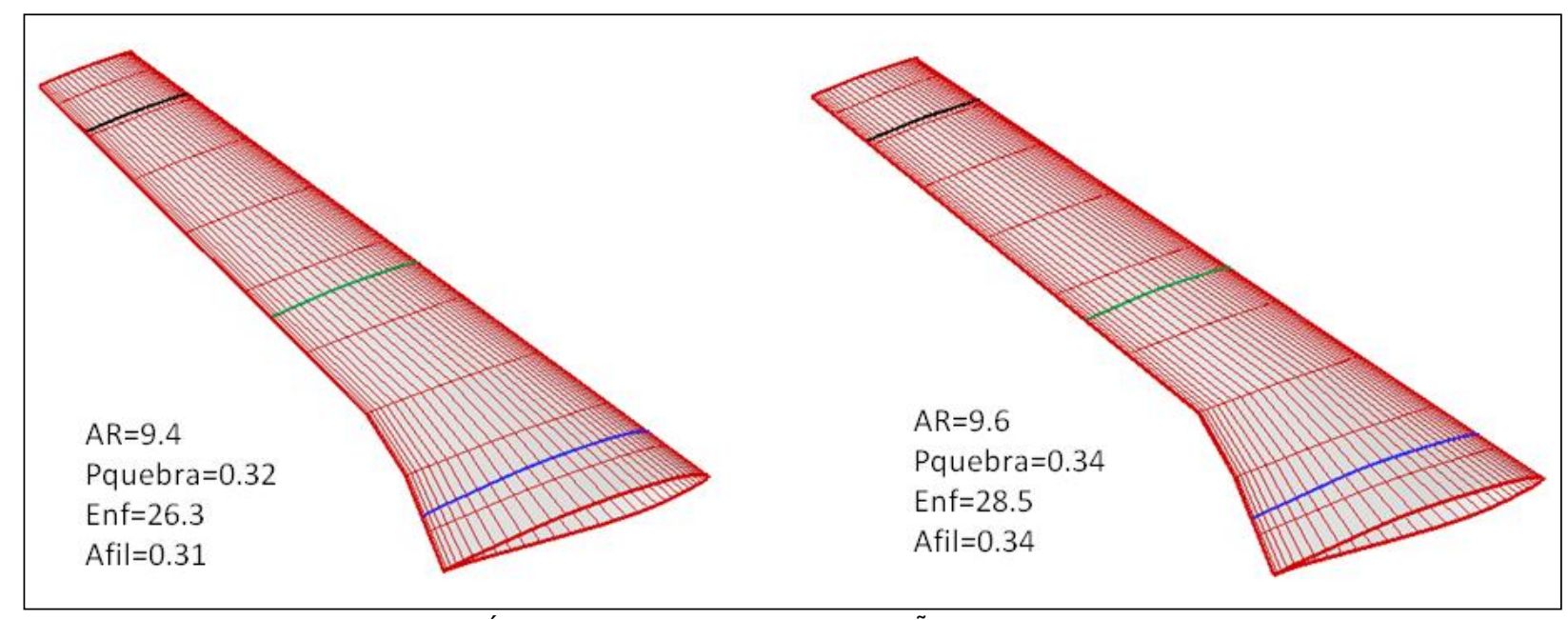

FIGURA 93: NOVOS INDIVÍDUOS GERADOS PARA VALIDAÇÃO - NUMEROS DE MACH MAIORES.

Optou-se por fazer a nova validação para comparação de desempenho das duas redes transônicas apenas na faixa superior de Mach, já que na validação anterior percebeu-se um desempenho semelhante. Os limites de número de Mach e ângulo de ataque escolhidos foram: 
TABELA 17: CONDIÇÕES DE VOO ESCOLHIDAS PARA A VALIDAÇÃO DAS REDES TRANSÔNICAS.

\begin{tabular}{|c|c|c|c|}
\hline Variável & Limite inferior & Limite superior & Incremento \\
\hline Número de Mach & 0.76 & 0.82 & 0.015 \\
\hline Ângulo de ataque & $-3.0^{\circ}$ & $3.0^{\circ}$ & $0.3^{\circ}$ \\
\hline
\end{tabular}

Assim, com 2 indivíduos, obteve-se um conjunto de validação com 210 pontos.

Ambas as redes foram validadas com este conjunto de validação. Dos 210 pontos submetidos às redes e ao CFD, 170 obtiveram convergência no CFD, o que possibilita uma comparação melhor para o limite superior de Mach.

\subsubsection{Resultados da Rede Neural de Perfis Variáveis - Transônica Balanceada}

As Figuras 94 a 98 mostram os resultados obtidos na validação da rede transônica balanceada comparados com os obtidos pela rede neural transônica nãobalanceada. Nestas figuras os circulos azuis mostram os resultados obtidos via CFD enquanto que a linha cheia na cor verde mostra os resultados obtidos pela rede neural balanceada e a linha cheia na cor vermelha traz os resultados obtidos pela rede neural não-balanceada.

Os resultados mostraram que a rede transônica balanceada foi capaz de representar melhor o comportamento da distribuição de pressão do que a rede transônica sem balanceamento, comprovando a tese de que o desbalanceamento do conjunto de treinamento poderia estar afetado o desempenho da rede para regiões de Mach e alfas grandes.

As Tabelas 17 e 18 mostram os resultados em termos de coeficientes de força e momento para as redes transônicas não-balanceada e balanceada. 
TABELA 18: RESULTADOS PARA REDE TRANSÔNICA NÃO BALANCEADA COM PERFIS VARIAVEIS.

\begin{tabular}{|l|l|}
\hline Média dos erros absolutos de CN & 0.0848 \\
\hline Média dos erros absolutos de CM & 0.0286 \\
\hline Média dos erros relativos de CN & 9.1013 \\
\hline Média dos erros relativos de CM & 0.4822 \\
\hline Desvio padrão dos erros relativos de CN & 0.0543 \\
\hline Desvio padrão dos erros relativos de CM & 0.0171 \\
\hline Erro médio quadrático & 0.1332 \\
\hline
\end{tabular}

TABELA 19: RESULTADOS PARA REDE TRANSÔNICA BALANCEADA COM PERFIS VARIAVEIS.

\begin{tabular}{|l|l|}
\hline Média dos erros absolutos de CN & 0.0209 \\
\hline Média dos erros absolutos de CM & 0.0099 \\
\hline Média dos erros relativos de CN & 0.3298 \\
\hline Média dos erros relativos de CM & 0.1331 \\
\hline Desvio padrão dos erros relativos de CN & 0.0150 \\
\hline Desvio padrão dos erros relativos de CM & 0.0071 \\
\hline Erro médio quadrático & 0.1176 \\
\hline
\end{tabular}

Pode-se perceber que o erro do coeficiente de força normal (CN) baixou cerca de quatro vezes. O coeficiente de momento de arfagem diminuiu cerca de três vezes da rede não-balanceada para a rede balanceada. Resultados semelhantes ocorreram com os desvios padrão destes coeficientes. Por estes resultados fica mais evidente a melhora na capacidade de generalidade da rede neural transônica. 


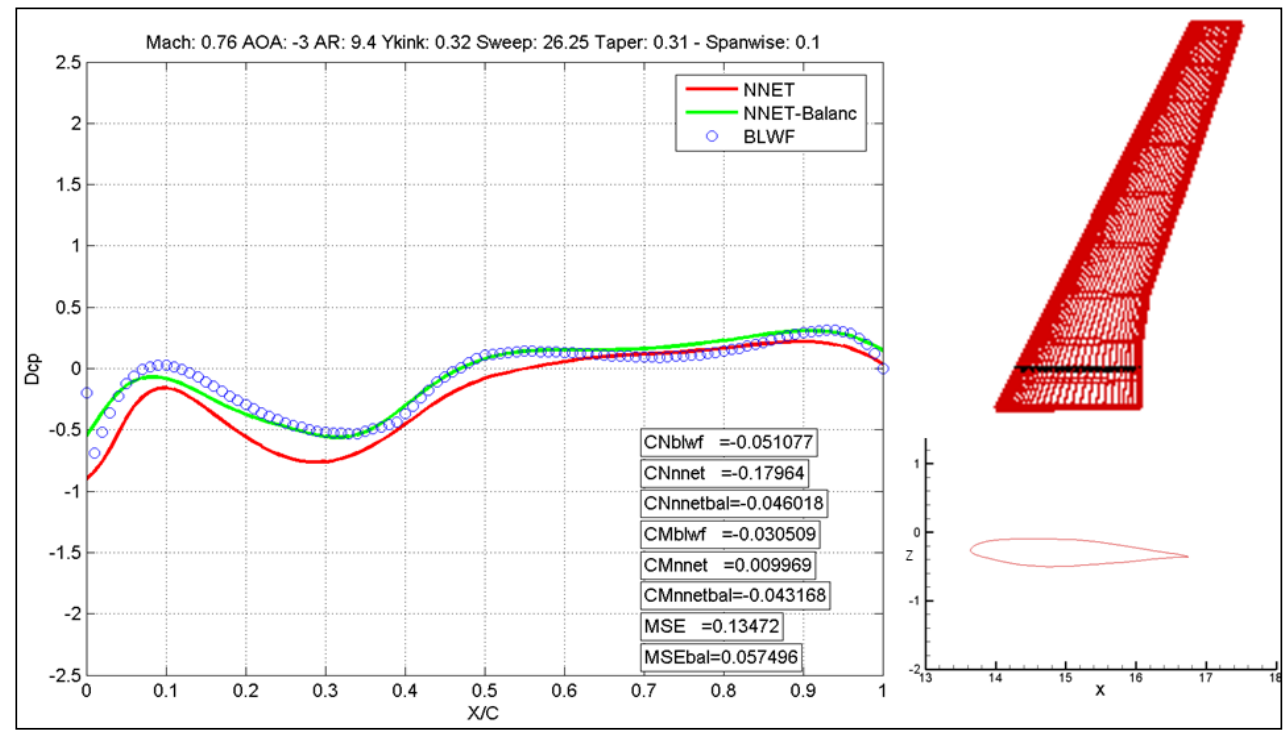

(a)

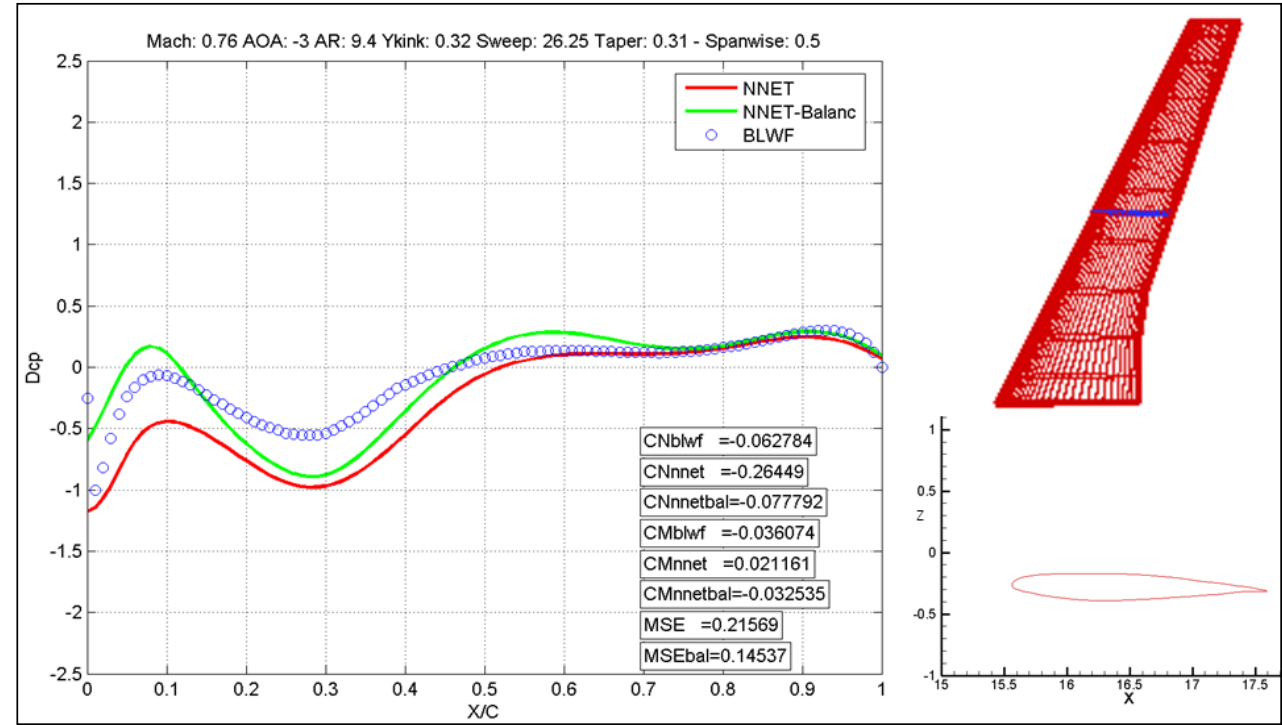

(b)

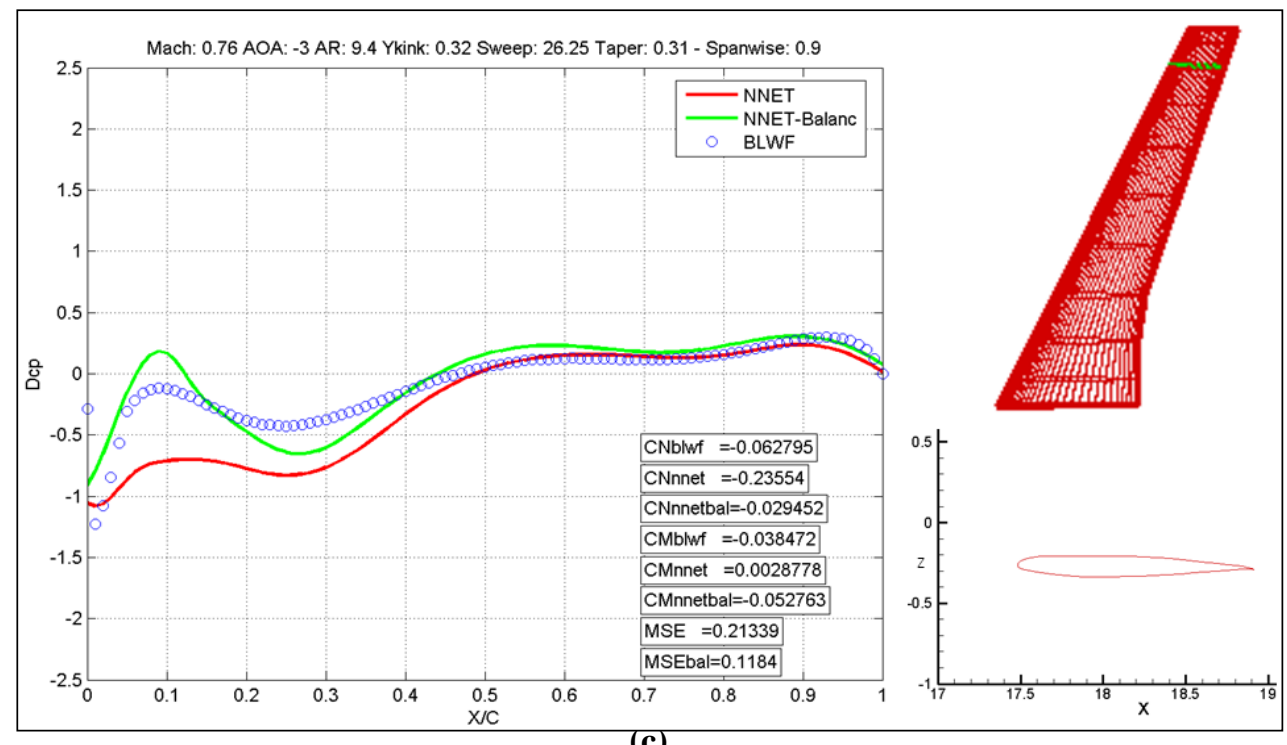

FIGURA 94: ESCOAMENTO TRANSONICO REDE BALANCEADA E NÃO BALANCEADA - INDIVUDUO 1: (A) ESTAÇÃO NA RAIZ (B) ESTAÇÃO NO MEIO DA ASA (C) ESTAÇÃO NA PONTA DA ASA. 


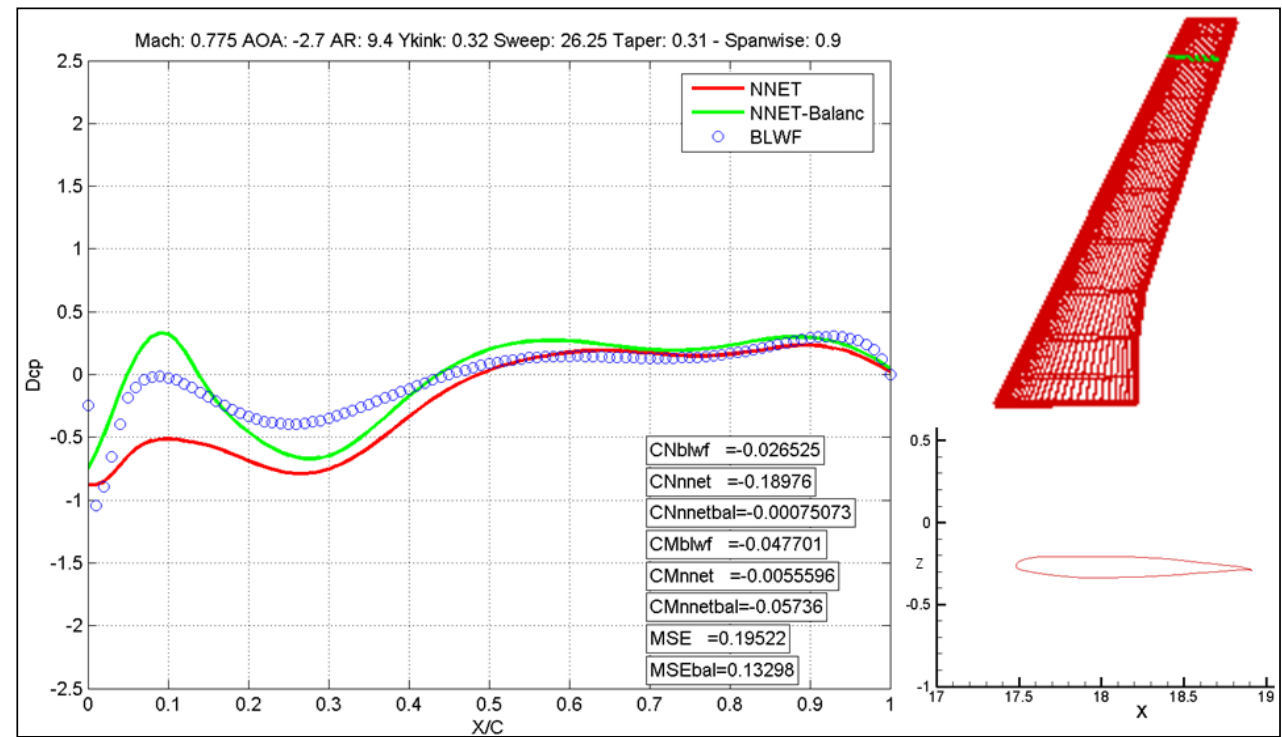

(a)

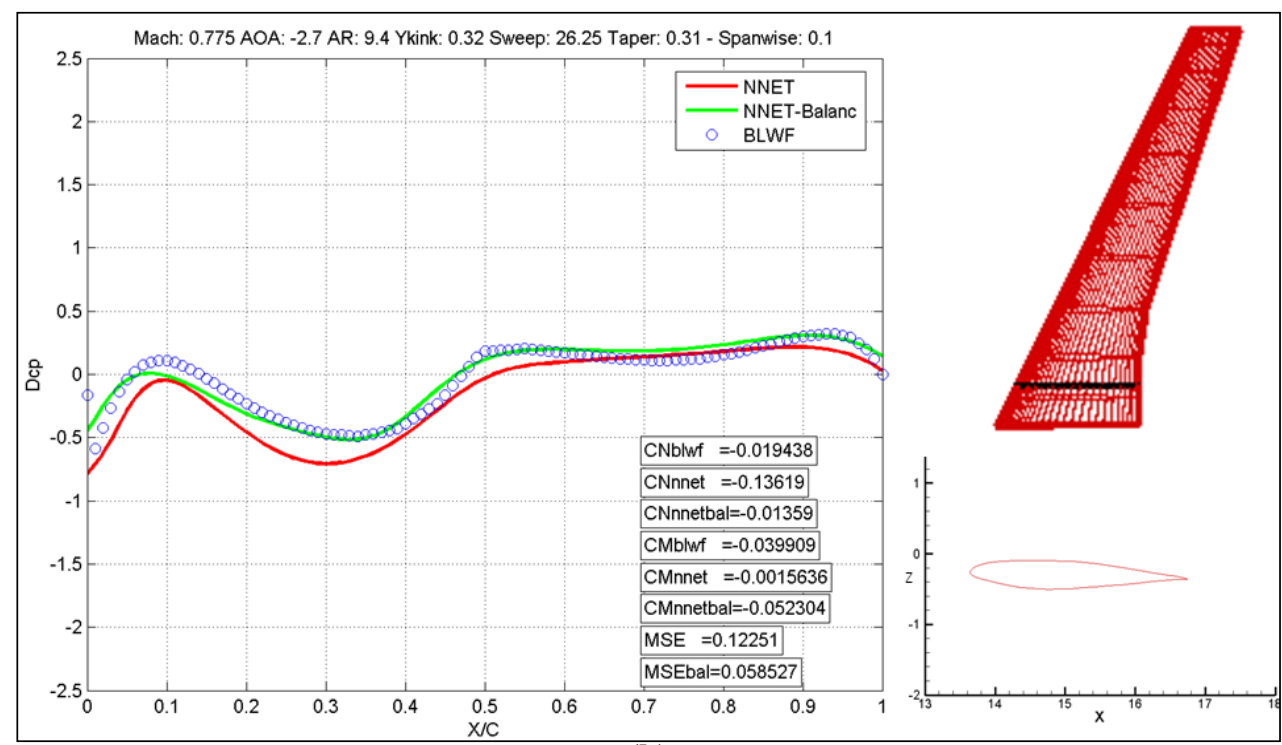

(b)

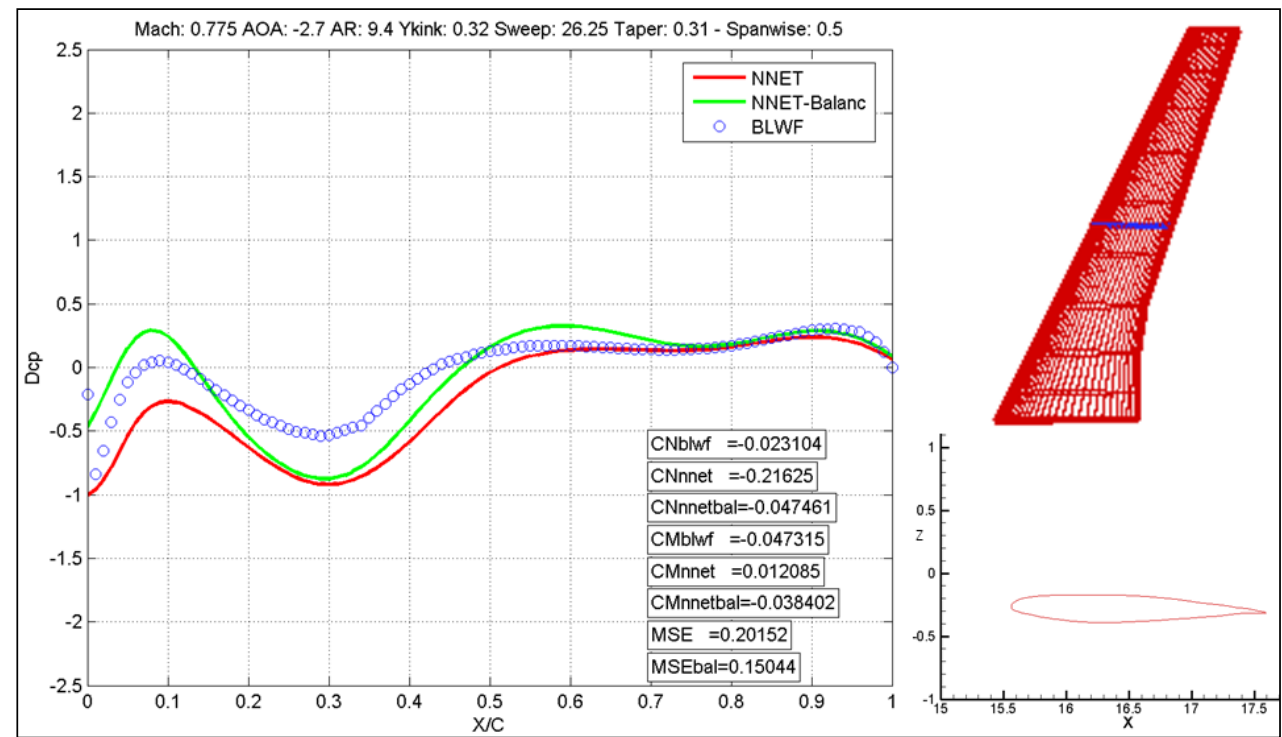

(c)

FIGURA 95: ESCOAMENTO TRANSONICO REDE BALANCEADA E NÃO BALANCEADA - INDIVUDUO 1: (A) ESTAÇÃO NA RAIZ (B) ESTAÇÃO NO MEIO DA ASA (C) ESTAÇÃO NA PONTA DA ASA. 


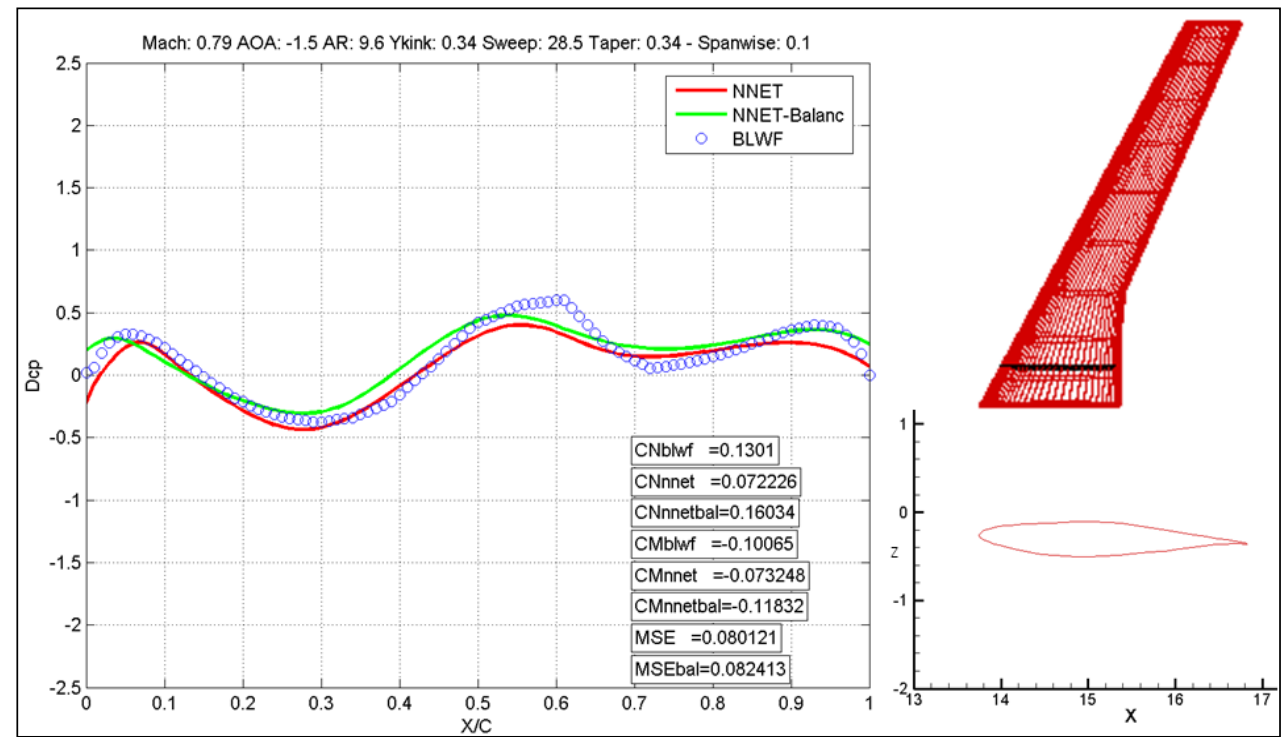

(a)

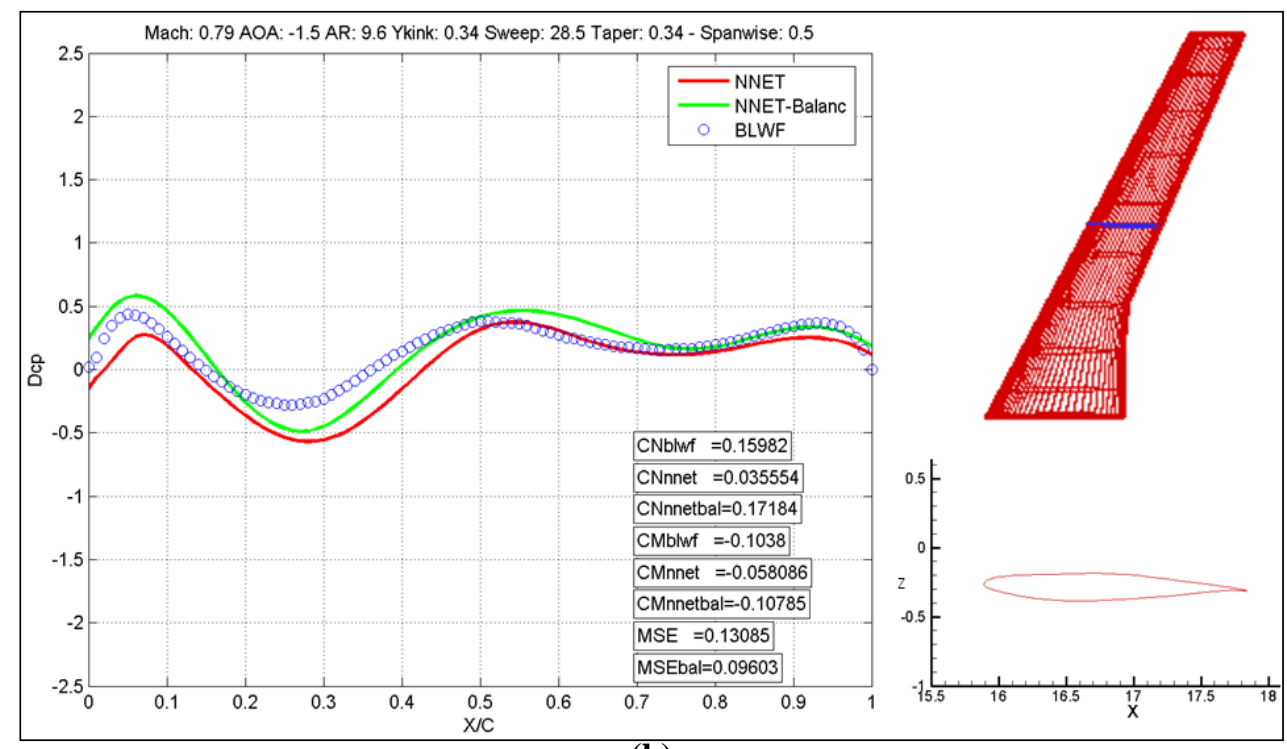

(b)

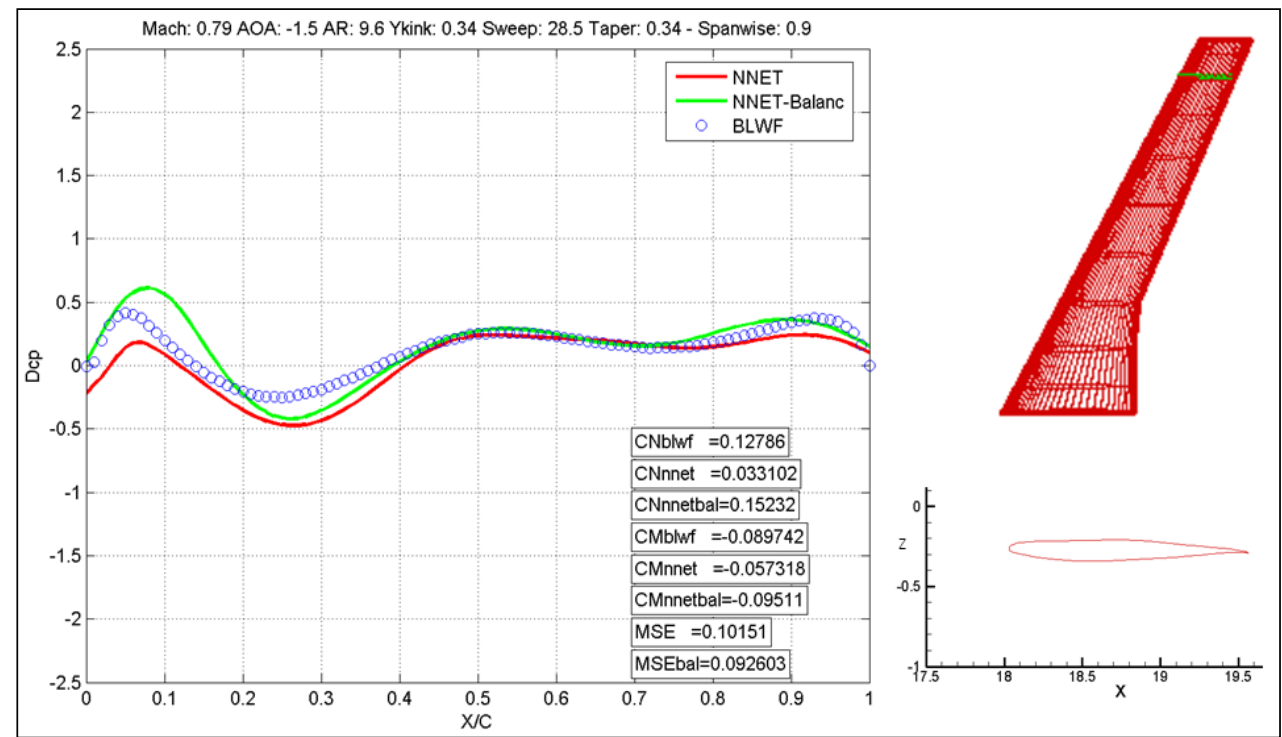

(c)

FIGURA 96: ESCOAMENTO TRANSONICO REDE BALANCEADA E NÃO BALANCEADA - INDIVUDUO 2: (A) ESTAÇ̃̃O NA RAIZ (B) ESTAÇÃO NO MEIO DA ASA (C) ESTAÇÃO NA PONTA DA ASA. 


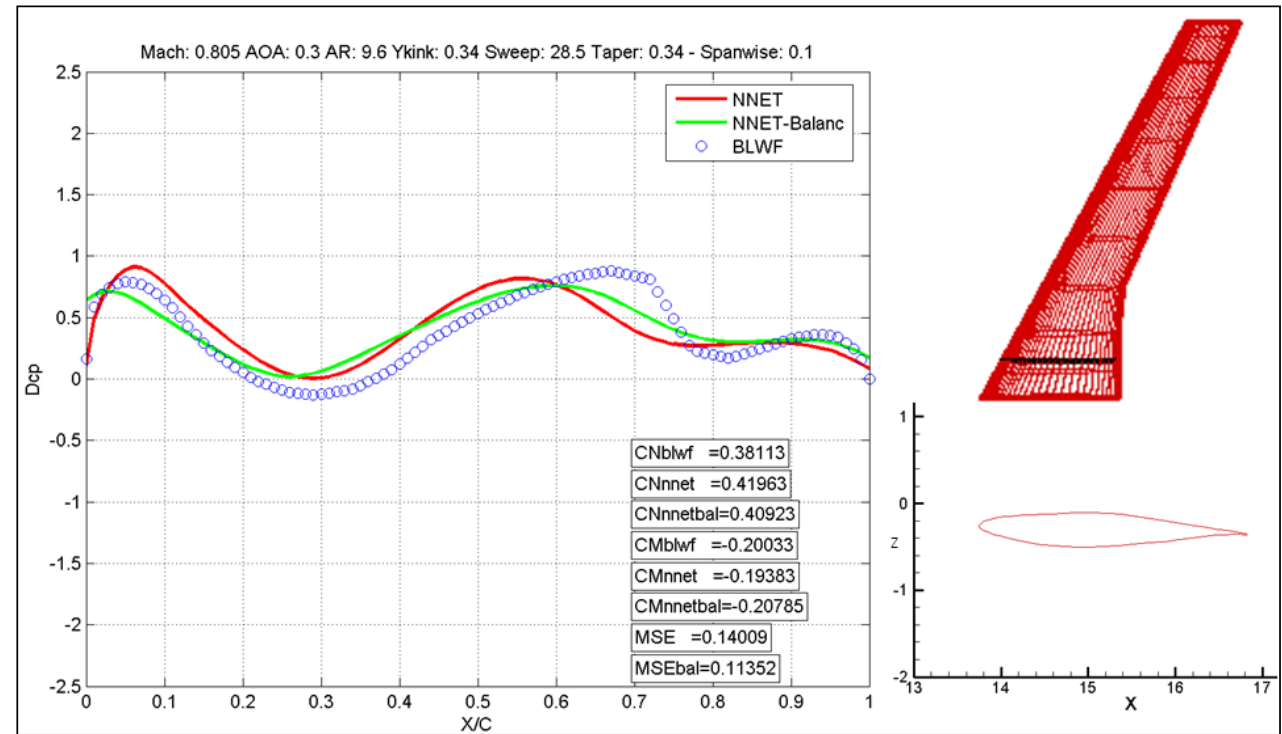

(a)

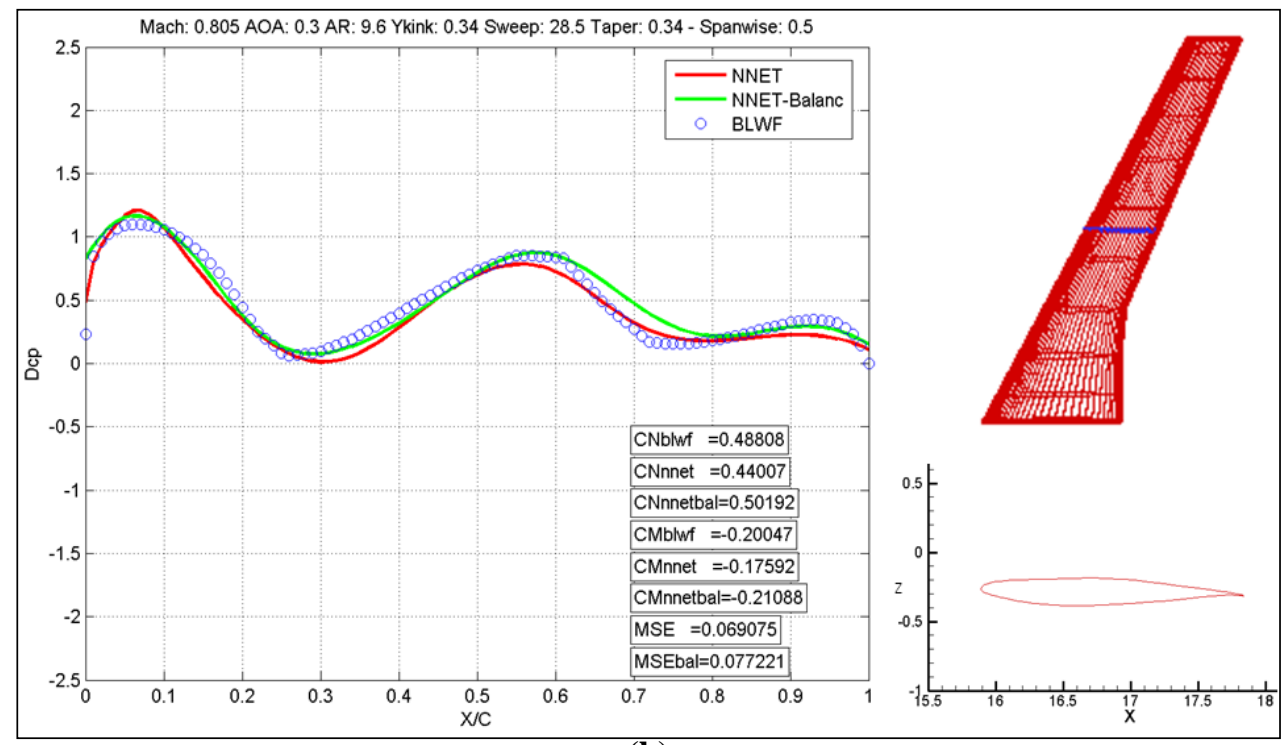

(b)

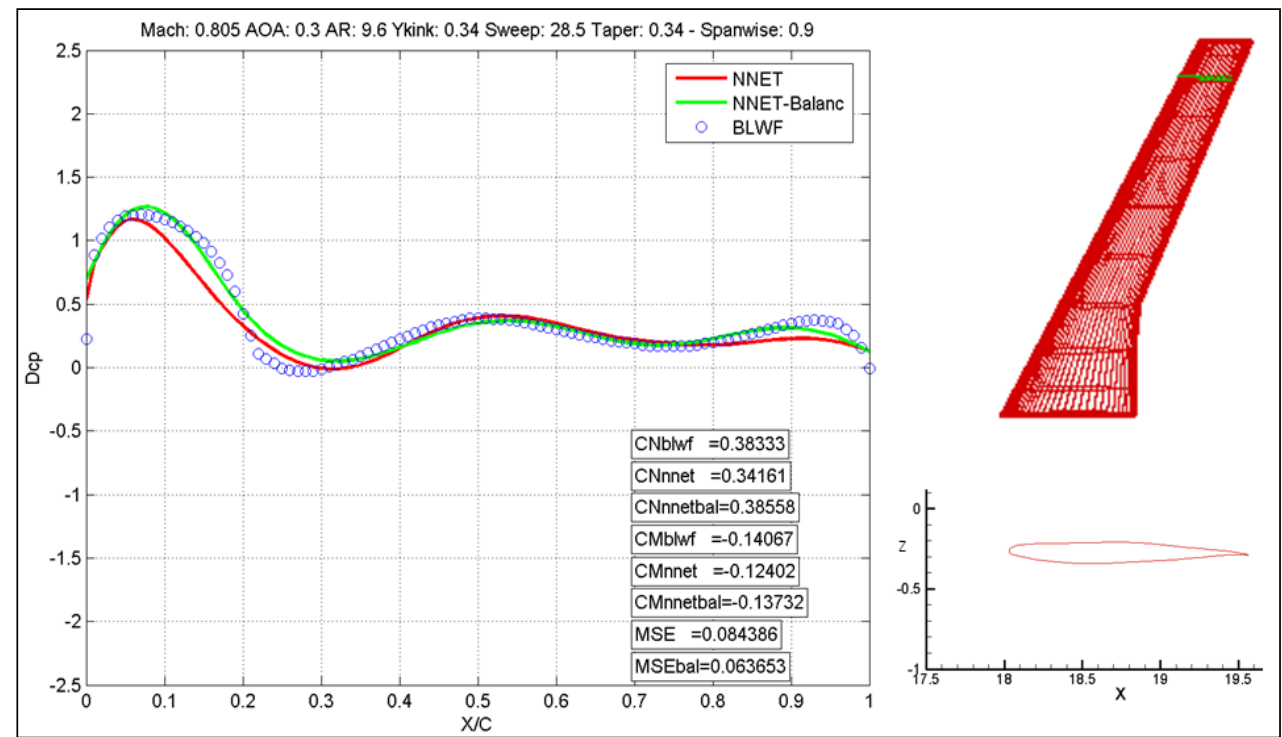

(c)

FIGURA 97: ESCOAMENTO TRANSONICO REDE BALANCEADA E NÃO BALANCEADA - INDIVUDUO 2: (A) ESTAÇ̃̃O NA RAIZ (B) ESTAÇÃO NO MEIO DA ASA (C) ESTAÇÃO NA PONTA DA ASA. 


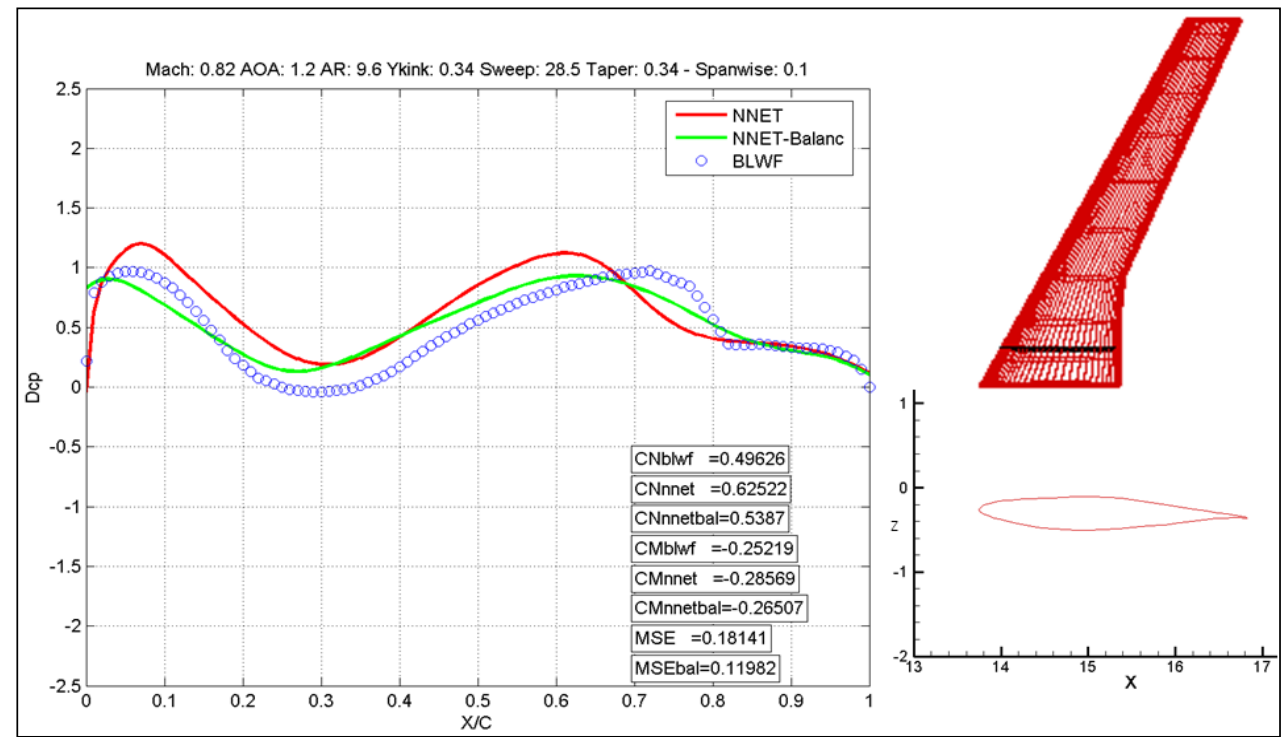

(a)

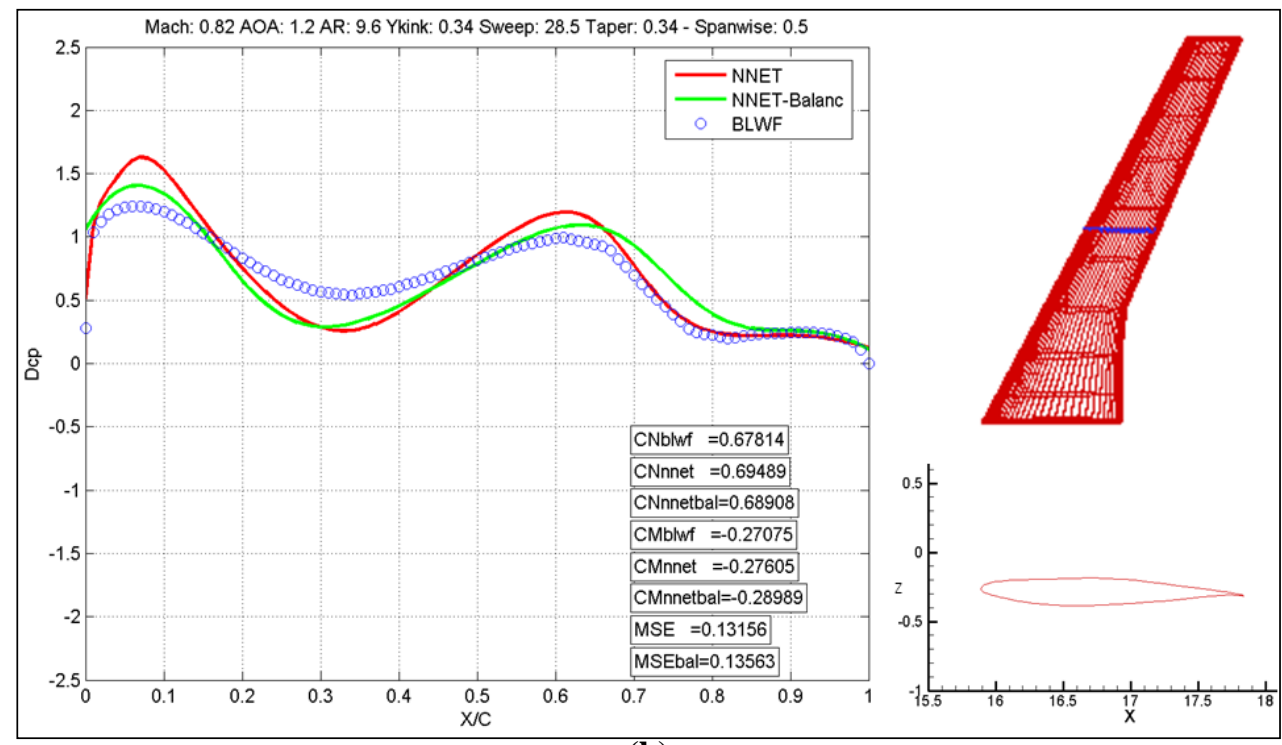

(b)

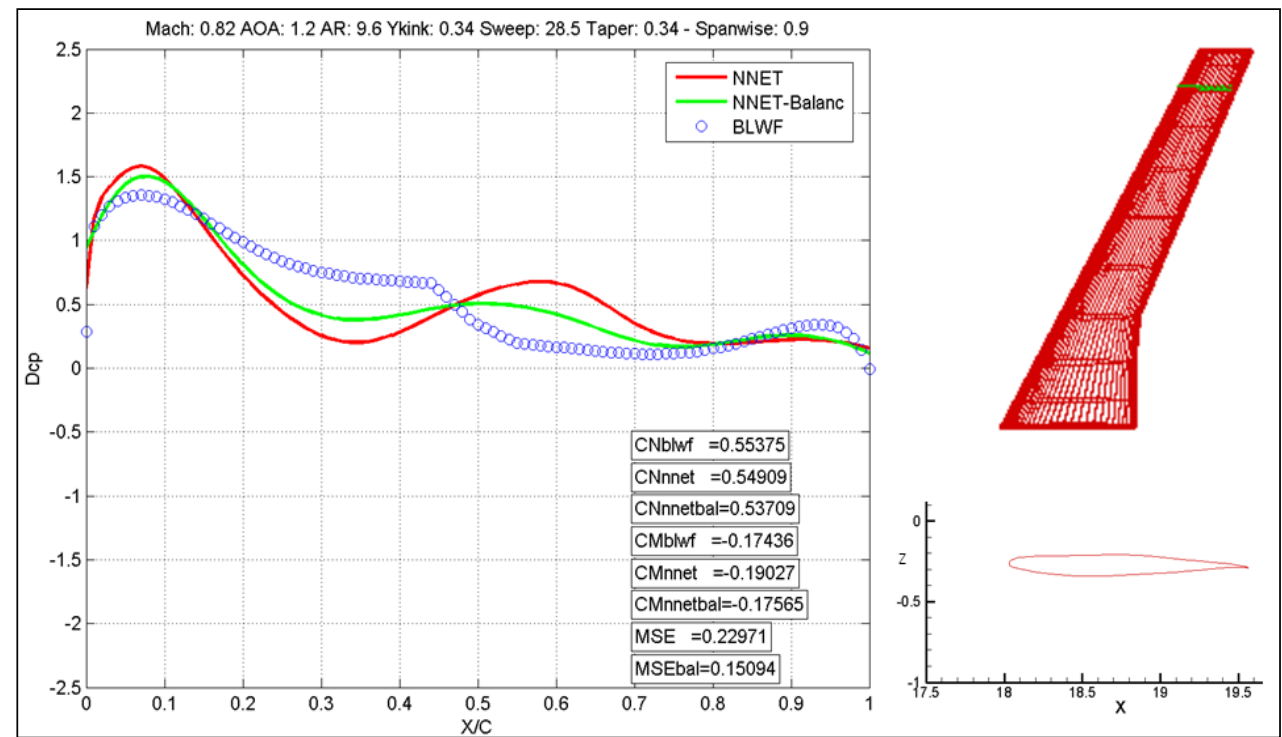

(c)

FIGURA 98: ESCOAMENTO TRANSONICO REDE BALANCEADA E NÃO BALANCEADA - INDIVUDUO 2: (A) ESTAÇ̃̃O NA RAIZ (B) ESTAÇÃO NO MEIO DA ASA (C) ESTAÇÃO NA PONTA DA ASA. 


\section{CONCLUSÃo}

Neste trabalho foram apresentadas, num primeiro momento, breves introduções a respeito das redes neurais artificiais e do BLWF versão 28, software de CFD aplicado na geração dos conjuntos de treinamento que alimentaram as redes neurais.

Posteriormente, foi feito a modelagem e a implementação das redes neurais estudadas para a obtenção de distribuições de pressão. Uma estratégia de aumento progressivo de complexibilidade foi empregada a fim de promover um maior entendimento do problema e das ferramentas utilizadas.

Este estudo pode ser dividido em três fases distintas. Na primeira fase, foram implementadas redes neurais de modo a obter a distribuição de pressão em asas com perfis fixos, tendo como variáveis apenas os parâmetros de forma em planta. $\mathrm{Na}$ segunda fase, as redes implementadas possuíam variáveis adicionais, como os parâmetros de um dos perfis, além dos parâmetros de forma em planta; neste momento, os parâmetros dos demais perfis eram parametrizados em relação ao perfil variável. $\mathrm{Na}$ terceira e última fase, os parâmetros dos três perfis foram considerados como variáveis independentes.

Finda a segunda fase do trabalho, foi feita uma análise de sensibilidade para mensurar a importância relativa de cada variável no resultado final. A variável diedro foi fixada como resultado por apresentar menor impacto do que as demais na distribuição de pressão.

Importante salientar que a fuselagem implementada para todas as redes neurais foi fixa, bem como que o modelo de CFD utilizado também não contemplava empenagens. 
Os resultados obtidos nas redes neurais das três fases apontaram para a validade da metodologia aqui desenvolvida, uma vez que esta conseguiu aproximar razoávelmente bem os resultados do CFD. Entretanto, não pode-se garantir que houve um alcance do ponto ótimo para cada rede neural, devido à complexibilidade do problema e à inexistência de leis bem definidas na determinação da arquitetura ótima para redes neurais aplicadas na solução de cada problema. Neste trabalho tanto o número de indivíduos dos conjuntos de treinamento quanto o número de neurônios foi determinado por meio de testes com as redes neurais.

Outro ponto importante é que no processo de treinamento não foi usada a validação cruzada. A validação cruzada consiste em medir o desempenho da rede, de épocas em épocas, obtendo resultados para alguns indivíduos distintos do conjunto de treinamento, durante o processo de treinamento. Conforme o treinamento se segue os resultados obtidos na validação cruzada tendem a cair e a idéia é que quando estes resultados comecem a subir o treinamento seja finalizado. Este procedimento é importante para garantir que não haja o super-treinamento da rede neural. Neste trabalho, contudo, imagina-se que devido ao grande número de indivíduos utilizados não houve super-treinamento, uma vez que dificilmente a rede seria capaz, com o número de neurônios utilizado, de memorizar tal número de dados.

Apenas duas malhas do BLWF foram usadas no estudo em questão, dada a satisfatória representatividade do resultado. Além disso, a intenção principal aqui é a validação da metologia, algo que praticamente independe do número de malhas aplicado. Não há, porém, impedimentos ao treinamento de uma rede com três malhas, pois, embora haja um consumo de tempo maior, este já possui arquitetura definida, obtida através dos estudos com duas malhas. 


\section{PROPOSTAS PARA TRABALHOS FUTUROS}

Com a legitimação do uso de redes neurais artificiais na obtenção de distribuições de pressão em asas, torna-se possível a implementação da mesma metodologia em estudos de distribuição de pressão em empenagens, winglets e até mesmo fuselagem. Para tanto, recomenda-se a versão 56 do BLWF, uma vez que ela permite a modelagem desses componentes sem abrir mão de sua principal característica: rodadas de grande agilidade.

Outra possibilidade de estudo reside na aplicação de outros softwares na construção dos conjuntos de treinamento, dado à independência do método em relação ao software empregado.

Um cuidado adicional que não foi tomado neste trabalho e é altamente recomendado é a adoção da validação cruzada durante a fase de treinamento das redes neurais como forma de evitar o super-treinamente e consequente perda de generalização da rede.

Outra sugestão de melhoria seria o estudo da utilização de outro tipo de gerador para os conjuntos de treinamento que não o Hipercubo Latino (LHSDesign do Matlab). Apesar das vantagens apresentadas durante o trabalho o LHSDesign faz parte do pacote do Matlab, que é um software comercial e envolve custos com licensas. Talvez a geração de conjuntos de treinamento considerando a distribuição normal de probabilidades em todas as dimensões do conjunto leve a resultados semelhantes ao obtido via LHSDesign. Também foi utilizado o Matlab para o treinamento das redes, e mais uma vez sugere-se que seja implementada uma rede neural em outro software gratuito, ou em Fortran, como uma maneira de não ficar dependente do Matlab. 
No entanto, a principal sugestão para trabalhos futuros é a utilização das distribuições de pressão obtidas via redes neurais em programas de otimização de asas, visto que a rede neural oferece bons resultados em um período de tempo muito inferior a qualquer outro software de CFD. 


\section{REFERÊNCIAS BIBLIOGRÁFICAS}

1. HAYKIN, S. Neural Networks: A comprehensive foundation, $2^{\text {nd }}$ edition, Prentice Hall, 1999.

2. FAUSSET, L. Fundamentals of Neural Networks: arquiteture, algorithms and applications, $2^{\text {nd }}$ edition. PrenticeHall, 1994.

3. LYRIO, J. A. A. et al. Wing and Airfoil Optimized Design of Transport Aircraft. In: $11^{\circ}$ Congresso Brasileiro de Ciências Térmicas e engenharia, 2006, Curitiba. ENCIT.

4. SOBIECZKY, H. Parametric Airfoils and Wings, vol 68, Vieweg, 1998.

5. ANDERSON, J, D, Jr. Computational Fluid dynamics: The basics with applications, McGraw-Hill, 1995.

6. ANDERSON, J, D, Jr, Fundamentals of Aerodynamics, $2^{\text {nd }}$ edition, Mc Graw Hill.

7. KARAS, KOVALEV, BLWF V. 28 - User manual

8. IMAN, L. R. A Modern Approach to Statistics with W. J. Conover, Wiley 1983.

9. SILVA, A. L. F., CAVALCANTI, C. J. M. T., CATALANO, F. M. Prediction of Pressure Distribution on Wings Using Neural Network. In - AIAA, 2008.

10.SANTIAGO RAMÓN Y CAJAL. In: WIKIPÉDIA, a enciclopédia livre. Flórida: Wikimedia $2009 . \quad$ Doundation, em: $<$ http://pt.wikipedia.org/w/index.php?title=Santiago Ram\%C3\%B3n y Cajal\& oldid=17170789 >. Acesso em: 7 dez. 2009.

11. KOCK, C., e I. SERGEV, eds., 1989. Methods in Neuronal Modeling: From Synapses to Networks, Cambridge, MA: MIT Press. 
12. CHURCHLAND, P.S., and T. J. SEJNOWSKI, 1992. The Computational Brain, Cambridge, MA: MIT Press. 


\section{ANEXOS}

\subsection{Introdução ao BLWF}

Em linhas gerais, o software Boundary Layer Wing-Fuselage (BLWF) versão 28 é um código de CFD 3D que utiliza um equacionamento potencial completo com correção de camada limite para um estado estacionário. Para esta correção, um modelo de turbulência simplificado é aplicado sob um esquema preditor-corretor. Esta versão do software está preparada para contemplar apenas os componentes asa e fuselagem. Existem, no entanto, outras versões posteriores do mesmo software que contemplam também as empenagens, naceles dos motores, e winglets, além de resolverem o campo de pressões para condições nãoestacionárias

A utilização do método potencial completo com aproximação de escoamento isentrópico é razoável até um limite de número de Mach próximo a 1.3. Neste trabalho utilizou-se o programa até o Mach de voo máximo de 0.82 , com posterior correção de camada limite. Em algumas regiões do avião, todavia, o número de Mach pode ultrapassar esse valor.

A estratégia de cálculo do programa é bastante interessante. Primeiramente ele gera, de forma automática, uma malha relativamente grosseira sobre o modelo geométrico de entrada, resolve e obtém rapidamente a distribuição de pressão na asa e fuselagem. Posteriormente é gerada uma malha mais refinada e os resultados obtidos anteriormente são utilizados como uma primeira aproximação nesta segunda malha. Este processo é repetido para uma terceira malha ainda mais refinada. Esta estratégia tem vários pontos positivos: facilita a convergência na malha mais refinada, com o uso de uma boa aproximação como valor inicial; possibilita ao 
usuário a utilização do resultado com apenas uma ou duas malhas; diminui o tempo de processamento, pois se fosse utilizada apenas a malha mais refinada o número de iterações necessárias, sem uma boa aproximação inicial, seria muito grande e lenta. A correção de camada limite é feita após certo número de iterações do campo potencial, sendo que o usuário é quem define este número de iterações. Esta correção pode ser aplicada em ambas as malhas.

Não obstante, uma característica indesejável desse método é a ocorrência de instabilidades no modelo de turbulência quando há separação da camada limite, o que faz com que o processo divirja. Deste modo, em condições de número de Mach alto com ângulos de ataque maiores, a convergência fica comprometida.

Este fato pode gerar um problema para a geração do conjunto de treinamento para as redes neurais, que é o desbalancemento da rede, ou seja, quando um DOE é criado utilizando o LHSdesign no Matlab todas as variáveis são uniformemente distribuídas por todo o espaço amostral, gerando um conjunto homogêneo e balanceado, porém quando submetemos os indivíduos deste conjunto para o BLWF o que normalmente ocorre é que os indivíduos com maiores números de Mach e alfa tem maiores chances de divergir, gerando uma região "menos povoada" no conjunto de treinamento final que será usado para alimentar a rede, gerando distorções indesejáveis no processo de treinamento. As ações para contornar este problema serão discutidas mais adiante neste trabalho.

O programa utiliza como entrada de dados apenas um arquivo texto, onde são indicadas todas as condições de vôo, parâmetros de refino e distribuição da malha, número de iterações e os dados geométricos do avião. Adicionalmente, na Seção 7.4 é apresentado na integra um arquivo de entrada do programa, gerado durante o processo de treinamento da rede. 
As geometrias, tanto da asa quanto da fuselagem, são informadas ao programa sob a forma de perfis em diferentes posições de envergadura para a asa e ao longo do comprimento para a fuselagem. Esse formato de entrada facilita a geração de inputs de maneira automática, modo como foi realizado este trabalho.

A distribuição de pressão sobre a asa e a fuselagem é fornecida como resultado final pelo programa em dois formatos: por arquivo texto, em cortes com posições ao longo da envergadura da asa pré-definidas pelo usuário; e sobre os nós de uma malha de saída. As Figuras 99 e 100 mostram a malha de saída onde são mapeados os resultados e a visualização dos coeficientes de pressão, respectivamente:

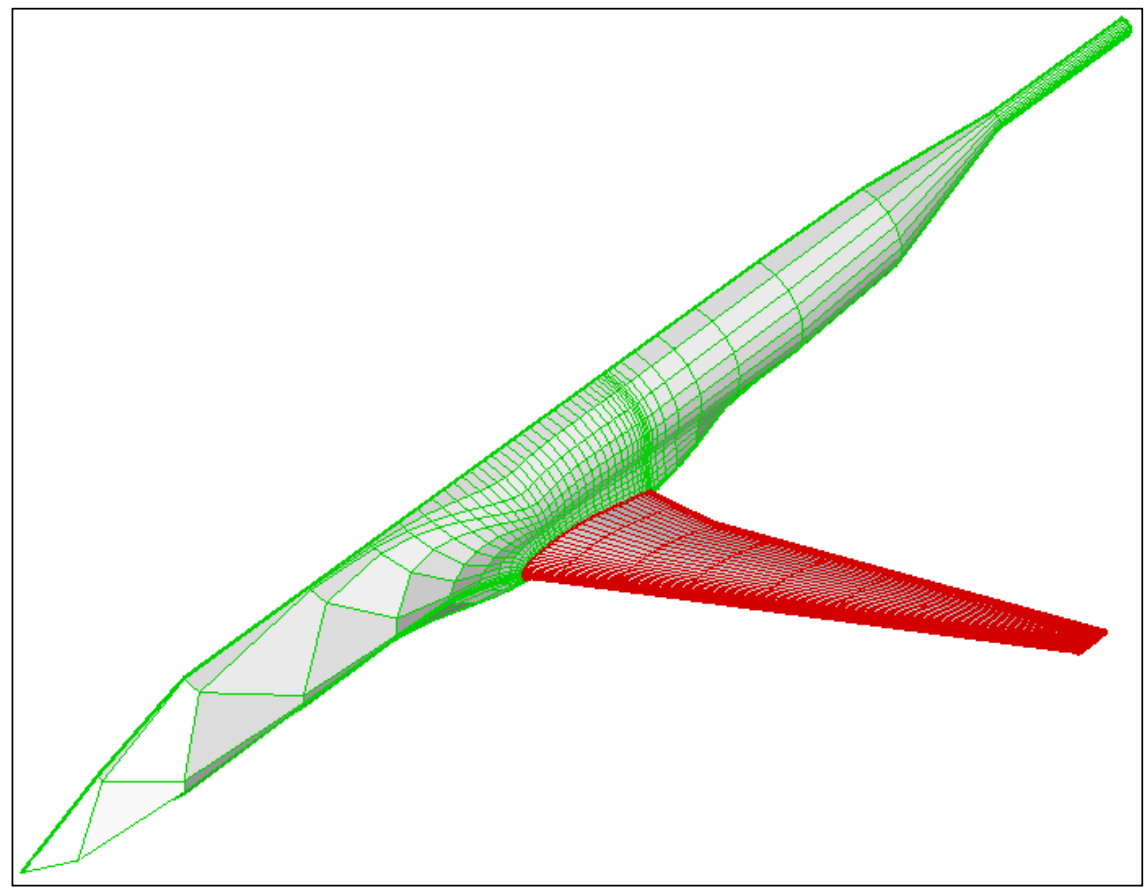

FIGURA 99: MALHA DE RESULTADOS DO BLWF. 


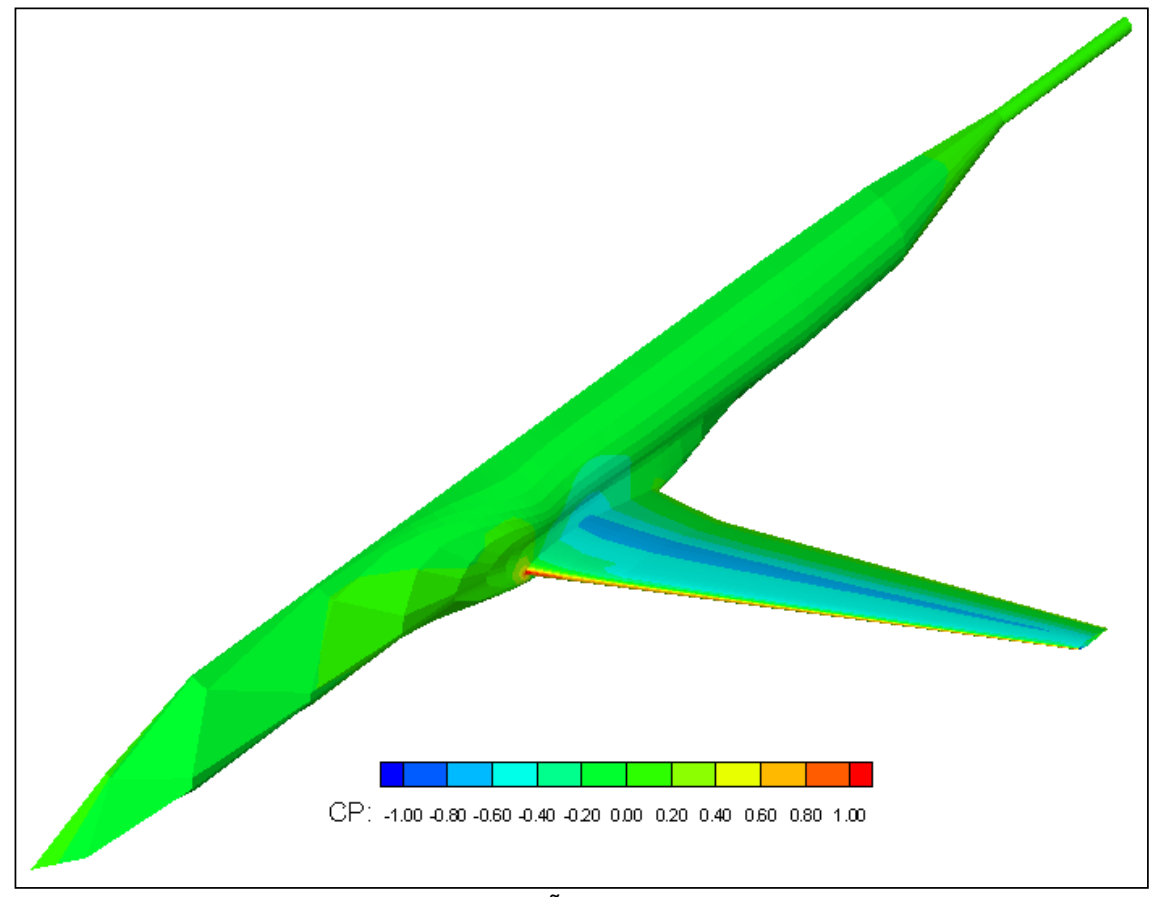

FIGURA 100: VISUALIZAÇÃO DO RESULTADO DO BLWF.

Usualmente uma rodada completa do programa, considerando três malhas com correção de camada limite leva em torno de três minutos em um microcomputador comum. Neste trabalho, para a construção dos conjuntos de treinamento e de validação, optamos por utilizar simulações com apenas duas malhas afim de viabilizar o estudo, uma vez que não se tinha idéia do número de indivíduos necessários para os treinamentos. Nesta configuração o CFD leva em torno de 30 segundos por rodada, no computador utilizado.

O computador usado para gerar os conjuntos de treinamento utilizados neste trabalho é um pentim 4, 3.0 GHz de núcleo único, com 3 Gb de memória ram. 


\subsection{Programa gera_treino.f90}

\section{Segue o código fonte do programa fortran "gera_treino", utilizado para geração dos conjuntos de treinamento das redes bem como para a validação.}

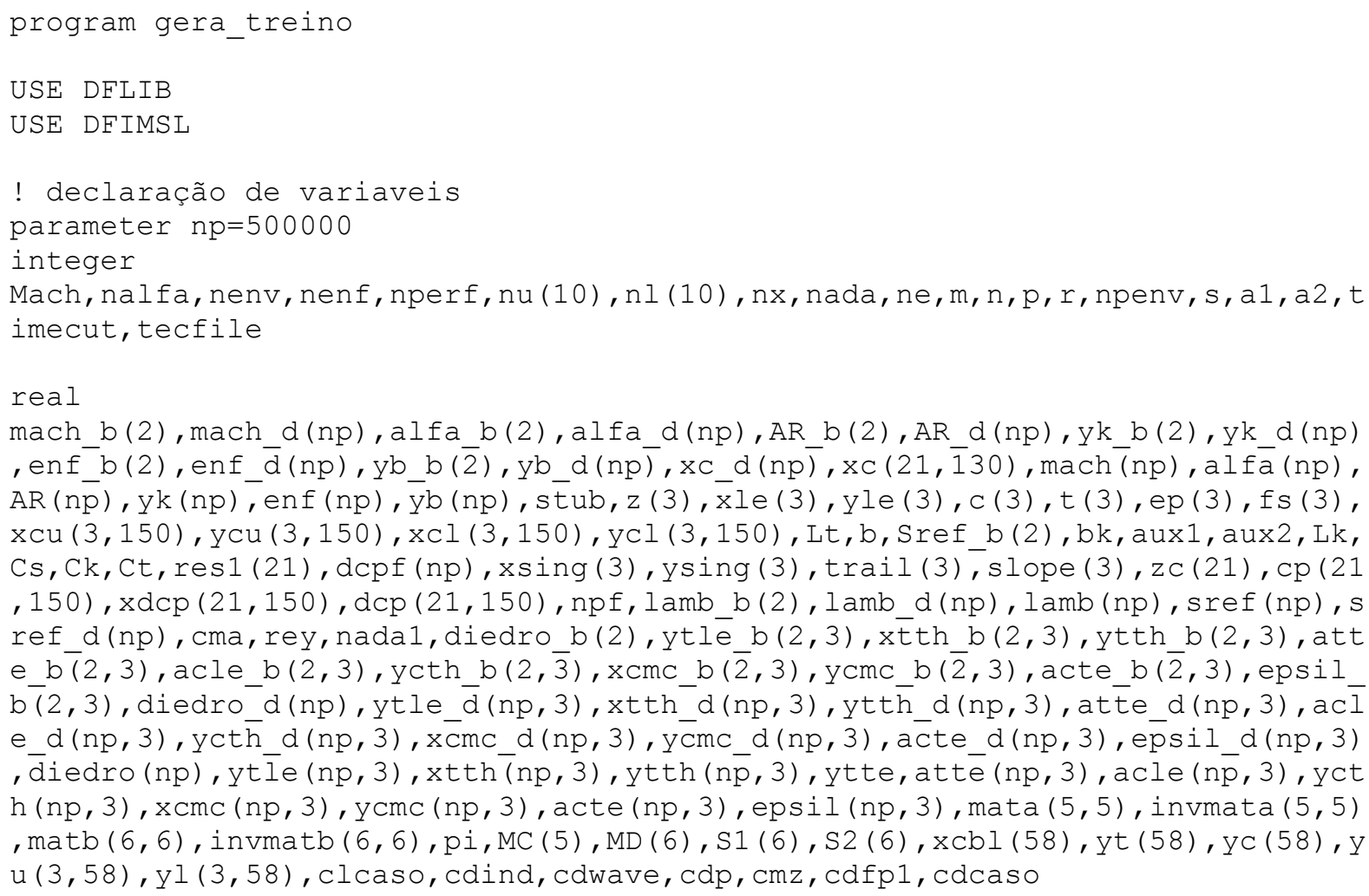




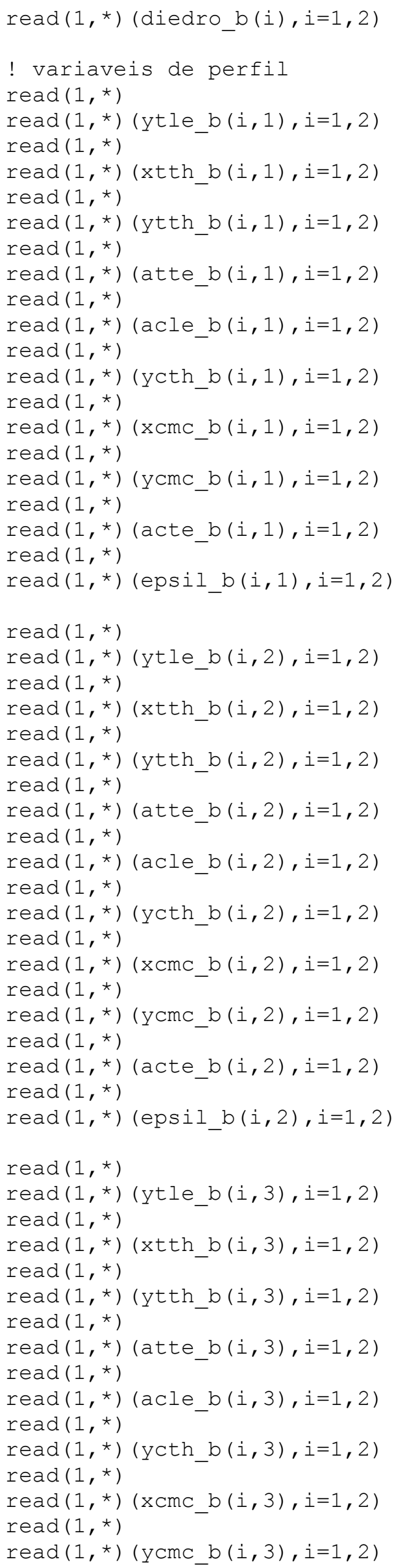




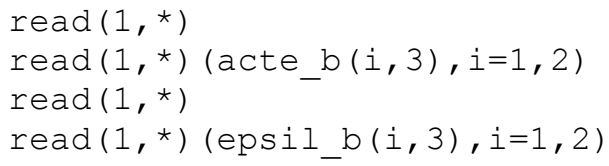
$\left.d(i), y t l e \_d(i, 1), x t t h \_d \overline{(i}, 1\right), y t \overline{t h} \_d(i, 1)$, atte_d $(\bar{i}, 1)$, acle_d $(i, 1), y \overline{c t h} d(i$, $\overline{1}), x \mathrm{cmc} d(\bar{i}, 1), \operatorname{ycmc} d(\bar{i}, 1)$, acte_d $(\bar{i}, 1)$, epsil_d $(i, 1), \operatorname{ytle} d \overline{(}(i, 2), x t t h \_d(i, 2)$ , ytth_d $(i, 2)$, atte_d $(i, 2)$, acle_d $(i, 2), y c t h \_d(\bar{i}, 2), x c m c \_d(\bar{i}, 2), y c m c \_d(\bar{i}, 2), a c$

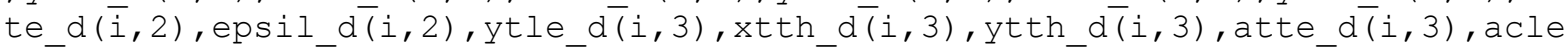

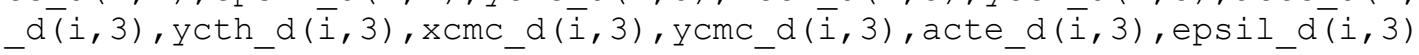

end do

close (10)

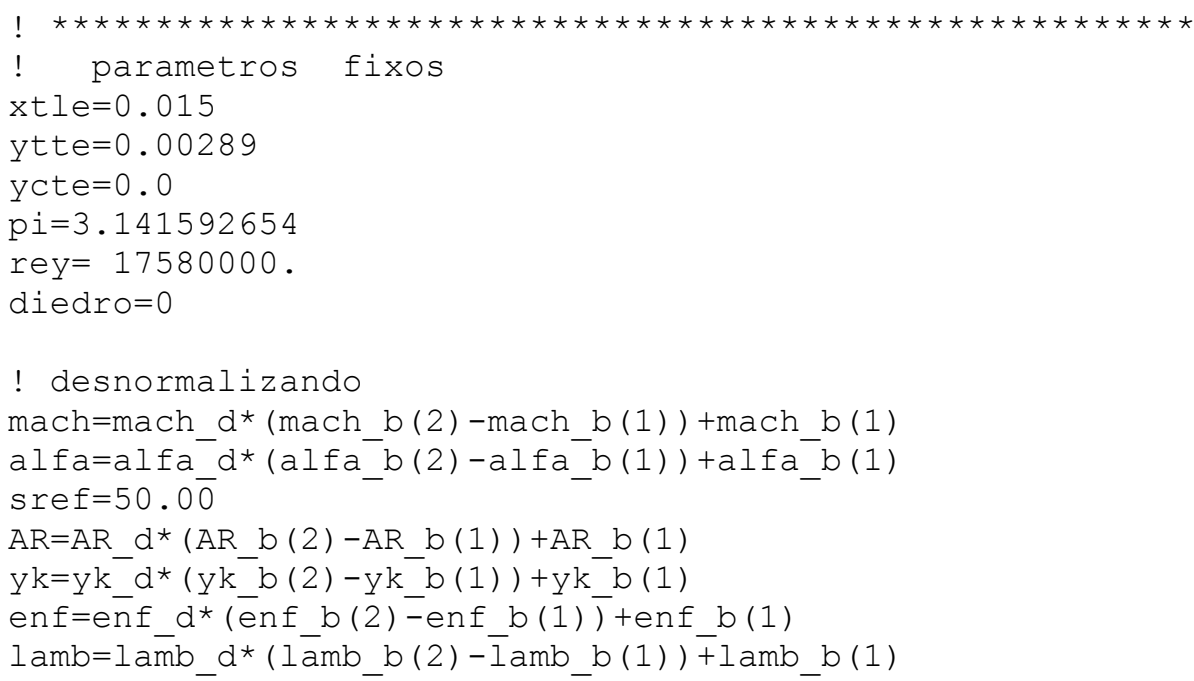




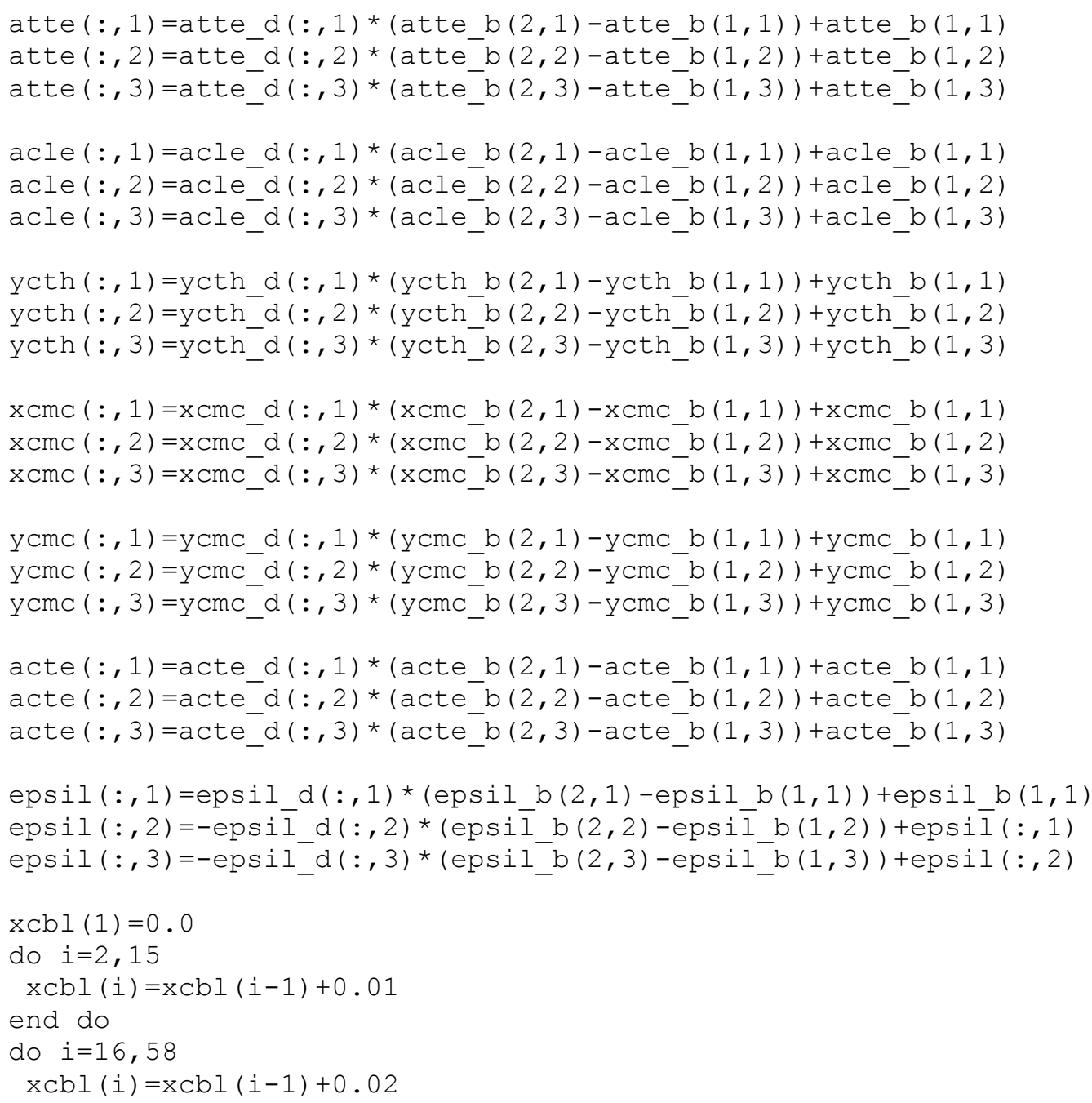

end do

if ( (modo.eq.'T') .or. (modo.eq.'t')) open (5, file='treinamento.txt') if ( (modo.eq.' 'V') .or. (modo.eq. ' $\left.\left.\mathrm{V}^{\prime}\right)\right)$ open (5, file='validacao.txt') if ( (modo.eq.' $\left.V^{\prime}\right)$.or. (modo.eq. ' $\left.\mathrm{V}^{\prime}\right)$ ) open ( 7 , file='validacao matlab.txt')

do $i=1$, nruns

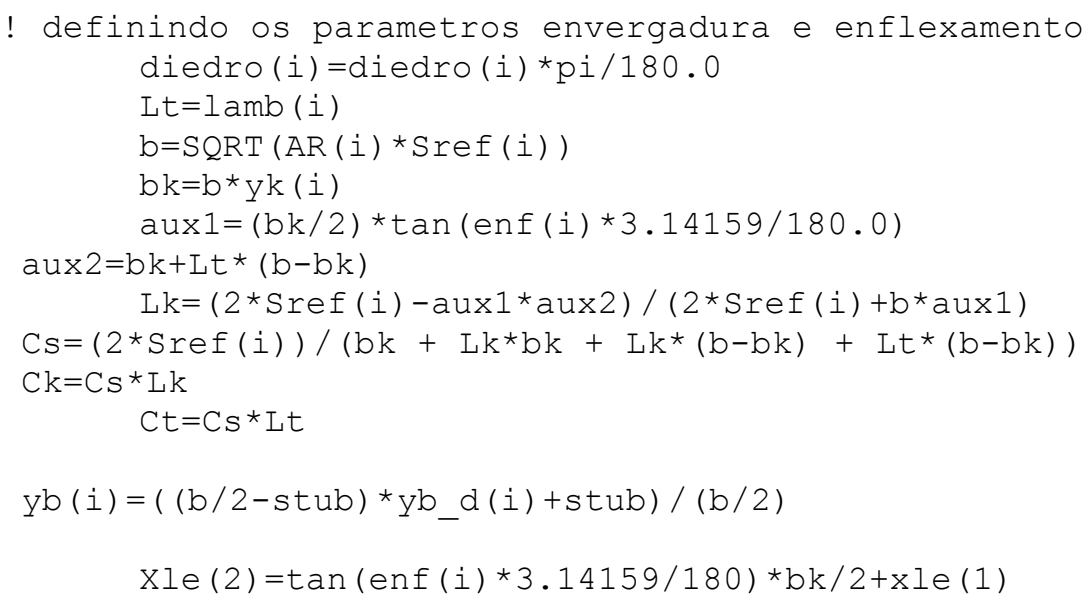




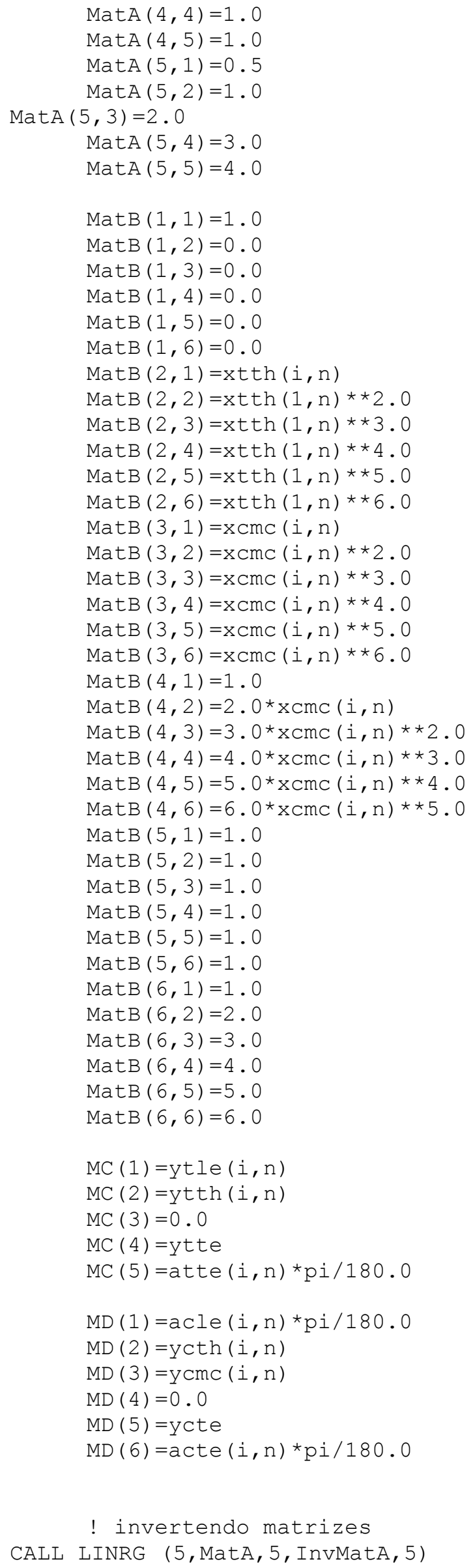


CALL LINRG (6, MatB, 6, InvMatB, 6)

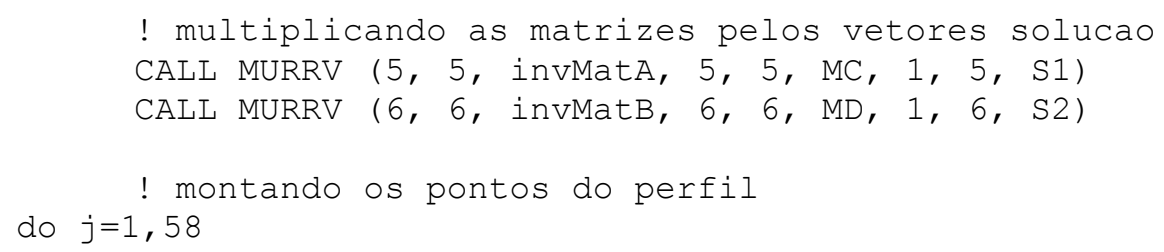


end do

close (3)

result $=$ GETDRIVEDIRQQ (drivedir)

bl=trim(drivedir) //' \blwf281.exe'

write (timeout, ' (i3)') timecut

cambl=trim (drivedir) //' \blwf281.exe'

camarq=trim (drivedir) / / ' '//trim (arq)

! executando O CFD para cada individuo

result=system('blwf281. exe model.in')

! lendo resultados de dcp do individuo

open (4,file='model.pl4', status=' old', err=400)

$\operatorname{read}(4, *, \operatorname{err}=400)$

read $(4, *)$

$\operatorname{read}(4, *)$ txt, nx, txt, ne

$\operatorname{read}(4, *)$

$\operatorname{read}(4, *)$

$\operatorname{read}(4, *)$

do $\mathrm{p}=1$, ne

$\operatorname{read}(4, *)$

$\operatorname{read}(4, *)$

$\operatorname{read}(4, *)$

$\operatorname{read}\left(4,{ }^{*}\right)$ txt, $\mathrm{zc}(\mathrm{p})$

read $(4, *)$

$\operatorname{read}(4, *)$

$\operatorname{read}(4, *)$

do $r=1, n x$

$\operatorname{read}(4, *)$ nada, $x c(p, r), c p(p, r)$

end do

do $r=1, n x / 2$

$x \operatorname{dcp}(p, r)=x c(p,((n x / 2)+r))$

if $(r . g t .1) \operatorname{dcp}(p, r)=c p(p,((n x / 2)-(r-1)))-c p(p,(n x / 2)+r)$

end do

end do

! Lendo dados de CL e CD

open (50, file='model. out', status='old', err=500)

do while(eof(50).ne..true.)

$\operatorname{read}(50, '(A)$ ') linha

if(linha (1:18).eq.'0 CL CDIND') then

read $(50, *, e r r=111)$ clcaso, cdind, cdwave, cdp, cmz, cdfpl

end if

end do

close (50)

if (2.eq.3) then

111 continue

cdind $=0$

cdwave $=0$

$\operatorname{cdfp} 1=0$

clcaso $=0$

close $(50)$

end if

cdcaso $=$ cdind + cdwave + cdfpl

result=system('del model.out') 


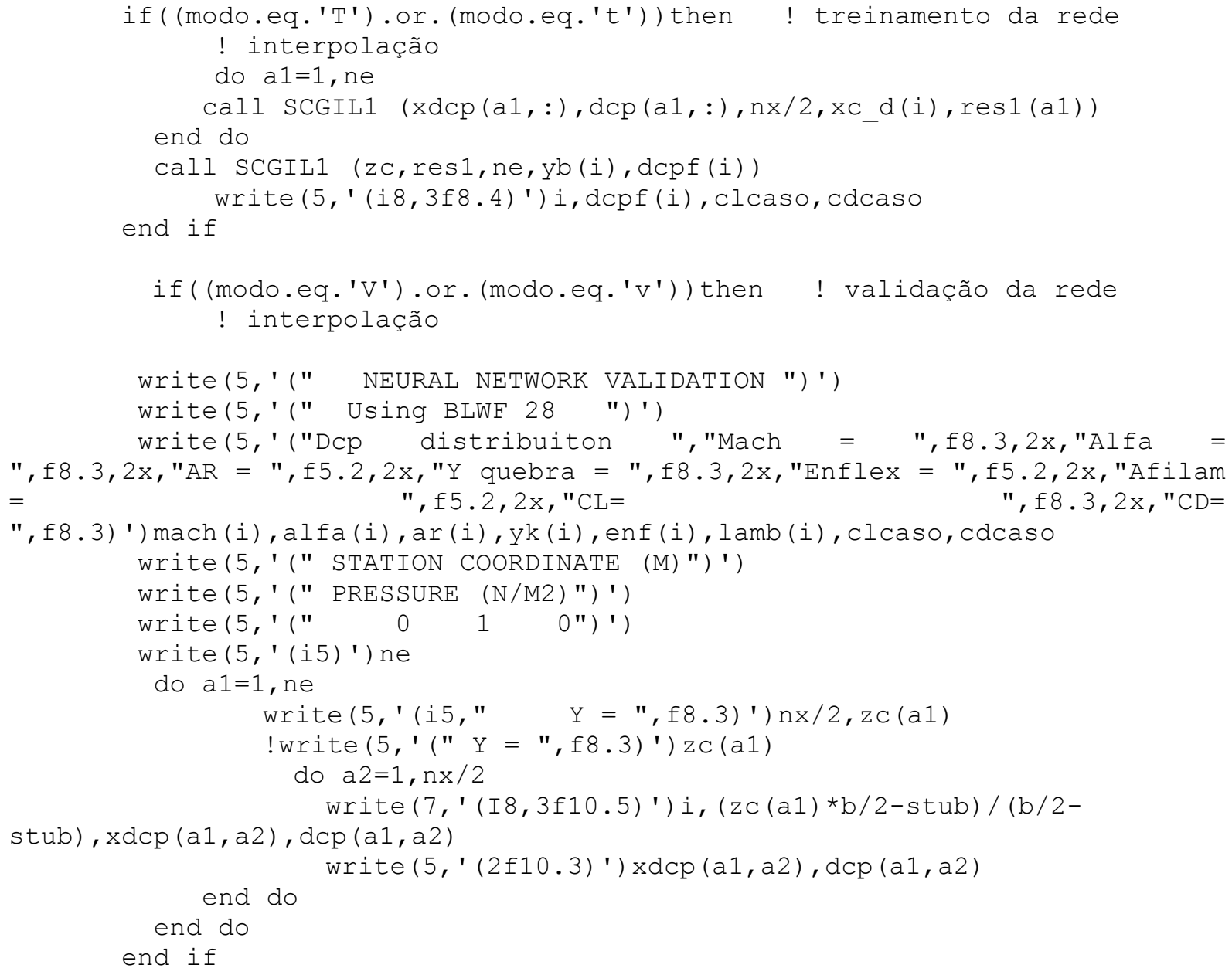

nome='tecplot_'//'M_'//trim(machname)//'A_'//trim(alfaname)//'AR_'//trim(ar name) //'Pbreak '// trim (quebname)//'Enf '//trim(enfname)//'Sref_'T/trim (snam e) //'Dih_'//trim (dihname)//'indiv_\#'//Erim(numrodada)//'. tec'

'//trim(nome))

$$
\text { result=systemqq ('rename ' //trim(tecplot) // ' }
$$
end if 


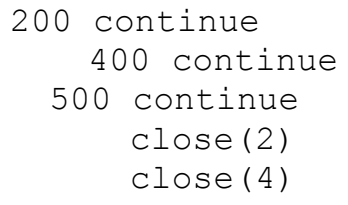

end do

end

SUBROUTINE SCGIL1 (X, Y, NP, XE, YS)

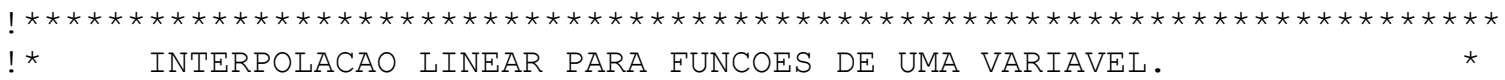

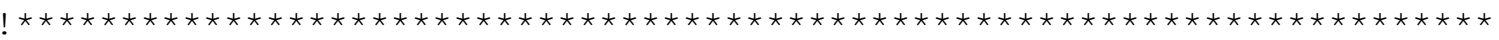

DIMENSION X (NP), Y (NP)

IF (X (2).GT.X(1)) THEN

IF (XE.LT.X(1)) THEN

ELSE

$Y S=(Y(2)-Y(1)) *(X E-X(1)) /(X(2)-X(1))+Y(1)$

IF (XE.GE.X(NP)) THEN

$Y S=(Y(N P)-Y(N P-1)) *(X E-X(N P)) /(X(N P)-X(N P-1))+Y(N P)$

ELSE

$\mathrm{DO} I=2, \mathrm{NP}$

IF (XE.LE.X(I)) THEN

1)

$Y S=(Y(I)-Y(I-1)) *(X E-X(I-1)) /(X(I)-X(I-1))+Y(I-$

$\begin{aligned} \text { GO } & \text { TO } 20 \\ \text { ENDIF } & \end{aligned}$

20

ENDDO

ENDIF

ELSE

IF (XE.GT.X (1)) THEN

ELSE

$Y S=(Y(2)-Y(1)) *(X E-X(1)) /(X(2)-X(1))+Y(1)$

IF (XE.LE.X (NP)) THEN

$Y S=(Y(N P)-Y(N P-1)) *(X E-X(N P)) /(X(N P)-X(N P-1))+Y(N P)$ ELSE

$\mathrm{DO} I=2, \mathrm{NP}$

IF (XE.GE.X(I)) THEN

$Y S=(Y(I)-Y(I-1)) *(X E-X(I-1)) /(X(I)-X(I-1))+Y(I-$

1)

40

GO TO 40

ENDIF

ENDDO

ENDIF

ENDIF

ENDIF

RETURN

END 


\subsection{Programa NNgen.m}

Segue o código fonte do programa Matlab® “NNgen.m”. Este programa foi utilizado para comandar o processo de treinamento e validação das redes neurais.

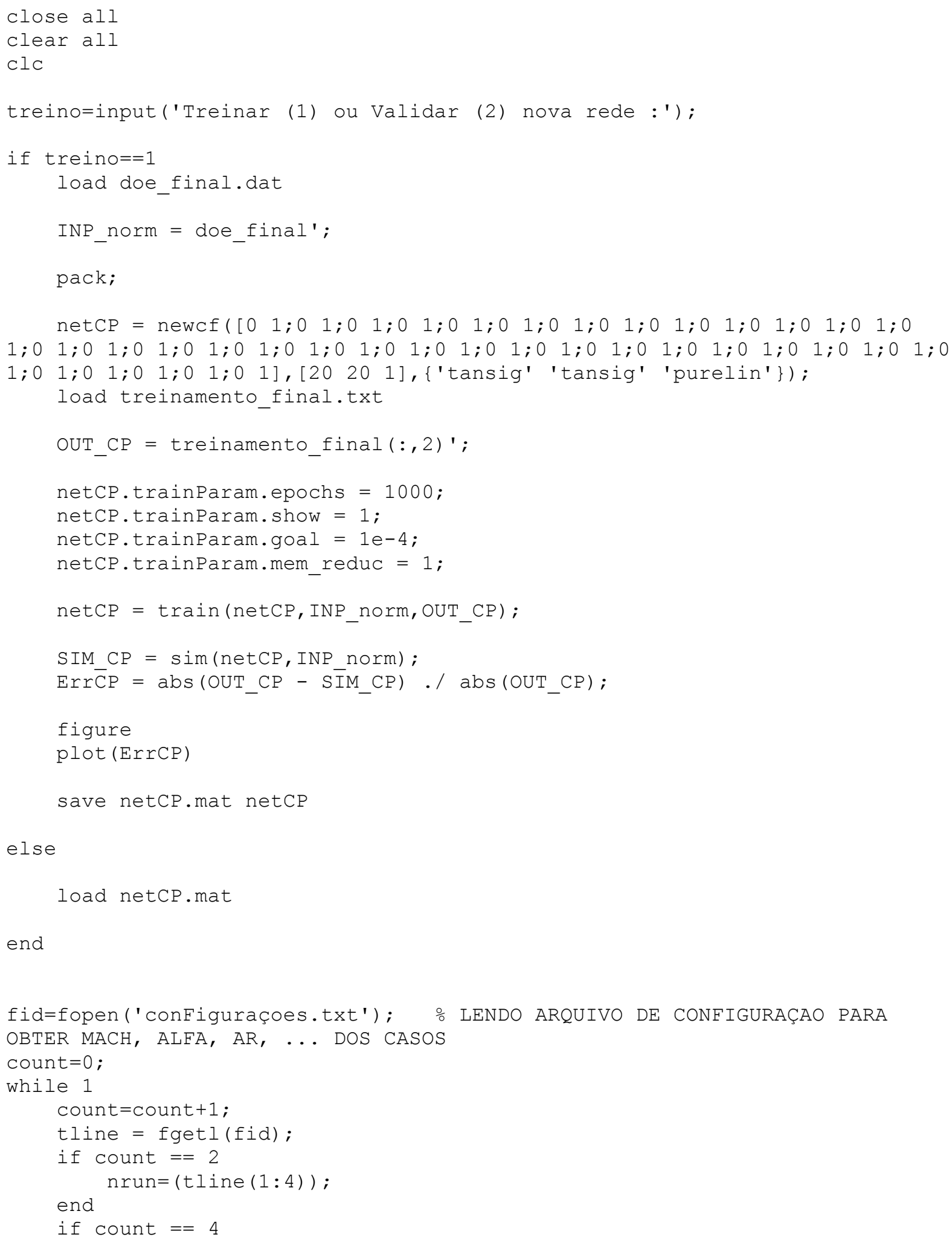




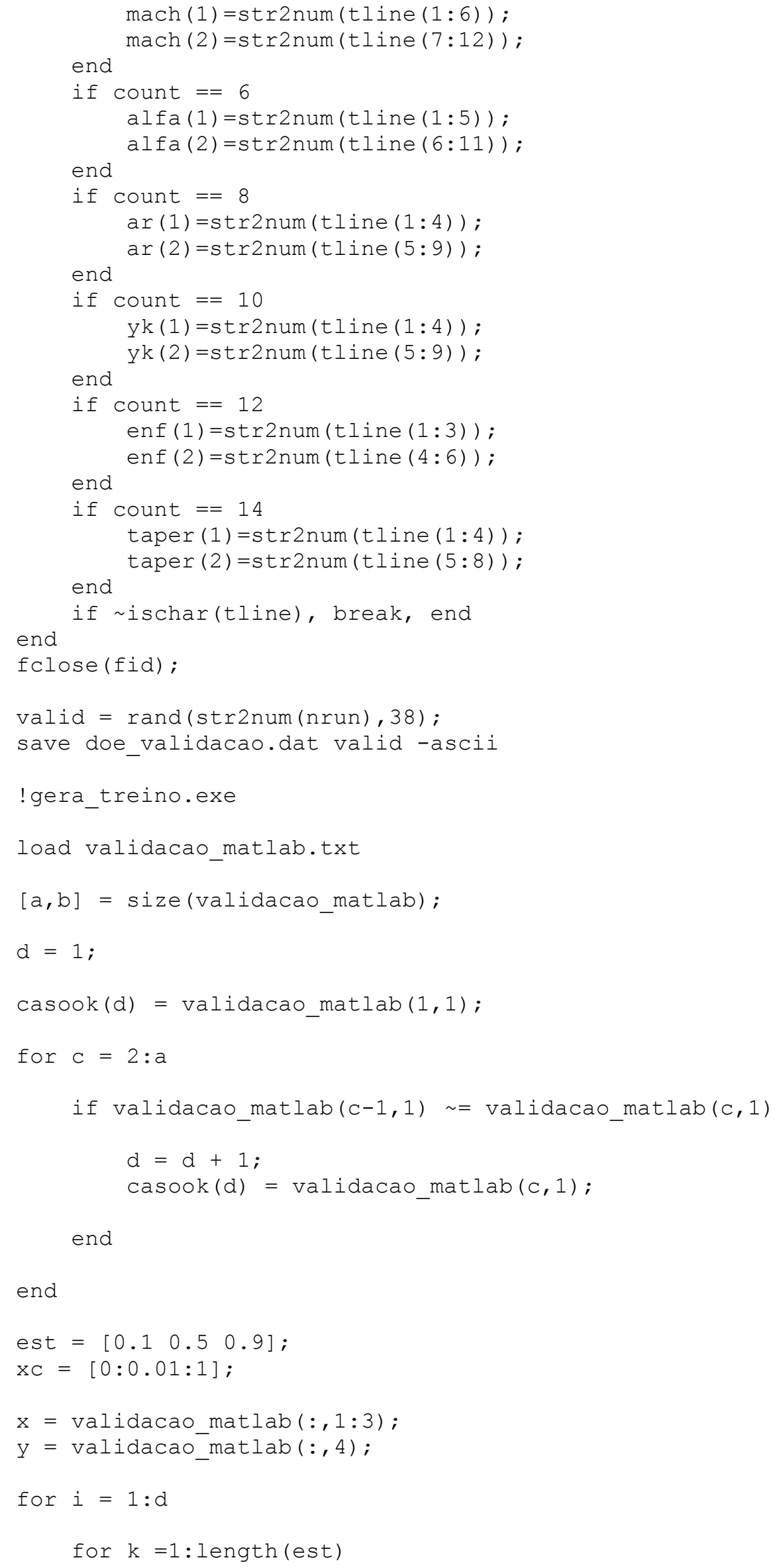




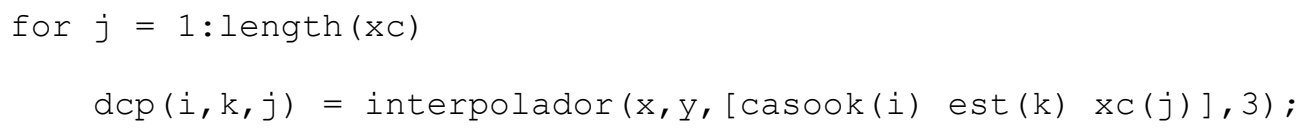




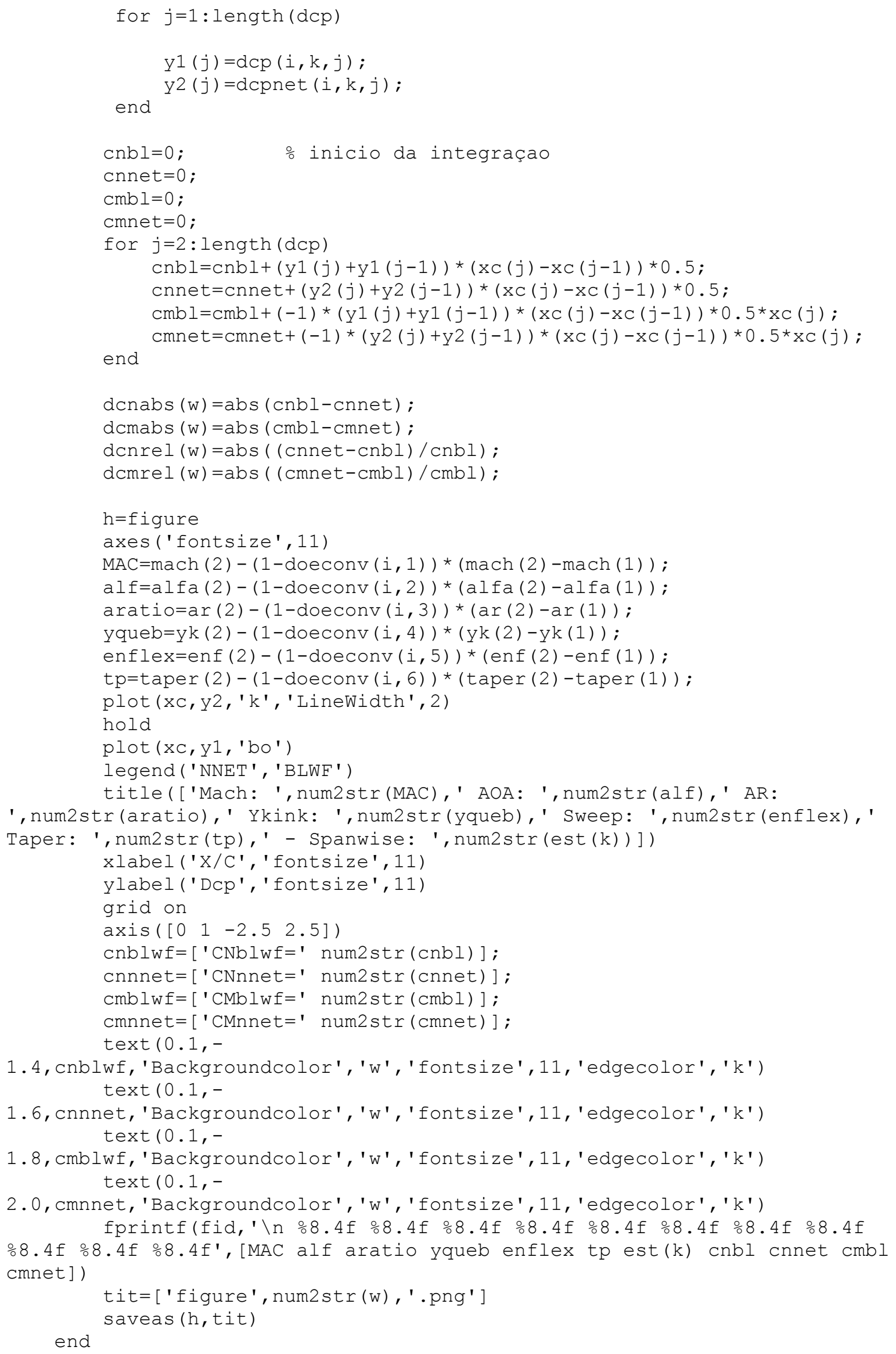




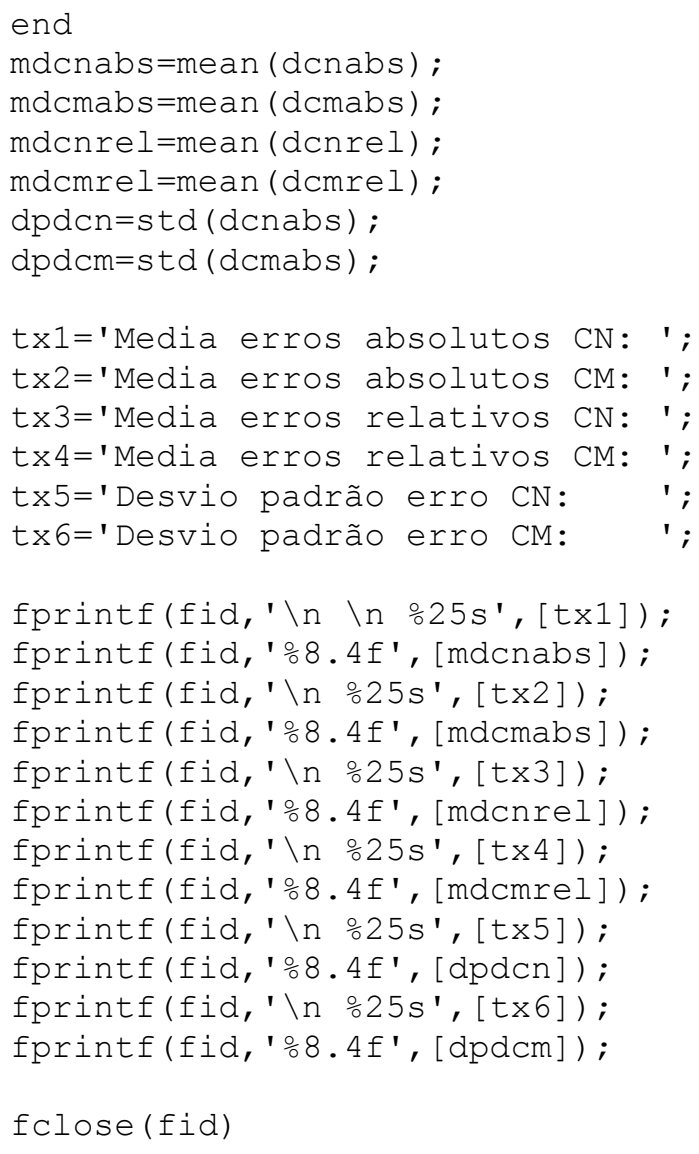




\subsection{Exemplo de arquivo de entrada do BLWF v. 28}

Nesta entrada, a asa é representada por 3 perfis e a fuselagem por 40 cortes ao longo do comprimento.

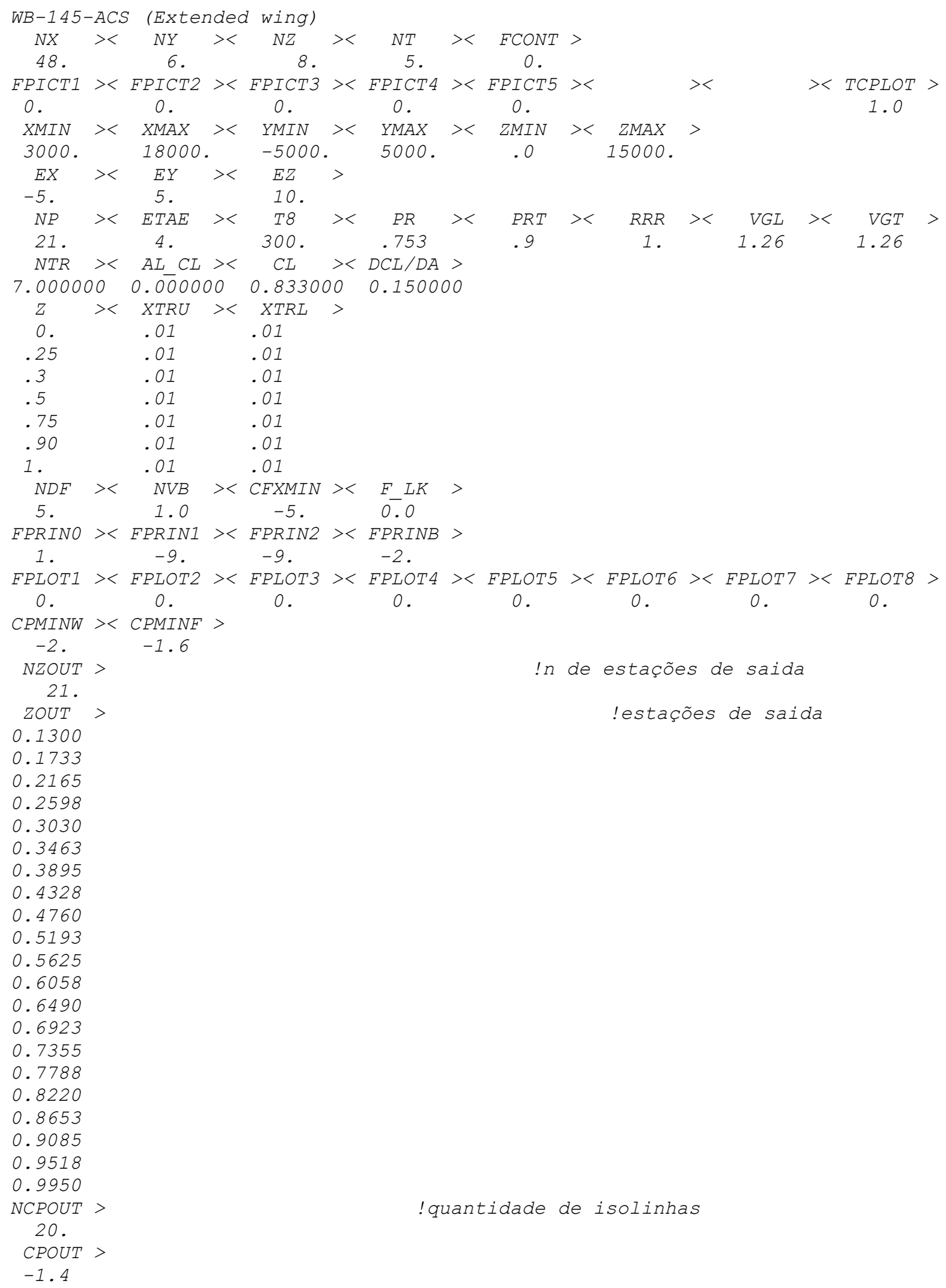




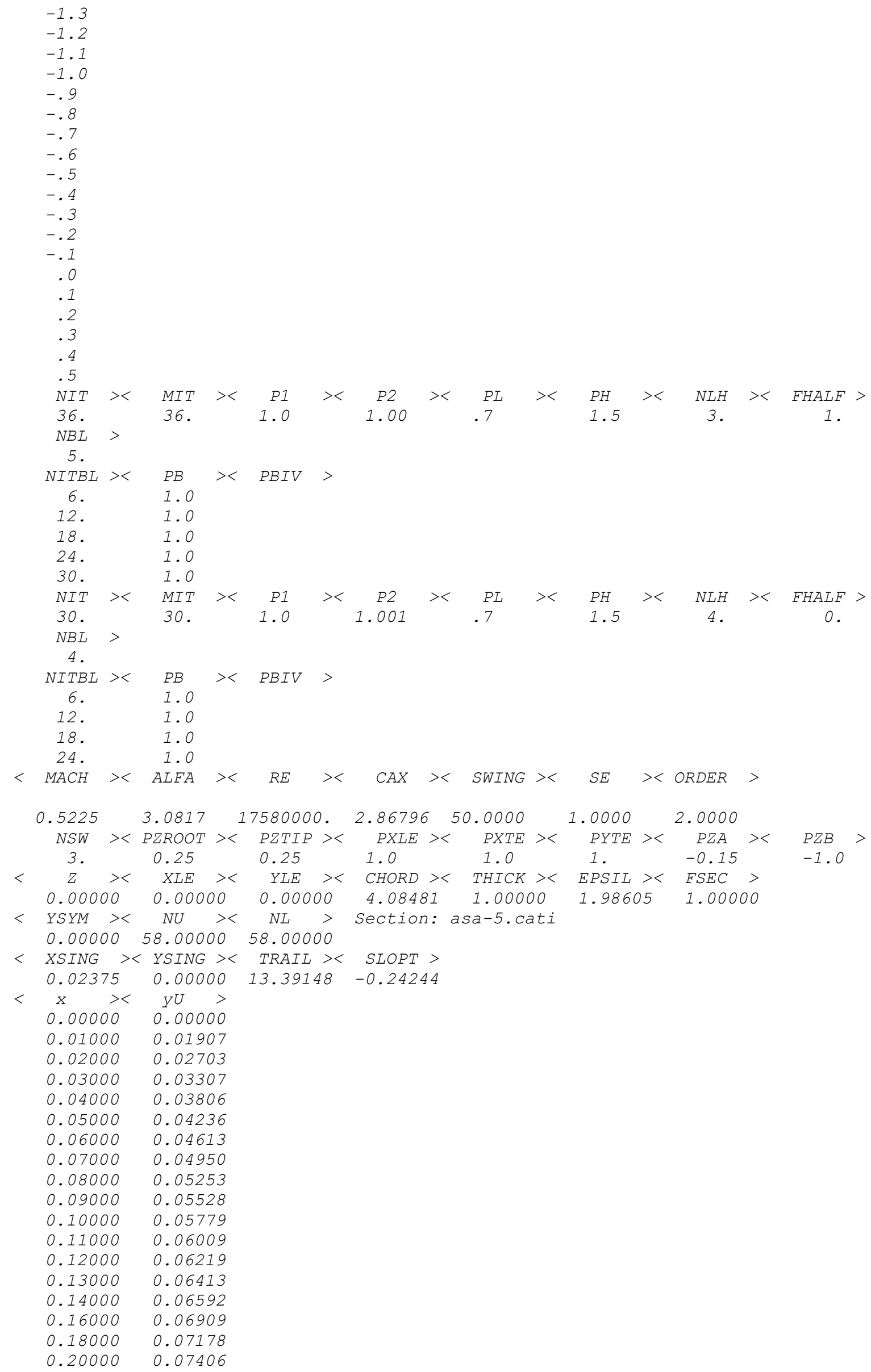



0.22000
0.07597
0.26000
0.07755
0.28000
0.07882
0.30000
0.07979
0.32000
0.08049
0.34000
0.08093
0.36000
0.08111
0.38000
0.08104
0.40000
0.08073
0.42000
0.08020
0.44000
0.07944
0.46000
0.07847
0.48000
0.07731
0.50000
0.07595
0.52000
0.07443
0.54000
0.07275
0.56000
0.07092
0.58000
0.06897
0.60000
0.06691
0.62000
0.06476
0.64000
0.06254
0.66000
0.06026
0.68000
0.05794
0.70000
0.05559
0.72000
0.05323
0.74000
0.05085
0.76000
0.04846
0.78000
0.04605
0.80000
0.04362
0.82000
0.04115
0.84000
0.03860
0.86000
0.03594
0.88000
0.03311
0.90000
0.03007
0.92000
0.02672
0.94000
0.02297
0.96000
0.01871
0.98000
0.01381
1.00000
0.00811
$<x><$
0.00144
0.00000
0.00000
0.01000
$-0.01954$
0.02000
$-0.02797$
0.03000
$-0.03446$
0.04000
$-0.03987$
0.05000
$-0.04454$
0.06000
$-0.04864$
0.07000
$-0.05228$
0.08000
$-0.05553$
0.09000
$-0.05842$
0.10000
$-0.06100$
0.11000
$-0.06329$
0.12000
$-0.06532$
0.13000
$-0.06711$
0.14000
$-0.06866$
0.16000
$-0.07114$
0.18000
$-0.07285$
0.20000
$-0.07388$
0.22000
$-0.07431$
0.24000
$-0.07420$
0.26000
$-0.07361$
0.28000
$-0.07261$
0.30000
$-0.07125$
0.32000
$-0.06958$
0.34000
$-0.06766$
0.36000
$-0.06552$
0.38000
$-0.06320$ 


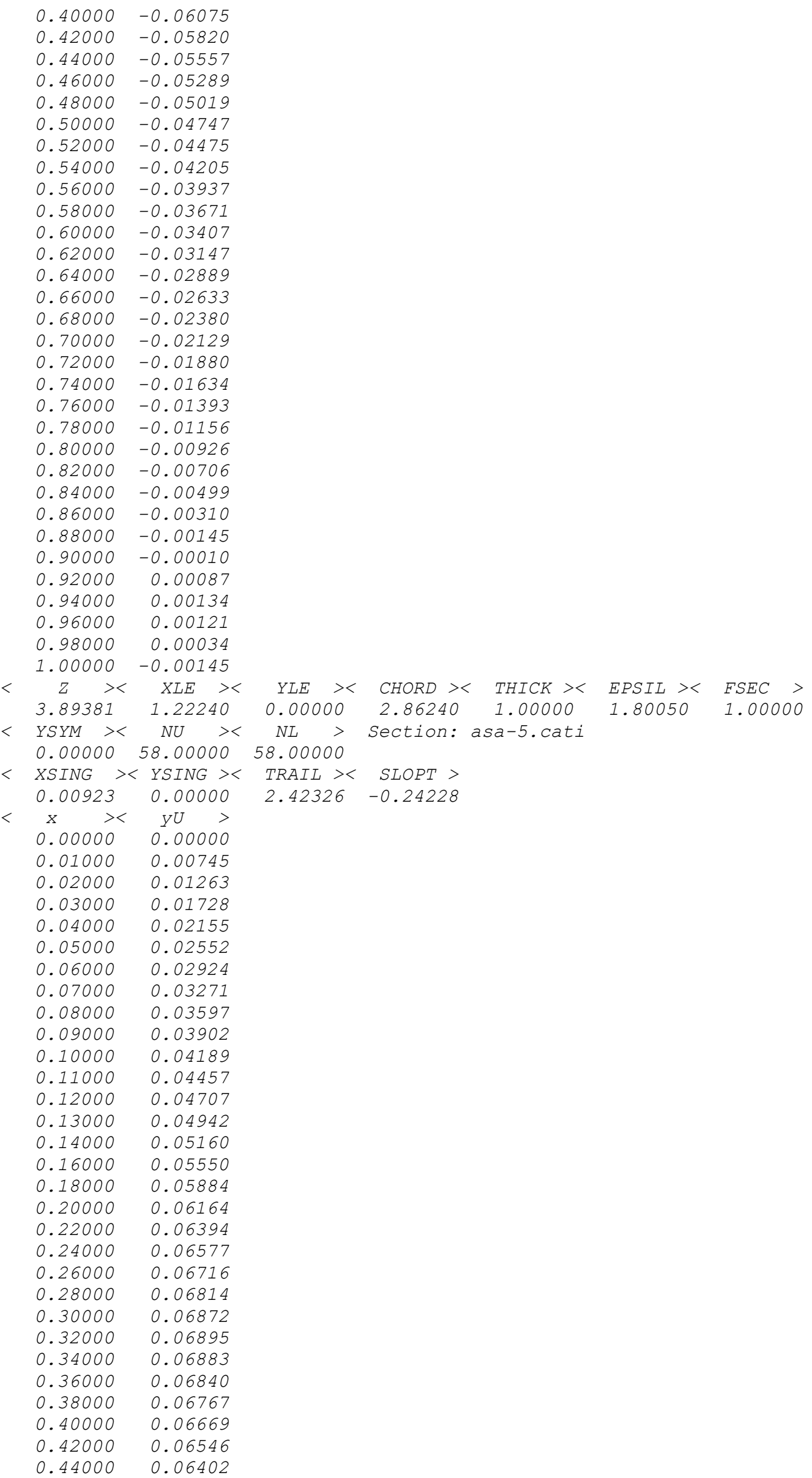



0.46000
0.06239
0.50000
0.06060
0.52000
0.05867
0.54000
0.05662
0.56000
0.05449
0.58000
0.05230
0.60000
0.05007
0.62000
0.04783
0.64000
0.04559
0.66000
0.04337
0.68000
0.04119
0.70000
0.03907
0.72000
0.03701
0.74000
0.03502
0.76000
0.03310
0.78000
0.03124
0.80000
0.02944
0.82000
0.02767
0.84000
0.02592
0.86000
0.02414
0.88000
0.02230
0.90000
0.02033
0.92000
0.01818
0.94000
0.01577
0.96000
0.01300
0.98000
0.00977
1.00000
0.00597
0.00144
$\begin{array}{lll}x & > & \\ 0.00000 & y L\end{array}$
$\begin{array}{rr}0.00000 & 0.00000 \\ 0.01000 & -0.00624\end{array}$
$0.02000-0.01026$
$0.03000-0.01380$
$0.04000-0.01701$
$0.05000-0.01996$
$0.06000-0.02268$
$0.07000-0.02519$
$0.08000-0.02751$
$0.09000-0.02965$
$0.10000-0.03163$
$0.11000-0.03343$
$0.12000-0.03509$
$0.13000-0.03659$
$0.14000-0.03795$
$0.16000-0.04025$
$0.18000-0.04205$
$0.20000-0.04337$
$0.22000-0.04425$
$0.24000-0.04474$
$0.26000-0.04485$
$0.28000-0.04464$
$0.30000-0.04412$
$0.32000-0.04333$
$0.34000-0.04230$
$0.36000-0.04106$
$0.38000-0.03962$
$0.40000-0.03802$
$0.42000-0.03627$
$0.44000-0.03439$
$0.46000-0.03240$
$0.48000-0.03032$
$0.50000-0.02816$
$0.52000-0.02594$
$0.54000-0.02366$
$0.56000-0.02133$
$0.58000-0.01898$
$0.60000-0.01660$
$0.62000-0.01422$

$<$ 


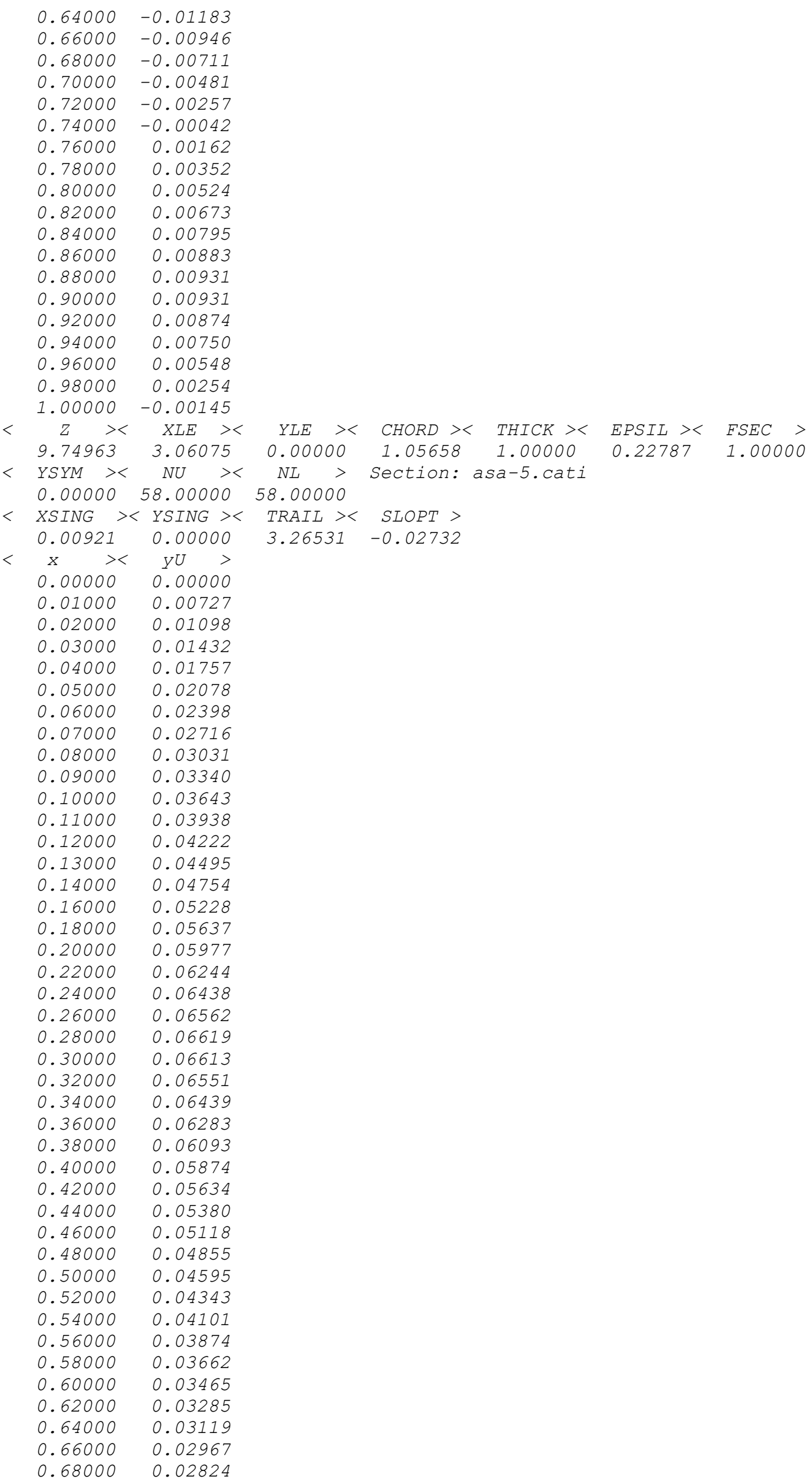



0.70000
0.02690
0.72000
0.02559
0.74000
0.02429
0.76000
0.02296
0.78000
0.02156
0.80000
0.02006
0.82000
0.01844
0.84000
0.01668
0.86000
0.01478
0.88000
0.01275
0.90000
0.01062
0.92000
0.00844
0.94000
0.00631
0.96000
0.00433
0.98000
0.00265
1.00000
0.00145
$<\quad x><$
yL >
0.01000
0.00000
0.02000
$-0.00748$
0.03000
$-0.01063$
0.04000
$-0.01275$
0.05000
$-0.01422$
0.06000
$-0.01521$
0.07000
$-0.01581$
0.08000
$-0.01612$
0.09000
$-0.01618$
0.10000
$-0.01606$
0.11000
$-0.01579$
0.12000
$-0.01541$
0.13000
$-0.01495$
0.14000
$-0.01444$
0.16000
$-0.01391$
0.18000
$-0.01285$
0.20000
$-0.01189$
0.22000
$-0.01114$
0.24000
$-0.01063$
0.26000
$-0.01042$
0.28000
$-0.01050$
0.30000
$-0.01086$
0.32000
$-0.01147$
0.34000
$-0.01230$
0.36000
$-0.01330$
0.38000
$-0.01441$
0.40000
$-0.01557$
0.42000
$-0.01674$
0.44000
$-0.01786$
0.46000
$-0.01887$
0.48000
$-0.01972$
0.50000
$-0.02038$
0.52000
$-0.02081$
0.54000
$-0.02098$
0.56000
$-0.02087$
0.58000
$-0.02049$
0.60000
$-0.01982$
0.62000
$-0.01888$
0.64000
$-0.01770$
0.66000
$-0.01629$
0.68000
$-0.01470$
0.70000
$-0.01297$
0.72000
$-0.01114$
0.74000
$-0.00928$
0.76000
$-0.00744$
0.78000
$-0.00568$
0.80000
$-0.00404$
0.82000
$-0.00260$
0.84000
$-0.00138$
0.86000
$-0.00043$ 


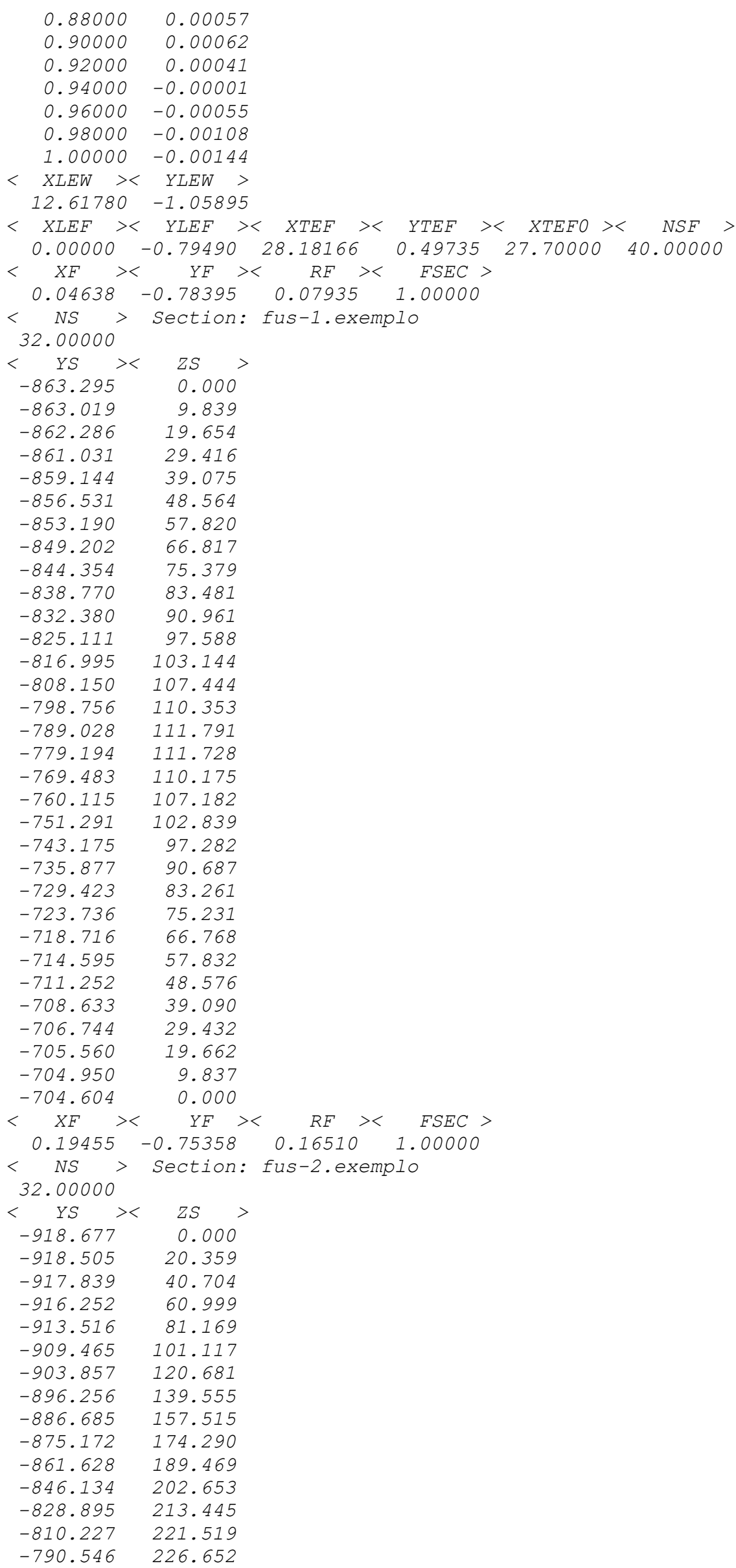




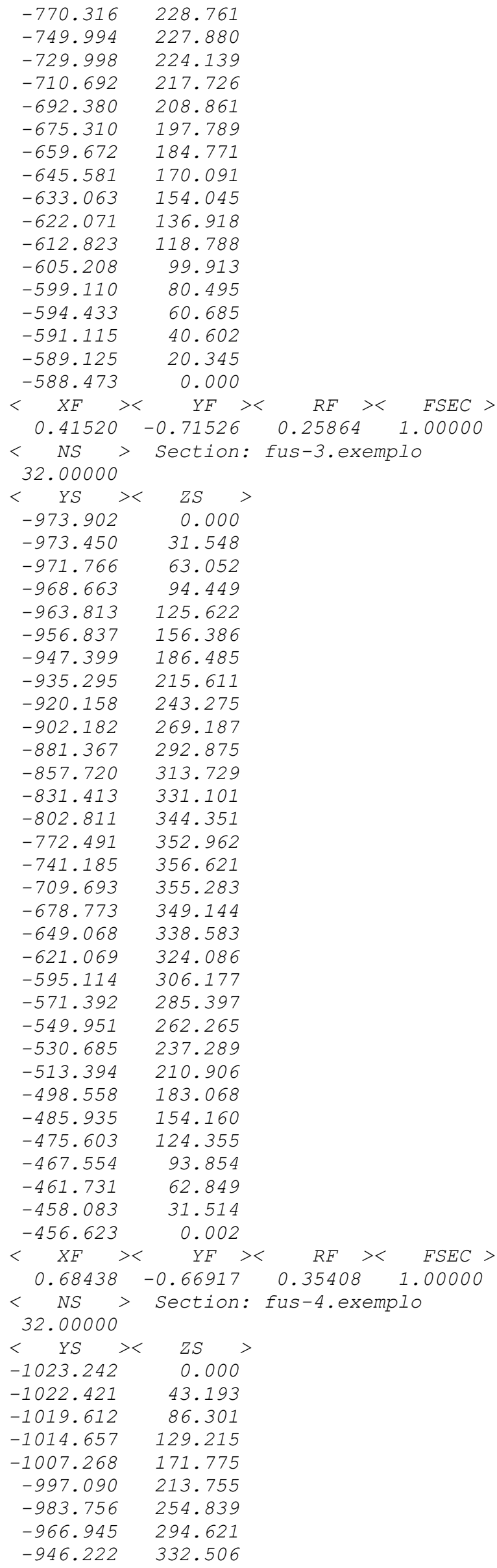




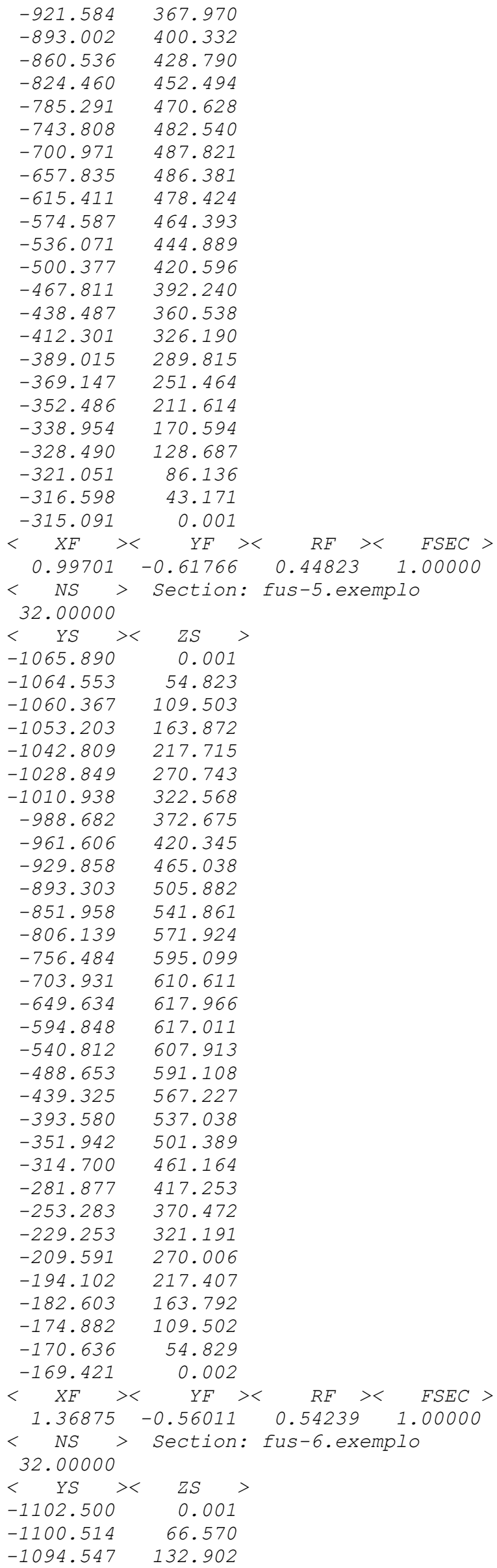




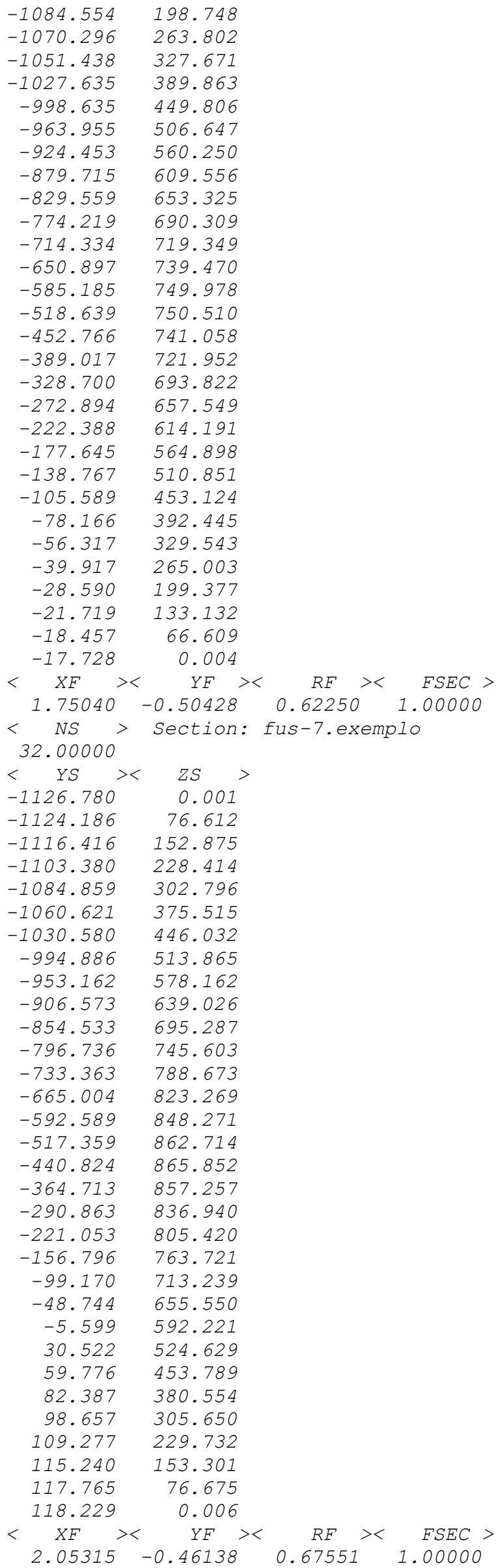




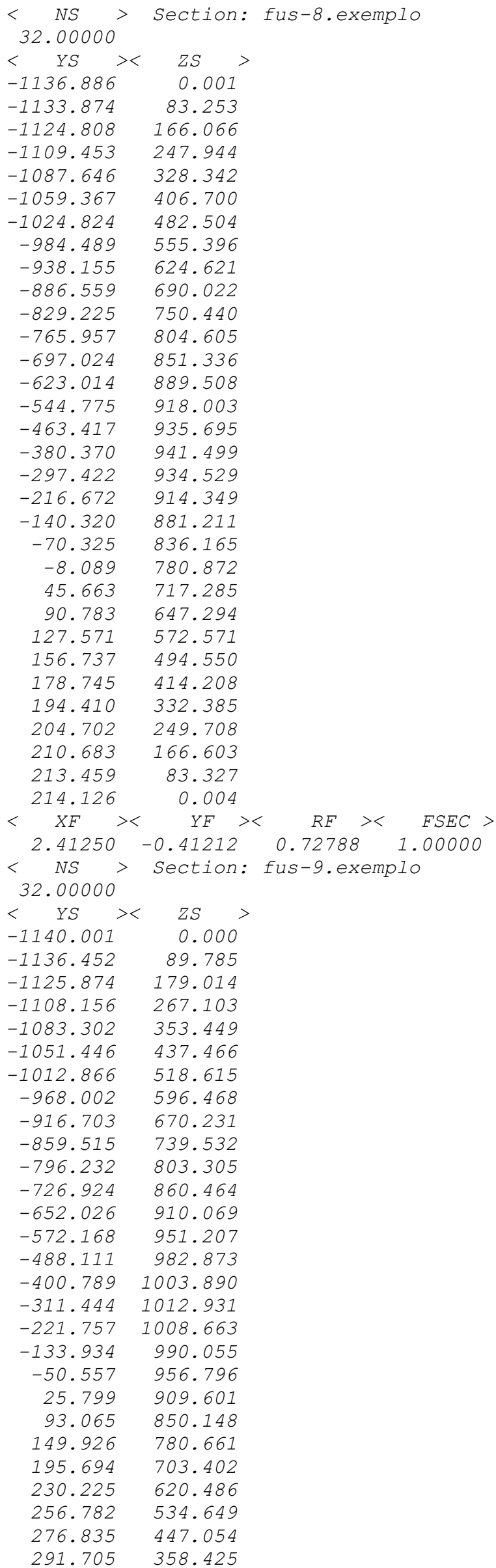




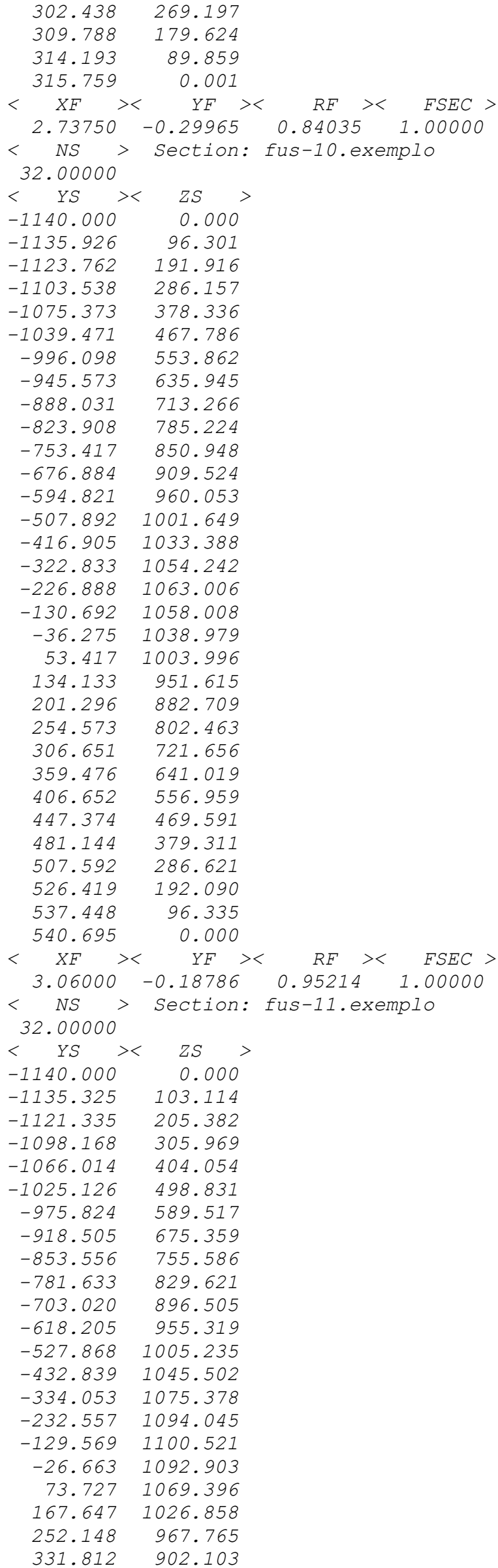




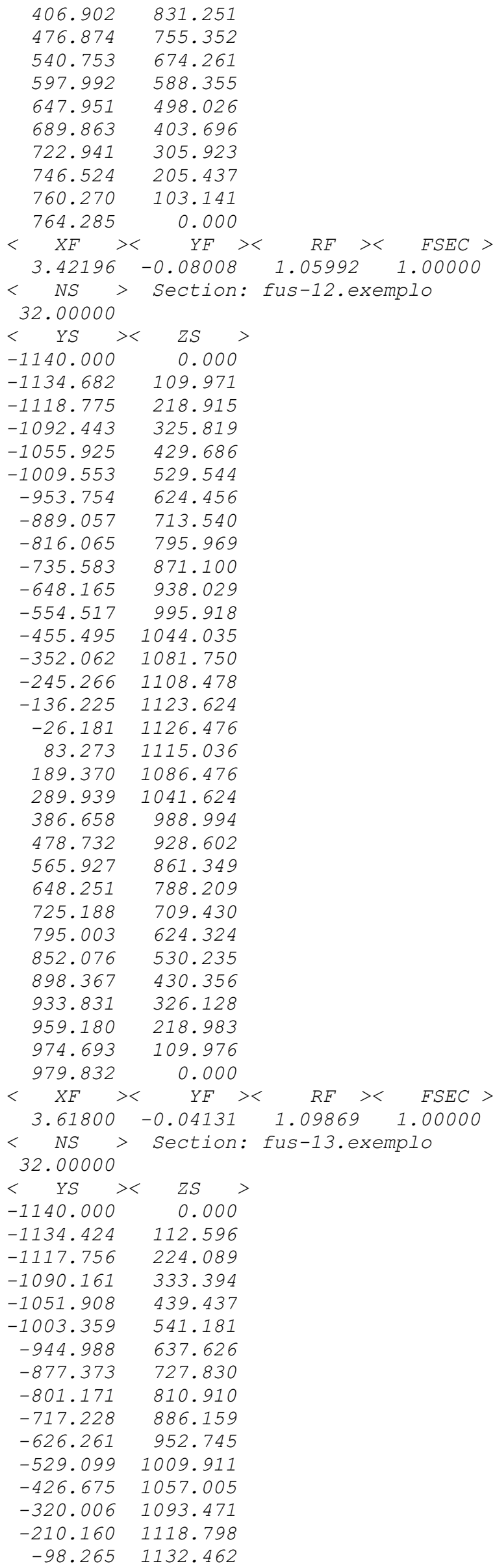




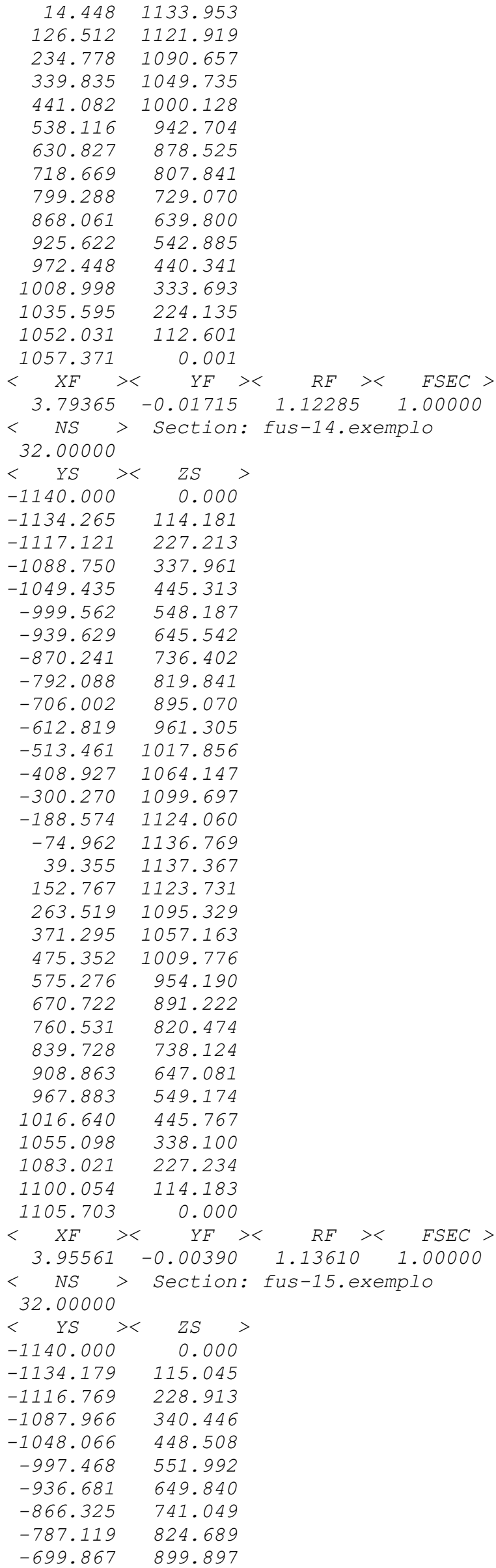




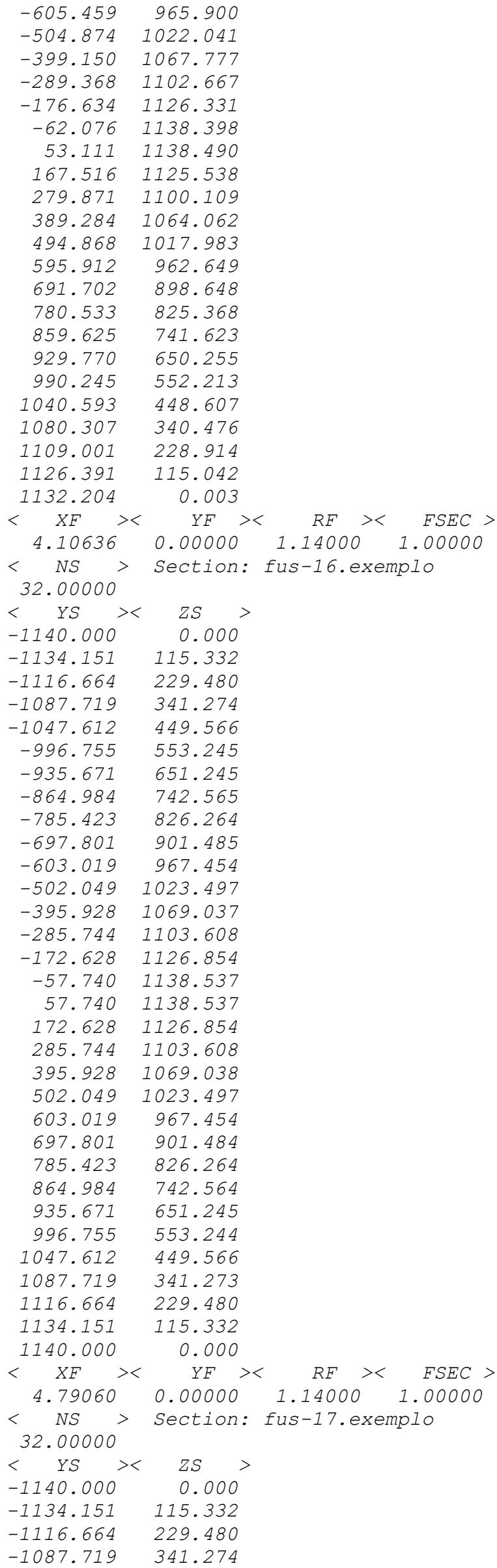




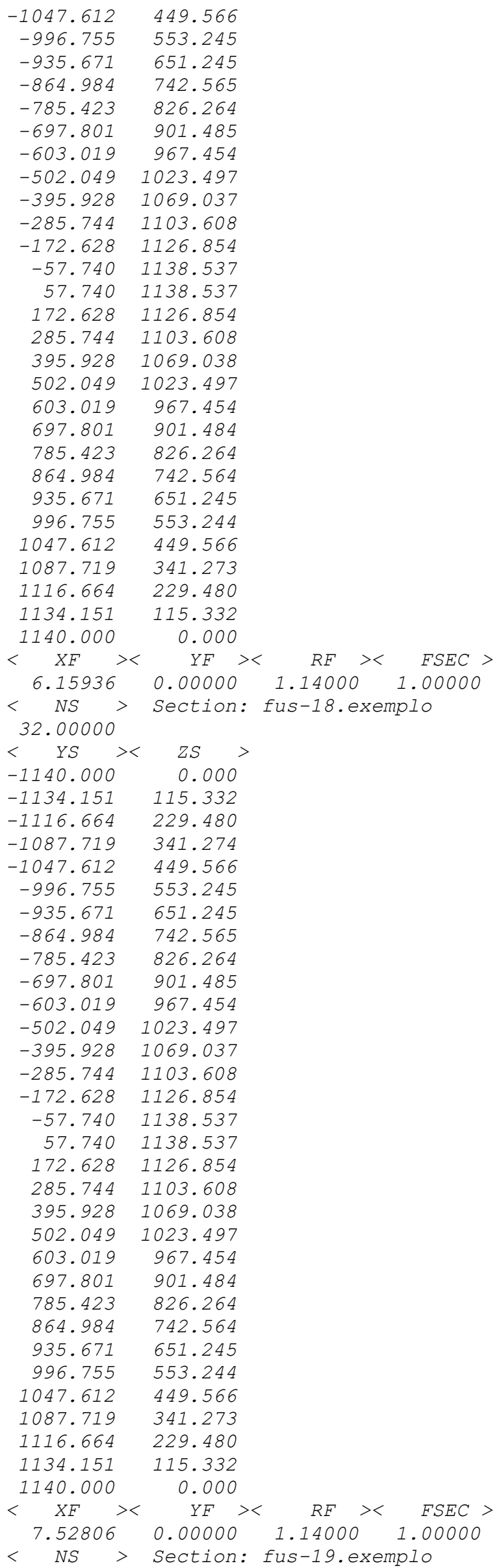




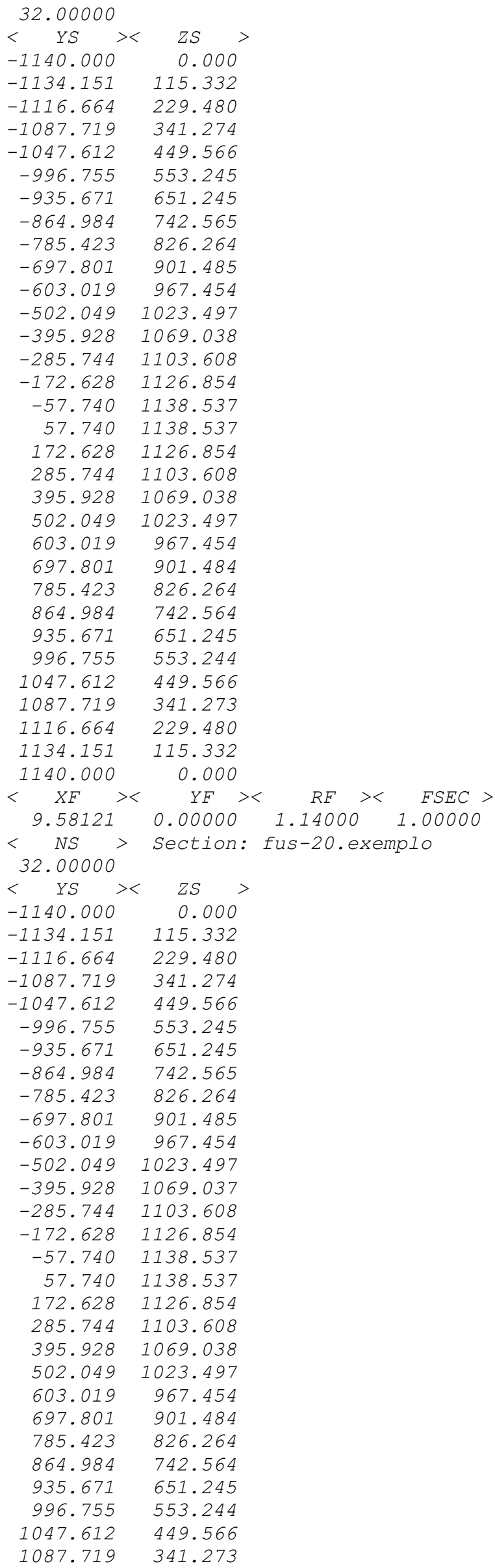




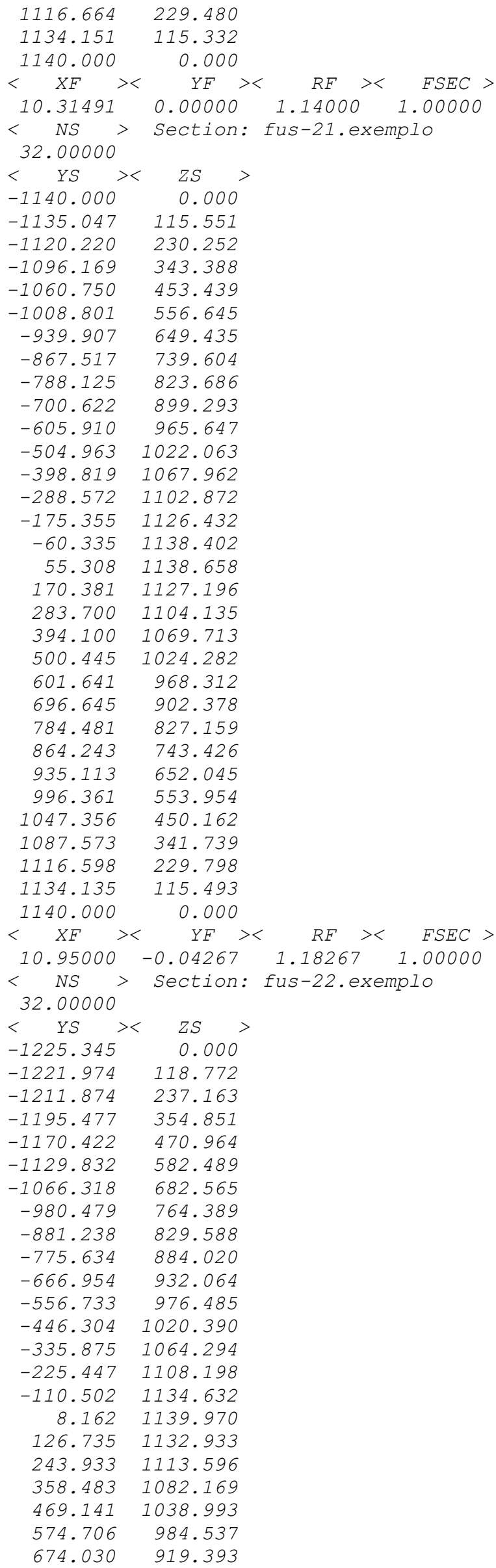




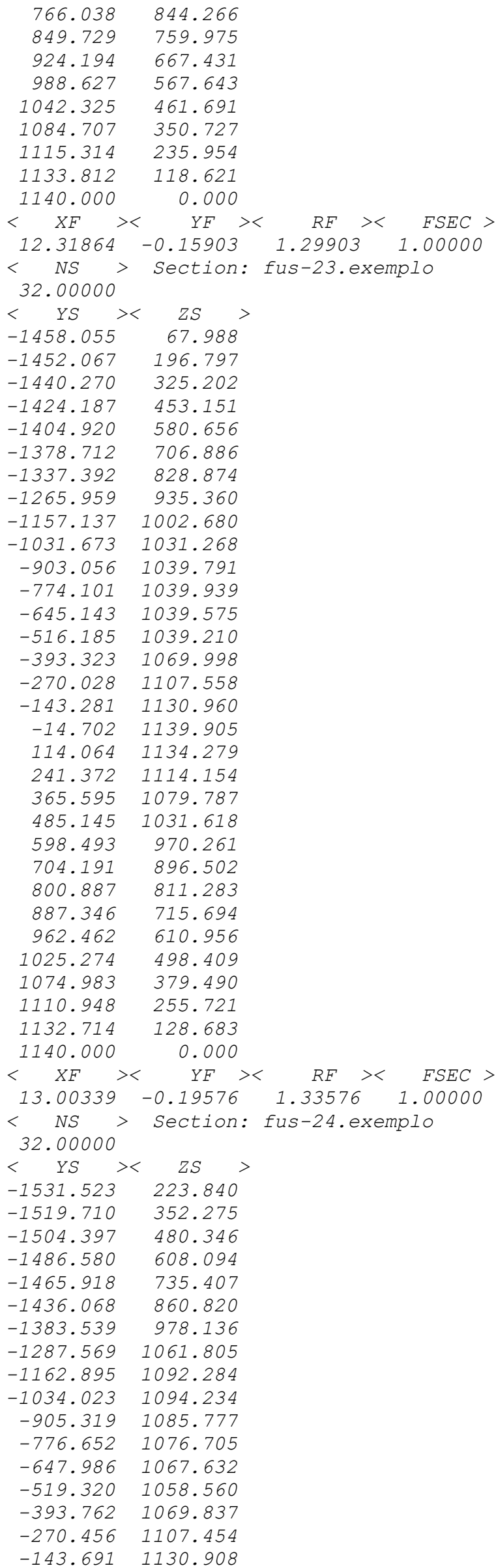




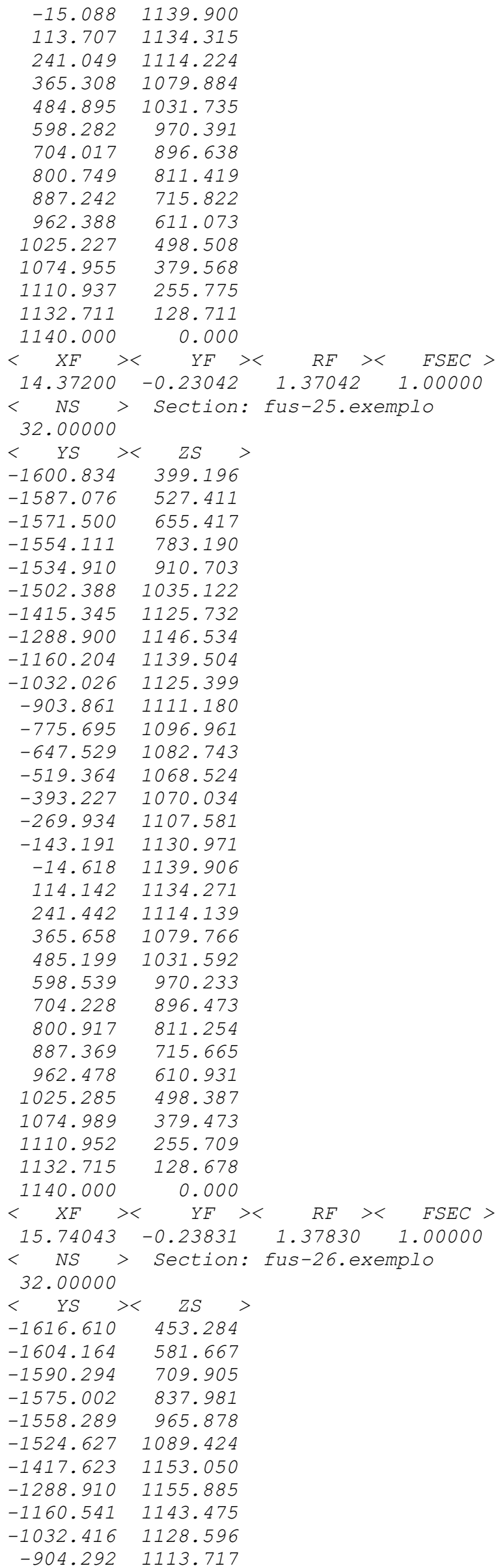




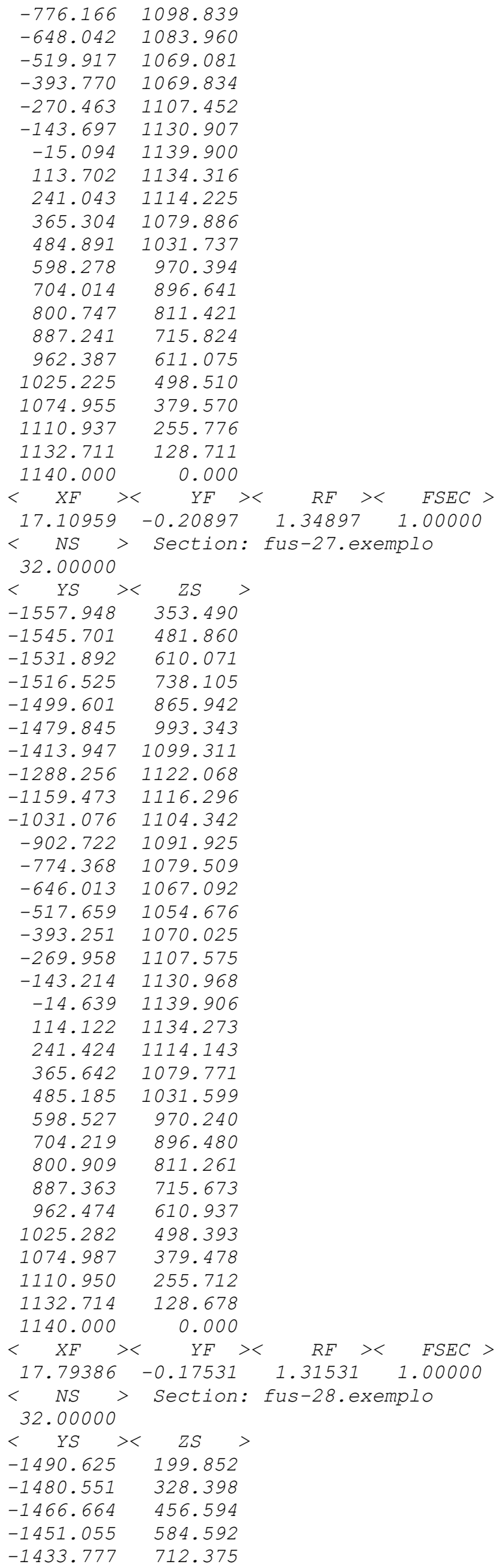




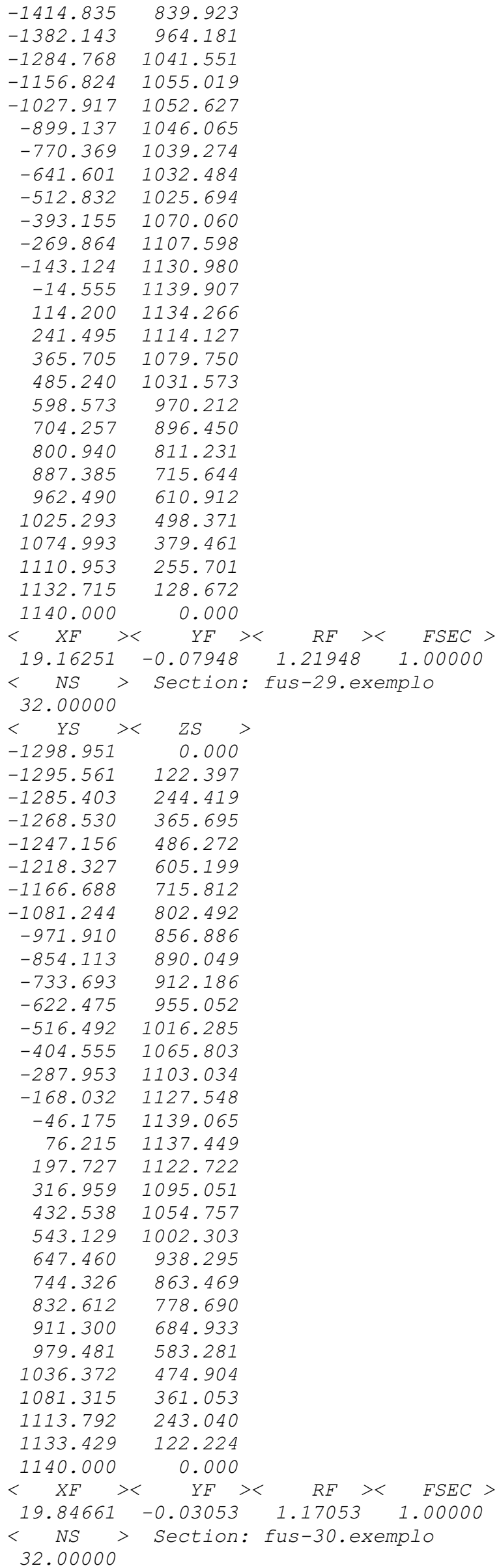




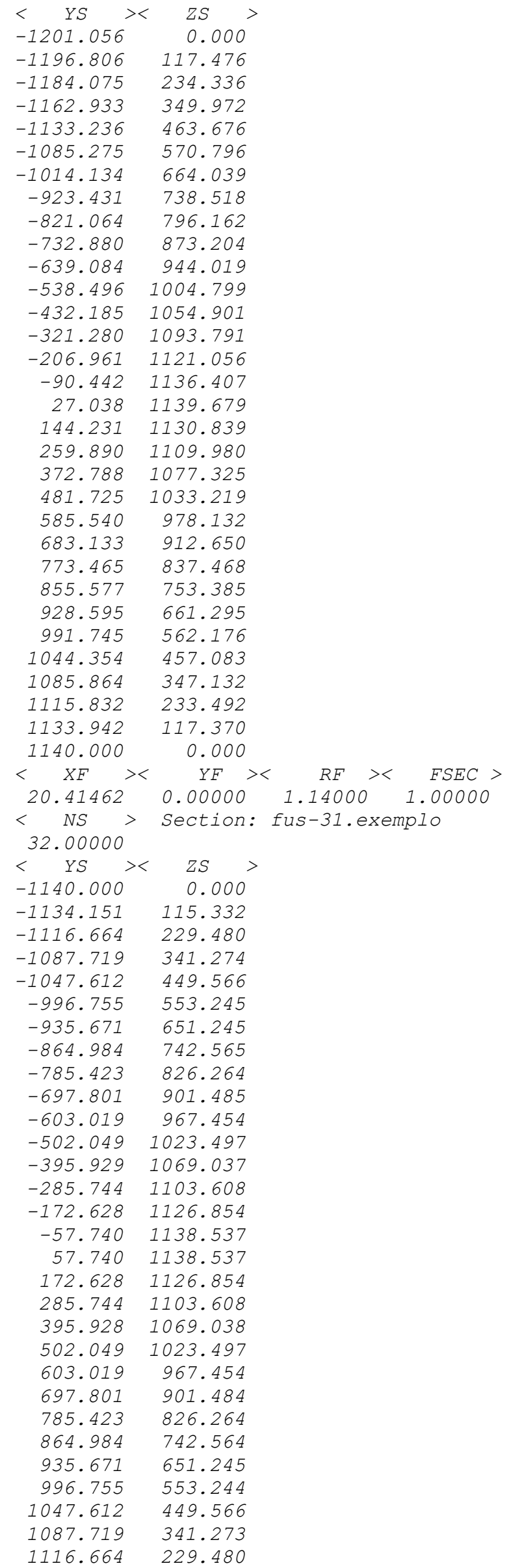




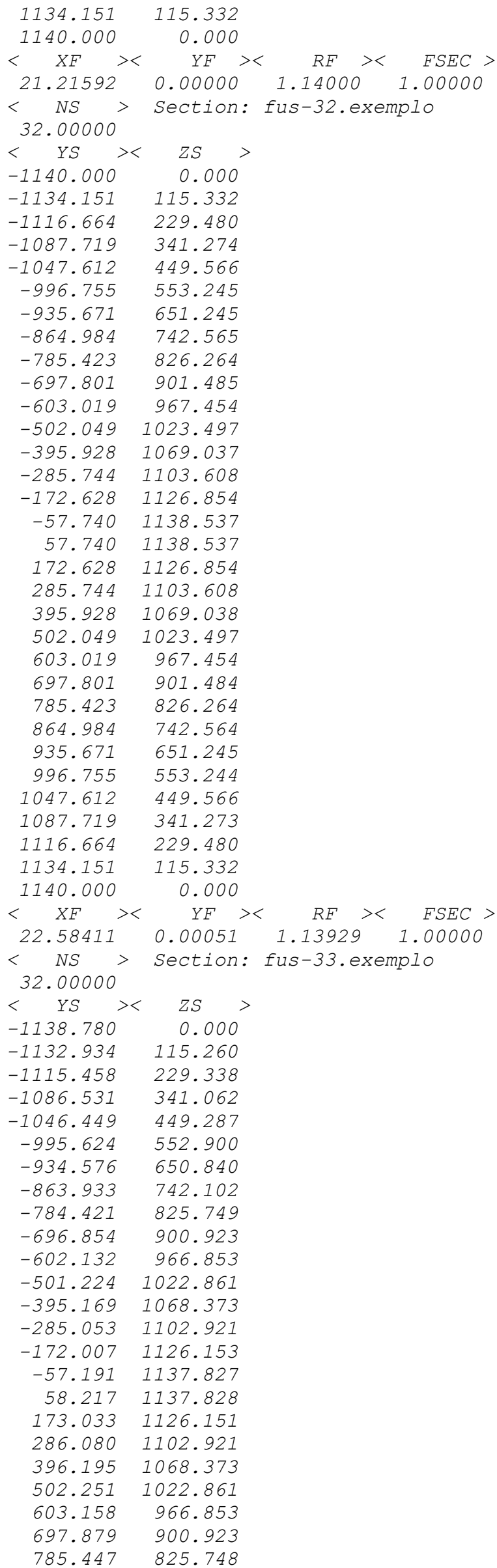




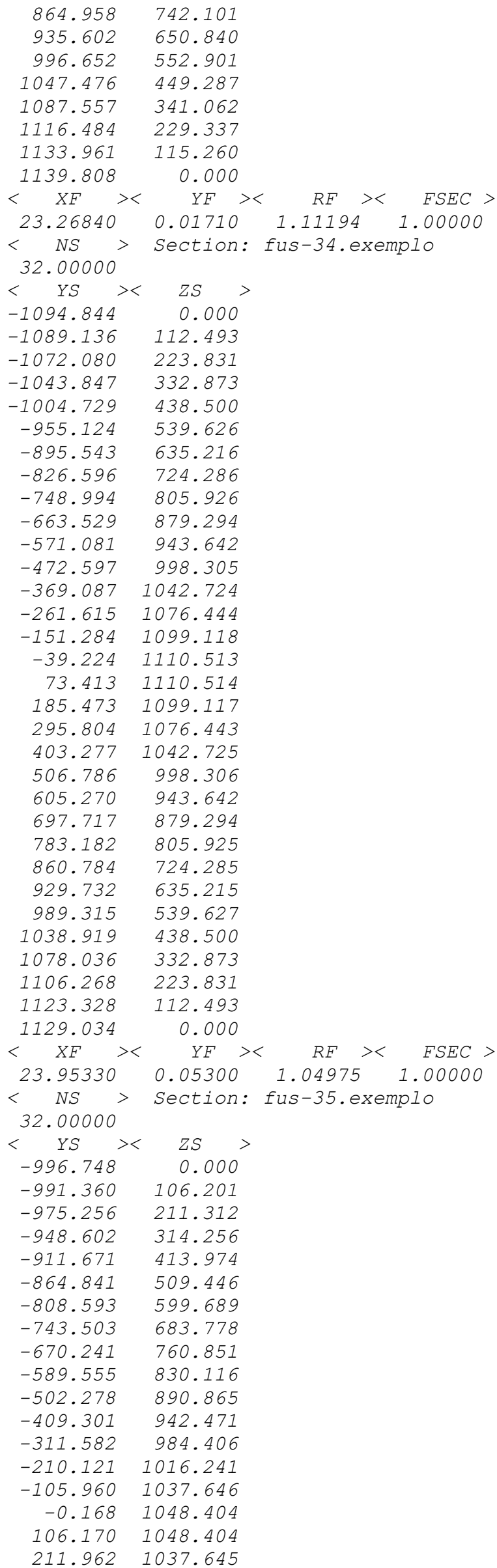




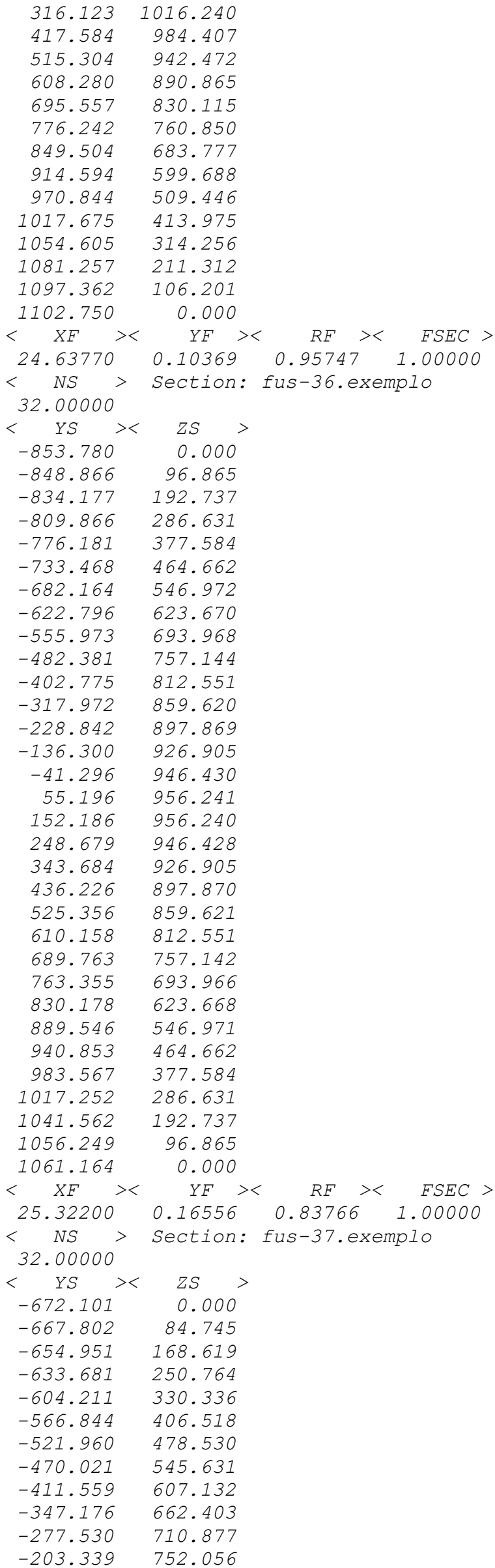




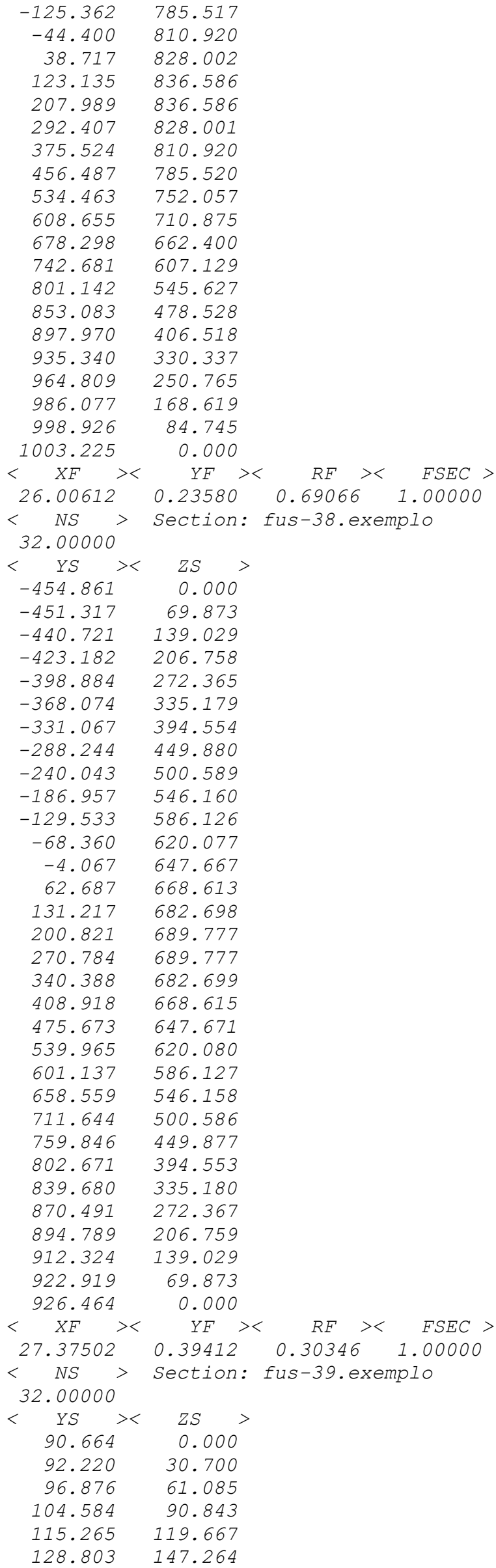




\begin{tabular}{|c|c|}
\hline 145.057 & 173.355 \\
\hline 163.867 & 197.668 \\
\hline 185.044 & 219.948 \\
\hline 208.378 & 239.960 \\
\hline 233.613 & 257.513 \\
\hline 260.491 & 272.429 \\
\hline 288.733 & 284.567 \\
\hline 318.059 & 293.779 \\
\hline 348.170 & 299.962 \\
\hline 378.754 & 303.063 \\
\hline 409.493 & 303.059 \\
\hline 440.075 & 299.951 \\
\hline 470.187 & 293.768 \\
\hline 499.517 & 284.569 \\
\hline 527.765 & 272.446 \\
\hline 554.642 & 257.528 \\
\hline 579.872 & 239.968 \\
\hline 603.195 & 219.944 \\
\hline 624.370 & 197.661 \\
\hline 643.183 & 173.350 \\
\hline 659.445 & 147.265 \\
\hline 672.990 & 119.670 \\
\hline 683.674 & 90.847 \\
\hline 691.374 & 61.088 \\
\hline 696.010 & 30.700 \\
\hline 697.581 & 0.000 \\
\hline$<\underset{28.05950}{X F}$ & $Y F><\quad R F><\quad F S E C>$ \\
\hline $\begin{array}{l}28.05950 \\
<\quad N S>\end{array}$ & $\begin{array}{lll}0.48126 & 0.08900 & 1.00000\end{array}$ \\
\hline${ }_{32.00000}^{N S}$ & Section: fus-40.exemplo \\
\hline$<\quad Y S \quad><$ & $Z S>$ \\
\hline 392.265 & 0.000 \\
\hline 392.721 & 9.004 \\
\hline 394.087 & 17.915 \\
\hline 396.348 & 26.642 \\
\hline 399.480 & 35.095 \\
\hline 403.450 & 43.190 \\
\hline 408.218 & 50.841 \\
\hline 413.734 & 57.972 \\
\hline 419.945 & 64.506 \\
\hline 426.789 & 70.374 \\
\hline 434.189 & 75.522 \\
\hline 442.072 & 79.897 \\
\hline 450.354 & 83.457 \\
\hline 458.954 & 86.159 \\
\hline 467.786 & 87.971 \\
\hline 476.755 & 88.881 \\
\hline 485.770 & 88.880 \\
\hline 494.739 & 87.968 \\
\hline 503.570 & 86.156 \\
\hline 512.172 & 83.458 \\
\hline 520.456 & 79.902 \\
\hline 528.339 & 75.527 \\
\hline 535.738 & 70.377 \\
\hline 542.578 & 64.505 \\
\hline 548.788 & 57.969 \\
\hline 554.306 & 50.840 \\
\hline 559.075 & 43.190 \\
\hline 563.047 & 35.096 \\
\hline 566.181 & 26.643 \\
\hline 568.439 & 17.916 \\
\hline 569.798 & 9.004 \\
\hline 570.259 & 0.000 \\
\hline
\end{tabular}

